\title{
DEVELOPMENT OF COST EFFECTIVE OXY-COMBUSTION RETROFITTING FOR COAL-FIRED BOILERS
}

\author{
Final Report
}

For

April 1, 2006 through December 31, 2010

Prepared By:

Hamid Farzan

Telephone No.: (330) 860-6628

Fax No.: (330) 860-6676

E-Mail address: $\underline{\text { HFarzan@ Babcock.com }}$

\&

Andrew Mackrory, B\&W

Denny McDonald, B\&W

Rajeev Prabhakar, Air Liquide

Bruce Sass, Battelle

Submitted By:

Babcock \& Wilcox Company Power Generation Group

20 South Van Buren Ave

P.O. Box 351

Barberton, Ohio 44203-0351

October 24, 2011

B\&W Contract No.: RCD 1464

DOE Contract No.: DE-FC26-06NT42747 


\section{LEGAL NOTICE}

ACKNOWLEDGMENT: "This material is based upon work supported by the Department of Energy under Award Number DE-FC26-06NT42747."

DISCLAIMER: "This report was prepared as an account of work sponsored by an agency of the United States Government. Neither the United States Government nor any agency thereof, nor any of their employees, makes any warranty, express or implied, or assumes any legal liability or responsibility for the accuracy, completeness, or usefulness of any information, apparatus, product, or process disclosed, or represents that its use would not infringe privately owned rights. Reference herein to any specific commercial product, process, or service by trade name, trademark, manufacturer, or otherwise does not necessarily constitute or imply its endorsement, recommendation, or favoring by the United States Government or any agency thereof. The views and opinions of authors expressed herein do not necessarily state or reflect those of the United States Government or any agency thereof." 


\section{ACKNOWLEDGMENTS}

The authors acknowledge numerous individuals from Air Liquide, B\&W, Battelle, and U.S. DOE who have contributed tremendously to the successful execution of this project. Special thanks are due to the following individuals:

- Jose Figueroa, the DOE NETL project manager, who contributed by many technical discussions and reviews

- Paul Terrien from Air Liquide for his help in ASU/CPU analysis

- Shengteng Hu, Bartev Sakadjian, and Dong Zeng for participating in the pilot-scale tests

- Luis Vargas and Behrooz Ghorishi for mercury sampling and analysis

- Jason Fennell, Brian Clark, and Vijay Parekh for instrumentation and data acquisition

- Rajani Varagani, Taekyu Kang, Vivek Gautam, Kenneth Kaiser, Chendhil Periasamy, Kaleem Robinson, and Yuan Xue of Air Liquide for their participation in the pilot-scale tests and management of the oxygen supply system

- Terry Wilson, Larry Mohr, Jeff Dudley, Rob Porter, Vernon Burch, Terry Bert, Mike Shea, Wynn Feess, and Rick Schreckengost for operation of the pilot-scale facility

- Jim Warchol and Ralph Bailey for assistance with the wet scrubber

- Zumao Chen and Rick Wessel for performing numerical modeling 


\section{TABLE OF CONTENTS}

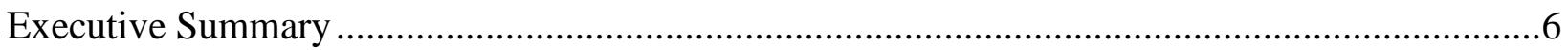

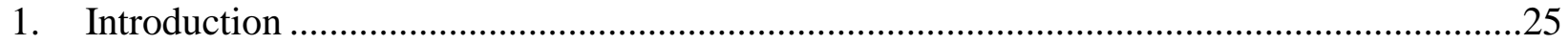

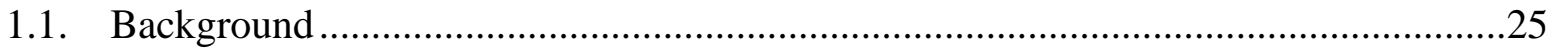

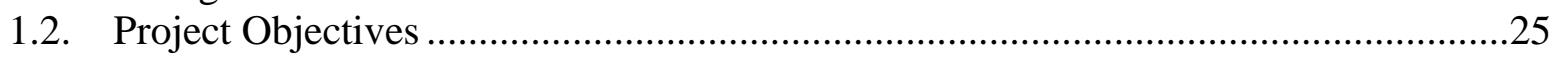

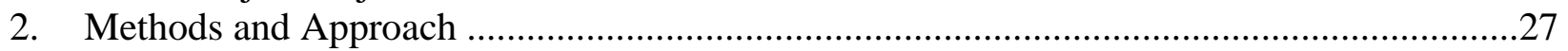

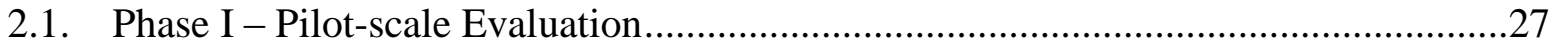

2.1.1. Pilot-scale Test Facility: SBS-II...............................................................27

2.1.2. Coal Analyses....................................................................................

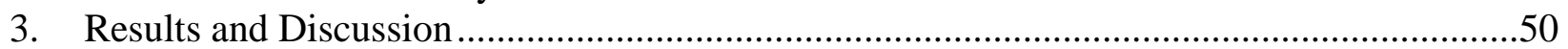

3.1. Phase I - Equipment Specification and Pilot-scale Evaluation ....................................50

3.1.1. Environmental Equipment Requirement .....................................................50

3.1.2. Flue Gas Purification and Compression Train ...............................................51

3.1.3. $\quad \mathrm{CO}_{2}$ Transportation and Sequestration ........................................................62

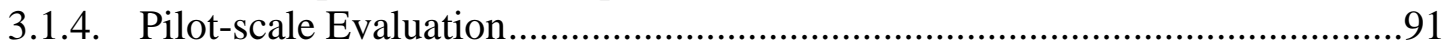

3.1.5. Computational Model Validation...............................................................127

3.1.6. Wall-firing Pilot Scale Testing and Analysis................................................147

3.2. Phase II, Part A - Engineering and Economic Evaluation .......................................161

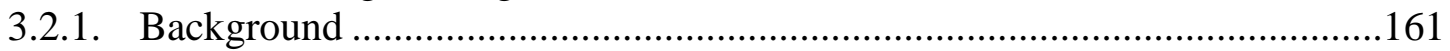

3.2.2. Performance Basis ................................................................................. 162

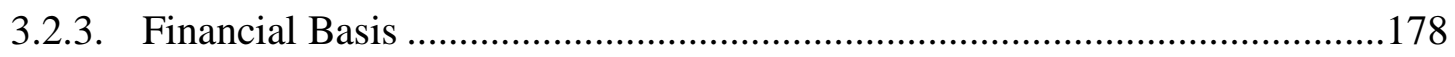

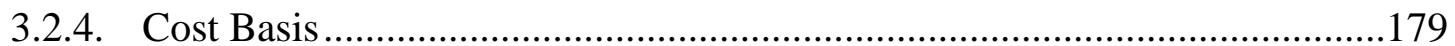

3.2.5. Base Case Performance and Economic Results and Discussion...................183

3.2.6. Comparison of Performance and Economic Results with Other Studies......197

3.2.7. Performance and Economic Results for Sensitivity Studies ..........................203

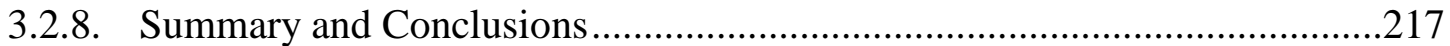

3.3. Phase II, Part B - Assessment of Potential for Geologic $\mathrm{CO}_{2}$ Storage for

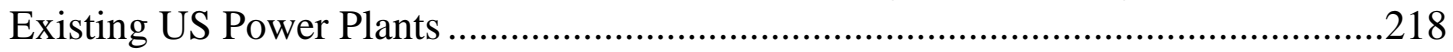

3.3.1. Site Screening to Identify Potentially Suitable Sequestration

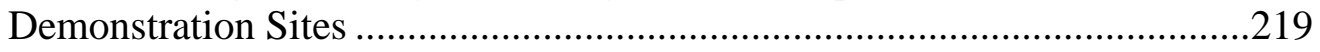

3.3.2. Results of Applying High-Level Screening Criteria .....................................221

3.3.3. Implications for Oxy-combustion Retrofitting of Coal-fired Power

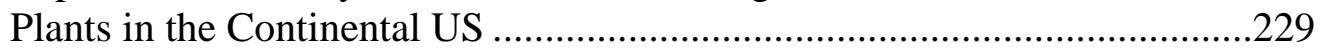

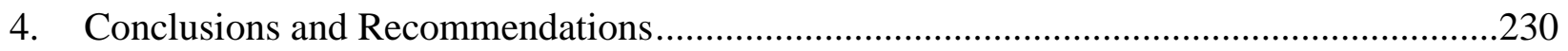

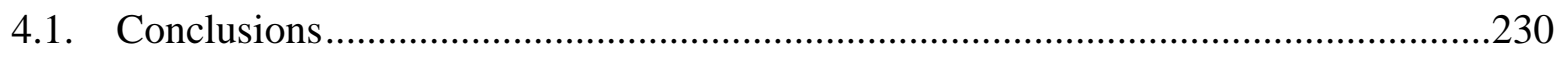

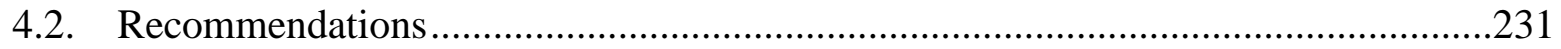

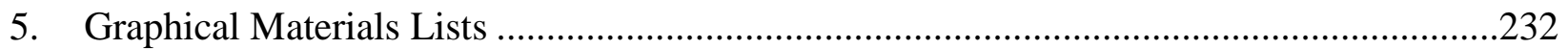

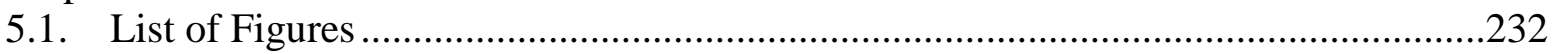

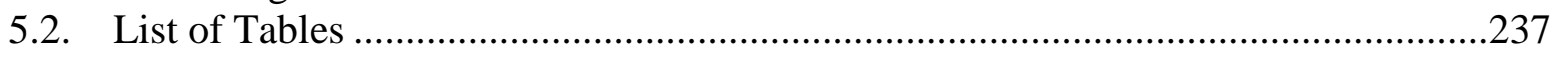

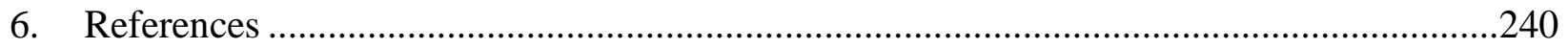

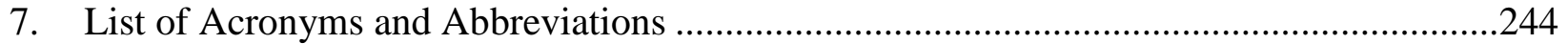

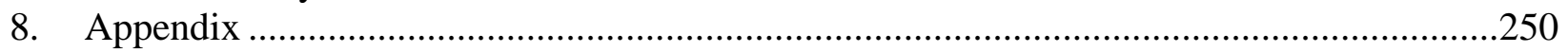

8.1. Methods for Flue Gas Purification \& Compression Train Study ............................250

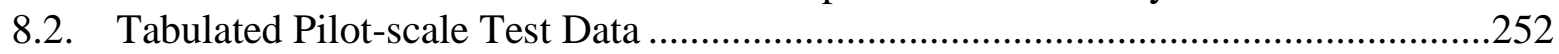

8.3. List of Boilers Evaluated for Geologic $\mathrm{CO}_{2}$ Storage Potential................................272 


\section{EXECUTIVE SUMMARY}

\section{Introduction}

To maintain economic competitiveness and meet growing energy demands, the U.S. must improve the utilization of its domestic resources. Our vast resources of coal will play a strategic role in future electric power production. Coal currently provides more than $50 \%$ of the United States' electricity. Hence, coal will continue to be a prime source for electricity generation. Over the past three decades, utilities have implemented emission control equipment to control $\mathrm{NO}_{\mathrm{X}}$, $\mathrm{SO}_{2}$, and particulate emissions to a large portion of existing coal-fired boilers. Fossil fuel combustion is also a primary contributor of increased greenhouse gas (GHG) emissions. As fossil fuels continue to be a dominant fuel source for electricity generation, reducing carbon emissions by capturing and sequestering $\mathrm{CO}_{2}$ from existing utility boilers is being considered to reduce these emissions and thereby control overall atmospheric GHG emissions.

The power industry has successfully met the challenge of reducing sulfur dioxide, oxides of nitrogen, particulate matter, and more recently mercury. Carbon dioxide challenges the industry in a new way because the quantities are vast and the technologies are still under development. Babcock \& Wilcox Power Generation Group (B\&W) and Air Liquide (AL) have been actively involved in the development of oxy-coal technologies for power generation for the past ten years. With the sponsorship of DOE and NETL through project NT42747, oxy-combustion was evaluated for existing wall-fired and Cyclone ${ }^{\mathrm{TM}}$ boilers.

\section{Objectives}

The overall objective of this project is to further develop the oxy-combustion technology for commercial retrofit in existing wall-fired and Cyclone boilers by 2012. To meet this goal, a twophase research project was conducted that included pilot-scale testing and a full-scale engineering and economic analysis.

Phase I objectives include:

- Evaluate at pilot-scale the effect of coal rank used in existing boilers (i.e., bituminous, subbituminous, and lignite) on oxy-combustion design.

- Determine the equipment requirements for the boiler island, including flue gas purification, $\mathrm{CO}_{2}$ compression, transportation, and storage for different coals and combustion systems (Cyclone and wall-fired).

- Investigate the potential for multi-pollutant $\left(\mathrm{NO}_{\mathrm{X}}, \mathrm{SO}_{2}\right.$, and particulate) reduction.

- Validate an existing 3-dimensional computational flow, heat transfer, and combustion model for oxy-combustion scale-up to a commercial size boiler.

Phase II objectives are as follow:

- Evaluate the impact of oxy-combustion implementation on net power production and cost of electricity for Cyclone and wall-fired applications.

- Determine the boiler population with close proximity to candidate geologic $\mathrm{CO}_{2}$ storage sites. 
- Conduct an engineering and economic assessment of the technology for commercialscale retrofit and greenfield application for Cyclone and wall-fired units.

- Assess potential $\mathrm{CO}_{2}$ control cost reductions via the integration of the air separation unit, flue gas purification, $\mathrm{CO}_{2}$ compression train, and $\mathrm{CO}_{2}$ transportation and sequestration.

\section{Pilot-scale Testing}

The objective of these tests was to evaluate the effect of coal rank used in existing boilers (i.e., bituminous, subbituminous, and lignite) on oxy-combustion design. Specifically the following parameters were investigated:

- Flame stability

- $\quad \mathrm{NO}_{\mathrm{X}}, \mathrm{CO}$, and unburned combustibles

- Radiant boiler and convection pass heat absorption

- Furnace exit gas temperature

- $\mathrm{SO}_{2} / \mathrm{SO}_{3}$ emissions under air and oxy-firing conditions

- Recycle gas moisture concentration

Approach:

Since B\&W had already demonstrated oxy-firing for wall-firing at 1.8 and $30 \mathrm{MW}_{\text {th }}$ (See Section 3.1.6), this pilot-scale evaluation was conducted with a Cyclone configuration. In Cyclone boilers, high temperatures are used to capture and remove the majority of ash as molten slag. Crushed coal is introduced tangentially into the Cyclone barrel, where the large particles burn in a slag layer and small particles in suspension. Slag tapping problems may occur if oxy-firing reduces the Cyclone temperature and prevents slag flow.

The $6 \mathrm{MBtu} / \mathrm{h}$ Small Boiler Simulator-II (SBS-II) was used for the pilot-scale tests. It is a new test facility (commissioned in 2009) and is designed for evaluating various fuels, combustion processes, air pollution control devices, and associated hardware for potential commercial use. The pilot facility simulates the firing conditions of full-scale steam generating boilers. The furnace may be equipped with either a single wall-fired burner, or a Cyclone furnace. Various environmental controls such as baghouses and scrubbers are available according to the need of each project. A wet flue gas desulfurization (WFGD) scrubber was used for bituminous coal only. Figure S.1 shows a schematic diagram of the system configuration for this project and how various components are connected by ductwork. A condensing heat exchanger ( $\mathrm{CHX})$ is available to remove heat and moisture from the recycled gas. "Cold recycle" tests were performed for the majority of the tests, where the recycled gas was cooled down to a nominal $100^{\circ} \mathrm{F}$. "Warm recycle" tests were performed with subbituminous coal without removing moisture or $\mathrm{SO}_{2}$ from the recycled gas. The recycled flue gas was mixed with oxygen and recycled to primary and secondary oxidant streams. Oxygen measurements were performed via in-situ oxygen probes to control the oxidant streams' oxygen concentrations. These oxygen concentration measurements were also used for safety interlocks.

Liquid oxygen was delivered to the test facility and stored on site in a 9000-gallon liquid oxygen tank. The liquid oxygen was vaporized using an ambient vaporizer and the oxygen was regulated to an appropriate pressure and delivered to the test area via stainless steel piping. 
Three coals were tested: an Ohio \#5 (Eastern bituminous), Black Thunder (Western subbituminous), and a lignite from North Dakota. Table S.1 shows the as-received fuel analyses.

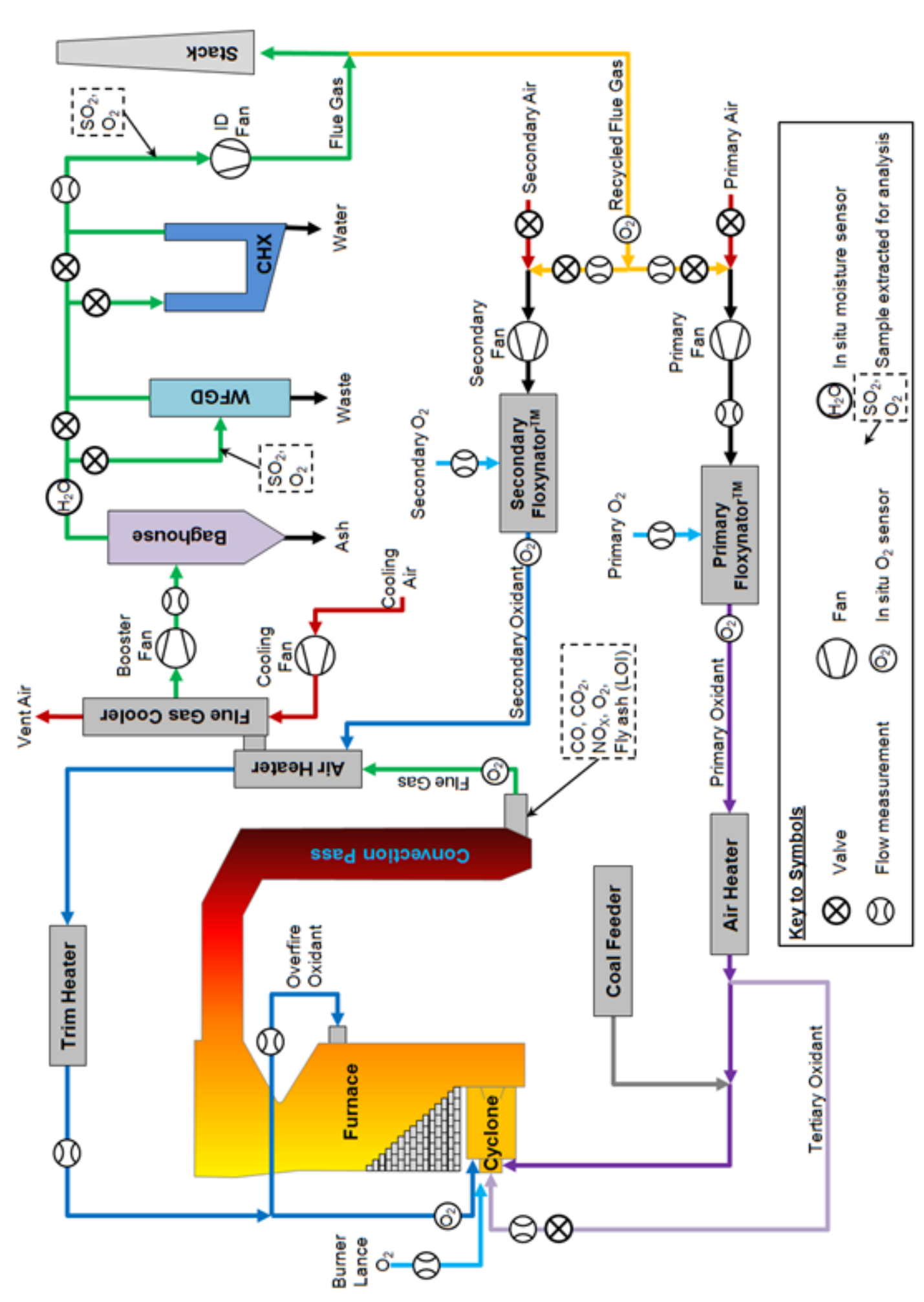

Figure S.1 Schematic diagram of the SBS-II facility

Page 8 of 279 


\begin{tabular}{|c|c|c|c|c|}
\hline & \multirow{3}{*}{$\begin{array}{c}\text { Eastern } \\
\text { Bituminous } \\
\text { Ohio \#5 } \\
\end{array}$} & \multirow{2}{*}{\multicolumn{2}{|c|}{$\begin{array}{c}\text { Western Sub-bituminous } \\
\text { Black Thunder } \\
\end{array}$}} & \multirow{3}{*}{$\begin{array}{c}\text { Lignite } \\
\text { North Dakota }\end{array}$} \\
\hline & & & & \\
\hline & & Cold recycle & Warm recycle & \\
\hline \multicolumn{5}{|c|}{ Proximate Analysis (wt $\%$, as received) } \\
\hline Moisture & 6.47 & 26.56 & 26.15 & 35.60 \\
\hline Ash & 5.57 & 4.94 & 4.64 & 6.79 \\
\hline Volatile Matter & 41.51 & 32.11 & 32.20 & 28.50 \\
\hline Fixed Carbon & 46.45 & 36.39 & 37.01 & 29.11 \\
\hline \multicolumn{5}{|c|}{ Ultimate Analysis (wt \%, as received) } \\
\hline Carbon & 71.10 & 50.98 & 51.80 & 41.91 \\
\hline Hydrogen & 5.02 & 3.84 & 3.83 & 3.04 \\
\hline Nitrogen & 1.41 & 0.76 & 0.81 & 0.64 \\
\hline Sulfur & 2.56 & 0.38 & 0.24 & 0.74 \\
\hline Oxygen & 7.87 & 12.53 & 12.53 & 11.29 \\
\hline \multicolumn{5}{|c|}{ Miscellaneous (as received, unless specified) } \\
\hline As-fired fuel sulfur (wt \%) & 2.70 & 0.39 & 0.26 & 0.66 \\
\hline Calorific Value (Btu/lb) & 12807 & 8841 & 8829 & 6938 \\
\hline
\end{tabular}

Table S.1 Proximate, ultimate, and miscellaneous analyses for the coals

$\underline{\text { Pilot-scale Demonstration Summary }}$

- Oxy-firing was successfully demonstrated in a slagging environment by optimizing Cyclone exit gas temperature to levels similar to air-firing.

- Smooth transition from air-firing to oxy-firing was achieved.

- Convection pass exit $\mathrm{CO}_{2}$ concentrations up to $90 \%$ were achieved. Figure S.2 shows the effect of air leakage on $\mathrm{CO}_{2}$ concentrations for different fuels and recycle gas configurations for $\mathrm{SO}_{2}$ and moisture level control. The lowest $\mathrm{CO}_{2}$ concentrations occurred with bituminous coal when the WFGD was in service and pressure drop across the environmental equipment was large. The highest $\mathrm{CO}_{2}$ concentrations were achieved with subbituminous coal when the WFGD was out of service and the pressure drop was lower.

- $\mathrm{NO}_{\mathrm{X}}$ and $\mathrm{CO}$ emissions, and unburned combustibles (LOI) were lower with oxy-firing than air-firing conditions (see Figure S.3).

- Heat absorption in oxy-firing was similar to air-firing under optimum conditions. Figure S. 4 shows the heat absorptions for the Cyclone. Radiant furnace and convection pass heat absorptions were similar for air- and oxy-firing.

- $\mathrm{SO}_{2}$ concentrations at the convection pass outlet increased by a factor of 4-5 with subbituminous and lignite coal when the WFGD was not in service (see Figure S.5); therefore, if oxy-firing is applied to a high sulfur coal, $\mathrm{SO}_{2}$ must be scrubbed from recycle gas to maintain acceptable boiler corrosion rates.

- Warm recycle increases convection pass outlet moisture levels to $34 \%$ of the total flue gas volume (see Figure S.6). 
- Higher $\mathrm{SO}_{3}$ concentrations were observed with oxy-firing relative to air-firing at the convection pass exit but were reduced by operation of the WFGD/CHX. Higher $\mathrm{SO}_{3}$ concentrations could increase corrosion if the flue gas temperature goes below the acid dew point.

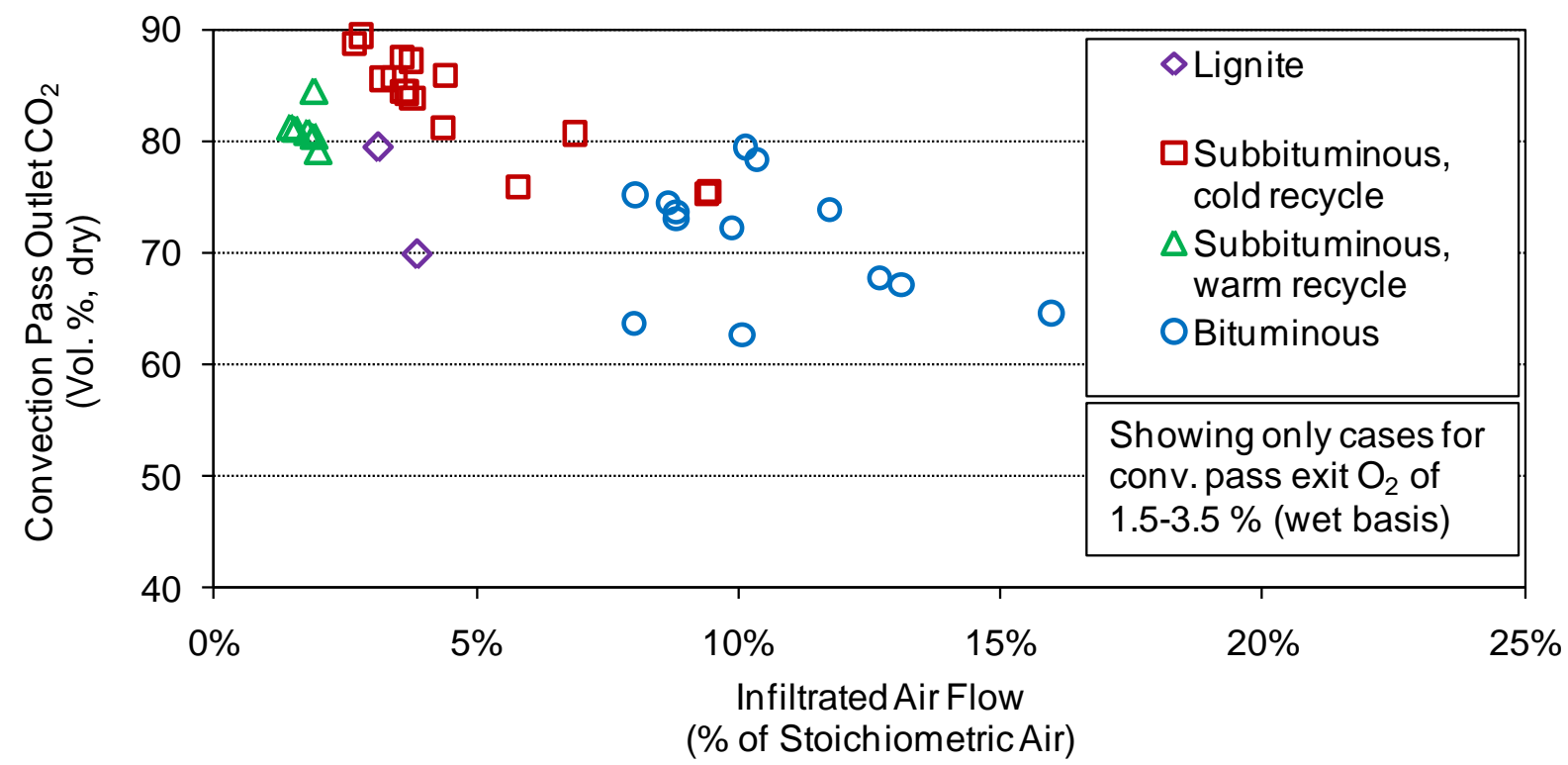

Figure $\mathrm{S} .2 \mathrm{CO}_{2}$ at convection pass outlet as a function of infiltrated air 

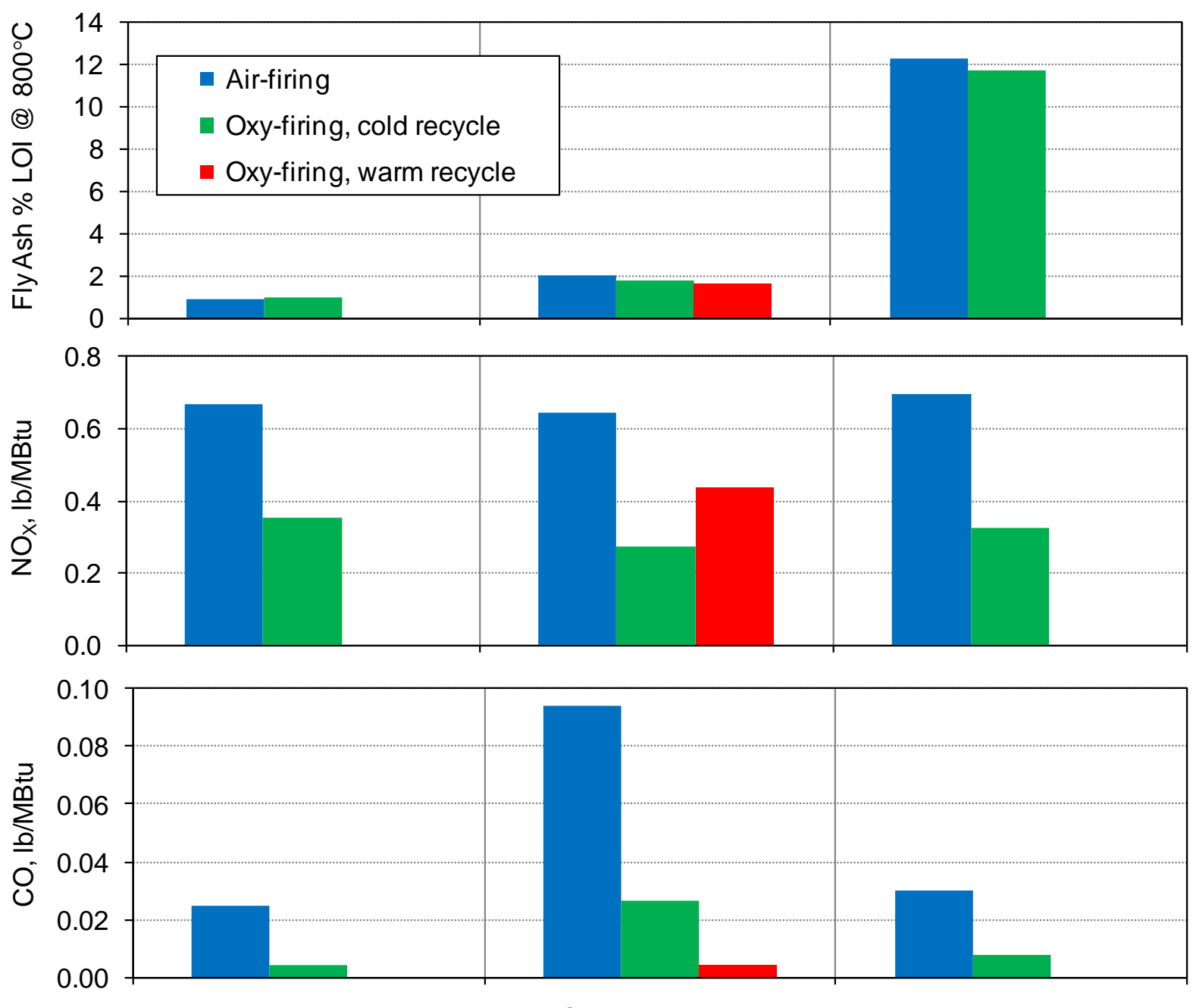

Lignite

Subbituminous

Bituminous

Figure S.3 Comparison of LOI, and emitted $\mathrm{NO}_{\mathrm{X}}$ and $\mathrm{CO}$ for optimum operating conditions 

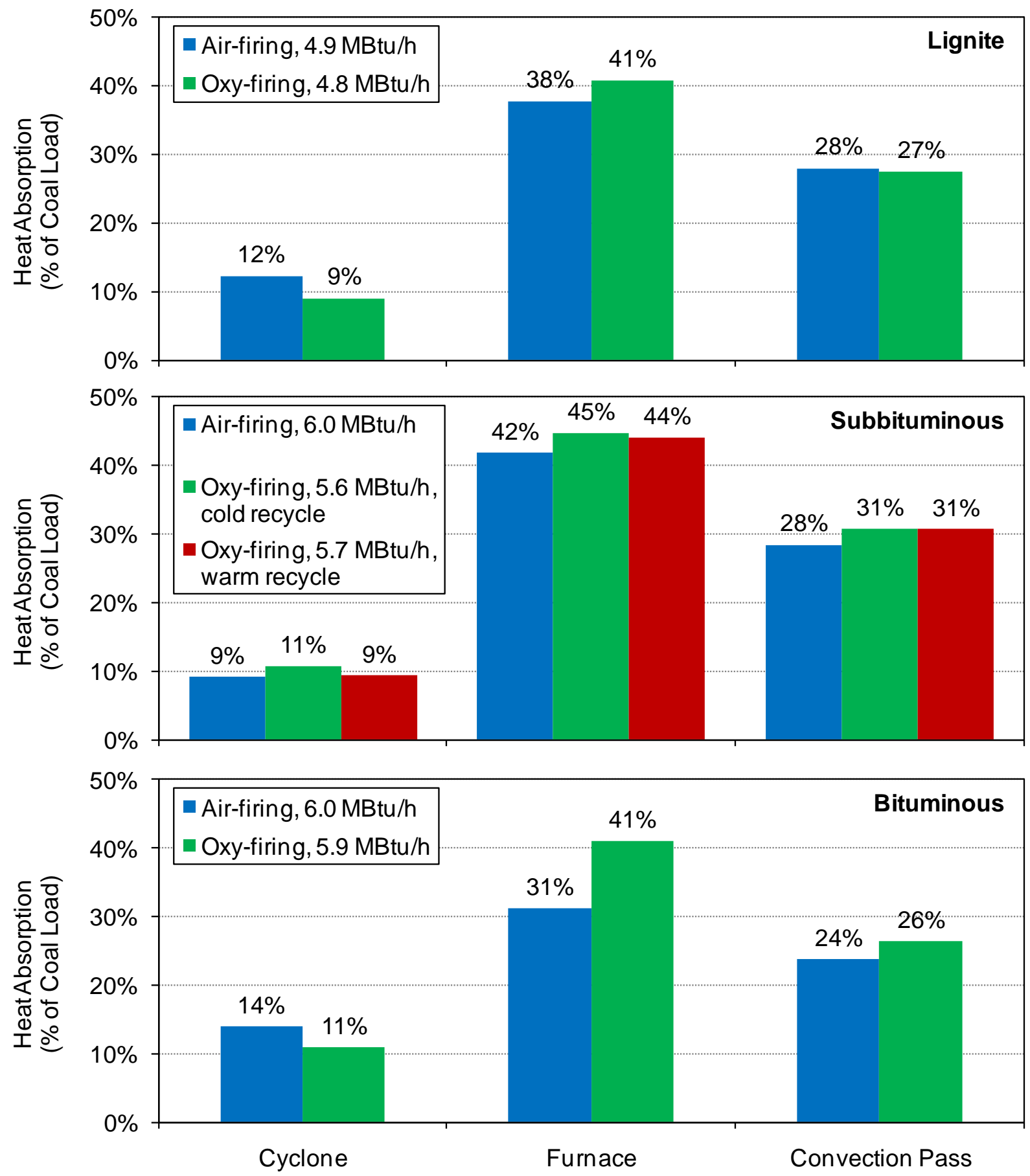

Figure S.4 Comparison of the Cyclone, furnace, and convection pass heat absorption for optimum operating conditions 


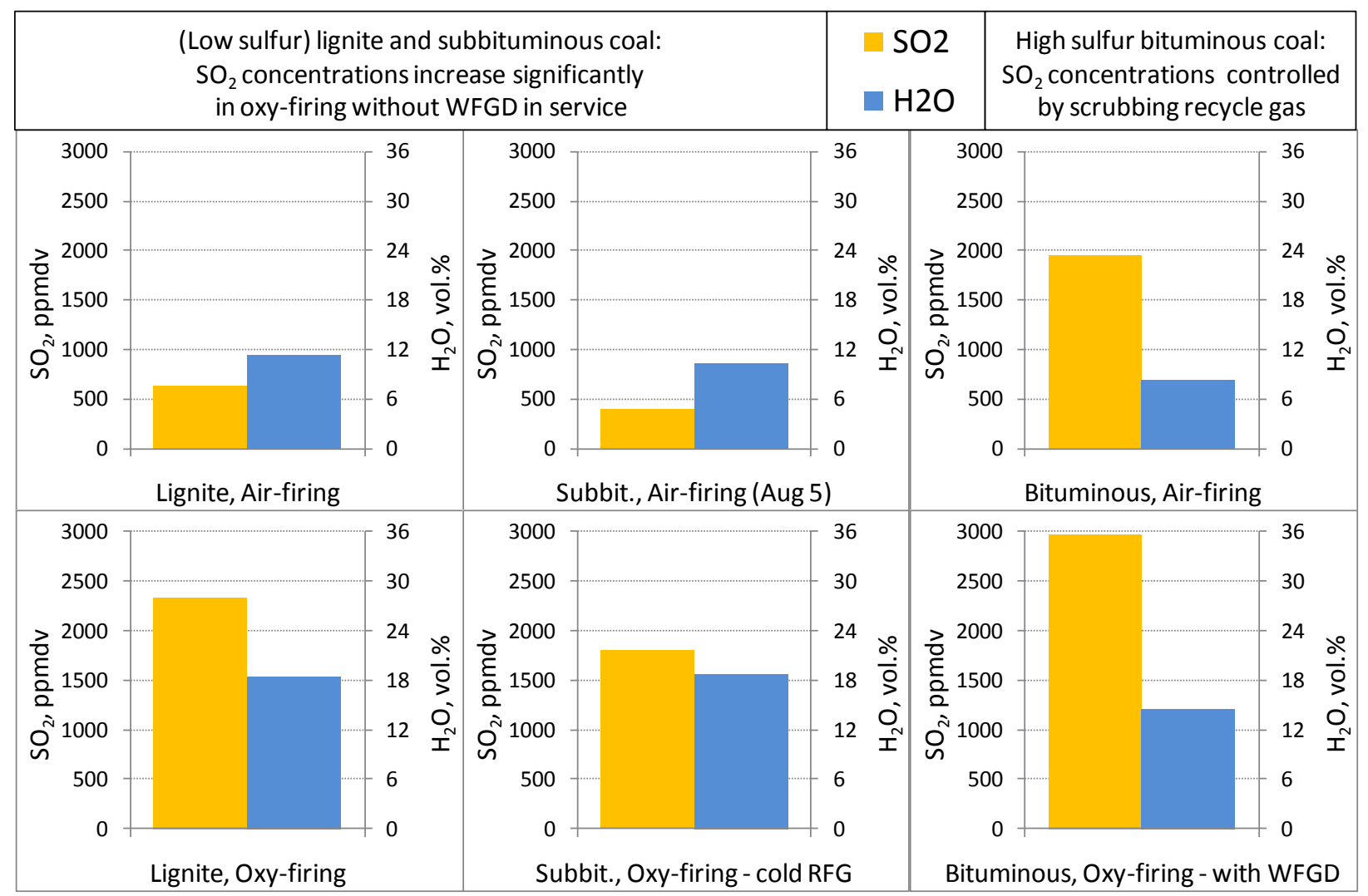

Figure S.5 Comparison of air and oxy-firing $\mathrm{SO}_{2}$ and moisture concentrations (convection pass exit) showing the effect of $\mathrm{SO}_{2}$ scrubbing of the recycle gas

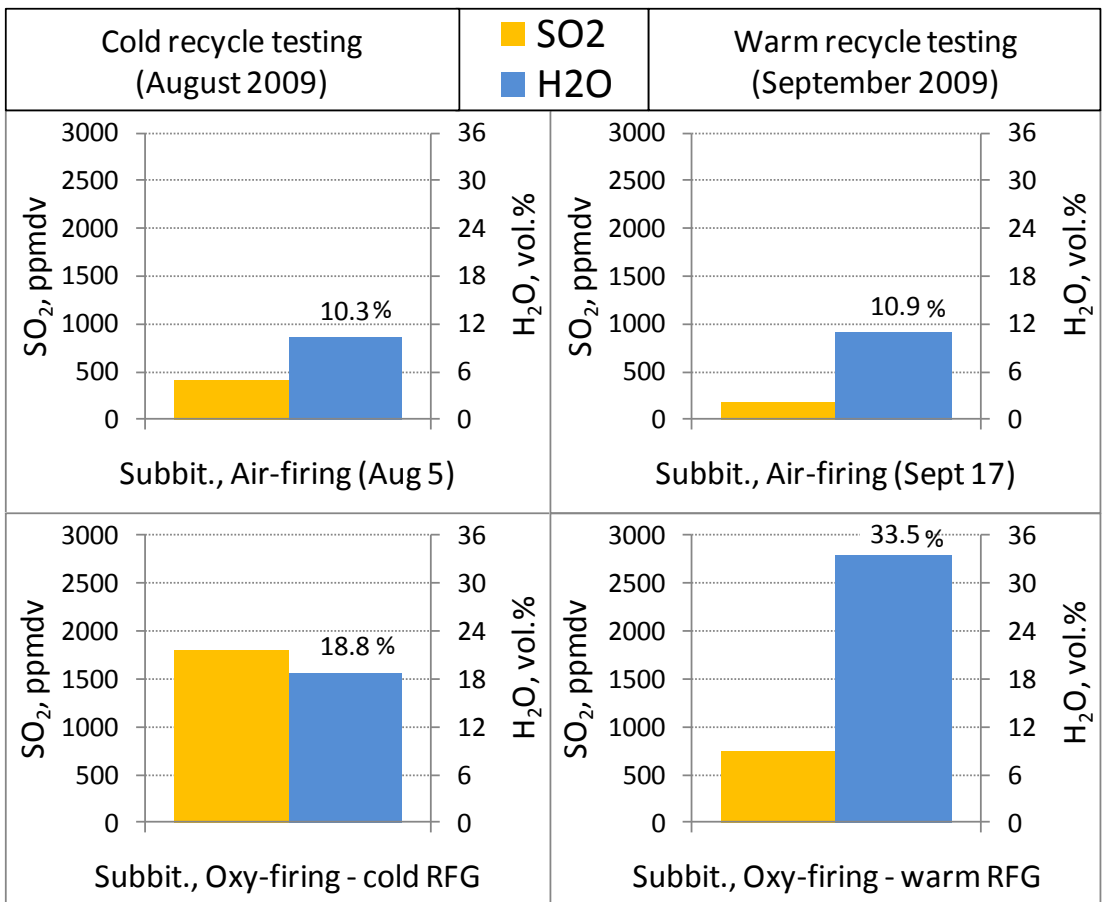

Figure S.6 Comparison of air and oxy-firing $\mathrm{SO}_{2}$ and moisture concentrations (convection pass exit) showing the effect of switching to warm recycle 


\section{$\mathrm{CO}_{2}$-CPU Process Modeling Study}

The primary goal of this study was to develop a $\mathrm{CO}_{2}$ compression and purification unit (CPU) that could accept flue gas from the boiler island and produce a purified $\mathrm{CO}_{2}$ stream to meet pipeline specifications. A secondary goal was to understand the source of the costs, especially operating costs, in the purification process so as to guide future research in attempting to relax product specifications and/or improve capture efficiency.

$\mathrm{B} \& \mathrm{~W}$ performed an evaluation of gas composition leaving the boiler for the compression and purification unit and/or recycled to the boiler. The purpose of this evaluation was to investigate the impact of coal type and air leakage on the flue gas composition. Three coals were used in this study: a North Dakota Lignite; Decker, a subbituminous coal from Montana; and Illinois No. 6, high volatile bituminous coal. The results were delivered to Air Liquide for CPU modeling.

Three purification schemes were studied to cover the spectrum of capture options and provide information about the costs of different processing steps within the CPU. The first case did not attempt any purification beyond dehydration of the flue gas to pipeline specifications. This case minimized processing operations in the CPU but resulted in large amounts of inerts present in the product stream to the pipeline. The second case provided a bulk separation of inert gases from the flue gas stream, in addition to dehydration, resulting in a smaller volume of higher purity $\mathrm{CO}_{2}$ product to the pipeline. The final scheme further processed the latter product stream to remove minor contaminants like $\mathrm{SO}_{\mathrm{X}}, \mathrm{NO}_{\mathrm{X}}$, and $\mathrm{O}_{2}$ down to ppm levels as required for some contaminants by current pipeline specifications (Kinder Morgan).

The main conclusion of the study is that removal of the inerts in a purification step leads to lower overall energy requirement of the CPU. This is because the compression of inerts to the high pipeline pressure ( $\geq 2200$ psig) requires more energy than that spent in separating inerts from the flue gas. As a result, it is better to perform bulk separation of inerts even if there are no technical barriers to introducing inerts into the pipeline or the sequestration reservoir. The extent of energy savings depends on the pipeline pressure, but is significant for all practical pipeline pressures for $\mathrm{CO}_{2}$ transport. Further treatment of the purified $\mathrm{CO}_{2}$ to remove minor contaminants did not incur significantly higher energy costs. Thus, it is relatively inexpensive from an energy perspective to distill the product stream to achieve current pipeline specifications.

The major energy expense in the process is in the compression steps. The compression energy requirement depends on the amount of inerts present in the flue gas, or in other words, the $\mathrm{CO}_{2}$ purity in the incoming flue gas. Higher $\mathrm{CO}_{2}$ purity corresponds to lower compression energy (See Figure S.7). Reducing the inert volume by 10 percentage points (i.e. reducing $\mathrm{N}_{2}$ from $20 \%$ to $10 \%$ by volume in the flue gas) led to a $15-18 \%$ decrease in the specific energy requirement of the CPU. Thus, reduction of air infiltration into the system can have a major impact on the overall expense of the $\mathrm{CO}_{2}$ capture process. 


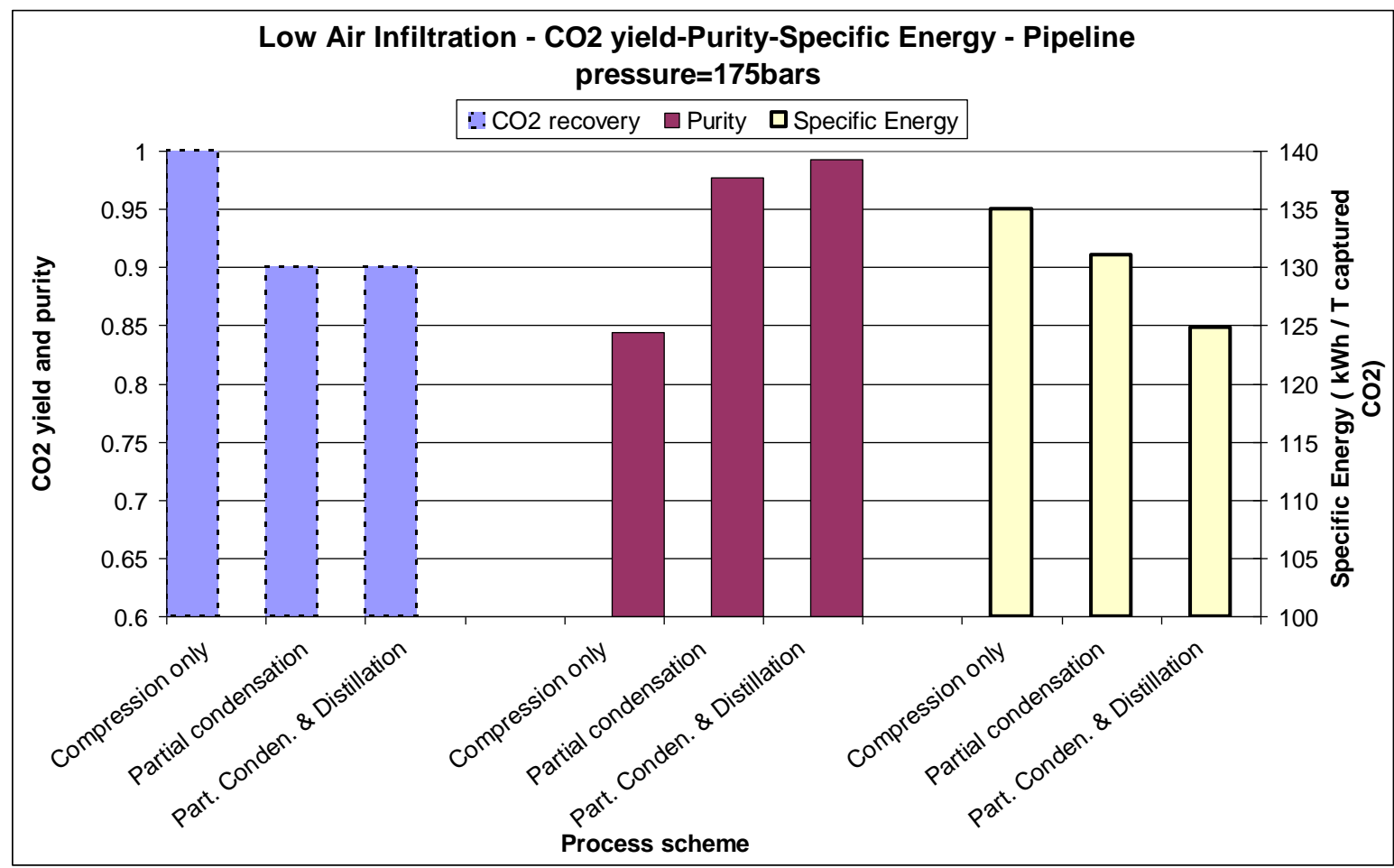

Figure $\mathrm{S} .7$ Comparison of $\mathrm{CO}_{2}$ yield (recovery), $\mathrm{CO}_{2}$ purity and specific energy of the $3 \mathrm{CO}_{2}$ capture processes for case of low air infiltration

In summary, purification of flue gas actually leads to lower specific energy expense due to the rejection of inerts at lower pressure than the final product pressure. It is possible to purify the flue gas to achieve current $\mathrm{CO}_{2}$ pipeline specifications of major North American pipeline companies such as Kinder Morgan.

\section{$\mathrm{CO}_{2}$ Sequestration Modeling}

Battelle performed the $\mathrm{CO}_{2}$ sequestration study and their activities were conducted in two phases. In the first phase, an assessment was made to understand processing requirements for flue gas treatment that would be necessary for injecting $\mathrm{CO}_{2}$ into deep geologic formations. In the second phase, Battelle conducted a broad screening level assessment of the potential for storing $\mathrm{CO}_{2}$ in deep geologic formations in the vicinities of selected existing boilers. These data were used to qualitatively determine the suitability of each selected plant for a more detailed sitespecific evaluation of $\mathrm{CO}_{2}$ storage. Parameters that were considered critical to the process were identified and established as criteria for distinguishing between plants that may be acceptable candidates for storage evaluation, vs. plants that may be unacceptable. These parameters were:

- Boiler size

- Proximity to a storage location

- Seismic risk

Two paradigms were considered for disposing of the flue gas. One approach was to consider collecting and compressing the entire gaseous effluent for injection into a suitable geologic 
formation (known as co-sequestration). The other approach looked at separating the gas components that may not be advantageous to long-term injection. For example, it may be advantageous to remove oxygen so that it does not react with metals and cause corrosion. Nitrogen and argon are non-condensable, inert gases that would take up pore space in the storage reservoir that otherwise could be used to store $\mathrm{CO}_{2}$. Furthermore, $\mathrm{SO}_{\mathrm{X}}$ and $\mathrm{NO}_{\mathrm{X}}$ may need to be removed to meet regulatory compliance for down-hole injection.

The concept of carbon capture and storage (CCS) has dealt largely with relatively pure (98-99\%) carbon dioxide $\left(\mathrm{CO}_{2}\right)$. The high purity of $\mathrm{CO}_{2}$ used in most demonstration studies to date is the result of opting for industrial quality gas, as opposed to scrubbed $\mathrm{CO}_{2}$ from a flue gas stream, or some other gas mixture containing dilute $(<20 \%) \mathrm{CO}_{2}$. Indeed, flue gas from coal combustion contains a number of impurities (such as $\mathrm{NO}_{\mathrm{X}}, \mathrm{SO}_{2}$, flyash, mercury etc.) that likely will have impact on compression, transportation, and storage. This investigation explores the potential need for conditioning oxy-coal flue gas to selectively remove compounds that would be problematic. A top down assessment was employed to understand the effects of flue gas impurities on the expected sequence of processes to assess economic viability (Figure S.8). The differences between the behaviors of pure $\mathrm{CO}_{2}$ and simulated oxy-combustion flue gas were examined to understand how each of the process steps is affected by impurities in the flue gas.

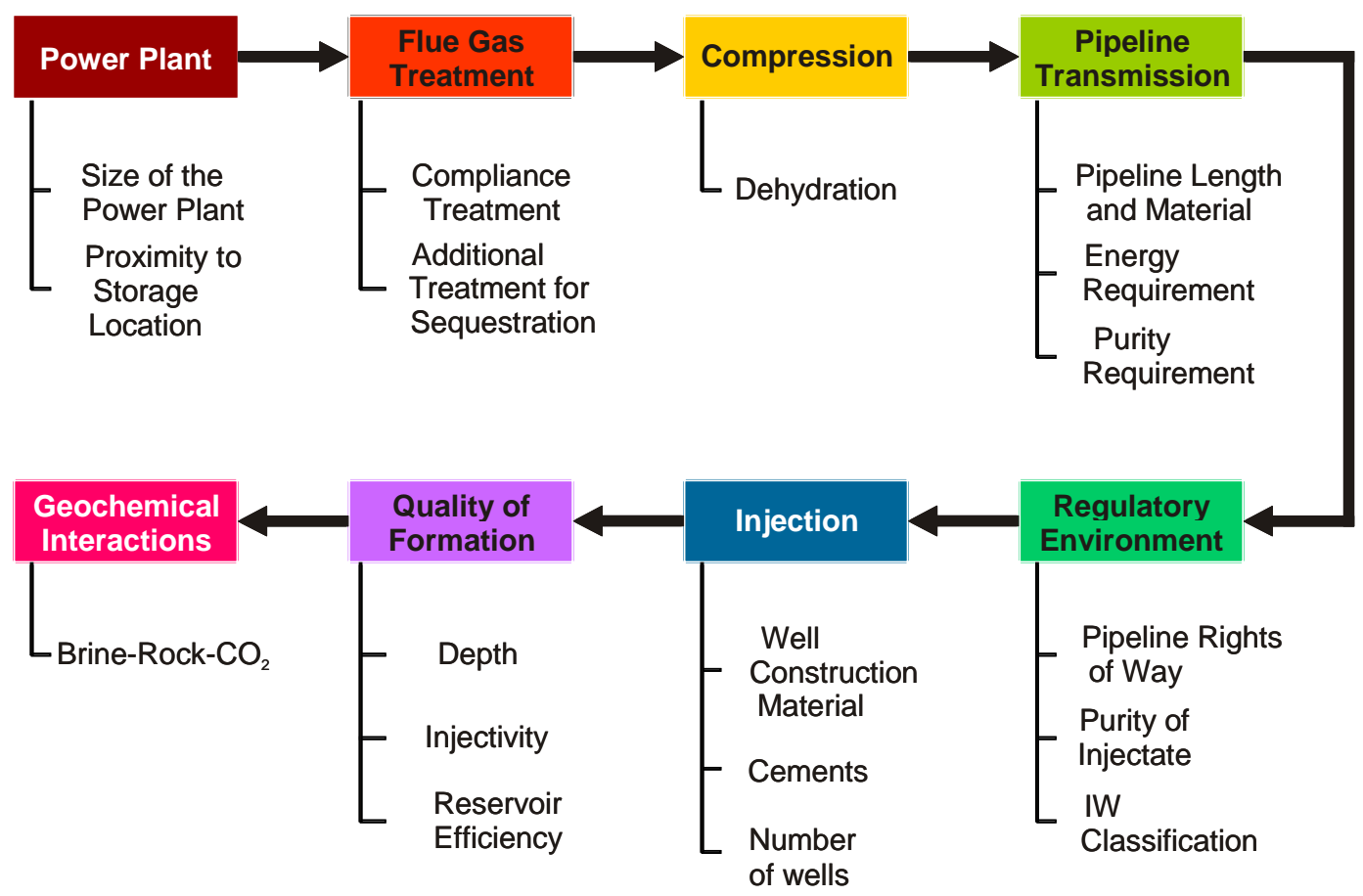

Figure S.8 Process description for flue gas interactions

Numerical simulations of injecting pure $\mathrm{CO}_{2}$ and oxy-combustion flue gas were conducted using the STOMP-WCS-R (water, $\mathrm{CO}_{2}$, salt and reactions) simulator (1). The STOMP code is capable of modeling complex, coupled hydrologic, chemical, and thermal processes, including multifluid flow and transport, partitioning of $\mathrm{CO}_{2}$ into the aqueous phase, and chemical interactions with aqueous fluids and rock minerals. Modeling showed that co-sequestration of oxy- 
combustion flue gas is possible in some of the geological sites. It was concluded that water vapor has to be removed to reduce pipeline corrosion. However, as mentioned earlier, CPU modeling (performed by Air Liquide) determined that removal of the impurities in a purification step leads to lower overall energy requirement of the CPU. Therefore, the engineering feasibility and economic evaluation was performed with a CPU to reduce impurities of flue gas before transportation and storage in a geological site.

\section{Engineering and Economic Evaluation}

The purpose of the economic evaluation was to determine the cost of the oxy-combustion technology for a variety of boilers. A sensitivity study was performed to determine the following key parameters:

- Boiler firing conditions: wall-firing and Cyclone firing (tangential-firing was excluded)

- Boiler load: $650 \mathrm{MWe}$ and $780 \mathrm{MWe}$

- Boiler steam cycle: subcritical, supercritical, and ultra-supercritical (greenfield application)

- ASU and CPU type: today's technology and upgraded technology that uses less power (ASU optimized for oxy-combustion).

- Overall, a 30\% reduction in the capital cost of the CPU is forecasted for future greenfield cases

- Fuel: bituminous, subbituminous, and lignite

- Oxy-firing process: cool recycle (partially scrubbed), and warm recycle

- Boiler air infiltration : 2 to $10 \%$ of theoretical air

- Oxygen purity: $80 \%, 85 \%, 90 \%$, and $95 \%$

$\mathrm{B} \& \mathrm{~W}$ and Air Liquide performed a joint study where B\&W determined the boiler firing conditions such as mass flow rates of oxygen required, flue gas recycle, and flue gas to purification unit. This data was delivered to Air Liquide for determinations of energy required and the cost of the ASU and CPU equipment. B\&W compiled all of the information and determined the overall cost of electricity. Most of the work was performed for existing boilers. In addition, greenfield applications were studied to evaluate the effect of higher boiler efficiency as well as future improvements to the ASU and CPU unit. Some of the pertinent findings are:

- $\quad$ The efficiency loss for retrofitting oxy-PC ranges between 7.9 and 8.9 percentage points and is fairly consistent whether for a subcritical or supercritical plant (see Figure S.9).

- The efficiency loss for oxy-PC in greenfield applications is considerably lower than for retrofit ranging between 5.3 and 6.4 percentage points. This is due to the ability to better integrate heat into the steam cycle and the higher efficiency of the steam cycle which reduces coal, oxidant, and $\mathrm{CO}_{2}$ flows and all associated power requirements (see Figure S.10). 


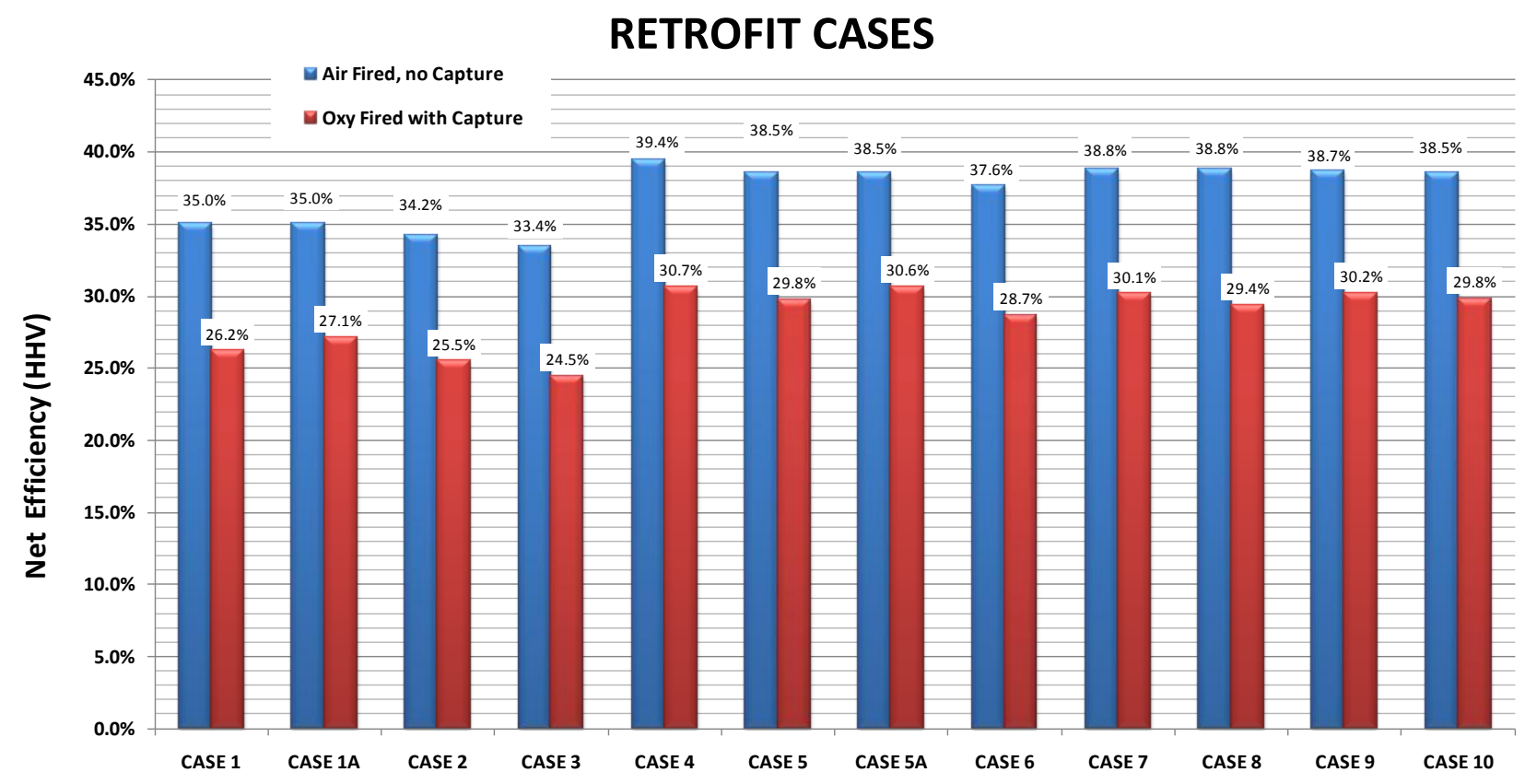

Figure S.9 Performance results for retrofit cases - net plant efficiency

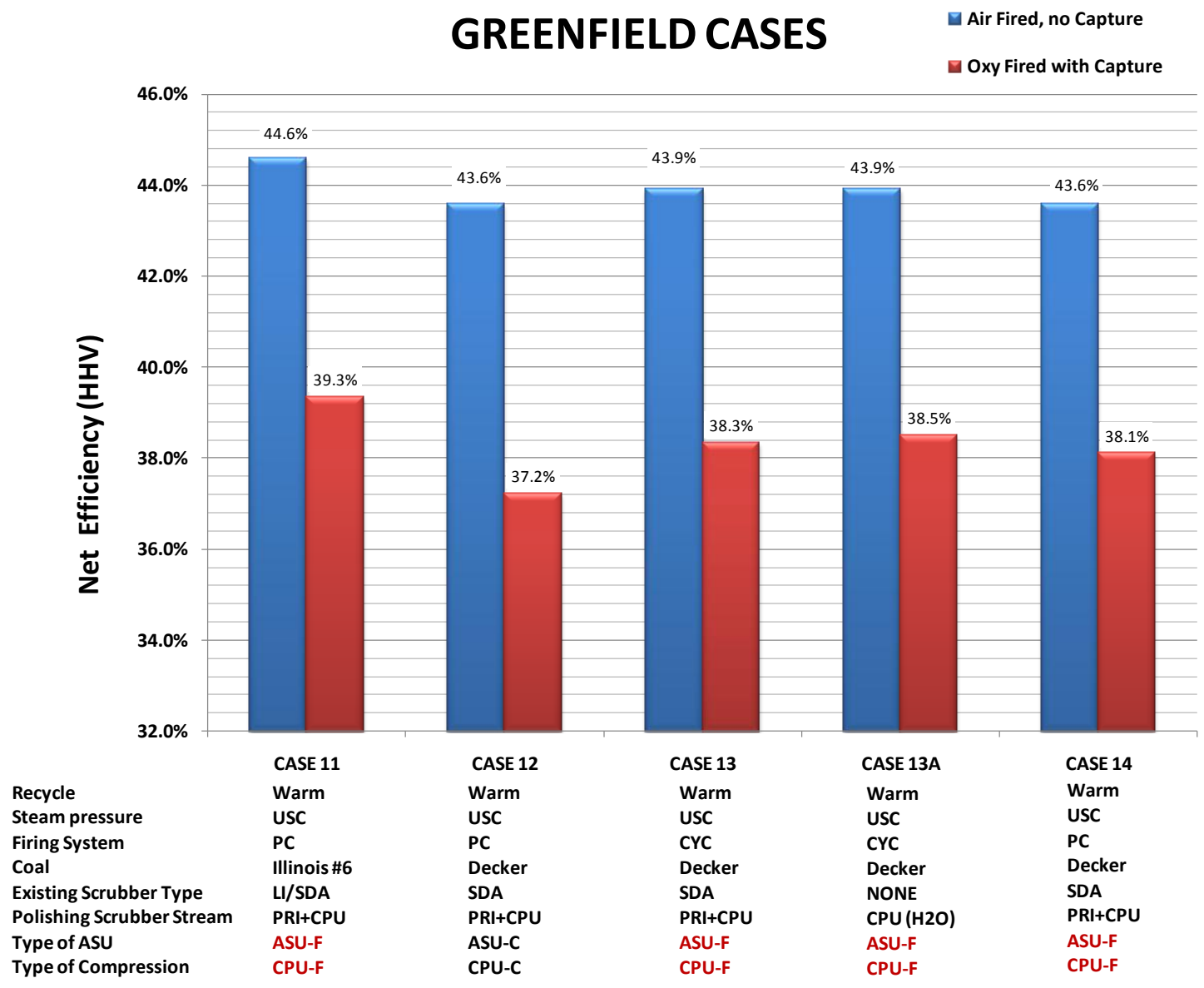

( $\mathrm{C}=$ current, $\mathrm{F}=$ Future)

Figure S.10 Performance results for greenfield cases - net plant efficiency 
- The air infiltration sensitivity analysis shows that air infiltration should be kept as low as possible and that the impact is steep between $2 \%$ and $5 \%$ and then moderates out to $10 \%$. Clearly no air infiltration is best but the amount of effort (cost) to minimize air infiltration must be weighed against the life-cycle cost. An investment on the order of $\$ 90$ million dollars could be justified to reduce air infiltration from $10 \%$ down to $2 \%$ (see Figure S.11). This represents about $12 \%$ of the total plant cost without $\mathrm{CO}_{2}$ transportation, storage, and monitoring (TS\&M).

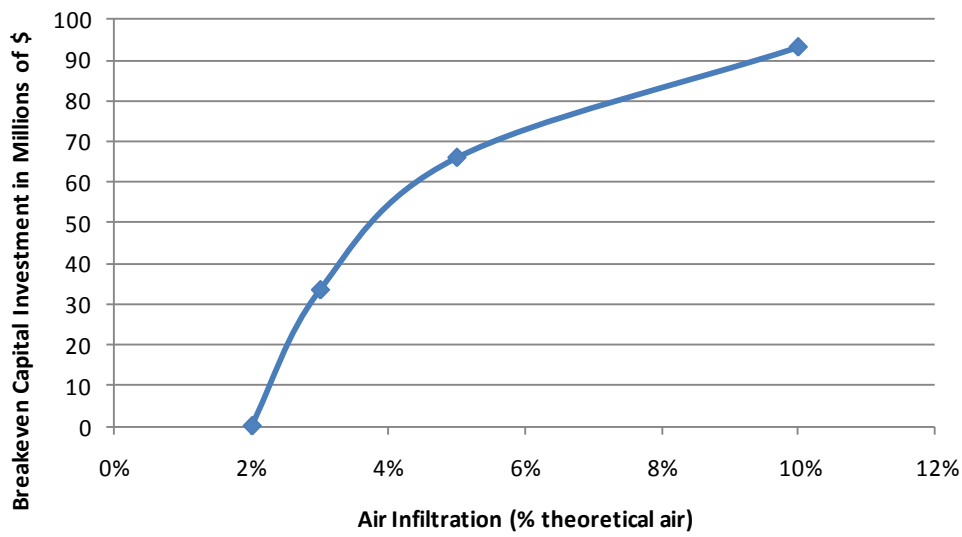

Figure S.11 Breakeven capital investment to mitigate air infiltration

- The oxidant purity sensitivity analysis shows that oxidant purity has considerably less impact than air infiltration and the trends in both net efficiency and LCOE are nearly linear. However, decreasing oxidant purity below $95 \%$ has no benefit in that it not only reduces net efficiency but it also raises LCOE. This demonstrates that at least $95 \%$ purity is beneficial, and higher purity may further increase benefits. However, current thinking is that $96.5 \%$ may become the standard in that above $96.5 \%$ there is a technology change that has a drastic impact on ASU operating cost (see Figure S.12).

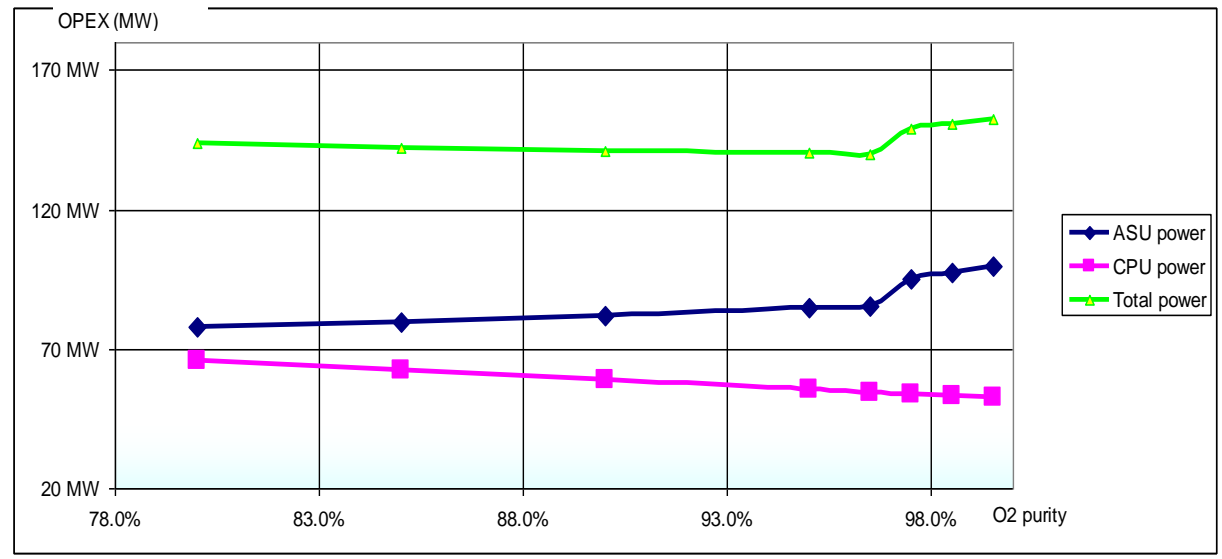

Figure S.12 Power consumption of ASU and CPU as a function of product oxygen purity 
- This study demonstrated that oxy-combustion is an economically viable technology for existing boilers. Figure S.13 shows that the incremental cost ${ }^{1}$ of oxy-combustion for existing boilers (subcritical and super-critical) varies between 5 to $7 \phi / \mathrm{kWh}$. Cost of electricity for greenfield boilers using oxy-combustion coupled with ultra-supercritical boilers was only $25 \%$ higher than LCOE for a supercritical boiler under air-firing, well below the DOE target of $35 \%$.

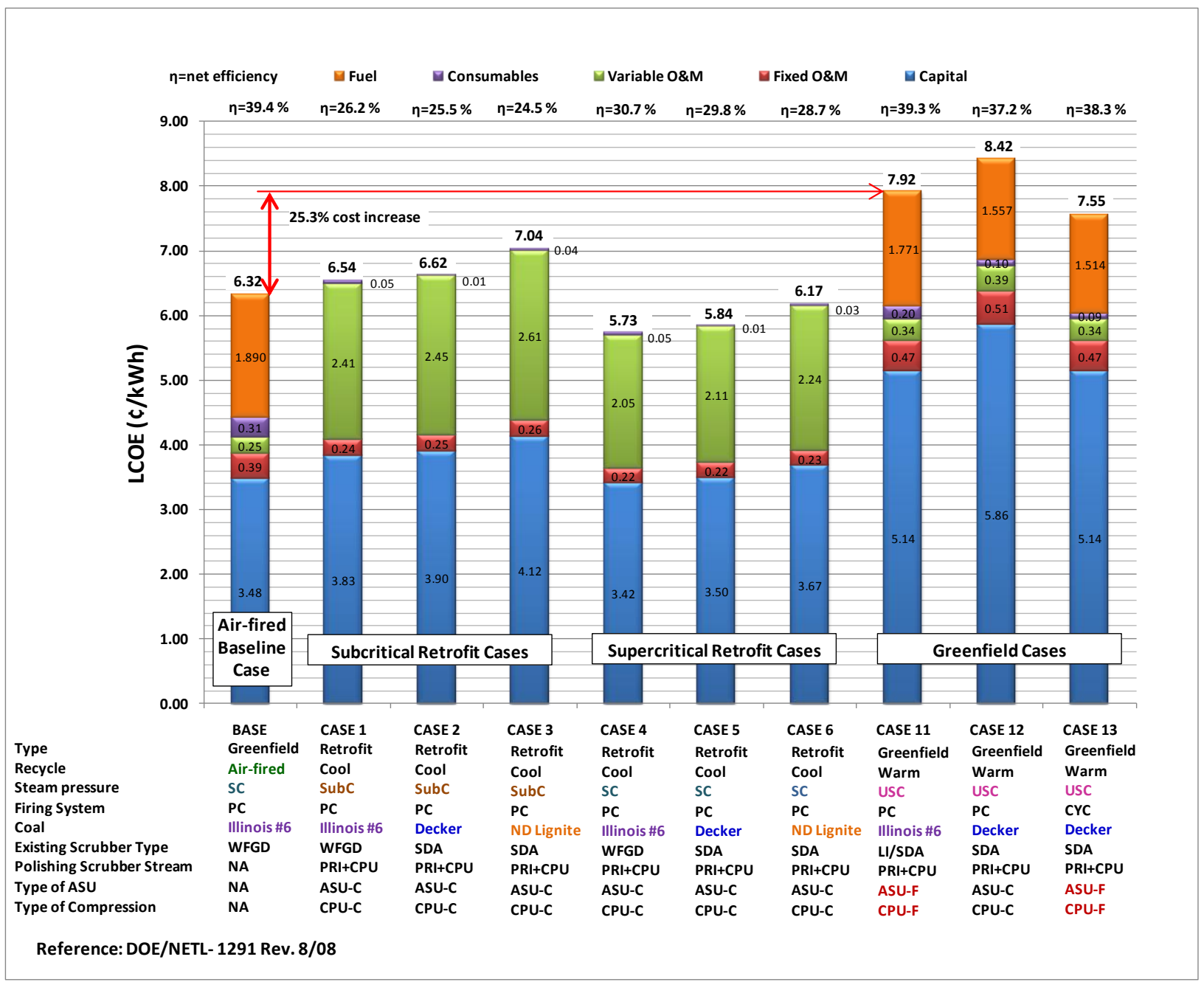

Figure S.13 Comparison of Levelized Cost of Electricity

${ }^{1}$ The LCOE reported for all retrofit cases is based on incremental LCOE meaning it assumed the plant is fully depreciated and there is no capital expense remaining. No costs associated with the base plant operation are included in the O\&M costs. Although this does not produce an LCOE comparable to a greenfield unit, this approach was taken to be consistent (and allow comparison with) previous DOE studies. 
- The incremental LCOE shown in Figure S.13 for retrofit applications is not directly comparable to greenfield LCOE. However, if the base plant capital expense is zero (fully depreciated), then a direct comparison can be made by simply adding the base case O\&M (fixed + variable), consumable, and fuel costs to the incremental retrofit LCOE. This total is comparable and could be used to compare the total cost of retrofit of an existing plant vs. building a new one. For example the LCOE for a greenfield USC plant for Decker coal would be $8.42 \phi / \mathrm{kWh}$ (see Case 12) compared to $8.68 \phi / \mathrm{kWh}$ for retrofitting an existing supercritical plant.

It is of prime importance to recognize the progress achieved to date. Earlier studies (2) showed oxy-combustion increased the LCOE by $44 \%$ for an ultra supercritical boiler. In a separate project sponsored by B\&W and Air Liquide, heat integration between ASU, steam turbine, and boiler was performed that increased the gross turbine output and reduced auxiliary power requirement for oxy-firing. This current study further optimized the ASU, CPU, and boiler operation resulting in the lowest LCOE increase of only $25 \%$ over air-firing operation. Continued R\&D funding is required to show its viability in commercial applications and to strive for reducing its cost.

\section{Applicability of the Technology}

Site Screening to Identify Potentially Suitable Sequestration Demonstration Sites An important aspect of the overall geologic storage task was to consider high-level screening criteria to identify potentially suitable site locations. The criteria selected by the project team to evaluate plant sites for $\mathrm{CO}_{2}$ storage potential were: boiler specifications; location in relation to deep sedimentary basins; and degree of seismic hazard. The boiler specification included nameplate rating (all exceeding $200 \mathrm{MWe}$ generating capacity, in the interests of controlling project cost on a $\$ / \mathrm{kW}$ basis), boiler type (wall-fired and Cyclone), and $\mathrm{CO}_{2}$ emission rate. Location, and especially distance of less than 50 miles to a deep sedimentary basin, is an important consideration to avoid long run pipelines. Seismic hazard was selected as a screening parameter to avoid expenses of additional construction requirements. The current screening is a high-level evaluation of boilers in relation to regional geological setting. Overall, the screening, site assessment, and sequestration design are a multiphase, multi-year effort. Once a site is identified, a more detailed feasibility study may be completed to identify storage intervals. If the project proceeds further, the future phases may consist of site-specific seismic surveys, drilling and characterization, detailed reservoir modeling and system design. The results of this initial assessment should not be viewed or interpreted as a definitive assessment of suitability of candidate geologic $\mathrm{CO}_{2}$ storage formations, the presence of suitable caprock, or sufficient injectivity to allow $\mathrm{CO}_{2}$ sequestration to be carried out in an economic manner. Rather, this should be used as an initial screening assessment for potential storage opportunities for the boiler sites.

Data used in this study came from a few widely recognized sources. The USGS Earthquake Seismic Hazards program provided the seismic hazard contour lines used to assign a seismic hazard value to each boiler location. The deep saline basins shape file used to determine if a boiler location was in or near a deep saline formation was provided by NatCarb, a project funded by the U.S. Department of Energy's National Energy Technology Laboratory. This work was performed using ESRI Arc Map 9.3.1, a part of ArcGIS Desktop 9.3.1. 
The criteria selected by the project team to evaluate plant sites for $\mathrm{CO}_{2}$ storage potential reduced the number of applicable boilers from 1924 down to 146. These boilers were predominantly located in the Ohio River Valley and the Gulf Coast with a few scattered around the intermountain West and the Dakotas. The boilers located near the Ohio River Valley and the Gulf Coast are especially good potential sites for CCS projects as they are located in areas with heavy $\mathrm{CO}_{2}$ emissions due to power plants and refineries.

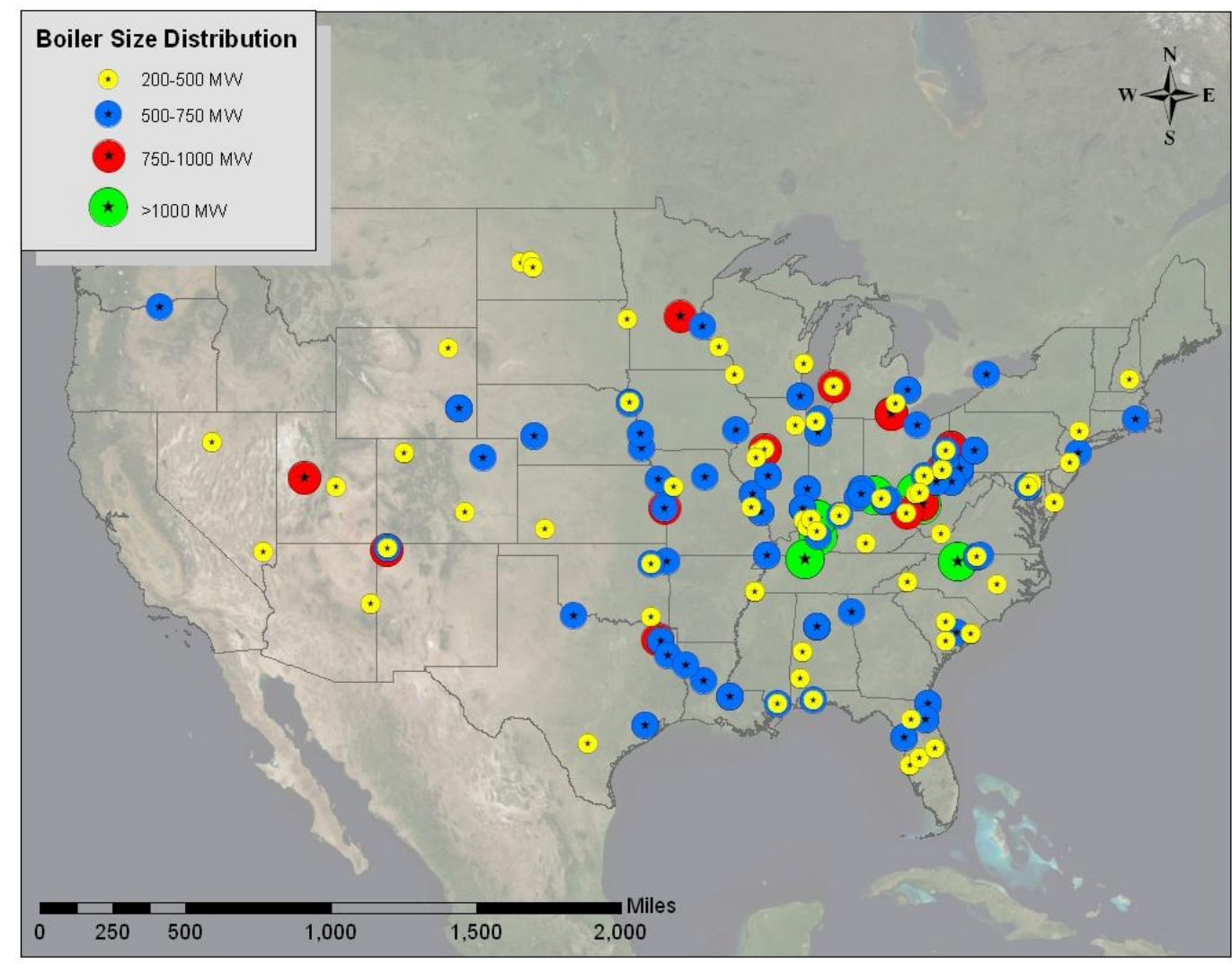

Figure S.14 Boilers meeting size requirements (>200 MWe)

\section{Conclusions and Recommendations}

The following conclusions and recommendations were drawn from the results of this project:

\section{Conclusions from the pilot scale evaluation:}

- Oxy-firing is a technically viable technology for wall-fired and Cyclone boilers firing bituminous coal, western subbituminous coal, and North Dakota lignite.

- Flame stability and Cyclone slagging characteristics were not negatively impacted by oxy-firing.

- Boiler $\mathrm{NO}_{\mathrm{X}}$ and $\mathrm{CO}$ emissions, and unburned combustibles are lower for oxy-firing than air-firing. 
- Radiant boiler and convection pass heat absorptions under oxy-firing conditions can be similar to air-firing by controlling flue gas recycle and oxygen flow rates.

- Flue gas concentrations of $\mathrm{CO}_{2}$ (up to $90 \%$, dry volume basis) were achieved when air leakage was minimized by minimizing pressure drop in the boiler back-end equipment.

- For application of oxy-firing to high sulfur coals, $\mathrm{SO}_{2}$ must be scrubbed from recycle gas to control boiler corrosion.

- Higher flue gas $\mathrm{SO}_{3}$ emissions were generated at the convection pass exit with oxy-firing than air-firing. The $\mathrm{SO}_{3}$ concentrations were reduced by operation of the wet scrubber and condensing heat exchanger. Higher $\mathrm{SO}_{3}$ concentrations could increase corrosion if the flue gas temperature goes below the acid dew point.

Conclusions from compression, purification, transportation and sequestration evaluation:

- Co-sequestration of $\mathrm{CO}_{2}$ and $\mathrm{SO}_{2}$ might be feasible in deep geological reservoirs.

- Pipeline transportation corrosion caused by acid gases can be minimized by removing the moisture from the flue gas.

- CPU modeling demonstrated that the overall energy requirement is lower if flue gas inerts are removed in the CPU rather than compressing the entire flue gas for pipeline transport.

Conclusions from the feasibility and economics evaluation:

- Oxy-firing is an economically viable CCS technology for existing boilers. The predicted incremental cost of oxy-firing for existing boilers (subcritical and supercritical) varies between 5 to $7 \phi / \mathrm{kWh}$ which is competitive with other CCS technologies.

- Levelized Cost of electricity for greenfield boilers using oxy-firing coupled with ultrasupercritical boilers was about $25 \%$ higher than LCOE for a supercritical boiler under airfiring, well below the DOE target of $35 \%$.

- A supercritical retrofit with cool recycle, would have marginally higher LCOE than a new warm recycle USC plant (e.g. 8.68 versus $8.42 \phi / \mathrm{kWh}$ for decker coal) but the capital investment for the new USC plant is over $67 \%$ higher than the retrofit which may be very attractive from a financing perspective for retrofitting an existing plant. This shows oxy-combustion retrofit of existing plants is a viable option. vs. building a new one.

- Oxy-firing can be applied to the majority of existing wall-fired and Cyclone boilers depending on space and existing equipment. The site requirements are very similar to those for post combustion capture but without process steam requirements (which impact the low pressure steam turbine).

- Units with $200 \mathrm{MWe}$ or larger generating capacity were considered for oxy-firing retrofit. A study of these units indicated that the majority of these units are within 50 miles of a major geological storage site. 
$\underline{\text { Recommendations for future study: }}$

- Oxy-firing $\mathrm{SO}_{3}$ emissions are important to corrosion but difficult to measure. Few data are available and the effectiveness of control processes is not well understood. Additional testing of $\mathrm{SO}_{3}$ formation and removal is highly recommended.

- Testing of wet scrubbing systems in oxy-firing has been performed by B\&W and others but little test data of dry scrubbing systems is available under oxy-firing conditions. Pilot testing with a dry scrubbing system is recommended since dry systems use less water, have lower capital cost, and better control acid gases $\left(\mathrm{SO}_{2}, \mathrm{SO}_{3}, \mathrm{HCl}\right.$, etc.). A better understanding of $\mathrm{SO}_{2}$, and acid gas removal, operation, and operating costs is needed.

- Testing with a direct contact cooler polishing scrubber added to the oxy-firing process is also recommended. These studies are necessary to understand the $\mathrm{SO}_{2}$ removal performance if very low levels of $\mathrm{SO}_{2}$ are a required specification for the CPU.

- An evaluation to determine the $\mathrm{SO}_{2}$ concentration requirements of the flue gas entering the compression and purification unit (CPU) is recommended. Currently, compressor manufacturers require very low levels of $\mathrm{SO}_{2}(<1 \mathrm{ppm})$.

- A site-specific engineering and economic oxy-firing retrofit study for an existing coalfired utility unit is recommended. This study would aid in developing a more reliable cost basis for evaluating retrofit of an existing unit with oxy-firing. A potential site for this engineering study is the AEP Conesville unit which would enable direct comparison with existing DOE studies using other technologies. 


\section{INTRODUCTION}

\subsection{Background}

The key to a strong, stable, and secure economy is readily available, reasonably-priced energy. To maintain economic competitiveness and meet growing energy demands, the US must improve the utilization of its domestic resources. Our vast resources of coal play a strategic role in electric power production but fossil fuel combustion is also a primary contributor of increased GHG emissions. As fossil fuels continue to be the dominant fuel source for electricity generation, reducing carbon emissions by capturing and sequestering $\mathrm{CO}_{2}$ from utility boilers is being considered to reduce these emissions and thereby control overall atmospheric GHG emissions. Development of the technologies that reduce GHG and minimize the cost of electricity is of a prime interest for existing coal-fired boilers. The Babcock \& Wilcox Company $(\mathrm{B} \& \mathrm{~W})$ and Air Liquide (AL) teamed to further develop the oxy-combustion technology for retrofit applications in existing coal-fired wall-firing and Cyclone ${ }^{\mathrm{TM}}$ boilers. The technology involves the replacement of the combustion air by pure oxygen diluted in recycled flue gases enabling $\mathrm{CO}_{2}$ capture from coal-fired power plants. It will be applicable with minimal pressure-part modifications to existing boilers. B\&W, AL and Battelle developed a preliminary design and prepared a budgetary cost estimate for the boiler retrofit. Air Liquide provided the expertise in the air separation unit (ASU), flue gas purification, and $\mathrm{CO}_{2}$ compression. Battelle provided expertise in $\mathrm{CO}_{2}$ transportation and sequestration.

\subsection{Project Objectives}

The overall objective of this project is to further develop the oxy-combustion technology for commercial retrofit in existing wall-fired and Cyclone boilers by 2012. To meet this goal, a twophase research project was conducted that included pilot-scale testing and a full-scale engineering and economic analysis.

Phase I objectives include:

- Evaluate at pilot -scale the effect of coal rank used in existing boilers (i.e., bituminous, subbituminous, and lignite) on oxy-combustion design.

- Determine the equipment requirements for the boiler island, including flue gas purification, $\mathrm{CO}_{2}$ compression, transportation, and storage for different coals and combustion systems (Cyclone and wall-fired).

- Investigate the potential for multi-pollutant $\left(\mathrm{NO}_{\mathrm{X}}, \mathrm{SO}_{2}\right.$, and particulate) reduction.

- Validate an existing 3-dimensional computational flow, heat transfer, and combustion model for oxy-combustion scale-up to a commercial size boiler.

Phase II objectives are as follow:

- Evaluate the impact of oxy-combustion implementation on net power production and cost of electricity for Cyclone and wall-fired applications.

- Determine the boiler population with close proximity to candidate geologic $\mathrm{CO}_{2}$ storage sites. 
- Conduct an engineering and economic assessment of the technology for commercialscale retrofit and greenfield application for Cyclone and wall-fired units.

- Assess potential $\mathrm{CO}_{2}$ control cost reductions via the integration of the air separation unit, flue gas purification, $\mathrm{CO}_{2}$ compression train, and $\mathrm{CO}_{2}$ transportation and sequestration.

Phase I activities entailed pilot-scale development of the technology at B\&W's 6-million Btu/h oxy-combustion pilot facility using different coal ranks. Parametric tests were conducted to optimize the oxy-combustion process and evaluate the Cyclone slagging, heat transfer, and overall operability. B\&W's computational fluid dynamics and combustion model was validated for oxy-combustion application with the pilot-scale data. Specifications for flue gas purification, compression, transportation, and sequestration were used to help design the environmental equipment required (e.g. scrubber, etc).

During Phase II, an engineering feasibility and economic evaluation was performed for Cyclone and wall-fired boilers. Various components of the oxy-combustion process such as ASU, flue gas purification, $\mathrm{CO}_{2}$ compression train, $\mathrm{CO}_{2}$ transportation, and sequestration were evaluated and the process was optimized. Net power production was calculated and the cost of electricity was estimated for retrofitting existing subcritical and supercritical boilers firing Eastern bituminous, Western subbituminous, and North Dakota lignite coals. For greenfield power applications ultrasupercritical boiler technology was considered and the cost of electricity was estimated. 


\section{METHODS AND APPROACH}

\subsection{Phase I - Pilot-scale Evaluation}

\subsubsection{Pilot-scale Test Facility: SBS-II}

\subsubsection{General SBS-II Facility Description}

The $6 \mathrm{MBtu} / \mathrm{h}\left(1.8 \mathrm{MW}_{\text {th }}\right.$ ) Small Boiler Simulator-II (SBS-II) was used for the pilot-scale tests. It is a new test facility and is designed for evaluating various fuels, combustion processes, air pollution control devices, and associated hardware for potential commercial use. The general layout is shown in Figure 2.1. There is a coal processing area, fan room, furnace with convection pass, heat exchangers, and various environmental controls such as baghouses and scrubbers. For oxy-firing there is an oxygen storage and delivery system, and ductwork for recirculation of flue gas. The furnace may be equipped with either a single wall-fired burner, or Cyclone furnace.

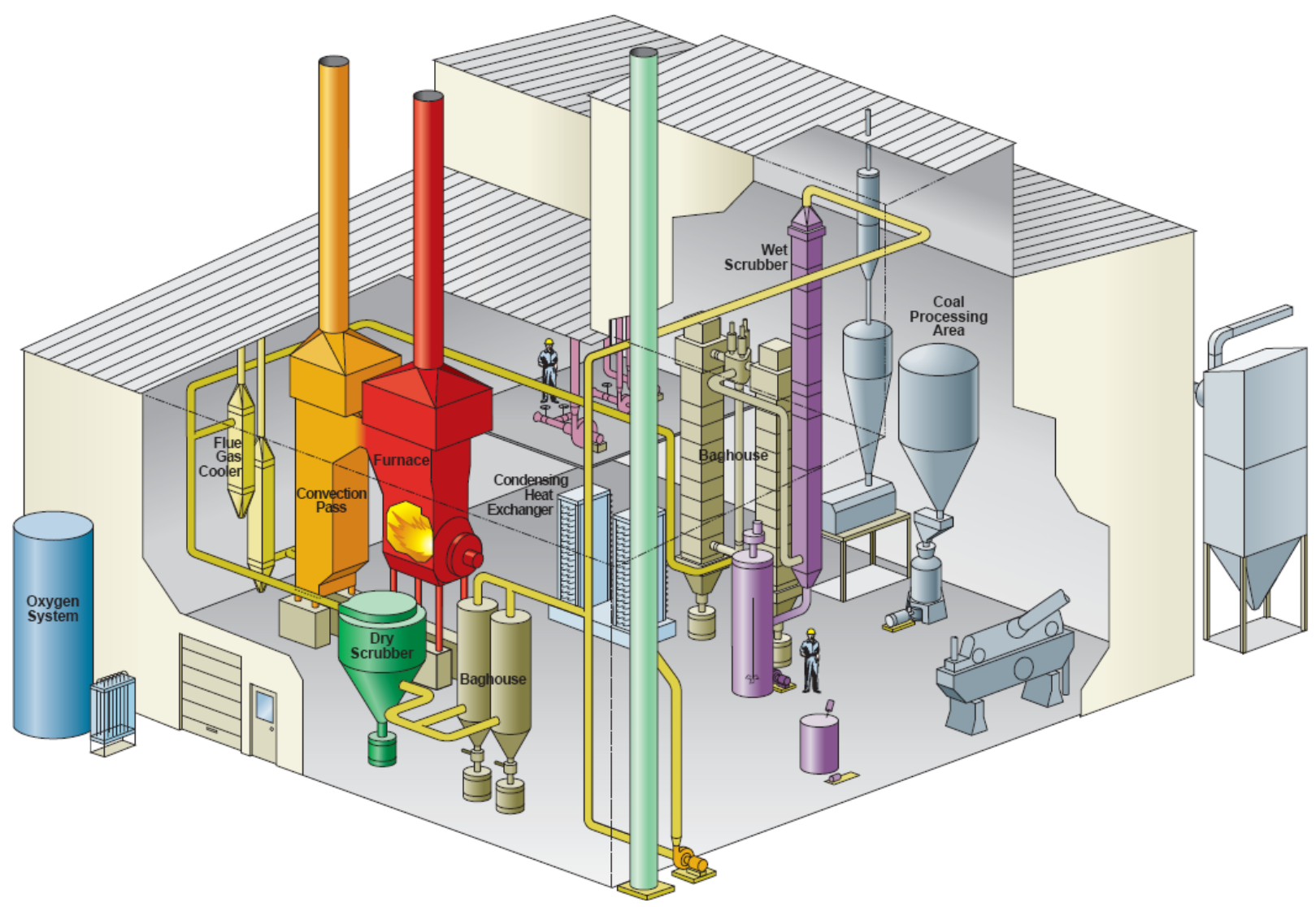

Figure 2.1 General layout of SBS-II pilot scale facility

The coal processing equipment consists of material handling equipment connecting a raw coal hopper to a coal dryer, coal crusher, crushed coal storage tank, MPS $32 \mathrm{~K}$ rolling mill (manufactured by Gebr. Pfeiffer AG, Germany), and pulverized fuel weigh feeder. If the asreceived coal is adequately dry and sized for the mill, the dryer and crusher may be bypassed. The SBS-II has an indirect firing configuration; i.e. the air used to sweep the mill is not the same 
gas used to convey the coal to the burner and initiate combustion. The mill is swept by air from a forced draft fan, and the pulverized coal (PC) and air mixture is delivered to a baghouse where the air is vented and the PC delivered to a storage tank. The coal fineness is controlled by a combination of mill settings and the variable speed of a single stage rotating classifier. During firing the coal is fed into the preheated primary air or oxidant stream by a gravimetric feeder. A full scale Cyclone burns crushed (as opposed to pulverized) coal. This physics of this pilot scale Cyclone (smaller diameter) requires pulverized coal, however with a lesser fineness requirement than a PC wall-fired burner.

The fan room contains the forced draft fans for the pulverizer, primary oxidant, and secondary oxidant. In addition, there is a booster fan that increases the pressure of the flue gas upstream of the environmental equipment. Downstream of the environmental systems, an induced draft (ID) fan (located outside of the building next to the stack) delivers flue gas to the stack. Ductwork from the outlet of the ID fan can also direct flue gas back to the fan room for recirculation. Each of the primary and secondary oxidant fans has two inlets - one for ambient air, and one for recirculated flue gas. Operator-controlled valves determine the ratio of air to recirculated flue gas for transition between air and oxy-firing. Figure 2.2 shows a schematic diagram of the system and how various components are connected by ductwork. Note that not all ductwork in the facility is represented, as some environmental equipment was not used for this work. In addition, it should be noted that bypass ducting exists for the wet flue gas desulfurization (WFGD) scrubber and the condensing heat exchanger (CHX).

Starting at the primary fan in the lower right of Figure 2.2, and following the directional arrows, the primary flow is metered prior to entering the Floxynator ${ }^{\mathrm{TM}}$ where oxygen may be injected. An electric heater preheats the primary stream to typically $150-350^{\circ} \mathrm{F}$ before tertiary oxidant is bled off to the Cyclone, and coal is added by the weigh feeder. Moisture evaporation from the coal usually lowers the temperature of the primary stream at this point. The primary stream then goes to the scroll burner of the Cyclone furnace where it enters tangentially. Tertiary oxidant also enters the scroll burner, flowing along the axis of the Cyclone for control of the ignition location.

The secondary fan also delivers air and/or recirculated flue gas to a Floxynator ${ }^{\mathrm{TM}}$ for oxygen addition during oxy-firing. The oxidant is then preheated in the air heater by hot flue gas leaving the convection pass. Independent control of the secondary oxidant temperature (desirable in a research facility) is possible by the gas-fired trim heater downstream of the air heater. Typical secondary oxidant temperatures are $600-700^{\circ} \mathrm{F}$. A venturi meters the total flow of hot secondary oxidant prior to splitting into burner and overfire streams. The bulk of the flow goes to the Cyclone furnace tangential secondary duct, and the smaller overfire stream is separately metered, and directed to two ports at the rear of the furnace below the arch. Pressure drop indicators across in-duct orifice plates allow balancing of flow between these two ports. In most oxy-firing tests, a lance is used to add additional oxygen to the secondary stream just prior to entering the Cyclone. 


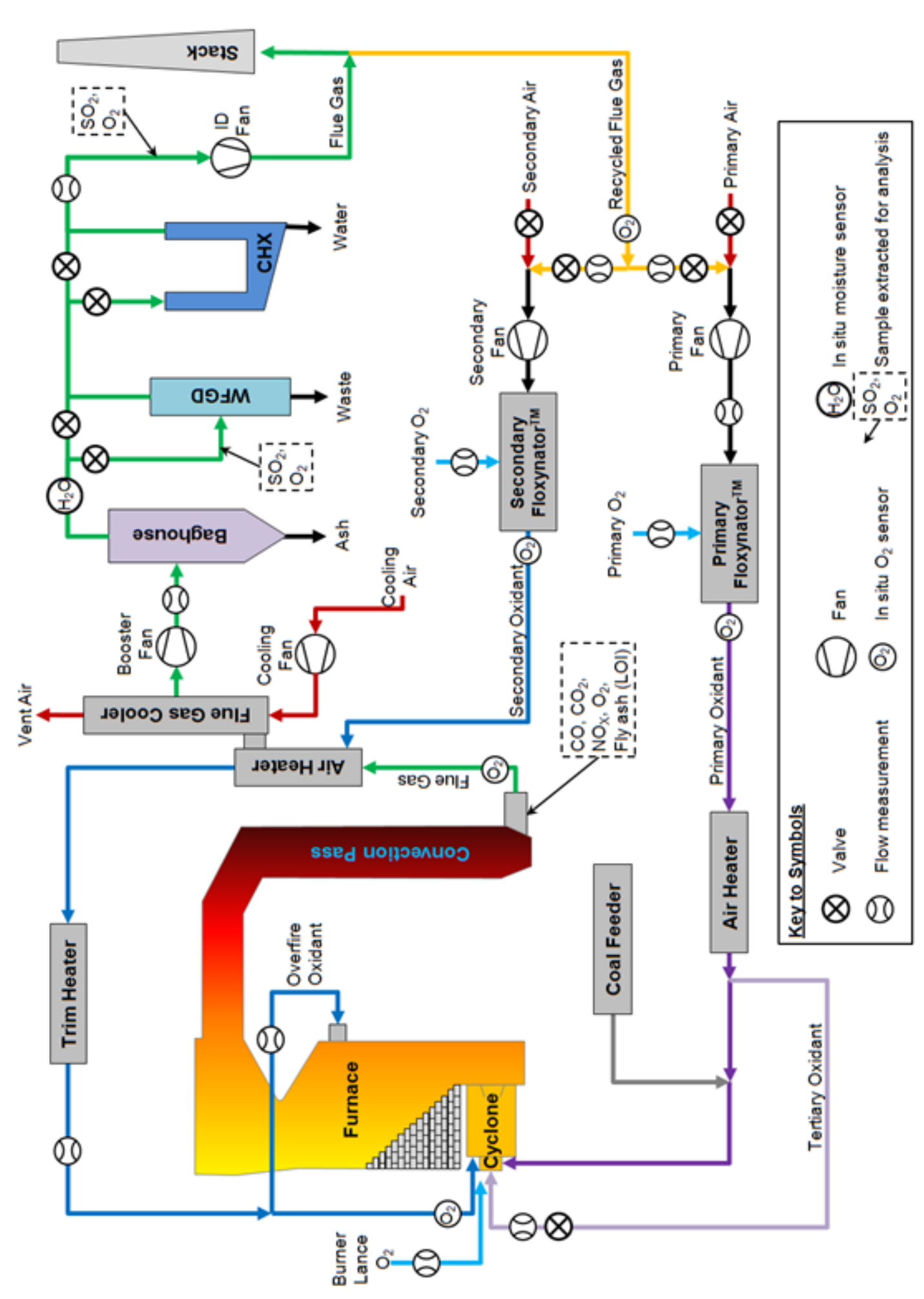

Figure 2.2 Schematic diagram of the SBS-II facility with selected instrumentation.

The WFGD and/or CHX may be bypassed. Locations of valves, flow measurement, and in situ $\mathrm{H}_{2} \mathrm{O}$ and $\mathrm{O}_{2}$ sensors are shown 
In the Cyclone furnace the intense mixing and rapid combustion generates sufficiently high temperatures to melt the ash, which collects on the walls of the Cyclone and runs out the slag tap into the water seal at the bottom of the SBS-II furnace. Fuel-rich combustion products, including some fine char particles, leave the Cyclone through the reentrant throat and complete combustion in the SBS-II furnace upon mixing with oxidant from the overfire ports.

The SBS-II furnace absorbs heat from the hot gases primarily by radiant heat transfer. These gases then enter the convection pass where seven banks of water cooled tubes cool the gases by convection heat transfer, simulating the time-temperature profile of a full-scale boiler convection pass. Flue gas exits the convection pass at about $800^{\circ} \mathrm{F}$.

Continuous emission monitors sample the gas at the convection pass exit for $\mathrm{O}_{2}, \mathrm{CO}, \mathrm{CO}_{2}$, and $\mathrm{NO}_{\mathrm{X}}$. Fly ash may also be sampled at this point for determination of unburned carbon, fly ash loading, and ash particle size distributions.

The flue gas leaving the convection pass is cooled further in the air heater as it preheats the secondary oxidant. A fan in the fan room supplies cooling air to an additional heat exchanger called the flue gas cooler to extract further heat from the flue gas. This cooling air is vented to the atmosphere. The use of shell and tube heat exchangers for these two processes prevents infiltration of air into the flue gas.

The next device in the system is a booster fan that is used to control pressures in the ducts and devices between the convection pass and ID fan. This is followed by a venturi flow meter, baghouse, wet scrubber, and condensing heat exchanger. Depending on the coal, and type of experiment being performed, the latter two devices may be bypassed. If the wet scrubber is used, the flue gas is sampled for $\mathrm{O}_{2}$ and $\mathrm{SO}_{2}$ at the scrubber inlet.

Just upstream of the ID fan the flue gas is sampled continuously for $\mathrm{O}_{2}$ and $\mathrm{SO}_{2}$. The flue gas then enters the stack through the ID fan. Recirculated flue gas is returned to the boiler from the stack by controlling the valves on the primary and secondary fan inlets. All fan shafts have seals placed around them to minimize the possibility of air infiltration during oxy-firing.

\subsubsection{Oxygen Delivery and Control System}

Liquid oxygen is delivered by trucks to the test facility and stored on site in a 9000-gallon oxygen tank. The liquid oxygen is vaporized in an ambient vaporizer, sized for winter operating conditions $\left(-7^{\circ} \mathrm{C} / 20^{\circ} \mathrm{F}\right.$ air temperature). The oxygen is regulated to an appropriate pressure and delivered to the test area via a stainless steel line. The oxygen delivery control system is integrated with the SBS control system, allowing oxygen flows to be controlled and monitored from a central location. It is also integrated into the boiler safety interlock system. Major components of the system are shown in Figure 2.3 


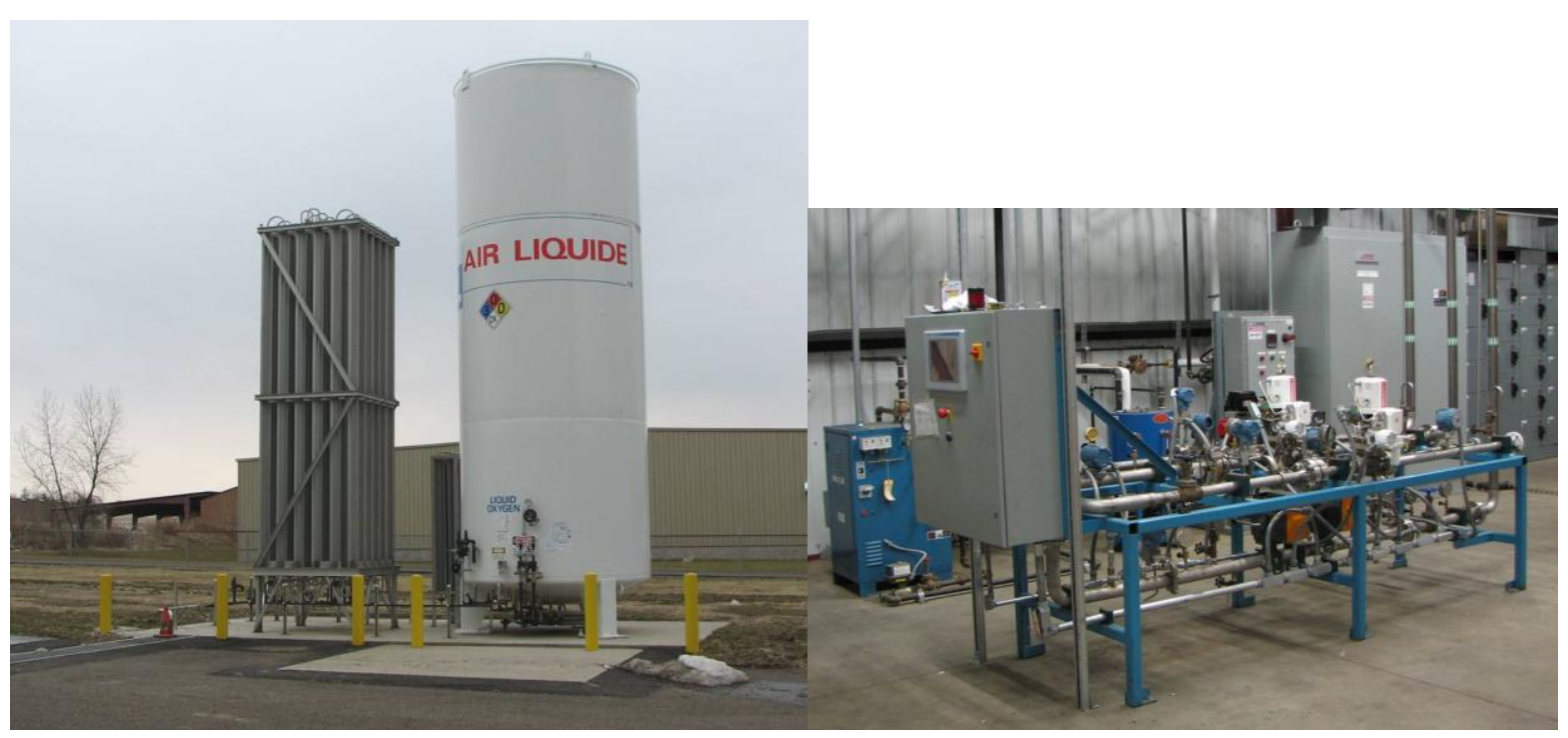

Figure 2.3 The liquid oxygen storage tank and vaporizer (left) and the oxygen flow control skid (right)

\subsubsection{Cyclone Burner and Oxygen Lances}

As mentioned above, and shown in Figure 2.4 and Figure 2.5, the primary oxidant and coal mixture enters the Cyclone furnace through a tangential inlet to the scroll burner. Tertiary oxidant also enters the scroll burner, flowing along the axis of the Cyclone. The combination of the tertiary flow and the position or angle of the primary inlet relative to the secondary inlet controls the ignition location inside the furnace. The secondary inlet (the largest of the three) is located on the cylindrical barrel of the furnace. The barrel is connected to the scroll burner by a tapered neck and to the SBS-II furnace by a reentrant throat. The neck, barrel, and throat each have their own cooling water circuit. The inside surfaces of the steel Cyclone are pin-studded and coated with refractory. A notch at the bottom side of the reentrant throat exists to allow molten slag to drain out of the furnace barrel into the SBS-II furnace where it can flow further down to the water-filled slag tank. The extent to which the notch in the throat was blocked by frozen slag during operation was frequently observed and recorded to determine how well the operating conditions were achieving the goal of removing ash from the furnace in the form of molten slag. 


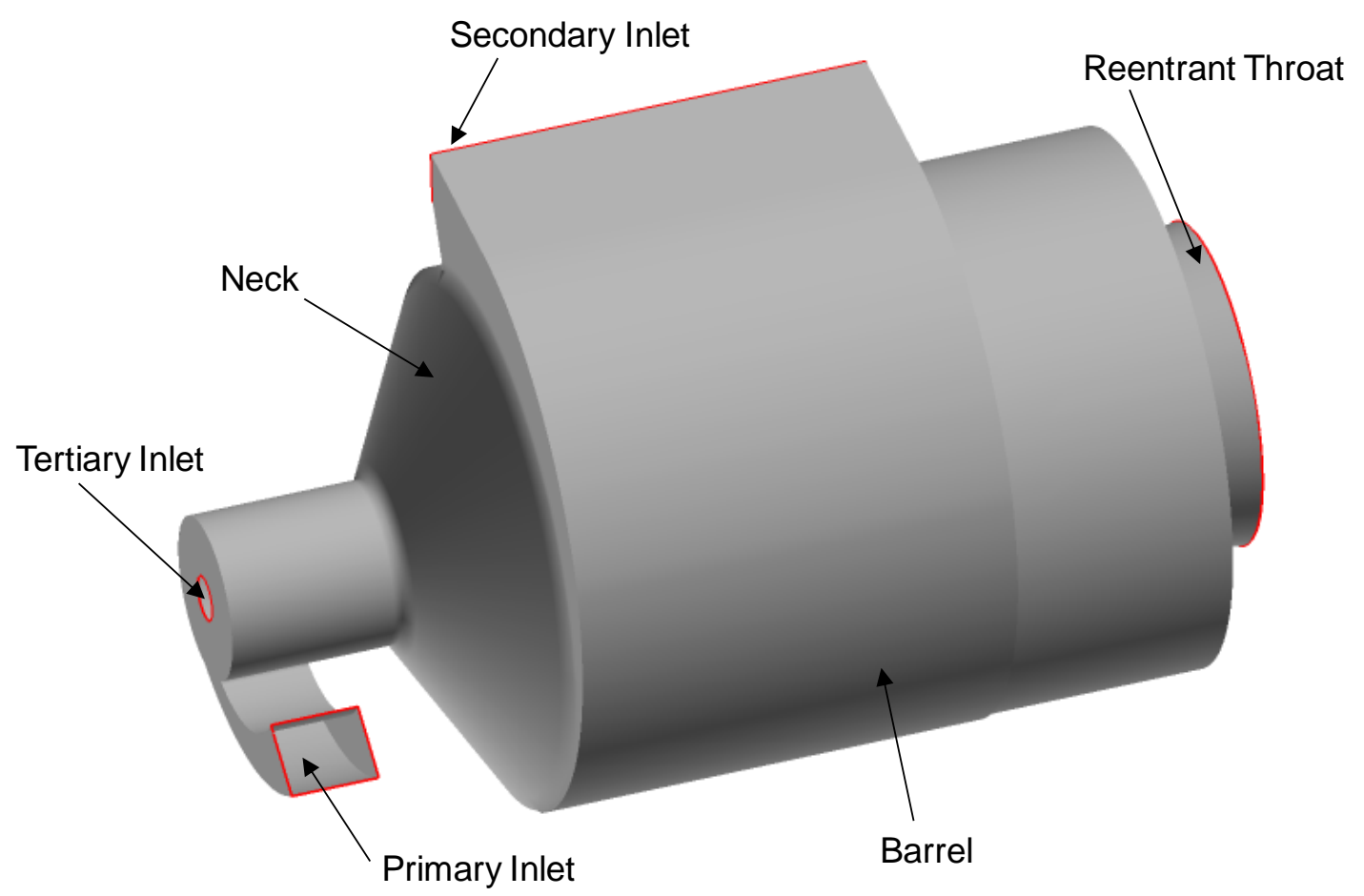

Figure 2.4 Diagram of the Cyclone furnace internal volume

Additional oxygen beyond that delivered with the primary, secondary, and tertiary oxidizer flows may be injected into the furnace with a lance. Three lance designs were used during testing, as indicated in the tabulated experimental data in the appendix:

- Secondary duct lance - The majority of tests were performed with a tube that spanned the secondary inlet to the Cyclone and had several holes on the leading edge along the length of the tube. The direction of the holes was selected to maximize mixing of the oxygen into the secondary flow before the flow entered the Cyclone barrel. The location of the port for this lance is indicated in Figure 2.5.

- Open tube on tertiary line - In one test oxygen was injected axially in the center of the tertiary flow, using only an open tube.

- Scroll lance - A lance that injected the oxygen tangentially from the center of the scroll burner, (swirling in the same direction as the primary air flow) was used during the warm recycle test series. This same lance was also sometimes withdrawn when not in use to minimize flow disturbances in the burner. This lance was inserted through the tertiary oxidant duct along the Cyclone axis. 


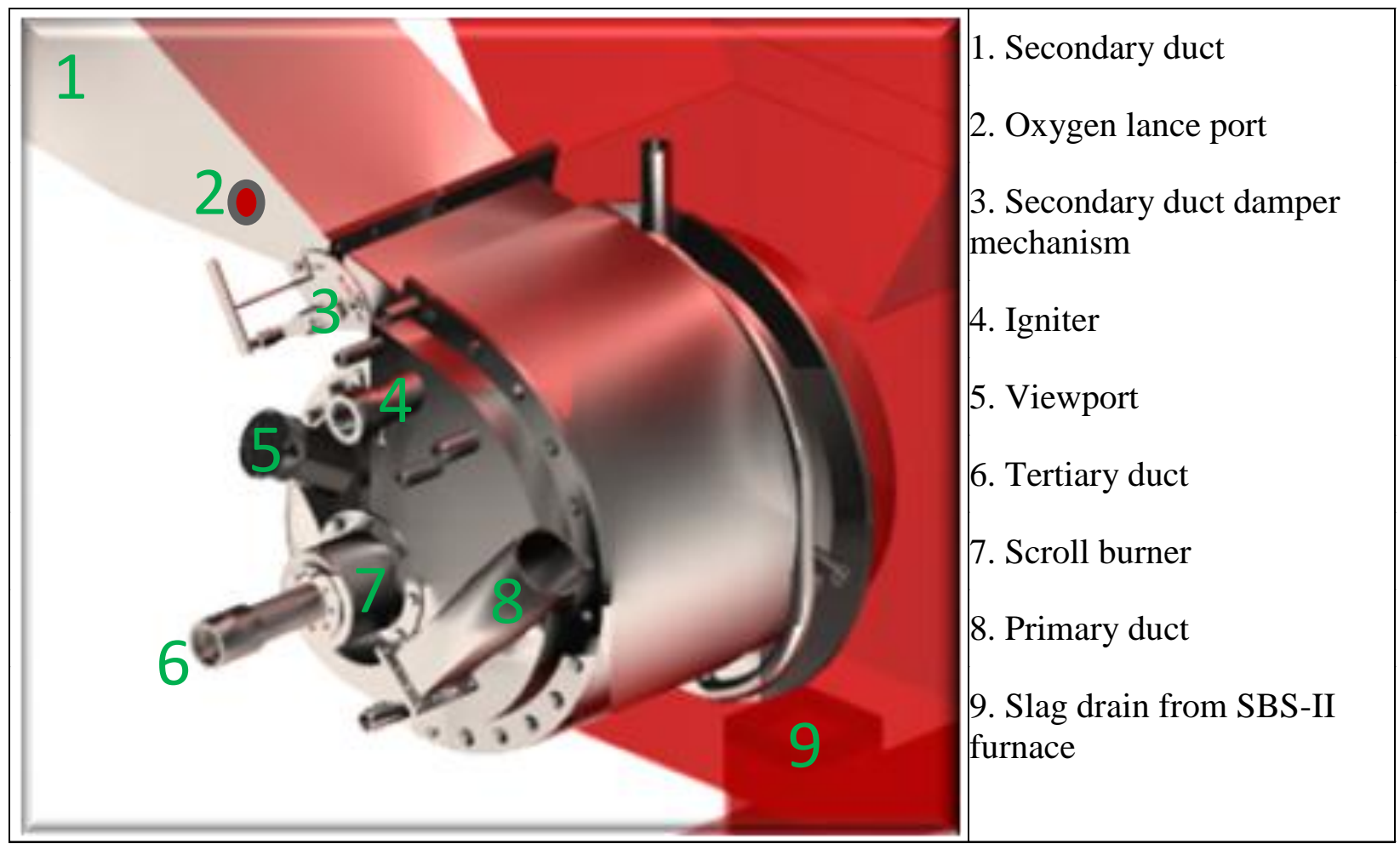

Figure 2.5 Rendering of the Cyclone furnace external features

\subsubsection{Furnace and Convection Pass}

The SBS-II is designed to accept both a wall-fired PC burner and a Cyclone furnace. When the conversion to Cyclone-firing from wall-firing is performed, the region of the SBS-II furnace required only for wall-firing is filled with removable firebrick as shown in Figure 2.6. The resulting internal volume of the furnace is then as illustrated in Figure 2.7. The same materials and equipment specifications used for air firing were used for oxy-firing.

Referring to Figure 2.7, the SBS-II furnace consists of a narrow primary furnace where gaseous products from the Cyclone turn upward to the lower furnace, and molten slag drains into a water tank/seal at the bottom of the structure. The primary, lower, and upper furnace are refractorylined water-filled walls. Water that boils to steam during operation is vented from an atmospheric drum at the top of the furnace. Not shown in the figure are numerous sampling and observation ports for sampling, access, or visual observation. One example of this is an access port angled upward toward the slag drain that allows access to mechanically remove frozen slag during operation with a jackhammer. On the rear wall below the furnace arch two overfire air ports deliver additional oxidizer. Just below these and also on the rear wall is the port through which a FlameView ${ }^{\mathrm{TM}}$ two color pyrometer camera can be inserted to view the flame exiting the Cyclone throat. 


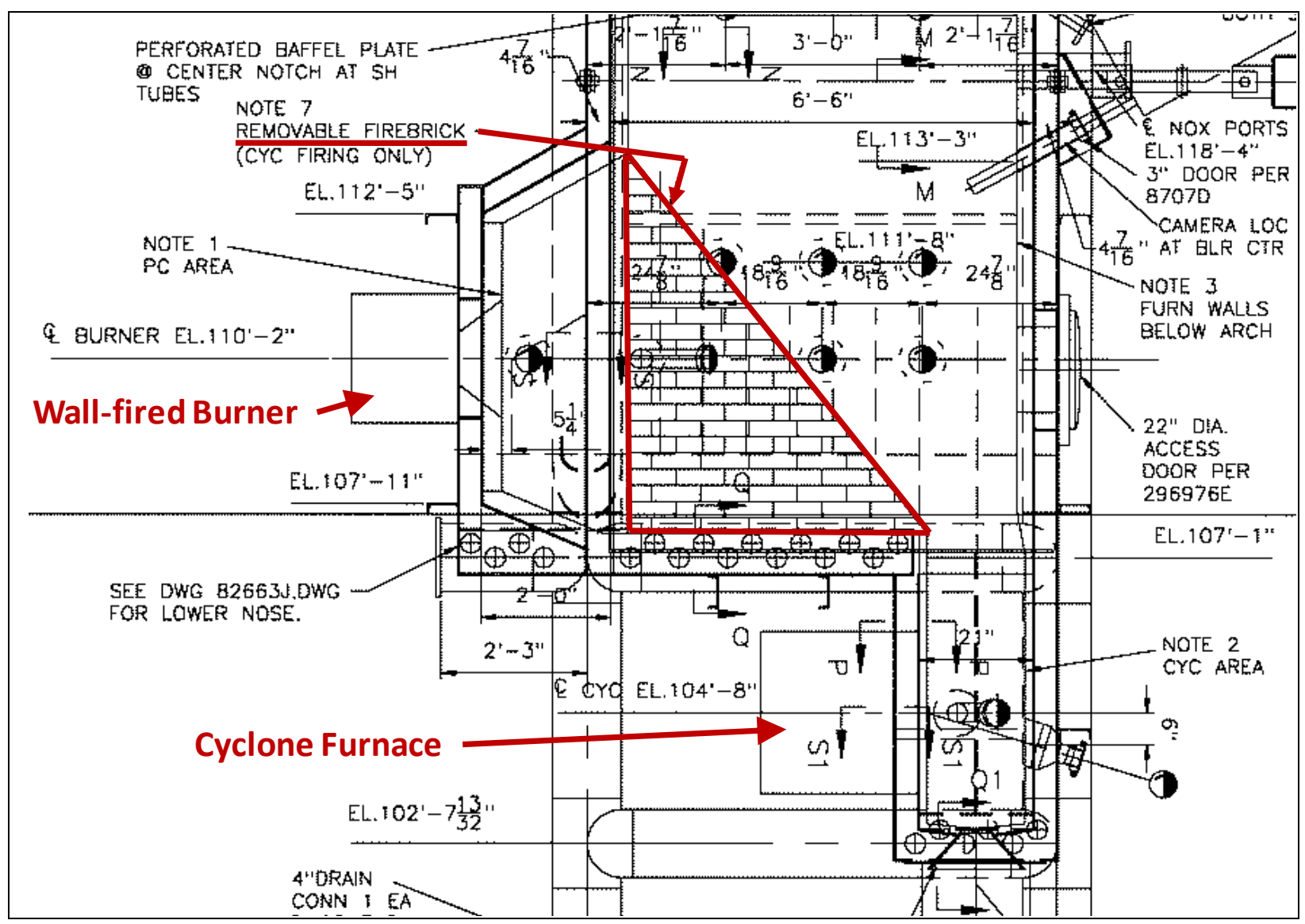

Figure 2.6 Drawing excerpt showing the location of firebrick installed in the SBS-II

The furnace exit gas temperature (FEGT) may be measured with an HVT (high velocity thermocouple) probe. The location of the port used for this probe is indicated in Figure 2.7 just above the furnace arch and before the first bank of convective cooling tubes. The convection pass consists of seven banks of tubes designed such that the SBS-II simulates the gas timetemperature profile of a full scale boiler. The first two tube banks are connected to the water drum above the furnace, and the remaining five to a water drum above the convection pass. This is important to interpretation of the heat transfer data presented in the results. Like the furnace water system, this system also vents steam at atmospheric pressure.

Gases exiting the convection pass enter an insulated duct to the air heater, and thence to other devices as previously described in connection with Figure 2.2. 


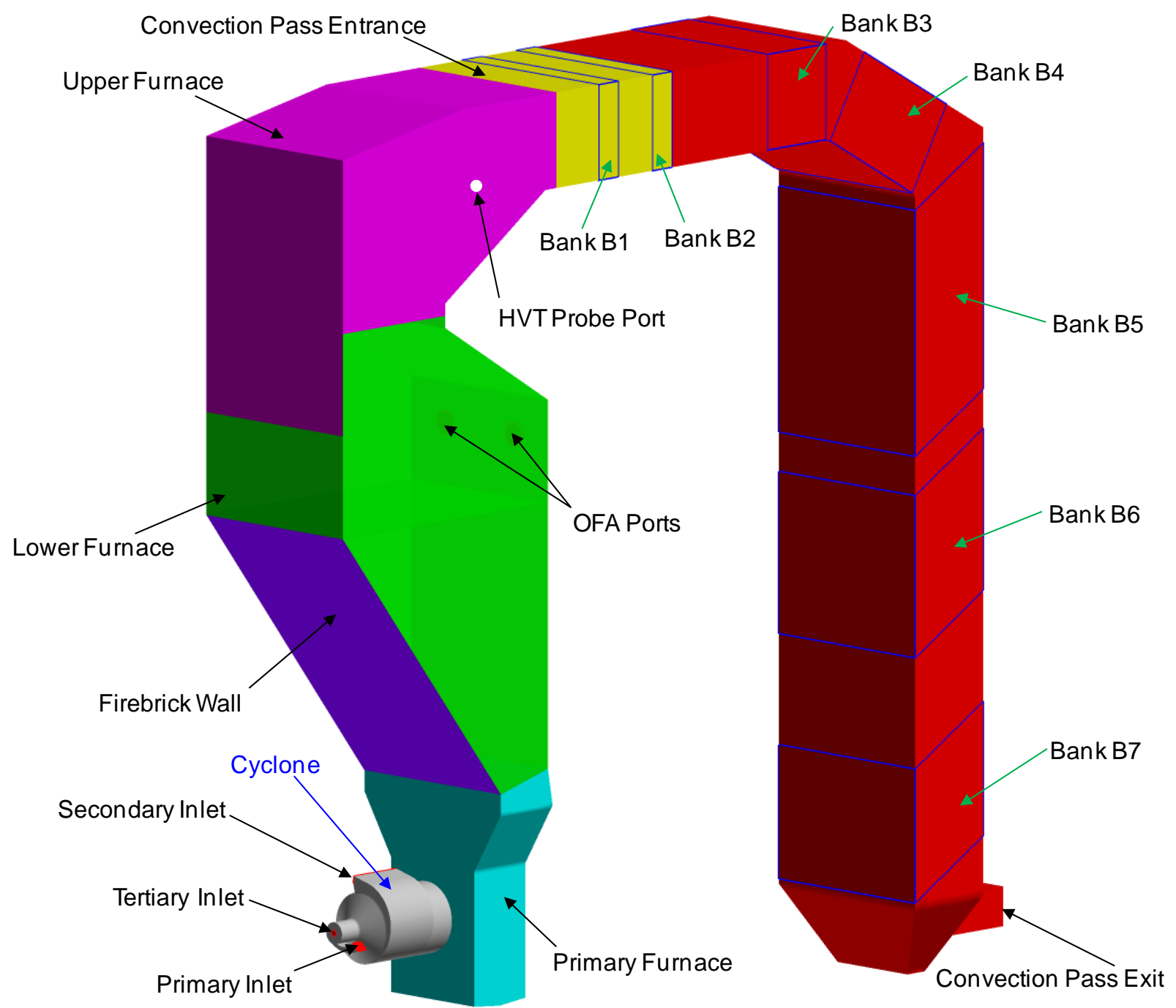

Figure 2.7 Internal volume of the SBS-II in Cyclone configuration

\subsubsection{5. $\quad \underline{\text { Baghouse }}$}

Particulate matter is removed from the flue gas in an SPE-AMEREX pulse jet fabric filter baghouse. The bags are cleaned to maintain the pressure drop between permitted limits. Generally the bags were not cleaned during tests. Fly ash collected in the hoppers at the bottom of the baghouse was removed through rotary valves. The baghouse was well sealed to prevent air infiltration; however the pulse air is a potential source of air in the system during oxy-firing.

\subsubsection{Wet Scrubber}

The wet scrubber (or WFGD) downstream of the baghouse serves to remove a fraction of $\mathrm{SO}_{2}$ from the flue gas. The reasons to do so in oxy-firing are twofold: first, to meet the requirements of the facility air permit (for the SBS-II this is $\leq 12 \mathrm{lb} / \mathrm{h} \mathrm{SO}_{2}$ ), and second, to maintain an acceptable $\mathrm{SO}_{2}$ concentration in the furnace for corrosion considerations $(<2000 \mathrm{ppm})$. The lignite and subbituminous coal had sufficiently low sulfur levels to meet these requirements without using the scrubber, and thus it was only employed for the Ohio \#5 bituminous coal tests. 
The WFGD subsystem includes the absorber tower with slurry recirculation tank, reagent feed system, mist eliminator system, and slurry dewatering and disposal system. It is designed to treat the entire flow of flue gas from the SBS-II facility while simulating a vertical section down through a commercial scrubber. Emphasis is placed on the duplication of gas/liquid interaction, minimization of wall impingement, and the proper simulation of operating parameters that affect $\mathrm{SO}_{2}$, particulate, and air toxics removal mechanisms. The design is based on B\&W's commercial scrubbers and incorporates a perforated-plate tray to increase gas-liquid contact. Figure 2.8 shows some of the details of the absorber tower, and primary design characteristics are summarized in Table 2.1.

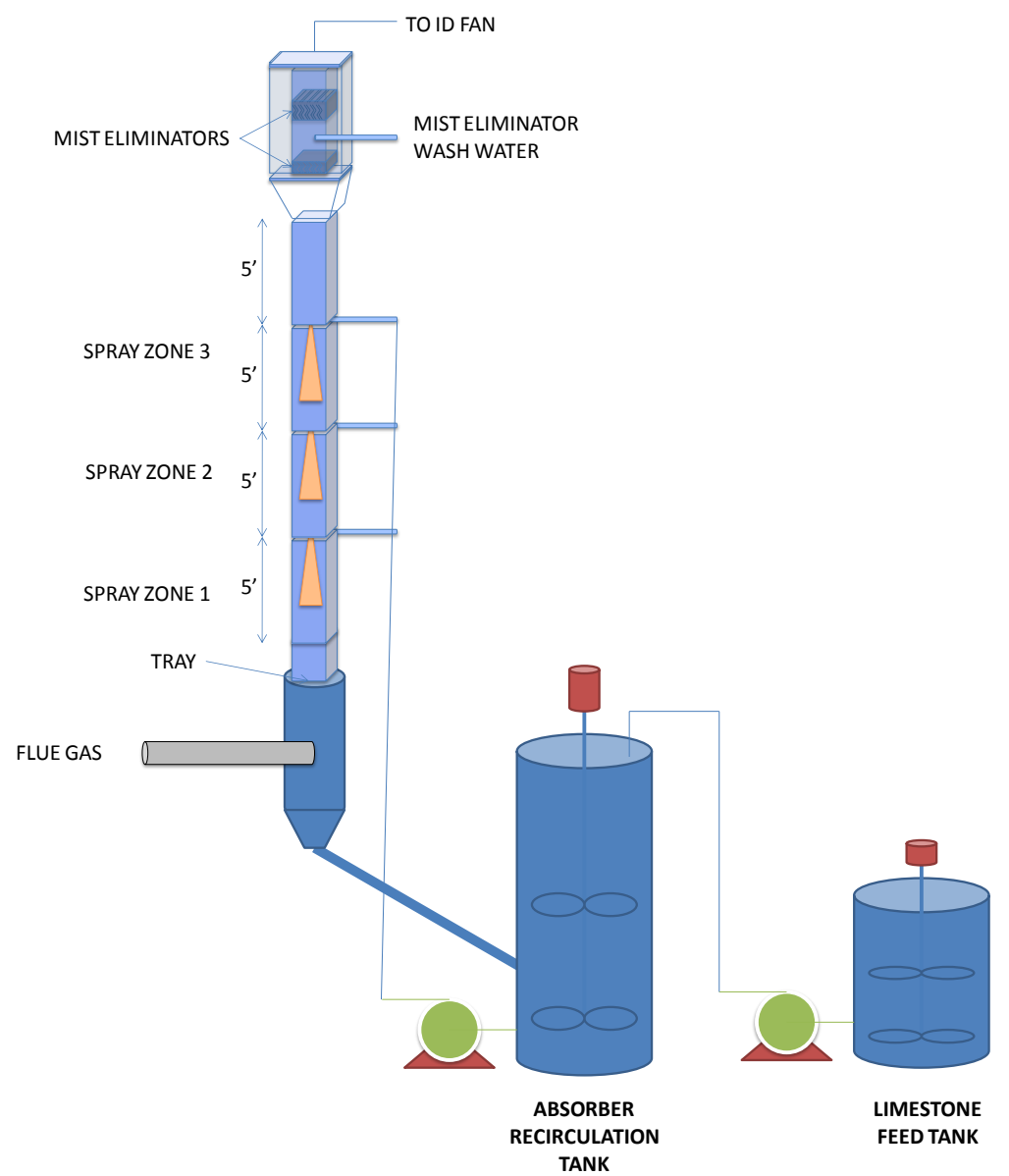

Figure 2.8 Schematic diagram of the wet scrubber absorber tower

\begin{tabular}{|r|l|}
\hline Capacity & $\begin{array}{l}5000-6000 \mathrm{lb} / \mathrm{h} \text { gas at up to } 4000 \mathrm{ppm} \mathrm{SO}_{2} \\
\text { or } 6 \mathrm{MBtu} / \mathrm{h}(\text { coal firing) }\end{array}$ \\
\hline Design limestone stoichiometry & $1.1 \mathrm{~mole} \mathrm{Ca} / \mathrm{mole} \mathrm{SO}_{2}$ absorbed \\
\hline Nominal $\mathrm{SO}_{2}$ removal & $90 \%$ \\
\hline Design liquid to gas $(\mathrm{L} / \mathrm{G}$ ) ratio & $190 \mathrm{gpm} / 1000 \mathrm{acfm}$ \\
\hline Normal L/G ratio & $120 \mathrm{gpm} / 1000 \mathrm{acfm}$ \\
\hline Tower velocity range & $5.0-20 \mathrm{ft} / \mathrm{s}$ \\
\hline
\end{tabular}

Table 2.1 Primary design characteristics of the wet scrubber 
Reaction products in the slurry leaving the absorber tower flow by gravity into the absorber recirculation tank (ART) below the tower. An air sparger system provides clean humidified air to the bottom of the tank for forced oxidation of the products. The ART is also equipped with an agitator to keep solids from settling. Slurry supplied to the spray headers of the absorber tower comes from the ART.

At the top of the absorber tower, mist eliminators minimize carryover of slurry and liquid droplets generated in the absorber tower. To prevent buildup and plugging, the mist eliminators are periodically washed by water spray nozzles.

Limestone slurry is prepared in batches in the limestone feed tank by mixing pulverized limestone with water. The limestone feed tank is equipped with an agitator and pump. The feed rate of limestone slurry from the limestone feed tank to the ART is controlled using the $\mathrm{pH}$ of the slurry stream from the ART to the spray nozzles (monitored continuously with an in-line $\mathrm{pH}$ sensor). The slurry density in the ART is monitored by a densitometer, which yields a solids concentration measurement. The solid gypsum product of the scrubber is periodically removed by pumping the slurry through a hydroclone and extracting the hydroclone underflow from the system. The same hydroclone can be operated to remove water from the system that accumulates during flue gas recirculation.

\subsubsection{Condensing Heat Exchanger (CHX)}

Downstream of the baghouse (and wet scrubber, if used) a condensing heat exchanger was used to lower the moisture content of the flue gas for all tests except the warm recycle test series. The term "warm recycle" implies that moisture is not removed from the recycled flue gas by cooling, which has the aim of improving plant efficiency relative to cold recycle operation. The heat exchanger is a Teflon ${ }^{\circledR}$-coated shell and tube design and is supplied with city water to remove the heat from the flue gas. Condensed moisture collected in the bottom of the heat exchanger is pumped to the ART of the wet scrubber system. The water (which contains impurities from the combustion process) is thereby handled with the waste water stream from the wet scrubber. Downstream of the heat exchanger the flue gas is saturated with moisture which allows determination of the moisture content by temperature measurement alone.

\subsubsection{8. $\quad$ Boiler Permissives and Interlocks}

The boiler uses conventional flame/combustion safety interlocks and controls in addition to other requirements unique to oxy-firing. Some of these are procedural and depend on operator training as indicated below:

- SBS-II control system and Air Liquide oxygen control system are communicating (interlock)

- The use of oxygen is only permitted after stable operation of the boiler on air has been established (operator-controlled permissive in SBS-II Control system)

- Initiation of oxygen flow is preceded by:

- Purging of the appropriate Floxynator ${ }^{\mathrm{TM}}$ or Lance (procedural)

- Opening of a manual valve (procedural)

In consultation with Air Liquide, alarm and trip conditions were established as follows: 
- Oxygen concentration (wet basis) at the secondary Floxynator ${ }^{\mathrm{TM}}$ in-situ oxygen monitor:

- $18 \%$ - Low alarm

- $25 \%$ - High alarm

- $28 \%$ - Master fuel trip (MFT)

- Oxygen concentration (wet basis) at the primary Floxynator ${ }^{\mathrm{TM}}$ in-situ oxygen monitor:

- $16 \%$ - Low alarm

- $21 \%$ - High alarm

- $23.5 \%$ - MFT

- The following items can also trip the Air Liquide oxygen skid:

- A master fuel trip (MFT) on the SBS-II

- Local emergency stop push button

- Loss of power

- Loss of instrument air pressure

- Low oxygen pressure

- Low oxygen temperature

In the event of a MFT, the following sequence is initiated:

- Oxygen flow shut down

- Natural gas supply shut down

- Coal feeder shut down

- Primary fan stops

- Secondary flue gas recirculation valve closes and secondary air intake valve opens

- Secondary fan adjusts to a pre-determined speed

- ID fan adjusts to a pre-determined speed

\subsubsection{Instrumentation and Laboratory Methods}

Oxy-combustion requires monitoring and control of oxygen in the ducts, measurement of oxygen flows and measurement of recycled gas flow. In this section, the instrumentation used and other analysis methods are discussed.

For this project, five (5) in situ $\mathrm{O}_{2}$ probes were used at the following locations:

- Cyclone secondary duct - oxidant concentration

- Secondary duct after secondary oxygen injection - oxidant concentration and interlock

- Primary duct after primary oxygen injection - oxidant concentration and interlock

- Recycle gas prior to oxygen injection - recycle gas oxygen concentration

- Convection pass exit - flue gas concentration

In addition to measuring the wet concentration of oxygen at their designated point in the process, these probes can be used to provide an output signal for safety interlocks. These analyzers were calibrated before and after testing. Note that the manufacturer's calibration procedure had to be modified: typically the sensors are calibrated at atmospheric pressure, but since the duct pressure at some locations can be different to atmospheric pressure the calibrations are performed at pressures representing the actual process pressure. An additional consideration is to maintain the calibration gas pressure at a value only slightly higher than the sensor pressure. Failure to follow 
these modifications to the calibration procedure results in significant offsets in the oxygen readings.

During the first series of tests with bituminous coal, an in situ moisture analyzer was located at the Cyclone secondary duct. After obtaining favorable comparisons between the measured moisture content and the value calculated independently from other data, the analyzer was permanently relocated to the baghouse outlet. The calculation of gas composition in the ducts (on which flow rate calculations are based) usually depends on a temperature measurement at a point, such as the wet scrubber outlet, where the gas is saturated with moisture. For the warm recycle tests where no point in the duct system can be assumed saturated; this moisture analyzer becomes important to the calculation of flue and recycle gas composition.

The SBS-II has three gas analysis systems. The convection pass system consists of gas analyzers for $\mathrm{O}_{2}, \mathrm{NO}_{\mathrm{X}}, \mathrm{CO}$, and $\mathrm{CO}_{2}$. The stack gas analysis system and the wet scrubber inlet system each consist of an $\mathrm{O}_{2}$ and $\mathrm{SO}_{2}$ analyzer. The corresponding sample locations are the convection pass exit, ID fan inlet, and wet scrubber inlet, as indicated in Figure 2.2. The gas samples are withdrawn with vacuum pumps, filtered, transported in a heated sample line to a refrigeration unit, and passed to the appropriate analyzers. All analyzers were calibrated once per shift during testing. The convection pass fly ash can be isokinetically sampled and analyzed for carbon content to determine carbon utilization in the system.

The SBS-II Cyclone, furnace, and convection pass are water cooled. Flow rates, levels, and temperatures of water in the system are important both for monitoring of operation, and determining heat absorption of the furnace. Figure 2.9 shows a process and instrumentation diagram (P\&ID) for the blowdown system. Locations of thermocouples (TE), flow elements (FE), and flow control valves (FCV) are shown. In addition to the instrumentation shown, there is a water level sensor in each of the furnace and convection pass stream drums that is used for control of the respective makeup water flow. 


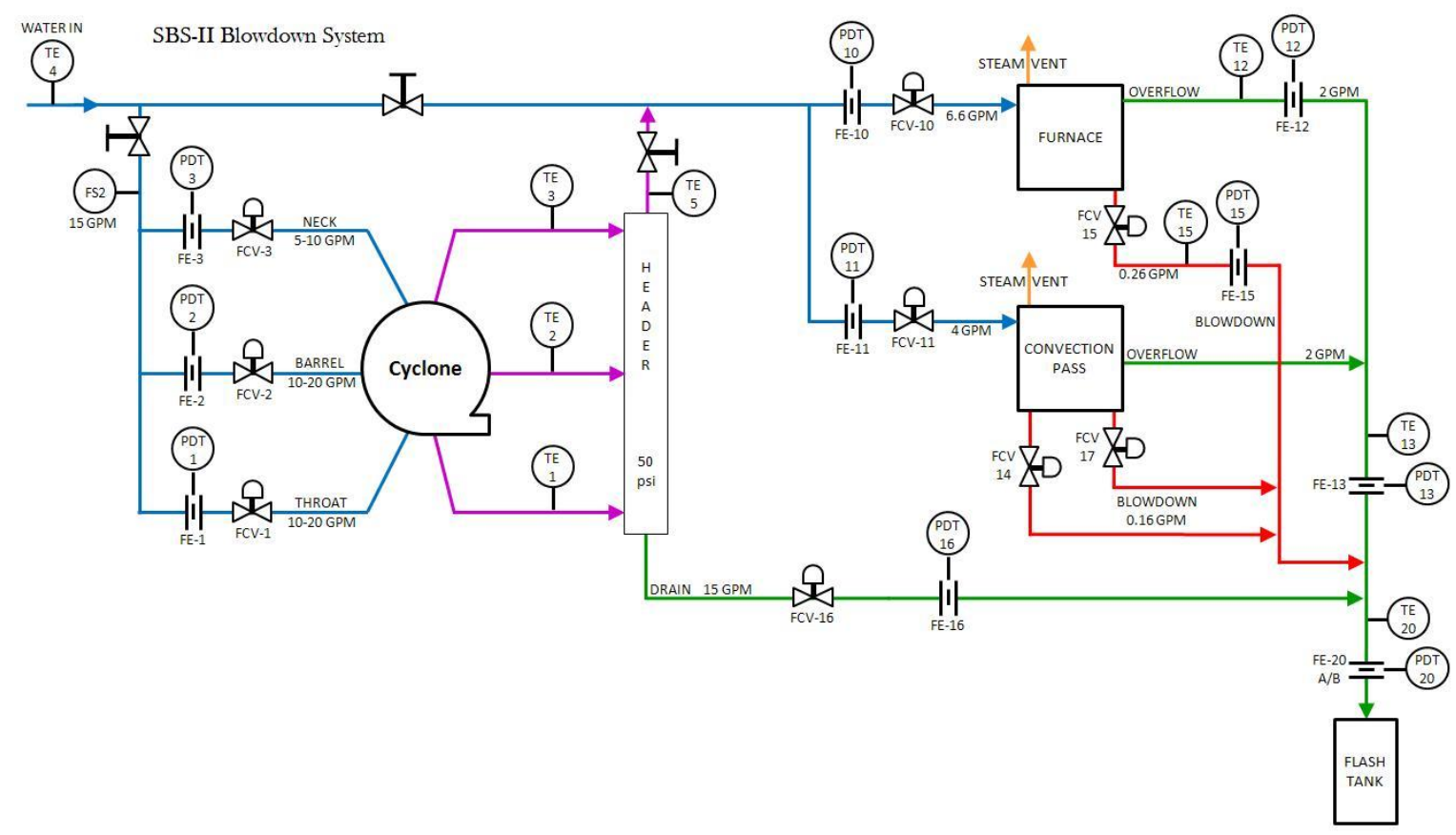

Figure 2.9 P\&ID for SBS-II water-side/blowdown system

The following measurement techniques and instrumentation were used during the SBS-II tests:

- Air and flue gas flow rates - Calibrated venturi flow meters, corrected for process temperature and pressure, and gas composition (molecular weight). Recycled flue gas flow was also calculated in some tests using the oxygen flow rate and oxygen concentrations before and after oxygen injection to the duct.

- Oxygen flow rates - Calibrated orifices

- Coal flow rate - Gravimetric coal feeder

- Ambient relative humidity and barometric pressure - Vaisala PTU 300 Combined Pressure, Humidity, and Temperature Transmitter

- Moisture

- Temperature measurement at saturated conditions

- MAC Instruments MAC 125 Analyzer (proprietary solid state sensor)

- $\mathrm{O}_{2}$ (wet basis, in situ) - Zirconium oxide sensors

- $\mathrm{O}_{2}$ (dry basis) - paramagnetic

- $\mathrm{CO}, \mathrm{CO}_{2}-\mathrm{NDIR}$

- $\mathrm{NO}_{\mathrm{X}}-$ Chemiluminescent

- $\mathrm{SO}_{2}-\mathrm{UV}$

- $\mathrm{SO}_{3}-$ CleanAir Method 8B

- $\mathrm{Hg}$ - Cold vapor atomic absorption spectrometry (CVAAS) with Zeeman background correction

- Fly ash unburned combustibles - High volume sampler at convection pass exit, unburned combustibles determined by mass loss on ignition (LOI) of collected ash

- $\quad$ FEGT - High Velocity Thermocouple (HVT)

- Flame Temperature - Two color optical pyrometry (FlameView ${ }^{\mathrm{TM}}$ Camera)

- Cyclone and boiler water flows - calibrated orifices 
Standard laboratory methods used for the analysis of the coals used and their constituents are listed in Table 2.2.

\begin{tabular}{|c|c|}
\hline Test & Method (ASTM unless otherwise specified) \\
\hline Proximate analysis: & D5142 or as listed below \\
\hline Moisture & D2961, D3302, D3173 \\
\hline Ash & D3174 \\
\hline VM & D3175M \\
\hline FC & D3172 \\
\hline Heating value (Btu/lb) & D5865 \\
\hline \multicolumn{2}{|l|}{ Ultimate analysis: } \\
\hline $\mathrm{C}$ & D3178, D5373 \\
\hline $\mathrm{H}$ & D3178, D5373 \\
\hline $\mathrm{N}$ & D3179, D5373 \\
\hline $\mathrm{S}$ & D4239 Method B \\
\hline $\begin{array}{l}0 \\
0\end{array}$ & D3176 \\
\hline $\begin{array}{l}\text { Major/minor elements in ash (XRF) } \\
\left(\mathrm{SiO}_{2}, \mathrm{Al}_{2} \mathrm{O}_{3}, \mathrm{Fe}_{2} \mathrm{O}_{3}, \mathrm{CaO}, \mathrm{MgO}, \mathrm{Na}_{2} \mathrm{O}\right. \\
\left.\mathrm{K}_{2} \mathrm{O}, \mathrm{P}_{2} \mathrm{O}_{5}, \mathrm{TiO}_{2}, \mathrm{BaO}, \mathrm{SrO}, \& \mathrm{SO}_{3}\right)\end{array}$ & D4326 \\
\hline Mercury in coal (CVAAS) & D6414 \\
\hline Chlorine in coal & D4208 \\
\hline Flyash - LOI @ 800C & B\&W Test Method (based on ASME reference 4.07) \\
\hline \multicolumn{2}{|l|}{ Coal sizing: } \\
\hline Screening & B\&W Test Method (based on D-197-30, D311) \\
\hline Microtrac Particle Size Analyzer & Light scattering \\
\hline Coal grindability test & D409 (Hardgrove Grindability Index) \\
\hline
\end{tabular}

Table 2.2 Standard laboratory methods used in coal analysis

\subsubsection{Data Acquisition System (DAS) and Analysis}

The SBS-II uses a Rockwell Automation data acquisition and control system that converts raw voltage and current signals from the instruments to engineering units in real time. Most data are displayed on the Human-Machine Interface (HMI) screens, and a selection of data is used as the input to an online data analysis program. The variables used by the data analysis are smoothed using the following equation:

$$
A_{\text {new }}=\left(\frac{n-1}{n}\right) \cdot A_{\text {old }}+\left(\frac{1}{n}\right) \cdot A_{\text {sensor value }}
$$

Where $n$ is an operator adjustable parameter to achieve the desired balance between smooth data and quick response to system changes. This smoothing is particularly important for pressure data where fluctuations of significant magnitude occur. The value of $n$ chosen for this test campaign, allows the system to respond $90 \%$ to a step change in 1.4 seconds, with acceptable smoothness in the data. The coal feeder has repeatable periodic features in the signal due to the conveyor belt 
seam passing over the scale, and thus for the measured coal feed rate only, a higher value of $n$ was applied.

This program (coded in Rockwell RS Logix structured text) runs continuously at a rate of about $30 \mathrm{~Hz}$ (times per second). Data such as flow rates, load, and pollutant emission rates are produced and also displayed on the HMI. A Rockwell Historian server logs data points at least every 60 seconds. The rate for storage of data is set by the operator, and during testing the time between samples was reduced from the maximum 60 seconds to 10 or 20 seconds. The logged data are a mixture of raw (sensor) values and calculated parameters. Every raw input used by the calculations is included in the logged data to allow off-line reprocessing of test data if required.

Data for a steady state test were exported from the historian server as summary data (i.e. average, standard deviation, minimum, maximum, and number of points). For data sets requiring off-line reprocessing, all logged data points over the time of interest were exported and reprocessed using a MATLAB routine that duplicated the calculations in the on-line system. The two primary purposes of reprocessing were 1) to allow replacement of data from failed sensors with values from backup sensors, and 2) to carefully select the time over which cyclic heat absorption data were averaged to produce more accurate averages for selected tests. More detail is given below.

Gas mass flow rates for pulverizer air, natural gas, primary and secondary air/oxidizer, overfire oxidizer, primary and secondary recycled flue gas (RFG), flue gas before environmental controls, and flow to the stack are calculated using flow venturi calculations with the manufacturers' calibration constants. These calculations are based on static pressure, temperature, and pressure drop measurements at the venturi. The adiabatic expansion factor is assumed constant. Molecular weight of the moist air or gas mixtures is calculated from humidity sensor and gas analyzer outputs. For safety, to provide meaningful flow rates to the operators in the event of a gas analyzer failure, the molecular weights are constrained between reasonable limits (for example between 28 and $42 \mathrm{lb} / \mathrm{lbmol}$ for gas exiting the convection pass). Oxygen mass flow rates are provided to the data acquisition system from the Air Liquide oxygen skid. They are calculated using the same principles as other gas mass flow rates.

Tertiary oxidizer is bled off the primary line just before coal is added (Figure 2.2). The flow is measured with a calibrated orifice, but static pressure is not measured locally and so is estimated to be equal to the static pressure for the primary flow. The tertiary flow measurement is for indication only and is not used in other calculations. Stoichiometry calculations are based on the primary flow which includes the tertiary stream. For the primary and secondary RFG streams the flow rates from the flow venturi calculations was not always consistent with calculation of these flow rates by other means. The RFG flow rates calculated from in-situ $\mathrm{O}_{2}$ measurements or from the flow meters downstream of the forced draft fans were believed to be more reliable. For the warm recycle oxy-firing cases that were reprocessed, all calculations based on secondary RFG flow used the flow rate calculated from in-situ $\mathrm{O}_{2}$ data. The ratio of infiltrated air to flue gas flow is calculated based on in-situ $\mathrm{O}_{2}$ measurements. The windbox measurement took priority over the secondary Floxynator ${ }^{\mathrm{TM}}$ reading in the calculations with the exception of the calculation of secondary RFG using the $\mathrm{O}_{2}$ concentrations.

Water flows for the Cyclone, furnace, and convection pass cooling are measured with calibrated orifices and displayed on the HMI in gallons per minute. These values were converted to mass 
flow for the furnace heat balance calculation using a correlation for water density variation with temperature. To simplify and increase the accuracy of the heat balance calculation, the drum levels are controlled within 0.2 inches, the overflow and blowdown lines (Figure 2.9) are not used, and the Cyclone drain flow measured for operator display is not used, but is replaced with the sum of inlet flows. The tight control on the furnace and convection pass drum levels results in a relatively rapid cyclic variation in calculated furnace and convection pass heat absorption as seen in Figure 2.10 below. High heat absorption for the furnace and convection pass is calculated when the makeup water valves are open, and zero heat absorption when they are closed. A complete cycle takes about 7 minutes. The true value of heat absorption is represented by the average of a whole number of these cycles. In the calculations (which are running at about $30 \mathrm{~Hz}$ ) there is a numerical integration of the flow rate to track the average valve activity between logging of data, thus the "instantaneous" heat absorption in the figure is the average since the last data point was logged. The instantaneous values range from 0 to $6.5 \mathrm{MBtu} / \mathrm{h}$, with the true average being on the order of $2 \mathrm{MBtu} / \mathrm{h}$. When data are reprocessed to improve the accuracy of the heat balance calculations, the primary difference between the reprocessed data and the original data is that the furnace and convection pass heat transfer data are averaged over a whole number of valve cycles rather than the unrelated test time.

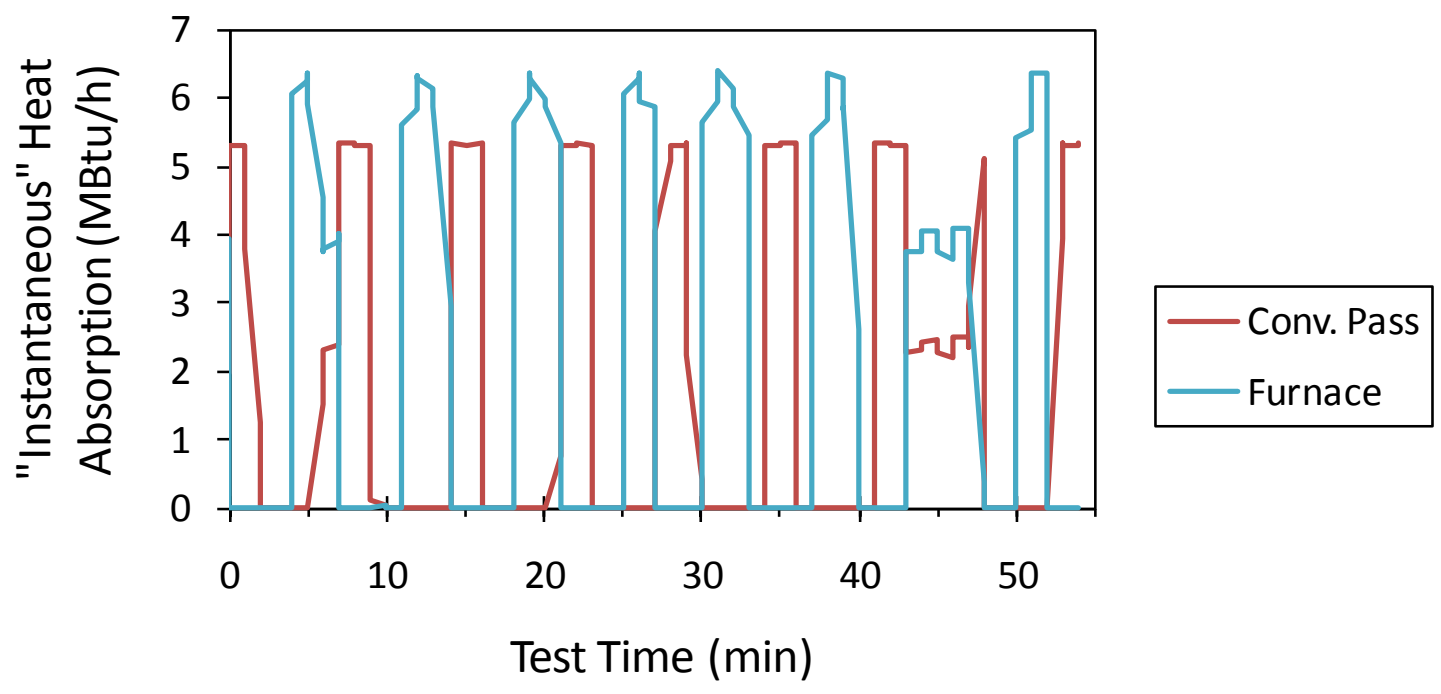

Figure 2.10 Furnace and convection pass heat transfer data illustrating the cyclic nature of the calculations based on instantaneous data.

There are three ways that the boiler load may be determined, each with different sources of uncertainty as follows:

- Heat transfer method, using water heat absorption as described above, combined with flue gas flow rate and convection pass exit temperature. This method is subject to uncertainties in the flow rates. The error associated with heat loss through the furnace insulation to the room was evaluated at less than $0.5 \%$ of heat input. 
- Coal input method, using feed rate from the gravimetric coal feeder, combined with the coal heating value. Variations in coal heating value, moisture, and ash, coal feeder calibration, combustion efficiency, as well as noise in the signal contribute to uncertainty for this method.

- Element balance method, using gas analysis and flow rates to solve an ideal combustion equation for the coal flow rate. This is subject to the uncertainties of the input parameters (flow rates, gas concentrations, and unaccounted air infiltration).

For the first method, the need to average make up water flows over a whole number of valve cycles makes it impractical to determine load by this method during a test. In addition, the thermal mass of the boiler requires long operation at steady state for acceptable accuracy. Coal flow calculated by the third method was more stable than that from the coal feeder and was used to determine load during testing. Averaged over the entire test campaign the agreement between the calculated and measured flows was within $7.1 \%$ of the mean value, with a range of 0.2 to $19.6 \%$. Over time and with decreased air infiltration the agreement generally improved, as leaks were found and eliminated, and operators gained experience. By the last day of testing agreement was within $4 \%$ on average, and in the worst case better than $10 \%$. Figure 2.11 illustrates the agreement between the latter two methods. The calculations used for the element balance method are described next.

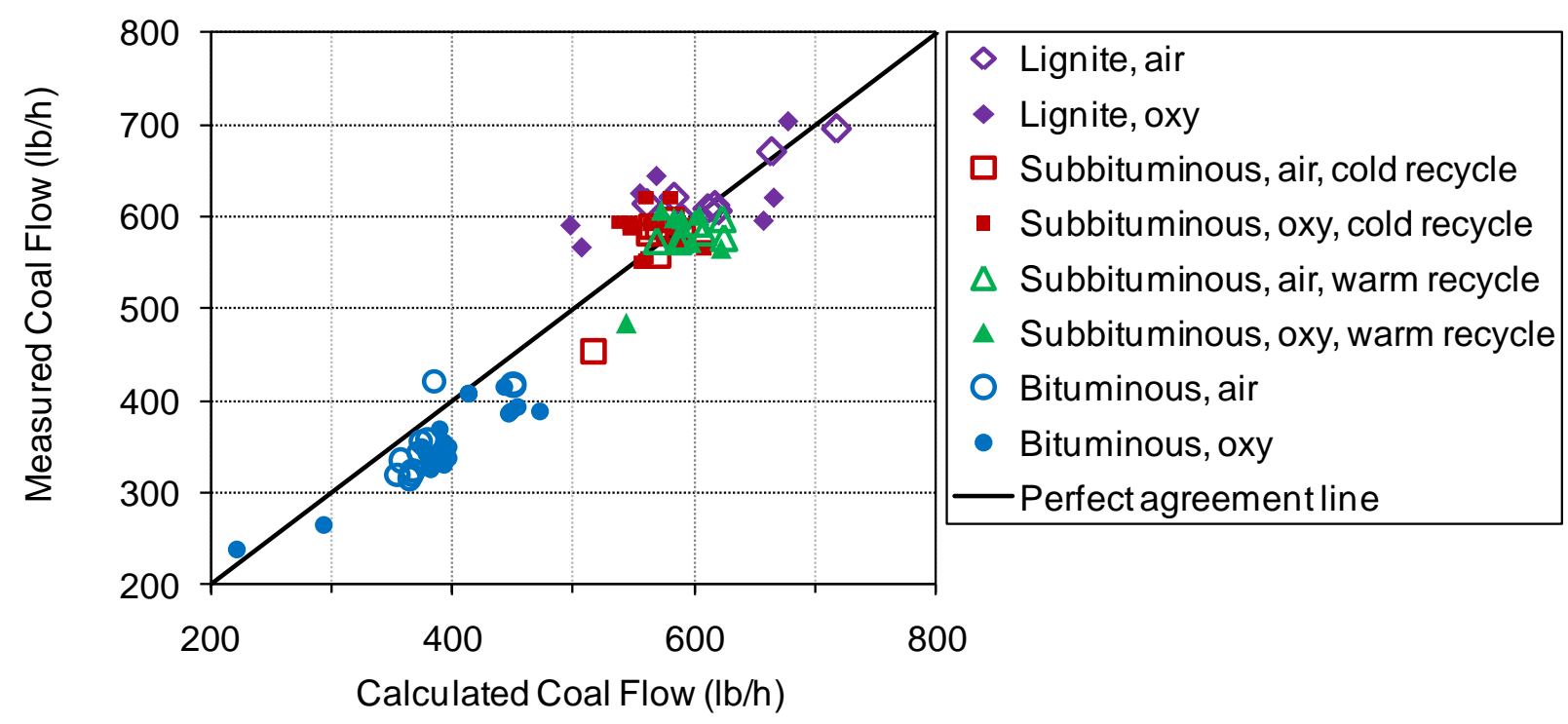

Figure 2.11 Comparison of measured and calculated coal flow rates

Calculation of the coal feed rate from other parameters is based on solving equations representing the basic combustion reaction below. This ideal reaction represents moist coal and/or natural gas burning in air and/or mixtures of $\mathrm{O}_{2}$ and recycled flue gas to produce $\mathrm{CO}_{2}$, water, and minor species such as $\mathrm{NO}_{\mathrm{X}}$ and $\mathrm{SO}_{2}$. Excess oxygen also appears on the product side. 
$\mathrm{C}_{\mathrm{x}} \mathrm{H}_{\mathrm{y}} \mathrm{N}_{\mathrm{z}} \mathrm{O}_{\mathrm{q}} \mathrm{S}_{\mathrm{w}} \mathrm{Cl}_{\mathrm{v}}+\mathrm{h} \mathrm{H}_{2} \mathrm{O}+\mathrm{K} \mathrm{NG}_{\mathrm{C}} \mathrm{NG}_{\mathrm{H}} \mathrm{NG}_{\mathrm{N}} \mathrm{NG}_{\mathrm{O}}+\ldots$

$\mathrm{A}\left[\left(\mathrm{O}_{2}+\mathrm{m} \mathrm{N}_{2}\right)+\mathrm{A}^{\prime} \mathrm{H}_{2} \mathrm{O}\right]+\mathrm{B}\left[(1-\mathrm{n}) \mathrm{O}_{2}+\mathrm{n} \mathrm{N}_{2}\right]+\ldots$

$\mathrm{CCO}_{2}+\mathrm{DH}_{2} \mathrm{O}+\mathrm{EO}_{2}+\mathrm{FSO}_{2}+\mathrm{GN}_{2}+\mathrm{HCl}_{2} \rightarrow$

$\left(\mathrm{x}+\mathrm{C}+\mathrm{K} \mathrm{NG}_{\mathrm{C}}\right) \mathrm{CO}_{2}+\left(\mathrm{y} / 2+\mathrm{h}+\mathrm{K} \mathrm{NG}_{\mathrm{H}} / 2+\mathrm{D}+\mathrm{A} * \mathrm{~A}^{\prime}\right) \mathrm{H}_{2} \mathrm{O}+\ldots$

$\left(\mathrm{z} / 2+\mathrm{K} \mathrm{NG}_{\mathrm{N}} / 2+\mathrm{m} * \mathrm{~A}+\mathrm{n} * \mathrm{~B}+\mathrm{G}\right) \mathrm{N}_{2}+(\mathrm{w}+\mathrm{F}) \mathrm{SO}_{2}+(\mathrm{v} / 2+\mathrm{H}) \mathrm{Cl}_{2}+\ldots$

$\left\{\left[\mathrm{q} / 2+\mathrm{h} / 2+\mathrm{K} \mathrm{NG}_{\mathrm{O}} / 2+\mathrm{A}\left(1+\mathrm{A}^{\prime} / 2\right)+\mathrm{B}(1-\mathrm{n})+\mathrm{C}+\mathrm{D} / 2+\mathrm{E}+\mathrm{F}\right]-\ldots\right.$

$\left.\left[\left(\mathrm{x}+\mathrm{C}+\mathrm{K} \mathrm{NG}_{\mathrm{C}}\right)+\left(\mathrm{y} / 2+\mathrm{h}+\mathrm{KNG}_{\mathrm{H}} / 2+\mathrm{D}+\mathrm{A}^{*} \mathrm{~A}^{\prime}\right) / 2+(\mathrm{w}+\mathrm{F})\right]\right\} \mathrm{O}_{2}$

In the above equation:

- A' (or "A prime") is the number of moles of water per mole of air (from the humidity sensor)

- $\quad \mathrm{m}$ is 3.77 moles of $\mathrm{N}_{2}$ per mole of air

- $\quad \mathrm{n}$ is the mole fraction of impurities (assumed $\mathrm{N}_{2}$ ) in the liquid oxygen (0.002)

- $\quad \mathrm{NG}_{\mathrm{C}}, \mathrm{NG}_{\mathrm{H}}, \mathrm{NG}_{\mathrm{N}}$, and $\mathrm{NG}_{\mathrm{O}}$ are the atoms of $\mathrm{C}, \mathrm{H}, \mathrm{N}$, and $\mathrm{O}$ respectively per equivalent natural gas molecule $(1.0396,4.0397,0.012$, and 0.0138$)$

All other symbols are in units of moles per hundred pounds of as-fired coal as follows:

- $\mathrm{x}$ - carbon in coal (from ultimate analysis)

- $y-$ hydrogen in coal (from ultimate analysis)

- $\mathrm{z}$ - nitrogen in coal (from ultimate analysis)

- $\mathrm{q}$ - oxygen in coal (from ultimate analysis)

- $\mathrm{w}$ - sulfur in coal (from ultimate analysis)

- $\mathrm{v}$ - chlorine in coal (from ultimate analysis)

- $\mathrm{h}$ - moisture in coal (from proximate analysis)

- A - air (including ambient moisture)

- $\mathrm{B}$ - oxygen from liquid oxygen supply

- $\mathrm{C}-\mathrm{CO}_{2}$ in recycled flue gas

- $\mathrm{D}-\mathrm{H}_{2} \mathrm{O}$ in recycled flue gas

- $\mathrm{E}-\mathrm{O}_{2}$ in recycled flue gas

- $\mathrm{F}-\mathrm{SO}_{2}$ in recycled flue gas

- $\mathrm{G}-\mathrm{N}_{2}$ in recycled flue gas

- $\mathrm{H}-\mathrm{Cl}_{2}$ in recycled flue gas

- $\mathrm{K}$ - equivalent natural gas

The coefficient of $\mathrm{O}_{2}$ on the product side may be further simplified to:

$$
\left\{\left[\mathrm{q} / 2+\mathrm{KNG}_{\mathrm{O}} / 2+\mathrm{A}+\mathrm{B}(1-\mathrm{n})+\mathrm{E}\right]-\left[\mathrm{x}+\mathrm{KNG}_{\mathrm{C}}+\mathrm{y} / 4+\mathrm{KNG}_{\mathrm{H}} / 4+\mathrm{w}\right]\right\}
$$

The coal proximate and ultimate analysis results are manually entered into the HMI. The nine letters $\mathrm{A}-\mathrm{K}$ are unknown in the above equation but can be solved using a system of nine equations below. These equations express measured quantities in terms of the variables in the combustion reaction equation above. 
Expressing the directly measured oxygen concentration (dry basis) at the convection pass in terms of the unknown variables yields:

$\mathrm{X}_{\text {Conv.Pass } 02 \text { (dry) }}=\frac{\left\{\left[\mathrm{q} / 2+\mathrm{K} * \mathrm{NG}_{\mathrm{O}} / 2+\mathrm{A}+\mathrm{B}(1-\mathrm{n})+\mathrm{E}\right]-\left(\mathrm{x}+\mathrm{K} * \mathrm{NG}_{\mathrm{C}}+\mathrm{y} / 4+\mathrm{K} * \mathrm{NG}_{\mathrm{H}} / 4+\mathrm{w}\right)\right\}}{\left[\mathrm{K} *\left(\mathrm{NG}_{\mathrm{O}}+\mathrm{NG}_{\mathrm{N}}-\mathrm{NG}_{\mathrm{H}} / 2\right) / 2+\mathrm{A} *(1+\mathrm{m})+\mathrm{B}+\mathrm{C}+\mathrm{E}+\mathrm{F}+\mathrm{G}+\mathrm{H}-\mathrm{y} / 4+\mathrm{z} / 2+\mathrm{q} / 2+\mathrm{v} / 2\right]}$

Similarly, expressing the dry basis concentrations of $\mathrm{CO}_{2}$ and $\mathrm{SO}_{2}$ at the convection pass (also directly measured) in terms of the unknowns:

$$
\begin{aligned}
& \mathrm{X}_{\text {Conv.PassCO2(dry) }}=\frac{\left(\mathrm{x}+\mathrm{C}+\mathrm{K}^{*} \mathrm{NG}_{\mathrm{C}}\right)}{\left[\mathrm{K}^{*}\left(\mathrm{NG}_{\mathrm{O}}+\mathrm{NG}_{\mathrm{N}}-\mathrm{NG}_{\mathrm{H}} / 2\right) / 2+\mathrm{A} *(1+\mathrm{m})+\mathrm{B}+\mathrm{C}+\mathrm{E}+\mathrm{F}+\mathrm{G}+\mathrm{H}-\mathrm{y} / 4+\mathrm{z} / 2+\mathrm{q} / 2+\mathrm{v} / 2\right]} \\
& \mathrm{X}_{\text {Conv.PassSO2(dry) }}=\frac{(\mathrm{w}+\mathrm{F})}{\left[\mathrm{K} *\left(\mathrm{NG}_{\mathrm{O}}+\mathrm{NG}_{\mathrm{N}}-\mathrm{NG}_{\mathrm{H}} / 2\right) / 2+\mathrm{A} *(1+\mathrm{m})+\mathrm{B}+\mathrm{C}+\mathrm{E}+\mathrm{F}+\mathrm{G}+\mathrm{H}-\mathrm{y} / 4+\mathrm{z} / 2+\mathrm{q} / 2+\mathrm{v} / 2\right]}
\end{aligned}
$$

Windbox $\mathrm{O}_{2}$ is directly measured by an in-situ sensor. Relating the windbox oxygen concentration (wet basis) to the flow rates of air, oxygen, and recycled flue gas into the windbox:

$$
\mathrm{X}_{\mathrm{WindboxO2}}=\frac{\left[\mathrm{A} * \dot{\mathrm{m}}_{\mathrm{SA}} / \dot{\mathrm{m}}_{\mathrm{Air}}+\mathrm{B} *(1-\mathrm{n}) * \dot{\mathrm{m}}_{\mathrm{Sec} \mathrm{O} 2} / \dot{\mathrm{m}}_{\mathrm{O} 2}+\mathrm{E} * \dot{\mathrm{m}}_{\mathrm{SecRF}} / \dot{\mathrm{m}}_{\mathrm{RFG}}\right]}{\left[\mathrm{A} *\left(1+\mathrm{m}+\mathrm{A}^{\prime}\right) * \dot{\mathrm{m}}_{\mathrm{SA}} / \dot{\mathrm{m}}_{\mathrm{Air}}+\mathrm{B} * \dot{\mathrm{m}}_{\mathrm{Sec} \mathrm{O} 2} / \dot{\mathrm{m}}_{\mathrm{O} 2}+(\mathrm{C}+\mathrm{D}+\mathrm{E}+\mathrm{F}+\mathrm{G}+\mathrm{H}) * \dot{\mathrm{m}}_{\mathrm{Sec} \mathrm{RFG}} / \dot{\mathrm{m}}_{\mathrm{RFG}}\right]}
$$

Where $\dot{\mathrm{m}}$ indicates mass flow in $\mathrm{lb} / \mathrm{h}$ of the stream indicated by the subscript:

- SA - secondary air (includes overfire air)

- Air - Total air (primary and secondary air including overfire air)

- Sec $\mathrm{O} 2$ - Oxygen to secondary Floxynator ${ }^{\mathrm{TM}}$

- O2 - Total oxygen (primary, secondary, and Cyclone lance)

- $\quad$ Sec RFG - Secondary recycled flue gas

- $\mathrm{RFG}$ - Total recycled flue gas

If either the wet scrubber (WFGD) or condensing heat exchanger (CHX) was in use the partial pressure of water vapor was calculated from saturated conditions. For warm recycle tests the mole fraction of water vapor was directly measured by the moisture analyzer. Expressing partial pressure (or mole fraction) of water in the recycled flue gas in terms of C, D, E, F, G, and H yields:

$$
X_{\mathrm{H} 2 \mathrm{ORFG}}=\frac{D}{(C+D+E+F+G+H)}
$$

The measured ratios of oxygen or recycled flue gas to air mass flows, expressed in terms of the variables in the combustion reaction equation are:

$$
\frac{\dot{\mathrm{m}}_{\mathrm{O} 2}}{\dot{\mathrm{m}}_{\mathrm{Air}}}=\frac{\{\mathrm{B} *[32 *(1-\mathrm{n})+28 * \mathrm{n}]\}}{\left[\mathrm{A} *\left(32 * 1+28 * \mathrm{~m}+18 * \mathrm{~A}^{\prime}\right)\right]}
$$


and:

$$
\frac{\dot{\mathrm{m}}_{\mathrm{RFG}}}{\dot{\mathrm{m}}_{\mathrm{Air}}}=\frac{(44 * \mathrm{C}+18 * \mathrm{D}+32 * \mathrm{E}+64 * \mathrm{~F}+28 * \mathrm{G}+71 * \mathrm{H})}{\left[\mathrm{A} *\left(32 * 1+28 * \mathrm{~m}+18 * \mathrm{~A}^{\prime}\right)\right]}
$$

The next equation equates the mass ratio of chlorine to carbon in the coal with that in the recycled flue gas. It assumes that chlorine exists as gas-phase $\mathrm{Cl}_{2}$, and does not drop out in the environmental equipment and recycle ducts. The equation does not apply when natural gas is flowing (during startup) as including this situation would make the equation system non-linear. The equation is included here for completeness of the documentation, but as the chloride content of coal was not used in the data analysis the equation was effectively deactivated. There was no instrumentation to measure $\mathrm{Cl}$ compounds beyond the off-site fuel analysis. The equation has minimal effect on the equation system as a whole due to the low levels of $\mathrm{Cl}$, and only has practical use for warm recycle (no WFGD) to estimate the upper limit of $\mathrm{Cl}\left(\mathrm{as}_{2}\right)$ in the recycle gas.

$$
\frac{35.5 * \mathrm{v}}{12 * \mathrm{x}}=\frac{71 * \mathrm{H}}{12 * \mathrm{C}} \text { or } \frac{\mathrm{v}}{\mathrm{x}}=\frac{2 * \mathrm{H}}{\mathrm{C}}
$$

The last of the nine equations expresses the ratio of mass flow of natural gas to air and oxygen mass flows (all measured) in terms of the variables in the combustion reaction equation:

$$
\frac{\dot{\mathrm{m}}_{\mathrm{NG}}}{\dot{\mathrm{m}}_{\mathrm{Air}}+\dot{\mathrm{m}}_{\mathrm{O} 2}}=\frac{\left[\mathrm{K} *\left(12 * \mathrm{NG}_{\mathrm{C}}+1 * \mathrm{NG}_{\mathrm{H}}+16 * \mathrm{NG}_{\mathrm{O}}+14 * \mathrm{NG}_{\mathrm{N}}\right)\right]}{\left\{\mathrm{A} *\left[32 * 1+28 * \mathrm{~m}+18 * \mathrm{~A}^{\prime}\right]+\mathrm{B} *[32 *(1-\mathrm{n})+28 * \mathrm{n}]\right\}}
$$

The nine equations form a linear system that may be expressed as a matrix equation and solved using elementary row operations. The specific algorithm used is known as LU decomposition because the procedure decomposes the matrix of coefficients to express it as the product of a lower (L) triangular matrix and an upper (U) triangular matrix. The results are used to calculate overall and burner stoichiometry, coal flow rate, load, total convection pass mass flow, and emissions rates.

\subsubsection{Data Reporting}

The data were prepared for publication using Microsoft Excel, and are shown graphically in the Results and Discussion chapter, and tabulated in the Appendix. Key points to note regarding the data are as follows:

- The $\mathrm{SO}_{2}$ emission rate is calculated using the concentration measurement at the stack. Some $\mathrm{SO}_{2}$ readings at the convection pass were acquired by an IR analyzer but were biased high (by up to $300 \mathrm{ppm}$ ) due to moisture interference and are not presented. Instead, the data from $\mathrm{UV} \mathrm{SO}_{2}$ analyzers at either the wet scrubber inlet or stack (as appropriate) were corrected to the oxygen concentration measured at the convection pass and reported as convection pass $\mathrm{SO}_{2}$.

- It is suspected that the thermocouple at the CHX outlet was wetted by condensate resulting in a low reading. This affects the calculation of moisture in the recycled flue 
gas, which because it is used in the system of equations above, has effects on several variables. The resulting error in calculated coal flow, load, and stoichiometry is however less than $1 \%$ (for a $14^{\circ} \mathrm{F}$ error in the $\mathrm{CHX}$ outlet temperature in test "prb oxy Cyclone test13"). From September $3^{\text {rd }}, 2009$ the problem was solved by calculating saturation conditions using the thermocouple at the ID fan inlet instead of that at the CHX outlet. Reprocessed test data (marked in the tables) also had this correction applied. The warm recycle tests did not use the $\mathrm{CHX}$.

- The reported moisture content of the primary oxidant stream does not include moisture from the coal that evaporates between the coal pickup point and the burner, as indicated by significant cooling of primary oxidizer when the coal is picked up. The energy balance calculations do account for this effect by using the primary oxidant temperature before coal addition.

- Bottled $\mathrm{CO}_{2}$ rather than compressed air was used in an eductor for fly ash sampling in the oxy-firing tests. This avoided introduction of unwanted compressed air to the system. The fly ash sampled was not captured under the targeted isokinetic conditions because the required pressure of $\mathrm{CO}_{2}$ could not be reached with the bottled gases.

- Coal was only sampled intermittently for coal fineness and as-fired moisture determination. Values were assumed to apply until the next time a sample was taken and analyzed.

- The maximum temperatures from the FlameView camera have a resolution of $100^{\circ} \mathrm{F}$ and may not be representative of the temperature map. See the temperature maps in Results and Discussion for more information.

- Data missing from the tables are due to them either not being applicable (e.g. $\mathrm{O}_{2}$ flows in an air-fired test), or being obviously bad values that are discarded. Some heat transfer data are discarded because the test time was insufficient for the averages to be accurate.

\subsubsection{Coal Analyses}

The coals tested were Ohio \#5 (an Eastern bituminous coal), Black Thunder (a Western subbituminous coal from the Powder River Basin (PRB)), and North Dakota Lignite. Proximate, ultimate, and other analysis data are shown in Table 2.3. Elemental ash analysis results are shown in Table 2.4. The subbituminous coal for the warm recycle testing was delivered in a separate shipment and notably differed in sulfur content from the subbituminous coal used previously. For this reason, both analyses are shown. Both as-received and as-fired sulfur contents are listed, as some sulfur is removed as pyrite during pulverizing. The high sulfur content of the bituminous coal is an important distinction between it and the other two coals for this work. 


\begin{tabular}{|c|c|c|c|c|}
\hline & \multirow{3}{*}{$\begin{array}{c}\begin{array}{c}\text { Eastern } \\
\text { Bituminous }\end{array} \\
\text { Ohio \#5 }\end{array}$} & \multirow{2}{*}{\multicolumn{2}{|c|}{$\begin{array}{c}\text { Western Sub-bituminous } \\
\text { Black Thunder }\end{array}$}} & \multirow{3}{*}{$\begin{array}{c}\text { Lignite } \\
\text { North Dakota }\end{array}$} \\
\hline & & & & \\
\hline & & Cold recycle & Warm recycle & \\
\hline \multicolumn{5}{|c|}{ Proximate Analysis (wt \%, as received) } \\
\hline Moisture & 6.47 & 26.56 & 26.15 & 35.60 \\
\hline Ash & 5.57 & 4.94 & 4.64 & 6.79 \\
\hline Volatile Matter & 41.51 & 32.11 & 32.20 & 28.50 \\
\hline Fixed Carbon & 46.45 & 36.39 & 37.01 & 29.11 \\
\hline \multicolumn{5}{|c|}{ Ultimate Analysis (wt \%, as received) } \\
\hline Carbon & 71.10 & 50.98 & 51.80 & 41.91 \\
\hline Hydrogen & 5.02 & 3.84 & 3.83 & 3.04 \\
\hline Nitrogen & 1.41 & 0.76 & 0.81 & 0.64 \\
\hline Sulfur & 2.56 & 0.38 & 0.24 & 0.74 \\
\hline Oxygen & 7.87 & 12.53 & 12.53 & 11.29 \\
\hline \multicolumn{5}{|c|}{ Miscellaneous (as received, unless specified) } \\
\hline As-fired fuel sulfur (wt \%) & 2.70 & 0.39 & 0.26 & 0.66 \\
\hline Calorific Value (Btu/lb) & 12807 & 8841 & 8829 & 6938 \\
\hline Chlorine (ppm) & & & 12 & 20 \\
\hline $\mathrm{Hg}(\mathrm{ppb})$ & & & 35 & 72 \\
\hline Hardgrove Grindability Index & 56 & & & 50 \\
\hline
\end{tabular}

Table 2.3 Proximate, ultimate, and miscellaneous analyses for the coals tested

\begin{tabular}{|r|r|r|r|r|}
\hline & \multirow{2}{*}{} & \multicolumn{2}{|c|}{ Sub-bituminous } & \multirow{2}{*}{ Lignite } \\
\cline { 3 - 5 } & Bituminous & \multicolumn{2}{|c|}{ Black Thunder } & \multirow{2}{*}{ North Dakota } \\
\cline { 2 - 5 } & Ohio \#5 & Cold recycle & Warm recycle & North \\
\hline $\mathrm{SiO}_{2}$ & & 25.92 & 31.60 & 21.98 \\
\hline $\mathrm{Al}_{2} \mathrm{O}_{3}$ & & 13.29 & 15.68 & 10.30 \\
\hline $\mathrm{Fe}_{2} \mathrm{O}_{3}$ & & 7.04 & 5.23 & 7.66 \\
\hline $\mathrm{CaO}$ & & 19.78 & 21.95 & 20.01 \\
\hline $\mathrm{MgO}$ & & 4.27 & 5.16 & 7.25 \\
\hline $\mathrm{Na}_{2} \mathrm{O}$ & & 0.81 & 1.22 & 4.05 \\
\hline $\mathrm{K}_{2} \mathrm{O}$ & & 0.50 & 0.41 & 0.26 \\
\hline $\mathrm{P}_{2} \mathrm{O}_{5}$ & & 1.34 & 1.83 & 0.28 \\
\hline $\mathrm{TiO}_{2}$ & & 0.82 & 0.95 & 0.33 \\
\hline $\mathrm{BaO}$ & & 0.49 & 0.67 & 0.78 \\
\hline $\mathrm{SrO}$ & & 0.28 & 0.40 & 0.71 \\
\hline $\mathrm{SO}_{3}$ & & 14.11 & 11.76 & 21.10 \\
\hline
\end{tabular}

Table 2.4 Elemental ash analysis of the coals tested 


\section{RESULTS AND DISCUSSION}

\subsection{Phase I - Equipment Specification and Pilot-scale Evaluation}

\subsubsection{Environmental Equipment Requirement}

\subsubsection{Task 1 - Specification of Flue Gas Purification, Compression, Transportation, and $\underline{\text { Sequestration }}$}

Optimization of the flue gas purification train and boiler enable cost saving. The key is to view the whole process of oxygen separation, coal combustion, steam generation, flue gas purification (if required), transportation, and sequestration together. Cost savings can be realized by optimizing the flue gas handling through two fundamental options: one is to compress the flue gas and inject it directly into a suitable geologic formation; another is to separate gas components that may not be advantageous to long-term injection. The former case will require less environmental control equipment (e.g., $\mathrm{SO}_{\mathrm{X}}$ and $\mathrm{NO}_{\mathrm{X}}$ removal). However, the feasibility of this option will require rigorous reservoir and geochemical modeling. In particular, noncondensable gases, such as nitrogen and oxygen, may affect the subsurface processes by creating a multi-phase flow situation that may reduce injectivity or reduce the capacity of the aquifer for $\mathrm{CO}_{2}$ over the lifetime of the power plant. If it is determined that additional purification is needed to remove certain impurities such as excess oxygen, nitrogen, or other post-capture impurities that may affect compression, handling, or regulatory requirements, then the equipment for scrubbing these impurities will need to be evaluated.

Our approach was to: 1) determine the flue gas composition from an oxy-fired boiler, 2) review the pipeline gas requirement, and 3) determine the steps that are required for the flue gas purification.

$\mathrm{B} \& \mathrm{~W}$ performed an evaluation of gas composition leaving the boiler for the purification system and/or recycled to the boiler. The purpose of this evaluation is to investigate the impact of coal type and air leakage on the flue gas composition. The next step then is then to consider what purification steps are required before sequestration of the gas. Three coals were used in this study: a North Dakota Lignite; Decker, a subbituminous coal from Montana; and Illinois No. 6, high volatile bituminous coal.

\begin{tabular}{|c|c|c|c|c|c|c|c|c|c|c|c|c|}
\hline \multirow[b]{3}{*}{ Item } & \multicolumn{4}{|c|}{ ND Lignite } & \multicolumn{4}{|c|}{ Decker } & \multicolumn{4}{|c|}{ Illinois \# 6} \\
\hline & \multicolumn{2}{|c|}{ Wet } & \multicolumn{2}{|c|}{ Dry } & \multicolumn{2}{|c|}{ Wet } & \multicolumn{2}{|c|}{ Dry } & \multicolumn{2}{|c|}{ Wet } & \multicolumn{2}{|c|}{ Dry } \\
\hline & $\mathrm{wt} \%$ & $\mathrm{~mol} \%$ & $\mathrm{wt} \%$ & $\mathrm{~mol} \%$ & $\mathrm{wt} \%$ & $\mathrm{~mol} \%$ & $\mathrm{wt} \%$ & $\mathrm{~mol} \%$ & wt $\%$ & $\mathrm{~mol} \%$ & wt $\%$ & $\mathrm{~mol} \%$ \\
\hline $\mathrm{H}_{2} \mathrm{O}$ & $8.61 \%$ & $17.41 \%$ & $0.00 \%$ & $0.00 \%$ & $8.64 \%$ & $17.42 \%$ & $0.00 \%$ & $0.00 \%$ & $8.70 \%$ & $17.43 \%$ & $0.00 \%$ & $0.00 \%$ \\
\hline $\mathrm{CO}_{2}$ & $72.08 \%$ & $59.63 \%$ & $78.87 \%$ & $72.20 \%$ & $72.20 \%$ & $59.57 \%$ & $79.03 \%$ & $72.14 \%$ & $70.96 \%$ & $58.18 \%$ & $77.73 \%$ & $70.46 \%$ \\
\hline $\mathrm{N}_{2}$ & $12.32 \%$ & $16.01 \%$ & $13.48 \%$ & $19.38 \%$ & $12.59 \%$ & $16.32 \%$ & $13.78 \%$ & $19.76 \%$ & $13.68 \%$ & $17.63 \%$ & $14.99 \%$ & $21.35 \%$ \\
\hline $\mathrm{O}_{2}$ & $3.60 \%$ & $4.10 \%$ & $3.94 \%$ & $4.96 \%$ & $3.53 \%$ & $4.00 \%$ & $3.86 \%$ & $4.85 \%$ & $3.64 \%$ & $4.11 \%$ & $3.99 \%$ & $4.97 \%$ \\
\hline $\mathrm{SO}_{2}$ & $0.67 \%$ & $0.3797 \%$ & $0.73 \%$ & $0.46 \%$ & $0.24 \%$ & $0.1350 \%$ & $0.26 \%$ & $0.16 \%$ & $0.18 \%$ & $0.1004 \%$ & $0.20 \%$ & $0.12 \%$ \\
\hline $\mathrm{Ar}$ & $2.63 \%$ & $2.40 \%$ & $2.88 \%$ & $2.90 \%$ & $2.75 \%$ & $2.50 \%$ & $3.01 \%$ & $3.03 \%$ & $2.77 \%$ & $2.50 \%$ & $3.04 \%$ & $3.03 \%$ \\
\hline $\mathrm{NO}_{2}$ & $0.078 \%$ & $0.0619 \%$ & $0.086 \%$ & $0.075 \%$ & $0.031 \%$ & $0.0248 \%$ & $0.034 \%$ & $0.030 \%$ & $0.048 \%$ & $0.0380 \%$ & $0.053 \%$ & $0.046 \%$ \\
\hline $\mathrm{CO}$ & $0.013 \%$ & $0.0165 \%$ & $0.014 \%$ & $0.020 \%$ & $0.013 \%$ & $0.0165 \%$ & $0.014 \%$ & $0.020 \%$ & $0.013 \%$ & $0.0165 \%$ & $0.014 \%$ & $0.020 \%$ \\
\hline
\end{tabular}

Table 3.1 Flue gas inlet compositions for three coal types (worst case scenario for air infiltration) 
It must be stressed that the compositions in Table 3.1 represent a worst-case-scenario of air infiltration into the boiler unit (i.e. boiler, ducts and air heaters). With investment in the plant to minimize leaks it is possible that nitrogen levels in the flue gas will be up to $50 \%$ lower than those shown above (based in pilot scale test results).

\subsubsection{Flue Gas Purification and Compression Train}

Among the goals of this work is the objective to develop a flue gas compression and purification train that processes flue gas from an oxy-combustion pulverized coal-fired boiler unit to recover at least $90 \% \mathrm{CO}_{2}$ (DOE target) at a composition suitable for sequestration with the lowest possible power consumption. This task is complicated by the fact that no clear definition exists for a 'sequestration-ready' gas stream. In fact, one of the goals of this project is to define acceptable ranges/limits for various flue gas components in a sequestration-ready gas stream. For the purposes of this section, a 'sequestration-ready' gas stream has been defined as follows:

A 'sequestration-ready' gas stream is the product of a compression and purification train that contains at least $90 \%$ of the $\mathrm{CO}_{2}$ present in the feed stream at a total pressure of 175 bar $(\sim 2540 \mathrm{psia})$ and a temperature of $95^{\circ} \mathrm{F}$. This stream also contains no more than $30 \mathrm{lb} \mathrm{H}_{2} \mathrm{O}$ per MMSCF of $\mathrm{CO}_{2}$ (equivalent to 600ppmv).

The above specification on water concentration is identical to the specification for pipeline transport of $\mathrm{CO}_{2}$ from Kinder Morgan (a major North American pipeline company). No restrictions are placed on other components in the gas stream because no specifications exist for $\mathrm{NO}_{\mathrm{X}} \& \mathrm{SO}_{\mathrm{X}}$ in commonly accepted pipeline specifications such as Kinder Morgan.

Several compression and purification schemes (Cases A-C in Figure 3.1 to Figure 3.3) were developed for converting flue gas obtained by combustion of 3 different coals to 'sequestrationready' gas (Quarterly Technical Progress Reports No. 3 \& 5). It was observed that the flue gases could be purified to a very large extent using partial condensation or distillation processes with similar or less expenditure of compression energy as a compression only process, for a product pressure of 175 bar. For Decker coal for example, Figure 3.5for specific energy in the range of 155 to $160 \mathrm{kWh} /$ ton captured $\mathrm{CO}_{2}$, one can obtain $100 \% \mathrm{CO}_{2}$ recovery with essentially feed $\mathrm{CO}_{2}$ concentration in a compression only process (Case A2a), or $94-95 \% \mathrm{CO}_{2}$ concentration in the product stream using partial condensation or distillation processes at $90 \% \mathrm{CO}_{2}$ recovery (Cases $\mathrm{B}$ and $\mathrm{C}$ ). Since the energy expenditure in purification and non-purification processes is close or lower for purification schemes, it is useful to consider purification and try to minimize the amount of 'contaminants' (i.e. gases other than $\mathrm{CO}_{2}$ ) sent to underground reservoirs for storage.

The above results formed the basis for selecting processes for detailed study. These processes are described below.

\subsubsection{Description of the Cases}

The basic process developed for processing flue gas to 'sequestration-ready' specifications is as follows:

- Compression of wet flue gas.

- Drying of the flue gas at the outlet of the "wet compression" step. 
- Flue gas purification (if considered).

- Compression of the dry product gas to a pressure at which it condenses at $20^{\circ} \mathrm{C}$.

- Pumping of the condensed product to pipeline pressure.

The combination of compression, condensation and pumping minimizes power consumption of the process. However, the condensation and pumping processes can be used only in cases where the condensation pressure is lower than the final product pressure. The calculation of power consumption in various stages of the above process is detailed in the Appendix (Section 8.1).

Three processes were designed, optimized and compared to arrive upon the process with the least specific energy requirement:

A. Compression and drying only: In this process, flue gas is compressed and dried to obtain a gas stream with $30 \mathrm{lb} \mathrm{H}_{2} \mathrm{O} / \mathrm{MMSCF} \mathrm{CO}_{2}$ at the desired pressure. No further purification is attempted. The 'dry' gas is then compressed, condensed and pumped to the product pressure. This process corresponds to a case of $100 \% \mathrm{CO}_{2}$ recovery.

B. Partial condensation: In this process, flue gas is compressed, dried, and then purified using a partial condensation scheme with 2 vessels in series to recover $90 \%$ of the $\mathrm{CO}_{2}$ in the feed stream. The purified stream is then compressed, condensed and pumped to the final product pressure.

C. Partial condensation and distillation: This process is an extension of process 2 . In this process, in addition to partial condensation, distillation is used to reduce $\mathrm{O}_{2}$ in the purified stream to $1 \mathrm{ppm}$. The purified stream, containing $90 \%$ of the $\mathrm{CO}_{2}$ from the feed stream, is then compressed, condensed and pumped to the final product pressure

The above processes are shown schematically in Figure 3.1 through Figure 3.3.

The purpose of this study is primarily to compare the three schemes. Therefore some assumptions and approximations are made consistently between the three cases but those won't be made for the detailed study (e.g. neglecting dryers' regeneration energy).

The processes above were simulated for flue gases obtained by oxy-combustion of 3 different types of coals - North Dakota Lignite, Decker, and Illinois \#6 - in retrofitted coal-fired boilers. Flue gas compositions were provided by B\&W (see Table 3.1 above). As noted in Section 3.1.1, the flue gas compositions represent a worst-case scenario of air infiltration into the boiler unit and it is possible to obtain $\mathrm{N}_{2}$ levels in the flue gas that are $50 \%$ lower than those currently shown. To understand the influence of excessive air infiltration expected in retrofitted units, a $4^{\text {th }}$ flue gas composition was generated by reducing $\mathrm{N}_{2}$ and $\mathrm{O}_{2}$ mole fractions in the flue gas to $10 \%$ and 3\% respectively and increasing the other gas components accordingly, as shown in Table 3.2. Each of the 3 processes above was simulated with this flue gas composition also, and the results provide an estimate of the potential specific energy savings by achieving low air infiltration in retrofit boilers.

The product pressure was fixed at $175 \mathrm{bar}(\sim 2540 \mathrm{psia})$. However, to ensure that the conclusions of this study are not overly biased by the product pressure, a study of the influence of product 
pressure on the specific energy was also undertaken and the results are discussed in Section 3.1.2.4, below.

In all the processes, an adsorption process was used to dry the gas. This drying is common to all three processes and won't affect the comparison. Power consumption for reactivation of the adsorbent was not taken into account in this study. Therefore, for the sake of simplicity, all calculations were performed on a dry basis. $\mathrm{CO}_{2}$ losses in dryers, water scrubbing or during compression were also not taken into account. These losses can account for up to $1 \%$ of total inlet $\mathrm{CO}_{2}$. Pressure losses in heat exchangers were $150 \mathrm{mbar}(\sim 2.2 \mathrm{psia})$ for each stream. However, more realistic assumptions are taken into account in the detailed study.

In Case A, the entire gas stream is compressed to the final product specifications and thus provides no opportunity for optimization. Case B was optimized by varying the pressure to the purification unit and the temperature of the first separation vessel in the purification unit. In Case $\mathrm{C}$, the pressure in the distillation column was used as an additional parameter for optimizing the process. Heat exchange within the purification units in Cases B and $\mathrm{C}$ was also optimized to achieve the lowest pressure loss during purification. Since comparisons are made on a specific energy basis (i.e. per unit captured $\mathrm{CO}_{2}$ ), the fact that Case $\mathrm{A}$ recovers $10 \%$ more $\mathrm{CO}_{2}$ than Cases $\mathrm{B}$ and $\mathrm{C}$ does not affect the conclusions.

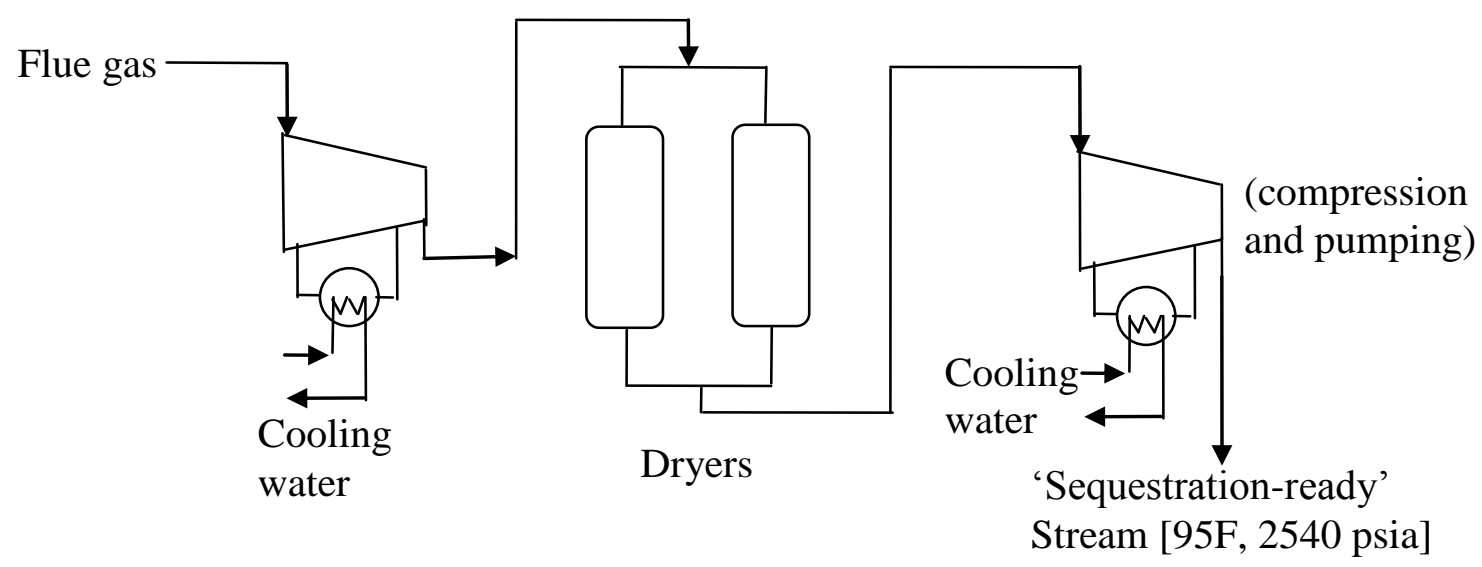

Figure 3.1 Schematic diagram for Case A: compression and drying only 


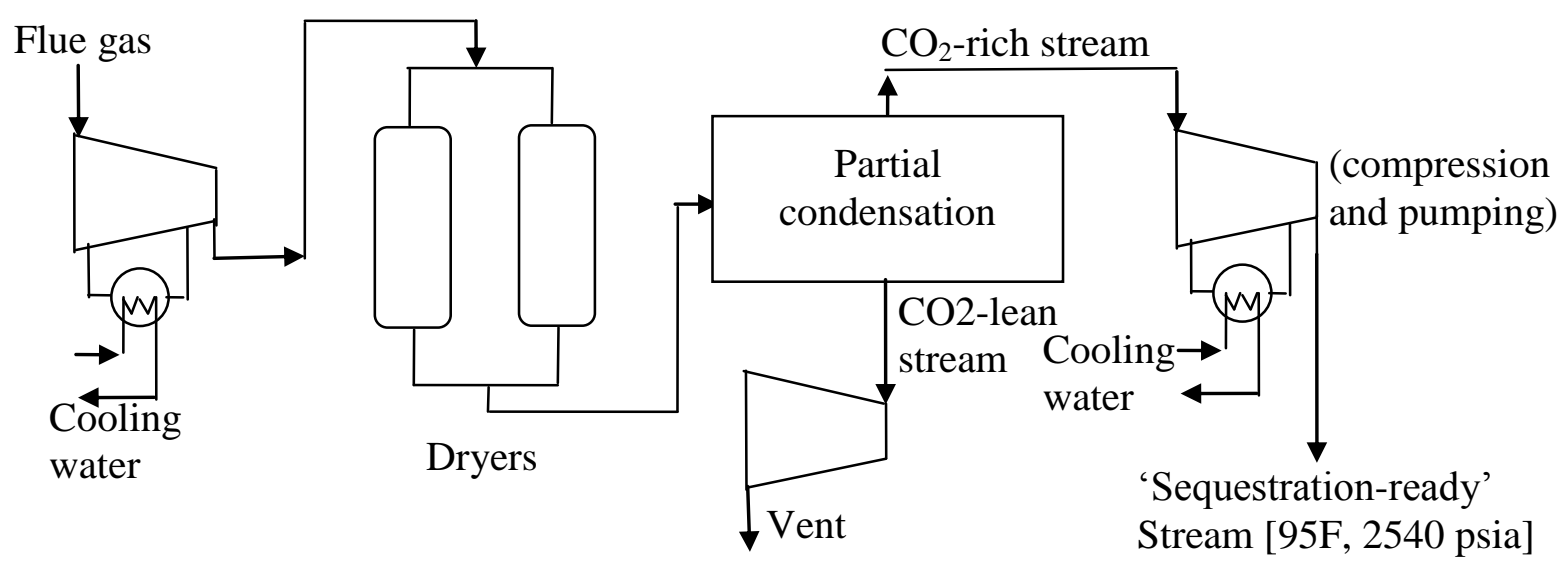

Figure 3.2 Schematic diagram for Case B: partial condensation

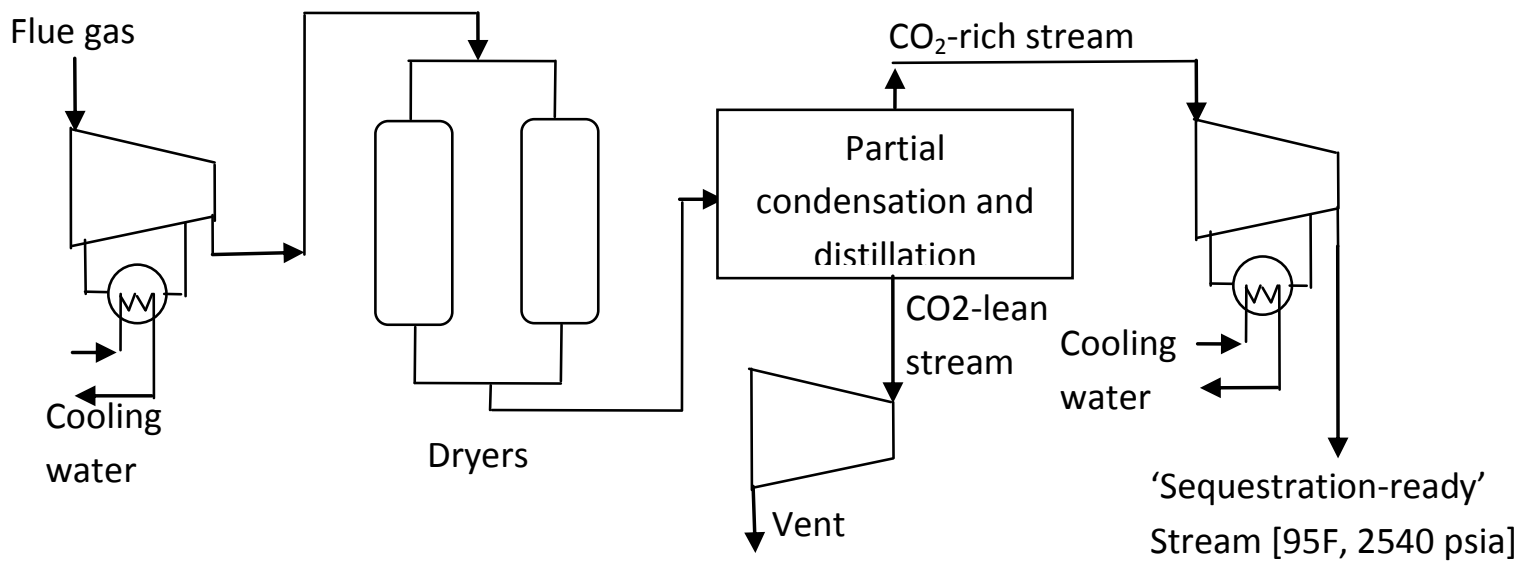

Figure 3.3 Schematic diagram for Case $\mathrm{C}$ : partial condensation and distillation

\begin{tabular}{|c|c|}
\hline Item & mol\% \\
\hline $\mathrm{H}_{2} \mathrm{O}$ & $0.00 \%$ \\
\hline $\mathrm{CO}_{2}$ & $84.38 \%$ \\
\hline $\mathrm{N}_{2}$ & $10 \%$ \\
\hline $\mathrm{O}_{2}$ & $3 \%$ \\
\hline $\mathrm{SO}_{2}$ & $0.5 \%$ \\
\hline $\mathrm{Ar}$ & $2 \%$ \\
\hline $\mathrm{NO}_{2}$ & $0.1 \%$ \\
\hline $\mathrm{CO}$ & $0.020 \%$ \\
\hline
\end{tabular}

Table 3.2 Flue gas composition (dry) for "low air infiltration" case

\subsubsection{2. $\quad$ Comparison of $\mathrm{CO}_{2}$ Capture Processes}

Table 3.3 lists the product composition achieved by each of the processes for the 3 coals. Figure 3.4 to Figure 3.6 compare the performance of the $\mathrm{CO}_{2}$ capture processes for North Dakota Lignite, Decker coal and Illinois \#6 coal, respectively. Each figure shows the $\mathrm{CO}_{2}$ recoveries 
achieved by the processes, $\mathrm{CO}_{2}$ concentrations in the product streams (purities) and the specific energies of the processes to achieve a product pressure of 175 bar ( 2540 psia). For each coal, the compression only case (Case A) provides $100 \% \mathrm{CO}_{2}$ recovery while the purification cases (B and C) are targeted to achieve $90 \%$ purity.

From Table 3.3 and Figure 3.4 to Figure 3.6, Cases B and C achieve significant purification of the flue gas stream for all coals. Partial condensation of the flue gas (Case B) provides $\sim 95 \%$ $\mathrm{CO}_{2}$ in the product, while addition of a distillation column to the partial condensation scheme $\left(\right.$ Case $\mathrm{C}$ ) gives $\mathrm{CO}_{2}$ product purities in excess of $99 \%$ for all 3 coals. Thus, there is not a significant effect of coal rank on the product stream purities achieved by a particular process. From Table 3.3, the distillation column in Case $\mathrm{C}$ mainly rejects the air gases $-\mathrm{N}_{2}, \mathrm{O}_{2}$ and Ar. The concentrations of $\mathrm{SO}_{2}$ and $\mathrm{NO}_{2}$ are virtually unchanged from Case $\mathrm{B}$, indicating that these components are condensed along with $\mathrm{CO}_{2}$ in the distillation column. Thus, the distillation column does not help in reducing the amount of $\mathrm{SO}_{2}$ and $\mathrm{NO}_{2}$ in the product stream.

From Figure 3.4 to Figure 3.6, the absolute magnitudes of the specific energies for each case are similar for ND Lignite and Decker coals, while the Illinois \#6 coal requires slightly higher specific energy. For example, for the compression only case, ND Lignite and Decker require $160 \mathrm{kWh} /$ ton $\mathrm{CO}_{2}$ while Illinois \#6 requires $164 \mathrm{kWh} /$ ton $\mathrm{CO}_{2}$. The slightly higher specific energy requirement for Illinois \#6 coal is due to the greater amount of 'contaminant' gases relative to $\mathrm{CO}_{2}$ in the flue gas. From Table 3.1 above, flue gases from ND Lignite and Decker coals contain $\sim 72 \mathrm{~mol} \% \mathrm{CO}_{2}$ on a dry basis while the flue gas from Illinois \#6 coal contains only $70.5 \mathrm{~mol} \% \mathrm{CO}_{2}$.

Interestingly, for a product pressure of 175 bar, the purification schemes require lower specific energy than the compression only scheme for all 3 coals. For example, for Decker coal (Figure 3.5), Cases $\mathrm{B}$ and $\mathrm{C}$ require $3 \%$ and $6 \%$ lower specific energy, respectively, than Case $\mathrm{A}$. Thus, the purification schemes provide significant enhancement in $\mathrm{CO}_{2}$ purity with lower energy requirement. From a compression energy minimization perspective, Case $\mathrm{C}$ is the best option as it provides the highest $\mathrm{CO}_{2}$ purity in the product with the lowest specific energy.

\begin{tabular}{|l|r|r|r|r|r|r|r|r|r|}
\hline \multirow{3}{*}{ Item } & \multicolumn{3}{|c|}{ ND Lignite } & \multicolumn{3}{c|}{ Decker } & \multicolumn{3}{c|}{ Illinois \#6 } \\
\cline { 2 - 10 } & Case A & Case B & Case C & Case A & Case B & Case C & Case A & Case B & Case C \\
\cline { 2 - 10 } & mol\% & mol\% & mol\% & mol\% & mol\% & mol\% & mol\% & mol\% & mol\% \\
\hline $\mathrm{CO}_{2}$ & $72.21 \%$ & $94.36 \%$ & $99.18 \%$ & $72.15 \%$ & $94.47 \%$ & $99.71 \%$ & $70.46 \%$ & $93.77 \%$ & $99.73 \%$ \\
\hline $\mathrm{N}_{2}$ & $19.38 \%$ & $3.01 \%$ & $0.00 \%$ & $19.76 \%$ & $3.28 \%$ & $0.00 \%$ & $21.35 \%$ & $3.84 \%$ & $0.00 \%$ \\
\hline $\mathrm{O}_{2}$ & $4.96 \%$ & $1.04 \%$ & $0.00 \%$ & $4.85 \%$ & $1.08 \%$ & $0.00 \%$ & $4.97 \%$ & $1.19 \%$ & $0.00 \%$ \\
\hline $\mathrm{SO}_{2}$ & $0.46 \%$ & $0.67 \%$ & $0.70 \%$ & $0.16 \%$ & $0.23 \%$ & $0.25 \%$ & $0.12 \%$ & $0.18 \%$ & $0.19 \%$ \\
\hline $\mathrm{Ar}^{2.90 \%}$ & $0.81 \%$ & $0.00 \%$ & $3.03 \%$ & $0.90 \%$ & $0.00 \%$ & $3.03 \%$ & $0.96 \%$ & $0.00 \%$ \\
\hline $\mathrm{NO}_{2}$ & $0.08 \%$ & $0.11 \%$ & $0.11 \%$ & $0.03 \%$ & $0.04 \%$ & $0.05 \%$ & $0.05 \%$ & $0.07 \%$ & $0.07 \%$ \\
\hline $\mathrm{CO}$ & $0.02 \%$ & $0.00 \%$ & $0.00 \%$ & $0.02 \%$ & $0.00 \%$ & $0.00 \%$ & $0.02 \%$ & $0.00 \%$ & $0.00 \%$ \\
\hline
\end{tabular}

Table 3.3 Product compositions (dry basis) obtained by subjecting flue gases from the 3 coals to the 3 processes of this study 


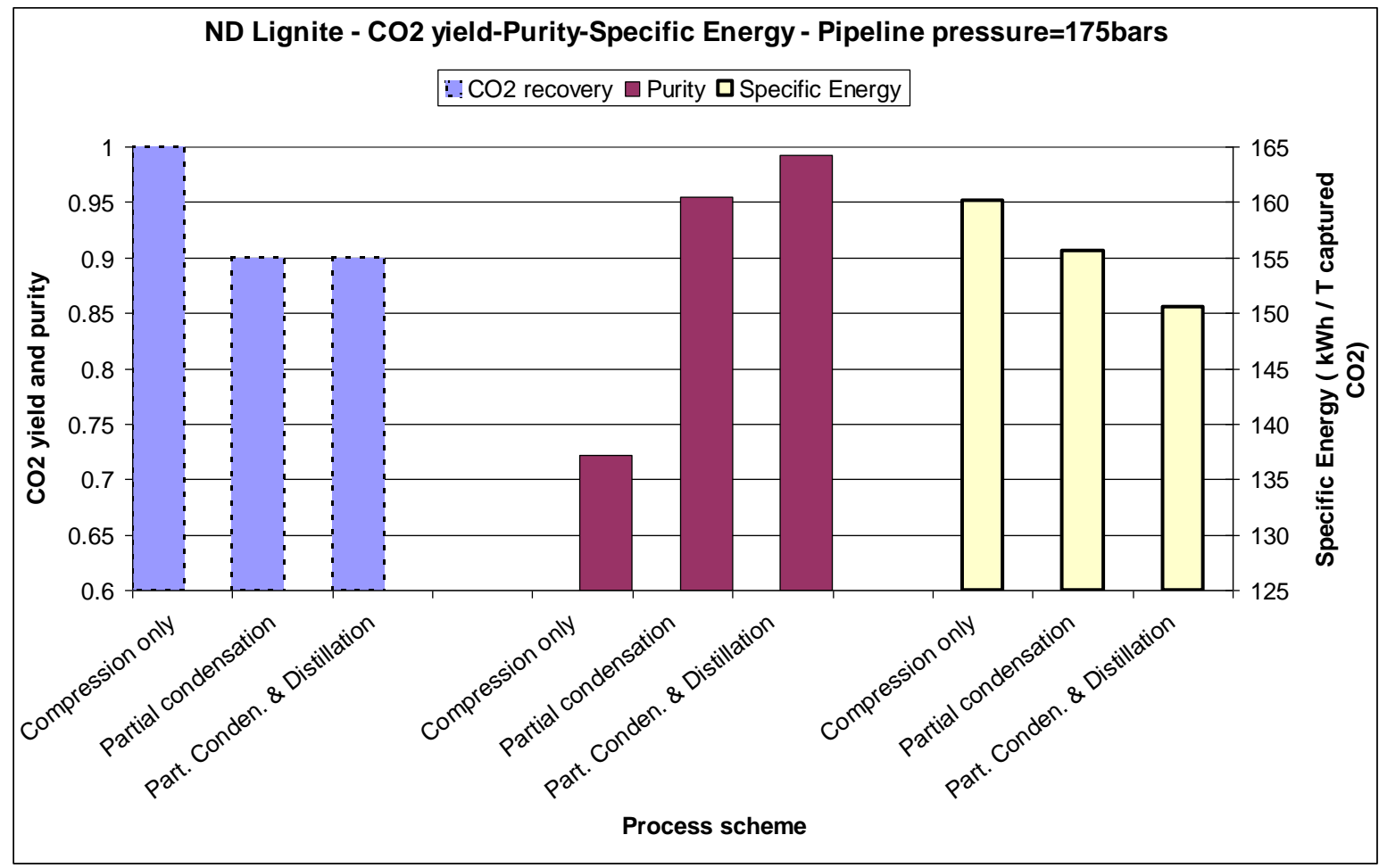

Figure 3.4 Comparison of $\mathrm{CO}_{2}$ yield (recovery), $\mathrm{CO}_{2}$ purity and specific energy of the $3 \mathrm{CO}_{2}$ capture processes for North Dakota Lignite

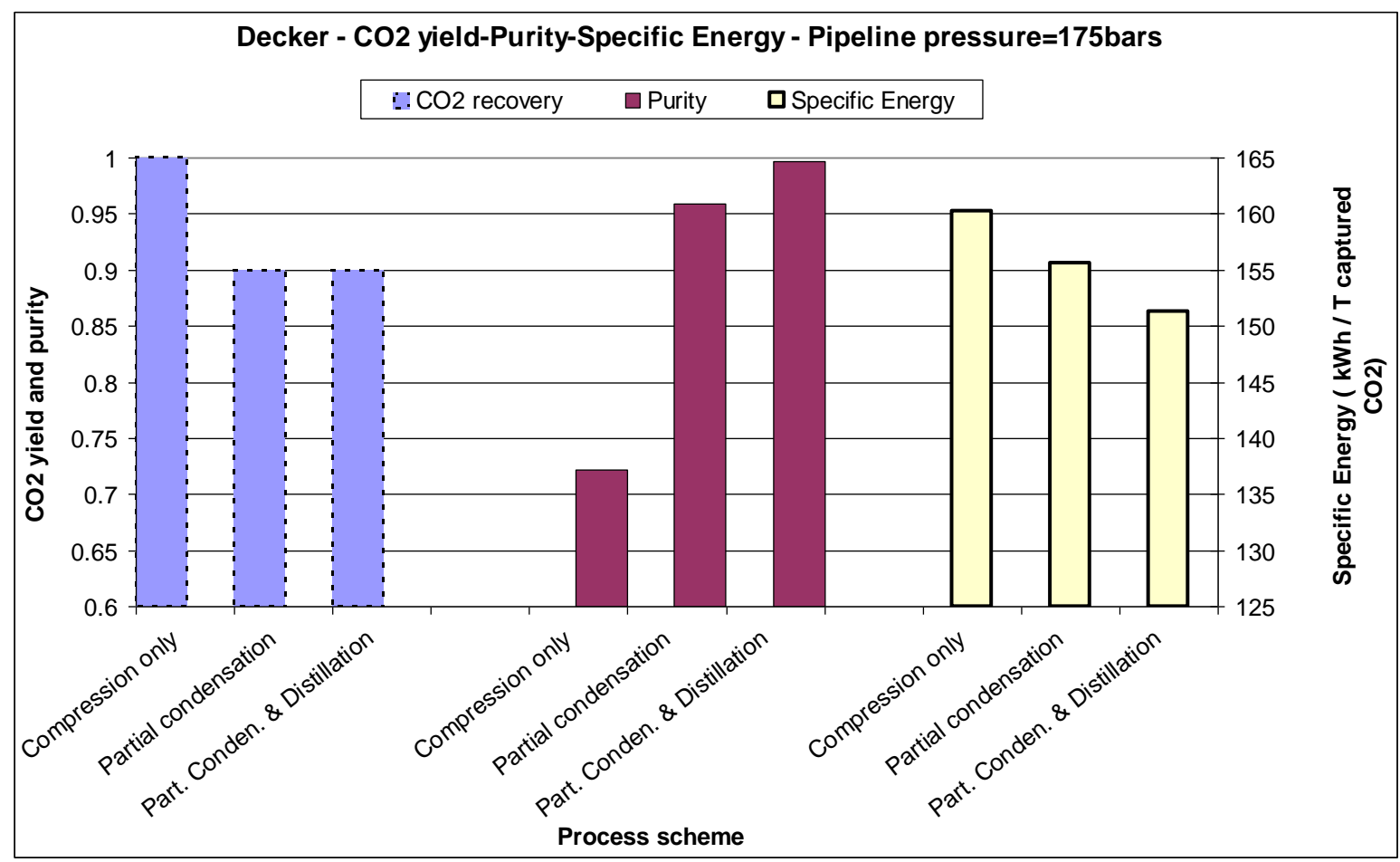

Figure 3.5 Comparison of $\mathrm{CO}_{2}$ yield (recovery), $\mathrm{CO}_{2}$ purity and specific energy of the $3 \mathrm{CO}_{2}$ capture processes for Decker coal 


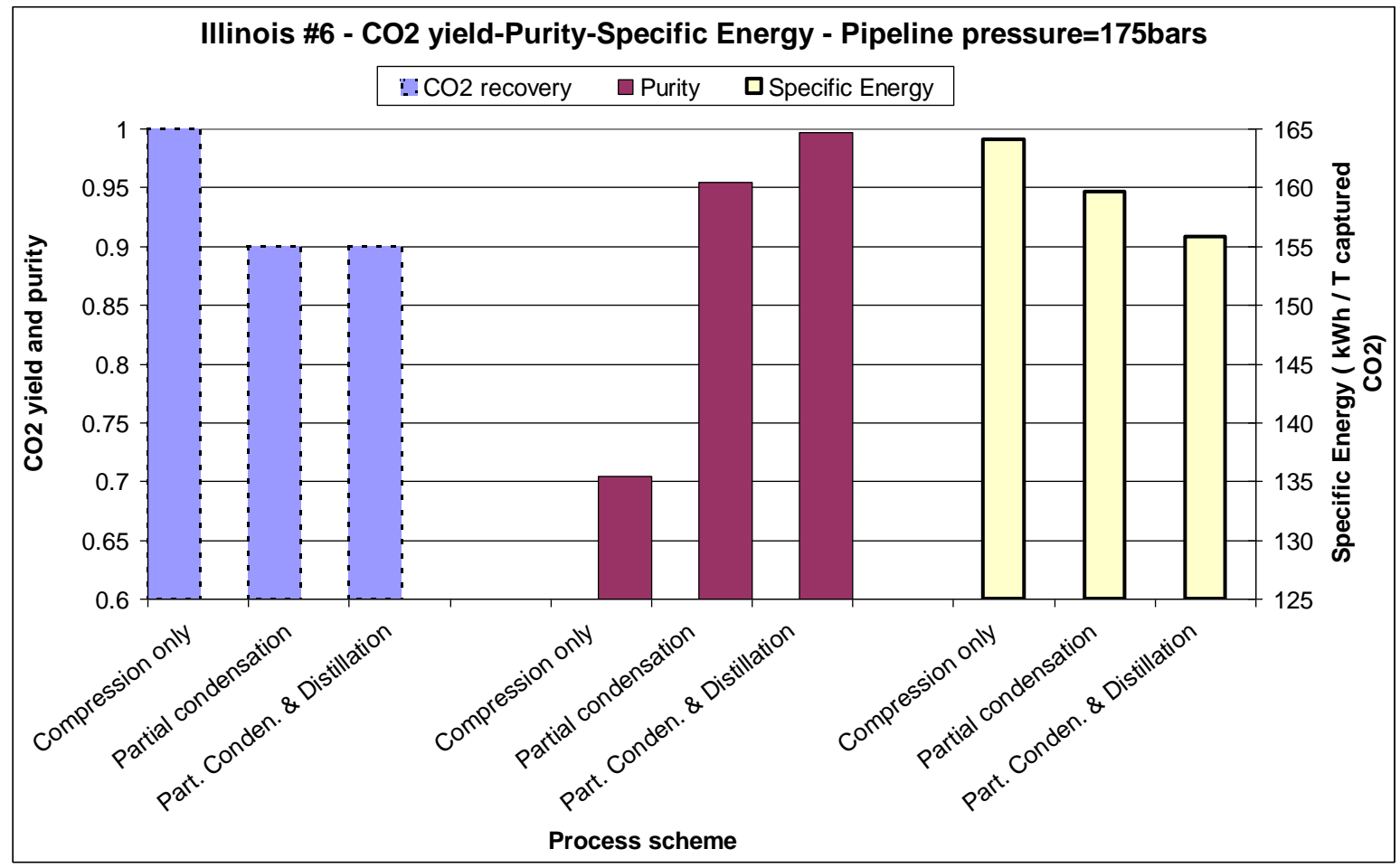

Figure 3.6 Comparison of $\mathrm{CO}_{2}$ yield (recovery), $\mathrm{CO}_{2}$ purity and specific energy of the $3 \mathrm{CO}_{2}$ capture processes for Illinois \#6 coal

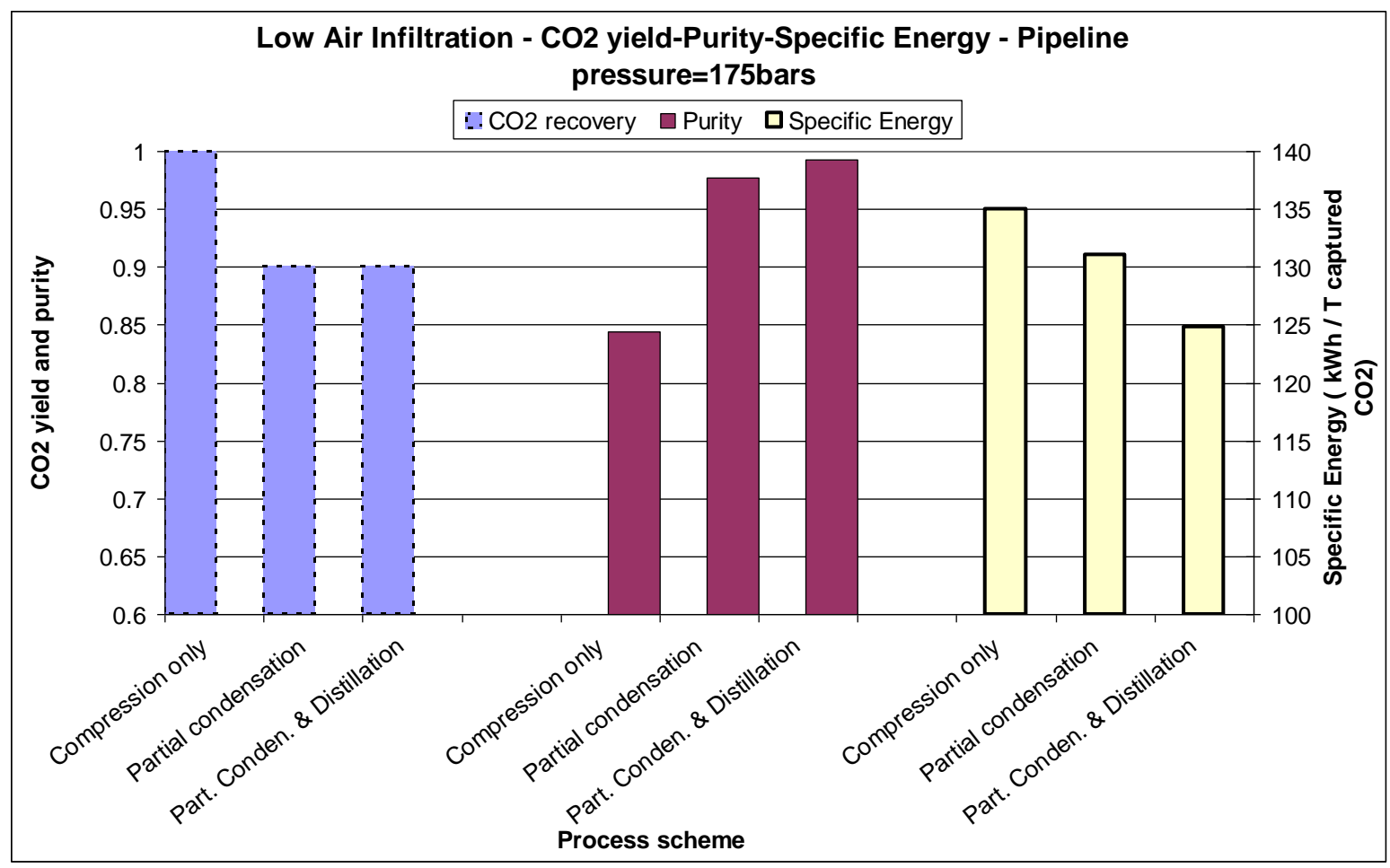

Figure 3.7 Comparison of $\mathrm{CO}_{2}$ yield (recovery), $\mathrm{CO}_{2}$ purity and specific energy of the $3 \mathrm{CO}_{2}$ capture processes for case of low air infiltration 


\subsubsection{Effect of Excess Air Infiltration}

As described in 3.1.2.1, to understand the parasitic effect of excess air infiltration in retrofit pulverized coal-fired boilers, a $4^{\text {th }}$ flue gas composition was generated by reducing $\mathrm{N}_{2}$ mole fraction in the gas to $10 \%$ (cf. Table 2). The performance of the 3 processes in capturing $\mathrm{CO}_{2}$ from this flue gas is shown in Figure 3.7 above and the corresponding product compositions are reported in Table 3.4.

\begin{tabular}{|l|r|r|r|}
\hline \multirow{2}{*}{ Item } & \multicolumn{3}{|c|}{ Low air infiltration case } \\
\cline { 2 - 4 } & Case A & Case B & Case C \\
\cline { 2 - 4 } & mol\% & mol\% & mol\% \\
\hline $\mathrm{CO}_{2}$ & $84.38 \%$ & $97.47 \%$ & $99.21 \%$ \\
\hline $\mathrm{N}_{2}$ & $10.00 \%$ & $0.97 \%$ & $0.00 \%$ \\
\hline $\mathrm{O}_{2}$ & $3.00 \%$ & $0.41 \%$ & $0.00 \%$ \\
\hline $\mathrm{SO}_{2}$ & $0.50 \%$ & $0.64 \%$ & $0.65 \%$ \\
\hline $\mathrm{Ar}$ & $2.00 \%$ & $0.38 \%$ & $0.01 \%$ \\
\hline $\mathrm{NO}_{2}$ & $0.10 \%$ & $0.13 \%$ & $0.13 \%$ \\
\hline $\mathrm{CO}$ & $0.02 \%$ & $0.00 \%$ & $0.00 \%$ \\
\hline
\end{tabular}

Table 3.4 Product compositions (dry basis) obtained by subjecting flue gases from the low air infiltration case to the 3 processes of this study

From Figure 3.7 and Table 3.4, several observations can be made. Similar to the higher air infiltration cases, the purification processes provide significant $\mathrm{CO}_{2}$ purity enhancement in the product with lower specific energy than the compression only case. Case $\mathrm{C}$ is the best option here too with the highest $\mathrm{CO}_{2}$ product purity at the lowest specific energy. However, the absolute magnitudes of the specific energies for the low air infiltration case are much lower than for the higher air infiltration cases above. For example, from Figure 3.4 through Figure 3.7, compression and drying (Case A) of flue gas from the high air infiltration flue gases requires $\sim 160 \mathrm{kWh} / \mathrm{ton}$ $\mathrm{CO}_{2}$ while the low air infiltration situation requires $135 \mathrm{kWh} /$ ton $\mathrm{CO}_{2}$, a decrease of $\sim 15 \%$. Similarly, treating the low air infiltration flue gas requires $15 \%$ and $18 \%$ lower specific energies in Cases B and C, respectively, than treating flue gases from the higher air infiltration cases. Thus, reductions in air infiltration can result in energy savings of about $15-18 \%$ to achieve a product pressure of 175 bar.

\subsubsection{Effect of Product (Pipeline) Pressure}

From Figure 3.5, compression and purification processes require much higher specific energy to achieve a product pressure of 2540 psia $\left(155-160 \mathrm{kWh} /\right.$ ton $\left.\mathrm{CO}_{2}\right)$ than to achieve a product pressure of $2200 \mathrm{psia}\left(136-138 \mathrm{kWh} /\right.$ ton $\left.\mathrm{CO}_{2}\right)$. At the lower product pressure, the specific energy of the partial condensation case (Case 5) is nearly equal to the compression only case (Case 2a) ( $<1.5 \%$ difference) while for the higher product pressure, the partial condensation requires $3 \%$ lower energy. Thus, conclusions about the lowest energy consuming process can be affected by the required product pressure. To understand the effect of product pressure on the specific energy requirement of the 3 processes, each of them were simulated at a range of product pressures from 80 to 180 bar (1160-2610 psia). Figure 3.8 to Figure 3.11 display the specific energies of the 3 processes as a function of product pressure for flue gases derived from North Dakota Lignite, Decker coal, Illinois \#6 coal and the low air infiltration case, respectively. 
From Figure 3.8 to Figure 3.11, similar trends are seen for the specific energy requirements of the 3 processes for all 4 flue gas compositions. The partial condensation and distillation process (Case $\mathrm{C}$ ) requires lower specific energy than partial condensation alone (Case B) over the entire range of product pressures considered. At the lower end of the product pressure range, the compression only process demands the lowest specific energy while at the top end of the range it requires the highest specific energy. Figure 3.12 shows the "cross-over" pressures at which the specific energy of the compression only case is identical to that of the purification cases. Above these pressures, the specific energy of Case A exceeds that of Case B or C, as the case may be. For the 3 coals, the specific energy of the compression only case exceeds that of Case $\mathrm{C}$ around 120-125 bar and that of Case B around 140 bar. Interestingly, for the low air infiltration case, the crossover pressures for Cases $\mathrm{B}$ and $\mathrm{C}$ are lower than the corresponding cross-over pressures of the higher air infiltration cases. The specific energy of Case A is lower for the low air infiltration case as compared to the other coals, due to the lower amount of non- $\mathrm{CO}_{2}$ gas components to be compressed relative to the amount of $\mathrm{CO}_{2}$. However, the lower cross-over pressures indicate that the purification processes experience an even bigger decline in specific energies than the compression only process due to the ease of recovering $\mathrm{CO}_{2}$ from a more concentrated stream.

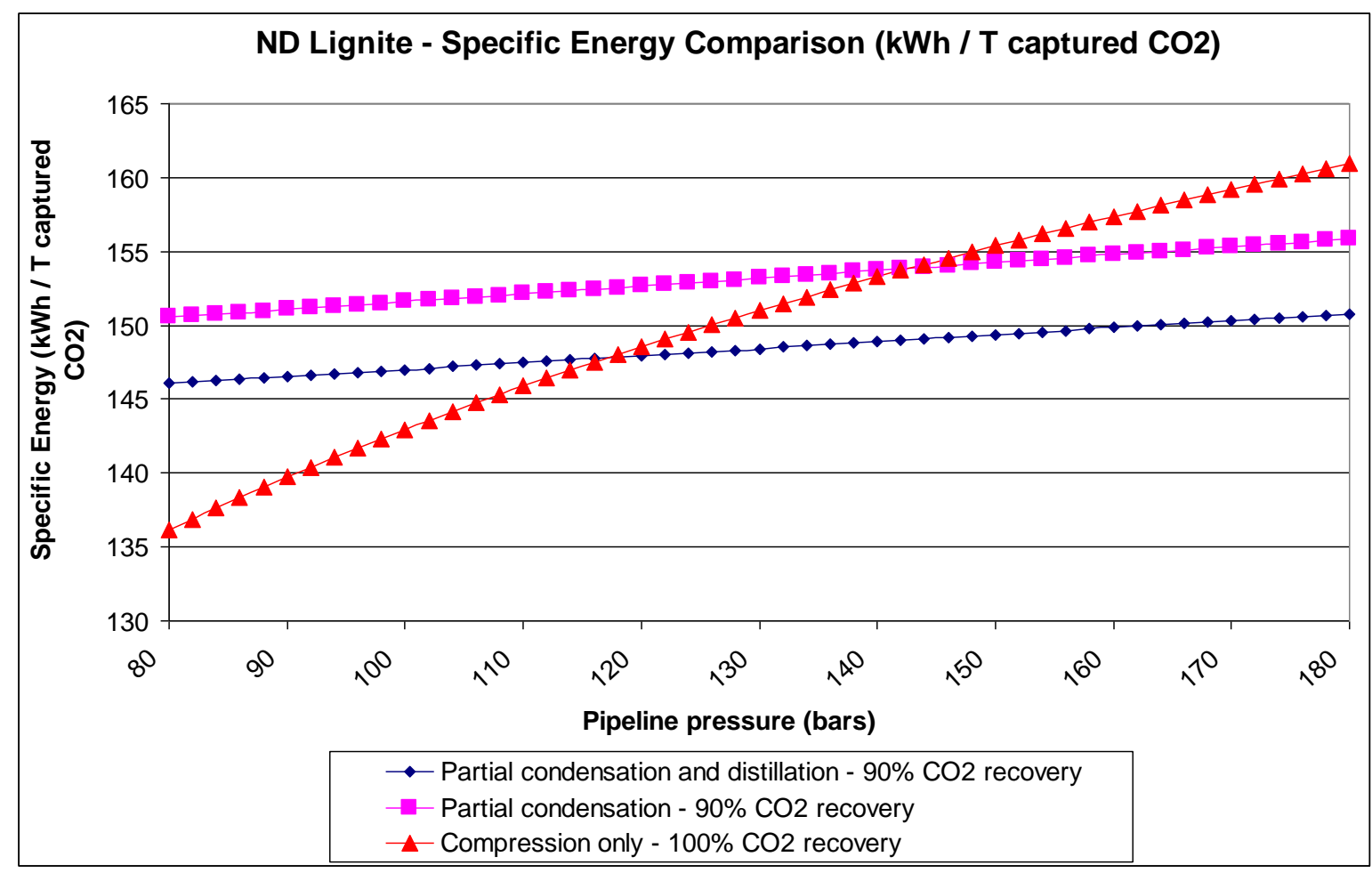

Figure 3.8 Specific energy requirement of the 3 processes as a function of the product (pipeline) pressure for North Dakota Lignite 


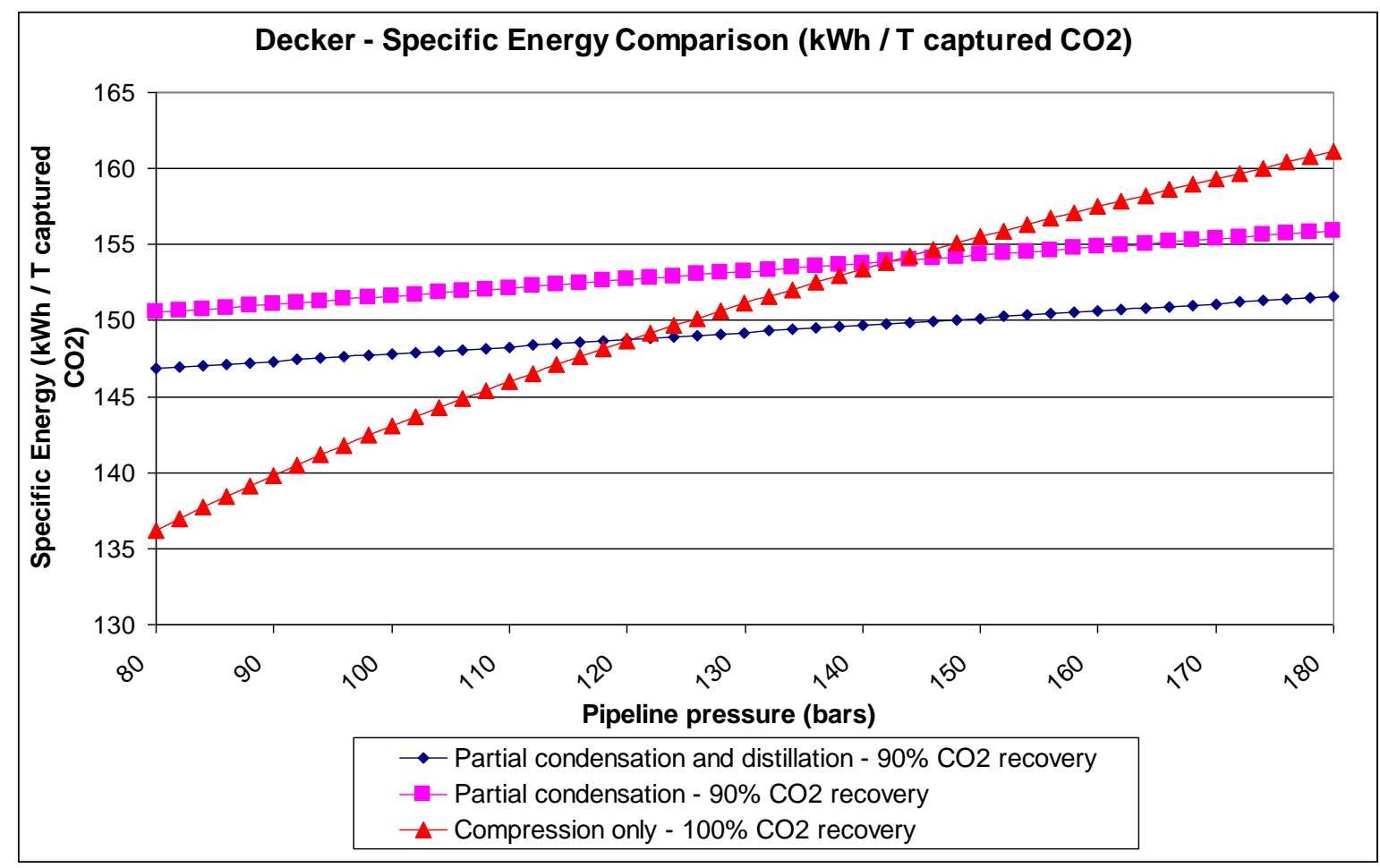

Figure 3.9 Specific energy requirement of the 3 processes as a function of the product (pipeline) pressure for Decker coal

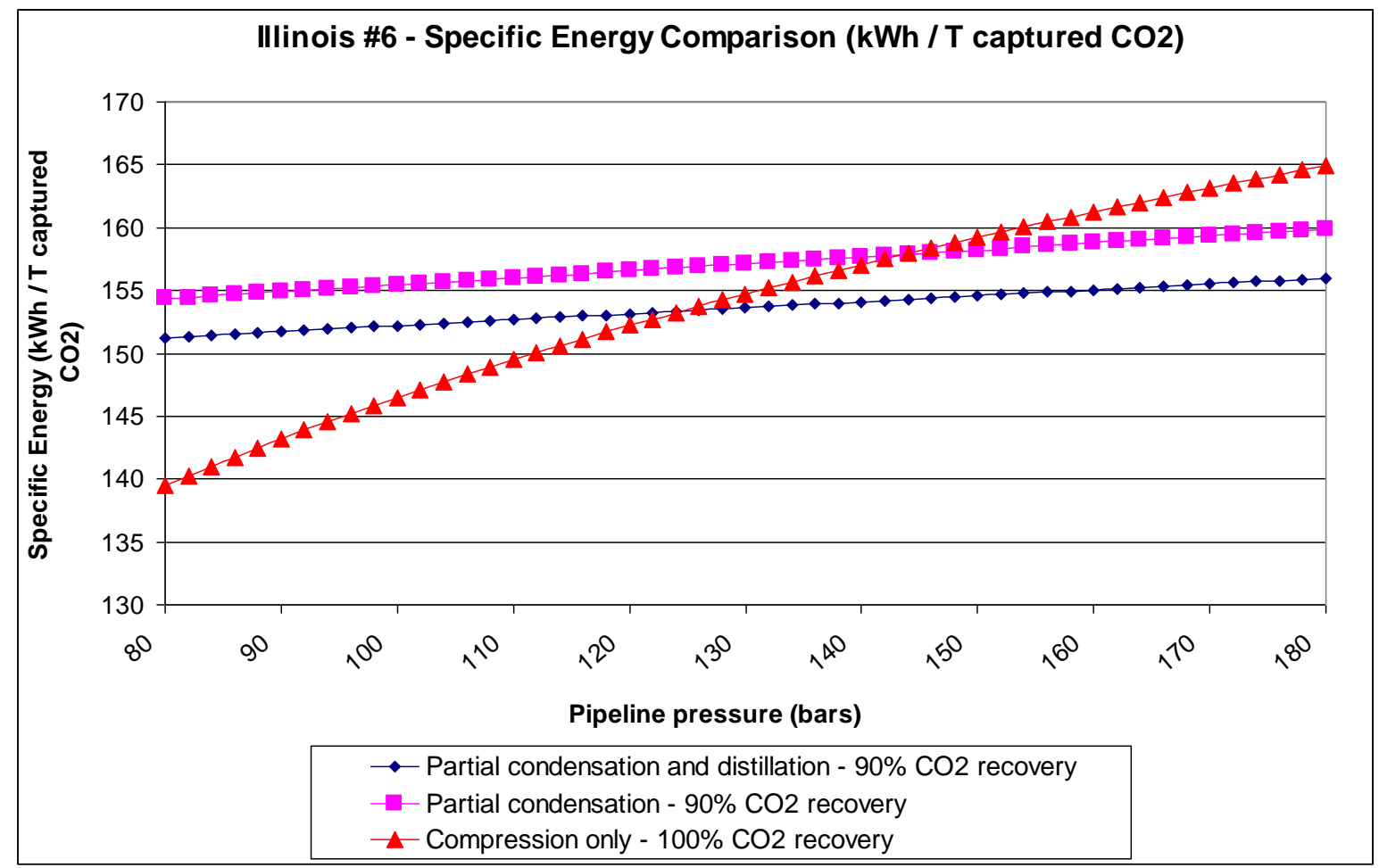

Figure 3.10 Specific energy requirement of the 3 processes as a function of the product (pipeline) pressure for Illinois \#6 coal 


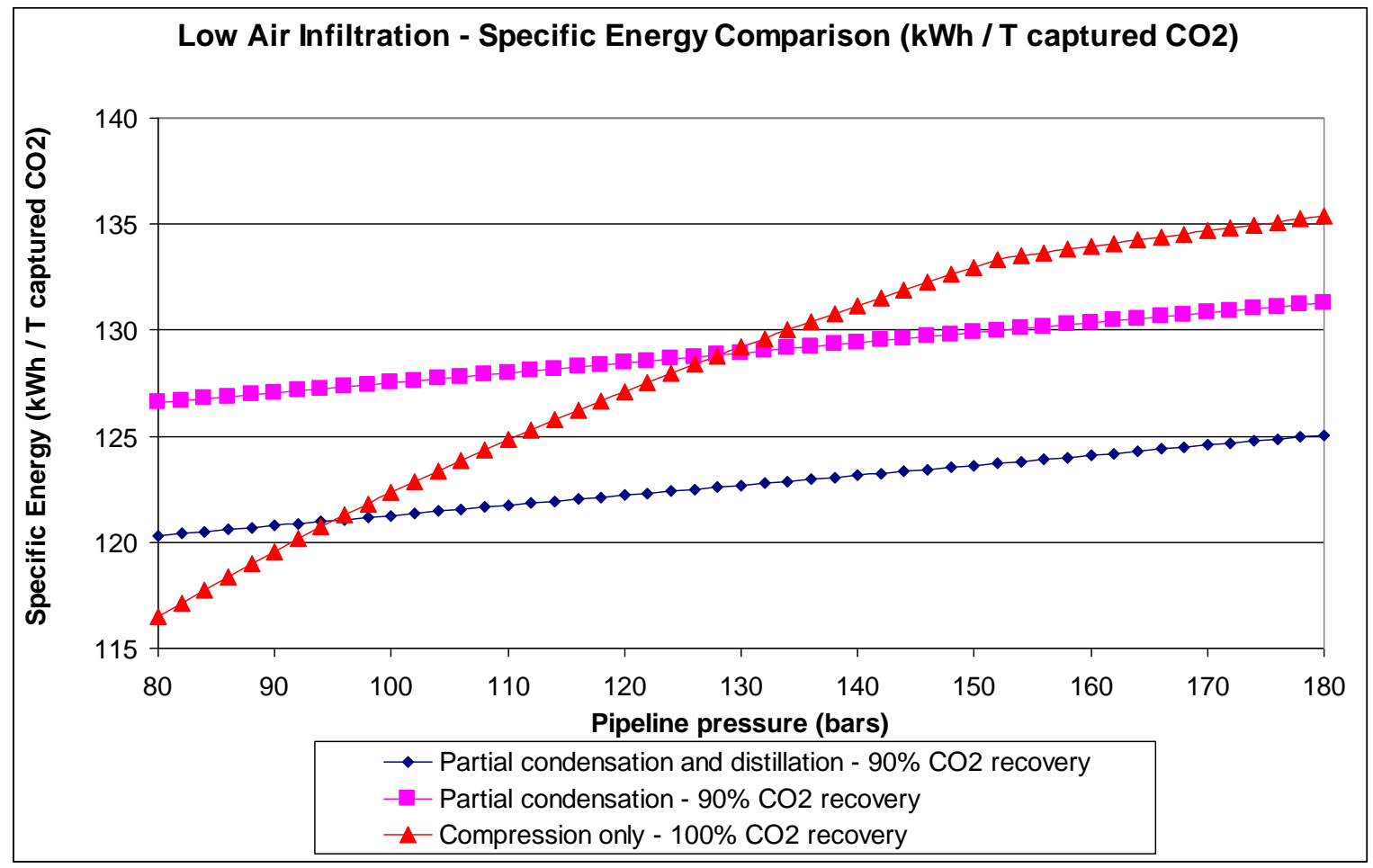

Figure 3.11 Specific energy requirement of the 3 processes as a function of the product (pipeline) pressure for the low air infiltration case

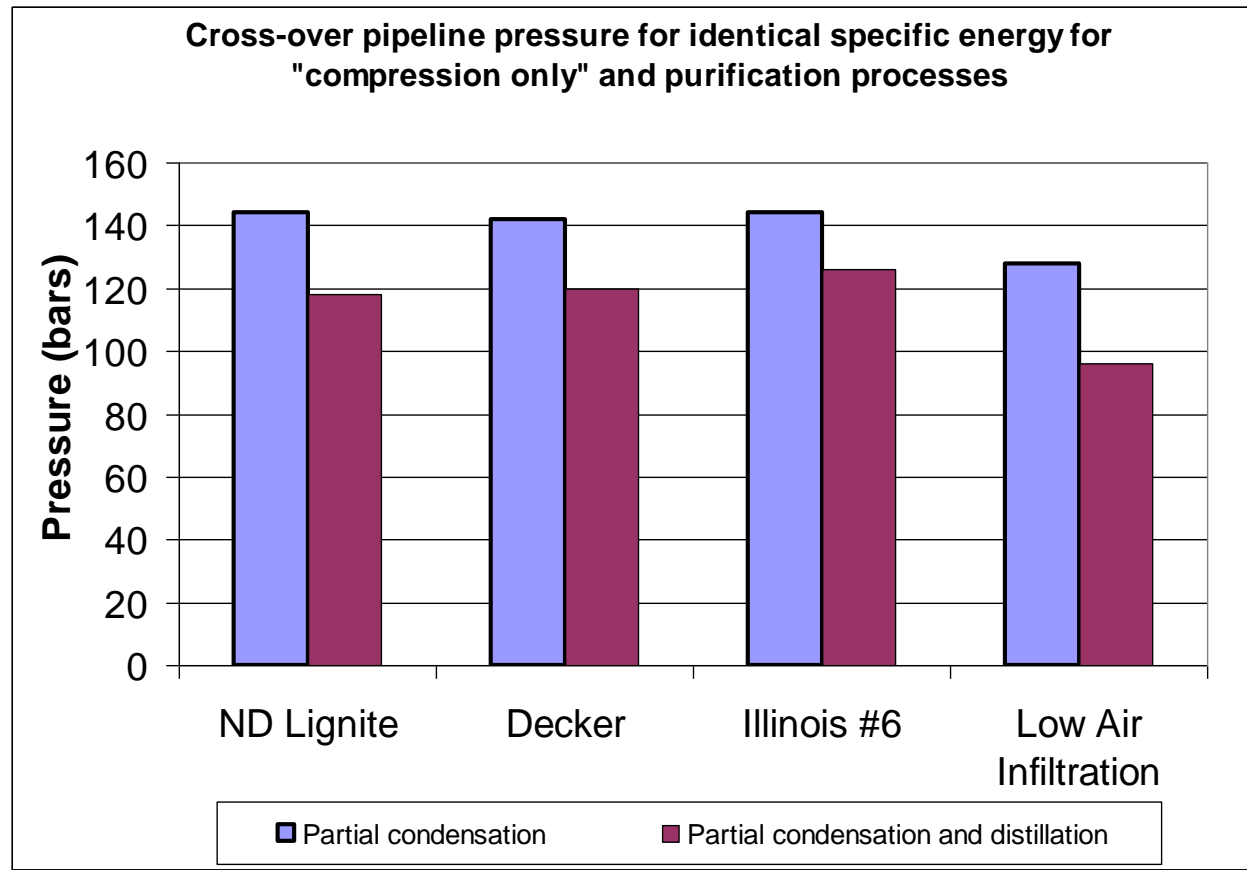

Figure 3.12 Cross-over pressures for the 4 flue gas compositions of this study. Below the cross-over pressure, the compression only process requires lower specific energy than the particular purification process, while above the cross-over pressure, the purification scheme has a lower specific energy requirement 
It was concluded that:

- Coal rank does not have a significant effect on the extent of $\mathrm{CO}_{2}$ purity achievable in the product stream at $90 \% \mathrm{CO}_{2}$ recovery by either of the purification processes considered in this study.

- The specific energy required by each process is similar for North Dakota Lignite and Decker coals and slightly higher for Illinois \#6 coal due to the higher amount of non- $\mathrm{CO}_{2}$ gas components in the flue gas relative to $\mathrm{CO}_{2}$ for this coal.

- The two purification processes provide a significant performance improvement over the compression only process at 175 bar product pressure because they significantly increase the $\mathrm{CO}_{2}$ purity in the product with lower specific energy requirement. Among the purification cases, the partial condensation and distillation scheme provides the highest $\mathrm{CO}_{2}$ purity in the product stream at the lowest specific energy for all 3 coals, for a product pressure of 175 bar. It must be noted that these conclusions are based on the current level of optimization of the purification designs. The net specific energies of the two purification processes are not very different (2-5\%), and it is not inconceivable that future improvements in design might change the relative order of energy requirements of these processes.

- The distillation column in Case $\mathrm{C}$ achieves high $\mathrm{CO}_{2}$ purity in the product mainly by rejecting air gases; $\mathrm{SO}_{2}$ and $\mathrm{NO}_{2}$ are not separated from $\mathrm{CO}_{2}$ in the column.

- Excess air infiltration results in an increase in specific energy. If $\mathrm{N}_{2}$ in the flue gas can be reduced by $50 \%$, it can result in $15-18 \%$ savings in specific energy, depending upon the compression and purification scheme.

- The final product pressure has a bearing on the determination of the least energy intensive process. The partial condensation and distillation process always has lower specific energy than the partial condensation process, over the product pressure range 80180 bars. However, for all the 3 coals, the compression only process has the lowest specific energy below about 120 bars. Above a product pressure of 120 bars, the partial condensation and distillation process has the lowest specific energy. At lower air infiltration, the partial condensation and distillation process becomes less energy intensive than the compression only process at lower product pressure.

\subsection{3. $\underline{\mathrm{CO}}_{2}$ Transportation and Sequestration}

\subsubsection{Introduction}

For Phase 1 of the project, Battelle assessed the flue gas preparation and equipment necessary for $\mathrm{CO}_{2}$ injection into deep geologic formations. At the outset of this project, two fundamental options were considered for disposing of the flue gas. One option was collecting and compressing the entire gaseous effluent for injection into a suitable geologic formation. Option 2 was separating the gas components (e.g., $\mathrm{SO}_{\mathrm{X}}$ and $\mathrm{NO}_{\mathrm{X}}$ removal) that may not be advantageous to long-term injection.

Regardless of whether post-combustion purification is needed, modeling is essential for developing a geologic and conceptual framework based on site characterization data and forms the basis for regulatory permits. It is also useful in developing the designs for $\mathrm{CO}_{2}$ injection (e.g., maximum injection pressure, radius of influence, and $\mathrm{CO}_{2}$ phase behavior) and monitoring 
program. It was envisaged that, at some later time, the modeling results could be used with the future injection data to upscale field tests for evaluation of full-scale, long-term injection of $\mathrm{CO}_{2}$. The principal tool used for reservoir simulation was the state-of-the-art STOMP-CO $\mathrm{CO}_{2}(1)$ multiphase, multi-component model, which previously has been used for modeling the geologic injection for a pilot demonstration project (American Electric Power's Mountaineer Plant site). It was anticipated that the US Department of Energy and the project team, would be able to use the knowledge gained from field tests to upscale the models for simulation of full-scale injection at these sites and evaluate the design, number of wells needed, and total storage potential for longterm, large-scale projects.

\subsubsection{Investigation of Potential for Multi-pollutant Reduction}

Concerns about global warming have prompted research into the mitigation of greenhouse gases through carbon capture and sequestration (CCS). Injection of $\mathrm{CO}_{2}$ into deep rock formations is an attractive option because suitable rock formations exist throughout the world with large storage capacities. Sequestration in geologic environments is considered a very promising and realistic long-term option for reduction of greenhouse gases from large point sources. Deep saline reservoirs, depleted oil and gas reservoirs, fractured basalts, and unmineable coal seams are potential reservoirs for long-term storage. Many of these formations are located in close proximity to major point sources of greenhouse gas emissions.

The concept of carbon capture and storage (CCS) has dealt largely with relatively pure (98-99\%) carbon dioxide $\left(\mathrm{CO}_{2}\right)$. However, flue gas from coal combustion contains impurities (such as $\mathrm{NO}_{\mathrm{X}}, \mathrm{SO}_{2}$, flyash, mercury etc.) which likely will have impact on compression, transportation, and storage. This investigation explores the potential need for conditioning oxy-coal flue gas to selectively remove compounds that would be problematic. From an economic point of view, it would be highly desirable if the flue gas could be injected into deep geologic formations with minimal treatment, such as dehydration. On the other hand, a worst-case situation in terms of economics would arise if the flue gas required extensive purification, as that would negate some of the expected benefits of oxy-combustion. A top down assessment was employed to understand the effects of flue gas impurities on the expected sequence of processes to assess economic viability. The differences between the behaviors of pure $\mathrm{CO}_{2}$ and simulated oxy-combustion flue gas were examined to understand how each of the process steps is affected by impurities in the flue gas.

It is important to view the entire system, which includes oxygen separation, coal combustion, steam generation, flue gas purification (if required), transportation, and geologic storage, together as an integrated collection of subsystems. The ultimate cost to dispose of the produced $\mathrm{CO}_{2}$ falls between two extremes: The lowest total cost would apply to an outcome where the flue gas is handled with minimal conditioning, then injected into a suitable geologic formation directly beneath the source. A more costly outcome, involves separating certain components that may be disadvantageous to injection and long-term storage in a formation that is a significant distance from the plant. The lower cost case could require less environmental control equipment than is commonly used in air-fired pulverized coal (PC) combustion units, which typically are required to remove sulfur oxides $\left(\mathrm{SO}_{\mathrm{X}}\right)$ and nitrogen oxides $\left(\mathrm{NO}_{\mathrm{X}}\right)$. The feasibility of this option will require a thorough understanding of reservoir mechanics and geochemistry. The reason is that non-condensable gases, such as nitrogen, oxygen, and argon, may adversely affect fluid 
transport properties in the subsurface. For example, the accumulation of non-condensable gases near the injection well could reduce injectivity and lower the capacity of the reservoir for $\mathrm{CO}_{2}$ storage over the lifetime of the power plant. Conversely, if some level of purification is needed to remove non-condensable gases or other impurities, then equipment for scrubbing the $\mathrm{CO}_{2}$ would need to be brought on line, thus adding to the cost of storing $\mathrm{CO}_{2}$. Considerations for flue gas purity as it leaves the boiler and is processed in downstream unit operations are illustrated in Figure 3.13. Whether some treatment of the flue gas (physical or chemical) is needed prior to storage may be determined based on the following tasks:

1) Quantify all flue gas components from an oxy-fired boiler

2) Determine whether the gas mixture meets safety and regulatory requirements for high pressure transport in a given pipeline material

3) Perform reservoir and geochemical modeling to determine whether prolonged injection into a deep geologic reservoir (with competent caprock) is feasible.
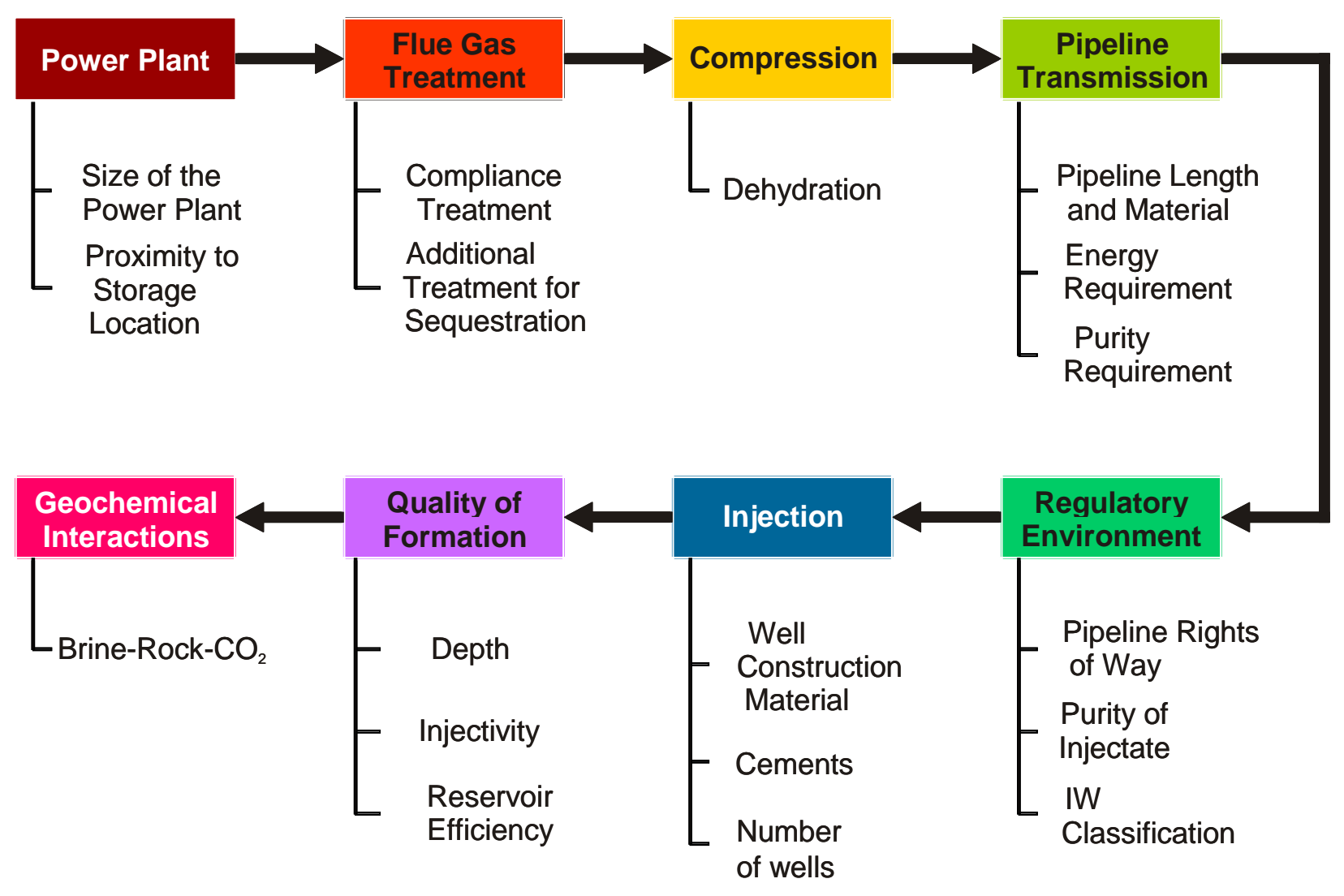

Figure 3.13 Process description for flue gas interactions

\subsection{Comparison of Flue Gas Properties to Pure $\mathrm{CO}_{2}$}

The physical properties of pure $\mathrm{CO}_{2}$ are well known for a wide range of temperatures and pressures. It is an important behavior of all gases that, near the critical point, a slight change in pressure or temperature has a large effect on density. For safety to equipment and human 
operators, abrupt changes in fluid properties near the critical point phase should be avoided throughout the transportation and injection processes. Therefore, the nominal pressure in the pipeline should be maintained well above the critical pressure of $\mathrm{CO}_{2}(7.39 \mathrm{MPa}$, or $1070 \mathrm{psi})$ when it is transported as a pure fluid. As a typical safety precaution, a $\mathrm{CO}_{2}$ pipeline would be operated at pressures no lower than 1400 or 1500 psi, which corresponds to a 30 to $40 \%$ increase above the critical pressure. When a pipeline runs a long distance or over elevated terrain, it may be necessary to install a booster pump wherever the pressure dips below the safety threshold. $\mathrm{CO}_{2}$ becomes a supercritical fluid when both the pressure and temperature conditions are above the critical points (the critical temperature is $31.0^{\circ} \mathrm{C}$ ).

Aspen-Plus simulations were performed by B\&W on models of retrofitted oxy-combustion boilers for three coal types: North Dakota Lignite, Decker (Montana), and Illinois \#6.

Compositions resulting from simulated flue gas streams cooled to $160^{\circ} \mathrm{F}$ are shown in Table 3.5 , where it can be seen that the $\mathrm{CO}_{2}$ content is between 58 and $60 \%$ by volume. When dehydration and oxygen scrubbing are performed on these same flue gas streams the $\mathrm{CO}_{2}$ content increases to between 74 and $76 \%$ by volume (Table 3.6).

\begin{tabular}{||l|c|c|c|c|c|c||}
\hline \multirow{4}{*}{ Coal Type } & $\mathbf{O}_{\mathbf{2}}$ & $\mathbf{H}_{\mathbf{2}} \mathbf{O}$ & $\mathbf{C O}_{\mathbf{2}}$ & $\mathbf{N}_{\mathbf{2}}$ & $\mathbf{A r}$ & $\mathbf{S O}_{\mathbf{2}}$ \\
\cline { 2 - 7 } & $(\%)$ & $(\%)$ & $(\%)$ & $(\%)$ & $(\%)$ & $(\mathrm{ppmv})$ \\
\hline North Dakota Lignite & 4.1 & 17.4 & 59.6 & 16 & 2.4 & 3825 \\
\hline Decker & 4.0 & 17.4 & 59.5 & 16.3 & 2.5 & 1348 \\
\hline Illinois \#6 & 4.1 & 17.4 & 58.1 & 17.6 & 2.5 & 1003 \\
\hline
\end{tabular}

Table 3.5 Estimated flue gas composition (molar \%) after cooling to $160^{\circ} \mathrm{F}$

\begin{tabular}{|l|c|c|c|c|c|c||}
\hline \multirow{2}{*}{ Coal Type } & $\mathbf{O}_{\mathbf{2}}$ & $\mathbf{H}_{\mathbf{2}} \mathbf{O}$ & $\mathbf{C O}_{\mathbf{2}}$ & $\mathbf{N}_{\mathbf{2}}$ & $\mathbf{A r}$ & $\mathbf{S O}_{\mathbf{2}}$ \\
\cline { 2 - 7 } & $(\mathrm{ppmv})$ & $(\mathrm{ppmv})$ & $(\%)$ & $(\%)$ & $(\%)$ & $(\mathrm{ppmv})$ \\
\hline North Dakota Lignite & 100 & 650 & 76.0 & 20.4 & 3.1 & 4877 \\
\hline Decker & 100 & 650 & 75.8 & 20.8 & 3.2 & 1718 \\
\hline Illinois \#6 & 100 & 650 & 74.2 & 22.5 & 3.2 & 1280 \\
\hline
\end{tabular}

Table 3.6 Estimated molar flue gas composition following dehydration and oxygen scrubbing

The critical properties of the pure flue gas components are shown in Table 3.7. Critical properties of gas mixtures are important in understanding their behavior in transportation and injection. However, these properties are not well known for multi-component systems near the critical point of $\mathrm{CO}_{2}$, and they are not easily estimated because such systems do not obey simple mixing rules. The thermophysical properties of fluid mixtures can be estimated using a combination of theoretical and empirical techniques which are based on evaluated data. These techniques have been tested and incorporated into interactive computer programs that generate a large variety of properties based upon the specified composition and the appropriate state 
variables. In this investigation, we have used the program REFPROP (ver. 8) (3), which was developed by the National Institute of Science and Technology (NIST).

\begin{tabular}{|c|c|c|c||}
\hline Component & Critical Pressure (MPa) & Critical Temperature $\left({ }^{\circ} \mathbf{C}\right)$ & Critical Density $\left(\mathbf{k g} / \mathbf{m}^{\mathbf{3}}\right)$ \\
\hline $\mathrm{CO}_{2}$ & 7.39 & 31.0 & 467.6 \\
\hline $\mathrm{N}_{2}$ & 3.39 & -147.0 & 313.3 \\
\hline $\mathrm{O}_{2}$ & 5.04 & -118.6 & 436.1 \\
\hline $\mathrm{Ar}$ & 4.87 & -122.4 & 535.6 \\
\hline $\mathrm{SO}_{2}$ & 7.87 & 157.8 & 525.0 \\
\hline $\mathrm{CO}$ & 3.49 & -140.3 & 303.9 \\
\hline
\end{tabular}

Table 3.7 Critical point conditions for the constituents of the flue gas

To illustrate the critical properties of a mixture, consider a gas containing 80 mole $\% \mathrm{CO}_{2}$ and 20 mole $\% \mathrm{~N}_{2}$. Using REFPROP the critical point properties were estimated to be of $\mathrm{P}_{\mathrm{c}}=$ 10.22 MPa, $\mathrm{T}_{\mathrm{c}}=12.0^{\circ} \mathrm{C}$, and $\rho_{\mathrm{c}}=480.3 \mathrm{~kg} / \mathrm{m}^{3}$. This example calculation gives a result that is counterintuitive, which is that the critical pressure of the mixture is much higher than either of the pure endpoints. This increase in critical pressure is a common behavior for mixtures of fluids and is well established for binary mixtures. A somewhat more typical flue gas that has been dehydrated is given by the following composition: $72.56 \% \mathrm{CO}_{2}, 19.50 \% \mathrm{~N}_{2}, 2.92 \% \mathrm{Ar}$, $0.02 \% \mathrm{CO}$, and $5.00 \% \mathrm{O}_{2}$ (mole basis). The estimated (REFPROP) critical properties of this mixture are $\mathrm{P}_{\mathrm{c}}=9.91 \mathrm{MPa}, \mathrm{T}_{\mathrm{c}}=-0.52{ }^{\circ} \mathrm{C}$, and $\rho_{\mathrm{c}}=478 \mathrm{~kg} / \mathrm{m}^{3}$. Compared with pure $\mathrm{CO}_{2}$ the dehydrated flue gas has a higher critical pressure and a lower critical temperature.

Most experience in the $\mathrm{CO}_{2}$ pipeline industry is product purity of $95.5 \%$ or greater. This is because most pipelines handle naturally occurring $\mathrm{CO}_{2}$ that usually does not require purification beyond dehydration. Commercial pipelines have a long operating history with a good safety record, which is on par with natural gas piping systems. For pipelines with significant amounts of constituents other than $\mathrm{CO}_{2}$, the composition has a significant impact on pipeline design, compressor power, pressure drop over a given distance, and capacity. These factors influence both the technical and economic feasibility of developing a carbon dioxide transport infrastructure. In principle, while pipelines can be designed using materials that can meet safety and handling requirements for almost any situation, the cost of such pipelines can increase significantly, such that resulting capital cost can be several times that for pure $\mathrm{CO}_{2}$.

Computational tools for predicting the fluid behavior of pipelines containing $\mathrm{CO}_{2}$ with significant levels of non-condensable gases, such as nitrogen, oxygen, and argon, are only recently being developed. An equation of state (EOS) method is often the simplest approach, but unfortunately, there are few experimental data for the plethora of possible compositions, to validate the results of such calculations. In addition, there is no consensus regarding the applicability of other types of modeling to estimate fluid properties within a pipeline. Additional work, particularly in model development and experimental verification, is required to understand the implications of impurities and to ensure that pipelines transporting $\mathrm{CO}_{2}$ are designed and operated safely and economically. If these issues are not considered in the pipeline design, transportation issues for $\mathrm{CO}_{2}$ with impurities could present significant problems. 
The composition of the product flow in the pipe has a significant impact on integrity and selection of materials. Water is the most important factor. Currently, $\mathrm{CO}_{2}$ pipelines operate with very low levels of water content, such that the water component is under saturated with respect to the liquid state at the lowest anticipated service temperature. The presence of liquid water in the presence of $\mathrm{CO}_{2}, \mathrm{SO}_{2}$, and $\mathrm{O}_{2}$ can lead to severe internal corrosion in steel pipelines, which is detrimental to the safety and operability of such pipelines. However, attaining dry product can add significant cost to the capture process. In situations where a chemical absorber is used upstream, it is possible that this may introduce small amounts of solvent vapor due to breakthrough, which could accelerate corrosion or initiate stress corrosion cracking in the pipeline steel. Detailed corrosion analysis is needed to assess the viability of carbon steel materials, as well as the array of corrosion resistant materials. Corrosion that occurs in pipelines where there is a liquid phase (condensate) is influenced by temperature, the partial pressure of $\mathrm{CO}_{2}$ (which may be close to the total pressure, depending on purity), other impurities such as soluble salts, flow velocity, water wetting, as well as the composition and surface condition of the steel.

In the presence of oxygen, $\mathrm{SO}_{2}$ reacts with water to form sulfuric acid, $\mathrm{H}_{2} \mathrm{SO}_{4}$. The formation of sulfuric acid modifies the iron carbonate layer by changing the electrolyte (solution) conditions in terms of the $\mathrm{pH}$ and the formation of corrosion products, such as $\mathrm{FeSO}_{4}$; further, the presence of oxygen can increase the kinetics of the anodic dissolution. The corrosion rate or metallic dissolution will be a function of chemical species and environmental parameters when steel pipelines are used as transmission line application.

By assuming a carbon steel material exposed to free liquid water under static conditions, corrosion rates can be calculated. Sample calculations for $\mathrm{SO}_{2}$ and $\mathrm{O}_{2}$ are given to illustrate the corrosion potential. Figure 3.14 shows the corrosion rate behavior in terms of $\mathrm{pH}$, the higher the concentration of $\mathrm{H}_{2} \mathrm{SO}_{4}$ (from $\mathrm{SO}_{2}$ oxidation and hydrolysis) the lower the $\mathrm{pH}$. The quantification of the $\mathrm{pH}$ is a function of the amount of $\mathrm{SO}_{2}$ dissolved in the mixture. Flow characteristics inside pipelines are often highly turbulent, which has the effect of increasing corrosion rates above that which would occur under static level. 


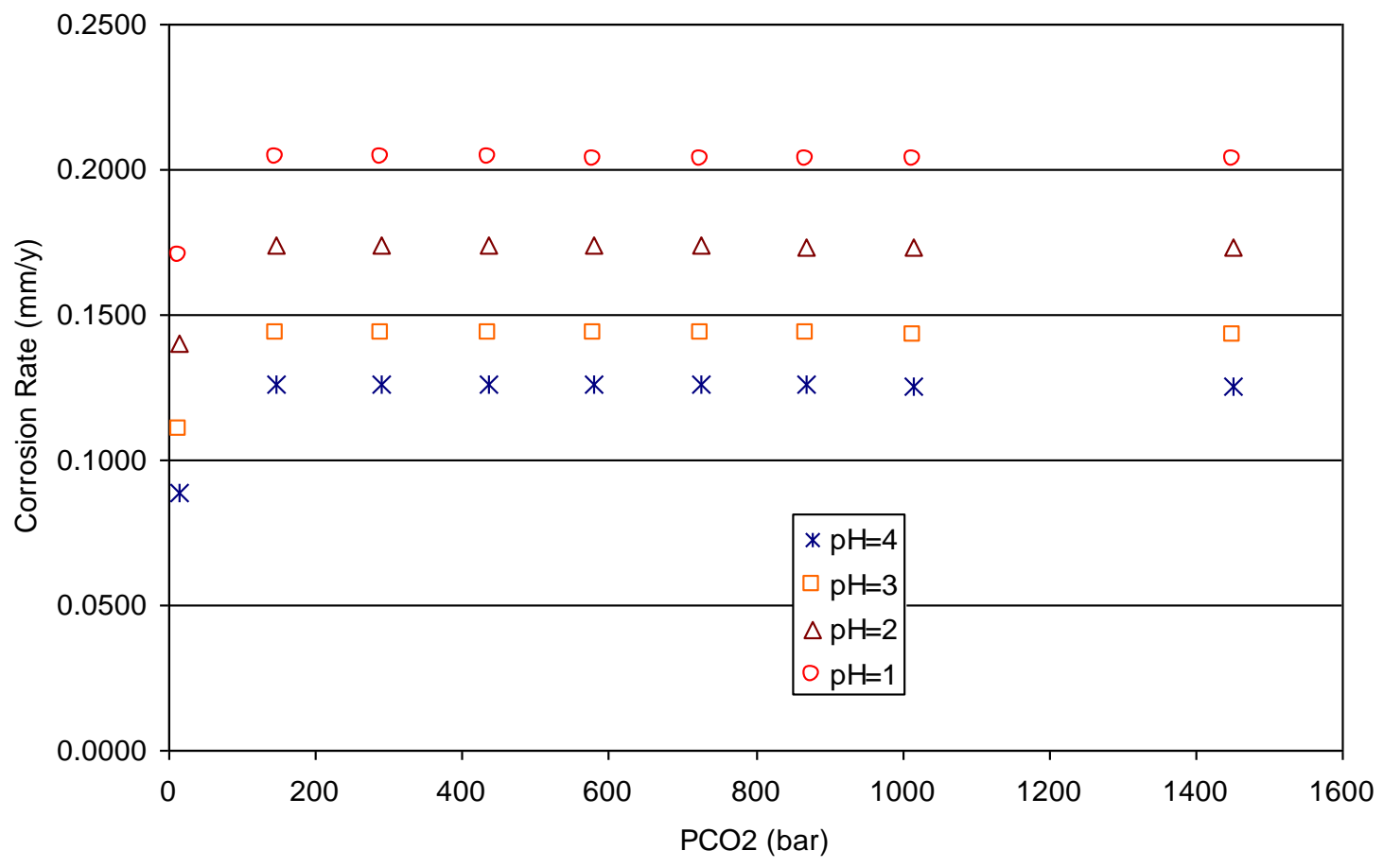

Figure 3.14 Corrosion rate of carbon steel exposed to different $\mathrm{H}_{2} \mathrm{SO}_{4}$ concentrations in terms of $\mathrm{pH}$ at different $\mathrm{CO}_{2}$ pressures (static conditions)

Figure 3.15 shows the corrosion rate in terms of oxygen content dissolved in the aqueous system at different $\mathrm{CO}_{2}$ partial pressure (concentration). The $\mathrm{SO}_{2}$ content will increase the corrosion rate by lowering the $\mathrm{pH}$ magnitude and the $\mathrm{O}_{2}$ content increases the corrosion rate. Figure 3.15 shows a potential corrosion rate of about $0.2 \mathrm{~mm}$ per year for static conditions. For 20 years of operation, the average loss of wall thickness would be $4 \mathrm{~mm}$. Since the nominal pipe wall thickness would be $12 \mathrm{~mm}$, a substantial amount of the pipe wall thickness could be lost to corrosion. Because a pipeline operating under such conditions would be subject to failure in a few decades, it would require, frequent regular safety verification, or else substituted with a more corrosion resistant material. Note that these calculations are for static conditions. They do not consider the additional effect of flow, which can add significantly to wear and abrasion. 


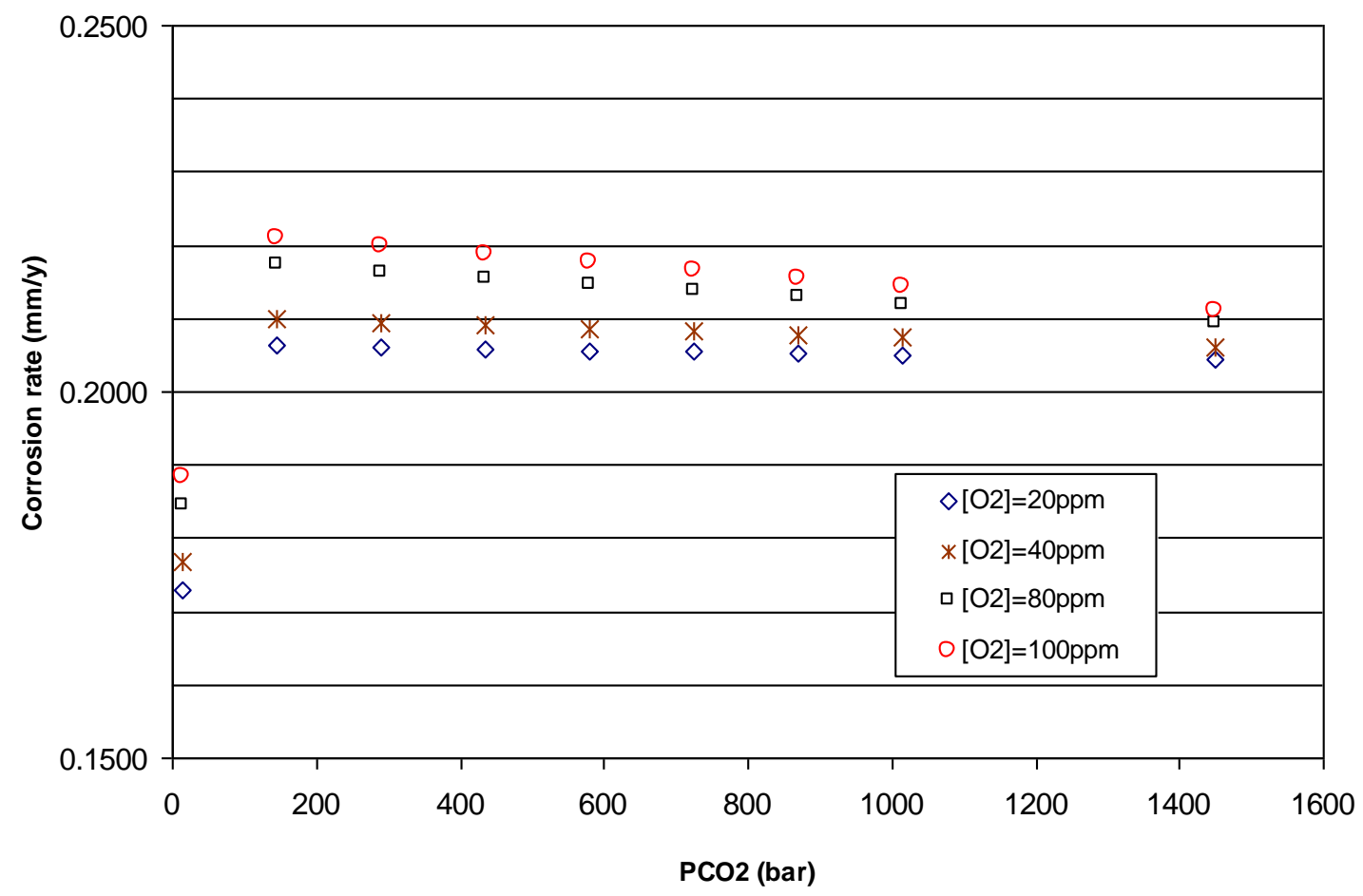

Figure 3.15 Corrosion rate of carbon steel exposed to different $\mathrm{O}_{2}$ concentrations at different $\mathrm{CO}_{2}$ pressures (static conditions)

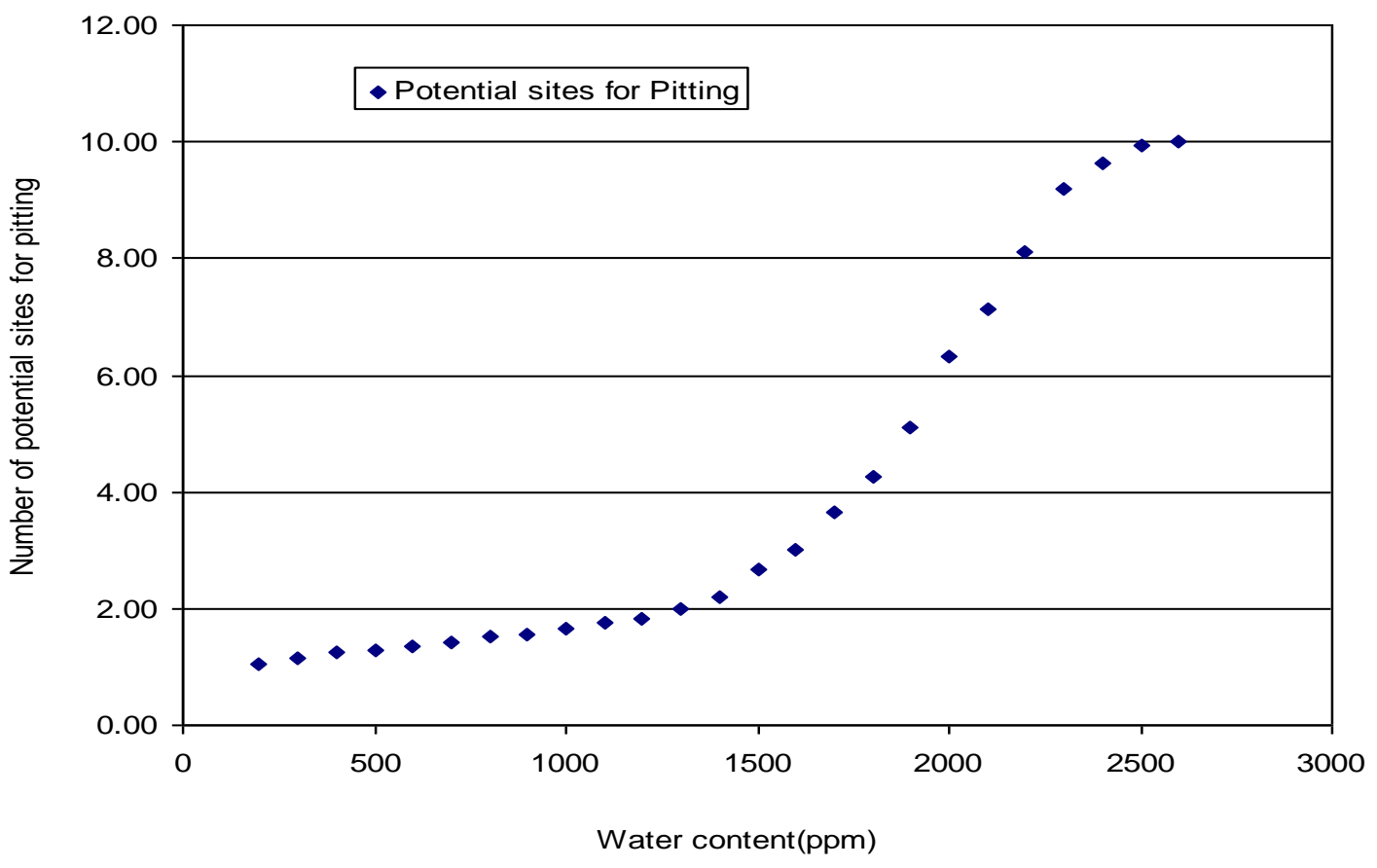

Figure 3.16. Water content vs. number of potential corrosion sites (per square meter for a corrosion rate of $0.2 \mathrm{~mm} / \mathrm{yr}$ ) 
While the concentrations of oxygen and sulfur compounds affect the overall corrosion rates, the water content defines the potential number of corrosion sites. Figure 3.16 shows the number of potential sites for pitting over a one square meter $\left(1 \mathrm{~m}^{2}\right)$ area associated with the $0.2 \mathrm{~mm} / \mathrm{yr}$ corrosion rate according to the water content. The low free water content minimizes the general corrosion conditions, but does not eliminate the number of localized spots in the pipeline wall. The $2500 \mathrm{ppm}$ of water in an area of $1 \mathrm{~m}^{2}$ might have 10 potential sites for localized corrosion at corrosion rates described in the previous two plots. The Kinder Morgan specification for water is $30 \mathrm{lb}$ per MMSCF in the vapor phase, which is equivalent to $650 \mathrm{ppm}$. Even under these relatively dry conditions, one or two corrosion sites could be expected to form per square meter of steel surface. Nevertheless, pipelines have operated safely for extended periods at this maximum level of moisture.

\subsection{System Optimization}

The plant design and operation define the amount of $\mathrm{CO}_{2}$ that needs to be stored and the rate at which it is delivered to the storage reservoir. Reservoir geology and depth determine the temperature and constrain the injection pressure to a lower limit needed to induce flow of $\mathrm{CO}_{2}$ into the formation and to an upper limit of approximately two-thirds the fracture pressure of the formation. However, an exact value must be determined by modeling rock mechanics. Design variables also need to be considered. For example:

- Smaller diameter pipelines are less expensive but can experience higher-pressure drops. The increased cost of a larger diameter pipeline must be traded against the cost of compression.

- The diameter of the well is significant variable since this is a principal source of pressure drop. The increased cost of a larger diameter well, or multiple wells, also needs to be factored against the cost of compression. The main driver for well diameter and number is the hydraulic conductivity of the host reservoir, which can vary greatly from one type of formation to another, and in fact, may vary significantly within a given formation.

That oxy-combustion flue gas contains nitrogen, oxygen, argon and several minor constituents in addition to $\mathrm{CO}_{2}$, has significant bearing on many of the fundamental parameters that affect fluid flow. For example, $\mathrm{N}_{2}$ mixed with $\mathrm{CO}_{2}$ reduces the density of the gas mixture compared with pure $\mathrm{CO}_{2}$, which decreases the hydrostatic pressure inside the well column. Wellhead pressure must be increased to compensate for the reduced bottom hole pressure (which determines the rate of fluid ingress), thus demanding higher compression pressures. Frictional factors also increase with mixing of $\mathrm{CO}_{2}$ with nitrogen and other incondensable gases. This causes a greater pressure drop, increases with pipeline distance, and again must be compensated with higher compression or more frequent recompression (booster) stations.

\subsection{Considerations for Pipeline Transport}

The flow characteristics for $\mathrm{CO}_{2}$ pipelines used in the US for enhanced oil recovery (EOR) are sufficiently well understood to enable safe and economic operation. However, transporting products comprised of multiple constituents can lead to significant problems. In the natural gas industry, additional engineering is needed for natural gas pipelines when even small amounts of heavier hydrocarbons are present. 
The composition of the product to be transported has a great impact on pipeline design, compressor power, recompression distance, pipeline capacity, and could also have implications on decompression behavior at potential points of pipeline failure. These effects have direct implications for both the technical and economic feasibility of developing a $\mathrm{CO}_{2}$ transport infrastructure.

Design equations for predicting $\mathrm{CO}_{2}$ transport in pipelines are well established. However, flow characteristics of a gas mixture are much more complicated than for a pure gas. Compared to pure $\mathrm{CO}_{2}$, mixtures create two major challenges:

- It is important to determine the mixture transport parameters for a given fluid state. The major component of the fluid is $\mathrm{CO}_{2}$, which is relatively compressible and undergoes significant changes in properties, hence constant properties cannot be assumed for the mixture even if the lesser constituents' transport properties were constant in behavior (which they are not). The phase behavior of the components must be compatible also since phase change during pipeline transport is typically avoided.

- The equilibrium composition needs to be studied to ascertain if any significant reactions are present as the fluid undergoes transport. For example, reactions between the species may be negligible for the surface pipe pressures and timescales. Deleterious chemical reactions may be substantially higher near the bottom of the well where the pressures are higher. Use of instruments to monitor chemical conditions at depth would be prudent.

The transport properties of fluid mixtures can be difficult to predict over a wide range of conditions. Many pure fluids have been tested experimentally and validated predictive equations of state exist, but arbitrary mixtures do not always have data. Binary mixtures can be predicted and ternary and multi-component mixture models continue to be developed (4). The behavior depends on the type of fluid, the composition, and the conditions. Predictions for mixtures depend heavily on the accuracy of the EOS and dependent empirical parameters.

If heat transfer in pipeline flow is ignored, then the main properties necessary for modeling transport behavior are the fluid viscosity and the fluid density. (The ratio of these properties, fluid viscosity / fluid density, is called the kinematic viscosity). An analysis performed using REFPROP shows that the kinematic viscosity of the dry flue gas mixture can range between 0.7 to 1.4 times that of pure $\mathrm{CO}_{2}$, as shown in Figure 3.17. This is an important transport quantity, because it will affect the pipeline flow, and most certainly affects the injectability into the geologic formation. Furthermore, fluid density is an important property because it contributes to the downhole pressure in a vertical well due to body forces. To perform a detailed analysis of an injection system, temperature and heat transfer would need to be considered, due to bottom hole pressure effects. 


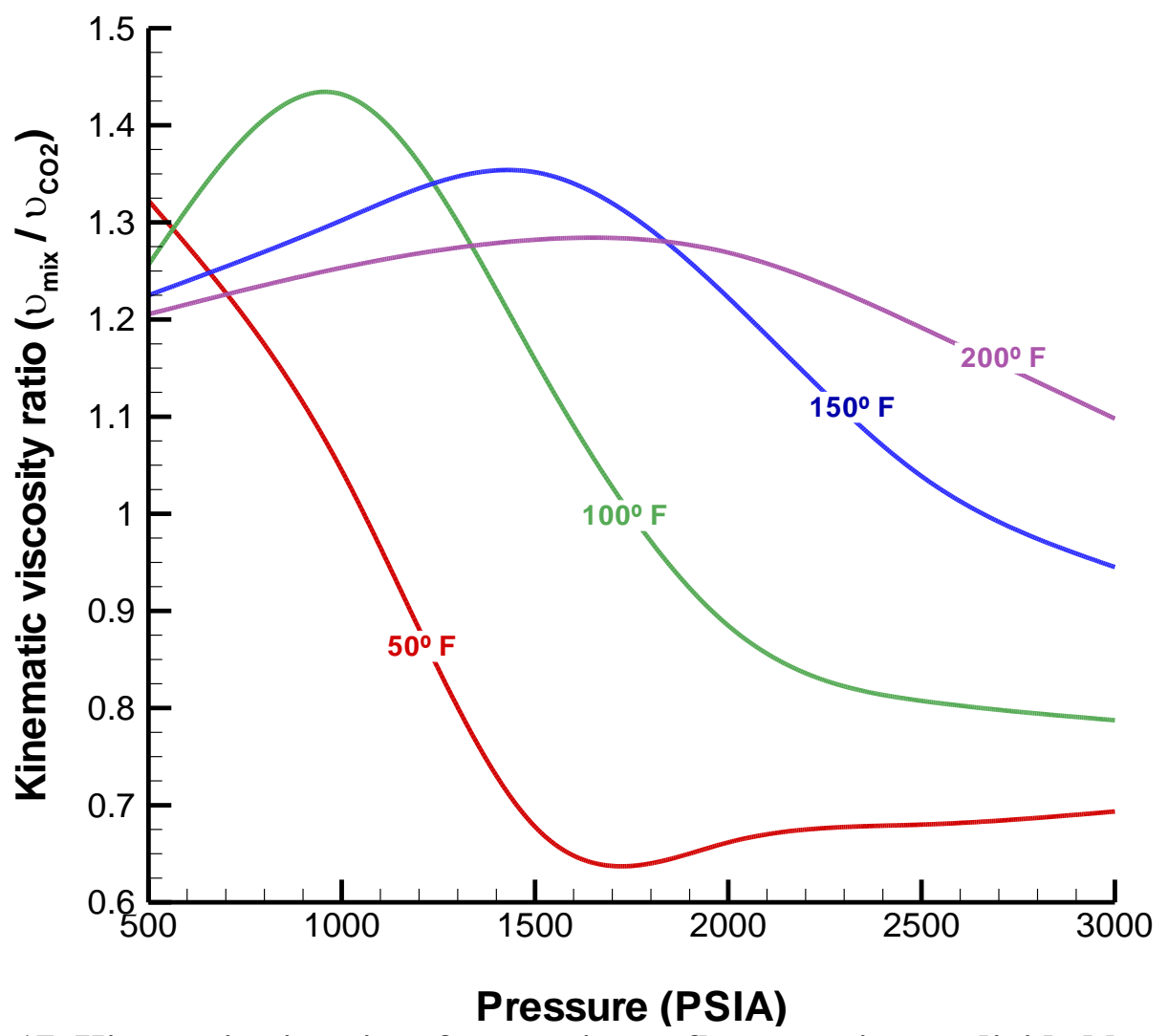

Figure 3.17. Kinematic viscosity of approximate flue gas mixture divided by the kinematic viscosity of pure $\mathrm{CO}_{2}$. Shown for various temperatures $\left(50^{\circ} \mathrm{F}\right.$ steps) and pressures (500 psi steps). Calculations were performed with NIST REFPROP v8.0. Mole fractions used: $0.7259 \mathrm{CO}_{2}, 0.1948 \mathrm{~N}_{2}, 0.0292 \mathrm{Ar}, 0.0002 \mathrm{CO}, 0.0499 \mathrm{O}_{2}$.

For large Reynolds number flows where the behavior is fully turbulent, the pressure difference required to move a given mass flow rate of fluid in a pipe depends more on the density of the fluid rather than the viscosity. For this flow regime, the friction factor remains fairly insensitive to the Reynolds number, and the predominant effect is the increase in pressure drop because of the lower density of the flue gas mixture. Figure 3.18 shows that the flue gas mixture is generally much less dense than pure $\mathrm{CO}_{2}$, hence the pressure requirement for a given total mass flow will be higher. The penalty will be even higher if the requirements are normalized by the $\mathrm{CO}_{2}$ fraction of the flow.

This effect applies to both the surface pipe and the well pipe. In addition, the well pipe will have comparatively less hydrostatic pressure gain because of the lower fluid density. Therefore, because of the lower density, the pressure required at the wellhead will be higher, for the same bottom hole pressure. In summary, both the surface and well pipeline capacities decrease when $\mathrm{CO}_{2}$ is mixed with non-condensable gases.

Simple porous-media transport models indicate that in the geologic formation the flow is proportional to the inverse of kinematic viscosity (5). As Figure 3.17 shows, the kinematic viscosity of the mixture is generally higher than that of pure $\mathrm{CO}_{2}$. Hence, reduced mass flow into the formation is expected. 


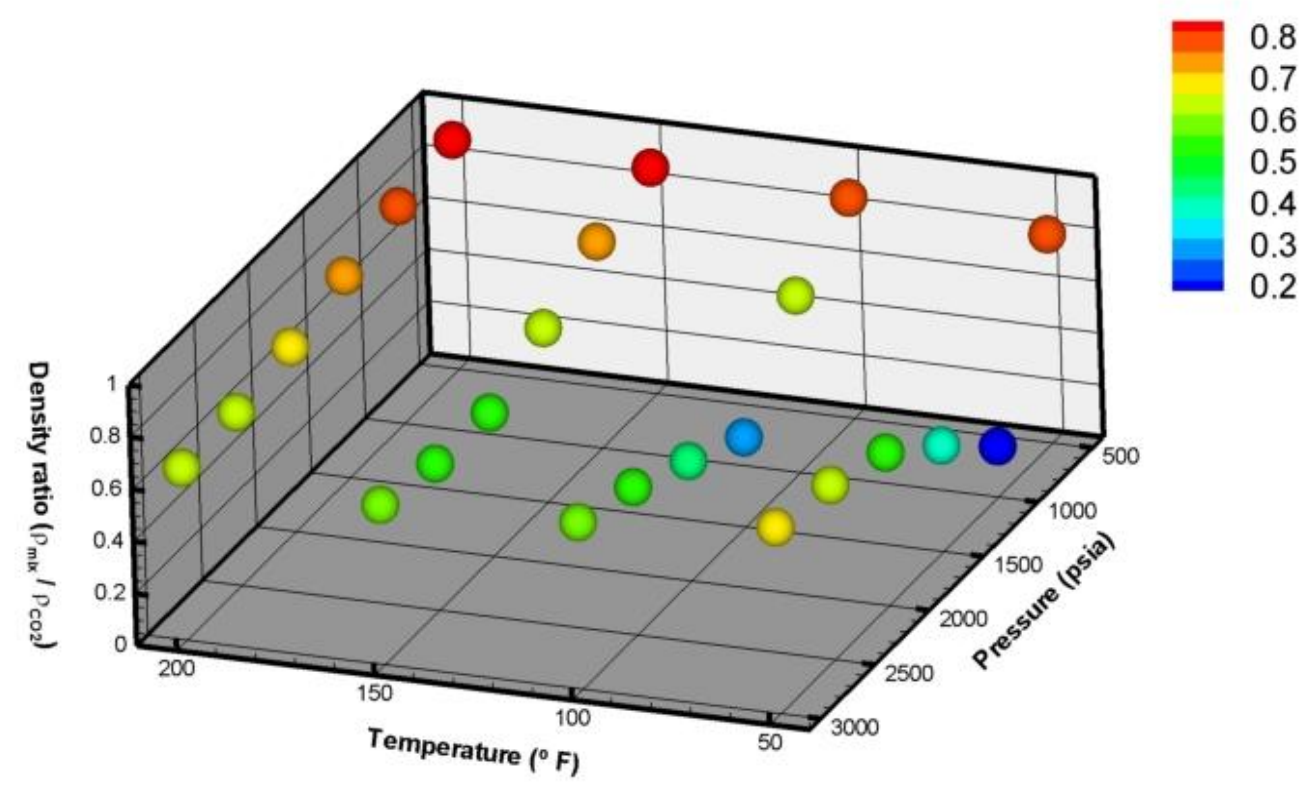

Figure 3.18. Density of approximate flue gas mixture divided by the density of pure $\mathrm{CO}_{2}$. Shown for various temperatures and pressures. See Figure 3.17 for additional notes. A large decrease in the density ratio occurs near the $\mathrm{CO}_{2}$ critical point

\subsection{Injection Well Permitting}

$\mathrm{CO}_{2}$ storage projects will require drilling permits, Underground Injection Control (UIC) permits, seismic road permits, and other construction permits associated with pipeline installation. Drilling permits require standard information on well location, construction specifications, and site restoration that any oil and gas well would necessitate. These permits are usually regulated by state agencies. Similarly, pipeline construction typically requires permits from the county road commission. A pipeline permit would require survey of the pipeline route, construction method, and restoration plan. Long pipelines (whether intra-state or inter-state) require negotiations of right of way routes and environmental assessments.

Injection wells will require a UIC permit application submitted to appropriate state or regional UIC programs. The permit application must include details on the injection target, injection operations, system monitoring, wells in the area of review, financial assurance, and other items necessary to fulfill UIC regulations. The UIC permit review process includes EPA technical review, a 30-day public comment period, and possibly a public hearing may be required. Consequently, the permit review process may require 3-9 months. Once the injection permit is issued, the EPA must approve the mechanical integrity test before they provide final permission to inject. During injection, monthly operating reports must be completed summarizing daily injection flow, injection pressure, and operations.

In response to CCS developments, EPA has recently proposed several new rules to regulate $\mathrm{CO}_{2}$ storage: 
- In July 2008, EPA proposed new requirements for geologic sequestration (GS) of carbon dioxide. The proposed rule would establish a new "Class VI" $\mathrm{CO}_{2}$ sequestration well. The proposed rule included regulations beyond those required for typical injection wells for enhanced oil recovery or hazardous waste disposal. In August 2009, EPA announced released "Notice of Data Availability" supplementing the UIC Class VI proposal, noting that the agency was evaluating the need for a more comprehensive regulatory framework for GS.

- In April 2010, the EPA proposed additional mandatory reporting of greenhouse gases for injection and geologic sequestration of carbon dioxide. These reporting requirements included an assessment of risk of leakage, strategy for detecting and quantifying $\mathrm{CO}_{2}$ leakage to the surface, strategy for establishing pre-injection environmental baselines, and tailor mass balance equation for $\mathrm{CO}_{2}$ sequestered. While separate from the proposed Class VI rule, in practice the mandatory reporting would be integrated into the Class VI permitting process.

- Several other guidance documents on site characterization, monitoring, and post-closure procedures have been announce by the EPA; although, no public versions of these documents have been released.

None of these proposed regulations has been added to the Federal Register at this time, and consequently, they do not represent official requirements for $\mathrm{CO}_{2}$ storage. However, these regulations may become mandatory during most CCS project timelines, and bear consideration during permitting. Many of the proposed regulations would require more site characterization, monitoring, reporting, and long term monitoring than have been applied at other deep well injection sites. 


\begin{tabular}{|c|c|c|c|}
\hline & 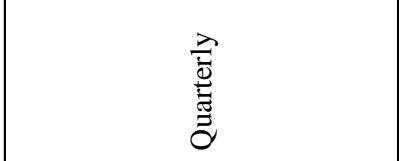 & 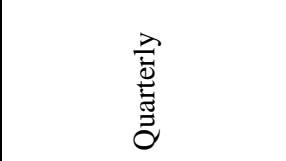 & 䟿 \\
\hline 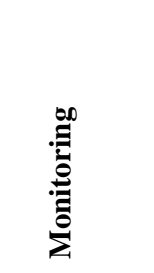 & 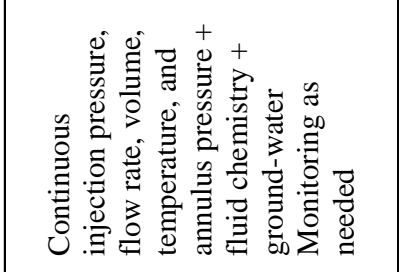 & 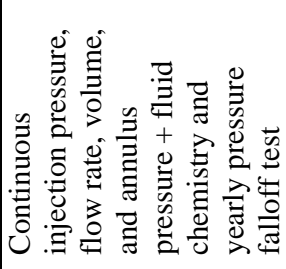 & 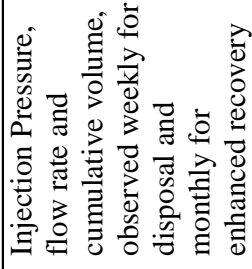 \\
\hline & 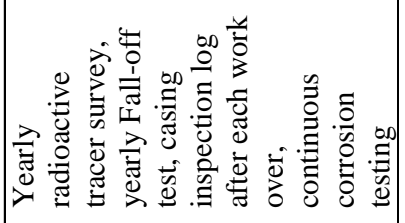 & 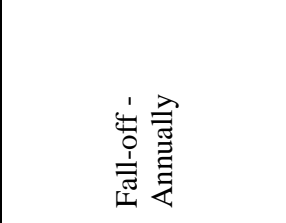 & 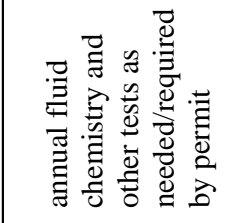 \\
\hline \multirow{2}{*}{ 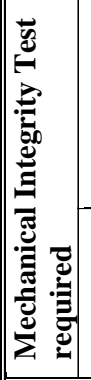 } & 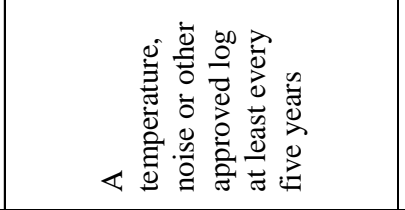 & $\begin{array}{l}n \\
5 \\
n \\
\frac{n}{0} \\
\text { II }\end{array}$ & 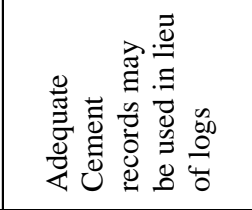 \\
\hline & 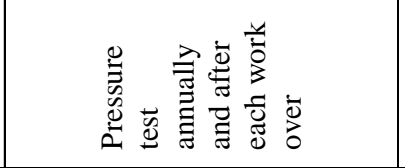 & 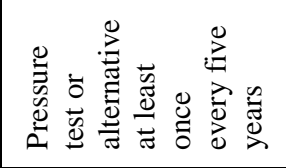 & 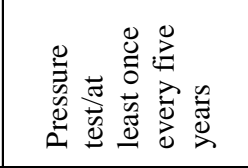 \\
\hline 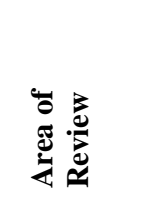 & 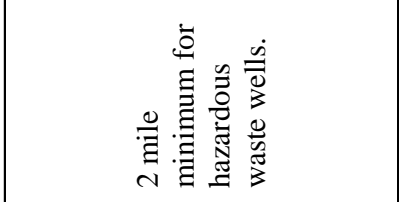 & 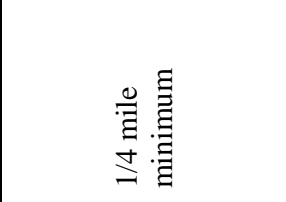 & 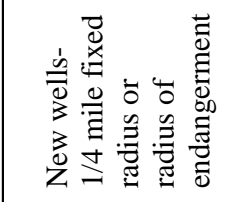 \\
\hline 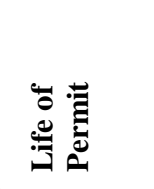 & 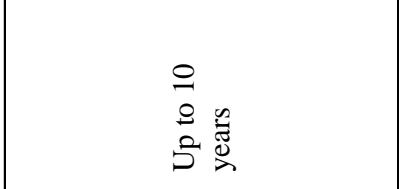 & 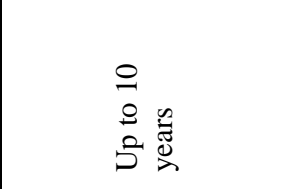 & 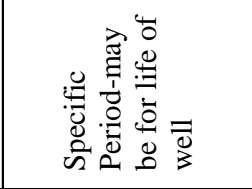 \\
\hline 串 & 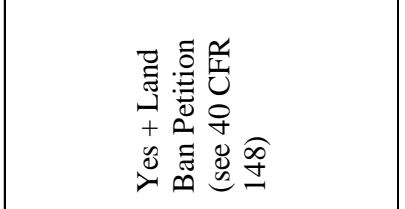 & $\stackrel{\otimes}{\nu}$ & 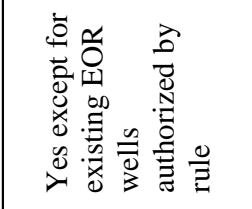 \\
\hline $\begin{array}{l}\frac{w}{\tilde{\omega}} \\
\frac{\tilde{\omega}}{U}\end{array}$ & $\Xi$ & $\underline{\underline{Z}}$ & $=$ \\
\hline
\end{tabular}

Table 3.8 Federal Regulation requirements of injection well classifications (6)

Table 3.8 continued on next page. 


\begin{tabular}{|c|c|c|c|}
\hline 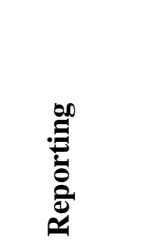 & 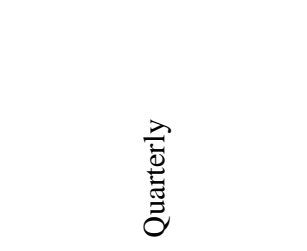 & 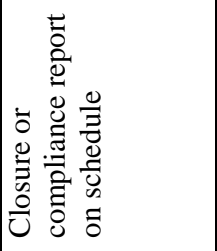 & 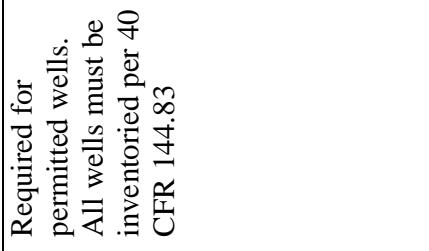 \\
\hline 离 & 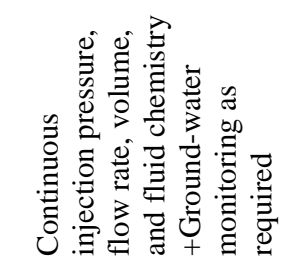 & 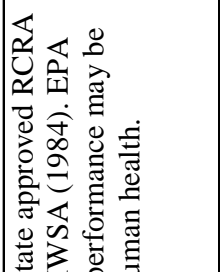 & 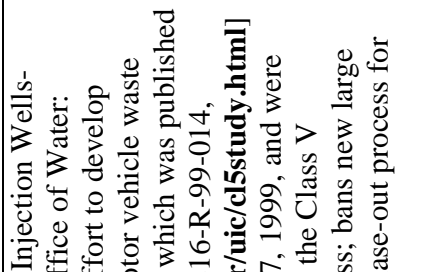 \\
\hline 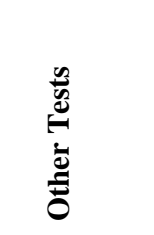 & 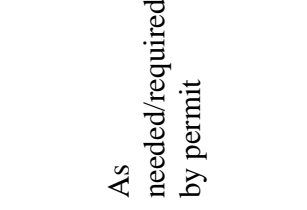 & 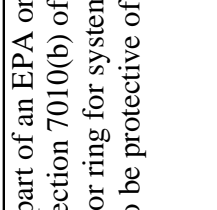 & 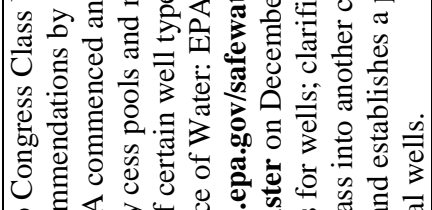 \\
\hline 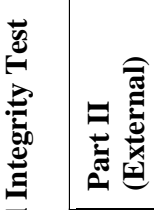 & 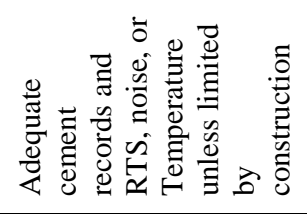 & 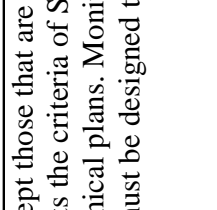 & 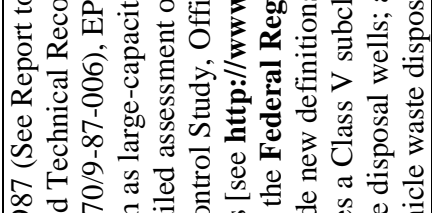 \\
\hline 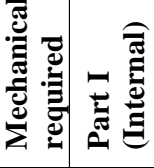 & 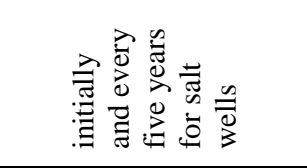 & 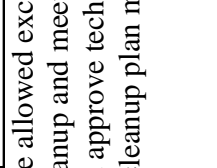 & 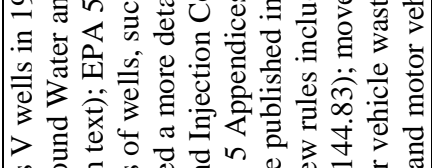 \\
\hline 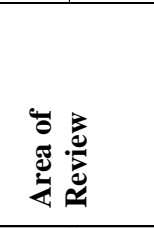 & 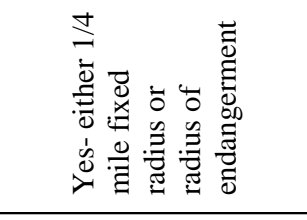 & 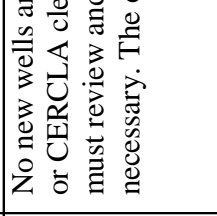 & 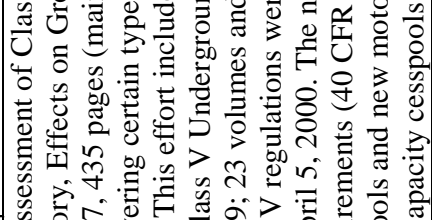 \\
\hline 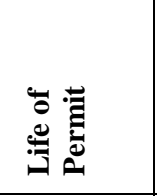 & 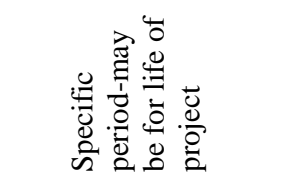 & 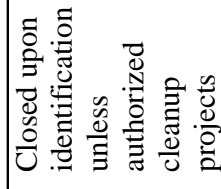 & 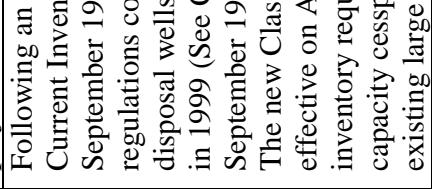 \\
\hline 产 & $\overbrace{}^{\infty}$ & 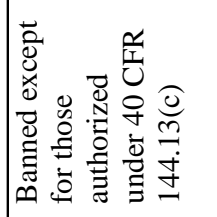 & 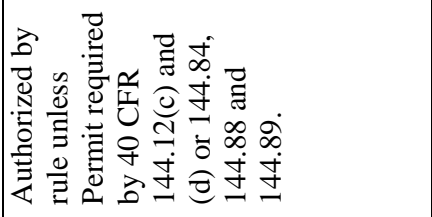 \\
\hline$\frac{\tilde{E}}{\tilde{\Xi}}$ & $\Xi$ & Z & $>$ \\
\hline
\end{tabular}

Continuation of

Table 3.8 Federal Regulation requirements of injection well classifications (6) 


\begin{tabular}{|l|l||}
\hline Class & Definitions \\
\hline I & $\begin{array}{l}\text { Inject hazardous, non-hazardous industrial or municipal waste, and radioactive waste, below } \\
\text { the lowermost formation containing a USDW within one quarter mile of the wellbore }\end{array}$ \\
\hline II & $\begin{array}{l}\text { Inject, for the purpose of disposal, fluids produced from downhole that are associated with oil } \\
\text { and gas production as well as fluids associated with the operation of natural gas storage } \\
\text { operation, methane gas dehydration and sweetening plant. Also includes wells used for the } \\
\text { enhanced recovery of oil and gas and the storage of hydrocarbons that are liquids at standard } \\
\text { temperature and pressure. }\end{array}$ \\
\hline III & Used for in-situ extraction of minerals. \\
\hline IV & Inject hazardous or radioactive waste fluids into or above USDW \\
\hline V & This category includes all other wells not covered in Classes I-IV \\
\hline
\end{tabular}

Table 3.9 Definitions of UIC defined classification of injection wells (6)

\begin{tabular}{|c|c|c|c|}
\hline $\begin{array}{l}\text { Citation in } \\
\text { Title 40, Code of } \\
\text { Federal } \\
\text { Regulations (7) }\end{array}$ & $\begin{array}{l}\text { Hazardous Waste } \\
\text { Characteristic }\end{array}$ & $\begin{array}{l}\text { Would flue gas } \\
\text { stream be expected } \\
\text { to possess this } \\
\text { characteristic? }\end{array}$ & Comments \\
\hline$\S 261.21$ & Ignitibility & No & - \\
\hline$\S 261.22$ & Corrosivity & Possibly & $\begin{array}{l}\text { A corrosive liquid as per the } \\
\text { regulations has a pH of less than } 2 \\
\text { or greater than } 12.5 \text {. The } \\
\text { determination of } \mathrm{pH} \text { of the flue gas } \\
\text { stream is important to determine } \\
\text { whether the stream is corrosive. A } \\
\text { stream can also be corrosive if it } \\
\text { can corrode steel at a rate of } 6.35 \\
\mathrm{~mm} \text { per year }\end{array}$ \\
\hline$\S 261.23$ & Reactivity & Possibly & $\begin{array}{l}\text { Assessment of the proposed waste } \\
\text { stream with respect to the } \\
\S 261.23(5) \text { criterion for sulfide } \\
\text { bearing waste must be performed } \\
\text { by the generator. }\end{array}$ \\
\hline$\S 261.24$ & Toxicity & Possibly & $\begin{array}{l}\text { The presence of trace amount of } \\
\text { mercury in the flue gas stream } \\
\text { might render it toxic. }\end{array}$ \\
\hline
\end{tabular}

Table 3.10 Hazardous waste characteristics and comparison of each with the flue gas stream characteristics

Table 3.8 and Table 3.9 define and explain UIC classifications and regulations on injection wells. The UIC guidelines are regulated by the EPA and have been set into place to comply with the Safe Water Drinking Act of 1980. The regulations are designed to protect drinking water supplies by establishing citing, operating, monitoring, closure, and review protocols. The UIC program entails various requirements for underground injection to protect human health and the environment. Unless a new class is established for $\mathrm{CO}_{2}$ sequestration wells they may fall into Class V. According to the UIC regulations, hazardous waste is not permitted to be injected into Class $\mathrm{V}$ wells, therefore everything that is injected with the $\mathrm{CO}_{2}$ must not be considered hazardous waste or have harmful components above allowed levels for non-hazardous waste. 
According to 40 CFR Part 261 Subpart D (1986), the four characteristics of a hazardous waste are: corrosivity, reactivity, ignitability, and toxicity(7). Under UIC regulations, underground injection of hazardous wastes requires a Class I UIC permit and a no-migration demonstration (40 CFR Sections 144.6 and 148.20). Table 3.10 is a list of all the characteristics of a hazardous waste and whether or not the flue gas from an oxy-fuel boiler possesses a particular characteristic.

In circumstances where regulated hazardous substances, such as mercury $(\mathrm{Hg})$ and $\mathrm{SO}_{2}$, are present in the effluent flue gas there is a possibility that the injection well cannot be permitted as Class V. Labeling the well as Class I, is a risk if impurities which are known as hazardous wastes are not carefully monitored and maintained at an acceptable level. Changing from Class $\mathrm{V}$ to a Class I injection well would increase the level of permitting needed and the amount of regulatory and public scrutiny placed on the injection well.

Testing should be done to monitor any aspect that could be considered hazardous or change the classification of the injection well. The EPA has published a document to encourage testing for corrosivity titled "Test Methods for Evaluating Solid Waste, Physical/Chemical Methods, and SW-846." Testing for $\mathrm{pH}$ should be done using EPA recommended test number 9040C. All other characteristics should be tested for using Toxicity Characteristic Leaching Procedure (test Method 1311) in EPA Publication SW-846 as a primary method. Maximum acceptable levels of contaminants which are metals can be found in Table 3.11.

Prior to injection, plans must be drawn up to adequately test for all aspects of the injectate which could be hazardous and therefore result in a hazardous waste classification. The system for injection should have a built in monitoring system to maintain the Class $V$ title instead of being classified as a Class I hazardous waste injection site. Levels of contaminants deemed hazardous must be removed before injection and EPA regulators should approve the system which should follow UIC guidelines. The majority of impurities in all likelihood will not affect injection, however the levels set forth by regulators must be adhered to in order to protect the classification of the well as well as the USDW ${ }^{2}$ systems nearby the injection site.

A number of field validation and development scale projects for geologic storage assessments are being conducted under the DOE's seven Regional Carbon Sequestration Partnerships (RCSP). The results of the Phase II (Validation Phase) of this program are likely to be available during late 2010 and will be useful in providing an assessment of field practices, storage potential, and monitoring technologies. For example, the Midwestern Regional Carbon Sequestration Partnership (MRCSP) has conducted deep saline injection projects in Michigan, Ohio, and Kentucky. These projects have also provided experience in obtaining the Class V injection well permits from EPA or relevant state authorities. Furthermore, these smaller-scale tests provide the necessary information for larger-scale deployment, as well as, the information needed for environmental impact assessments for larger projects.

${ }^{2}$ Underground source of drinking water 


\begin{tabular}{|l|l|l|l||}
\hline EPA HW & & CAS & \\
Number & Contaminant & Number & Regulatory Level $(\mathbf{m g} / \mathbf{L})$ \\
\hline D004 & Arsenic & $7440-38-2$ & 5.0 \\
\hline D005 & Barium & $7440-39-3$ & 100.0 \\
\hline D006 & Cadmium & $7440-43-9$ & 1.0 \\
\hline D007 & Chromium & $7440-47-3$ & 5.0 \\
\hline D008 & Lead & $7439-92-1$ & 5.0 \\
\hline D009 & Mercury & $7439-97-6$ & 0.2 \\
\hline D010 & Selenium & $7782-49-2$ & 1.0 \\
\hline D011 & Silver & $7440-22-4$ & 5.0 \\
\hline \hline
\end{tabular}

Table 3.11 Maximum concentrations of metal contaminants for toxicity characteristics

\subsection{Overview of Deep Sedimentary Basins in the US}

Deep sedimentary basins in the United States are of three primary types: oil and gas reservoirs, unmineable coal seams, and saline reservoirs. Other potential geologic sequestration options include basalt formations and organic rich shales.

\section{Oil and Gas Reservoirs}

Oil and Gas Reservoirs consist of layers of permeable rock, saturated with hydrocarbons, which are capped by impermeable rocks in sedimentary or structural traps. Such reservoirs have successfully contained the associated hydrocarbons in the subsurface for millions of years until their discovery in subsequent exploration. The conditions that trap the oil and gas are also the conditions for the successful sequestration of carbon dioxide in the subsurface. Additionally, $\mathrm{CO}_{2}$ injection into previously explored oil and gas reservoirs may be used as a method of EOR (Enhanced Oil Recovery) that provides additional incremental hydrocarbon reserves while reducing the net economic cost of injection.

Oil and Gas Reservoirs are found in certain regions throughout the continental United States and Alaska, as well as offshore. Much characterization of these reservoirs has previously been done in private industry with only limited amounts of the relevant data released into the public domain. 2007 estimates from the DOE Carbon Sequestration Atlas (8) are on the order of 91 billion tons of $\mathrm{CO}_{2}$ for carbon storage in oil and gas reservoirs in the United States.

\section{Unmineable Coal Seams}

Unmineable coal seams are uneconomic resources of coal that cannot be mined due to depth or insufficient thickness. Coal beds all contain some amount of methane that can be recovered either via primary recovery methods, such as dewatering and depressurization, or via secondary recovery by $\mathrm{CO}_{2}$ sweep. Similar to EOR in oil and gas reservoirs, coal beds can be another method of storing $\mathrm{CO}_{2}$ while increasing the availability of gas reserves. At this time, early state analyses are being performed to determine feasibility and economics. 2007 estimates from the DOE Carbon Sequestration Atlas (8) are on the order of 173 to 203 billion tons of $\mathrm{CO}_{2}$ for carbon storage in unmineable coal seams in the United States. 


\section{Deep Saline Reservoirs}

Deep saline reservoirs are layers of sedimentary rock in which the pore space has become saturated with brine. These are much more extensive than either hydrocarbon-bearing rock or coal seam formations and therefore represent the best potential for $\mathrm{CO}_{2}$ sequestration by available volume. A suitable saline reservoir must have adequate porosity and permeability, such as is found in many sandstone and carbonate formations. Additionally, the formation must be located at a depth suitable to keep $\mathrm{CO}_{2}$ in its supercritical state. Finally, the saline reservoir must be capped by impermeable rock, such as shale, in order to keep the injected $\mathrm{CO}_{2}$ from migrating up and out of the storage zone.

Characterization of deep saline reservoirs has previously been much sparser than the characterization of economic hydrocarbon and coal reservoirs. There is a great amount of uncertainty regarding the suitability of specific reservoirs with regards to CCS. As more work is done, a greater volume of data will be available for estimating $\mathrm{CO}_{2}$ capacity at any given site. 2010 estimates from the DOE Carbon Sequestration Atlas (9 p. 27) range from 1,822 to 22,281 billion tons of $\mathrm{CO}_{2}$ for deep saline reservoir storage in the United States. At present, reservoir data are most abundant in the northeast, northwest, and Midwestern regions.

\subsection{Injection Process}

The injection process relies on moving the injection stream from the wellhead, through the injection tubing, and into the storage formation. Assuming a supply of $\mathrm{CO}_{2}$ at the wellhead at supercritical conditions, no additional compression may be necessary at shallower depths. Deeper injection targets may require additional booster compression to reach injection pressures.

Despite the added complexity, impurities in the injection stream are unlikely to be detrimental to the concept of $\mathrm{CO}_{2}$ storage by deep well injection. As long as the gas stream has low level of impurities, $\mathrm{CO}_{2}$ production wells (10) and sour gas $\left(\mathrm{H}_{2} \mathrm{~S}\right)$ injection wells (11) generally encounter few problems with operations. The gas components would be in either supercritical or liquid phase at the wellhead. In pure phase, the compounds $\mathrm{CO}_{2}, \mathrm{SO}_{2}$, and $\mathrm{NO}_{2}$ are not reactive until they react with water to form acids. Ar and $\mathrm{N}_{2}$ are inert gases while $\mathrm{O}_{2}$ can promote corrosion of well materials.

The main cost and operational issues with regard to injection are summarized below:

- Volumetric increase - The overall injection volume with impurities will be greater than a pure $\mathrm{CO}_{2}$ stream. Additional injection wells, larger casing, larger diameter tubing, and associated equipment may be necessary to inject $\mathrm{CO}_{2}$ on a mass basis. The added costs associated with this additional volume are likely to be a fraction (10-25\%) of the capital and operation costs associated with an injection system. However, this increase may be substantial for larger sources (e.g. 10 million tonnes per year for $\mathrm{CO}_{2}$ with impurities versus 12 million tonnes per year for $\mathrm{CO}_{2}$ only stream).

- Injection pressures - The impurities will lower the density of the injection stream to some extent, mainly due to $\mathrm{N}_{2}$ and Ar. The injection process relies on the weight of the fluid column in the injection well to complement injection pressures. Thus, a lighter injection stream will require additional injection pressure and associated compression commensurate with the lower density of the fluid. 
- Enhanced oil recovery limitations - Impurities may limit potential to utilize the gas stream for enhanced oil recovery projects. $\mathrm{NO}_{\mathrm{X}}$ can decrease oil recovery, and $\mathrm{SO}_{\mathrm{X}}$ may improve oil recovery, but at the specified concentrations, the compounds are not likely to affect recovery rates. Oxygen can react exothermally with oil in the reservoir and limit recovery. It can also promote bacterial growth and corrosion of metallic tools or instruments. For these reasons, oxygen is always removed from water for water flooding EOR operations. Nitrogen is often used for EOR floods, but it may reduce the effectiveness of $\mathrm{CO}_{2}$ oriented EOR because the two gases facilitate oil displacement by slightly different processes.

\subsection{Injection Materials}

Corrosion of injection materials is a significant concern for impurities. $\mathrm{CO}_{2}$ related corrosion and well-bore leakage has been identified as a significant issue for $\mathrm{CO}_{2}$ storage projects, in both injection wells and abandoned wells that penetrate the storage target (12); (13); (14). Consequently, the effect of impurities on the various injection materials was examined in more detail. Materials for deep injection wells typically include wellhead fittings, casing, well cement, injection tubing, packers, annulus fluid, and other monitoring/metering equipment. However, corrosion is most likely to affect the casing, tubing, and well cements at depth as the $\mathrm{CO}_{2}$ stream mixes with formation waters and moves into the areas around and overlying the injection well.

Table 3.12 summarizes compatibility of the injection stream components with well materials. $\mathrm{N}_{2}$ and $\mathrm{Ar}$ are generally inert gases unlikely to affect well materials. $\mathrm{CO}_{2}, \mathrm{SO}_{2}$, and $\mathrm{NO}_{2}$ are similar to some extent in that they form weak to moderately strong acids with water, which then can cause corrosion in steel. $\mathrm{O}_{2}$ is well known to cause corrosion and bacterial growth in deep wells with water floods. While $\mathrm{CO}$ is present in natural gas production, not as much is known as to injecting this compound.

\begin{tabular}{|l|l|l||}
\hline Compound & Compatibility & Comments \\
\hline $\mathrm{CO}_{2}$ & Corrosive with water & Forms carbonic acid with water \\
\hline $\mathrm{O}_{2}$ & Strong oxidizer & $\begin{array}{l}\text { Causes oxidation of iron and other } \\
\text { metals }\end{array}$ \\
\hline $\mathrm{SO}_{2}$ & Potentially corrosive & Forms sulfuric acid with water and $\mathrm{O}_{2}$ \\
\hline $\mathrm{N}_{2}$ & Inert & $\begin{array}{l}\text { Commonly used in oil and gas industry } \\
\text { for fracking and EOR }\end{array}$ \\
\hline $\mathrm{Ar}$ & Inert & May behave similar to $\mathrm{N}_{2}$ \\
\hline $\mathrm{NO}_{2}$ & Potentially corrosive & Forms nitric acid with water and $\mathrm{O}_{2}$ \\
\hline $\mathrm{CO}$ & Unknown & $\begin{array}{l}\text { CO not common in natural gas } \\
\text { production }\end{array}$ \\
\hline
\end{tabular}

Table 3.12 Summary of impurity compatibility with well materials

\section{Well Casing and Tubing}

A variety of materials, alloys, and coatings are available to address corrosion of well casings and tubing. Table 3.13 summarizes well materials, applications, and limitations. Injection casing and 
tubing are classified by American Petroleum Institute (API) type of steel (H-Q) and minimum yield pressure (40-125+ thousand pounds per square inch). In general, higher grades of steel are specified for deeper wells, higher temperatures, higher pressures, and corrosion resistance. Many grades of steel are designed to be more ductile to prevent brittle failure from $\mathrm{H}_{2} \mathrm{~S}$ gas, also known as "sour gas."

\begin{tabular}{|c|c|c|c|}
\hline Material & Type & Applications & Limitations \\
\hline $\begin{array}{l}\text { Carbon and Low- } \\
\text { Alloy Steel }\end{array}$ & $\begin{array}{l}\text { Hardness } \\
<\text { HRC } 22\end{array}$ & $\begin{array}{l}\text { “Dry” } \mathrm{CO}_{2} \text { transmission, shallow } \\
\text { casing (i.e., conductor casing). }\end{array}$ & $\begin{array}{l}\text { Brittle at temperatures }<-20^{\circ} \mathrm{F} . \\
\text { Corrodes in presence of wet } \mathrm{CO}_{2} \\
\text { or } \mathrm{H}_{2} \mathrm{~S} \text {. Corrodes more rapidly } \\
\text { when } \mathrm{CO}_{2} \text { partial pressure exceeds } \\
15 \text { psia or temperature }>300^{\circ} \mathrm{F} \text {. } \\
\end{array}$ \\
\hline $\begin{array}{l}\text { Stainless Steel } \\
\text { (Martensitic) }\end{array}$ & $\begin{array}{l}\text { Hardness } \\
\text { <HRC } 22 \text { (AISI } \\
410 ; 9 \mathrm{Cr} / 1 \mathrm{Mo})\end{array}$ & “Dry" or "wet" $\mathrm{CO}_{2}$ transmission. & $\begin{array}{l}\text { Oxygen, } \mathrm{H}_{2} \mathrm{~S}, \mathrm{H}_{2} \mathrm{O} \text {, increasing } \\
\text { partial pressures of } \mathrm{CO}_{2} \text {, or } \mathrm{Cl} \\
\text { rapidly increase corrosion rates, } \\
\text { especially at temperatures }> \\
200^{\circ} \mathrm{F} \text {. }\end{array}$ \\
\hline $\begin{array}{l}\text { Stainless Steel } \\
\text { (Austenitic) }\end{array}$ & $\begin{array}{l}\text { Hardness < } \\
\text { HRC 22; 35 } \\
\text { (AISI 304, 316; } \\
\text { Nitronic-50) }\end{array}$ & “Dry" or "wet" $\mathrm{CO}_{2}$ transmission. & $\begin{array}{l}\text { Oxygen, } \mathrm{H}_{2} \mathrm{~S}, \mathrm{H}_{2} \mathrm{O} \text {, and } \mathrm{Cl} \text { increase } \\
\text { corrosion rate, especially at } \\
\text { temperatures }>150^{\circ} \mathrm{F} \text {. }\end{array}$ \\
\hline Bimetallic & $\begin{array}{l}\text { Carbon steel } \\
\text { outer, } \\
\text { corrosion- } \\
\text { resistant inner } \\
\text { (Alloy 625) } \\
\end{array}$ & $\begin{array}{l}\text { Inexpensive carbon steel } \\
\text { handles stresses, is protected } \\
\text { from corrosion by liner. Cheaper } \\
\text { than high-alloy steel pipe. }\end{array}$ & $\begin{array}{l}\text { Segments must be joined by } \\
\text { special welding technique. Very } \\
\text { susceptible to problems (including } \\
\text { galvanic corrosion) if holes form in } \\
\text { liner. }\end{array}$ \\
\hline $\begin{array}{l}\text { Other Internally- } \\
\text { coated Carbon } \\
\text { Steel }\end{array}$ & $\begin{array}{l}\text { Phenolics, } \\
\text { epoxy- } \\
\text { phenolics, } \\
\text { glass epoxies, } \\
\text { nickel } \\
\end{array}$ & \begin{tabular}{|l} 
Provides extra protection to \\
inexpensive steels (alternative \\
to more expensive material).
\end{tabular} & $\begin{array}{l}\text { Only effective when not damaged } \\
\text { (i.e., scratched). Damaged areas } \\
\text { will corrode quickly. }\end{array}$ \\
\hline Fiberglass & - & $\begin{array}{l}\text { Can be used alone or as an } \\
\text { outer covering to protect carbon } \\
\text { steel from corrosion. }\end{array}$ & $\begin{array}{l}\text { Pure fiberglass may not withstand } \\
\text { high pressures, can be brittle when } \\
\text { cold, and its length can vary } \\
\text { dramatically with temperature. }\end{array}$ \\
\hline $\begin{array}{l}\text { Fiberglass- } \\
\text { Reinforced } \\
\text { Plastic (FRP) }\end{array}$ & $\begin{array}{l}\text { Polyester/glass, } \\
\text { epoxy/glass }\end{array}$ & $\begin{array}{l}\text { Currently used in natural } \mathrm{CO}_{2} \\
\text { production and oil-field injection. }\end{array}$ & $\begin{array}{l}\mathrm{CO}_{2} \text { swells and alters resin, worse } \\
\text { at increasing pressures. Results in } \\
\text { brittleness, delamination. } \mathrm{H}_{2} \mathrm{~S} \text { limits } \\
\text { service temperatures. Length } \\
\text { varies dramatically with } \\
\text { temperature. }\end{array}$ \\
\hline
\end{tabular}

Table 3.13 Casing/tubing materials, applications, and limitations

$\mathrm{CO}_{2}$ is referred to as "sweet gas" when encountered in the oil and gas industry and can cause pitting and pinhole leaks in casing, joints, tubing, and packers. API grade of L-80 or greater is recommended for these applications. If the $\mathrm{NO}_{2}$ and $\mathrm{SO}_{2}$ result in a similar acidic corrosion process, then the same grade of steel may be sufficient for these compounds as well. Other options for corrosion resistance include alloy plating (nickel, chrome, etc), polymer coatings, stainless steel, and fiberglass casing. These options are typically more expensive and more 
difficult to handle in the field and are susceptible to damage. Many operators use common steel grades (J-55) with few problems so long as they produce or inject relatively pure $\mathrm{CO}_{2}$. Some EOR fields encounter significant corrosion when injecting alternating cycles of water and $\mathrm{CO}_{2}$ (the water alternating gas or WAG process).

\section{Well Cement}

Cement also must be able to withstand the pressures, temperatures, and chemical impurities expected in the borehole. Table 3.14 summarizes basic well field cements and their properties. Basic ASTM (American Society for Testing and Materials) Portland cement mixes are typically used to cement wells. American Petroleum Institute class cement may be available in certain areas with established oil and gas operations. Various additives may be used to fortify the cement and extend temperature and pressure ranges. Acid resistant additives may be added to the cement to prevent corrosion. Well cements are specifically designed by an engineer for the well based on various parameters such as well depth, lithology, pressures, temperatures, and fluids in the borehole.

\begin{tabular}{|l|l|l|l||}
\hline API Class & Description & ASTM Equivalent & $\begin{array}{l}\text { Normal Density } \\
(\mathbf{p p g})\end{array}$ \\
\hline A & $\begin{array}{l}\text { Surface to 6,000 feet. Basic cement when } \\
\text { special properties are not required. }\end{array}$ & Type I & 15.6 \\
\hline B & $\begin{array}{l}\text { Surface to 6,000 feet. Moderate to high } \\
\text { sulfate-resistance. }\end{array}$ & Type II & 15.6 \\
\hline C & $\begin{array}{l}\text { Surface to 6,000 feet. High early strength. } \\
\text { Fine grind. }\end{array}$ & Type III & 14.8 \\
\hline G & $\begin{array}{l}\text { Surface to 8,000 feet. Basic cement. } \\
\text { Popular in Western US. }\end{array}$ & Type IV & 15.8 \\
\hline H & $\begin{array}{l}\text { Surface to 8,000 feet. Basic cement with } \\
\text { high sulfate resistance. Popular in Gulf } \\
\text { Coast and Central US }\end{array}$ & Type IV & 16.5 \\
\hline $\begin{array}{l}\text { Note: several other specialized classes of cements are available for extreme conditions. } \\
\text { ppg = pounds per gallon }\end{array}$
\end{tabular}

Table 3.14 Typical well field cements

Portland-based cements undergo chemical reactions in the presence of $\mathrm{CO}_{2}$, mainly the formation of limestone, which can alter the physical and mechanical properties of Portland-filled annular spaces over the life of a $\mathrm{CO}_{2}$ injection well. Limestone production in the cement is typically not a problem. However, water and $\mathrm{CO}_{2}$ mix in the pore spaces and create carbonic acid, which is corrosive to the casing inside the cement sheath.

One possible way to minimize reactions is to use a high-solids Portland cement mix. By filling additional cement porosity with solids, rather than gas or liquid, seepage of $\mathrm{CO}_{2}$ and water into the cement is slowed. Remaining pore spaces can be filled, and $\mathrm{CO}_{2}$ infiltration can be further slowed, with the addition of a latex-based polymer to the high-solids Portland cement. Research also is currently being conducted on $\mathrm{CO}_{2}$-resistant epoxy-based cements. These cements are expected to offer good containment of $\mathrm{CO}_{2}$, but have several drawbacks including being relatively untested, expensive, and difficult to emplace in the well. 


\subsection{Injection Operations}

A deep well injection system typically consists of a several deep wells connected to a supply pipeline. The wells are open to a porous rock formation that receives the injection stream, which is sequestered in the deep rock formation. Deep injection wells are installed by drilling progressively smaller borings and cementing steel casing in the hole after each drilling run to stabilize the well and protect near surface groundwater supplies (Figure 3.19). Injection tubing is then secured in the well with an expanding packer system to isolate the injection interval. The annular space between the tubing and the casing is then filled with a dense annulus fluid designed to shut in the well in case of some mechanical failure in the well.

To a large extent, well casing and injection tubing are subject to the same physical and chemical corrosion issues as identified in the surface pipeline analysis. Many of the same metal alloy and coating options are applicable to the well casing and tubing.

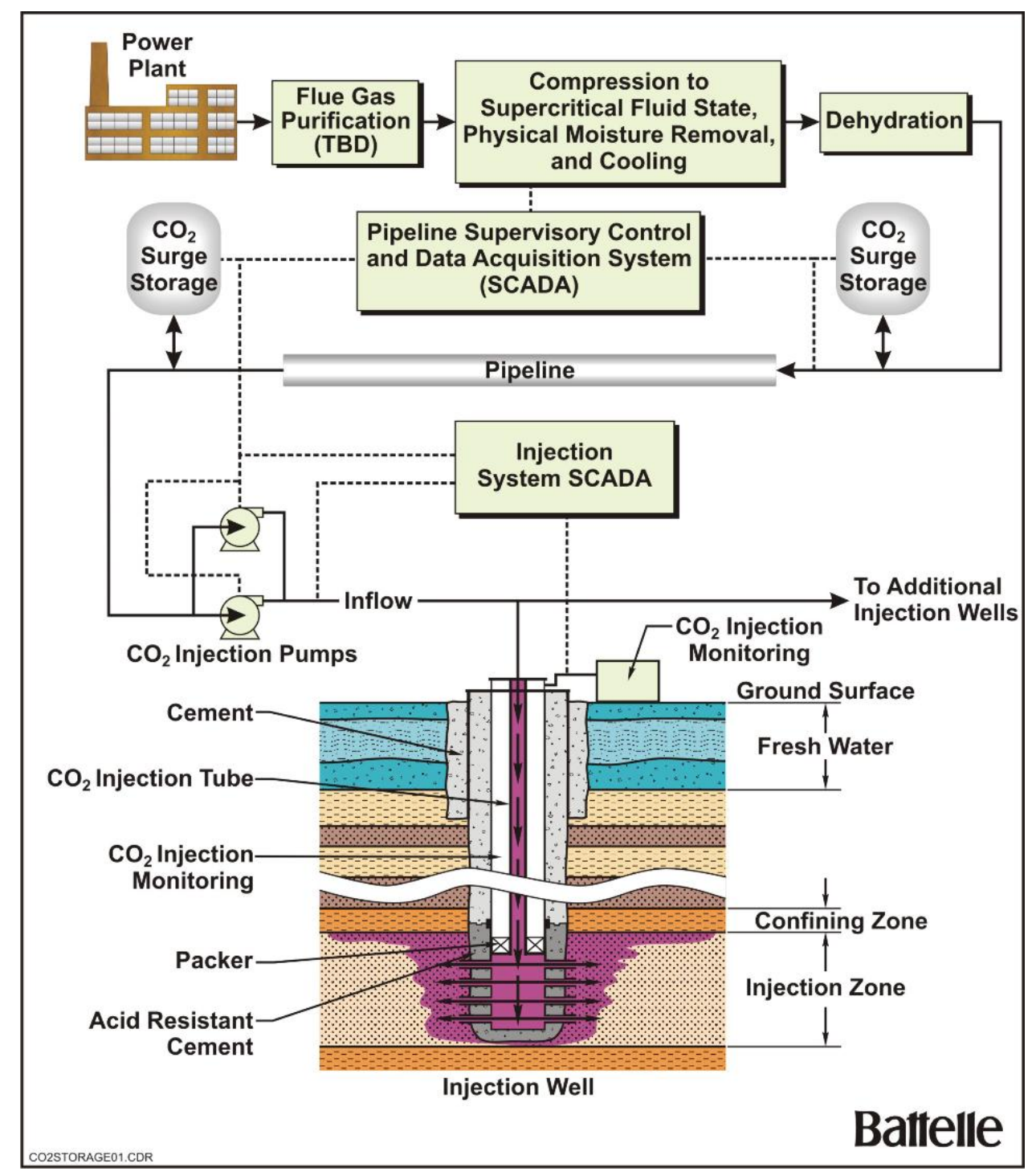

Figure 3.19. Injection well components 
However, once the injection stream reaches the targeted rock formation, there are more chances for the compounds to react with the formation water and affect the injection system and well materials (Scherer, 2004; Huerta, 2007). Until relatively recently, most of the experience with injection well performance and well materials came from the oil and gas industry and waste injection. Future guidance on storage issues will come from studies and actual $\mathrm{CO}_{2}$ injection tests by the MRCSP (http://www.mrcsp.org/) and other partnerships.

\subsection{Numerical simulations}

Numerical simulations of injecting pure $\mathrm{CO}_{2}$ and oxy-combustion flue gas were conducted using STOMP-WCS-R (water, $\mathrm{CO}_{2}$, salt and reactions) simulator (1). The STOMP code is capable of modeling complex, coupled hydrologic, chemical, and thermal processes, including multi-fluid flow and transport, partitioning of $\mathrm{CO}_{2}$ into the aqueous phase, and chemical interactions with aqueous fluids and rock minerals. Because an EOS for a flue gas mixture was not available at the time these simulations were conducted, a mixture of $72 \% \mathrm{CO}_{2}$ and $28 \%$ air was used instead. Other parameters used in the model are summarized in Table 3.15. The STOMP computer code has been verified against other codes used for simulation of geologic disposal of $\mathrm{CO}_{2}$ as part of the GeoSeq code intercomparison study (15), and has been used in previous investigations of $\mathrm{CO}_{2}$ injection potential at the Mountaineer Power Plant site (16).

\begin{tabular}{|l|l|}
\hline Property & Value \\
\hline Aqueous-Phase Salt Mass Fraction & 0.1 \\
\hline Temperature & $90 \% \mathrm{~F}$ \\
\hline Saturated Intrinsic Permeability & $100 \mathrm{mD}$ \\
\hline Porosity & $15 \%$ \\
\hline Rock Type & Homogeneous, isotropic sandstone \\
\hline Saturation Function & Berea Sandstone, Brooks and Corey Extended: Air Entry \\
& Pressure $=42 \mathrm{~cm}, \lambda=3.033$, Residual Saturation $=0.299$ \\
\hline Aqueous/Gas Relative Permeability & Burdine pore distribution function \\
\hline Formation Thickness & $100 \mathrm{ft}$ \\
\hline Depth to bottom of formation & $3600 \mathrm{ft}$ \\
\hline Hydrostatic Gradient & $0.433 \mathrm{psi} / \mathrm{ft}$ \\
\hline Injection Rate & $0.5 \mathrm{MMT} /$ year \\
\hline Injection Time & 61 days \\
\hline Simulation Time & 1 year \\
\hline Coordinate System & 2 dimensional cylindrical \\
\hline Radial Grid spacing & 67 nodes, variable spacing from $0.26 \mathrm{ft}$ to $206 \mathrm{ft}$ \\
\hline Vertical Grid Spacing & 100 to 400 nodes, uniform $1 \mathrm{ft}$ spacing \\
\hline $\begin{array}{l}\text { Upper and Lower Boundary } \\
\text { Conditions }\end{array}$ & no flow \\
\hline Boundary Condition at R & $0:$ Axis of Symmetry \\
\hline Boundary Condition at R & $3342 \mathrm{ft}$ Hydrostatic Gradient $=0.433 \mathrm{psi} / \mathrm{ft}$ \\
\hline \hline
\end{tabular}

Table 3.15 Model input parameters 
At the modeled temperature of $90^{\circ} \mathrm{F}$, the flue gas plume (Figure 3.20) is more buoyant than the $\mathrm{CO}_{2}$ plume (Figure 3.21) due to the lower density of air. $\mathrm{CO}_{2}$ (Figure 3.22) is over an order of magnitude more soluble in brine than air (Figure 3.23) at this temperature. For this reason, $\mathrm{CO}_{2}$ solubility in brine is not appreciably different when injected with flue gas, rather than pure $\mathrm{CO}_{2}$ (Figure 3.24). The pressure distribution around the well during injection is relatively similar for Flue Gas (Figure 3.25) and $\mathrm{CO}_{2}$ (Figure 3.26). The pressures are slightly higher for flue gas injection. Because air is less dense than supercritical $\mathrm{CO}_{2}$, higher pressures are needed to achieve the same mass injection rate for the flue gas plume, relative to the pure $\mathrm{CO}_{2}$ plume.

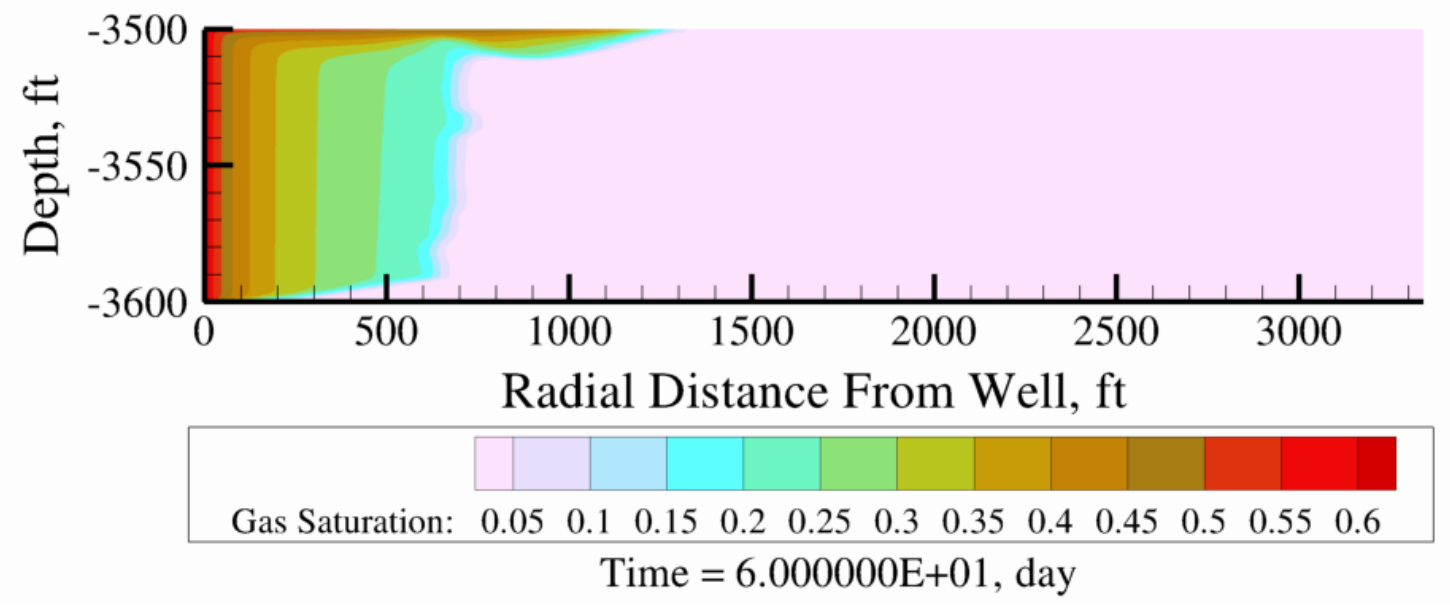

Figure 3.20. Gas-phase saturation after 60 days of flue gas injection

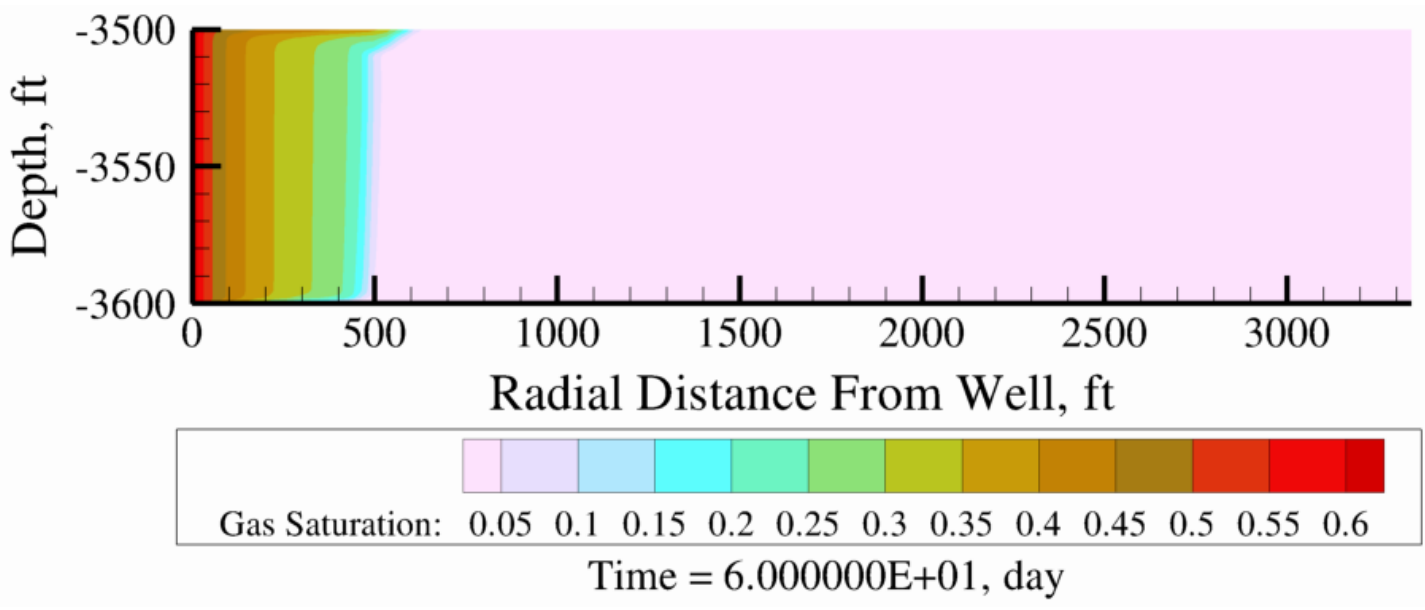

Figure 3.21. Gas-phase saturation after 60 days of $\mathrm{CO}_{2}$ injection 


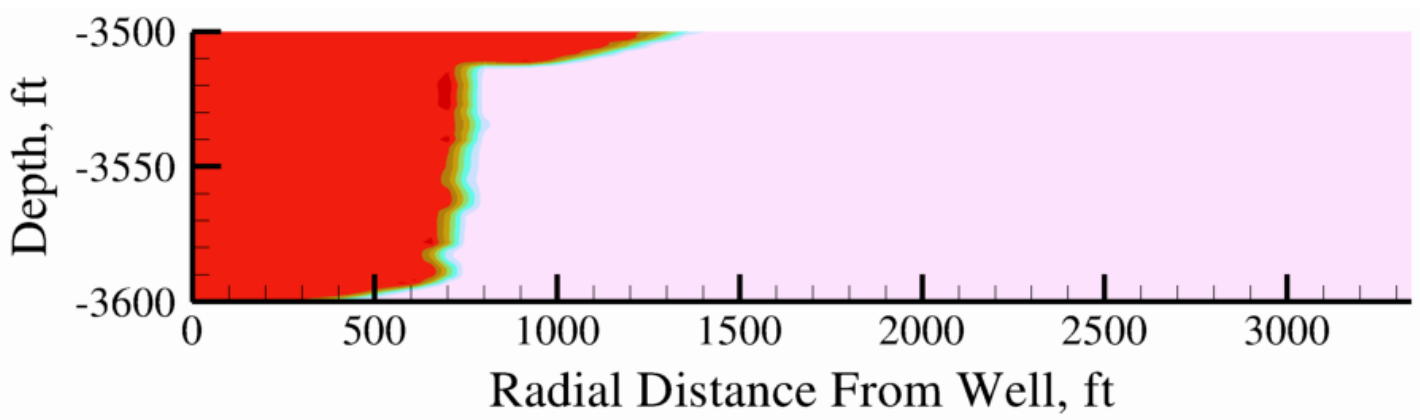

$\begin{array}{llllllll}\text { Aqueous CO2 Mass Fraction: } & 0.005 & 0.01 & 0.015 & 0.02 & 0.025 & 0.03 & 0.035\end{array}$

Time $=6.000000 \mathrm{E}+01$, day

Figure 3.22. Aqueous-phase $\mathrm{CO}_{2}$ mass fraction after 60 days of flue gas injection

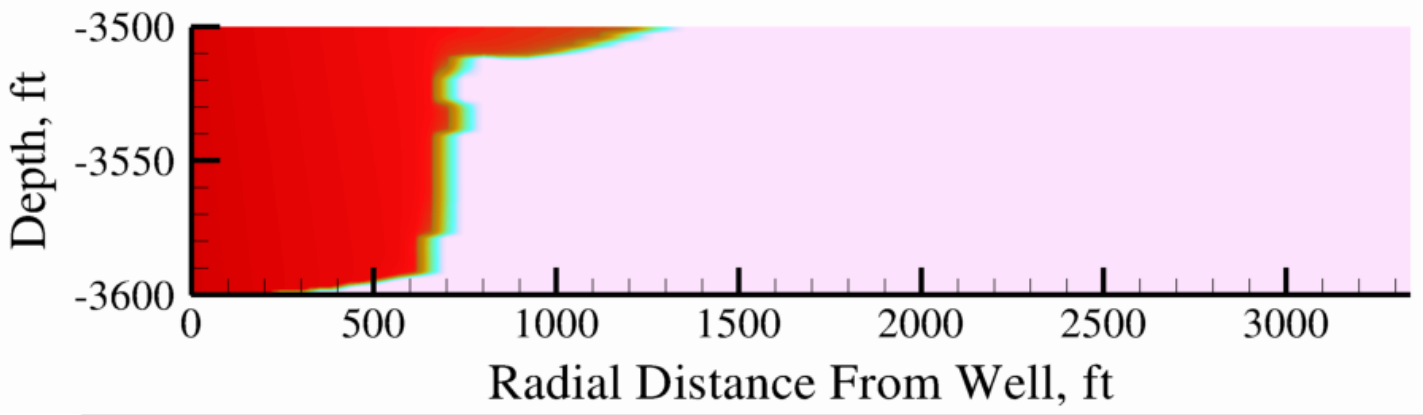

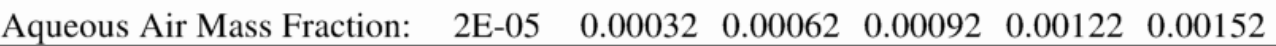

Time $=6.000000 \mathrm{E}+01$, day

Figure 3.23. Aqueous-phase air mass fraction after 60 days of flue gas injection

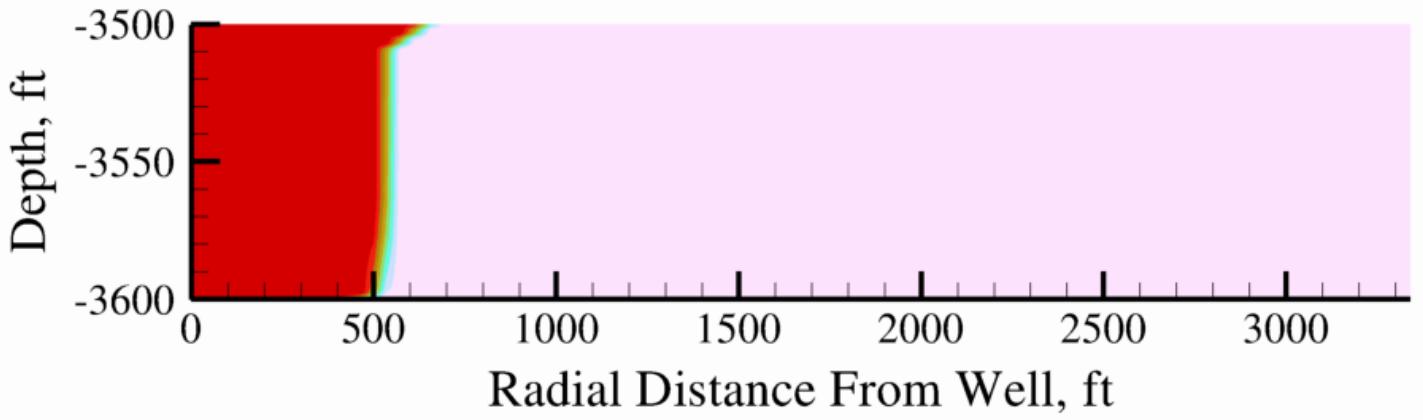

$\begin{array}{llllllll}\text { Aqueous CO2 Mass Fraction: } & 0.005 & 0.01 & 0.015 & 0.02 & 0.025 & 0.03 & 0.035\end{array}$

Time $=6.000000 \mathrm{E}+01$, day

Figure 3.24. Aqueous-phase $\mathrm{CO}_{2}$ mass fraction after 60 days of pure $\mathrm{CO}_{2}$ injection 


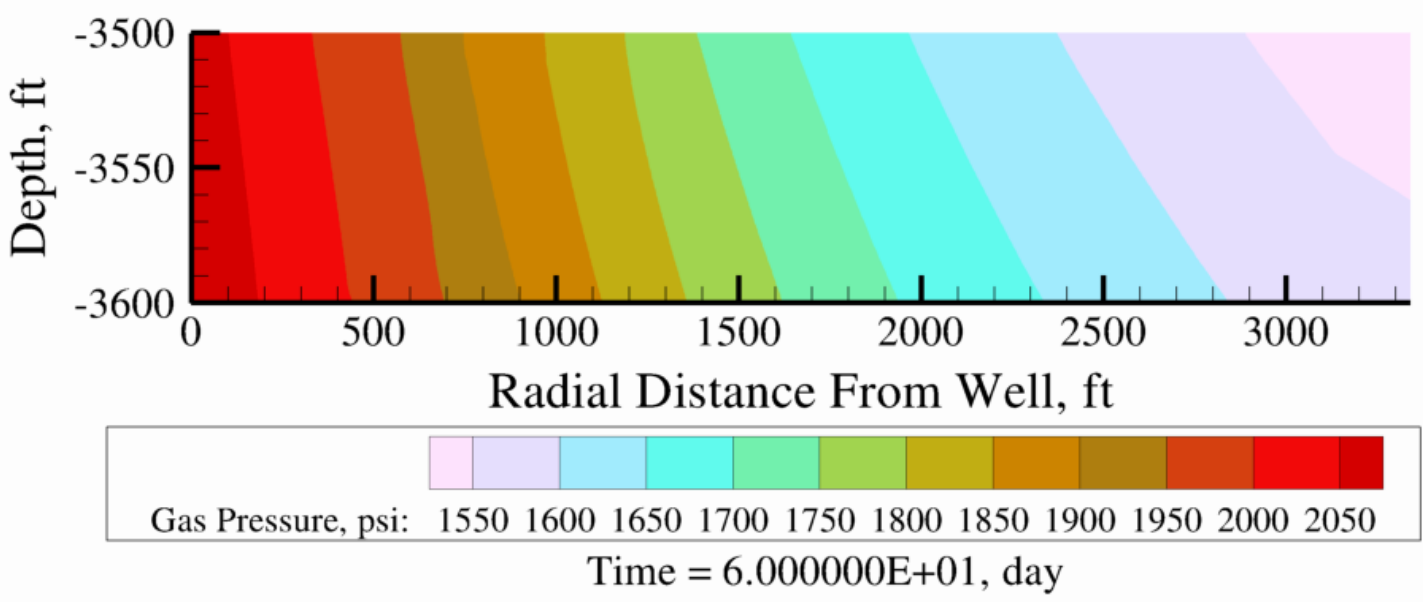

Figure 3.25. Gas-phase pressure after 60 days of flue gas injection

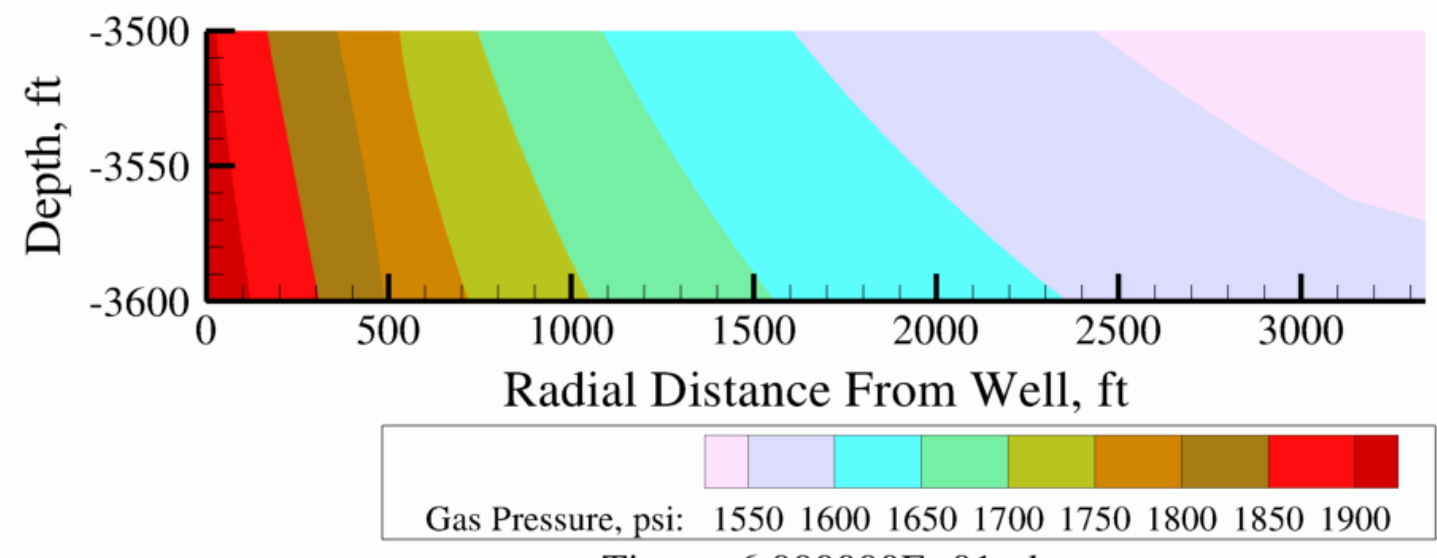

Time $=6.000000 \mathrm{E}+01$, day

Figure 3.26. Gas-phase pressure after 60 days of $\mathrm{CO}_{2}$ injection

\subsection{Considerations for Injection Well Placement}

\section{Depth Requirements}

The estimated phase behavior of the flue gas indicates that for the stream to trend towards a phase with supercritical properties, the pressures would need to be marginally greater (10-20\%) than that of pure $\mathrm{CO}_{2}$. The only way to increase the storage pressure is to inject into a deeper formation. Initial calculations show the minimum formation depth for flue gas may have to be several hundred meters deeper than the minimum depth needed for pure $\mathrm{CO}_{2}$.

For example, in the Midwestern United States, pure $\mathrm{CO}_{2}$ will be supercritical at an approximate depth of 800 meters. To create supercritical type conditions for the oxy-combustion flue gas in the Midwest, that depth would need to be extended to between 1200 and 1500 meters. 


\section{Density and Volume Changes}

Density is an important factor in effective storage. A less dense fluid will take up more volume per given mass and will reduce the storage capacity of a formation. This, in turn, will lead to more wells as each well will have to be abandoned with less mass stored.

Due to lower compressibility of some flue gas components, the density of the flue gas is much lower than the density of pure $\mathrm{CO}_{2}$. In addition, the flue gas cannot be compressed to a point where the density will approach that of $\mathrm{CO}_{2}$, even if deeper (hence warmer) storage formations are used. Preliminary calculations show that the density of the flue gas will be between $1 / 4$ and $1 / 2$ that of compressed $\mathrm{CO}_{2}$ (Figure 3.18). Consequently, the injected flue gas will take 2 to 4 times more pore space to sequester than the pure $\mathrm{CO}_{2}$.

A volume increase of 2 to 4 times will have significant effects on aspects of storage such as monitoring and permitting. The predicted plume size will be much larger, causing the area of review for permitting to be extended. If the goal of the monitoring plan is to track the areal extent of the plume, more monitoring points will be needed to image the larger area.

An injection well will have a finite lifetime over which injection can occur. Eventually, the near borehole formation will be saturated with injectate and the injection pressures required to continue to push injectate into the formation will exceed the fracture pressure. In this scenario, the well would need to be abandoned. For the lower density flue gas, the need for new wells would occur much sooner than with pure $\mathrm{CO}_{2}$. If specialized well materials are needed, building new wells would be a very large cost driver.

\section{Injectivity}

Injectivity is a function of both rock and fluid properties. Holding the rock properties constant, the effects of fluid properties can be determined. For a given pressure and temperature, the viscosity and density of the fluid are the main factors. Permeability is a measure of a fluid's ability to travel through a rock over a given time period. Furthermore, assuming two different fluids are traveling through the same rock, at a given temperature and pressure, the differences in the kinematic viscosities of the fluids will control the differences in permeability.

The ratio of kinematic viscosities for pure $\mathrm{CO}_{2}$ and flue gas, over the range of pressures and temperatures likely to been seen in a storage formation, is close to one. There is likely to be little change in injectivity of the flue gas from that of pure $\mathrm{CO}_{2}$.

\section{Other Geologic Constraints}

Many of the geologic constraints on sequestration of either flue gas or $\mathrm{CO}_{2}$ are site specific. Each potential site will need to be evaluated for sequestration potential; however, some of the potential geologic pitfalls are presented here.

As mentioned above, for the flue gas to remain in supercritical state, it must be injected into formations with higher pressure than would be needed if the gas were pure $\mathrm{CO}_{2}$. However, the injectivity for the two gasses is comparable. In a typical sedimentary column, the porosity and permeability are preserved over a certain depth interval, and then there a significant decline in these properties due to compaction and cementation. The depth at which this occurs is site specific. In essence, the addition of the flue gas in a given geologic regime lowers the upper 
bound but does not lower the bottom. In essence, there is effectively less rock to choose from for potential storage of flue gas $\mathrm{CO}_{2}$.

Another possible constraint is the structural geology in the area of interest. In an unbounded system where displaced brine can continue to travel out of the formation allows the pressure increase to dissipate over time. Nevertheless, at many sites, an unbounded system is probably unrealistic. A sealing fault system cutting the injection formation may allow for the pressures to build up as the displaced brine and the injectate velocities are reduced in the fault zone. Other features, such as regional dip or anticlines may also allow the formation pressures to increase.

Effects such as these will be studied as site-specific scenarios are examined.

\section{Geochemical Interactions}

Brines cannot contain as much dissolved gas as pure water at the same temperature and pressure because high concentrations of dissolved salts (up to 400,000 parts-per-million) in brines inhibit solubilization of gases and other non-electrolytes. This phenomenon is often referred to as the "salting out" effect. On the other hand, pressures typical of deep saline reservoirs favor dissolution of $\mathrm{CO}_{2}$ up to 5-10\%. For example, the hydrostatic head at $800 \mathrm{~m}$ is $1140 \mathrm{psia}$. Once gas phase $\mathrm{CO}_{2}$ is converted to the dissolved (aqueous) form, hydrolysis reactions convert the $\mathrm{CO}_{2}$ to carbonic acid. In the absence of natural buffers, such as carbonate minerals, the brine will become mildly acidic ( $\mathrm{pH} \sim 4.5)$.

Geochemical modeling with PHREEQC ${ }^{3}$ was used to understand the interaction between the injectate (consisting of $\mathrm{CO}_{2}$ ), the brine, and rock minerals, including carbonates (dolomite and calcite). Dissolution of carbonate minerals enhances the solubility of $\mathrm{CO}_{2}$ due to the following chemical reaction:

Dolomite $+2 \mathrm{CO}_{2}+2 \mathrm{H}_{2} \mathrm{O} \leftrightarrow 4 \mathrm{HCO}_{3}^{-}+\mathrm{Ca}^{+2}+\mathrm{Mg}^{+2}$

As indicated in Equation 3.1, two moles of $\mathrm{CO}_{2}$ are converted to aqueous bicarbonate for each mole of dolomite dissolved from the formation matrix. This geochemical reaction creates "solubility storage" within the formation and represents an additional mechanism for enhancing long-term sequestration of $\mathrm{CO}_{2}$. Residual formation water saturation also provides an additional storage mechanism for $\mathrm{CO}_{2}$ within the reservoir horizon.

However, if the brine contains high concentrations of sulfate, then precipitation of gypsum may take place by the following chemical reaction:

$$
\text { Dolomite }+2 \mathrm{CO}_{2}+\mathrm{SO}_{4}^{-2}+4 \mathrm{H}_{2} \mathrm{O} \leftrightarrow \mathrm{Gypsum}^{-4}+\mathrm{HCO}_{3}^{-}+\mathrm{Mg}^{+2}
$$

Equation 3.2 describes an equilibrium condition involving two solid phases, dolomite and gypsum (or anhydrite at temperatures above $55^{\circ} \mathrm{C}$ ). Modeling results (Figure 3.27) indicate that dolomite dissolution is larger on a molar (and volumetric) basis than gypsum precipitation. If

${ }^{3}$ http://wwwbrr.cr.usgs.gov/projects/GWC_coupled/phreeqc/ 
that were the case, $\mathrm{CO}_{2}$ injection might increase the effective porosity of the formation and enhance injectivity and storage capacity within the host reservoir. On the other hand, transient effects such as partial dissolution of dolomite followed by displacement and mobilization of mineral fragments could fill pore spaces, thereby reducing formation permeability. The likelihood and consequences of these short-term gypsum precipitation effects should be assessed experimentally with core flood tests to ascertain the risks of clogging prior to an actual demonstration in the field.

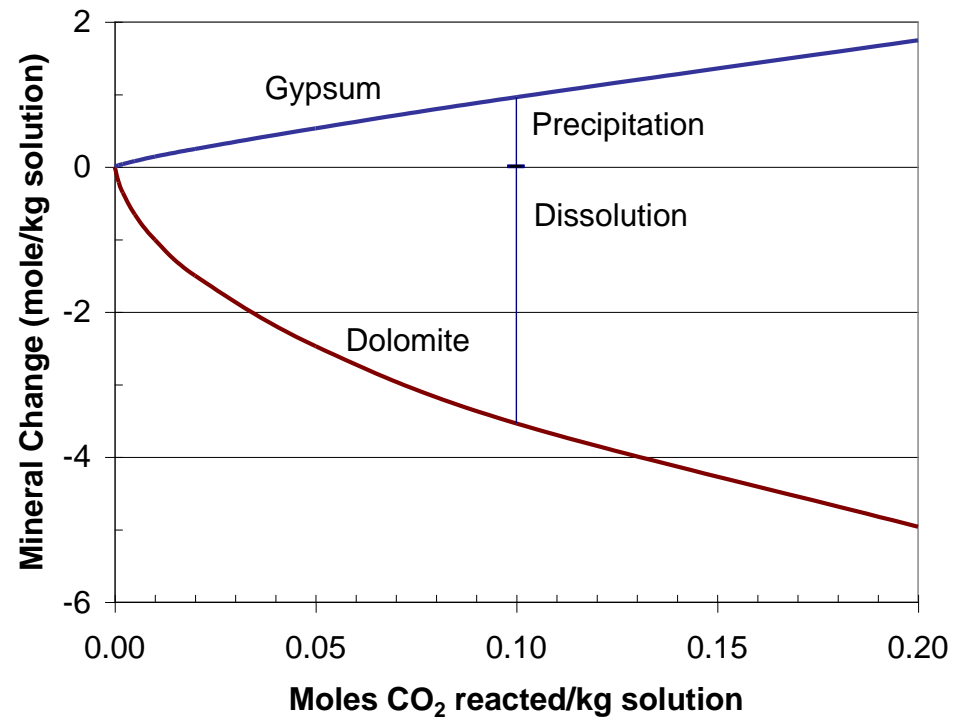

Figure 3.27. Geochemical modeling results for Equation 3.2

In addition, co-sequestration of $\mathrm{CO}_{2}$ and $\mathrm{SO}_{2}$ appears to be technically feasible in many, if not most deep saline reservoirs. Injection of up to, say, $1 \% \mathrm{SO}_{2}$ in a $\mathrm{CO}_{2}$ stream, does not appear to favor side reactions that would reduce the usable lifetime of the reservoir. However, models would need to be run for specific formations and injectate compositions to ensure that no undesirable precipitation reactions can take place.

\subsubsection{Pilot-scale Evaluation}

Pilot-scale evaluation focused on Cyclone boilers because B\&W had already demonstrated the oxy-firing technology for wall-fired application at $30 \mathrm{MW}_{\text {th }}$ for a wide range of coals (See Section 3.1.6). Pilot scale testing of oxy-combustion in a Cyclone furnace was performed in the SBS-II facility described above. Baseline tests with air were also performed, and the data gathered was used to determine differences between air and oxy-firing in terms of emissions, and boiler heat absorption. These results are described below.

\subsubsection{1. $\quad \mathrm{NO}_{\mathrm{x}}$ Emissions and Carbon Conversion}

Typically, combustion modifications to control $\mathrm{NO}_{\mathrm{X}}$ suffer from a tradeoff between conditions conducive to complete combustion of carbon, and conditions favorable for $\mathrm{NO}_{\mathrm{X}}$ reduction. Thus it is advantageous to discuss these topics together. Carbon conversion is quantified by measured 
$\mathrm{CO}$ emissions and carbon remaining in flyash, estimated by the weight loss of flyash samples on ignition (LOI). In this section $\mathrm{NO}_{\mathrm{X}}$ and $\mathrm{CO}$ emissions between tests are compared using units of $\mathrm{lb}$ of the pollutant per MBtu to eliminate the influence of varied recycled flue gas flow on the comparison. Concentration measurements such as ppm do not allow an objective comparison of emissions, although they are important to understanding chemical reaction rates in various processes.

In the pilot scale data the term "emissions" refers to pollutants directed to the stack after the extraction of gas used in flue gas recycle. In a CCS plant this stream would be directed to the CPU island. Pollutants in the recycled flue gas are not included in emissions data.

Figure 3.28 presents the $\mathrm{NO}_{\mathrm{X}}$ emissions data with separate trend lines for air and oxy-firing as a function of the stoichiometry in the Cyclone. As the Cyclone stoichiometric ratio is lowered (staged combustion) the amount of $\mathrm{NO}_{\mathrm{X}}$ decreases, consistent with expectations. However, at all stoichiometries, oxy-firing emits less $\mathrm{NO}_{\mathrm{X}}$ than air firing. In addition, as the Cyclone stoichiometric ratio is increased, the air fired cases increase in $\mathrm{NO}_{\mathrm{X}}$ at a faster rate than oxyfiring. This reduced sensitivity to stoichiometric ratio under oxy-firing conditions may be due to a number of reasons including the lack of $\mathrm{N}_{2}$ available for thermal and prompt $\mathrm{NO}_{\mathrm{X}}$ formation, and the increased rates of recycled $\mathrm{NO}_{X}$ reduction as the $\mathrm{NO}_{X}$ concentration in the recycled flue gas increases. Note that the stoichiometry values used in the plots are derived from the analysis described in Section 2.1.1.10 that includes the effects of infiltrated air.

The bituminous coal produced the most $\mathrm{NO}_{\mathrm{X}}$ at a given stoichiometry under both air and oxyfiring conditions, whereas the lower rank coals were comparable to each other. This is consistent with the coals' nitrogen content with the higher rank coal having roughly twice the nitrogen content of the other two.

In some tests with subbituminous coal, difficulties were experienced in keeping the flame inside the Cyclone. This was detected by observing the data for Cyclone heat absorption, which was low when the flame was not retained. When the flame was successfully retained in the Cyclone the $\mathrm{NO}_{\mathrm{X}}$ analyzer experienced an operational problem, hence the error bar on the data point in Figure 3.28. The error bar was sized using the available data for air combustion with the flame in and out of the Cyclone, and led to the conclusion that with the flame inside the Cyclone, $\mathrm{NO}_{\mathrm{X}}$ emissions for warm and cold recycle conditions with this coal are probably similar. 

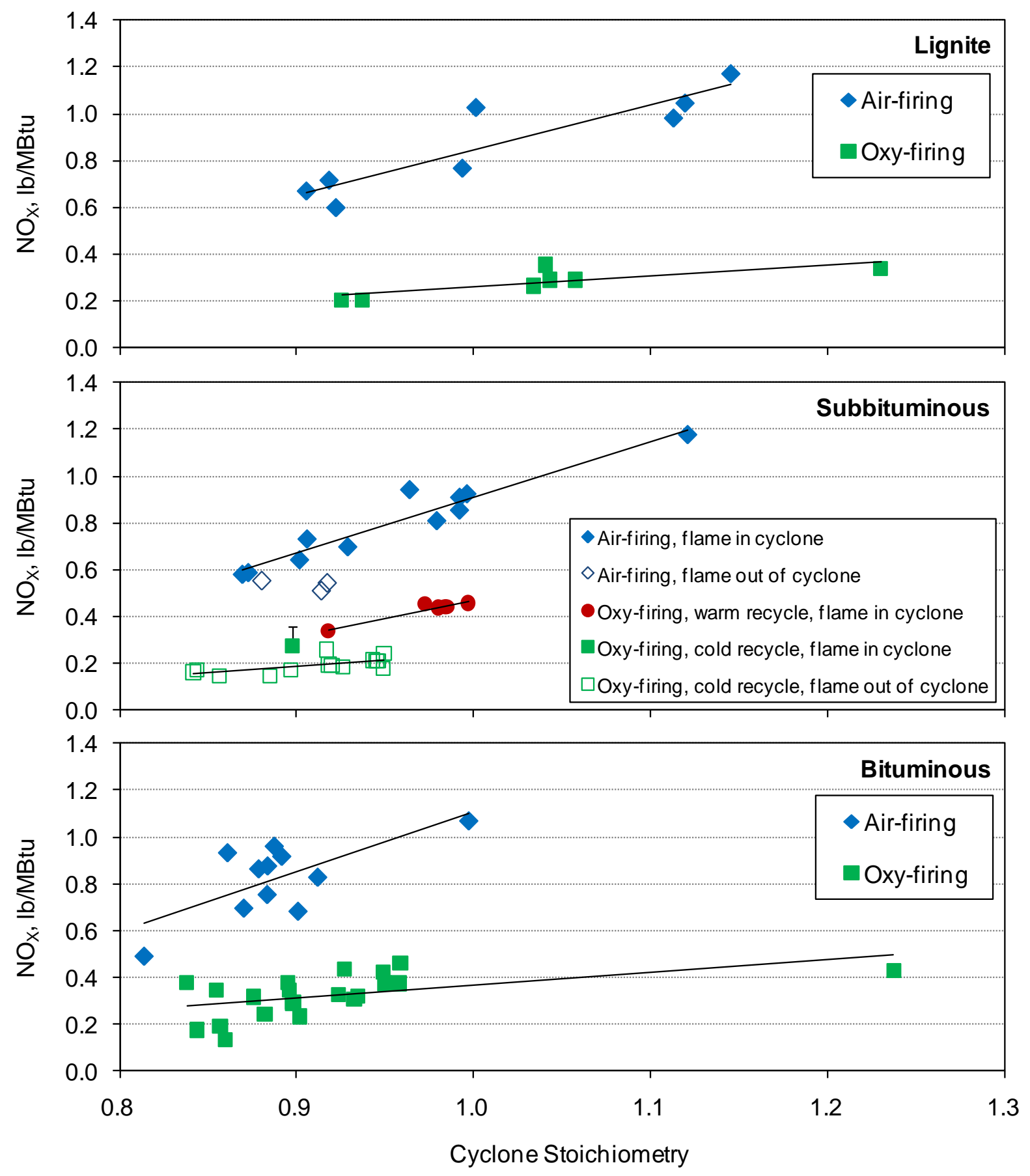

Figure 3.28 Comparison of $\mathrm{NO}_{\mathrm{x}}$ emissions between air and oxy-firing for three coals fired

Figure 3.29 shows the expected reduction in $\mathrm{NO}_{\mathrm{X}}$ emissions when changing from air to oxyfiring for the three coals. This figure is based on the trend lines in Figure 3.28 at a Cyclone stoichiometric ratio of 0.9 . The reduction in $\mathrm{NO}_{\mathrm{X}}$ ranges from $53-67 \%$, and there is no clear trend with coal rank. Over $60 \% \mathrm{NO}_{\mathrm{X}}$ reductions were achieved with bituminous and lignite coals. The $\mathrm{NO}_{\mathrm{X}}$ reduction with the subbituminous coal was lower $(53 \%)$ which is caused by lower air-firing 
$\mathrm{NO}_{\mathrm{X}}$ emissions with this coal. As expected, air-firing $\mathrm{NO}_{\mathrm{X}}$ emissions with subbituminous coal was lower than other two coals since the subbituminous coal fuel-nitrogen content was very low. There may be competing effects or multiple factors that determine the $\mathrm{NO}_{\mathrm{X}}$ reduction, including volatile yield and nitrogen content.

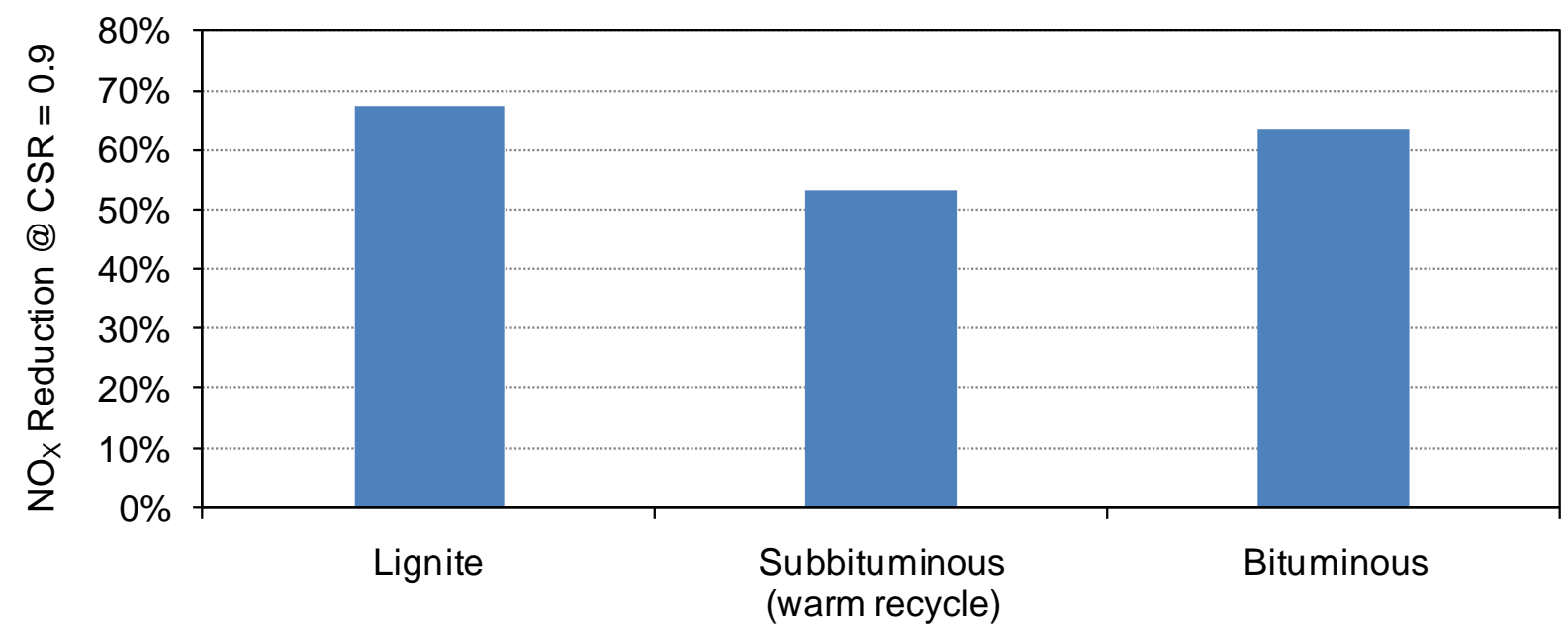

Figure 3.29 Expected reductions in $\mathrm{NO}_{\mathrm{X}}$ emissions when changing from air to oxy-firing for the three coals based on trend lines at a Cyclone stoichiometric ratio of 0.9

The data presented above are in terms of emitted $\mathrm{NO}_{\mathrm{X}}$, which is lower in oxy-firing. Counter to intuition developed from air firing experience, these lower emissions are associated with a higher concentration, as most of the flue gas flow is recycled to the boiler. $\mathrm{NO}_{\mathrm{X}}$ has the opportunity in the boiler to be reduced in the combustion zone to $\mathrm{N}_{2}$, and thus the enrichment of $\mathrm{NO}_{\mathrm{X}}$ in the flue gas during oxy-firing is not as great as experienced for other species (such as $\mathrm{SO}_{2}$ ) that are not amenable to control by combustion. As shown by the lignite test results in Figure 3.30, $\mathrm{SO}_{2}$ concentrations may increase by a factor of 3-5 in oxy-firing (relative to air firing) where as $\mathrm{NO}_{\mathrm{X}}$ in the same tests only increased in concentration by a factor of 2 or less.

An example of $\mathrm{CO}$ emissions in terms of concentration at the convection pass exit is shown in Figure 3.31. Overall the concentration was slightly higher for oxy-firing relative to air at the same Cyclone stoichiometry, but like $\mathrm{NO}_{\mathrm{X}}, \mathrm{CO}$ is easily converted to other species (e.g. $\left.\mathrm{CO}_{2}\right)$ on recycling and does not show the high levels of enrichment seen with $\mathrm{SO}_{2}$ during oxy-firing.

Figure 3.31 also shows an increase in $\mathrm{CO}$ with deeper staging (lower Cyclone stoichiometry), as would be expected. Also seen are very high values of $\mathrm{CO}$ at the lower stoichiometries. These are attributable to fluctuations in coal flow that occurred in a few tests. The $\mathrm{CO}$ data over time for these tests show generally low values with occasional sharp peaks that raise the average $\mathrm{CO}$ reported. For example, test "Warm Rec-PRB Air Test $2 \mathrm{a}$ " has an average CO concentration of $428 \mathrm{ppm}$, with standard deviation of 707, minimum level 10, and maximum corresponding to the analyzer range limit (2073). 


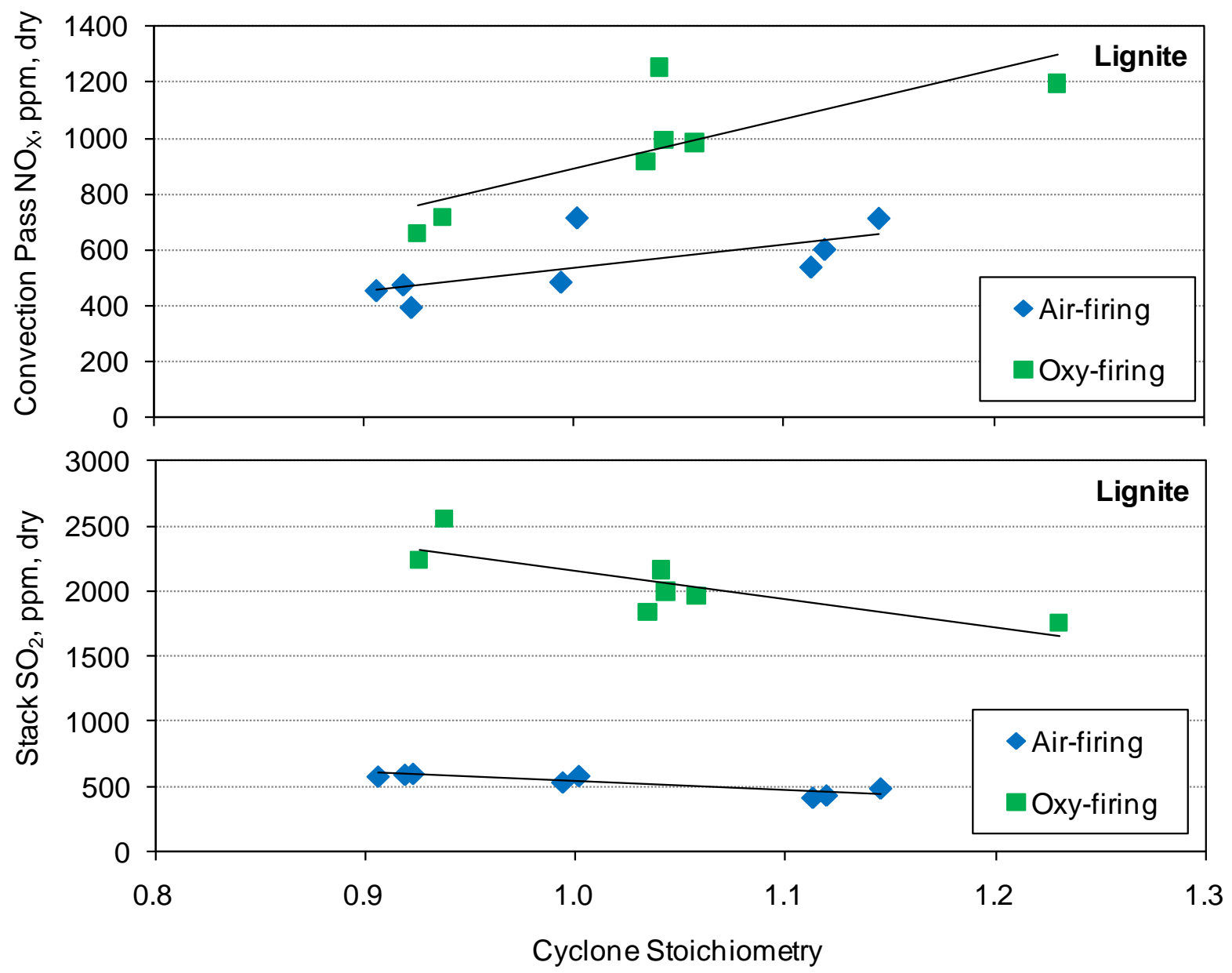

Figure 3.30 Data showing the enrichment of pollutants $\mathrm{NO}_{\mathrm{X}}$ and $\mathrm{SO}_{2}$ by flue gas recycling for the lignite tests 


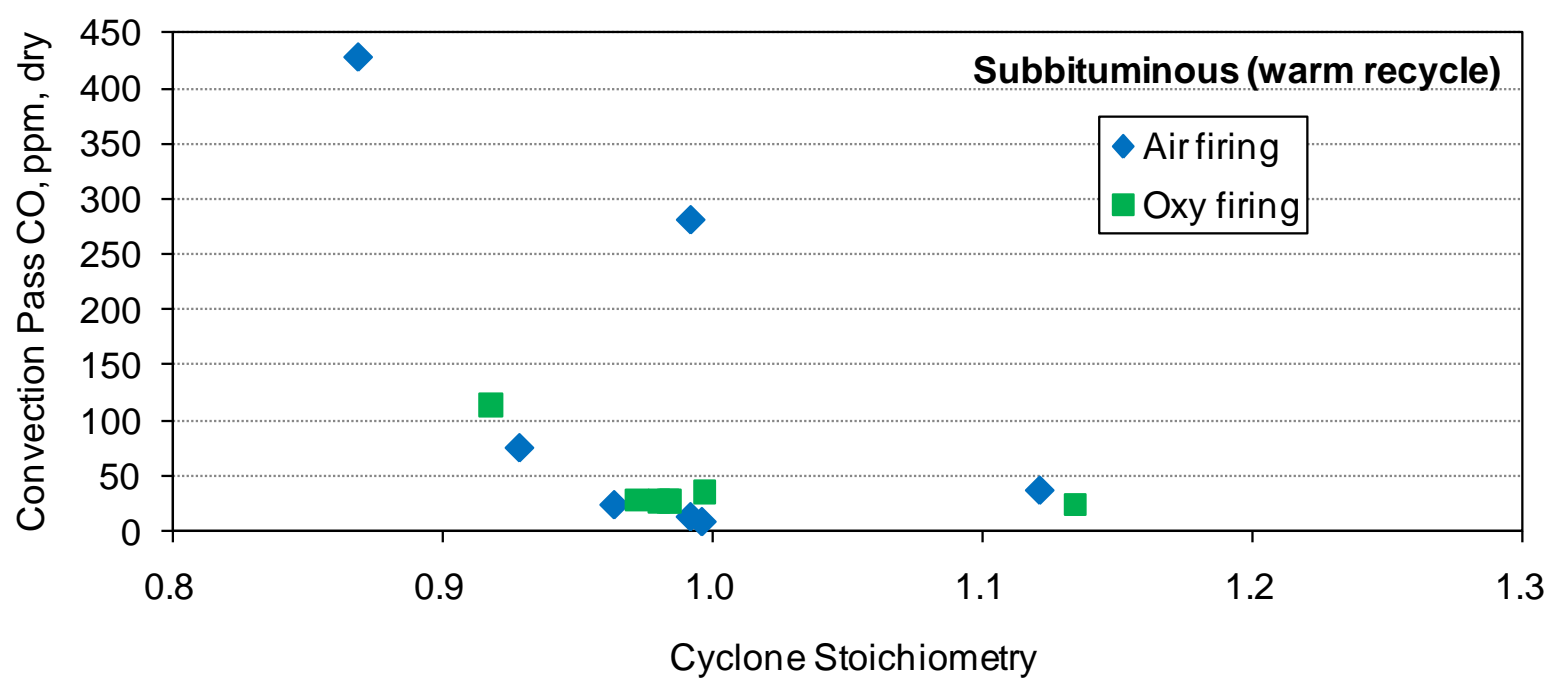

Figure 3.31 Example $\mathrm{CO}$ concentration data at the convection pass exit: Subbituminous coal for air-firing and warm recycle oxy-firing

As only a fraction (29-41\% in these tests) of the flue gas is directed to the stack, the emitted CO (lb/MBtu) is on average lower (by $62 \%$ averaged over all tests) in oxy-firing than air-firing, as demonstrated by the data in Figure 3.32. For the subbituminous coal no significant difference is observed between cold and warm recycle conditions.

Figure 3.33 presents the measured loss on ignition (LOI) of fly ash samples for all tests. Two trends can be easily observed: first, LOI increases with the coal rank, consistent with known trends in char reactivity with rank; and second, deeper staging tends to increase LOI. Overall it appears that the LOI measured in oxy-firing is slightly lower than an equivalent air-firing condition, with the difference increasing with the coal rank. While scatter in the data is present, LOI measurements for cold and warm recycle oxy-firing are comparable.

In summary, despite higher concentrations of $\mathrm{CO}$ and $\mathrm{NO}_{\mathrm{X}}$ in oxy-firing flue gas, the recycling of the majority of flue gas results in lower emitted quantities and the increased opportunity to convert these pollutants to desired products in the furnace. A comparison of emitted levels of these pollutants for optimum test cases is presented in Figure 3.34, along with LOI data which is also slightly lower under oxy-firing conditions. For this comparison, the optimum test cases were selected based on good slag flow in the Cyclone combined with acceptable emissions and heat transfer performance. These data indicate that for $\mathrm{NO}_{\mathrm{X}}$ emissions and carbon utilization, oxyfiring is superior to air-firing. 

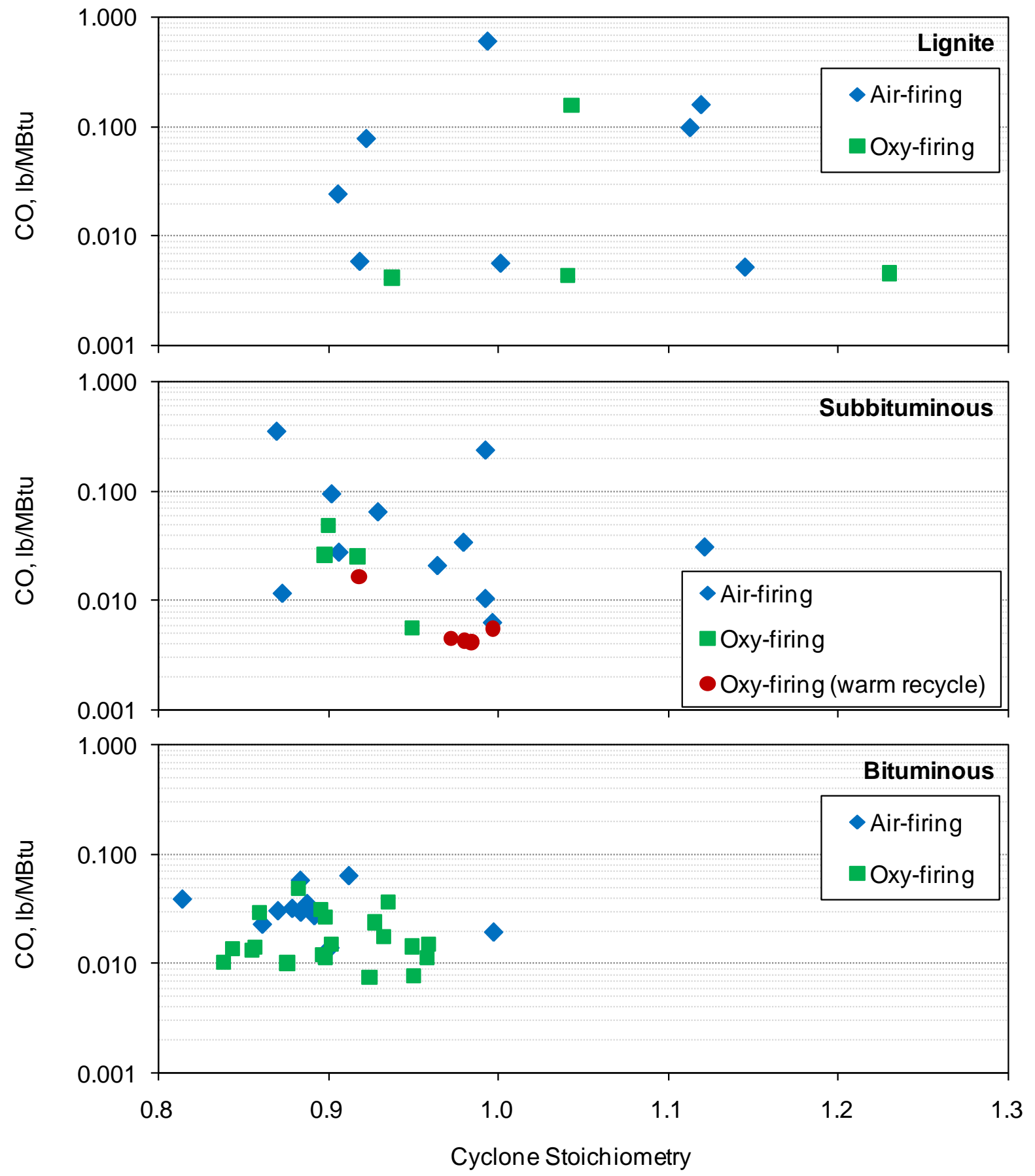

Figure 3.32 CO emissions data for all tests as a function of Cyclone stoichiometry 

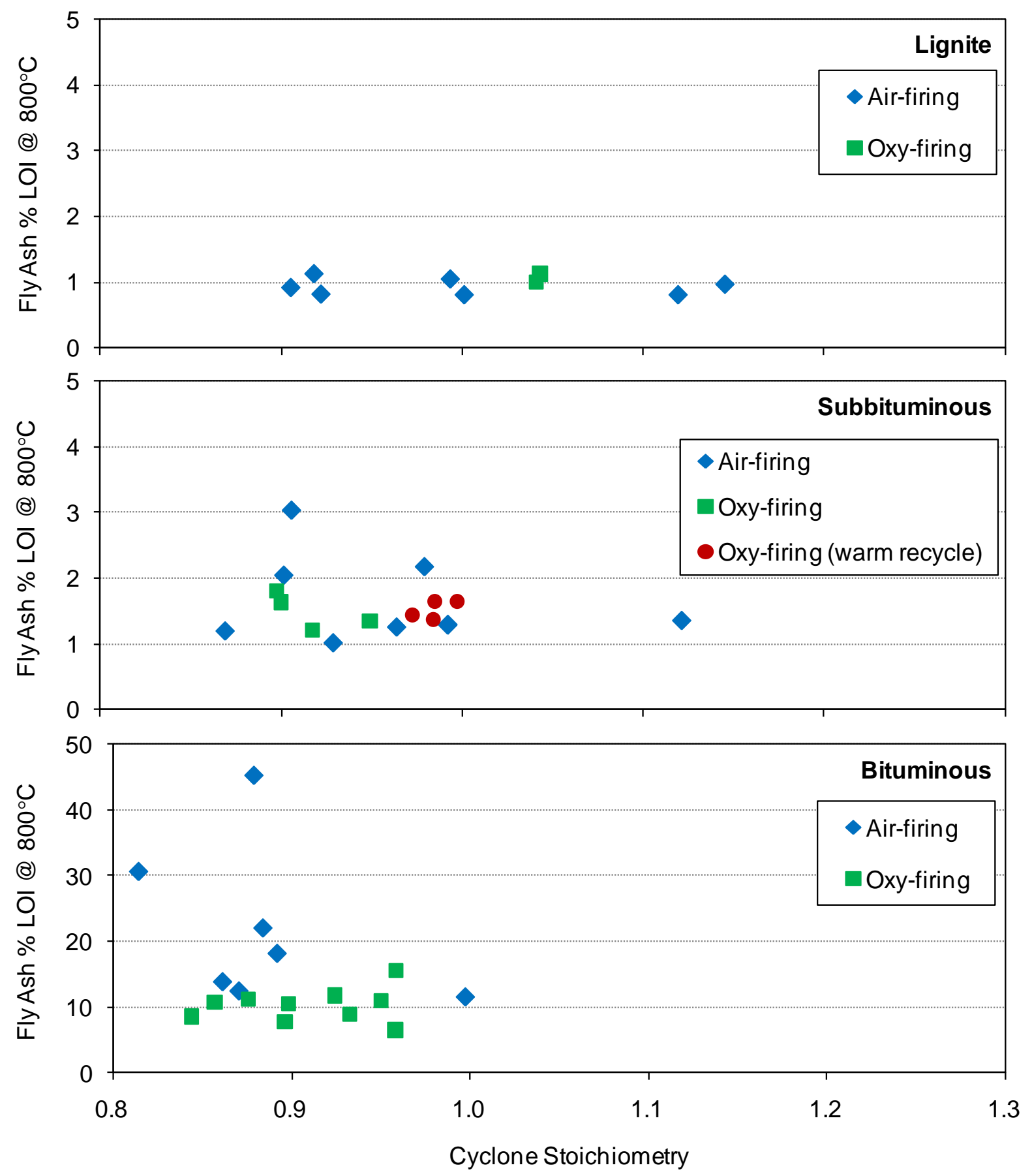

Figure 3.33 LOI data for all tests as a function of Cyclone stoichiometry 

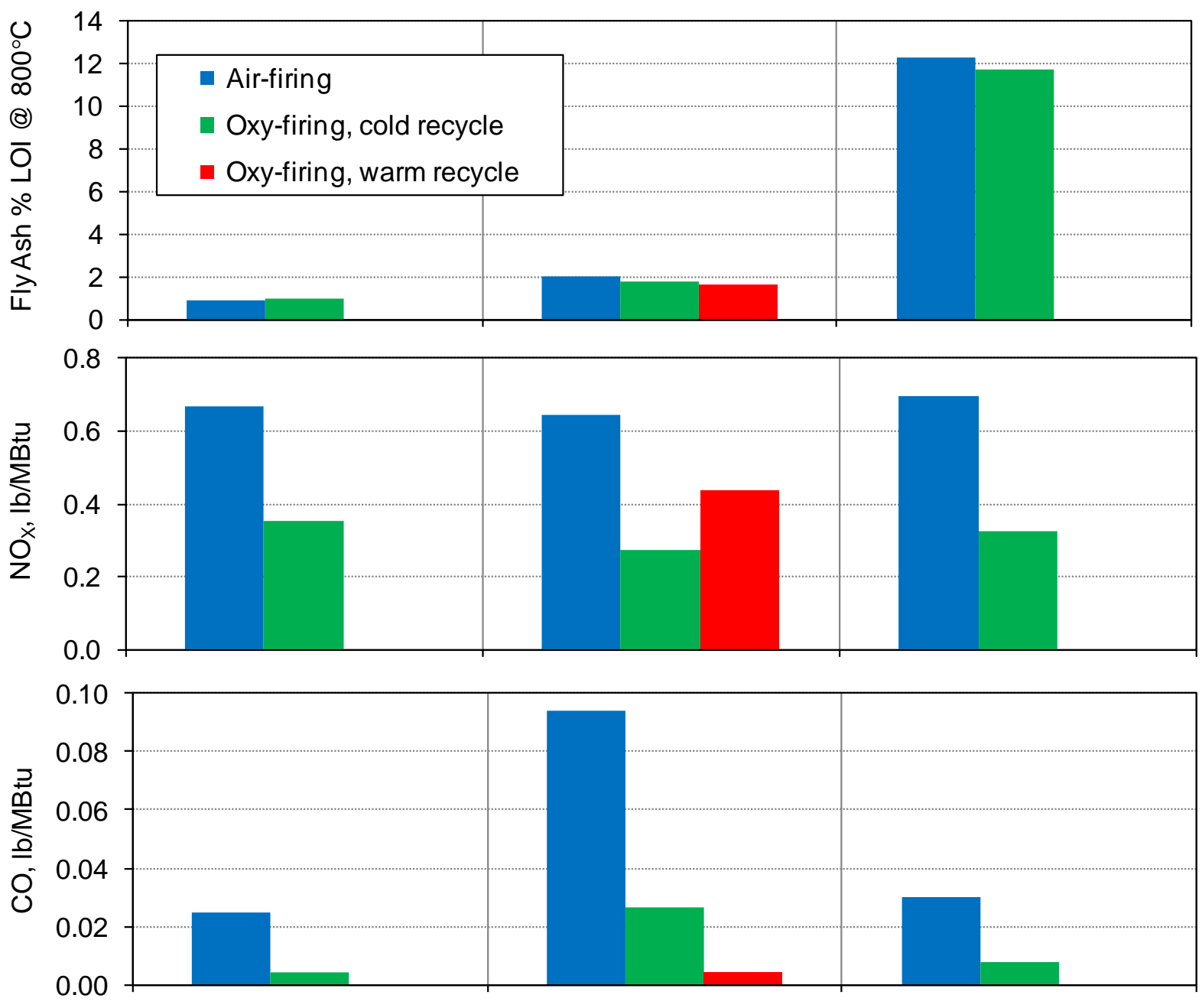

Lignite Subbituminous

Bituminous

Figure 3.34 Comparison of LOI, and emitted $\mathrm{NO}_{\mathrm{X}}$ and $\mathrm{CO}$ for optimum operating conditions

\subsubsection{2. $\quad \underline{\mathrm{SO}}_{2}$ Emissions and Flue Gas Moisture}

As mentioned in the discussion of $\mathrm{NO}_{\mathrm{X}}$ emissions, $\mathrm{SO}_{2}$ in an oxy-firing system is enriched as flue gas is recycled. For the same optimum combustion cases presented in Figure 3.34, flue gas $\mathrm{SO}_{2}$ and moisture concentrations are presented in Figure 3.35 and Figure 3.36. For the lignite measurements in the right column of Figure 3.35, the $\mathrm{SO}_{2}$ concentration in oxy-firing is 3.6 times higher than in air, and for the bituminous coal (left column) the increase is by a factor of 1.5. This difference illustrates the role of flue gas desulfurization in the recycle loop to limit the enrichment of $\mathrm{SO}_{2}$. Enrichment of water in oxy-firing for the lignite and bituminous cases is 1.6 and 1.7 times respectively, comparable because both tests made use of the condensing heat exchanger. 


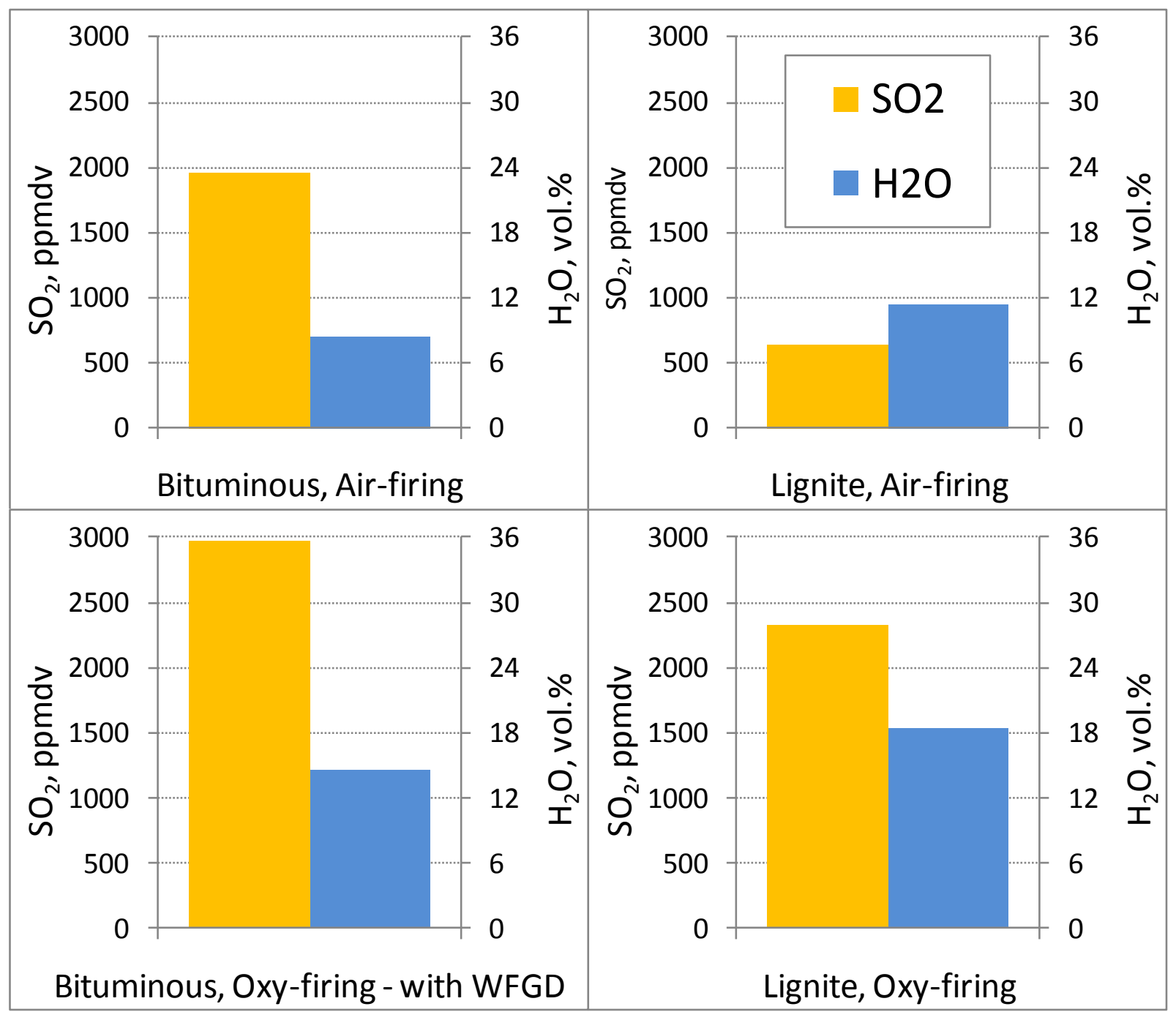

Figure 3.35 Comparison of flue gas $\mathrm{SO}_{2}$ and moisture concentrations (convection pass exit) between air and oxy-firing for bituminous coal and lignite

Figure 3.36 indicates the effect of removing the condensing heat exchanger from the system. In the cold recycle test results (left column) the moisture is enriched in oxy-firing by 1.8 times, but in warm recycle tests (right column) the moisture is increased by a factor of 3 . Note that $\mathrm{SO}_{2}$ in both cases is significantly enriched (4.5 times in cold recycle and 3.8 times in warm recycle). The $\mathrm{SO}_{2}$ data are presented on a dry basis, removing the influence of the water on the $\mathrm{SO}_{2}$ comparison. Note that as previously mentioned, the subbituminous coal used in the warm recycle tests had lower sulfur content than used in the cold recycle subbituminous tests.

The increased moisture levels in warm recycle may have several effects including altered oxidant properties (heat capacity, density etc.) and increased importance of char gasification by $\mathrm{H}_{2} \mathrm{O}$ in the furnace. In this work the similarities noted above in LOI, and CO emissions, and that the oxygen concentration required in the Cyclone secondary oxidizer was not higher under warm recycle conditions for satisfactory operation, it appears that these differences may not be important from a furnace operating standpoint. There may however be a need to consider the 
increased potential for condensation of moisture with dissolved acid gases in the ductwork to prevent corrosion.

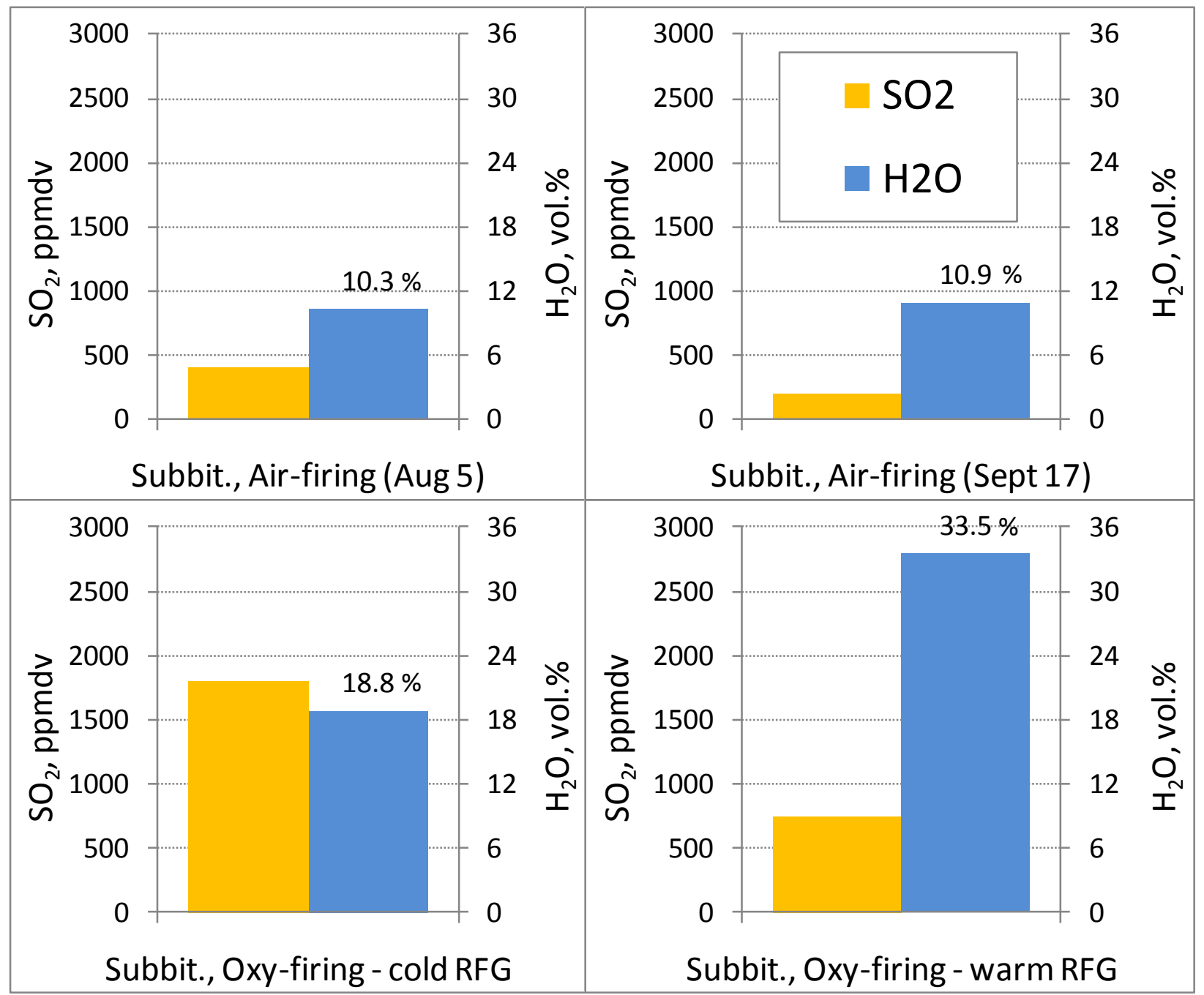

Figure 3.36 Comparison of flue gas $\mathrm{SO}_{2}$ and moisture concentrations (convection pass exit) between air and oxy-firing for subbituminous coal (warm and cold recycle)

As noted for $\mathrm{NO}_{\mathrm{X}}$ and $\mathrm{CO}$, the quantity of $\mathrm{SO}_{2}$ emitted is actually lower in oxy-firing despite the higher concentrations in the flue gas. Average test data are presented in Figure 3.37. The greatest reduction in $\mathrm{SO}_{2}$ occurs for the bituminous coal, which is to be expected because the recycled $\mathrm{SO}_{2}$ will have multiple passes through the wet scrubber and therefore increased capture potential. The reduction observed for the other coals was investigated further by performing a sulfur balance calculation where predicted levels of $\mathrm{SO}_{2}$ in the flue gas where compared with those actually measured. $\mathrm{SO}_{2}$ at the furnace exit was predicted by assuming $\mathrm{SO}_{2}$ measured in the recycled flue gas simply passed through the boiler and $100 \%$ of fuel sulfur (as-fired, after pyrite removal in the pulverizer) was oxidized to $\mathrm{SO}_{2}$. Results of this analysis are shown in Table 3.16. Measurements of $\mathrm{SO}_{3}$ were not taken into account and are discussed in Section 3.1.4.3. 


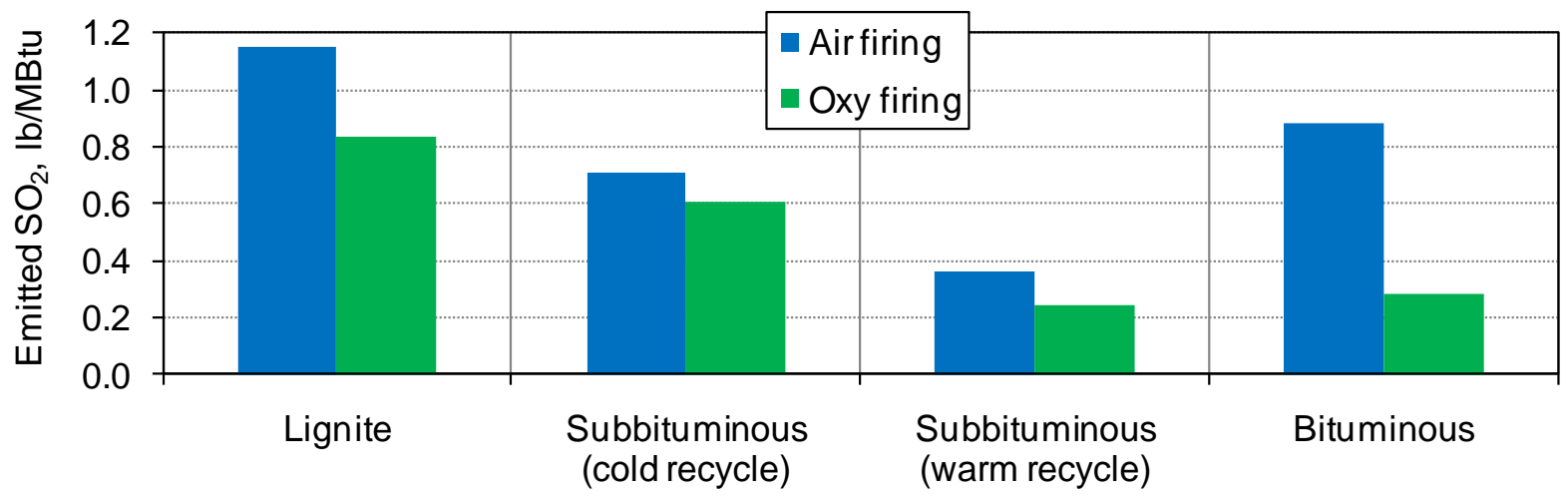

Figure 3.37 Average $\mathrm{SO}_{2}$ emitted between air and oxy-firing for each coal

Referring to Table 3.16, for all cases the measured $\mathrm{SO}_{2}$ after the baghouse was lower than the predicted level of $\mathrm{SO}_{2}$ after the furnace. The difference is greater in the oxy-fired cases than in air-firing for all coals. No significant trends in the data with variables such as temperature were found. The differences between air and oxy-firing on the same day with the same coal require further testing to explain.

\begin{tabular}{|c|c|c|c|c|c|c|c|c|}
\hline \multirow{2}{*}{\begin{tabular}{r|} 
Coal: \\
Firing Mode:
\end{tabular}} & \multicolumn{2}{|c|}{ Bituminous } & \multicolumn{2}{|c|}{ PRB 1st Shipment } & \multicolumn{2}{|c|}{ Lignite } & \multicolumn{2}{|c|}{ PRB 2nd Shipment } \\
\hline & \begin{tabular}{|c|} 
Air, \\
with WFGD
\end{tabular} & $\begin{array}{c}\text { Oxy, } \\
\text { with WFGD }\end{array}$ & Air & Oxy & Air & Oxy & Air & $\begin{array}{c}\text { Oxy } \\
\text { (warm recycle) }\end{array}$ \\
\hline Date: & $7 / 30 / 2009$ & $7 / 30 / 2009$ & $8 / 5 / 2009$ & $8 / 25 / 2009$ & $9 / 3 / 2009$ & $9 / 3 / 2009$ & 9/17/2009 & $9 / 17 / 2009$ \\
\hline Time: & $11: 23$ & $17: 16$ & $10: 08$ & $14: 53$ & $10: 21$ & $16: 37$ & $10: 02$ & 18:02 \\
\hline As-fired Fuel Sulfur (wt \%)* & 2.70 & 2.70 & 0.39 & 0.39 & 0.66 & 0.66 & 0.26 & 0.26 \\
\hline As-fired Fuel HHV (Btu/lb)* & 13201 & 13201 & 9627 & 9627 & 8649 & 8649 & 9709 & 9709 \\
\hline $\begin{array}{l}\text { Stack } \mathrm{SO}_{2} \text { (Air Firing) } \\
\left(\text { ppmdv, @ 3\% } \mathrm{O}_{2}\right)\end{array}$ & 140 & & 403 & & 643 & & 194 & \\
\hline $\begin{array}{l}\text { Recycled Flue Gas } \mathrm{SO}_{2} \text { (Oxy Firing) } \\
\left(\mathrm{ppmdv}, @ 3 \% \mathrm{O}_{2} \text { ) }\right.\end{array}$ & & 492 & & 1689 & & 2416 & & 773 \\
\hline $\begin{array}{l}\text { Expected } \mathrm{SO}_{2} \text { After Conv. Pass } \\
{\left[\left(\text { Fuel S } \rightarrow \mathrm{SO}_{2}\right)+\mathrm{RFG} \mathrm{SO}_{2}\right]} \\
\left(\text { ppmdv, @ } 3 \% \mathrm{O}_{2}\right)\end{array}$ & 2182 & 3460 & 410 & 1785 & 829 & 2774 & 280 & 1007 \\
\hline $\begin{array}{l}\text { Measured } \mathrm{SO}_{2} \text { After Baghouse } \\
\left(\mathrm{ppmdv}, @ 3 \% \mathrm{O}_{2}\right)\end{array}$ & 1963 & 3126 & 403 & 1689 & 642 & 2416 & 194 & 773 \\
\hline $\begin{array}{l}\text { Expected } \mathrm{SO}_{2}-\text { Measured } \mathrm{SO}_{2} \\
\left(\mathrm{ppmdv}, @ 3 \% \mathrm{O}_{2}\right)\end{array}$ & 219 & 335 & 7 & 96 & 186 & 357 & 86 & 234 \\
\hline
\end{tabular}

Table 3.16 Comparison of predicted and measured $\mathrm{SO}_{2}$ levels in the flue gas

Others (17) have reported increased sulfur capture with ash under oxy-firing conditions. This has yet to be fully investigated, but it is safe to say that the recycling of $\mathrm{SO}_{2}$ gives increased opportunity to a given $\mathrm{SO}_{2}$ molecule to be scrubbed in the recycle loop by either flue gas 
desulfurization or a suitable flyash. Increased $\mathrm{SO}_{2}$ and moisture concentrations may also play a role.

\subsubsection{3. $\quad \underline{\mathrm{SO}_{3}} \underline{\text { Emissions }}$}

Higher $\mathrm{SO}_{3}$ emissions could be a negative side effect of the oxy-firing technology with high sulfur coals. If $\mathrm{SO}_{3}$ is not scrubbed and condenses in equipment, it could cause corrosion. One of the objectives of the SBS-II program was to assess the $\mathrm{SO}_{3}$ concentrations in the recycled flue gas. $\mathrm{SO}_{3}$ sampling tests (using the controlled condensation method) were performed while firing the Ohio \#5 bituminous coal. Additional tests with the Black Thunder subbituminous coal and North Dakota lignite were ruled out due to the low sulfur content of these fuels.

Repeated $\mathrm{SO}_{3}$ testing was performed by CleanAir Engineering for both air- and oxy-firing at two locations:

- $\quad$ Air heater outlet (flue gas side)

- ID fan inlet

The first point is located before all environmental equipment and demonstrates the conversion of fuel sulfur to $\mathrm{SO}_{3}$ inside the radiant furnace and convection pass. Measurements at the ID fan inlet show the $\mathrm{SO}_{3}$ concentration after all environmental equipment (baghouse, WFGD, CHX) in the flue gas recycled to the boiler.

Figure 3.38 shows the $\mathrm{SO}_{3}$ concentration in the recycled flue gas for air- and oxy-firing. The $\mathrm{SO}_{3}$ concentration after the environmental equipment was $0.2 \mathrm{ppm}$ for air-firing and $1.7 \mathrm{ppm}$ (average) for oxy-firing. At this location, the temperature ranged from 94 to $109^{\circ} \mathrm{F}$ and as expected, no $\mathrm{SO}_{3}$ in the form of vapor was detected. Non-vapor $\mathrm{SO}_{3}$ could be calcium sulfate carryover from WFGD but little carryover was seen with air-firing. Therefore the $\mathrm{SO}_{3}$ must be in the form of aerosol which was absorbed in the probe liner. The $\mathrm{SO}_{3}$ concentration ranged from 0.2 to 4 ppmdv during oxy-firing. Further investigation is required to determine if the cause was combustion conditions and/or the operation of environmental equipment.

Table 3.17 provides a list of SO3 test names to allow cross-referencing with other pilot-scale test data tabulated in the Appendix (Section 8.2). 


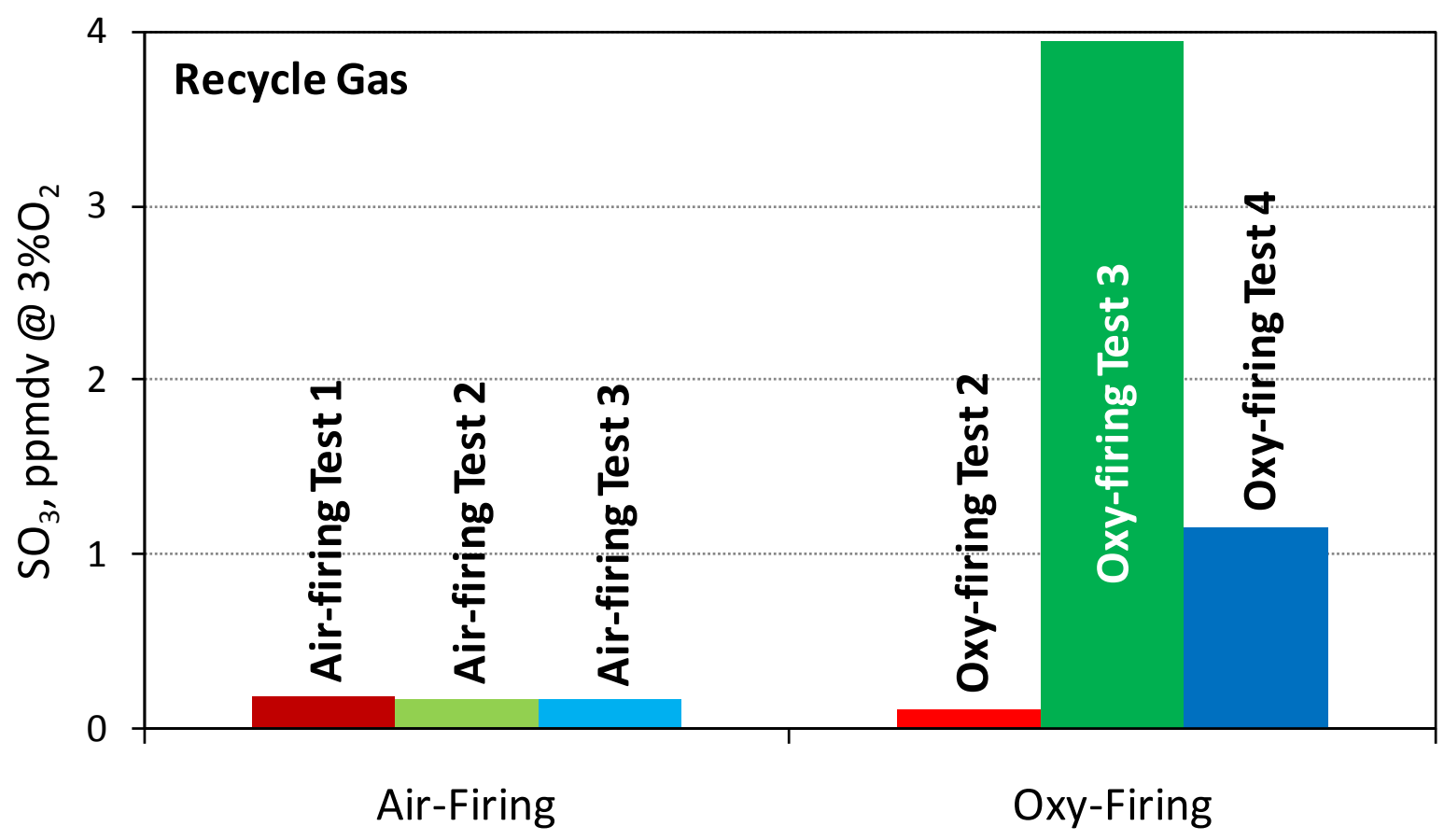

Figure 3.38 Total $\mathrm{SO}_{3}$ concentration after environmental equipment (bituminous coal, vapor and non-vapor $\mathrm{SO}_{3}$ forms combined)

Figure 3.39 shows that oxy-firing generated higher $\mathrm{SO}_{3}$ in the radiant furnace and convection pass than air-firing. The average $\mathrm{SO}_{3}$ concentrations for air- and oxy-firing were 8.1 and $48.2 \mathrm{ppm}$ respectively. At these high temperatures ( 375 to $\left.400^{\circ} \mathrm{F}\right)$, the majority of $\mathrm{SO}_{3}$ was in vapor form and the remainder was absorbed by fly ash. From these data, it is concluded that oxyfiring produces higher concentrations of $\mathrm{SO}_{3}$ but the combination of baghouse, wet scrubber, and condensing heat exchanger employed in these tests was capable of reducing $\mathrm{SO}_{3}$ to very low levels as illustrated by Figure 3.38 .

\begin{tabular}{|c|l|c|}
\hline \multicolumn{1}{|c|}{ SO $_{3}$ Test } & \multicolumn{1}{|c|}{ Test Name in Appendix } & $\begin{array}{c}\mathbf{S O}_{3} \text { Test Start Time } \\
\text { (Duration 60 minutes) }\end{array}$ \\
\hline Air-firing Test 1 & OH \#5 Air Long Term \#1 & $7 / 21 / 20098: 59$ \\
Air-firing Test 2 & OH \#5 Air Long Term 3 & $7 / 21 / 200911: 18$ \\
\hline Air-firing Test 3 & OH \#5 Air Long Term 4 & $7 / 21 / 200914: 18$ \\
\hline Oxy-firing Test 1 & Ohio \#5 Oxy Long Term Test 1 & $7 / 22 / 200911: 46$ \\
Oxy-firing Test 2 & Ohio \#5 Oxy 7 Long Term 2 & $7 / 28 / 200912: 52$ \\
\hline Oxy-firing Test 3 & Ohio \#5 Oxy 7 Long Term 3 & $7 / 28 / 200916: 45$ \\
\hline Oxy-firing Test 4 & Ohio \#5 Oxy 7 Long Term 4 & $7 / 28 / 2009$ 19:05 \\
\hline
\end{tabular}

Table 3.17 $\mathrm{SO}_{3}$ test names and corresponding names in the Tabulated Pilot-scale Test Data (Appendix Section 8.2) 


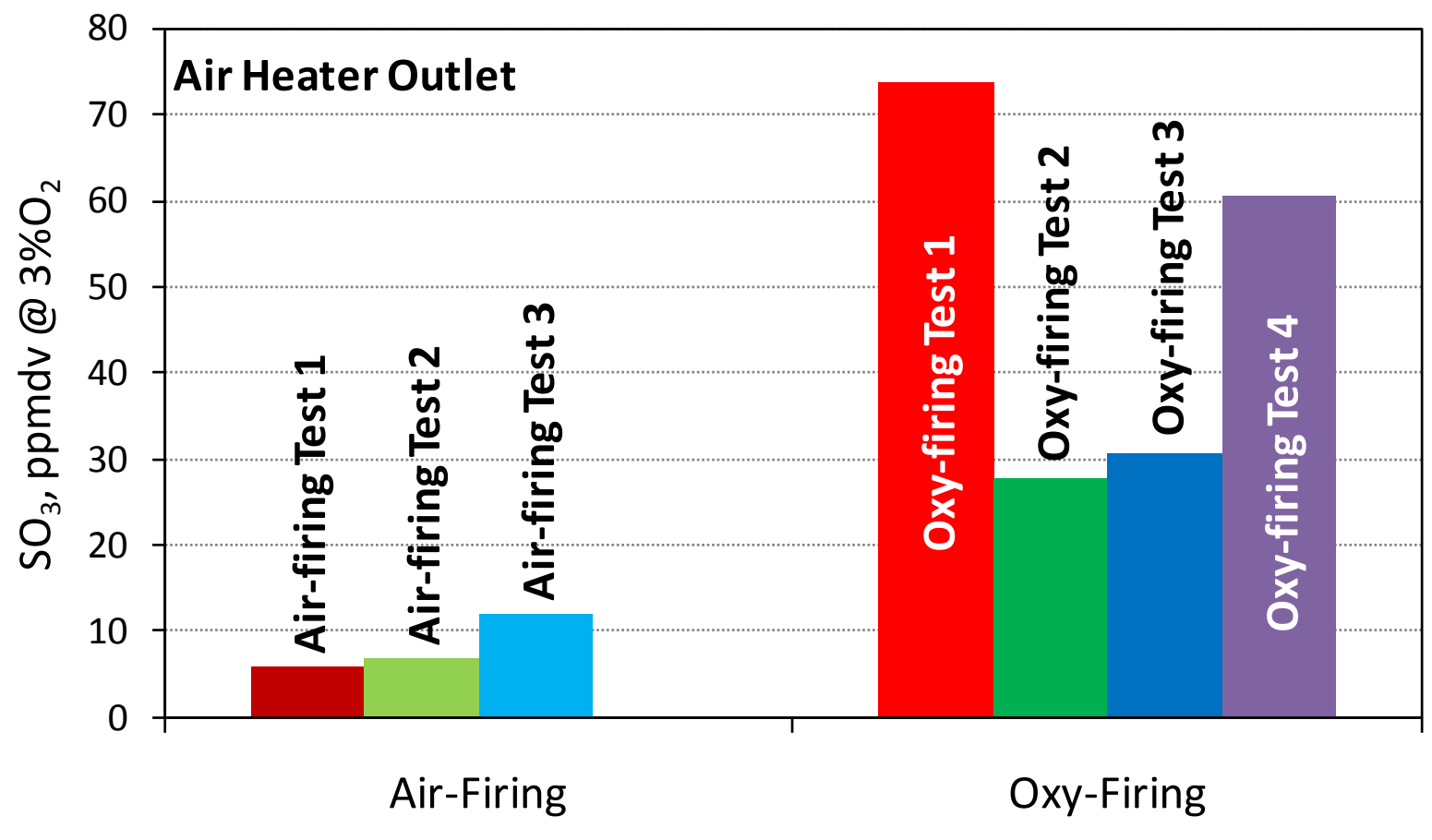

Figure 3.39 Total $\mathrm{SO}_{3}$ concentration before environmental equipment (bituminous coal, vapor and non-vapor $\mathrm{SO}_{3}$ forms combined)

In an attempt to determine the fate of $\mathrm{SO}_{3}$, Figure 3.40 and Figure 3.41 show the vapor and nonvapor forms of $\mathrm{SO}_{3}$ concentrations at the air heater outlet before the environmental equipment. For oxy-firing conditions (Figure 3.40) an average of 24\% of $\mathrm{SO}_{3}$ was non-vapor (absorbed by flyash or an aerosol). This particle-bound or aerosol $\mathrm{SO}_{3}$ could be easily captured in the baghouse. As a result, an average 37 ppm vapor phase $\mathrm{SO}_{3}$ would enter the WFGD. After the WFGD and CHX only 1.7 ppm was detected in the recycle gas. A WFGD can capture some $\mathrm{SO}_{3}$ but is not very effective for capturing aerosols. Our previous investigation (18) in the $30 \mathrm{MW}_{\text {th }}$ Clean Environment Development Facility (CEDF) showed that $23 \%$ of $\mathrm{SO}_{3}$ was captured in the WFGD. Although there are many differences between the SBS-II and CEDF, if we assume the WFGD removes $23 \%$, the WFGD outlet concentration would be $28 \mathrm{ppm}$, suggesting that the majority of $\mathrm{SO}_{3}$ was removed in the $\mathrm{CHX}$.

A commercial oxy-firing plant could employ other strategies to eliminate or reduce $\mathrm{SO}_{3}$ and the associated corrosion potential such as: (1) increasing recycle gas temperature above the acid vapor dew point, (2) reducing $\mathrm{SO}_{3}$ by a dry sorbent injection system, (3) using a dry scrubber. 


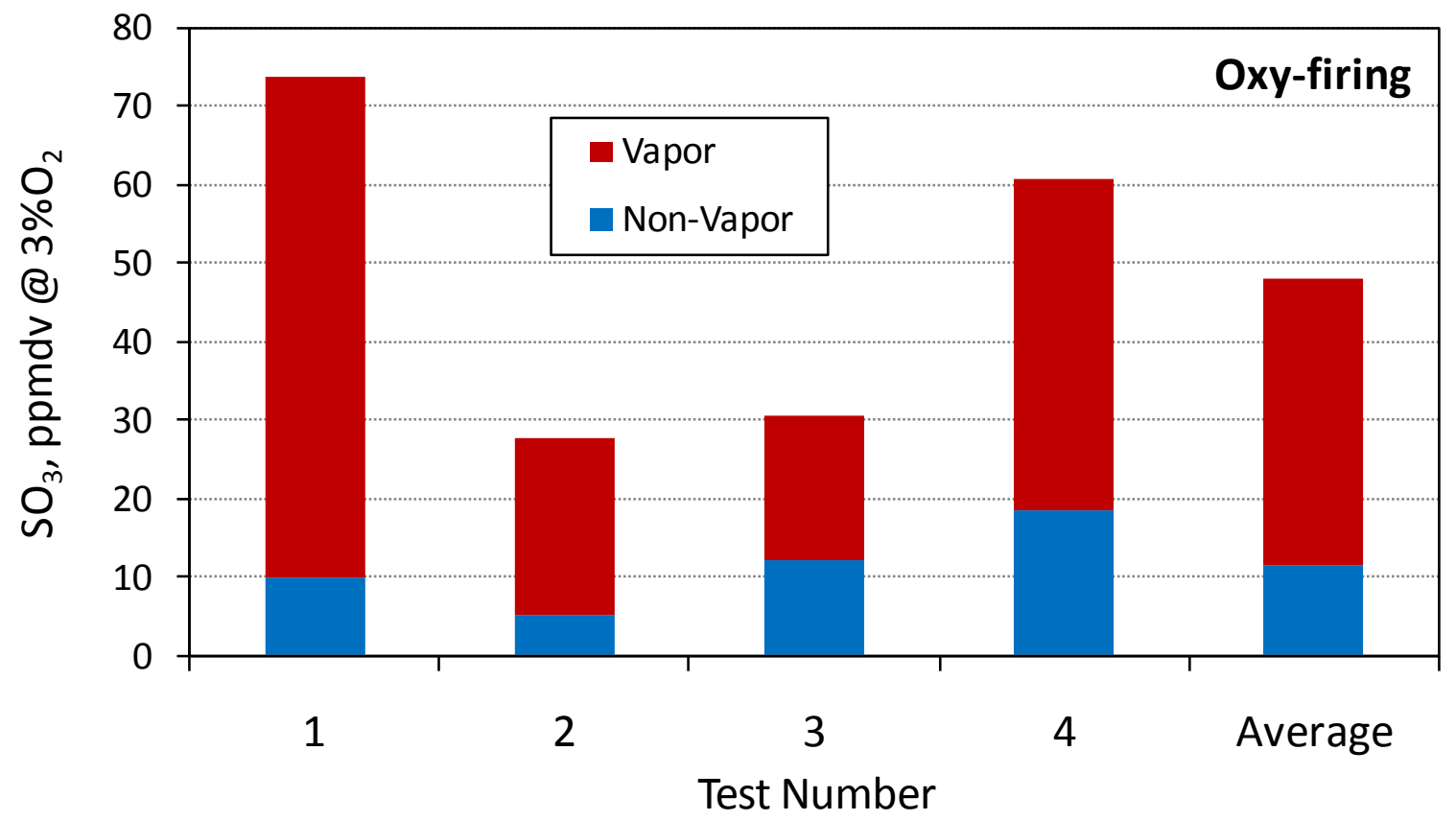

Figure 3.40 Vapor and non-vapor $\mathrm{SO}_{3}$ concentrations at the air heater outlet during oxy-firing

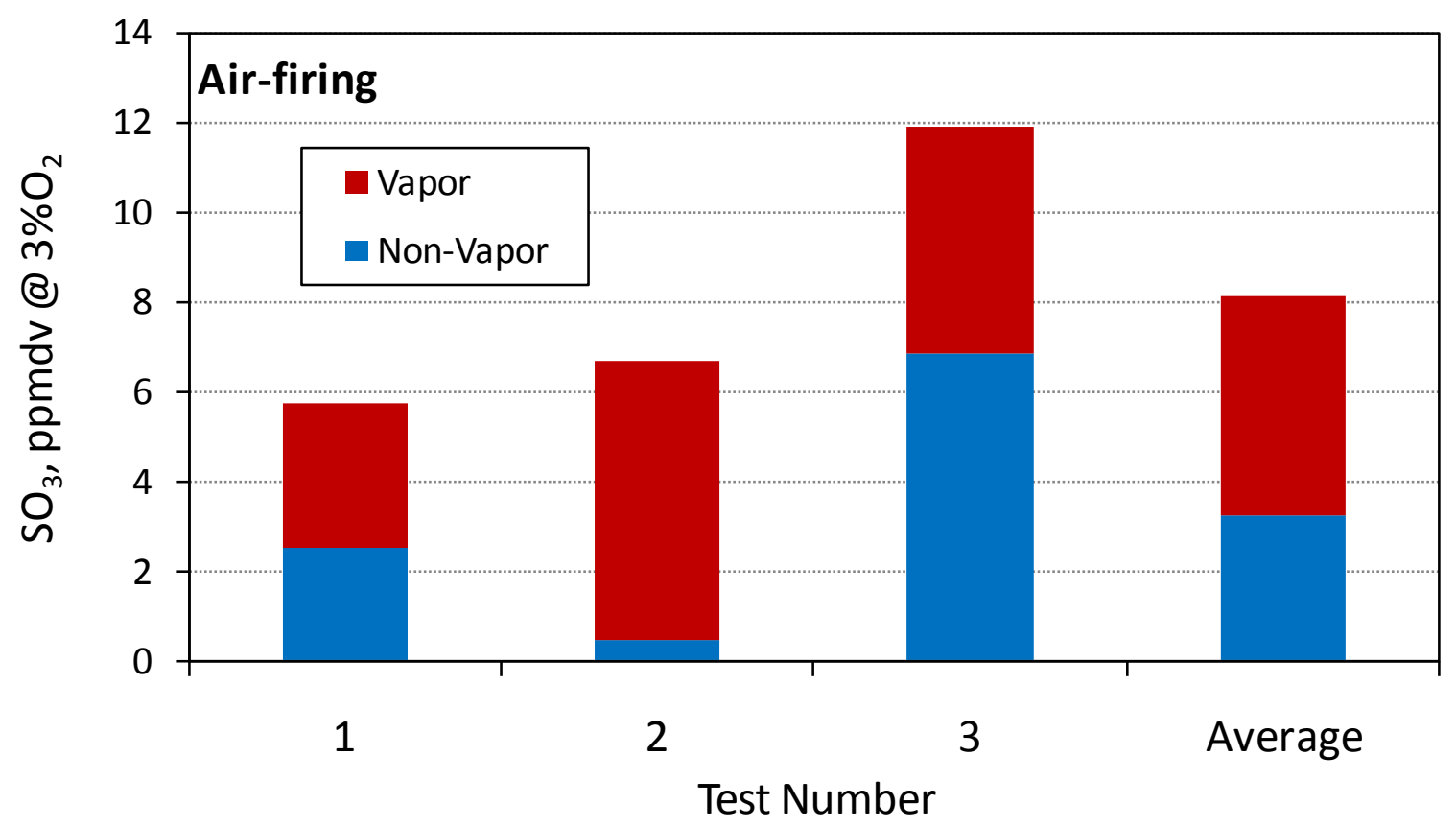

Figure 3.41 Vapor and non-vapor $\mathrm{SO}_{3}$ concentrations at the air heater outlet during air-firing 


\subsubsection{Mercury Emissions Measurements}

The mercury concentration in the flue gas was measured using a Field Transportable Mercury Analyzer (FTMA). The FTMA consists of a sampling probe, mercury scrubber, oxidized-toelemental thermal mercury converter, and a total mercury analyzer (Ohio Lumex Mini CEM 915). The probe samples a small portion of the flue gas, which is filtered to remove particulate and diluted with air at a given ratio. The total mercury concentration is measured by sending a portion of the clean and diluted sample to the total mercury analyzer. In order to measure elemental mercury, another portion of the diluted sample is sent first to a scrubber to remove oxidized mercury only, and then to the total mercury analyzer while the unscrubbed portion bypasses the analyzer. This latter reading corresponds to the amount of elemental mercury in the gas. The concentration of oxidized mercury can be calculated by subtracting the amount of elemental mercury from the total mercury measurement.

The FTMA was calibrated before and after each test using standard gases with a known mercury concentration. The gases were generated using a HOVOCAL® system. The standard gases were introduced in random order for statistical validity. The measured and the expected mercury concentrations were fitted to a straight line with a zero intercept. Using the slope of the line generated, the mercury readings were corrected. As shown in Figure 3.42 the probe calibration did not change significantly through the duration of the tests.

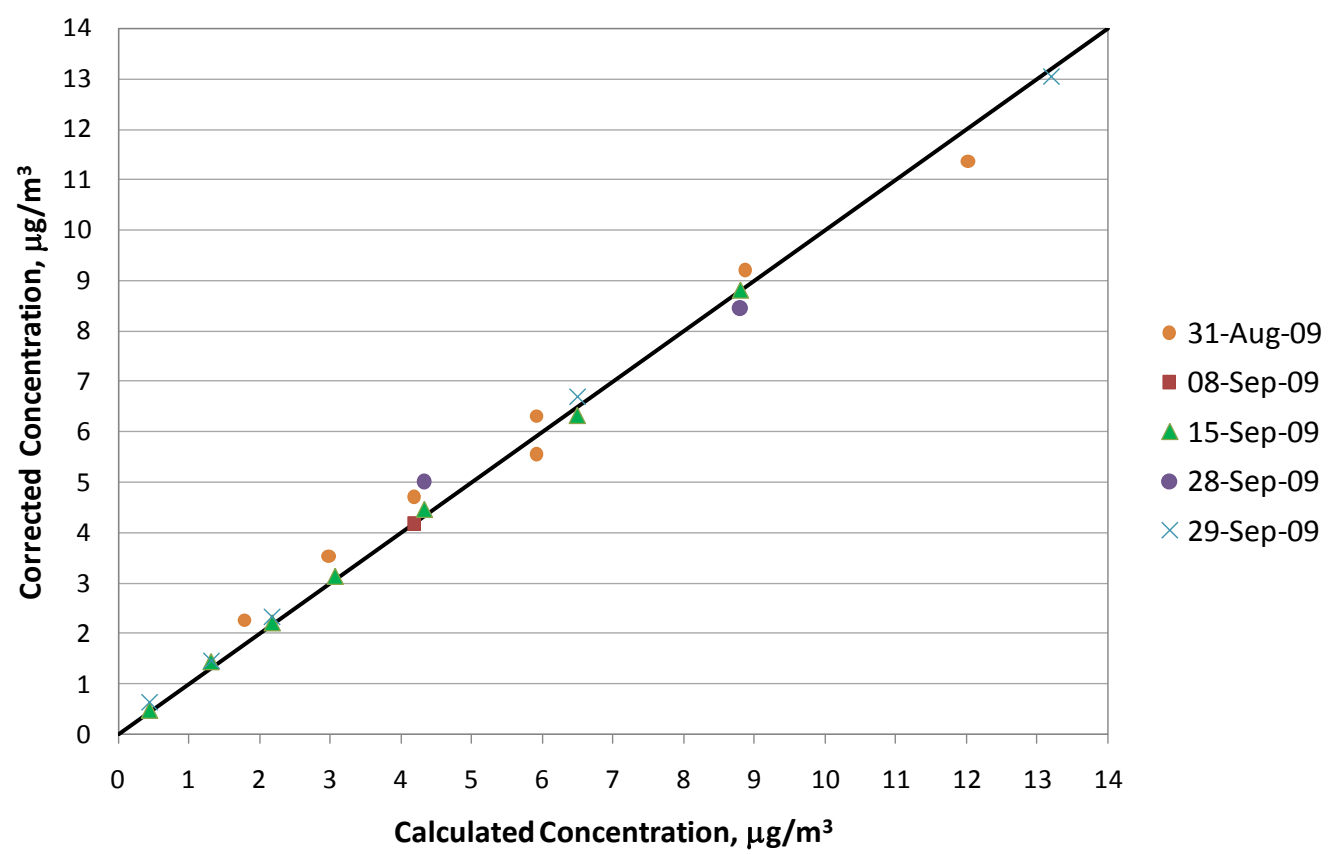

Figure 3.42 Mercury analyzer calibration data

Figure 3.43 shows mercury measurements taken on July 21, 2009 during combustion of Ohio \#5 bituminous coal in air. No flue gas was recycled. Initially, measurements were taken at the outlet of the wet flue gas desulfurization scrubber. Due to problems on this day with the probe 
calibration $^{4}$, these values are not accurate and can only be discussed qualitatively. The ratio of oxidized to elemental mercury, however, is valid and is representative of the test because both the oxidized and the elemental mercury measurements are affected by the same calibration factor.

As can be seen in Figure 3.43, prior to time 13:27, the oxidized and the total mercury have similar values. The difference between the total and the elemental mercury corresponds to the oxidized mercury, which appears negligible. Hence, downstream of the WFGD the mercury in the flue gas is in its elemental form $\left(\mathrm{Hg}^{0}\right)$.

Between 13:27 and 14:30 (indicated by two vertical lines in the figure) the probe was moved to the inlet of the scrubber. As can be seen the mercury concentration at the inlet of the scrubber is higher, and about $90 \%$ of the mercury is in an oxidized form $\left(\mathrm{Hg}^{2+}\right)$. The oxidized mercury concentration, however, slowly decrease with time. It is suspected that this decrease in mercury concentration was due to the accumulation of unburned carbon particles on the filters in the baghouse.

Wet scrubbers are known to capture oxidized mercury as was observed here. Comparing the outlet and the inlet readings we can see that the oxidized mercury was captured in the scrubber, while elemental mercury passes through it. Negligible amounts of oxidized mercury were detected at the outlet.

${ }^{4}$ For the data taken July 21 , the mercury sampling probe was exposed to fly ash which partially blocked a flow orifice in the sample dilution system, and thereby affected the calibration. Once this problem was discovered and remedied the calibrations were valid (see Figure 3.42). 


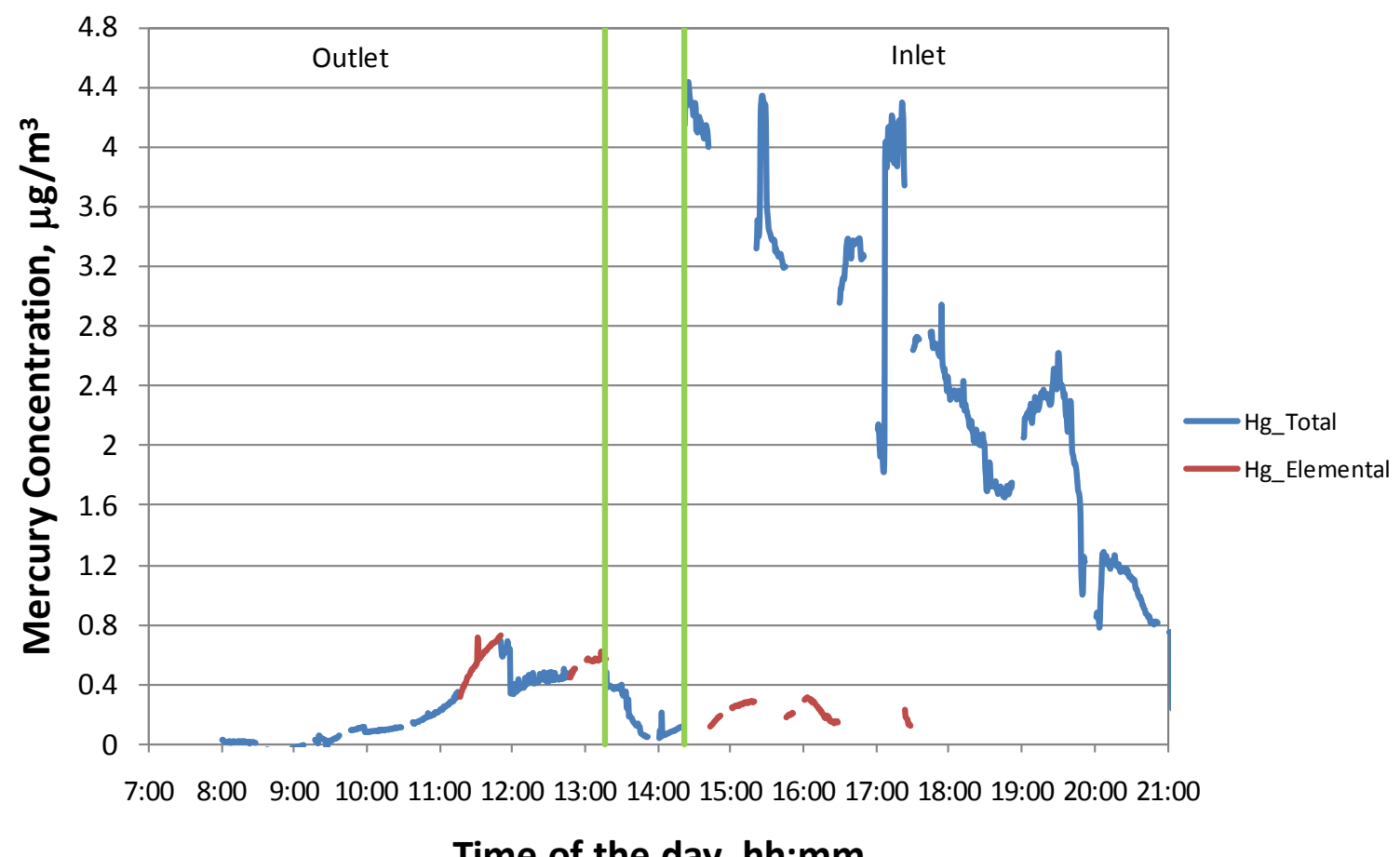

Figure 3.43 Mercury concentration at the outlet and inlet of the wet scrubber for tests performed on July 21, 2009 (Qualitative data only) Ohio \#5 bituminous coal, air-firing

Figure 3.44 shows mercury measurements taken on September 3 firing lignite. The probe was located between the baghouse and condensing heat exchanger, downstream of the bypassed wet scrubber.

The unit was started in air firing mode and transition to oxy-firing began at 11:30. Complete transition to oxy-firing was achieved at 16:25. Between 10:00 AM and 12:00 PM, the mercury readings were unstable. The reason for this noise is probably related to unstable combustion in the boiler as indicated by the large fluctuations in convection pass exit $\mathrm{CO}$.

During the transition period, the total and elemental mercury concentrations increased as the flue gas recycle flow rate increased. The $\mathrm{CO}_{2}$ concentration is also shown in Figure 3.44 for reference. As can be seen, the $\mathrm{CO}_{2}$ and total mercury concentration followed similar trends.

The ratio of oxidized mercury to elemental mercury, on the other hand, was not constant. For example, at about 13:00, the ratio of oxidized to elemental mercury is close to 0.25 . At full recycle (16:25), the ratio of oxidized to elemental mercury is about 1.64 . The increase in the oxidized-to-elemental mercury ratio indicates that oxy-firing with flue gas recycle generates larger proportions of oxidized mercury. At 18:25 the unit tripped and coal combustion stopped. The mercury concentration dropped accordingly. 


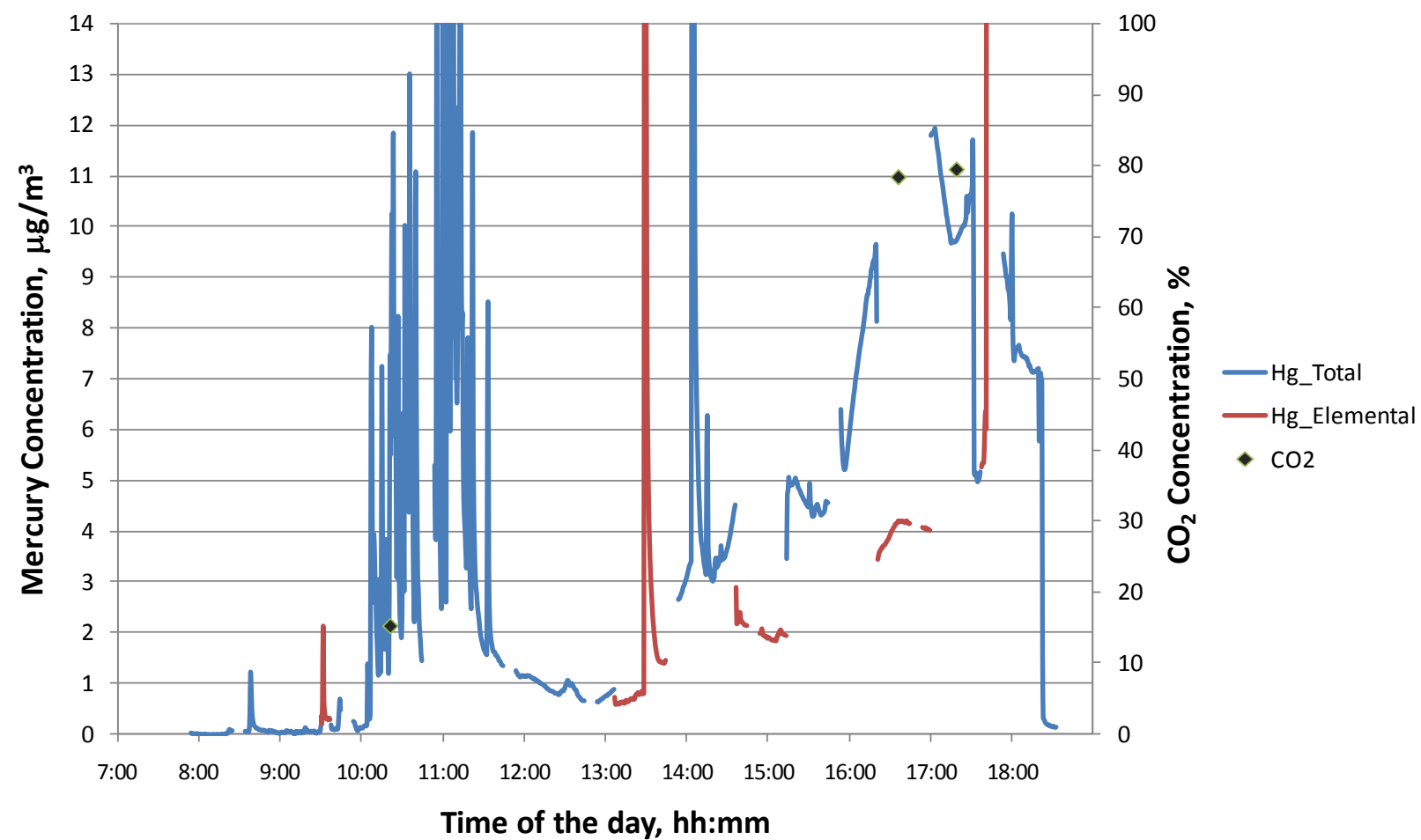

Figure 3.44 Mercury concentration for tests performed on September 3, 2009 firing lignite

Figure 3.45 shows mercury measurements taken during warm recycle tests on September $17^{\text {th }}$. In this test the probe was located downstream of the baghouse and the bypassed wet scrubber. Downstream of the sample location the CHX was also bypassed.

The unit was started on air, firing subbituminous coal. Transition to oxy-firing started at 10:20 and was complete at 12:45. Flue gas $\mathrm{CO}_{2}$ content increased from $16 \%$ to $79 \%$ during this period. For the remainder of the day, the $\mathrm{CO}_{2}$ concentrations remained constant around $80 \%$. As can be seen in Figure 3.45, mercury concentrations slowly increased until reaching a maximum concentration around 16:00. Between 16:00 and 17:25, the mercury concentration was stable, and decreased thereafter. Some of these trends are easily explained by considering the operating conditions. For each test condition starting at 12:45 the flue gas recycle flow rate was incrementally increased. At about 17:25 a combustion condition corresponding to the highest mercury concentration and highest flue gas recycle flow with stable combustion was achieved. Thereafter, further increases in flue gas recycle flow led to unstable combustion, and higher unburned carbon in the flue gas, which could explain the decrease in mercury after 17:25. The gradual rise in mercury during the baseline test period may be related to capture of mercury in cold ductwork and on unburned carbon in the ducts, which gradually decreases as the unit warms up, and the available capture sites become saturated. 


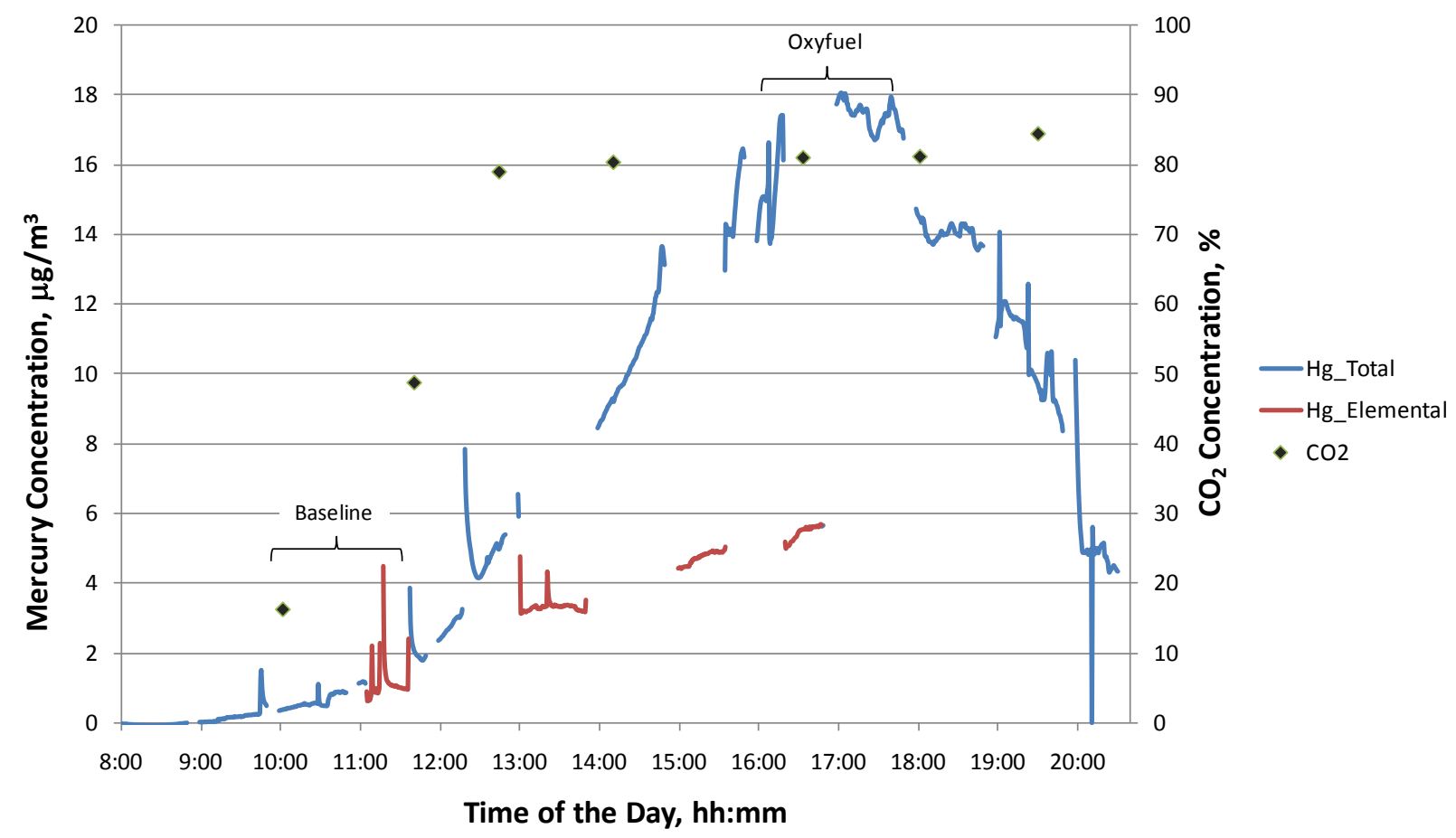

Figure 3.45 Mercury and $\mathrm{CO}_{2}$ concentration data obtained during warm recycle tests (September 17 2009) firing PRB coal

Since the scrubber and $\mathrm{CHX}$ were not in operation during this test, the amount of $\mathrm{CO}_{2}$, elemental mercury, and oxidized mercury could be expected to increase proportionally with the recycling of flue gas. However, as shown in Figure 3.45, and consistent with the results already discussed in connection with Figure 3.44, $\mathrm{CO}_{2}$ and total mercury increased as expected, but the ratio of oxidized to elemental mercury increased under oxy-firing conditions.

Figure 3.46 shows the average values for elemental and oxidized mercury during air and oxyfiring from the periods marked as "Baseline" and "Oxyfuel" in Figure 3.45. Also shown is the ratio of oxidized-to-elemental mercury. During air combustion, the ratio of oxidized-to-elemental mercury is near zero, which is expected based on experience with Powder River Basin coals such as this with low chloride content. During full recycle oxy-firing mode, the oxidized-to-elemental mercury ratio is about 2 , which is only possible if part of the elemental mercury in the recycled flue gas is converted to its oxidized form in the boiler. Since oxidized mercury is water soluble, the use of a wet scrubber in the recycle loop combined with a higher oxidized-to-elemental mercury ratio in oxy-firing may lead to higher levels of mercury removal in oxy-firing relative to air firing. Quantification of this however requires further investigation as the mercury removal efficiency of a scrubber depends not only on the oxidized-to-elemental mercury ratio, but also the rate of re-emission of oxidized mercury that is reduced to elemental mercury in the scrubber. Longer-term combustion studies are recommended to establish the effect of oxy-combustion on mercury speciation. Longer tests will also demonstrate the effect of a scrubber (either in the recycle loop, or on the flue gas flow to the stack), on mercury speciation as the presence of a wet scrubber may affect the ratio of oxidized-to-elemental mercury by removing chlorine compounds from the gas that could be important to the oxidation of mercury in the boiler. A wet scrubber 
would not be economical for mercury capture alone, however if a wet scrubber in the recycle loop is employed for $\mathrm{SO}_{2}$ and $\mathrm{SO}_{3}$ control, the question of mercury speciation would be of great importance in determining whether a separate method of mercury capture is required.

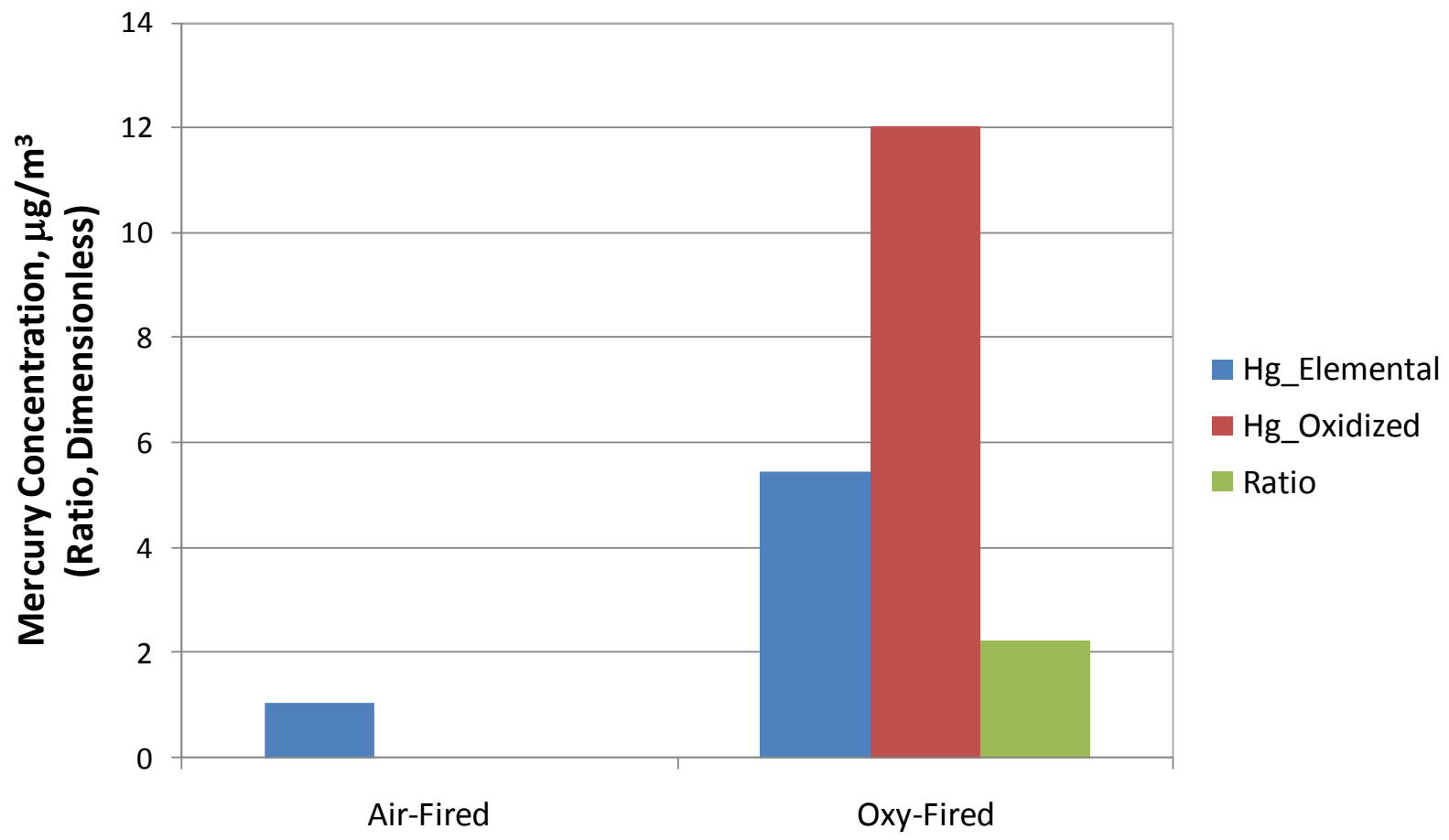

Figure 3.46 Average elemental and oxidized mercury results from the warm recycle test series (PRB subbituminous coal)

\subsubsection{5. $\quad$ Boiler Thermal Conditions and Heat Transfer}

As will be discussed below in Section 3.1.5 - Computational Model Validation, gas emissivity, specific heat, and other heat transfer variables are changed considerably by the difference in gas composition between air and oxy-firing. During the pilot-scale tests, the radiant furnace and convection pass heat absorptions were directly measured and compared with air-firing to assess the impact on boiler steam generation. In general, oxy-firing does not seem to overly impact the boiler heat transfer conditions in the radiant furnace and the convection pass as long as the mass flow through the furnace is the same as air-firing.

Figure 3.47 shows the overall heat input to SBS-II for different conditions. The majority of the heat is introduced by coal and hot secondary air. These tests were conducted at approximately $6 \mathrm{MBtu} / \mathrm{h}$ for bituminous and subbituminous coals. Lignite tests were conducted at approximately $5 \mathrm{MBtu} / \mathrm{h}$. 


\section{Energy Input to SBS-II}

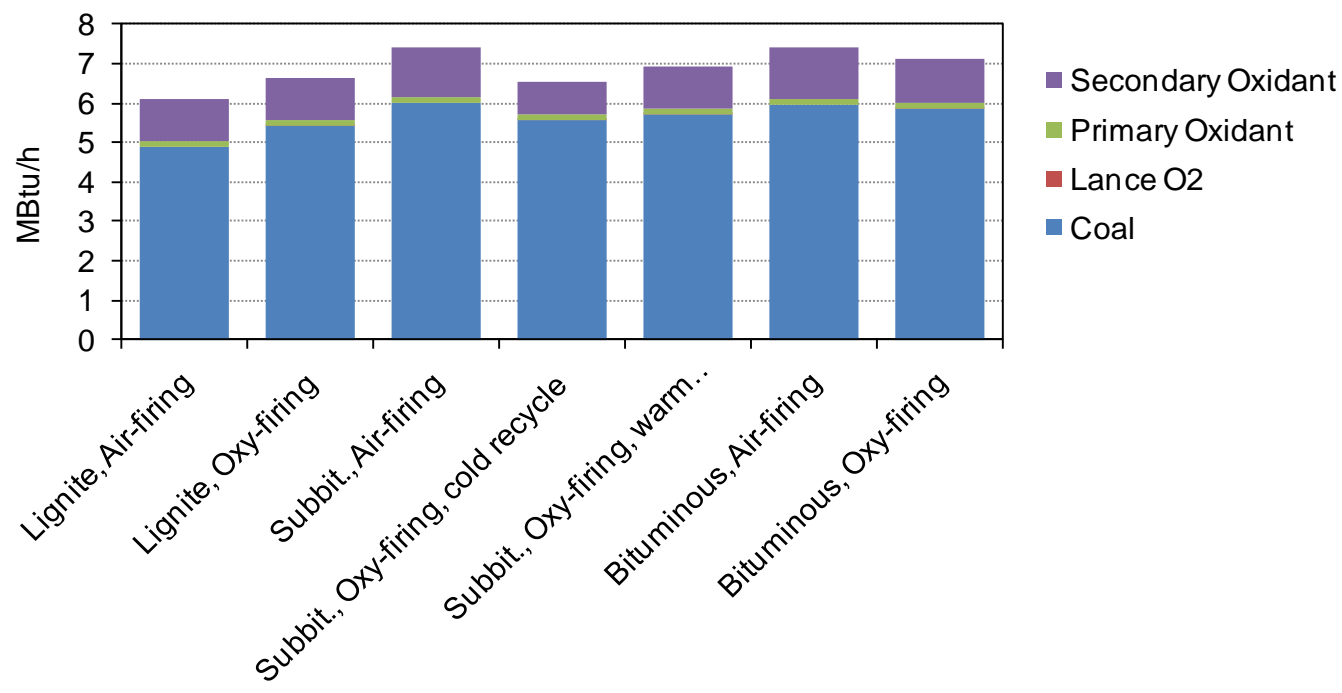

Figure 3.47 Available heat with various conditions

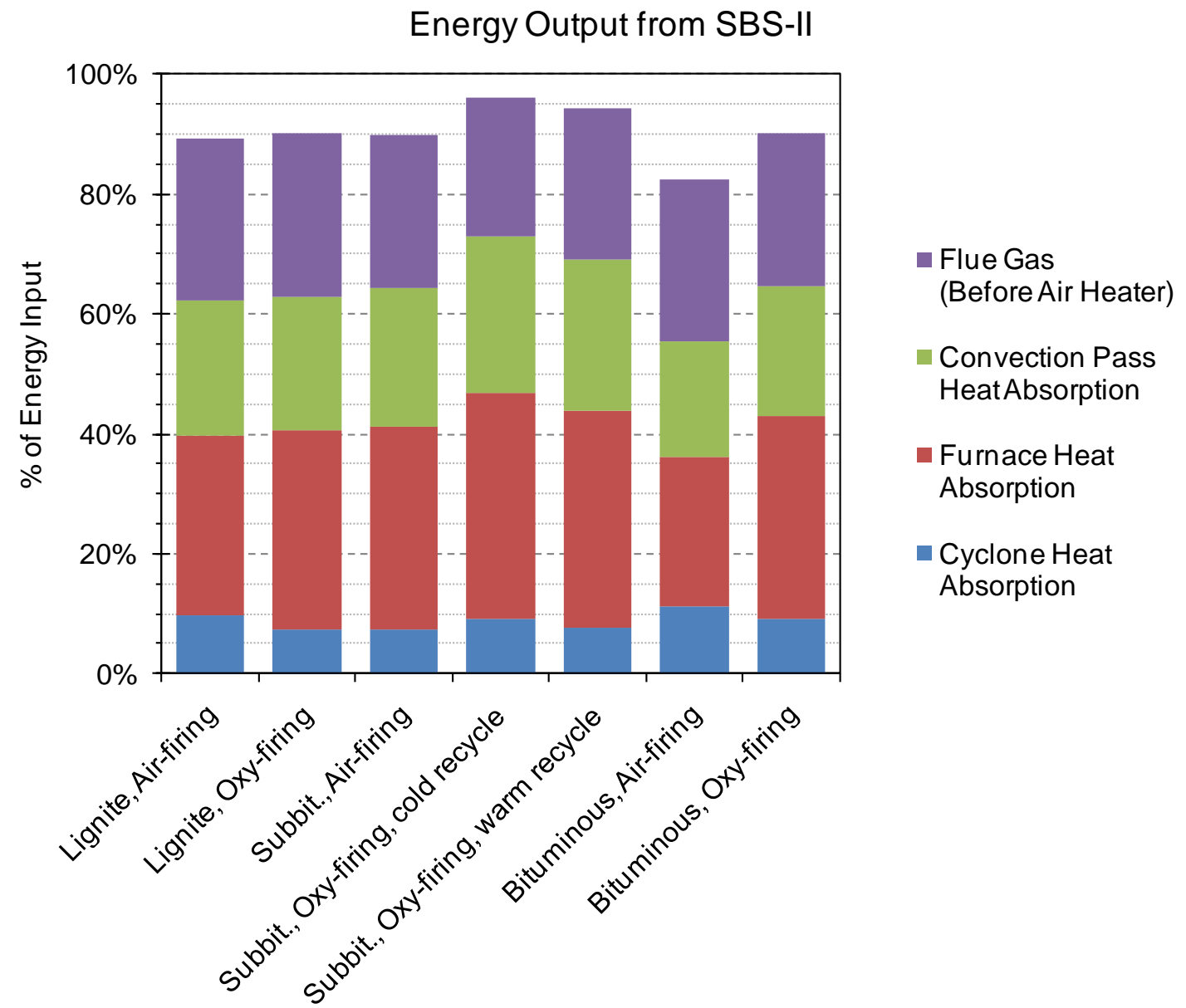

Figure 3.48 Overall heat absorption

Page 113 of 279 
Generally, very good heat balance was obtained for these tests. Figure 3.48 shows the energy balance in the SBS-II. Cyclone furnace, primary furnace, and convection pass heat absorptions were determined from the water side of the boiler. Heat loss for the flue gas was computed from flue gas composition and temperature. Overall $95 \%$ heat balance was obtained for subbituminous coal tests and over $90 \%$ closure was obtained for the remainder of the tests. The air-firing tests with the bituminous coal on average had the highest uncertainty.

Figure 3.49, Figure 3.50, and Figure 3.51 show the Cyclone furnace, primary furnace, and convection pass heat absorptions, respectively. Generally, these data demonstrate that the heat absorptions are not drastically different between air- and oxy-firing. To further investigate the impact on heat absorption, the optimum conditions for each coal were selected and compared. Figure 3.52 shows that under the optimum conditions, Cyclone, primary furnace, and convection pass heat absorptions are not negatively impacted by oxy-firing. The heat absorptions are almost identical for subbituminous coal and lignite tests when over $95 \%$ heat balance was obtained. The difference in the primary furnace heat absorption with the bituminous coal may be due to lack of closure in the heat balance rather than actual differences in heat absorption as heat balance closure was approximately $80 \%$ ). Boiler heat absorption is further discussed in connection with numerical modeling in Section 3.1.5. 

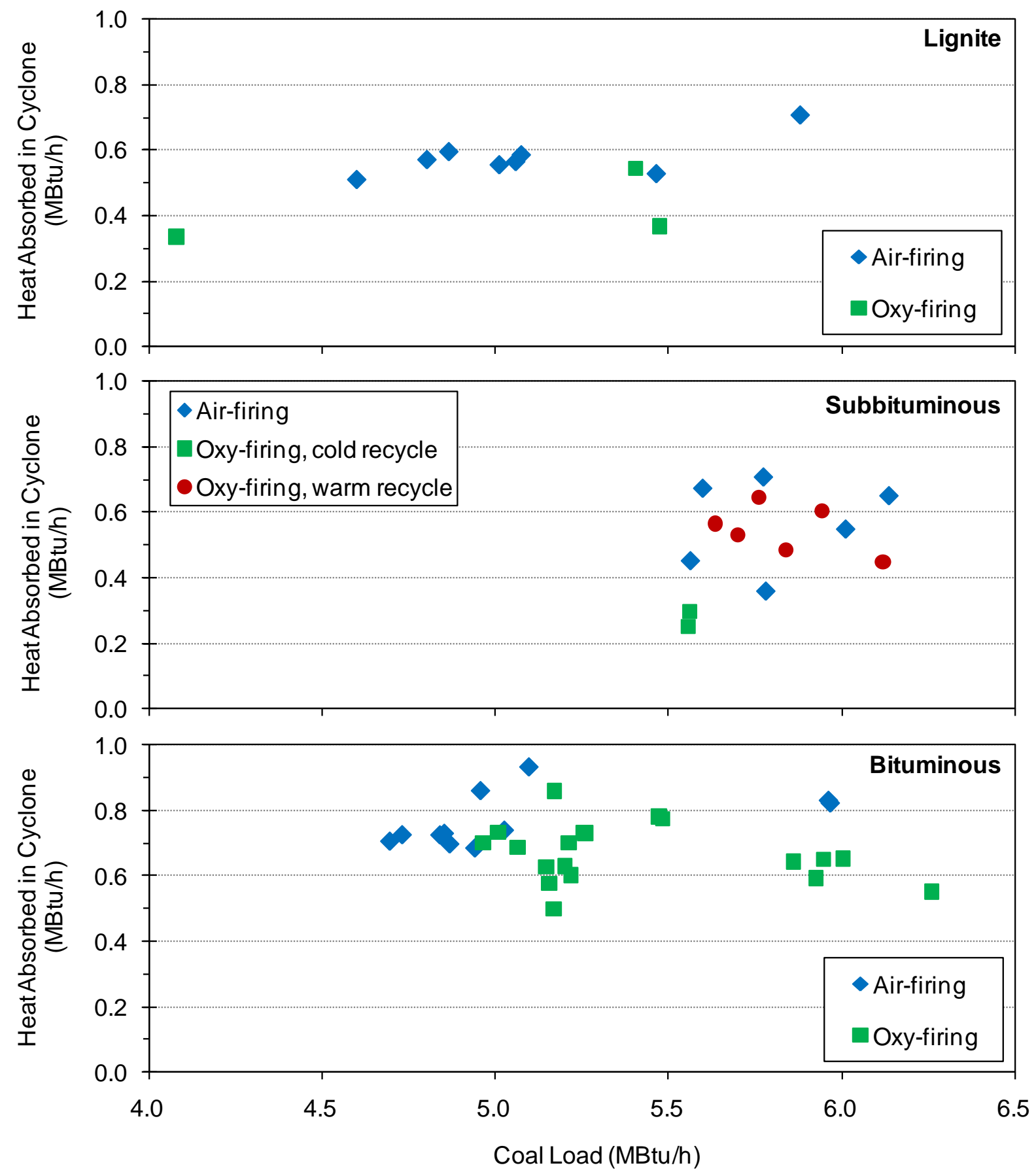

Figure 3.49 Cyclone furnace heat absorption 

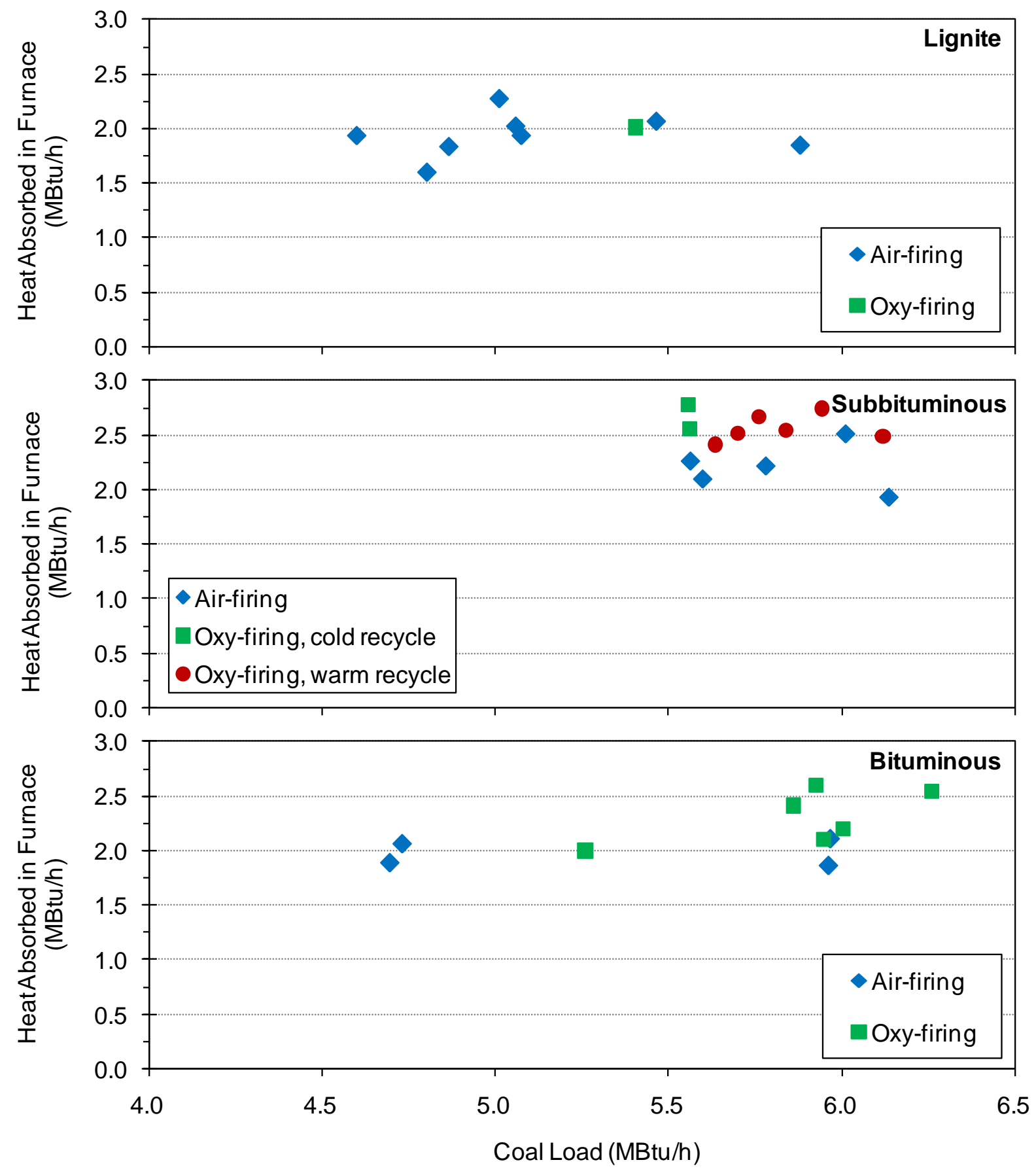

Figure 3.50 Primary furnace heat absorption 

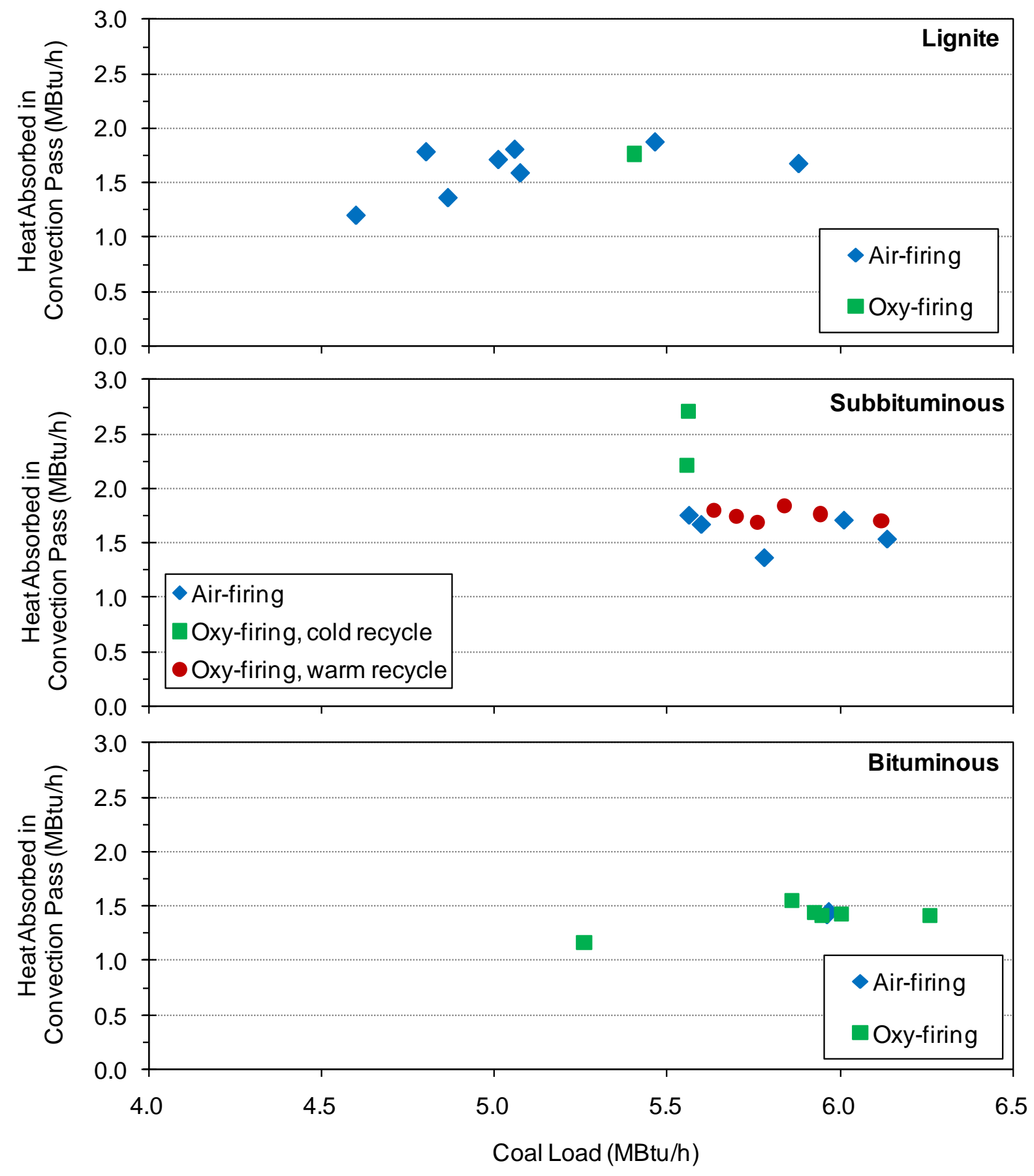

Figure 3.51 Convection pass heat absorption 

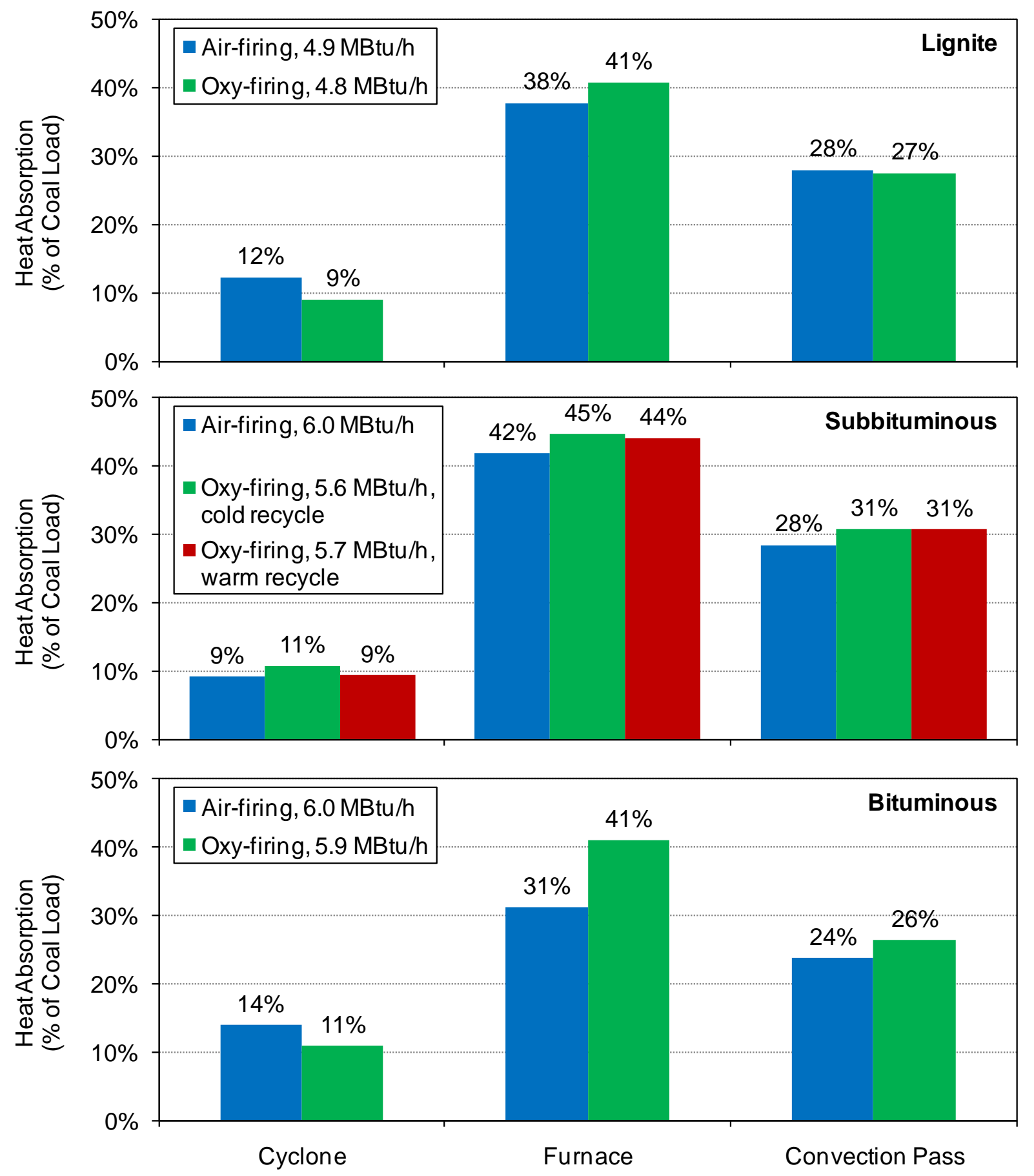

Figure 3.52 Comparison of heat absorption in Cyclone, primary furnace and convection pass

In addition to furnace heat absorption, the impact of oxy-firing on the flame temperature and furnace exit gas temperature (FEGT) was evaluated. As mentioned earlier, flame temperature was measured with an in-furnace pyrometer and FEGT with a High Velocity Thermocouple (HVT). Figure 3.53, Figure 3.54, and Figure 3.55, show examples of two-dimensional 
measurements of the flame temperature exiting the Cyclone furnace. Although oxy-firing flame temperatures can be substantially different from air-firing, by optimization of oxy-firing conditions, a similar flame temperature could be obtained.

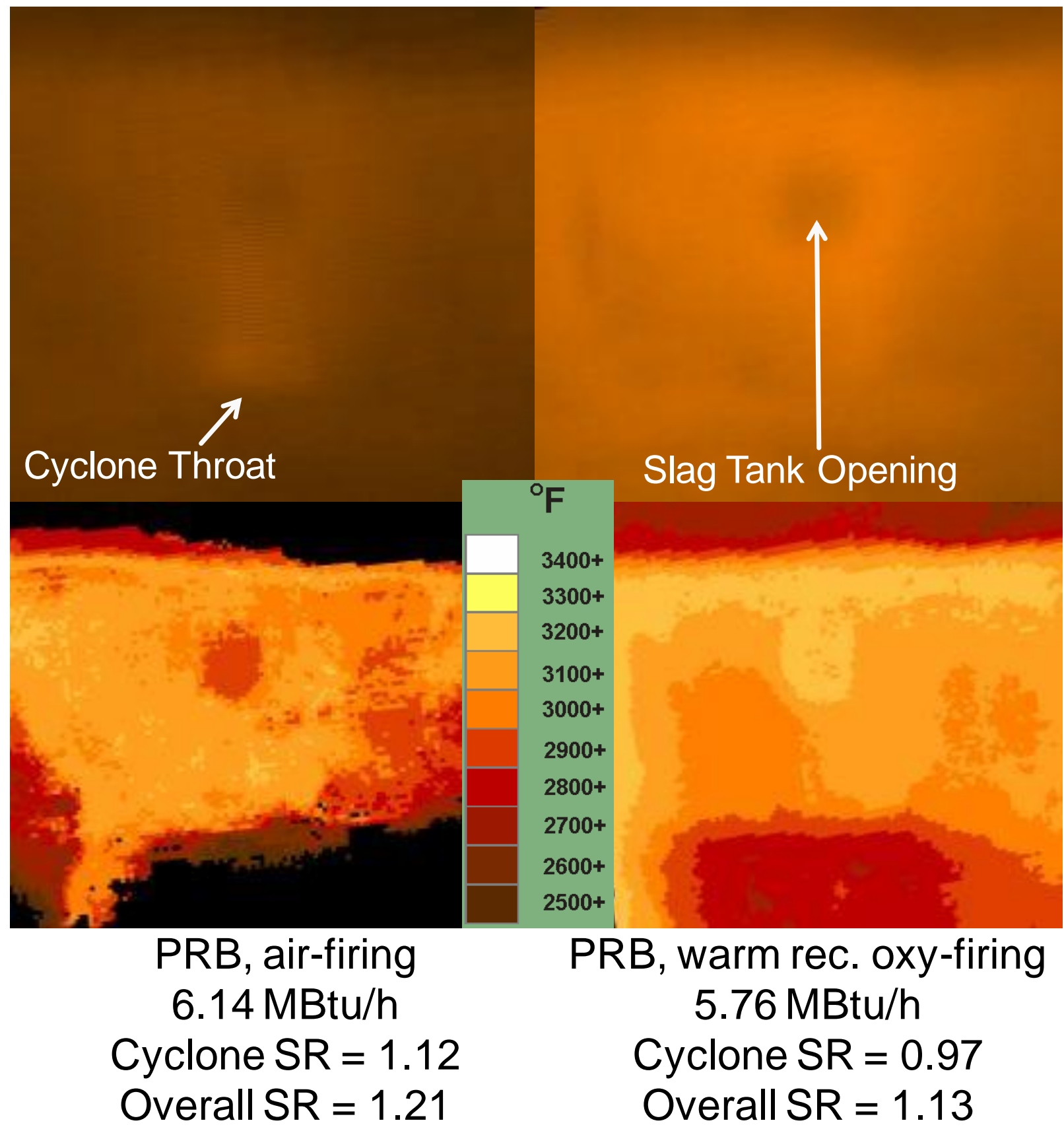

Figure 3.53 FlameView images and temperature maps for subbituminous coal 


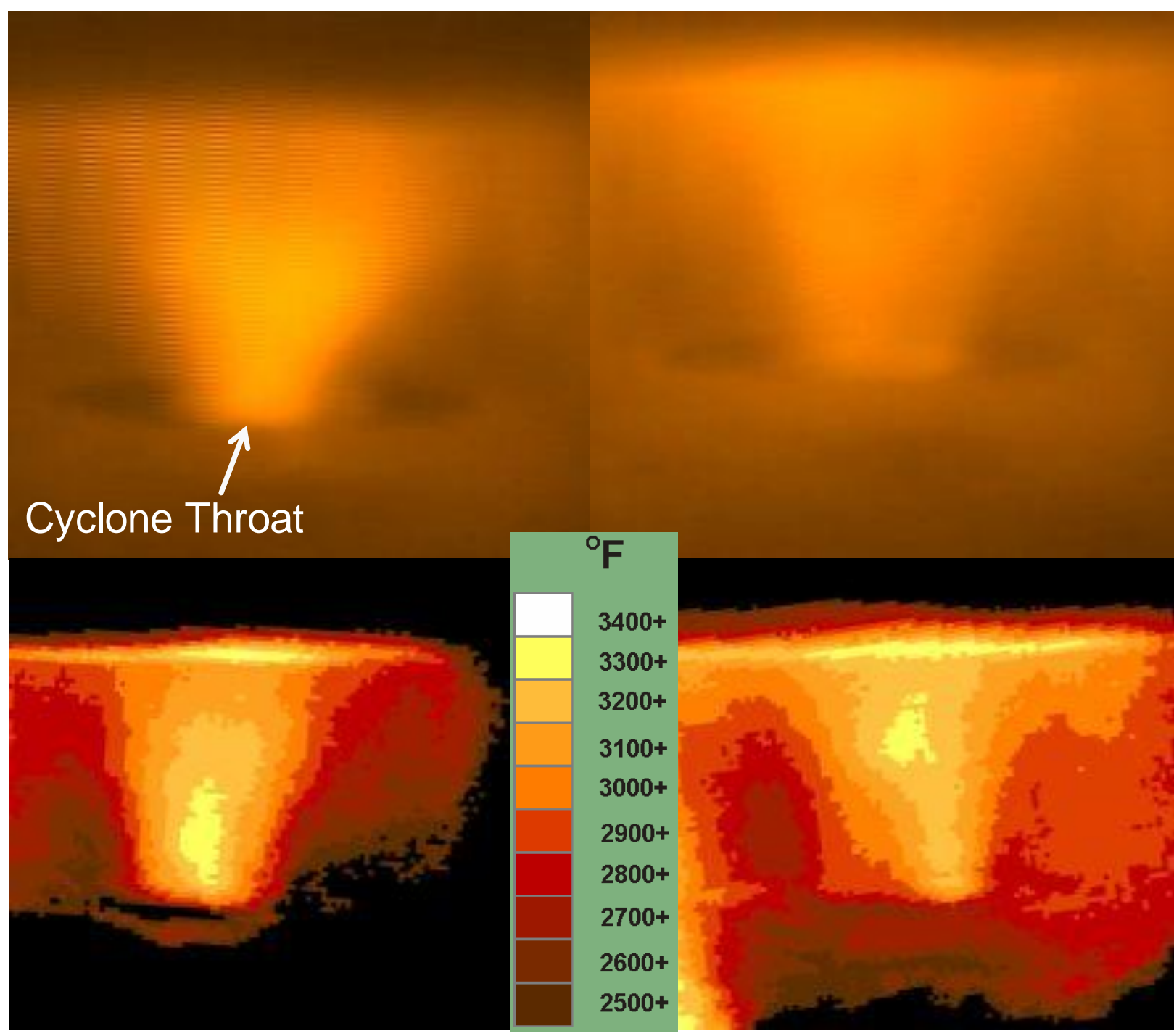

Bituminous, air-firing 4.87 MBtu/h Cyclone $S R=1.00$ Overall $S R=1.17$

Bituminous, oxy-firing 6.00 MBtu/h Cyclone $S R=0.93$ Overall $S R=1.16$

Figure 3.54 FlameView images and temperature maps for bituminous coal 


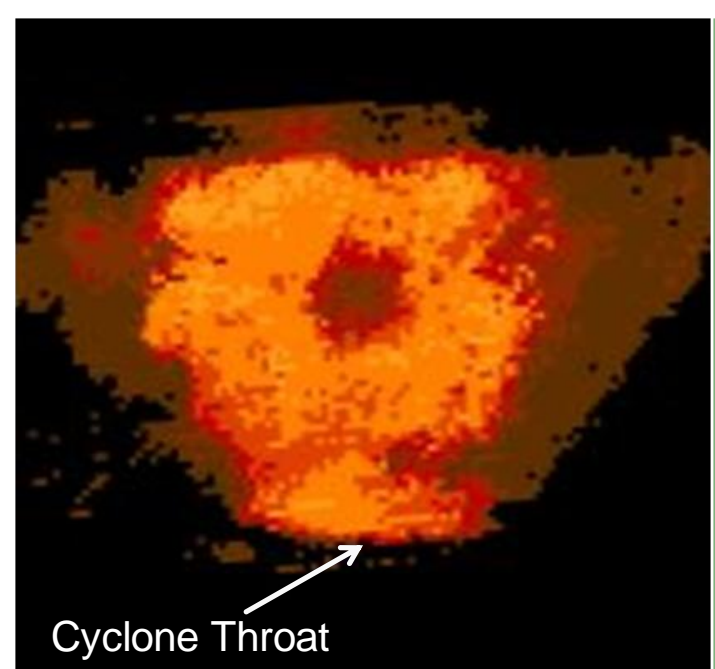

Lignite, air-firing $5.5 \mathrm{MBtu} / \mathrm{h}$

Cyclone $S R=0.99$

Overall $\mathrm{SR}=1.28$

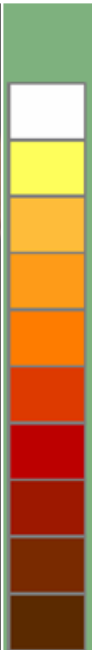

${ }^{\circ} \mathrm{F}$

$3400+$

$3300+$

$3200+$

$3100+$

$3000+$

$2900+$

$2800+$

$2700+$

$2600+$

$2500+$

Figure 3.55 FlameView temperature maps for lignite

Figure 3.56 shows the calculated adiabatic flame temperature for air-firing and oxy-firing with "Cold-Recycle" and "Warm-Recycle". In these calculations, the total mass flow rate to the boiler was the same for air-firing and oxy-firing conditions. Due to higher specific heat of $\mathrm{CO}_{2}$ than nitrogen, as expected, adiabatic flame temperature under air-firing conditions is higher than the flame temperature under the oxy-firing conditions. In addition, the adiabatic flame temperature under the oxy-firing with "Cold-Recycle" is higher than the adiabatic flame temperature under the oxy-firing with "Warm-Recycle" because less water vapor exists in the flue gas under the "Cold-Recycle" than "Warm-Recycle". This could be troublesome and prevent adequate slagging for some of the Cyclones, but as Figure 3.56 shows by strategic addition of oxygen into the Cyclone, the temperature can be increased and alleviate the potential slagging problem. Experimental measurements of flame temperature obtained from the FlameView camera (Figure 3.57) show trends consistent with the calculations.

Numerous FEGT measurements were performed during these pilot-scale tests to assess the impact of oxy-firing on FEGT. Figure 3.58 indicates that for optimum operating conditions, when coal fineness was within the specified range and flame was in the Cyclone, the FEGT under oxy-firing conditions is comparable to the FEGT under air-firing. There could be some exception to this general statement such as the results with the bituminous coal which showed the FEGT was approximately $100^{\circ} \mathrm{F}$ lower during oxy-firing conditions (see Figure 3.59 ). This general trend was also observed in the numerical modeling (see Section 3.1.5). 


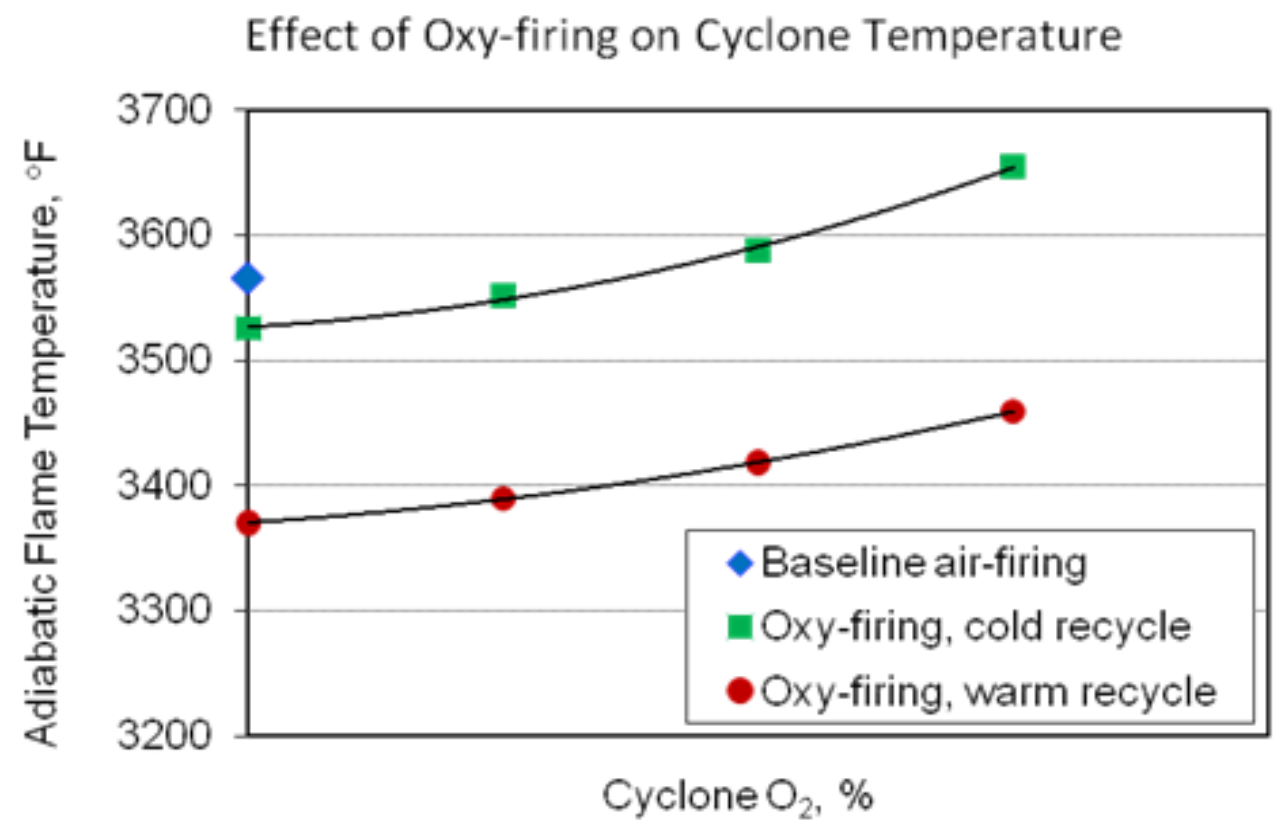

Figure 3.56 Calculated adiabatic flame temperatures for various conditions

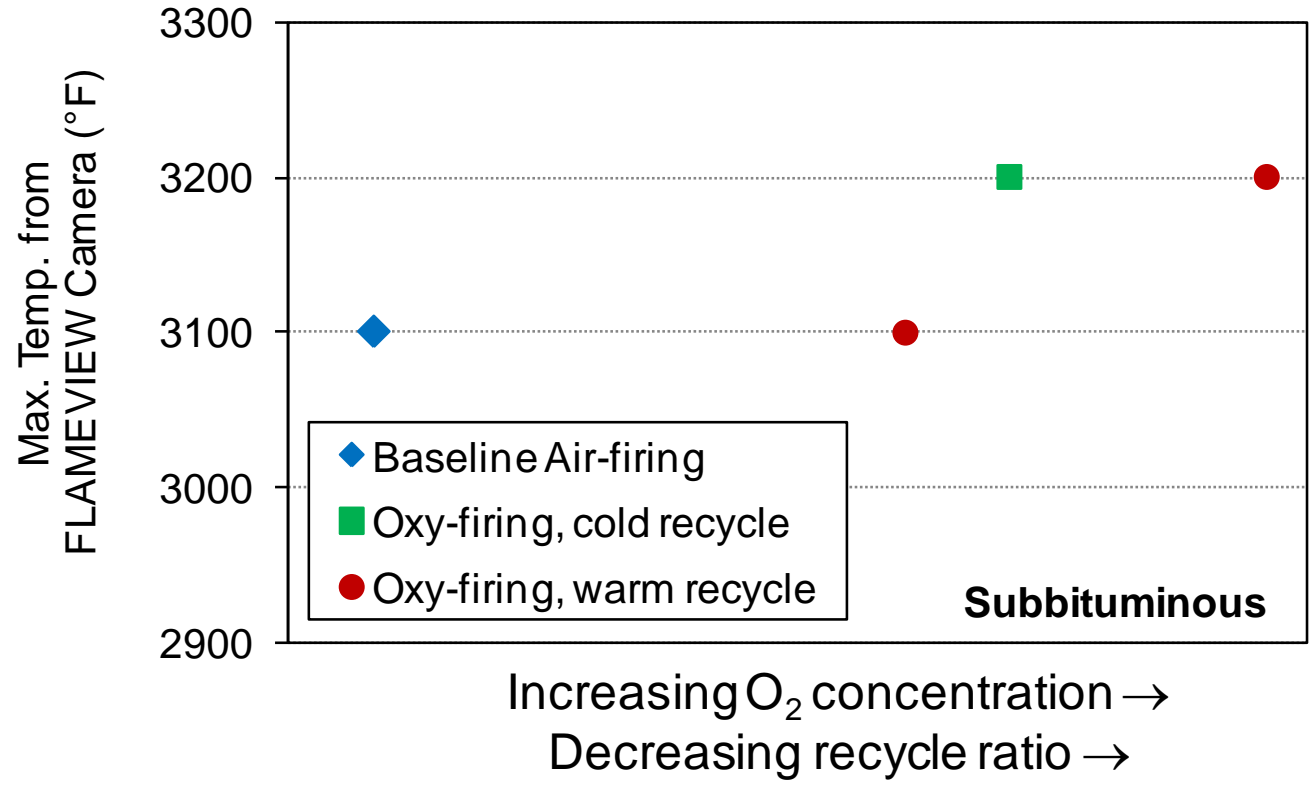

Figure 3.57 Experimental flame temperature data for various conditions (compare Figure 3.56) 

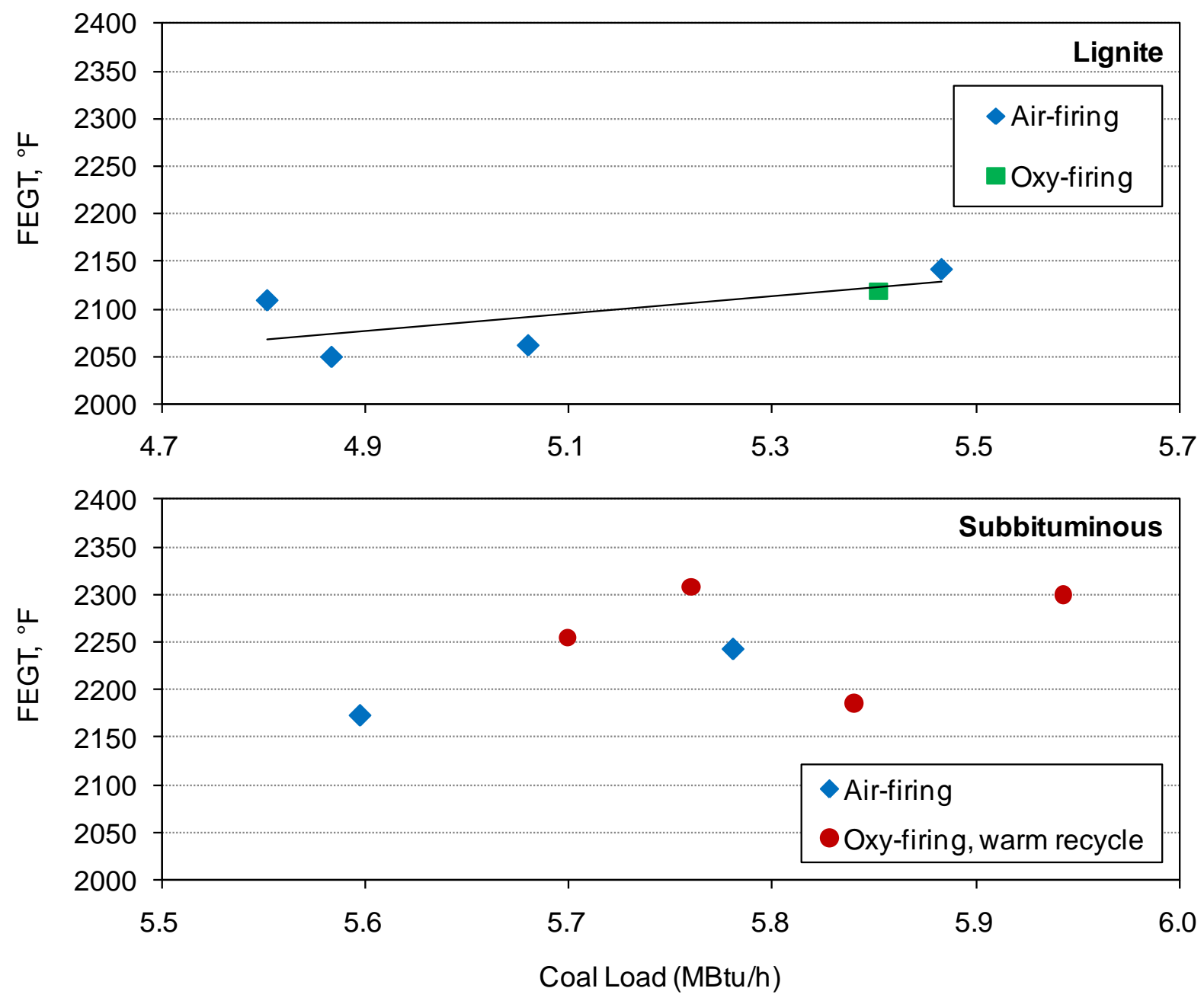

Figure 3.58 Comparison of FEGT for various conditions 


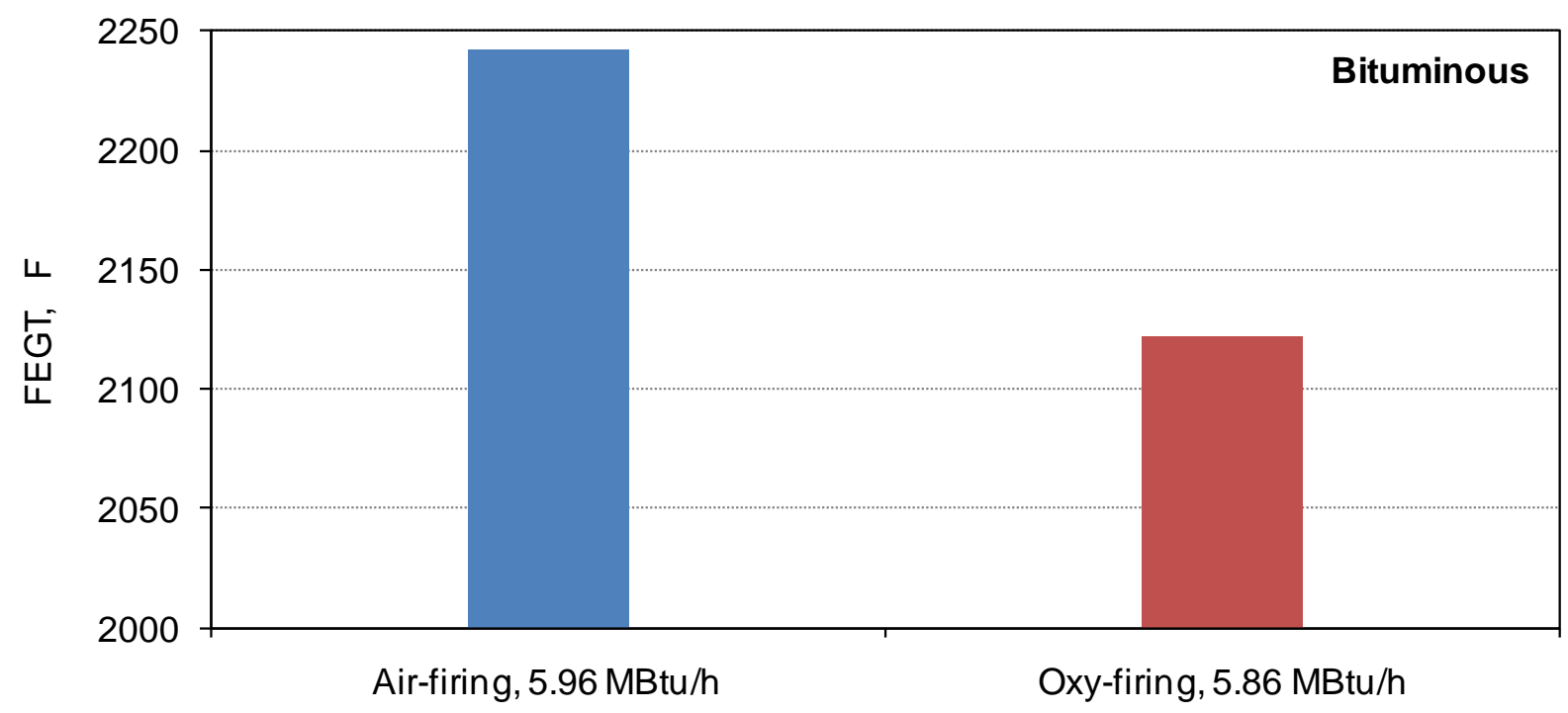

Figure 3.59 Comparison of FEGT for bituminous coal

The impact of oxy-firing on FEGT can be substantial in non-optimum conditions. Figure 3.60 shows the impact of the mass flow rate through the boiler on FEGT. In air firing the mass flow at a given load is controlled by excess air. In oxy-firing the recycle flue gas flow is the dominant factor and a wider range of mass flow per unit heat input is possible. FEGT for air- and warm recycle oxy-firing is comparable when the mass flow rate through the boiler is the same but the FEGT, as expected, has a strong dependence on recycle flow rate. It should be noted that Cyclone tapping is improved at lower RFG flow, presumably due to higher Cyclone temperature.

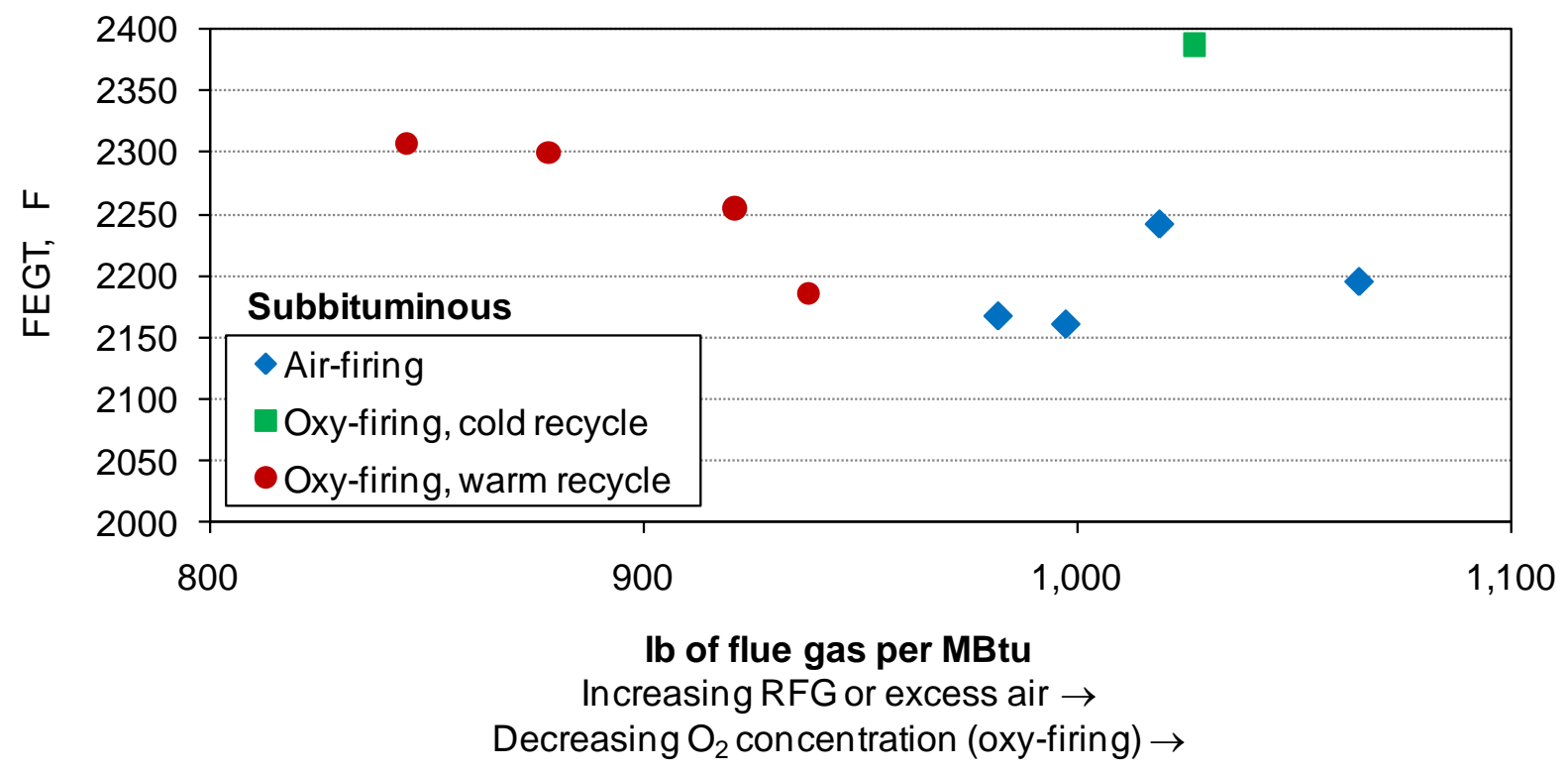

Figure 3.60 Effect of reduced flue gas recycle on FEGT 
Further discussion of heat transfer, temperature profiles, and gas radiation properties appears in Section 3.1.5.

\subsubsection{6. $\quad$ Factors that Affect and Control $\mathrm{CO}_{2}-{ }_{2}$ Concentrations (Air Infiltration)}

As the primary purpose of oxy-firing is generating a $\mathrm{CO}_{2}$-rich flue gas that can be easily stored, the concentration of $\mathrm{CO}_{2}$ is of prime interest. $\mathrm{CO}_{2}$ concentrations are affected by air infiltration and impurities introduced to the process with the oxygen. There is also some nitrogen in coal that is partially converted to $\mathrm{N}_{2}$, but the amount is typically small in comparison with the other aforementioned sources. During these pilot-scale tests, liquid oxygen was used (purity above 99.8\%); therefore, the only major source of impurities was air infiltration which will be discussed.

Air infiltration is an influx of outside air into the process gas. The sources of air infiltration are areas in the process that operate under negative pressure primarily located between the convection pass outlet and the ID fan inlet. Air can also infiltrate at the inlets of the primary and secondary forced draft fans. When a unit is run under air-firing conditions, the impact on flue gas composition is unimportant because it mixes with the flue gas and goes up the stack, but in oxyfiring when flue gas is recycled, it is a significant factor since nitrogen is introduced into the process, diluting the $\mathrm{CO}_{2}$ concentration.

During fabrication and erection of SBS-II, with insight gained from the previous oxy-firing R\&D projects (see Section 3.1.6 - Wall-firing Pilot Scale Testing and Analysis), an attempt was made to seal as many sources of air infiltration, such as fan shafts, fan inlets, flue work, as was practical. During start-up and shakedown of the SBS-II, the unit was checked and several air leaks were located and repaired. A major leak was found in the connection at the duct work at the outlet of CHX. Figure 3.61 shows a large difference between the oxygen measurements at the inlet and outlet of $\mathrm{CHX}$ indicating an air leak.

Boiler operation can minimize the air in the boiler. For a balanced draft boiler, a balance point is typically set at the radiant boiler, before the convection pass and minimal air infiltration is expected in the radiant boiler and convection pass. A significant factor on the amount of air infiltration is pressure drop across the major back-end equipment. The boiler back-end equipment is operating under negative pressure and is a large source of the air infiltration. The pilot-scale investigation showed that air infiltration increased when the pressure drop between the convection pass outlet and the ID fan inlet went up. Figure 3.62 shows the effect of air infiltration on $\mathrm{CO}_{2}$ concentration during oxy-firing. It should be noted that during oxy-firing with bituminous coal, a wet FGD was used to scrub $\mathrm{SO}_{2}$ and the overall back-end pressure drop was higher than the tests with lignite and subbituminous coal.

Figure 3.63 shows the $\mathrm{CO}_{2}$ concentration at the optimum conditions. For the subbituminous coal, up to $90 \% \mathrm{CO}_{2}$ was achieved while the $\mathrm{CO}_{2}$ for bituminous coal was $73 \%$ due to the additional pressure drop caused by the scrubber. The high level of $\mathrm{CO}_{2}$ concentration achieved in the SBSII is remarkable and helps reduce the energy requirement and cost of the CPU system as discussed in Section 3.2.2.3.2 of this report. 


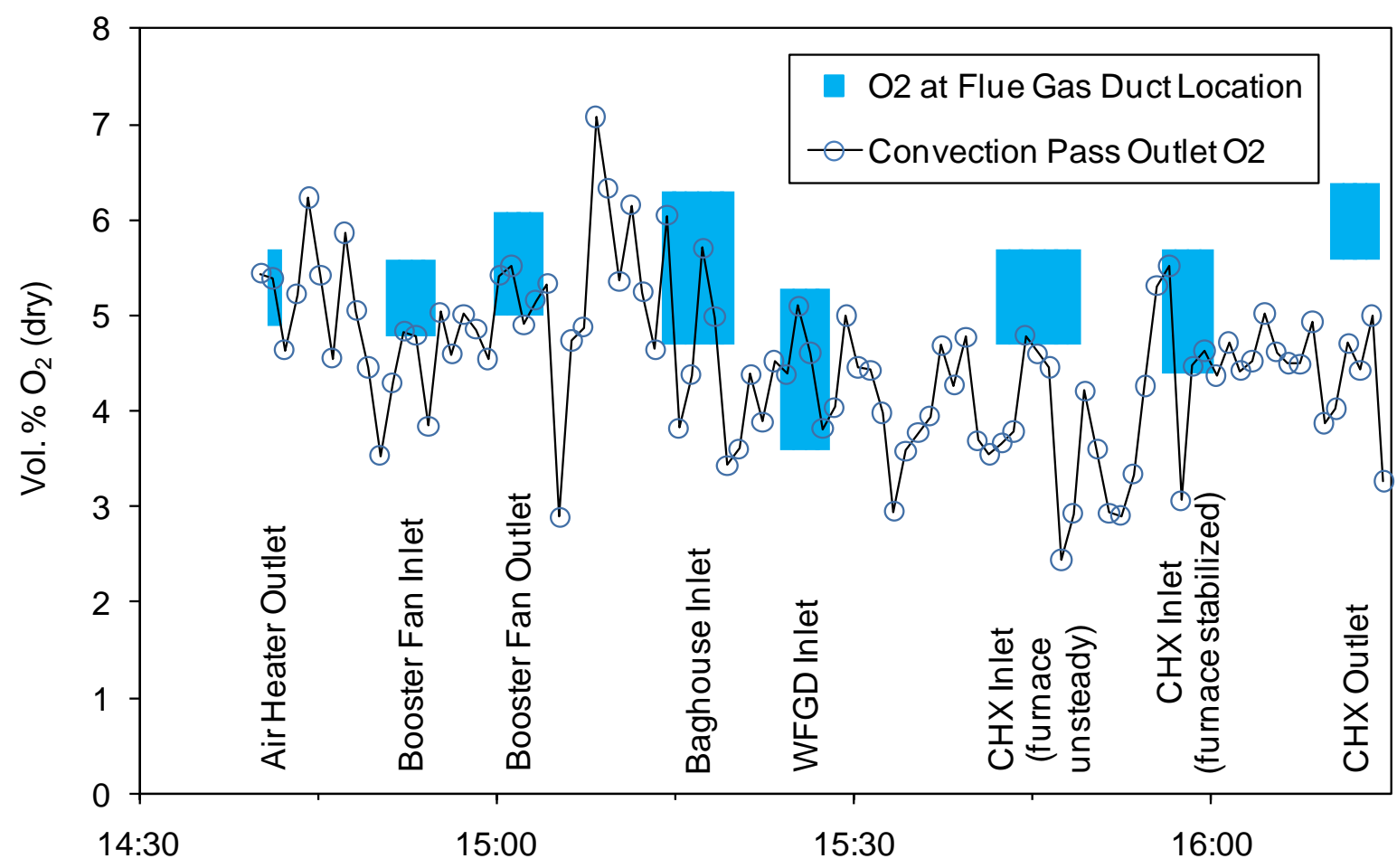

Figure 3.61 Oxygen measurements in the flue gas path compared to simultaneous measurements of convection pass exit $\mathrm{O}_{2}(7 / 29 / 2009)$

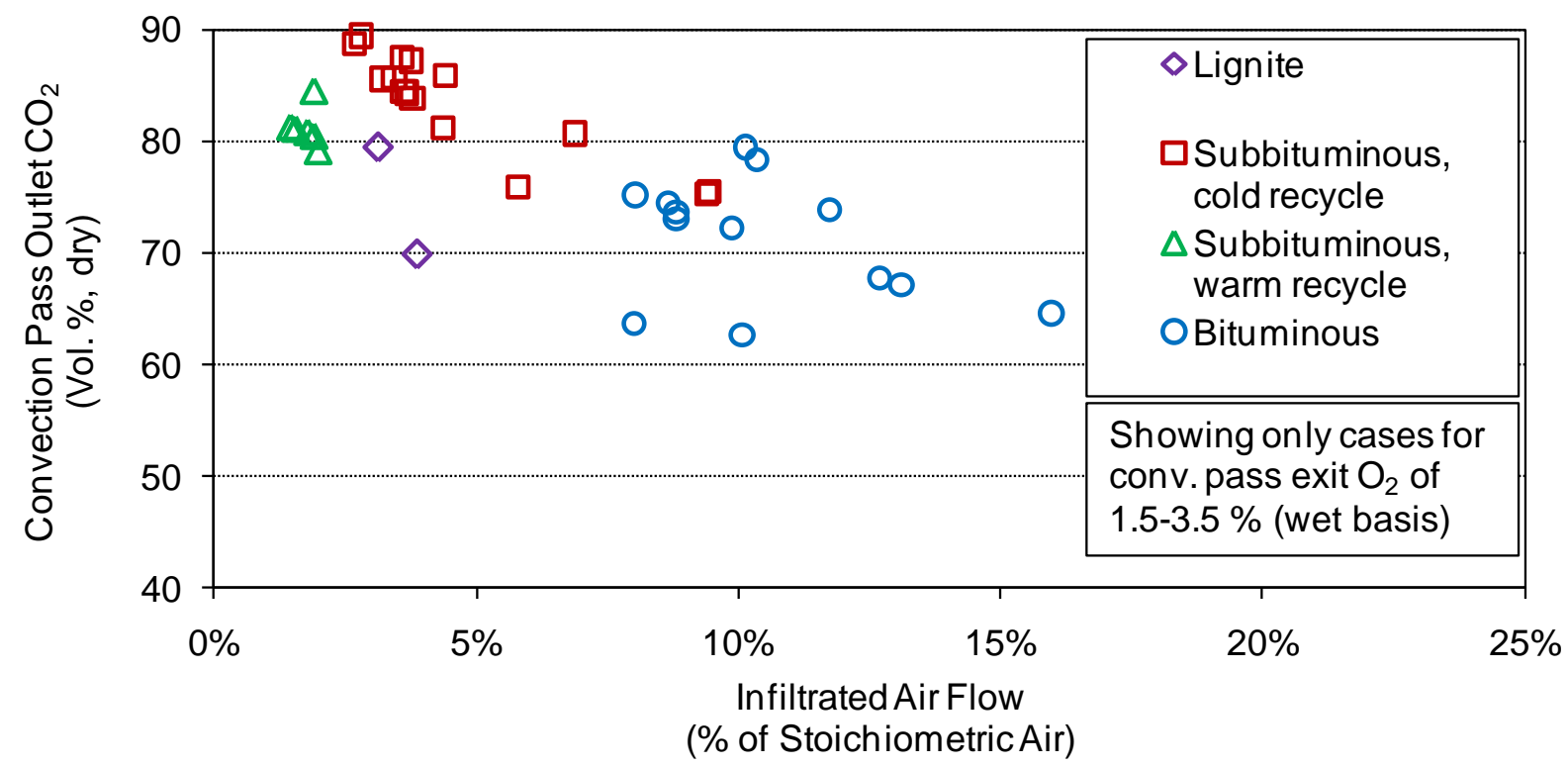

Figure 3.62 Effect of air infiltration on $\mathrm{CO}_{2}$ concentration 


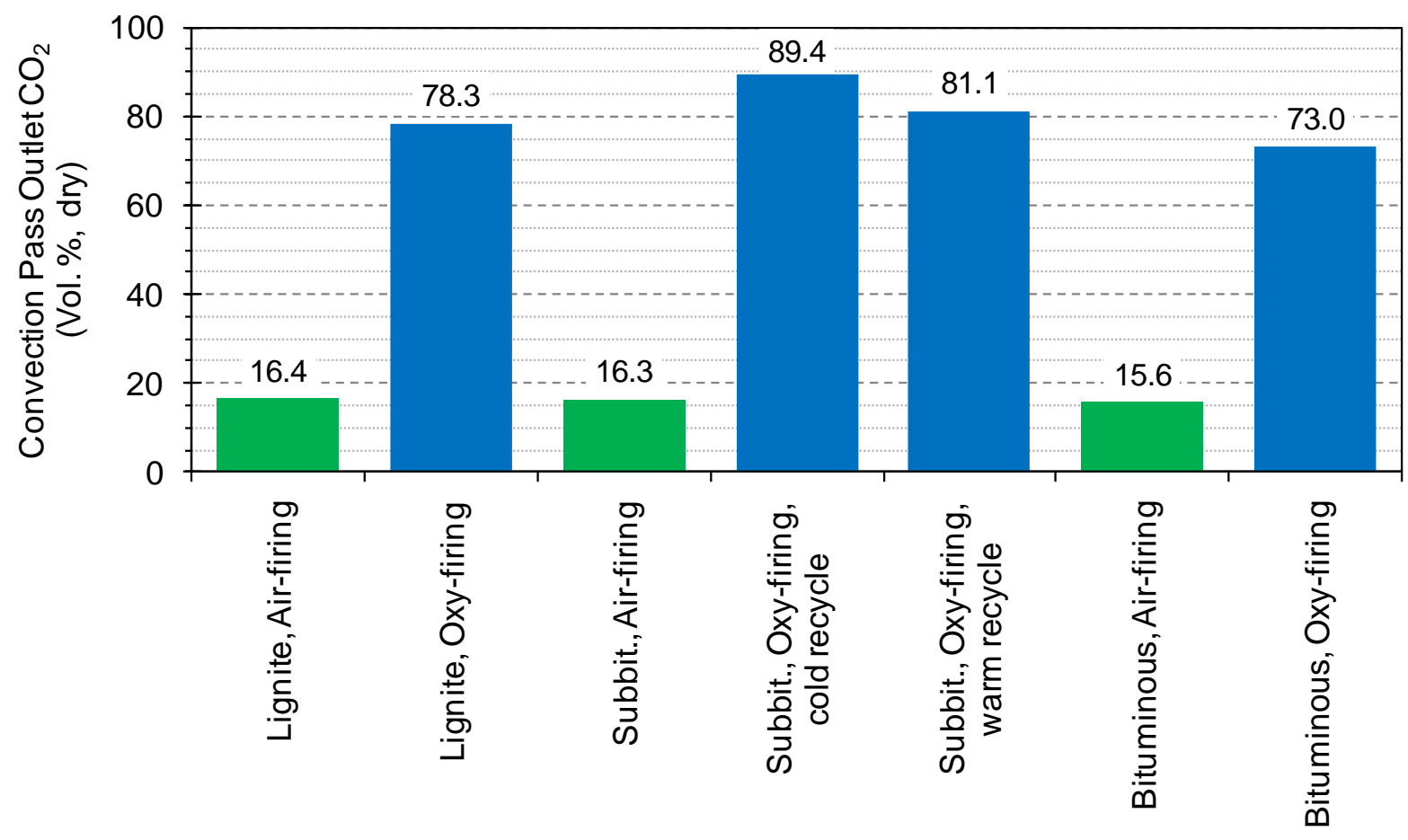

Figure 3.63 $\mathrm{CO}_{2}$ concentrations achieved with various coals and oxy-firing process

\subsubsection{Computational Model Validation}

As part of this research project, numerical modeling was conducted with the objective of seeing: 1) if state of the art computational fluid dynamics could reasonably predict heat absorption under different conditions; and 2) to better understand the heat transfer characteristics in the furnace under oxy-firing conditions.

B\&W has leading edge capabilities for computational fluid dynamics (CFD) and combustion modeling. These capabilities were developed over the past 25 years and have culminated in the proprietary combustion model $\mathrm{COMO}^{\mathrm{SM}}$. This model has been used routinely at $\mathrm{B} \& \mathrm{~W}$ for more than a decade for improving the design and operation of boilers, boiler components, and combustion equipment. The CFD model uses an unstructured mesh with a mixture of element shapes for greater geometric flexibility, and adaptive mesh refinement to control resolution in regions of high gradients (e.g. turbulent jets, diffusion flames, etc.). COMO includes advanced capabilities for simulating turbulent flow, energy and radiation, heterogeneous reactions, particle transport, deposition, surface reactions, gas phase reactions, and tube banks. Physical models for coal combustion and emissions $\left(\mathrm{CO}\right.$ and $\left.\mathrm{NO}_{\mathrm{X}}\right)$ are maintained and improved on a continuous basis.

Specialized capabilities for Cyclone combustors were developed for predicting coal particle deposition and combustion on Cyclone walls and furnace walls. Combustion reactions of coal deposits on these surfaces include coal drying, devolatilization, and char combustion/gasification which are an extension of coal particle combustion mechanisms to planar surfaces of porous char deposits. Combustion reactions are controlled by heterogeneous chemical kinetics and heat/mass 
transfer with local gas species near the surface. The model assumes quasi-steady state conditions, in which fuel reacts wherever particles are deposited. Equations for mass and energy balances are solved at every surface element of the mesh where coal-ash deposition and reactions occur, and are included in the calculation of deposit surface temperature and wall heat absorption. Conduction heat transfer through the water-cooled metal wall, refractory, and slag layer is calculated using a thermal heat conductance which is specified as input for each wall boundary.

The primary limitation of the model for Cyclone combustion applications is that it does not predict molten slag flow, char transport, slag melting/solidification, or slag build-up on the walls. Therefore, the model does not consider these effects on local slag thickness and wall thermal conductance. Future development of coal combustion sub-models is planned (or proposed) to include these mechanisms with more extensive validation from bench- and pilot-scale combustion data.

The model was based on as-built furnace dimensions and insulation specifications. Figure 2.4 and Figure 2.7 presented in the Methods and Approach section show the furnace geometry used in this model. The oxygen lance in the cases modeled was in the secondary duct position intended to mix the oxygen before the Cyclone entrance, thus, in the model, the oxygen from the oxygen lance was premixed with the Cyclone secondary oxidant. The numerical model contained approximately 1,220,000 control volumes.

Pilot scale test data as given in this report for the subbituminous coal warm recycle testing was used to model three cases as shown in Table 3.18: air firing, oxy-firing with low levels of recycled flue gas, and oxy-firing with high levels of recycled flue gas. Case 3 has a secondary oxidant flow rate about $21 \%$ higher than that for Case 2, which leads to a shorter gas residence time in the furnace, potentially altering the heat transfer characteristics.

\begin{tabular}{|r|l|l|l|}
\hline Model Case: & Case 1 & Case 2 & Case 3 \\
\hline $\begin{array}{r}\text { Conditions: } \\
\text { Test Name }\end{array}$ & Air Firing & Oxy-firing (Low RFG) & Oxy-firing (High RFG) \\
\hline $\begin{array}{r}\text { (see Tabulated Pilot- } \\
\text { scale Test Data } \\
\text { in the Appendix) }\end{array}$ & $\begin{array}{c}\text { Warm Rec- } \\
\text { PRB Air Test 2e }\end{array}$ & Warm Rec PRB Oxy 1 & warm rec oxy prb 5 \\
\hline
\end{tabular}

Table 3.18 List of pilot scale tests modeled with CFD

The thermal input and the Cyclone stoichiometry for the three cases were similar. The furnace stoichiometric ratio for the air-firing case was slightly higher than that for the oxy-firing conditions. The oxygen concentration in the primary and tertiary streams was approximately the same for all three cases, but that in the secondary stream was significantly higher for the oxyfiring conditions. Air infiltration is simulated using the nitrogen content of the oxidant streams calculated by the pilot scale data analysis system. For the oxy-firing conditions, the oxidant streams contained roughly $10 \%$ (by volume) nitrogen.

Thermal boundary conditions such as wall conductance and emissivity of the furnace walls, which represent a combination of insulation and ash deposits, were assumed to be the same for all the cases presented here. An adiabatic boundary condition was used for the wall insulated with firebricks shown in Figure 2.7. A uniform surface emissivity of 0.9 was used for the 
Cyclone furnace and an emissivity of 0.6 was used for the SBS-II to account for ash deposition on the surfaces.

The model predictions of mass-averaged gas temperature, mass-averaged gas species concentrations, and heat absorption are shown in Table 3.19. Pilot scale test data are also shown for comparison.

In Table 3.19 the predicted gas temperatures at the Cyclone exit are shown first. During the testing, a FlameView ${ }^{\mathrm{TM}}$ camera was used to measure the gas temperature at the Cyclone exit. For Case 2, a maximum gas temperature of $3200^{\circ} \mathrm{F}$ was observed, while the model predicts a maximum temperature of $3586^{\circ} \mathrm{F}$ and an average gas temperature of $3197^{\circ} \mathrm{F}$. For Case 3 , the measured maximum gas temperature is $3100^{\circ} \mathrm{F}$, while the predicted maximum and average gas temperatures are $3318^{\circ} \mathrm{F}$ and $3047^{\circ} \mathrm{F}$, respectively. For the air-firing case, no test data was reported. Case 2 is expected to have a higher maximum gas temperature due to a lower recycled flue gas flow rate and a higher oxygen concentration in the secondary oxidant stream.

The furnace exit gas temperature (FEGT) was sampled using a high velocity thermocouple (HVT). A probe was inserted into the furnace from the right-hand side wall, and gas temperature at five different locations was measured. An average of the measured gas temperatures, corrected for radiation heat loss from the thermocouple to surrounding surfaces (19) is reported in Table 3.19 and in Figure 3.64, in comparison with the model predictions. The predicted FEGT is in good agreement with the measured gas temperature for Cases 1 and 3. However, for Case 2, the disparity between the predicted and the measured FEGT is $106^{\circ} \mathrm{F}$. Possible reasons for this disparity will be discussed shortly.

Table 3.19 also shows the predicted mass-averaged gas temperature at the convection pass exit in comparison with measurements. For Cases 1 and 3, the difference between the predicted gas temperature and the measurements is within $40^{\circ} \mathrm{F}$. For Case 2 , the difference is $79^{\circ} \mathrm{F}$. Note that the predicted temperatures are mass-averaged values, while the measurements were made at a single point. Examination of the predicted gas temperature distribution at the convection pass exit for Case 2 indicates that the difference between the maximum and minimum gas temperatures is about $60^{\circ} \mathrm{F}$. The non-uniform temperature distribution at the convection pass exit may partially contribute to the difference in gas temperature between the model predictions and test data.

Concentrations of gas species at the convection pass exit (the model exit) are compared in Table 3.19. For major gas species, the model predictions are generally in agreement with the measurements, indicating that the fuel to oxidant ratios used in the model are similar to the actual test conditions. For all the cases, the model predicts negligible $\mathrm{CO}$ emissions at the convection pass exit, while the measured $\mathrm{CO}$ concentrations were less than $30 \mathrm{ppm}$. Predicted gas species concentrations at the Cyclone exit are also reported in Table 3.19 for reference. CO concentrations at this location are $2 \%$ or higher for all three cases. 


\begin{tabular}{|c|c|c|c|c|c|c|c|}
\hline \multirow{2}{*}{\multicolumn{2}{|c|}{ Predicted Furnace Effluents }} & \multicolumn{2}{|c|}{ Case 1} & \multicolumn{2}{|c|}{ Case 2} & \multicolumn{2}{|c|}{ Case 3} \\
\hline & & Test & сOMO & Test & сомо & Test & COMO \\
\hline \multicolumn{2}{|c|}{ Firing Mode } & \multicolumn{2}{|c|}{ Air-Firing } & \multicolumn{2}{|c|}{ Oxy-Firing: Low RFG } & \multicolumn{2}{|c|}{ Oxy-Firing: High RFG } \\
\hline \multicolumn{2}{|c|}{ Test Date } & \multicolumn{2}{|c|}{$9 / 15 / 2009$} & \multicolumn{2}{|c|}{ 9/17/2009 } & \multicolumn{2}{|c|}{$9 / 17 / 2009$} \\
\hline \multicolumn{2}{|c|}{ Test Start Time } & \multicolumn{2}{|c|}{$8: 44$} & \multicolumn{2}{|c|}{$12: 45$} & \multicolumn{2}{|c|}{ 18:02 } \\
\hline \multicolumn{2}{|c|}{ Gas Temperature } & & & & & & \\
\hline Cyclone Exit & $\left({ }^{\circ} \mathrm{F}\right)$ & - & 3185 & 3200 (max) & 3197 & 3100 (max) & 3047 \\
\hline FEGT (corrected) & $\left({ }^{\circ} \mathrm{F}\right)$ & 2259 & 2253 & 2381 & 2275 & 2249 & 2251 \\
\hline Convection Pass Exit & $\left({ }^{\circ} \mathrm{F}\right)$ & 821 & 820 & 809 & 730 & 831 & 795 \\
\hline \multicolumn{2}{|c|}{ Gas Composition (Cyclone Exit) } & & & & & & \\
\hline \multirow[t]{7}{*}{ wet, vol.\% } & $\mathrm{H}_{2} \mathrm{O}$ & - & 14.12 & - & 34.79 & - & 35.54 \\
\hline & $\mathrm{CO}_{2}$ & - & 13.74 & - & 51.34 & - & 52.64 \\
\hline & $\mathrm{O}_{2}$ & - & 1.48 & - & 2.14 & - & 1.93 \\
\hline & $\mathrm{N}_{2}$ & - & 68.41 & - & 8.67 & - & 7.33 \\
\hline & $\mathrm{CO}$ & - & 1.94 & - & 2.59 & - & 2.17 \\
\hline & $\mathrm{H}_{2}$ & - & 0.17 & - & 0.24 & - & 0.18 \\
\hline & minors & - & 0.14 & - & 0.23 & - & 0.22 \\
\hline \multicolumn{8}{|c|}{ Gas Composition (Convection Pass Exit) } \\
\hline \multirow[t]{2}{*}{ dry, vol. \% } & $\mathrm{CO}_{2}$ & 15.52 & 15.37 & 79.03 & 82.21 & 81.22 & 83.60 \\
\hline & $\mathrm{O}_{2}$ & 3.98 & 4.00 & 4.25 & 3.99 & 4.66 & 4.66 \\
\hline dry, ppm & $\mathrm{CO}$ & 23 & 0.00 & 28 & 0.00 & 27 & 0.00 \\
\hline Flue Gas Flow Rate & (lb/hr) & 5922 & 5932 & 4869 & 4791 & 5477 & 5389 \\
\hline \multicolumn{2}{|c|}{ Heat Absorption } & & & & & & \\
\hline Cyclone & (MBtu/hr) & 0.45 & 0.44 & 0.64 & 0.45 & 0.49 & 0.43 \\
\hline Furnace & (MBtu/hr) & 2.26 & 2.15 & 2.67 & 2.41 & 2.54 & 2.20 \\
\hline Convection Pass & (MBtu/hr) & 1.76 & 2.22 & 1.69 & 2.13 & 1.84 & 2.28 \\
\hline Total Absorption & (MBtu/hr) & 4.47 & 4.80 & 5.00 & 4.99 & 4.87 & 4.91 \\
\hline Total Available Energy* & (MBtu/hr) & 4.83 & 4.83 & 4.84 & 4.99 & 4.83 & 4.91 \\
\hline Net Balance & (\%) & 7.49 & 0.54 & -3.28 & -0.05 & -0.92 & 0.06 \\
\hline \multicolumn{2}{|c|}{ Carbon Exiting with Slag (\% of Initial C) } & - & 0.17 & - & 0.02 & - & 0.03 \\
\hline Entrained Carbon Exit & $\%$ of Initial C) & - & 3.31 & - & 2.70 & - & 2.48 \\
\hline Entrained Ash Exiting & f Initial Ash) & - & 18.58 & - & 17.19 & - & 15.68 \\
\hline
\end{tabular}

* Total available energy is based on inlet fuel and oxidant, outlet flue gas flow and slag flow leaving the system at their respective temperatures. Slag flow rate and temperature for test conditions were estimated assuming $80 \%$ of the fuel ash leaving the system as molten slag at ash fluid temperature under reducing conditions.

\section{Table 3.19 Summary of modeling predictions compared to available pilot-scale test data.}




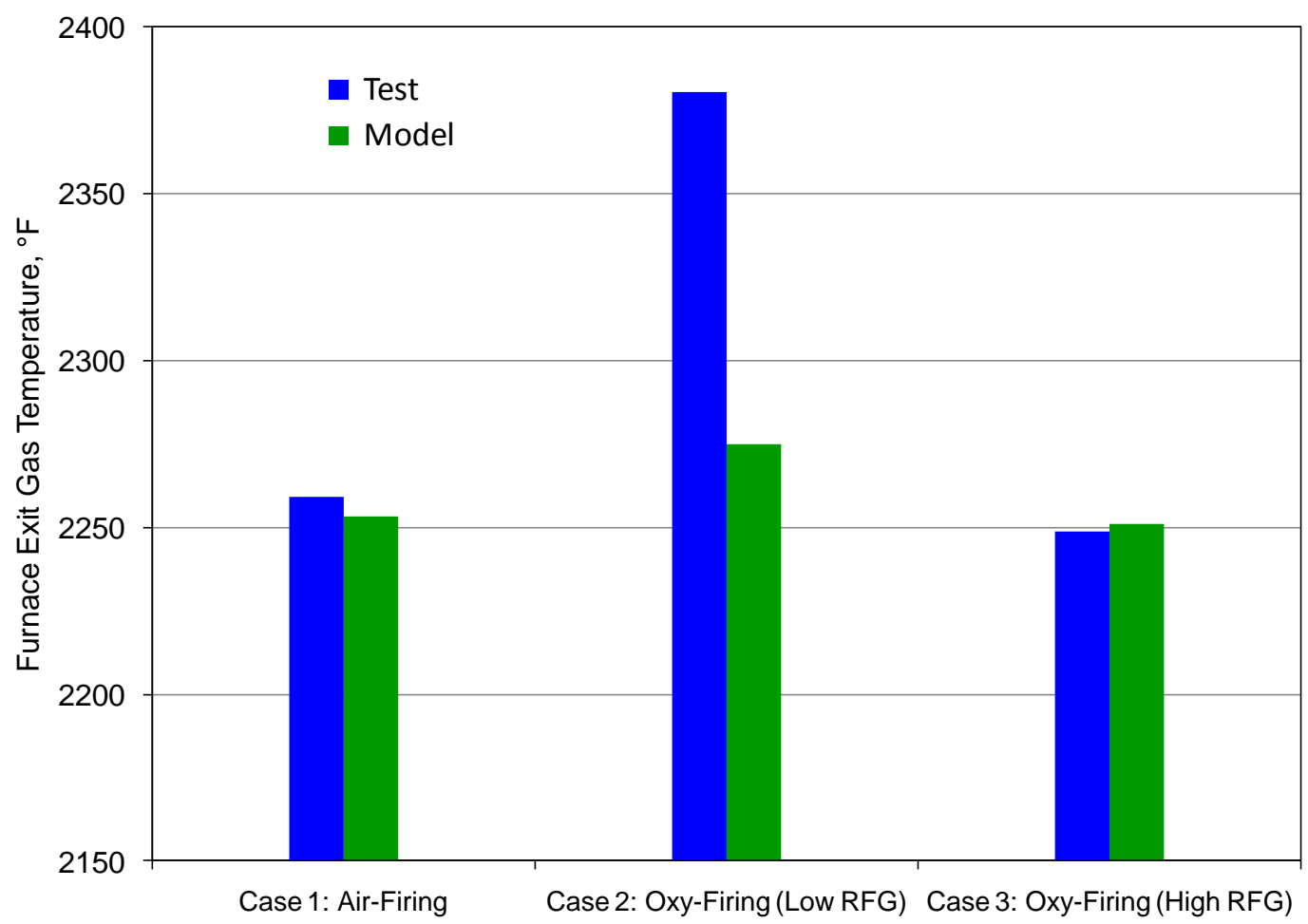

Figure 3.64 Comparison of FEGT between model predictions and measurements: air-fired baseline and two warm recycle cases

Also compared in Table 3.19 are predicted and measured heat absorption totals in the Cyclone, furnace, and convection pass. For the Cyclone, the model predictions are in good agreement with the measurements for both Case 1 and Case 3. For Case 2, the difference is about 30\%. This disparity may be attributed to changes in the surface conditions, such as changes in ash deposition and slag flow. During the testing, build-up was observed in the slag tap of the Cyclone for Cases 1 and 3, with Case 3 having more slag accumulation on the Cyclone surfaces. For Case 2, the slag tap was clear with little slag accumulation on the Cyclone surfaces. As mentioned earlier, the same thermal conductance was used for the Cyclone walls in the model for all three cases. Since the model does not predict molten slag flow and slag build-up on the walls, it appears that different thermal conductance would be required for different cases to improve agreement, especially for Case 2 in which Cyclone wall surfaces were cleaner than the other two cases.

Figure 3.65 illustrates the predicted heat flux through the Cyclone walls for the three cases. The model predicts very similar heat flux distributions for the air-firing and oxy-firing cases. The maximum heat flux occurs on the Cyclone barrel wall adjacent to the neck of the Cyclone, and is similar in magnitude for all three cases. The heat flux to the neck is lower than that to the barrel of the Cyclone. Particle deposition rate predictions (Figure 3.66) for the three cases are also similar and indicate particle deposition occurs mostly on the neck of the Cyclone, while the particle deposition on the barrel surface is very small. 


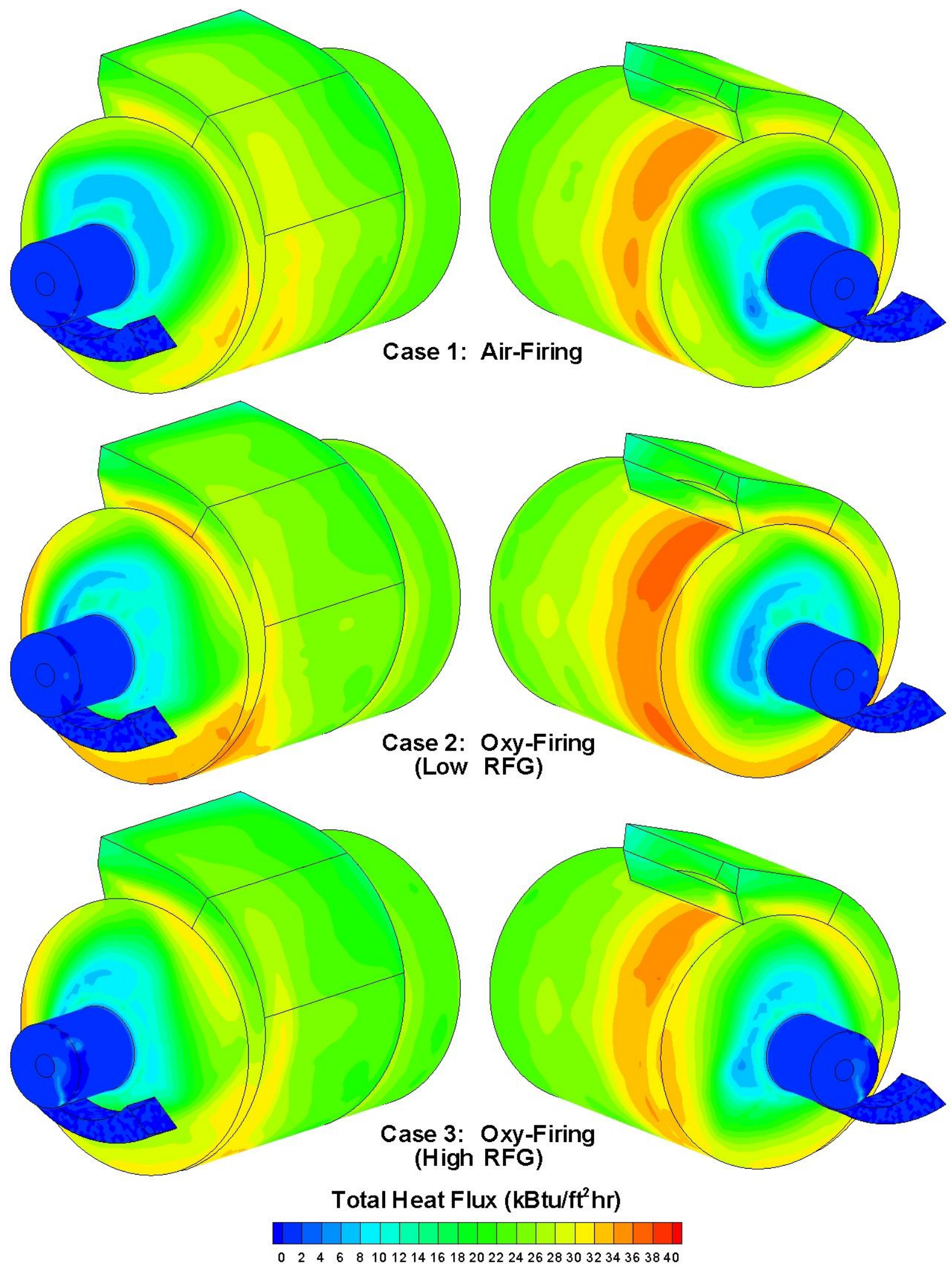

Figure 3.65 Predicted heat flux distribution on the Cyclone wall surfaces 


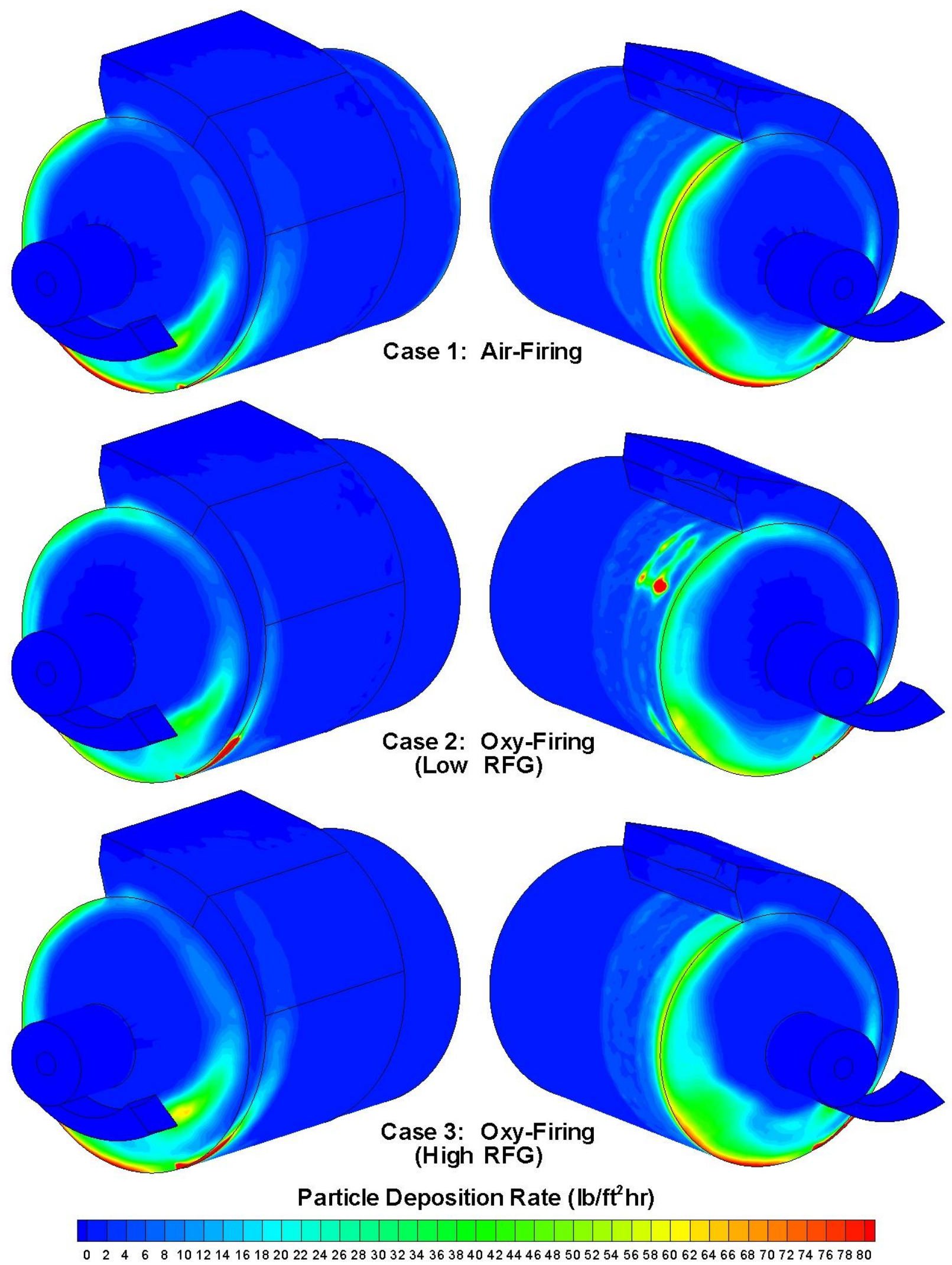

Figure 3.66 Predicted particle deposition rates on the Cyclone wall surfaces 

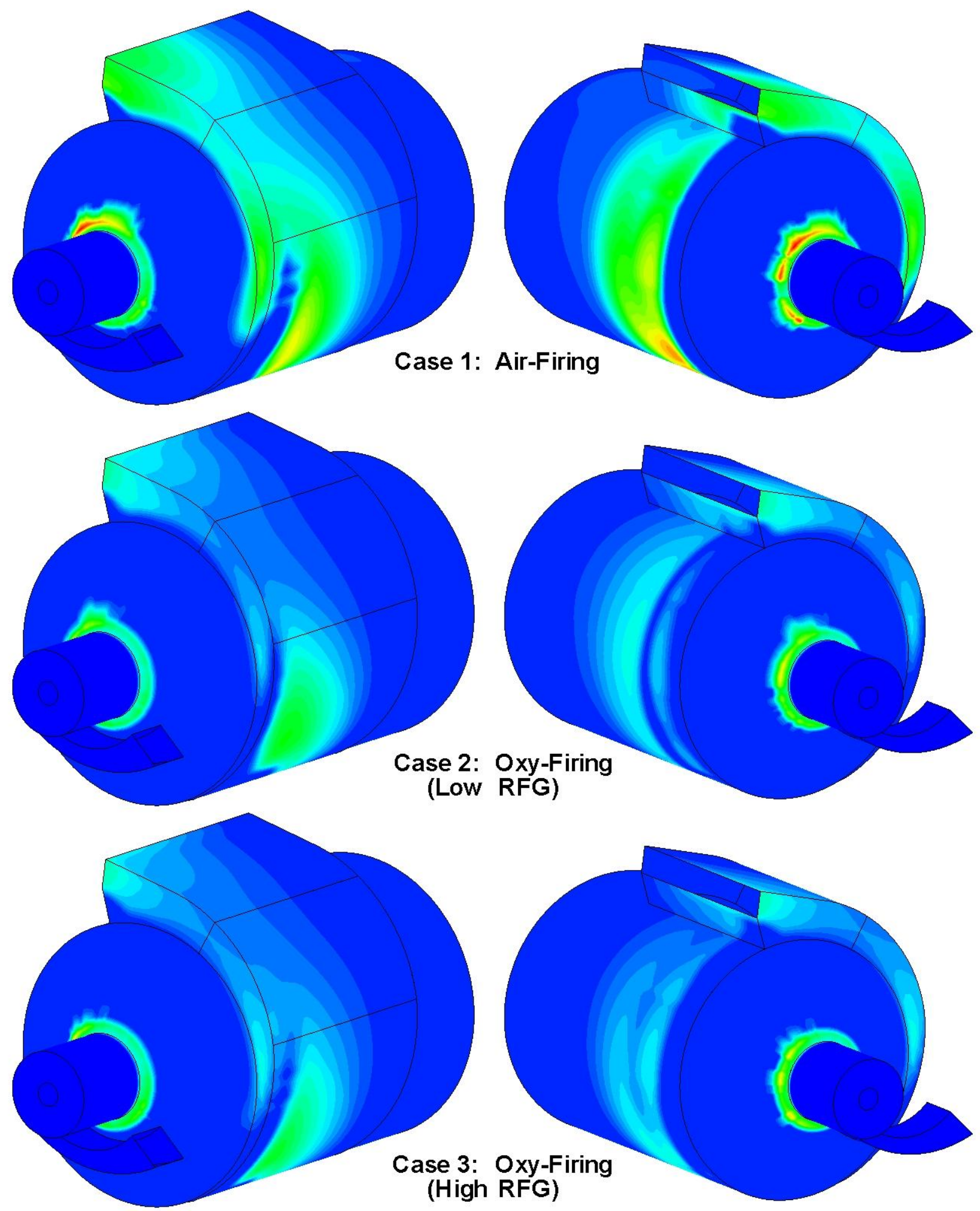

Carbon Oxidation Rate (lb/ft ${ }^{2} \mathrm{hr}$ )

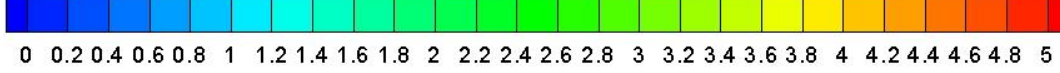

Figure 3.67 Predicted oxidation rate of deposited carbon on the Cyclone wall surfaces 

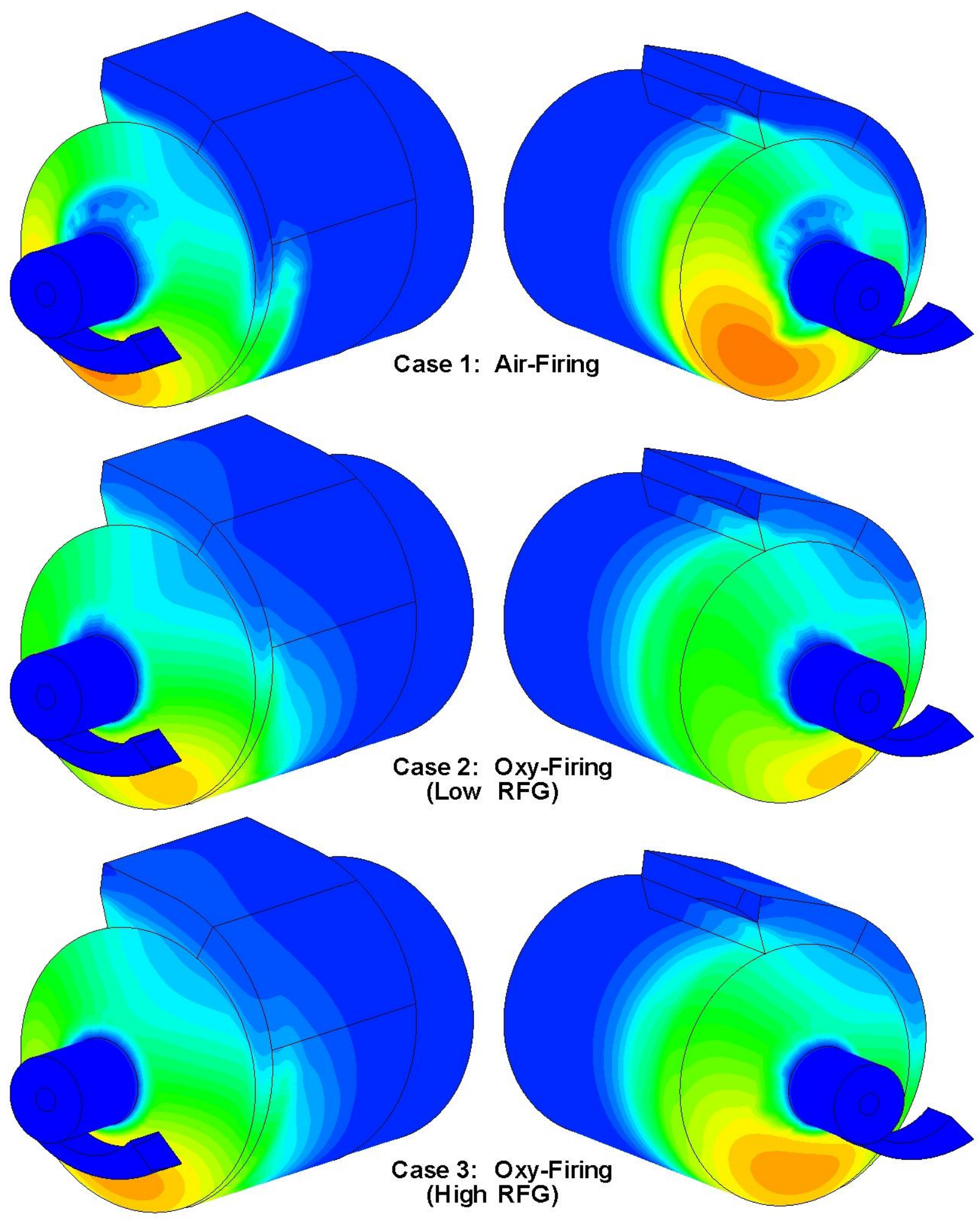

Carbon Gasification Rate (lb/ $\mathrm{ft}^{2} \mathrm{hr}$ )

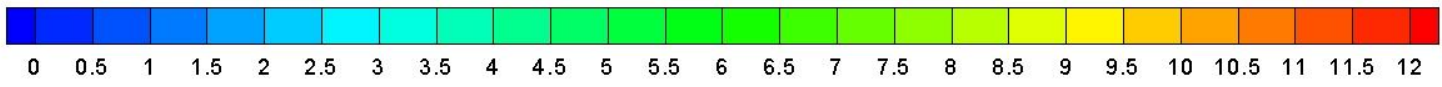

Figure 3.68 Predicted gasification rate of deposited carbon on the Cyclone wall surfaces 
The oxidation and gasification rates for the deposited carbon were also calculated (Figure 3.67 and Figure 3.68). Carbon oxidation rates are predicted higher on the barrel surface near the secondary inlet and on the neck around the scroll burner where oxygen concentration (Figure 3.69) is higher. At some regions of the neck where oxygen concentration is low and temperatures (Figure 3.70) are high carbon gasification rates are higher than carbon oxidation rates.
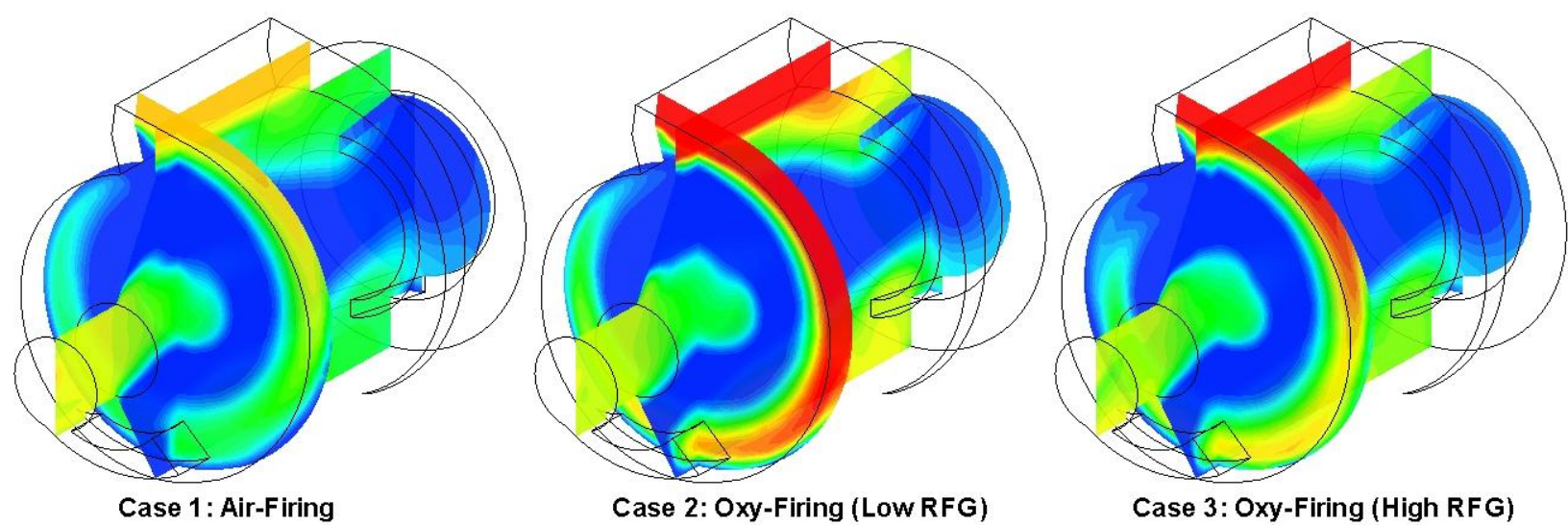

Oxygen Concentration (vol.\%, wet)

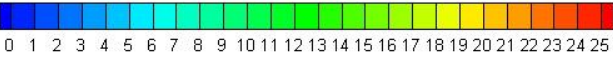

Figure 3.69 Predicted oxygen concentration profiles in the Cyclone
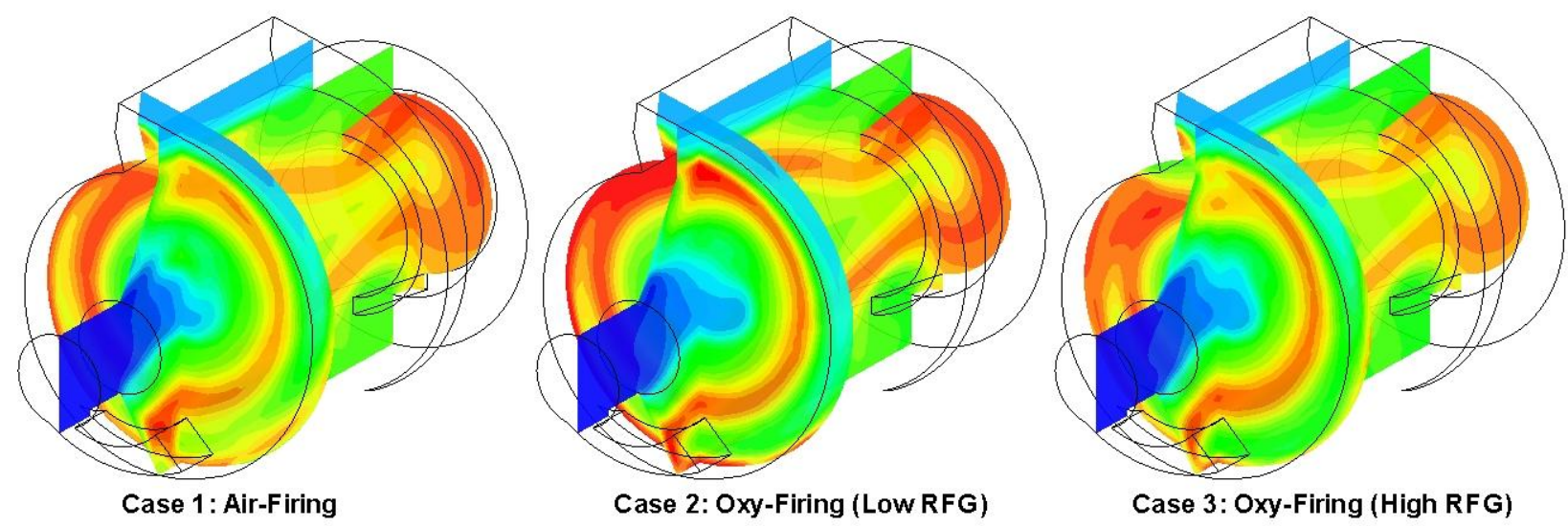

Gas Temperature $\left({ }^{\circ} \mathrm{F}\right)$

Figure 3.70 Predicted gas temperature profiles in the Cyclone

A comparison of predicted and measured heat absorption totals are shown in Figure 3.71 through Figure 3.73 for the Cyclone, furnace, and convection pass. The predictions for the furnace are in 
reasonable agreement with the measurements for all the three cases. The model also correctly predicts the trend in the measured convection pass heat absorption for the three cases; however, the predictions are higher by $26 \%$ for Cases 1 and 2, and 24\% for Case 3 . The reason for this disparity is attributed to lack of closure in the energy balance in the measurements, with most of the measurement error in the convection pass, indicated in Table 3.19. Note that the predicted heat absorption is in excellent agreement with the available energy calculated from a simple balance for all the three cases, with a maximum error of $0.54 \%$, while the test data has errors in the energy balance ranging from $-3.28 \%$ to $7.49 \%$.

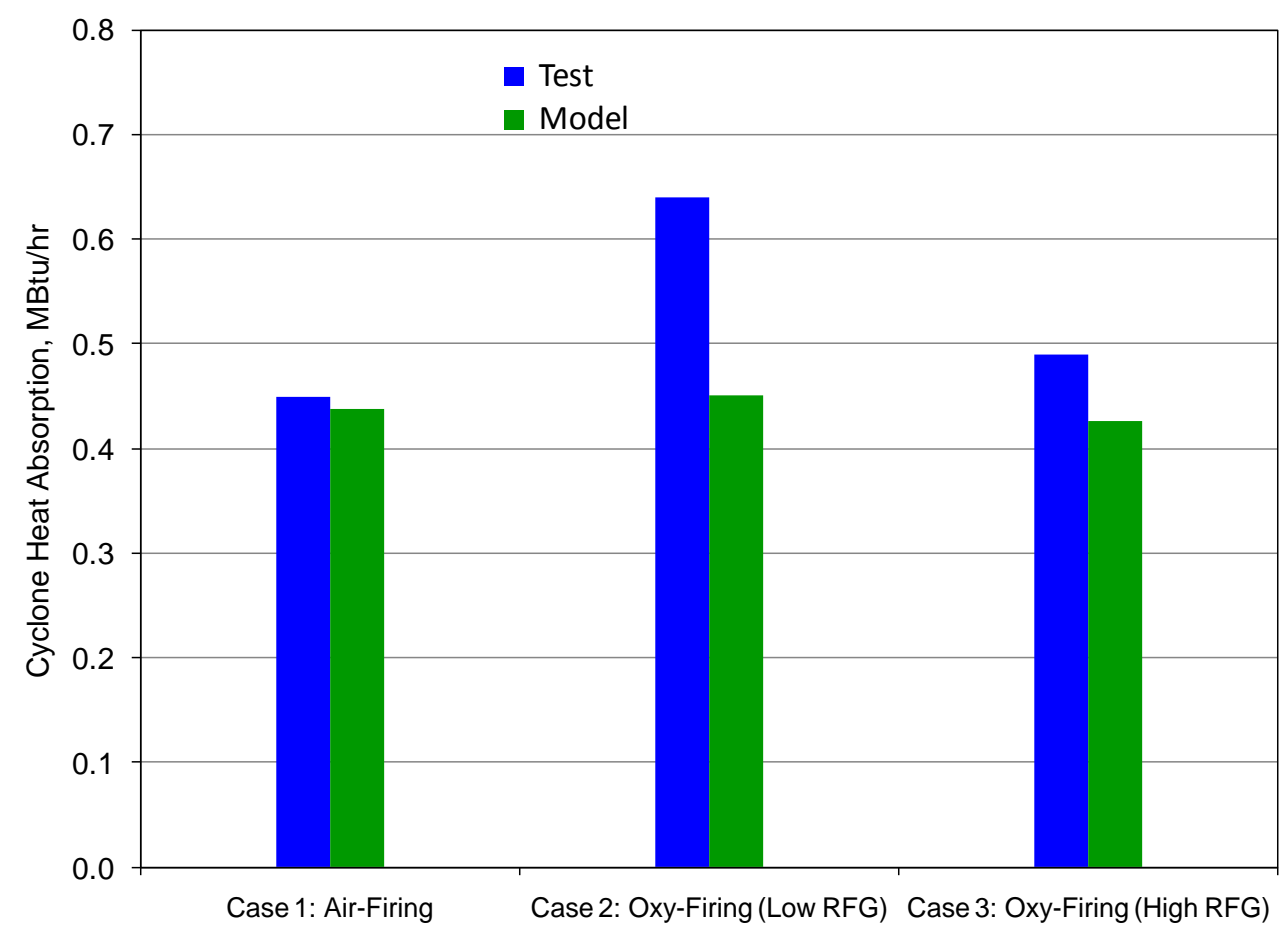

Figure 3.71 Comparison of measured and predicted heat absorption in the Cyclone: air-fired baseline and two warm recycle cases

Comparing modeling results and measurements, the largest disparities are noted for Case 2. Predicted gas temperatures at the furnace exit and the convection pass exit are lower than measured, while predicted heat absorption in the Cyclone and the furnace is also consistently lower. In addition to the changes in the surface conditions as discussed above, another possible cause for this disparity is experimental error in the fuel flow rate and other operating conditions used as inputs to the model. It is expected that model predictions for Case 2 would be in better agreement with measurements if fuel and oxidant flow rates were all increased proportionally to match the FEGT. 


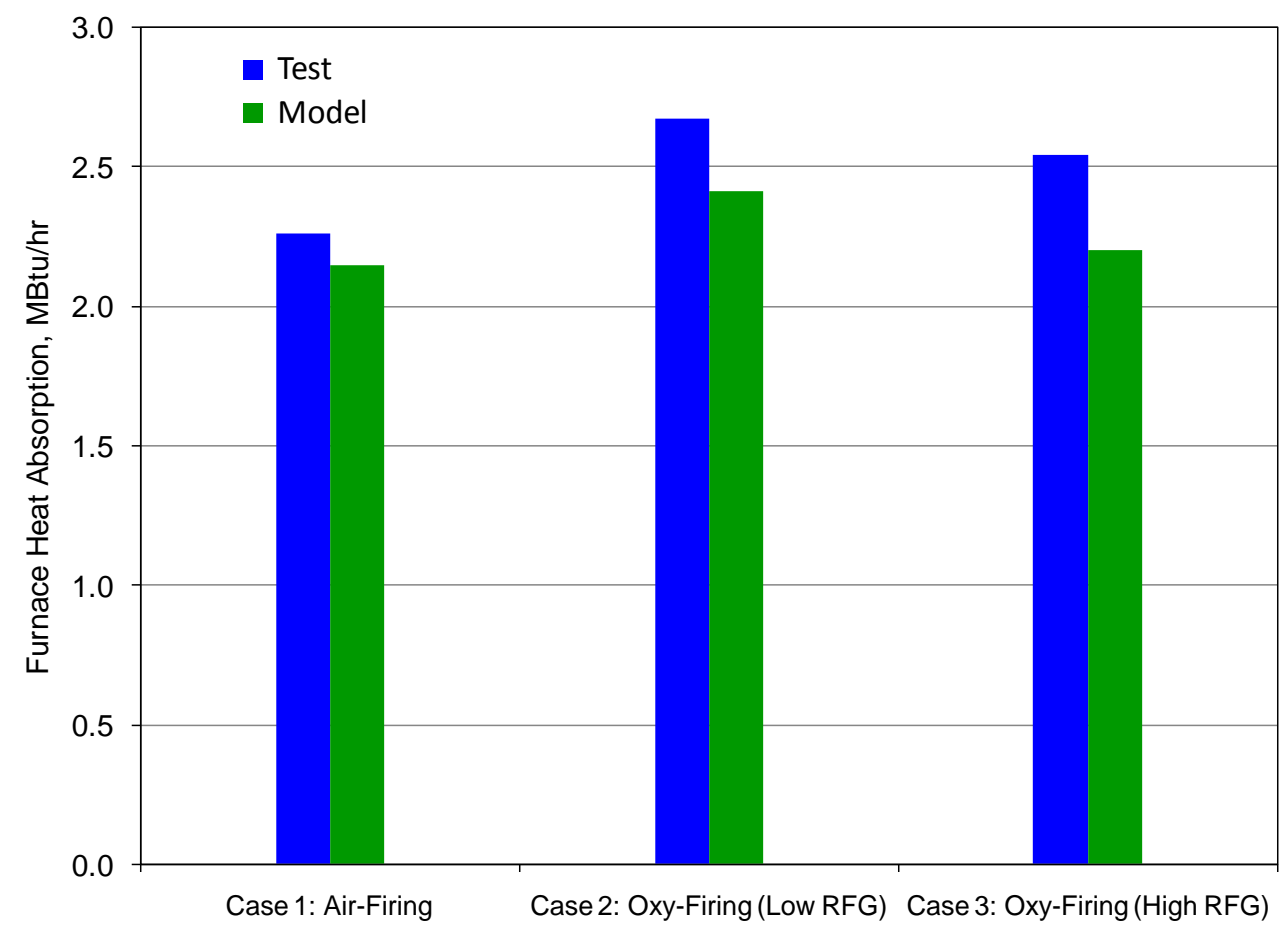

Figure 3.72 Comparison of measured and predicted heat absorption in the furnace (including the first two tube banks of the convection pass): air-fired baseline and two warm recycle cases 


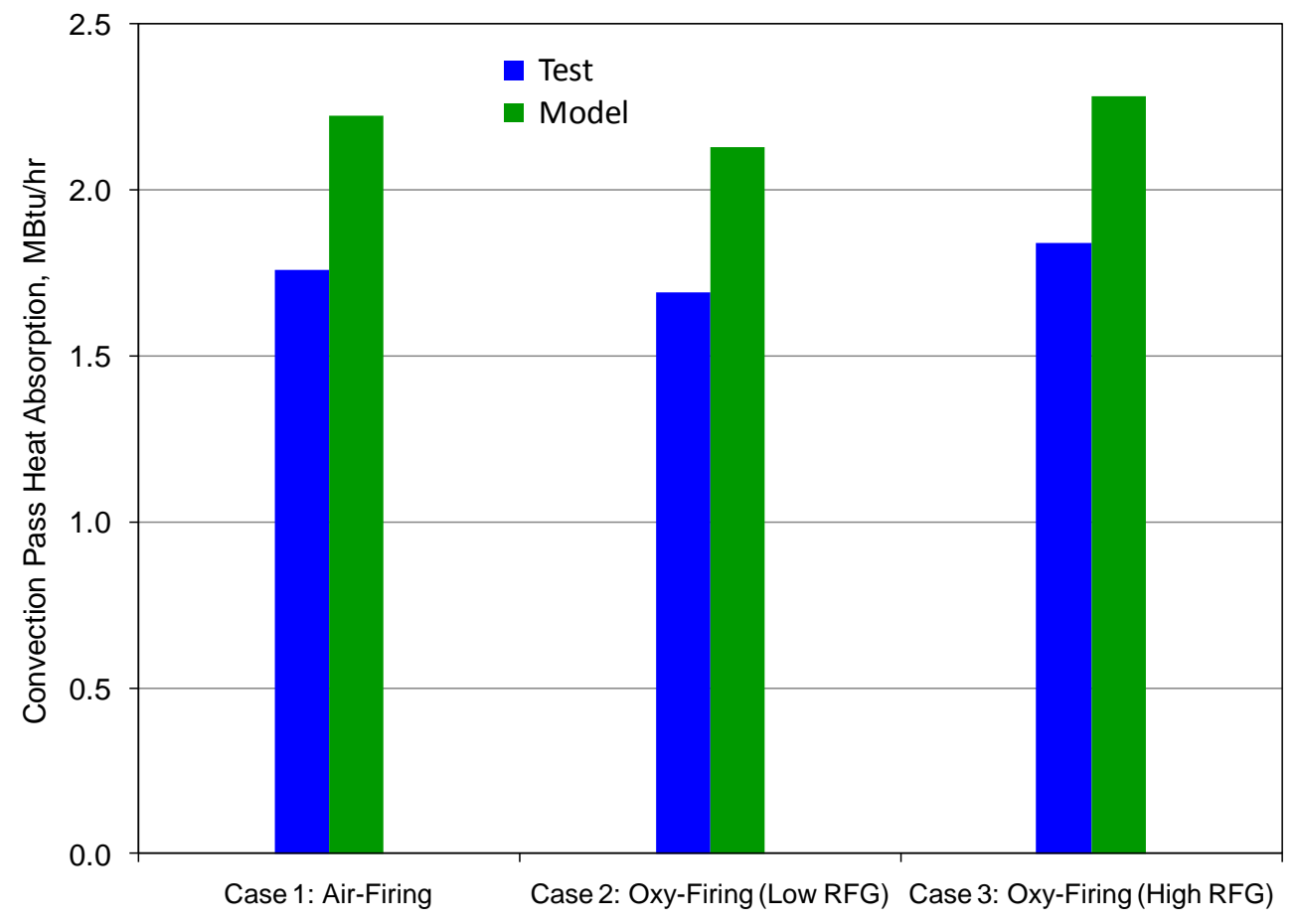

Figure 3.73 Comparison of measured and predicted heat absorption in the convection pass: air-fired baseline and two warm recycle cases (excluding tube banks 1 and 2)

The final predictions presented in Table 3.19 are unburned carbon trapped in molten slag, and carbon and ash carryover from the Cyclone to the furnace. For all the cases, the unburned carbon in slag is very small: $0.17 \%$ for the air-firing case and less than $0.03 \%$ for the oxy-firing cases. The carbon carryover from the Cyclone is in the range of $2.5 \%$ to $3.3 \%$, and the ash carryover is less than 20\%; the remainder of the fuel ash deposits on the Cyclone wall as molten slag.

The computational model also allows an exploration of heat transfer characteristics to compare air and oxy-firing. Local gas properties are extracted from the modeling results for comparison, along a centerline path shown in Figure 3.74. 


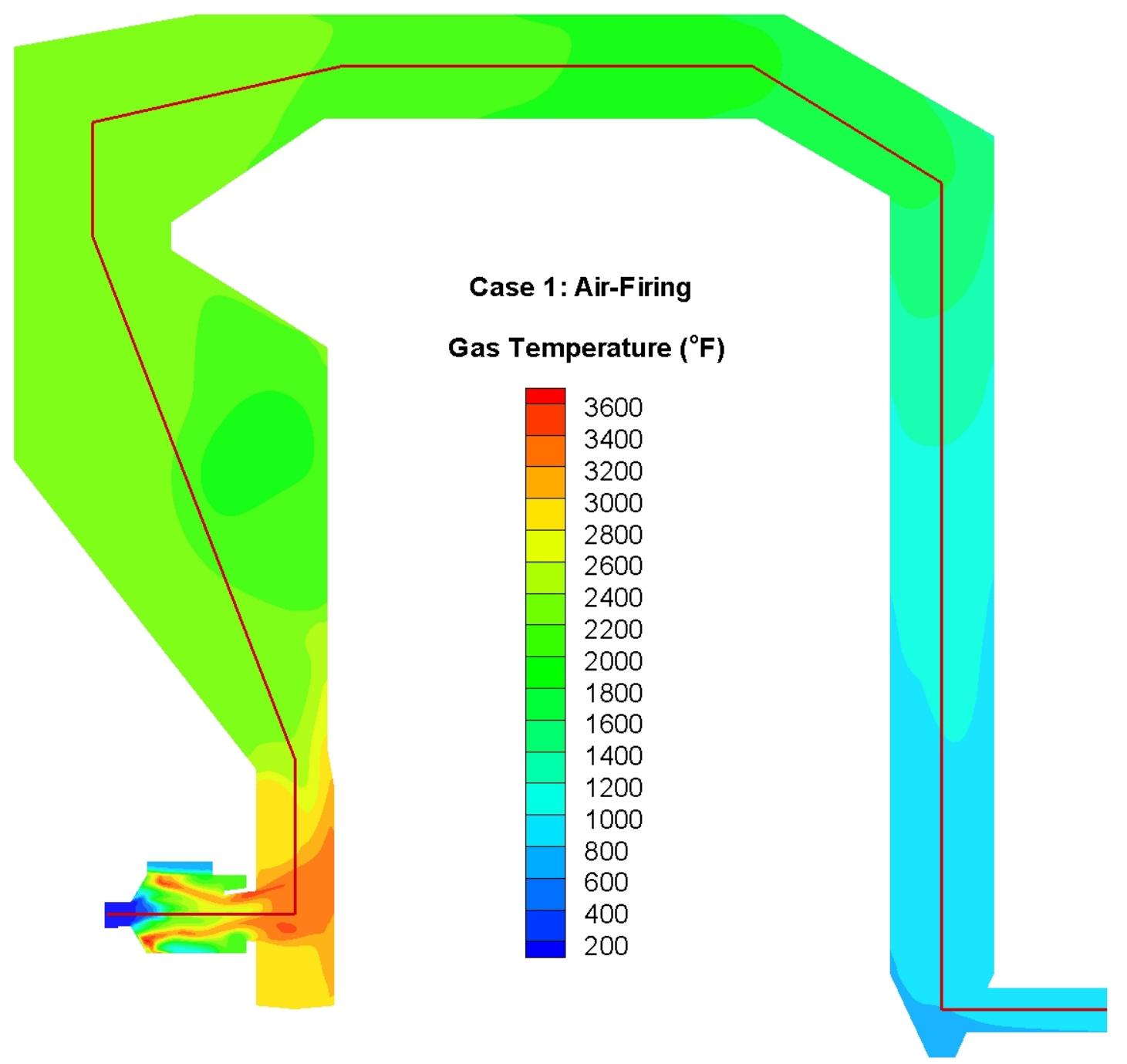

Figure 3.74 Path for extracting local gas properties in the Cyclone and SBS-II

Figure 3.75 presents the predicted local gas temperature as a function of the distance from the Cyclone tertiary inlet along the path shown in Figure 3.74. In this and similar figures the furnace is defined as the region from the Cyclone exit to the plane in the upper furnace/convection pass entrance that is the vertical extension of the furnace rear wall. The largest difference between air and oxy-firing appears in the region slightly below the OFA ports. The temperature profiles in Figure 3.76 suggest greater penetration of the OFA jets in the air-firing case, which is consistent with the higher mass flow in Case $1(1170 \mathrm{lb} / \mathrm{h})$ versus oxy-firing Cases 2 and 3(612 and $725 \mathrm{lb} / \mathrm{h}$ respectively). With this difference excepted, the predicted gas temperature profiles are qualitatively similar for the three cases. As suggested by the measurements for Case 1 and Case 3 (Table 3.19), with the appropriate operating conditions the furnace exit gas temperature could be matched for air and oxy-firing. However, the predictions indicate that when FEGT is matched, convection pass exit temperature is not. To understand these differences the various parameters affecting heat transfer are examined. 


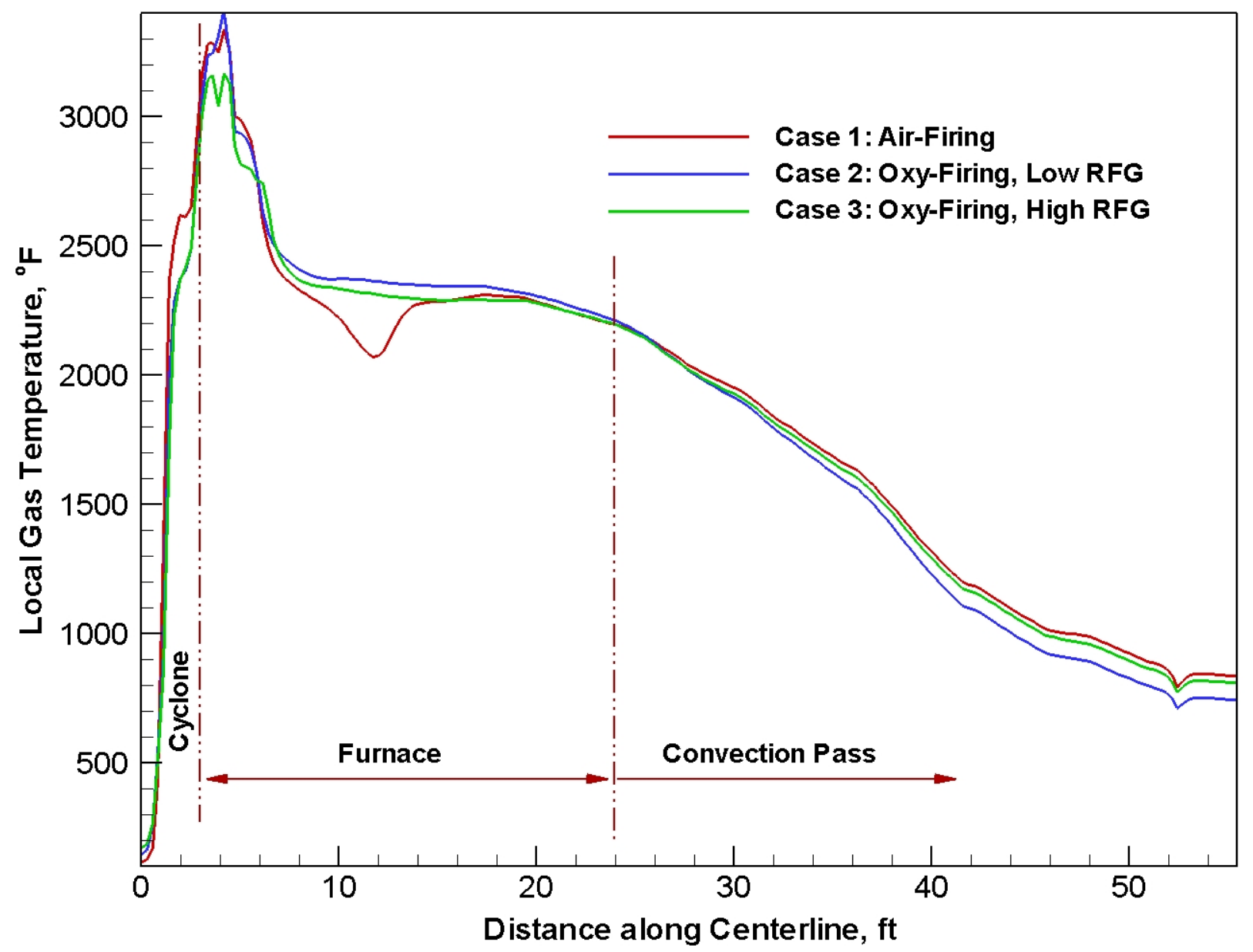

Figure 3.75 Predicted local gas temperature along the path shown in Figure 3.74: air-fired baseline and two warm recycle cases 


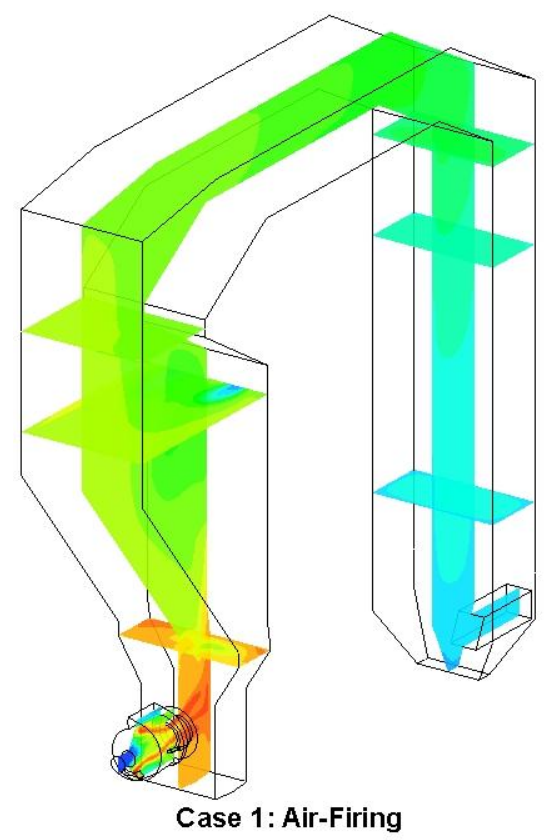

Case 1: Air-Firing

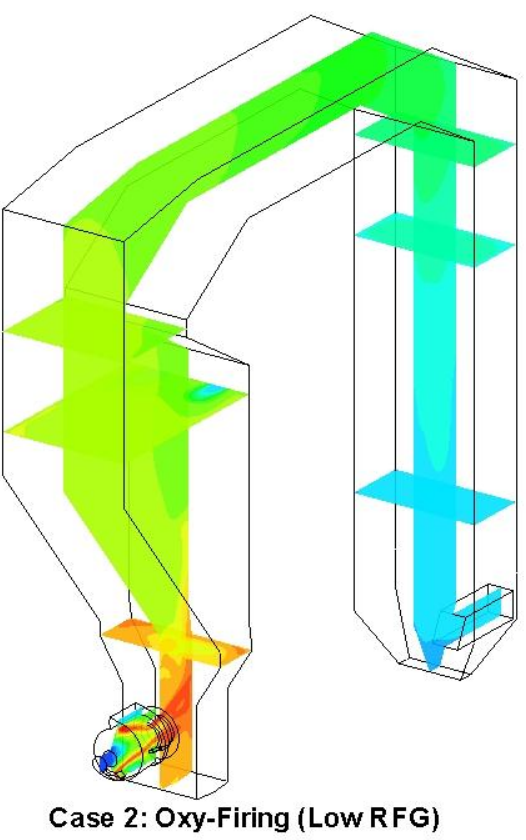

Gas Temperature ( $\left.{ }^{\circ} \mathrm{F}\right)$

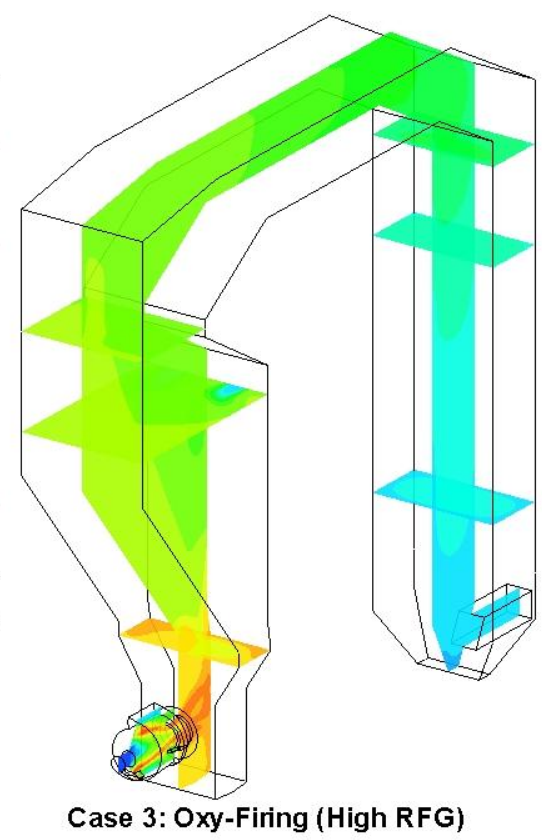

$100 \quad 300 \quad 5007009001100130015001700190021002300250027002900310033003500$

Figure 3.76 Predicted gas temperature profiles under air and two warm recycle oxy-firing conditions

The significant differences between the three modeled cases include flue gas flow rate, higher moisture and $\mathrm{CO}_{2}$ concentrations in the oxy-firing cases, and the resulting changes to gas density, emissivity, and heat capacity.

The predicted local gas emissivity is reported in Figure 3.77. The sharp changes in the gas emissivity in the convection pass are due to the presence of the tube banks. The local gas emissivity increases roughly $65 \%$ when switching from air-firing to oxy-firing, which is consistent with data reported in the literature for small boilers or short beam lengths (20); (21); (22); (23). Gupta et al., 2006(21) calculated gas emissivity using a wide band model for air-firing and oxy-firing conditions for a range of radiation path lengths and found that the difference in gas emissivity for the air-firing and oxy-firing conditions could be $25 \%$ for larger boilers and $40 \%$ for smaller furnaces. When the beam length was in the order of $1 \mathrm{~m}$, as in the current work, they found that gas emissivity could increase as much as $100 \%$ when changing from air-firing to oxy-firing. Andersson and Johnsson (23) also found that total gas emissivity increased about 20$30 \%$ in a range of gas temperature from 1300 to $2372^{\circ} \mathrm{F}$ when changing from air-firing to oxyfiring with an oxygen concentration of $27 \%$ (by volume). For comparison, gas emissivity increased $34 \%$ for earlier oxy-firing studies in the $30 \mathrm{MW}_{\text {th }}$ Clean Environment Development Facility (CEDF) (24) and 22\% for a commercial scale boiler (25) when switching from air-firing to oxy-firing conditions. 


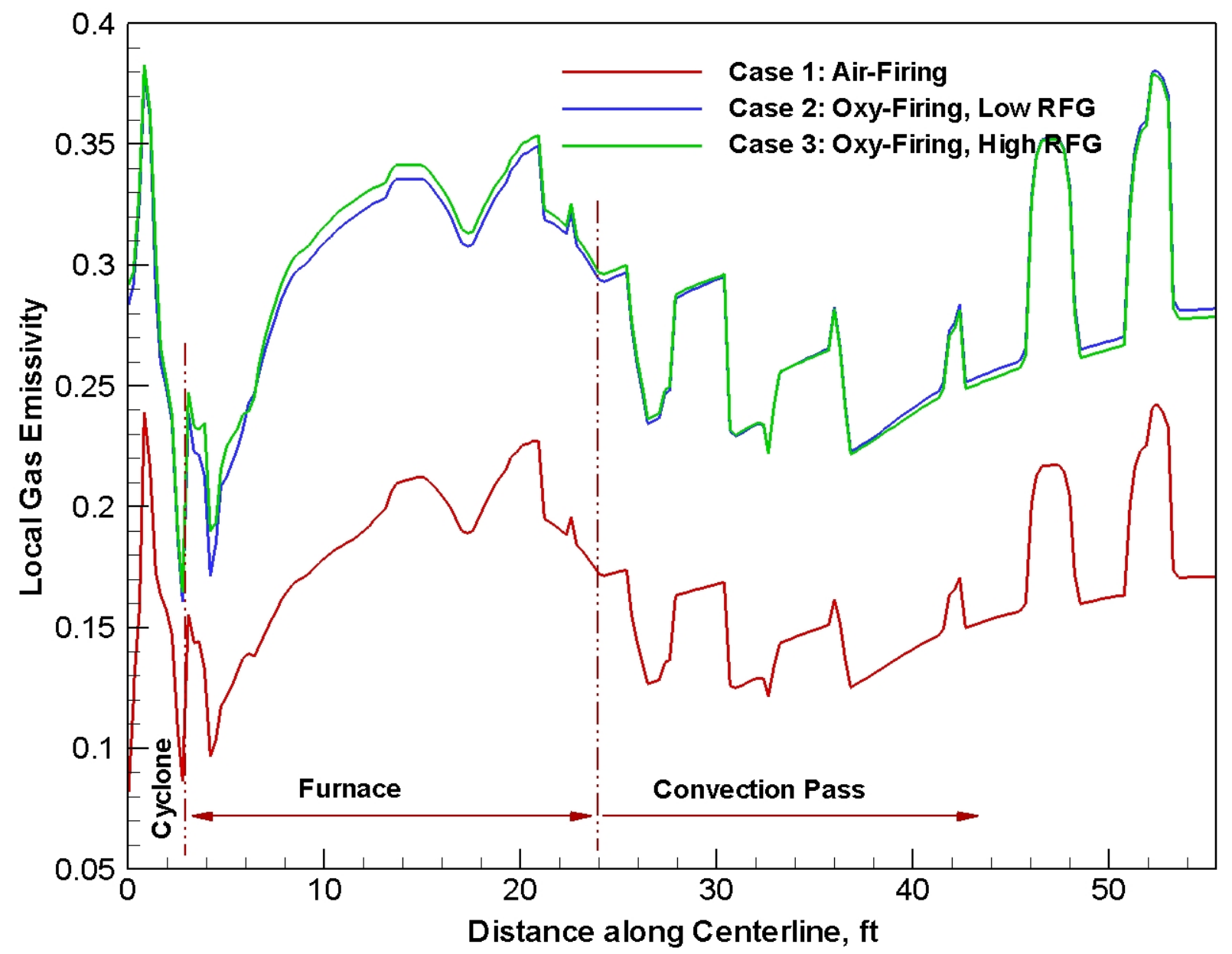

Figure 3.77 Predicted local gas emissivity along the path shown in Figure 3.74: air-fired baseline and two warm recycle cases

Predictions of local gas heat capacity are shown in Figure 3.78. The gas heat capacity under the oxy-firing conditions is approximately $10-20 \%$ higher than that under the air-firing conditions in the furnace, since water vapor and carbon dioxide concentrations are $2 \frac{1}{2}$ and $3 \frac{3}{4}$ times higher respectively for the oxy-firing conditions; and both gas species have a higher heat capacity than nitrogen which dominates under air-firing conditions. A higher heat capacity of the flue gas leads to a lower adiabatic flame temperature under the oxy-firing conditions when the oxygen concentration in the oxidant stream is similar. However, the total mass flow rate of the flue gas is about 10\% lower for Case 3 under the oxy-firing conditions than that in Case 1, which increases the adiabatic flame temperature. Since the oxygen concentration in the secondary oxidant stream is higher in Case 3 than that in Case 1, the net effect is a higher adiabatic flame temperature for Case 3. 


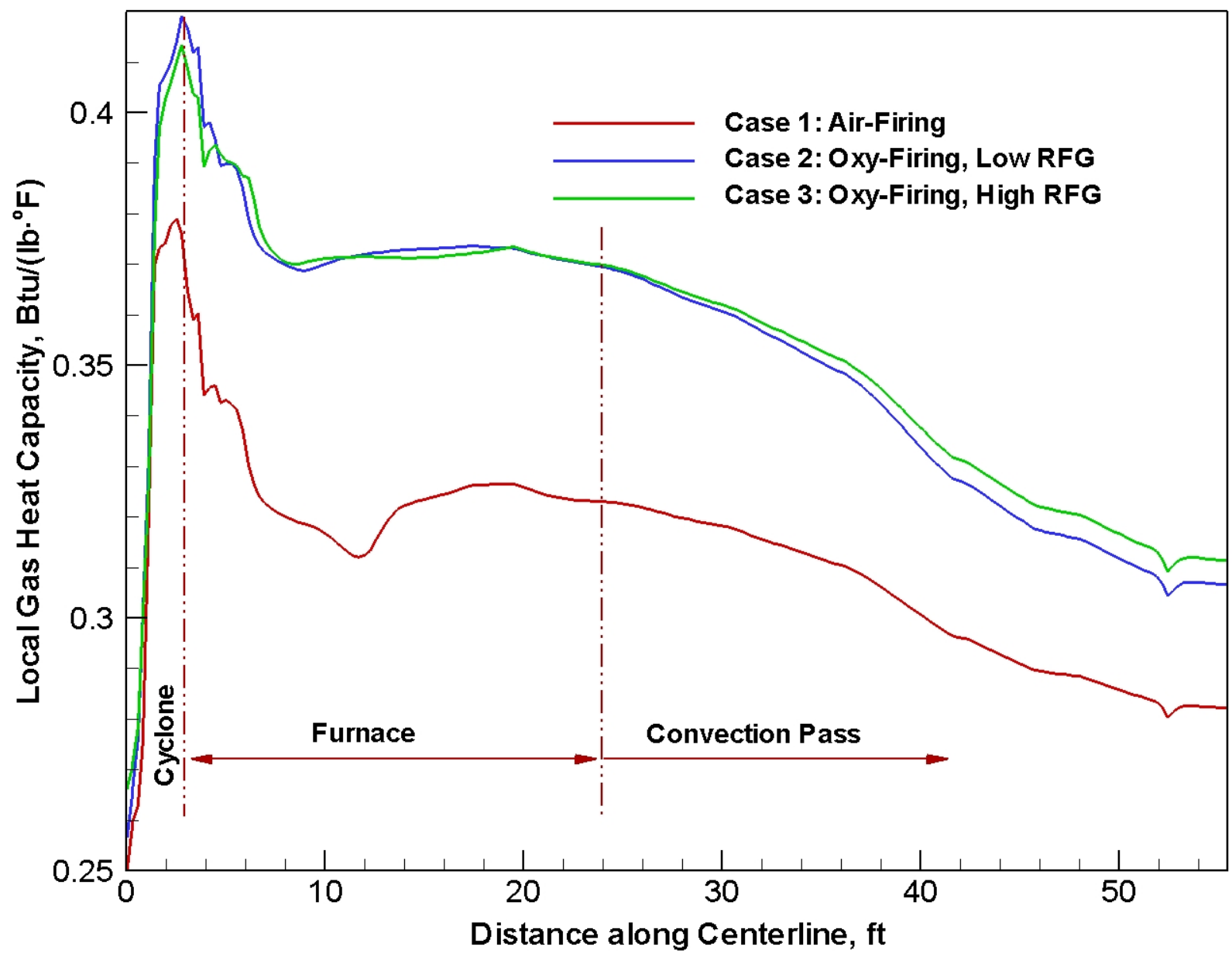

Figure 3.78 Predicted local gas heat capacity along the path shown in Figure 3.74: air-fired baseline and two warm recycle cases

The predictions of local gas density along the data extraction path are shown in Figure 3.79. The gas density for the oxy-firing cases is approximately 10-20\% higher than in the air-firing case in the furnace, because of higher $\mathrm{CO}_{2}$ concentrations. Since the total mass flow rate of the flue gas is lower under the oxy-firing conditions, the volumetric flow rate is roughly $20-25 \%$ lower, leading to an increase in gas residence time and a possible increase in heat transferred to the furnace walls.

The above modeling results are consistent with those found in two previous projects for comparison of heat transfer characteristics between air-firing and oxy-firing in a modeling study of a commercial scale utility boiler (25) and in a modeling and experimental study of a large pilot-scale test facility (24).

As mentioned earlier, Case 2 and Case 3 were modeled to examine the influence of changes in the flow rate of the recycled flue gas on the performance of the SBS-II. The flow rate of the Cyclone secondary stream for Case 3 was about $21 \%$ higher than that for Case 2 . The other flow rates were similar. 
As shown in Figure 3.77 through Figure 3.79, local emissivity, heat capacity, and density are similar for both oxy-firing cases. Since the oxygen concentration in the secondary oxidant stream is higher and the oxidant flow rate is lower in Case 2 than Case 3, the adiabatic flame temperature is expected to be higher for Case 2. As a result, the gas emissive power $\left(\varepsilon \sigma \mathrm{T}^{4}\right)$ is higher in Case 2, leading to higher radiative heat transfer to the Cyclone and the furnace, as shown in Table 3.20. Note that in this table the convective heat transfer in the Cyclone and the furnace is very similar for both oxy-firing cases.

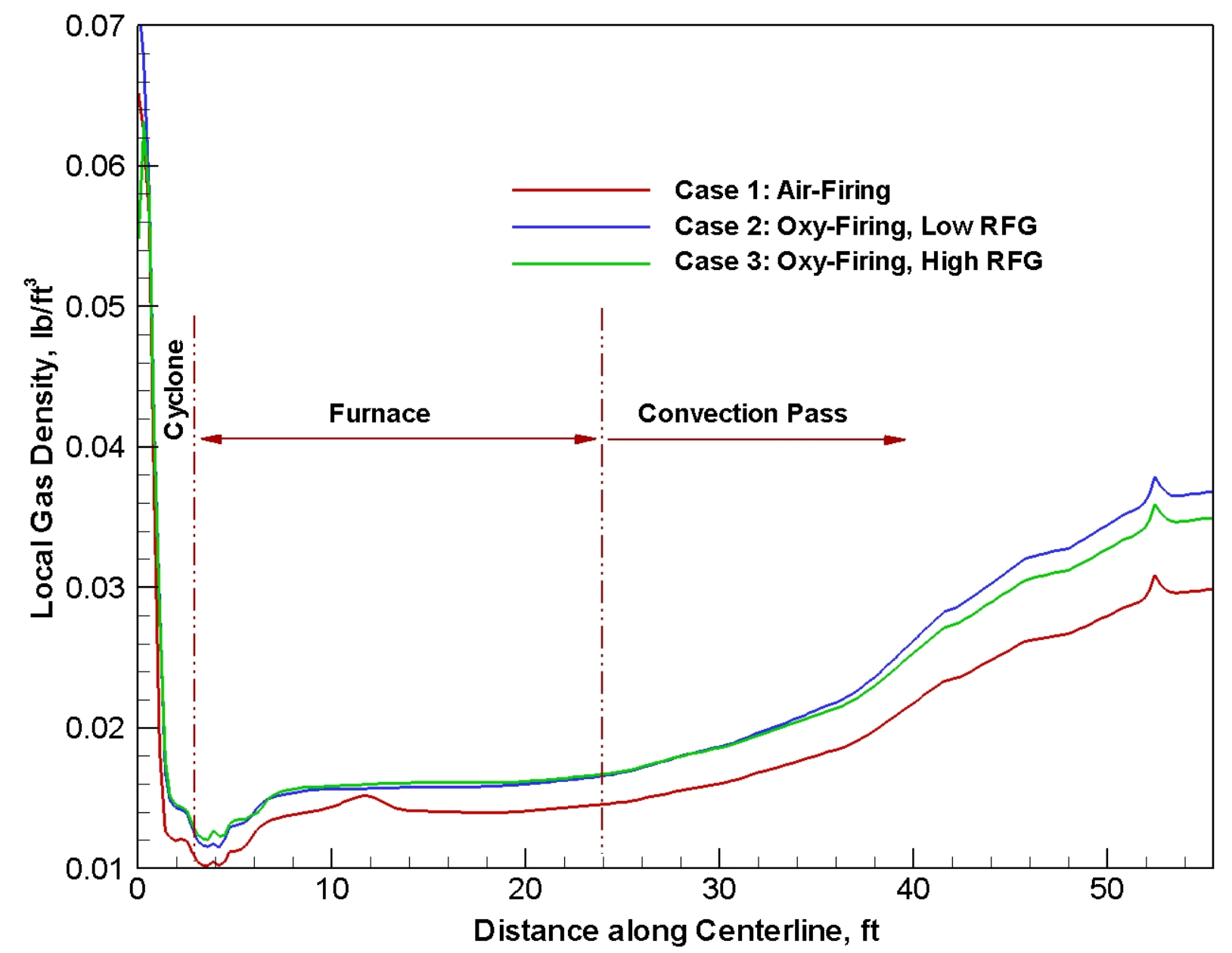

Figure 3.79 Predicted local gas density along the path shown in Figure 3.74: air-fired baseline and two warm recycle cases

Despite a higher heat loss to the Cyclone and the furnace, both the test data and the model predictions Table 3.19 indicate that the FEGT is higher in Case 2 than that in Case 3. This is attributed to a higher adiabatic flame temperature in Case 2. 


\begin{tabular}{|c|c|c|c|c|}
\hline \multicolumn{2}{|c|}{ Heat Absorption } & Case 1 & Case 2 & Case 3 \\
\hline \multicolumn{2}{|c|}{ Firing Mode } & Air-Firing & Oxy-Firing: Low RFG & Oxy-Firing: High RFG \\
\hline \multicolumn{2}{|c|}{ Test Date } & $9 / 15 / 2009$ & 9/17/2009 & 9/17/2009 \\
\hline \multicolumn{2}{|c|}{ Test Start Time } & $8: 44$ & $12: 45$ & 18:02 \\
\hline \multicolumn{5}{|c|}{ Radiative Heat Transfer } \\
\hline Cyclone & (MBtu/hr) & 0.351 & 0.399 & 0.387 \\
\hline Furnace & (MBtu/hr) & 1.459 & 1.835 & 1.623 \\
\hline Convection Pass & (MBtu/hr) & 1.144 & 1.312 & 1.388 \\
\hline \multicolumn{5}{|c|}{ Convective Heat Transfer } \\
\hline Cyclone & (MBtu/hr) & 0.108 & 0.114 & 0.113 \\
\hline Furnace & (MBtu/hr) & 0.705 & 0.585 & 0.584 \\
\hline Convection Pass & (MBtu/hr) & 1.079 & 0.818 & 0.895 \\
\hline \multicolumn{5}{|c|}{ Deposit Absorption } \\
\hline Cyclone & (MBtu/hr) & 0.022 & 0.062 & 0.074 \\
\hline Furnace & (MBtu/hr) & 0.019 & 0.008 & 0.008 \\
\hline Convection Pass & (MBtu/hr) & 0.000 & 0.000 & 0.000 \\
\hline
\end{tabular}

\section{Table 3.20 Predictions of heat transfer divided into radiative, convective, and deposition process components: air-fired baseline and two warm recycle cases}

In the convection pass, both the radiative heat transfer and the convective heat transfer are lower in Case 2, in comparison with Case 3. The total heat absorption in the convection pass in Case 2 is about $7 \%$ lower than that in Case 3. However, the flue gas flow rate in Case 2 is approximately $12 \%$ lower. Therefore, a higher temperature drop is expected in the flue gas for Case 2 .

Consistent with this conclusion, the predictions and test data exhibit a lower convection pass exit temperature in Case 2 than Case 3.

Finally, it is worthy of note that the sum of the radiative and convective heat transfer in Table 3.20 is different from the net heat absorption given in Table 3.19. The difference is due to heat absorption by the deposits on the walls, which is also summarized in Table 3.20. Deposit heat absorption includes the exchange of enthalpy by particle deposition, chemical reaction, slag removal, and mass transfer with the gas.

In summary,

- The model predicts that less than $0.2 \%$ of unburned carbon is trapped in molten slag in the Cyclone for both air-firing and oxy-firing conditions, and that the ash carryover from the Cyclone to the furnace is less than $20 \%$.

- The predicted total heat absorption is in good agreement with the net thermal input. The predicted heat absorption for both the Cyclone and the furnace is in reasonable agreement with the test data. The model correctly predicts the trend in the measured heat absorption in the convection pass for different cases; however, the difference between the test data 
and the model predictions is relatively large. The predicted furnace exit gas temperature compares favorably with the corresponding test data.

- Model predictions are generally in good agreement with pilot-scale measurements. The largest disparities occur in Case 2, which are probably due to the effect of Cyclone ash build-up on thermal boundary conditions, and possibly experimental uncertainty in the inputs to the model.

- Higher concentrations of $\mathrm{H}_{2} \mathrm{O}$ and $\mathrm{CO}_{2}$ in the flue gas under oxy-firing conditions lead to increases in the gas specific heat, gas density, and gas emissivity compared to air-firing conditions.

- The increase in the specific heat tends towards lower adiabatic flame temperatures, but this may be offset by lower flow rates of recycled flue gas.

- The increase in the gas density tends to increase gas residence time, and hence higher heat transfer to the furnace walls.

- The increase in gas emissivity $(\varepsilon)$ may be offset by a decrease in the adiabatic flame temperature $(\mathrm{T})$. The net result is that similar gas emissive power $\left(\varepsilon \sigma \mathrm{T}^{4}\right)$ and similar radiation heat transfer to the furnace walls may be maintained when changing from air to oxy-firing conditions.

- The higher specific heat of the flue gas also reduces the impact of cooling on gas temperature under oxy-firing conditions.

- The furnace exit gas temperature and the furnace heat transfer can be similar when switching from air-firing to oxy-firing conditions. The flow rate of recycled flue gas can be used to adjust the adiabatic flame temperature if needed.

It is recommended that future testing should include measurements of gas temperature and composition at the Cyclone exit to provide further validation of the model. Slag carbon content should also be analyzed in future tests. Possible avenues for model improvement include development of detailed models to improve predictions of carbon conversion in char deposits, and to describe molten slag flow and slag build-up on Cyclone walls.

\subsubsection{Wall-firing Pilot Scale Testing and Analysis}

Previously, with DOE sponsorship B\&W had performed oxy-combustion evaluation at $1.5 \mathrm{MW}_{\text {th }}$ using PRB coal in a wall-fired configuration. This early development was performed between 2001 and 2004 in B\&W's Small Boiler Simulator-I (SBS-I) and provided encouraging operational and performance data that led to further testing with various coal ranks and with a cyclone configuration. When approached by a commercial customer in 2005-2006, B\&W decided to modify the existing $30 \mathrm{MW}_{\text {th }}$ Clean Environment Development Facility (shown in Figure 3.80) to operate in full oxy-fired mode. In early October of 2007, the unit was operated in full oxy-fired mode; a world first at this scale. This section describes that work, which was funded by $\mathrm{B} \& \mathrm{~W}$, Air Liquide, and a consortium of electric utilities and is included here to support the engineering and economic evaluation discussion below. 


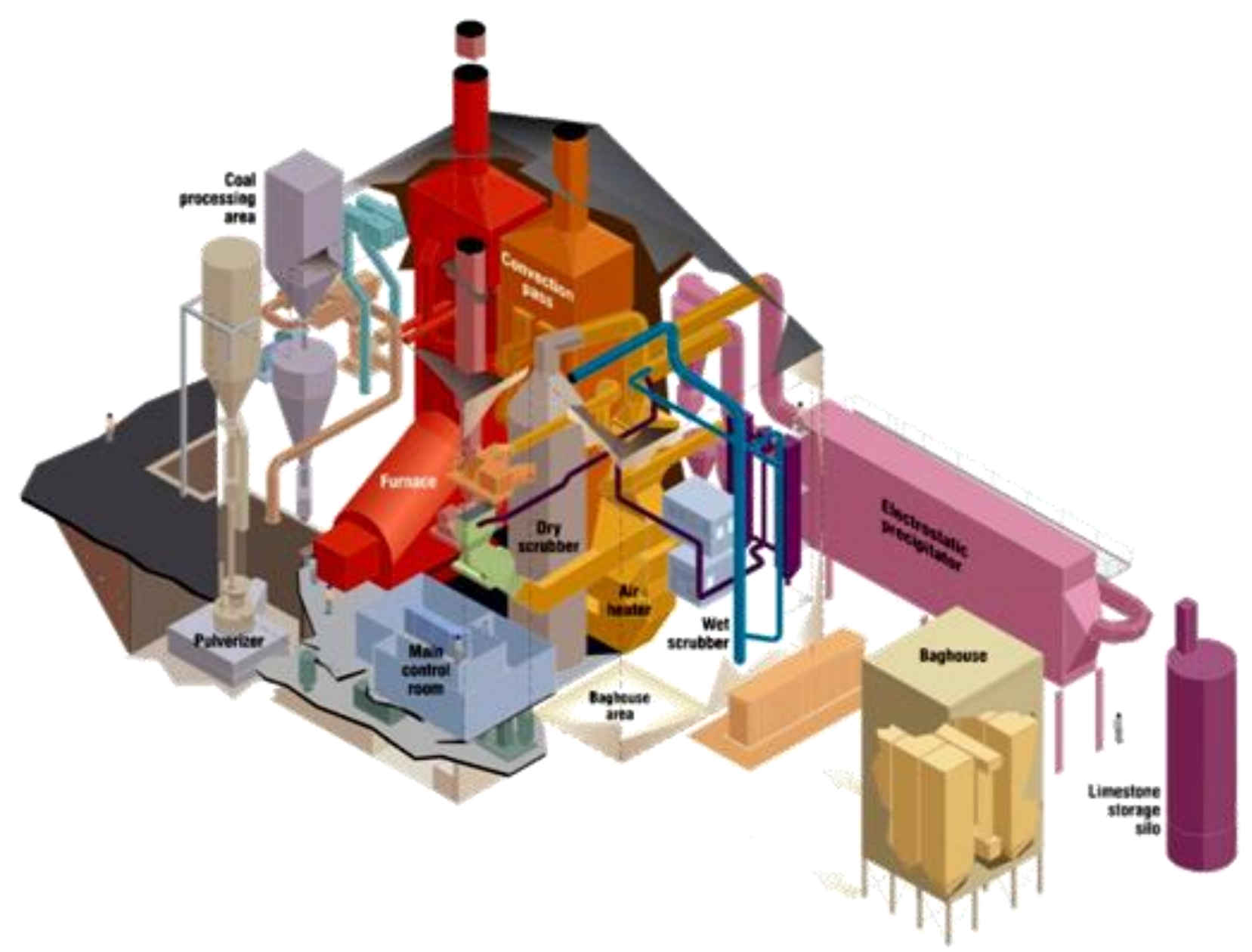

Figure 3.80 B\&W's $30 \mathrm{MW}_{\text {th }}$ Clean Environment Development Facility

\subsubsection{Facility Description}

In 1993 the Clean Environment Development Facility (CEDF), funded by B\&W, DOE, and the Ohio Coal Development Office, was started up. It was initially designed as a combustion facility for burner development with provisions for performing emissions control and air toxics testing. As such, the furnace and convection pass were specially designed to provide the same flue gas time-temperature profile as found in full scale utility boilers and a full complement of AQCS equipment was installed including ESP or baghouse and wet or dry scrubbers. In addition to development of several generations of low $\mathrm{NO}_{\mathrm{X}}$ burners and SNCR, it was used in support of the U.S. DOE Combustion 2000 program, the "Advanced Emissions Control Development Program" (AECDP) as well as early mercury testing, and has produced excellent data. In 2005, in cooperation with AL, work began to modify the facility to test oxy-firing with flue gas recycle. In 2007-2008, three coals and two process configurations were tested and data gathered on all process equipment except air separation (vaporized liquid oxygen was used) and $\mathrm{CO}_{2}$ compression and purification (the concentrated $\mathrm{CO}_{2}$ flue gas was vented to atmosphere). The pulverizer was also operated using recycle flue gas and the burner direct fired with both subbituminous and lignite coals. 
A process flow diagram for the facility in its current form showing both equipment and key measurement locations is provided in Figure 3.81. The blue components represent modifications to the original facility to permit full oxy-combustion operation and testing.

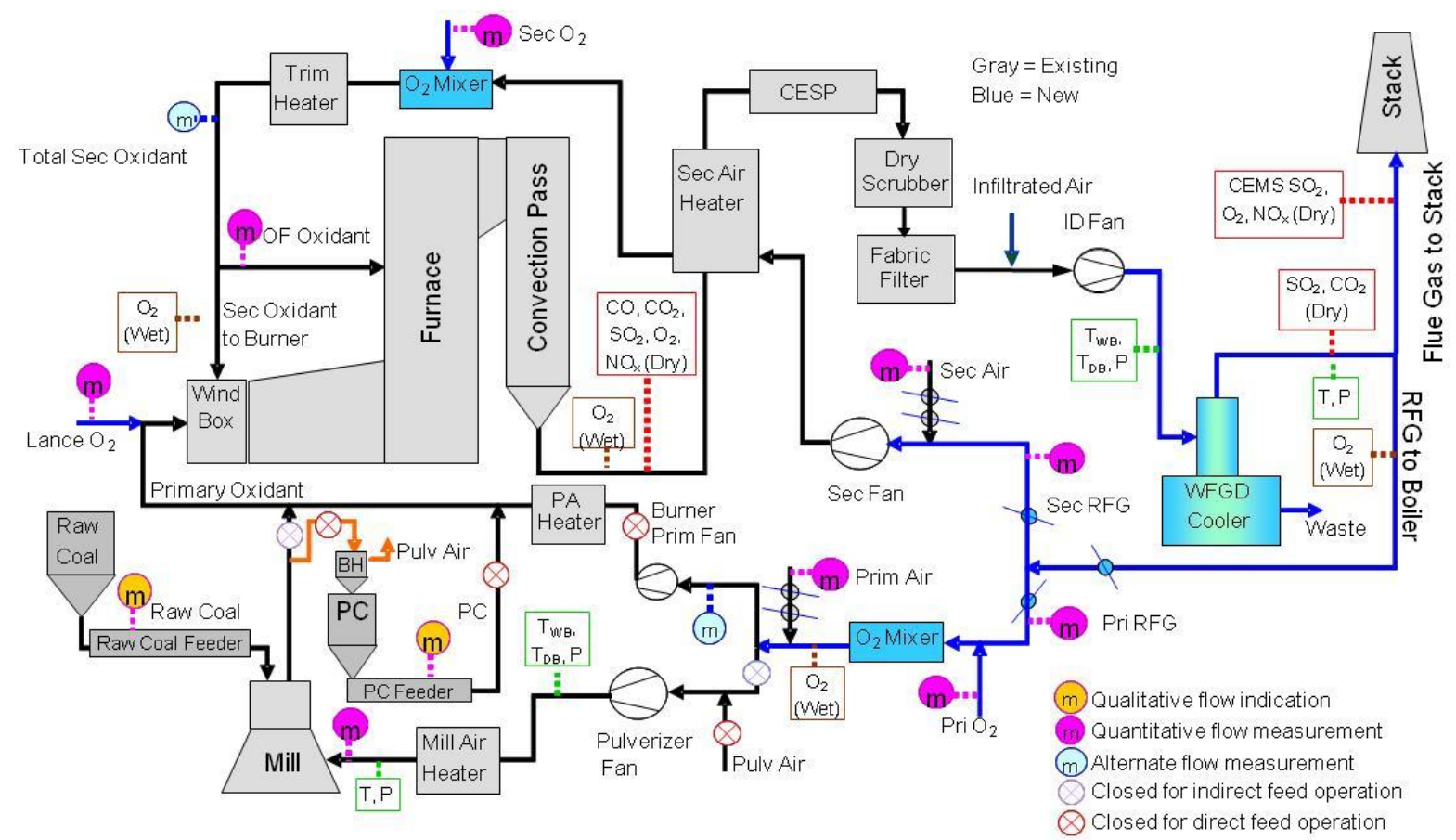

Figure 3.81 Clean Environment Development Facility process flow diagram

The facility was designed for a heat input of $100 \mathrm{MBtu} / \mathrm{hr}$ burning pulverized coals ranging from bituminous to North Dakota lignite to test essentially full-scale industrial or utility size burners. It was also designed to produce flue gas conditions and composition typical of a commercial plant in order to test pollutant removal equipment and evaluate air toxics and control methods.

Pulverized coal (PC) is supplied to the burner by an indirect or "bin feed" system so that a wide range of coal types, air-to-fuel ratios, fuel moistures, and PC size distributions can be independently controlled and studied. Raw coal with 2 inch top size can be dried, if necessary, and conveyed to a 50 ton raw coal storage silo. A gravimetric feeder meters the raw coal into a B\&W EL-56 pulverizer (mill) equipped with a B\&W dynamically staged, variable speed $\left(\right.$ DSVS $^{\circledR}$ ) classifier capable of online adjustment from $70 \%$ to $90 \%$ through 200 mesh.

Coal can be fed to the burner either directly or indirectly. For indirect feed, a dedicated constant speed pulverizer primary fan and direct natural gas-fired preheater provide the drying and conveying medium to the pulverizer that discharges into a baghouse. The pulverized coal is separated from the humid air and discharged into a 16 ton $\mathrm{PC}$ bin equipped with $\mathrm{CO}_{2}$ inerting. A second gravimetric feeder meters the PC into a coal pipe that conveys it to the burner. The primary flow for conveying the coal to the burner is provided by a second variable speed burner primary fan and preheated by an indirect natural gas-fired heater. The fuel feed system can be converted to dry and convey the coal directly to the burner (direct feed). This is accomplished using the burner primary fan with its indirect fired preheater to provide flow to the pulverizer. 
Instead of sending the dried pulverized coal to the PC bin, it is sent directly to the burner. Which fuel delivery approach is used is dictated by the test requirements and the fuel relative to the pulverizer capacity.

A variable speed secondary fan supplies secondary air to the windbox and overfire (OFA) ports and enables control of the primary-to-secondary air ratio. The secondary flow is preheated to about $500^{\circ} \mathrm{F}$ by a plate-type recuperative heater using flue gas after the convection pass. An indirect natural gas-fired heater downstream provides trim control of the temperature of the secondary flow to the windbox. Flow monitors are used to measure secondary flow.

The boiler and convection pass are specially designed to produce the same time-temperature profile as found in conventional utility scale units. The furnace is a refractory lined water jacketed enclosure, and the convection banks are double walled water cooled surfaces where the outer wall emulates tube metal typical temperatures. The steam generated is vented to atmosphere.

After the boiler, the flue gas enters a plate type secondary air heater followed by a cooler to reduce gas temperature leaving the convection pass from $700^{\circ} \mathrm{F}$ to approximately $350^{\circ} \mathrm{F}$. The hot flue gas from the unit is used to preheat the secondary air to $500^{\circ} \mathrm{F}$, and the cooler uses ambient air to control the final temperature to the inlet of the gas cleanup systems.

As Figure 3.81 shows, the flue gas can be directed through an idle electrostatic precipitator (CESP) to a $13.5 \mathrm{ft}$. diameter by $60 \mathrm{ft}$. tall full-flow spray dry absorber (SDA). $\mathrm{SO}_{2}$ is removed using atomized hydrated lime slurry sprayed into the tower with a single B\&W DuraJet ${ }^{\mathrm{TM}}$ atomizer. The dry scrubber is designed to comfortably meet the U.S. Environmental Protection Agency's (EPA) emission limit of $1.2 \mathrm{lb} / \mathrm{MBtu}$ continuously with a 3.5\% sulfur coal. A sixmodule full-flow pulse-jet fabric filter follows the SDA to collect particulate before entering the ID fan.

An induced-draft (ID) fan with variable inlet vane controls furnace draft and balances pressure losses in the system, depending on the combination of full-flow and slip-stream equipment that is in operation. The flue gas exits the ID fan and flows through a full-flow wet scrubber. From the wet scrubber the flue gas flows to the stack in air firing mode or is split between recycle and the stack when in oxy mode. The stack is 200 feet tall and houses a continuous emissions monitoring system (CEMS) to monitor sulfur dioxide $\left(\mathrm{SO}_{2}\right)$, nitrogen oxides $\left(\mathrm{NO}_{\mathrm{X}}\right)$ and opacity.

The system can be configured for wet scrubbing using the ESP with the SDA idle, and the very small amount of particulate leaving the ESP would be caught in the fabric filter. The fabric filter could also be used alone by leaving the ESP idle.

In addition to installing a new full-flow wet scrubber with patented integrated dehumidification, the key equipment added to provide oxy-combustion capability are an oxygen supply system, oxygen mixers, and the interconnecting flues. The oxygen supply and mixing system, provided by Air Liquide, vaporizes liquid oxygen (LOX) stored in large tanks. The oxygen distribution system (ODS) supplies the controlled flow of oxygen to the burner and oxygen flue gas mixers. The ODS also interfaces with the burner management system to ensure safe use of oxygen. Mixing of oxygen and flue gas is achieved by AL's Floxynator ${ }^{\mathrm{TM}}$ technology which mixes in the 
center of the flue, safeguarding the walls from higher oxygen concentrations. Figure 3.82 shows the oxygen supply system.

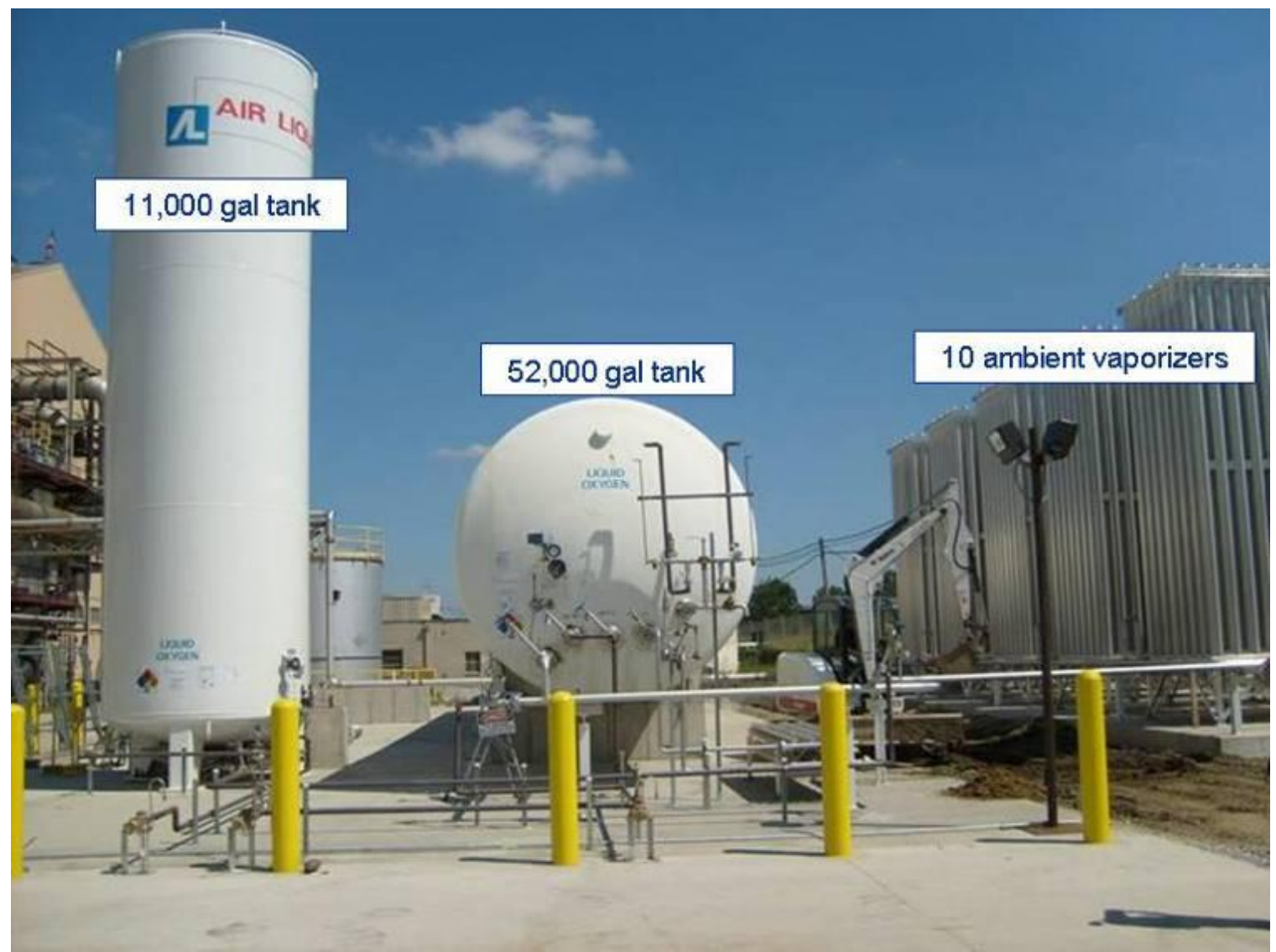

Figure 3.82 Oxygen supply system

\subsubsection{2. $\quad$ Test Description and Methods}

The testing addressed the impact of oxy-firing and the full range of coals on coal preparation, combustion, precipitator and wet scrubber performance, and operation with different flue gas compositions. Testing included control concepts for transitioning from air-to-oxy and oxy-to-air firing, load changing, and major trips including Master Fuel Trip, and supported nearly full-scale testing of a new oxy-burner for PRB and lignite. These tests were in the configuration of ESPWFGD. Testing with bituminous coal (indirect fired) focused on burner, ESP, Floxynators, and WFGD performance in the full oxy-mode compared to air-firing. In addition to gas composition, impact on $\mathrm{SO}_{2}$ removal and sulfur trioxide $\left(\mathrm{SO}_{3}\right)$ formation were also measured. Subbituminous and lignite testing focused on performance of the new burner and the pulverizer in the directfired mode, and the ESP.

The objectives were to demonstrate for all three coals: optimum burner design for each coal, $\mathrm{NO}_{\mathrm{X}}$ emissions, efficient oxygen mixing, pulverizer performance, furnace exit gas temperature (FEGT), boiler/convection pass heat transfer, ESP and WFGD performance, $\mathrm{SO}_{2}$ removal, $\mathrm{SO}_{3}$ formation, flue gas moisture control via B\&W's novel concept, mercury speciation with oxy- 
combustion, corrosion insights for materials development, and evaluate the impact of air infiltration.

\subsubsection{3. $\quad \underline{\text { Results }}$}

Test campaigns were successfully conducted for each of the three coals shown in Table 3.21. In addition to cold recycle, testing was conducted with the sub-bituminous coal to emulate the much higher moisture levels in the secondary recycle associated with the warm recycle design. The higher moisture did not adversely impact operation or significantly change the results from testing with cold recycle.

\begin{tabular}{|l|r|r|r|}
\hline \multicolumn{4}{|c|}{ As-Received Coal Analyses } \\
\hline \hline & $\begin{array}{c}\text { Bituminous } \\
\text { Mahoning \#7 }\end{array}$ & $\begin{array}{c}\text { Sub-Bituminous } \\
\text { Black Thunder }\end{array}$ & $\begin{array}{c}\text { Lignite } \\
\text { SaskPower }\end{array}$ \\
\hline Air Dry Loss Moisture (\%) & 0 & 2.56 & 3.85 \\
\hline Proximate Analysis (\%) & & & 32.92 \\
\hline Moisture & 3.34 & 28.03 & 8.09 \\
\hline Ash & 7.48 & 4.17 & 28.31 \\
\hline Volatile Matter & 37.02 & 31.83 & 30.69 \\
\hline Fixed Carbon & 52.16 & 35.96 & \\
\hline Ultimate Analysis (\%) & & & 41.85 \\
\hline Carbon & 76.28 & 49.97 & 2.86 \\
\hline Hydrogen & 5.16 & 3.69 & 0.3 \\
\hline Nitrogen & 1.58 & 0.55 & 0.34 \\
\hline Sulfur & 1.52 & 0.25 & 13.65 \\
\hline Oxygen & 4.64 & 13.33 & 7142 \\
\hline Calorific Value, Btu/lb & 13261 & 8815 & \\
\hline
\end{tabular}

Table 3.21 Coals tested in the $30 \mathrm{MW}_{\text {th }} \mathrm{CEDF}$

For both sub-bituminous and lignite coals, the unit was direct-fired and the higher density of the primary recycle gas permitted a reduction in the primary flow to coal flow ratio without impact on mill performance (Figure 3.83). In addition, the primary recycle dried and conveyed the coal over the load range without difficulty. 


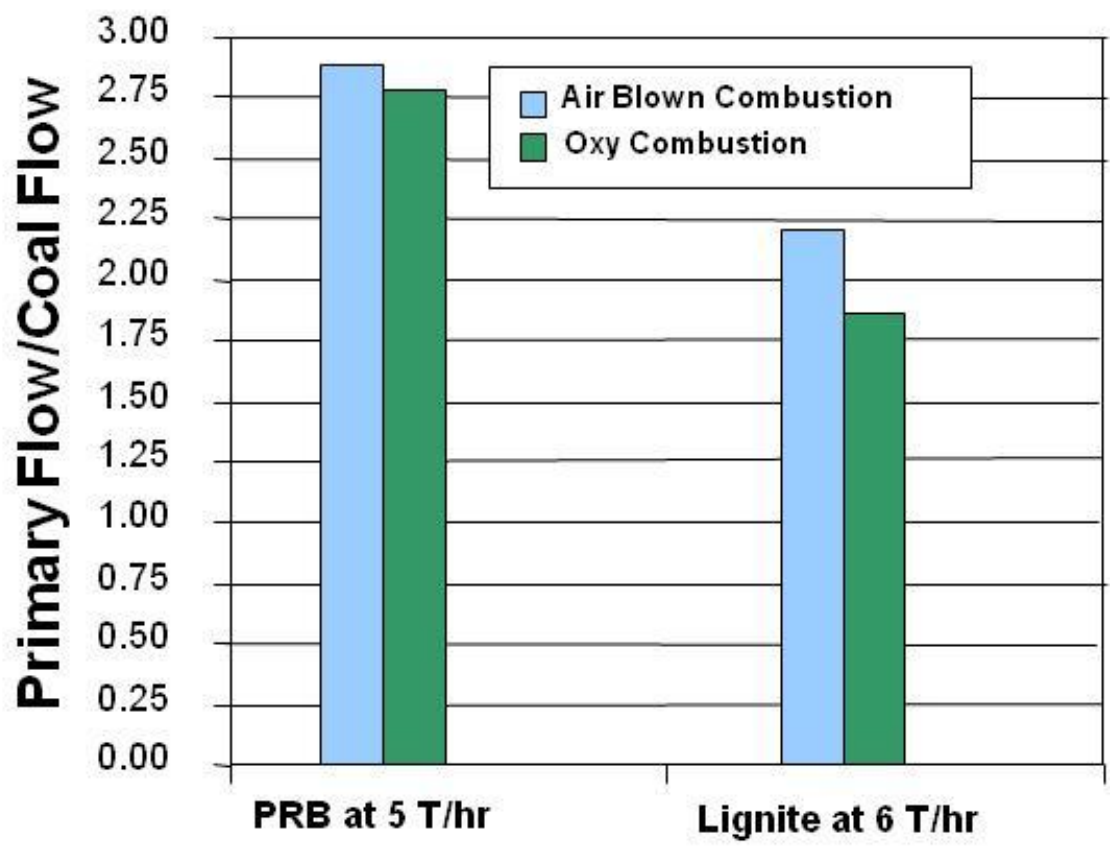

Figure 3.83 Comparison of air-fired and oxy-combustion primary flow to coal flow for the direct-fired fuels

Previous small pilot test results showing 50\%-70\% reduction in $\mathrm{NO}_{\mathrm{X}}$ were also verified at larger scale as shown in Figure 3.84. 


\section{$\%$ NOx Reduction Air vs. Oxy Firing}

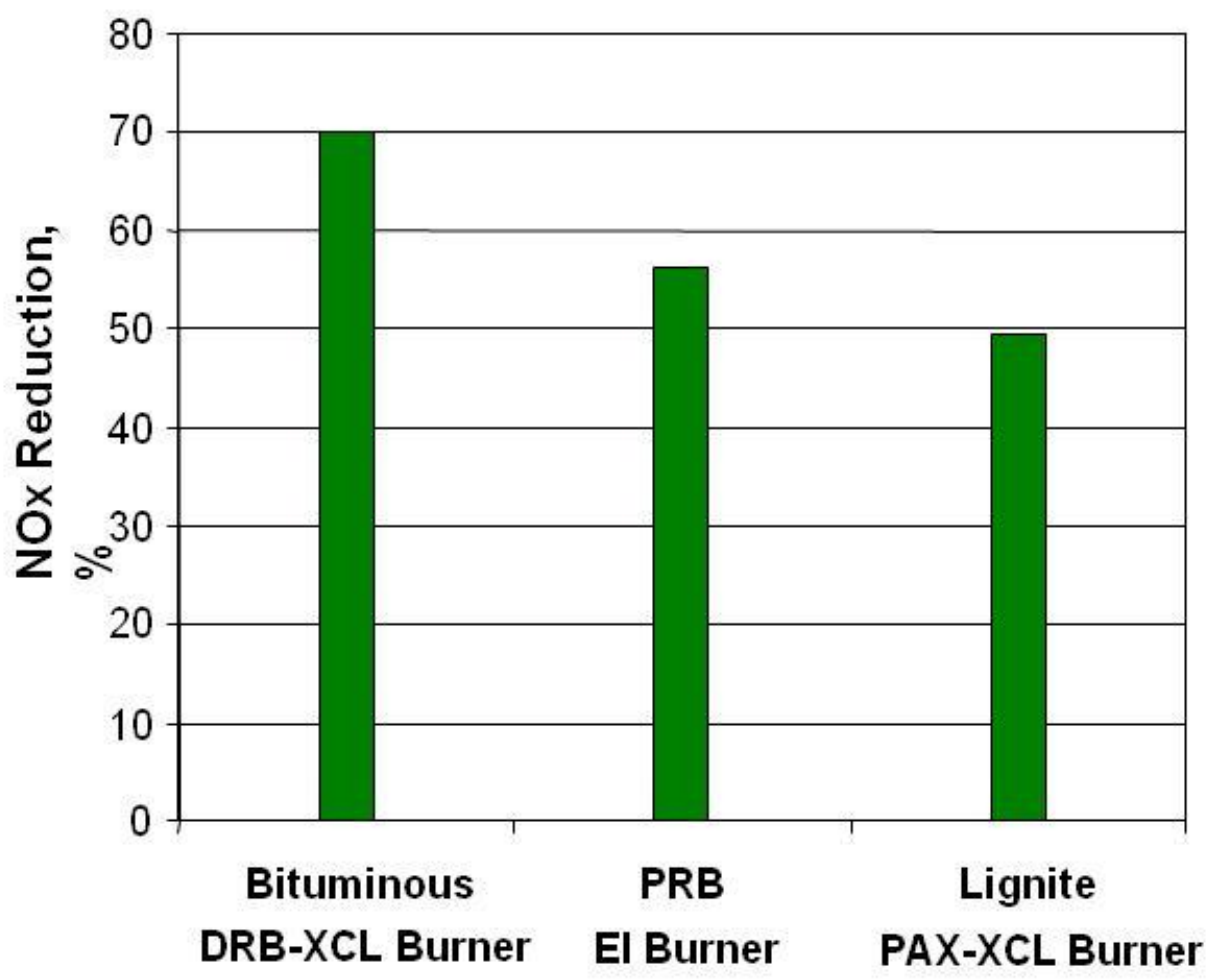

Figure 3.84 Reductions in $\mathrm{NO}_{\mathrm{X}}$ in the $\mathrm{CEDF}$ switching from air-firing to oxy-combustion

For these tests the mass flow through the boiler was about the same for air and oxy firing. To evaluate heat transfer in the furnace, a water cooled tube panel with chordal thermocouples was installed. Although this data provided qualitative information, the CEDF's refractory furnace affected these results, so it is not quantitative or conclusive. Figure 3.85 shows that with normal air firing, heat fluxes in the test panel were as much as double those experienced with oxy firing and cold recycle. This difference is due to changes in gas density and emissivity resulting from higher $\mathrm{CO}_{2}$ concentration, and the impact of moisture content on flame temperature. 


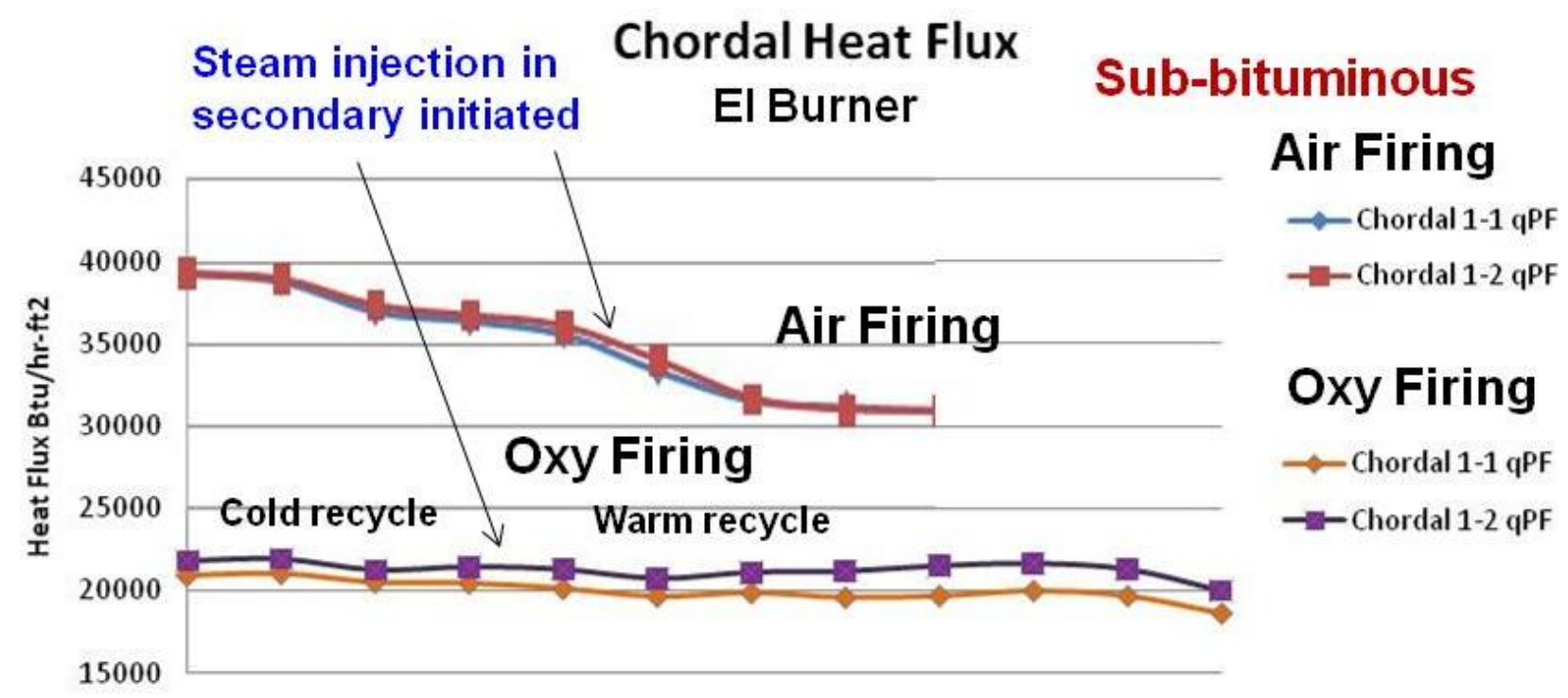

Figure 3.85 Impact of oxy-firing on heat transfer in the CEDF

For the air firing curve, the flue gas moisture content began at about $13 \%$ by volume at the boiler outlet which is typical of an air fired unit burning sub bituminous coal. As indicated, steam injection into the secondary air stream was initiated, and as it was increased, heat fluxes decreased significantly. However, they remained much higher than with oxy firing due to the lower $\mathrm{CO}_{2}$ concentration and gas density in air-firing relative to oxy-firing.

In the oxy firing mode flue gas moisture was around $25 \%$ by volume at the boiler outlet for the cold recycle tests. To simulate warm recycle, steam injection was initiated in the secondary recycle stream which increased the moisture content at the boiler outlet to about $33 \%$.

Interestingly, steam injection had little impact on heat fluxes, which is probably due to the already high moisture content.

During testing $\mathrm{SO}_{2}$ was removed by a full flow limestone forced-oxidation wet scrubber. Test data showed that it performed as well in the oxy mode as when air firing. In fact there is some indication that removals were 5\%-10\% higher during oxy firing under the same conditions as shown in Figure 3.86.

Removal of moisture was accomplished by B\&W's patented method of controlling the saturation temperature at the outlet of the wet scrubber. As Figure 3.87 shows, this method worked extremely well. Control of moisture from the scrubber does not affect $\mathrm{SO}_{2}$ removal performance. 


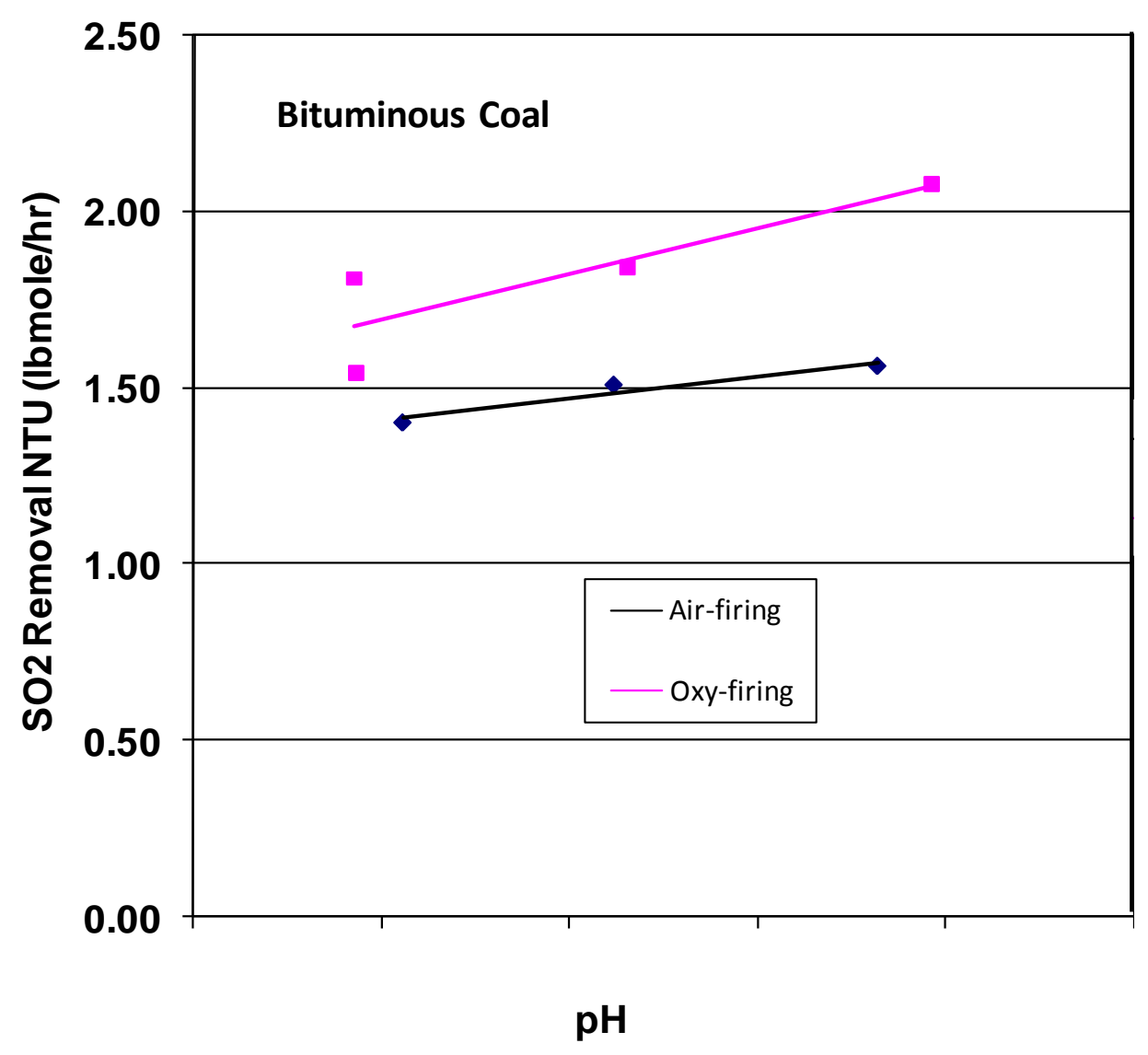

Figure 3.86 Effect of oxy-firing on $\mathrm{SO}_{2}$ removal performance of the wet scrubber 


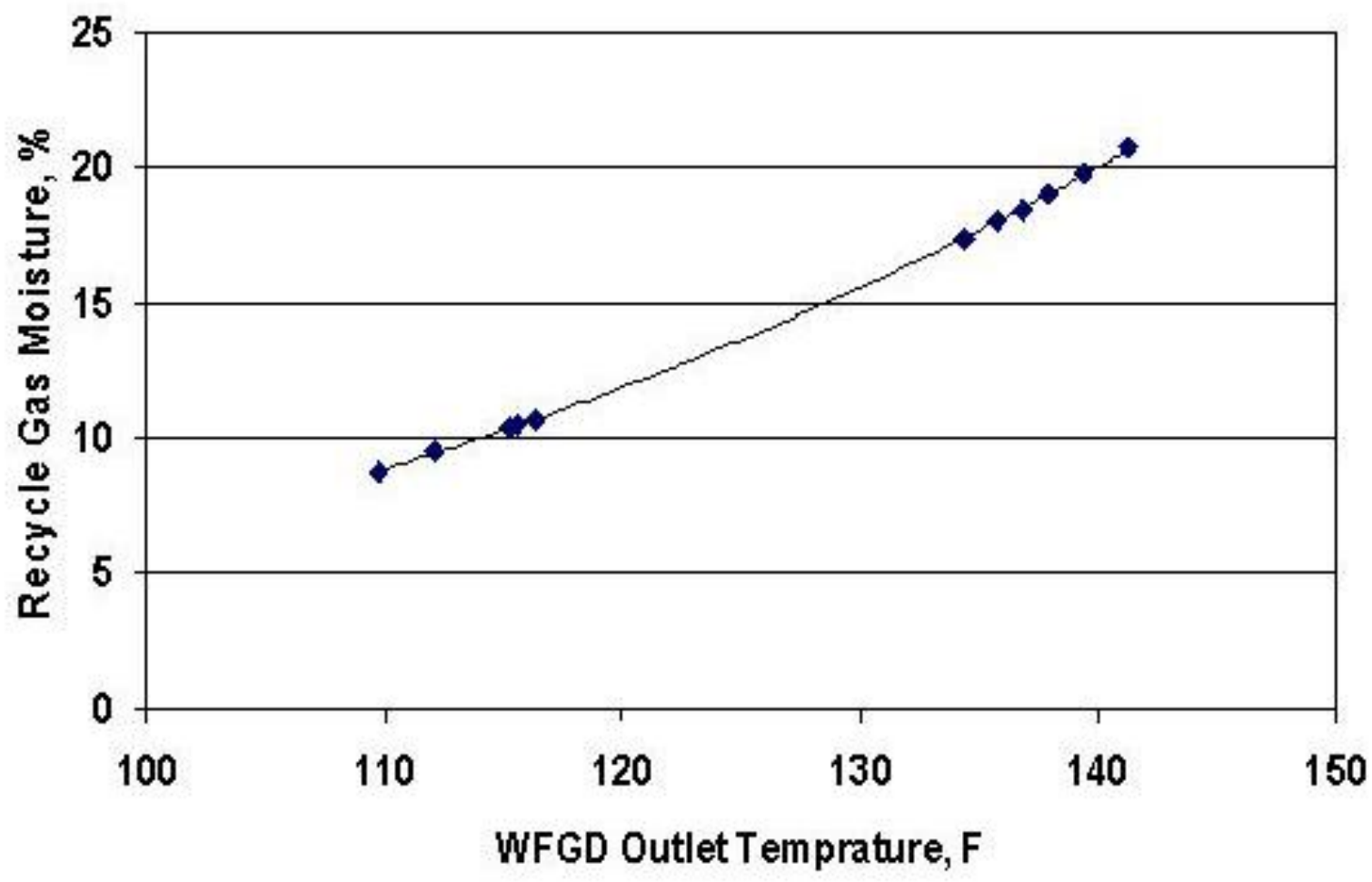

Figure 3.87 Moisture removal

Limited $\mathrm{SO}_{3}$ measurements were also taken during the bituminous campaign, but data indicated a doubling of $\mathrm{SO}_{3}$ formation in the oxy mode when expressed on a heat input basis. The heat input basis removes the effect of nitrogen dilution with air firing, and allows an objective comparison. As stated earlier further investigations in SBS-II facility confirmed the CEDF results (see section 3.1.4.3). Higher $\mathrm{SO}_{3}$ concentration raise the acid dew point temperature so care must be taken to either remove $\mathrm{SO}_{3}$ or prevent condensation and resulting corrosion in any commercial system.

During these test campaigns the electrostatic precipitator was used to remove particulate. In general it performed similarly in either air or oxy-firing. However, during oxy-firing the field ESP voltage had to be slightly increased to achieve the same removal as Figure 3.88 illustrates. This is due to the higher concentrations of moisture and ash in the flue gas during oxycombustion. 


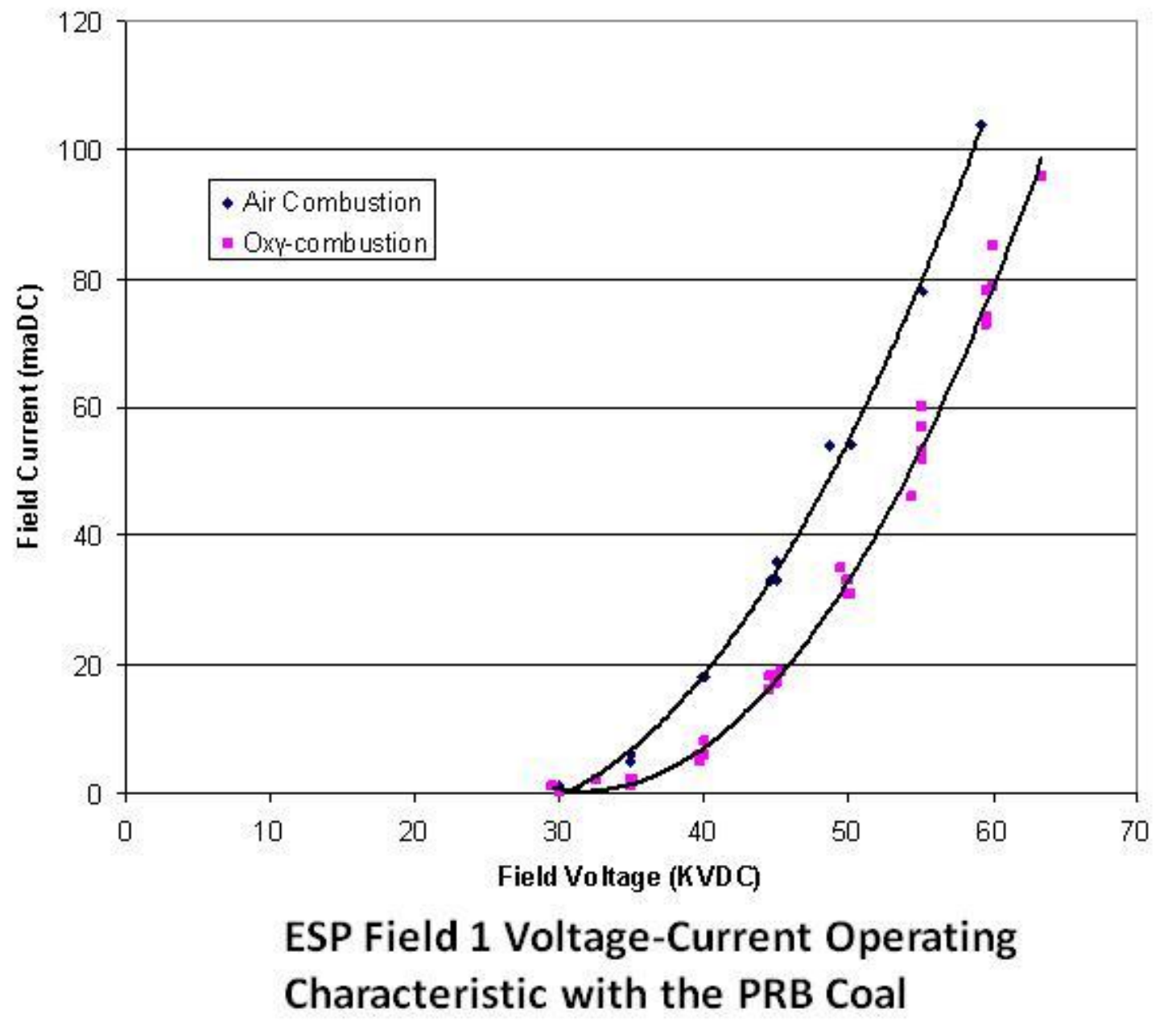

Figure 3.88 Effect of oxy-combustion on ESP operating characteristics

Air Liquide supplied the liquid oxygen system. Control and coordination of the oxygen splits and flows with the burner management system worked very well. For the addition of oxygen to recycled flue gas specially designed (by AL) oxygen mixers kept the higher oxygen concentrations in the center of the flues (away from the walls) and minimized the difference between the highest and lowest oxygen concentrations, as shown in Figure 3.89. 


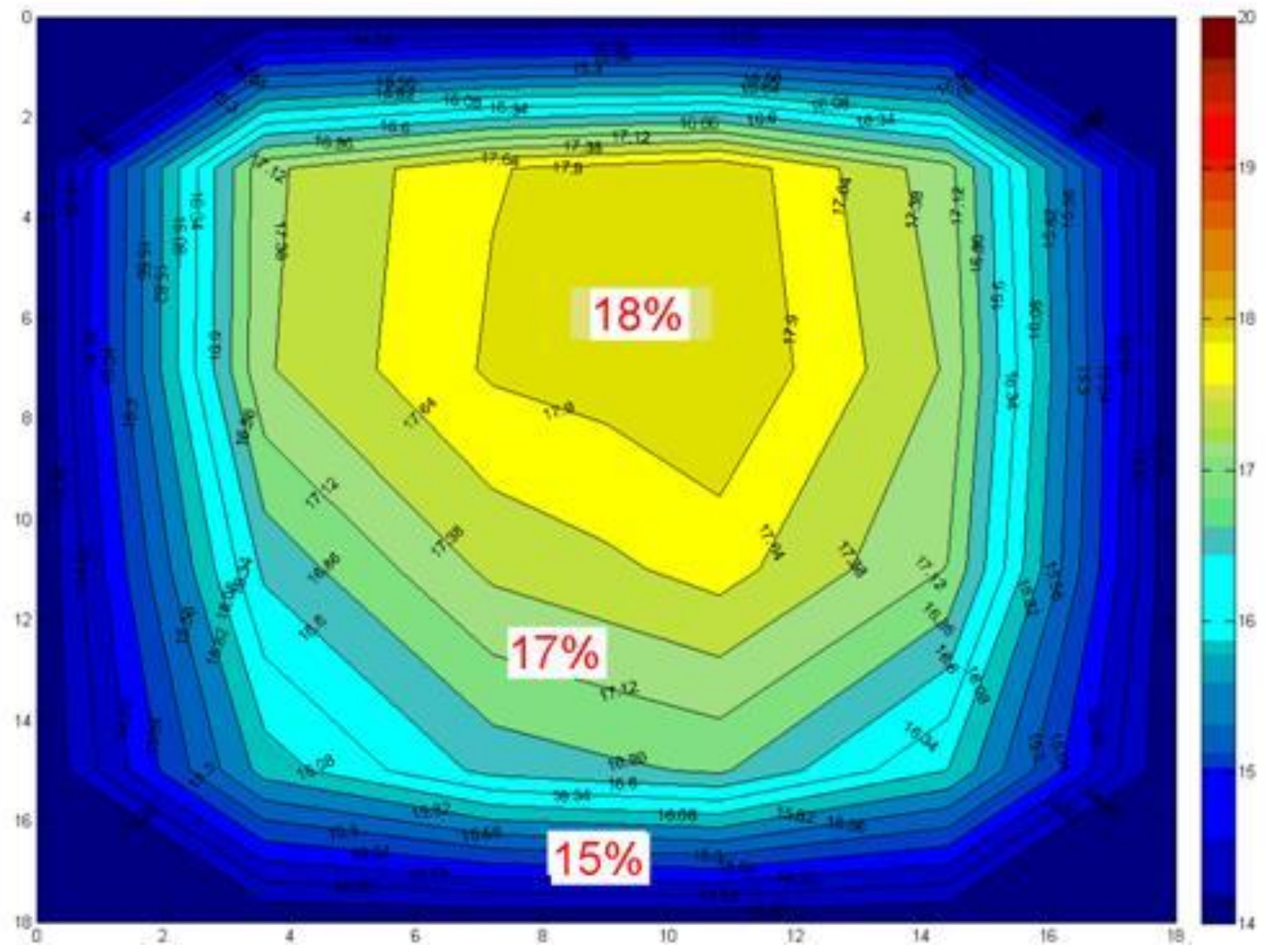

Figure 3.89 Oxygen mixing in the flue gas ducts

On-line mercury measurements were recorded during the lignite testing. As expected, the level of mercury oxidation with air firing was low, about $25 \%$. As the unit transitioned from air to oxy- firing and the nitrogen was purged from the system, the mercury concentration increased accordingly. Data also indicated that the oxidation increased to about $30 \%$. This indicates that mercury removal in the scrubbers with oxy-combustion will be no worse and perhaps better than air firing. In a commercial plant mercury is also removed in the CPU.

Air infiltration between the boiler and ID fan inlet can be an issue with oxy-combustion because it introduces unwanted nitrogen into the process. This additional nitrogen adds mass and volume flow, which results in increased ID fan and CPU power to fire the same amount of fuel and process the same amount of $\mathrm{CO}_{2}$. If it becomes excessive it can limit plant load. In addition, it reduces fuel efficiency because more fuel must be fired to heat the additional gas. The CEDF was originally designed for air firing, so air infiltration was high, in the worst case $11.5 \%$ (\% of theoretical air) in spite of reasonable efforts to minimize it. The major sources were the ESP and fan inlets where the negative static pressure is high, and the inlet vane connection to the fan was not designed to be gas tight. Idle equipment in the flow path (dry scrubber and baghouse) also contributed. With proper design considerations, a commercial plant should be able to maintain no more than $5 \%$ air infiltration. As Figure 3.90 shows this will produce $\mathrm{CO}_{2}$ concentrations 
between $80 \%$ and $85 \%$, high enough to minimize impact on fans and for efficient operation of the CPU.

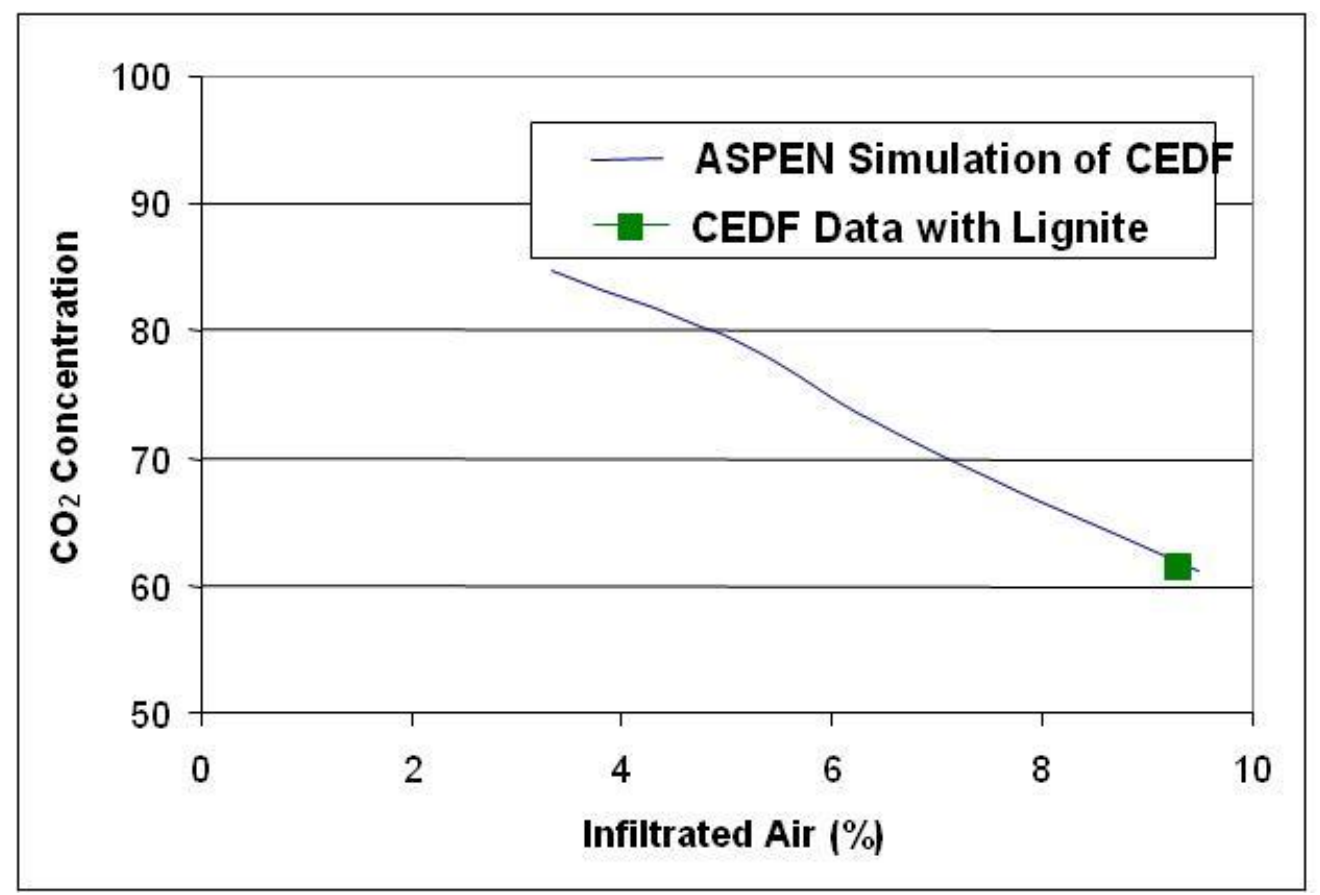

Figure 3.90 ASPEN simulation results of the effect of air infiltration on flue gas $\mathrm{CO}_{2}$ concentration

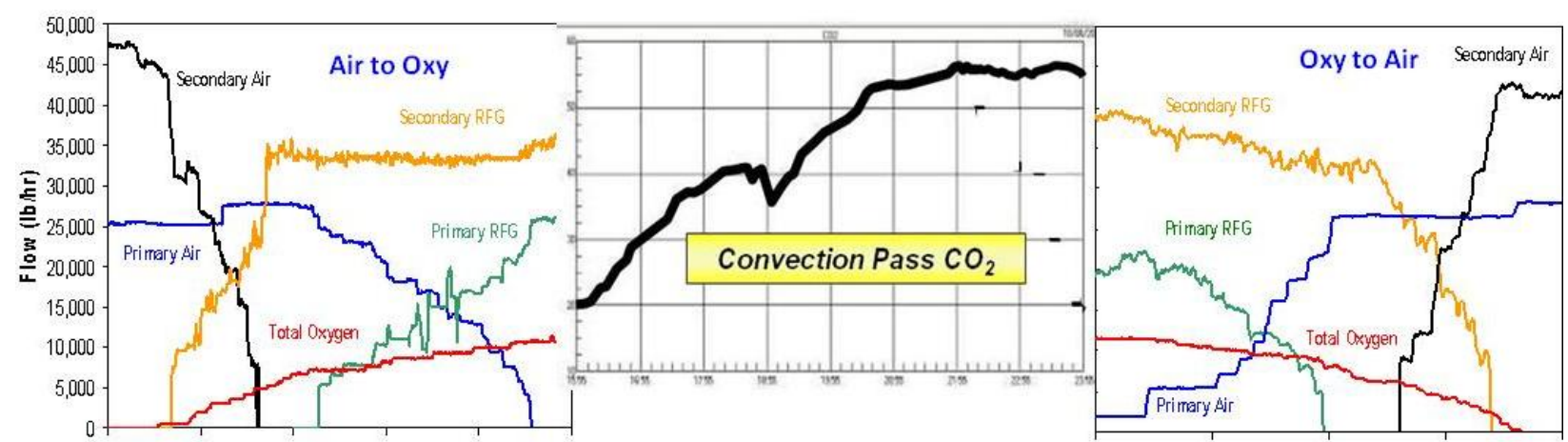

Figure 3.91 Operational data for transition between air and oxy-firing

Control of the transition from air to oxy and back was experienced many times. In Figure 3.91 the left chart shows how the secondary air flow is decreased and the secondary recycle is increased until the secondary air is completely replaced by oxygenated recycle. The same process is used for the primary flow until there is no air entering the process and the unit is in full oxy mode. The center portion of the figure shows how the $\mathrm{CO}_{2}$ concentration increases, and the right chart shows the transition from oxy back to air firing. Though most transitions took about 40 minutes due to test conditions, and maintaining manual control of the process. The process could be easily automated and would take less than a half hour for a commercial plant. During 
our four test campaigns, all of the major trips and upsets that would be experienced in a commercial plant, including master fuel trips and pulverizer trips, were experienced and safely managed.

\subsection{Phase II, Part A - Engineering and Economic Evaluation}

\subsubsection{Background}

With climate change legislation and carbon dioxide regulation under serious consideration, the need to address $\mathrm{CO}_{2}$ emission from existing power plants while maintaining the ability to use the most abundant and lowest cost domestic energy resource, coal, for electricity production is economically essential. Carbon Capture and Storage (CCS) is being developed to meet that need. Three technologies are at the demonstration stage, Integrated Gasification Combined Cycle (IGCC), post-combustion capture (PCC), and oxy-combustion capture (OCC).

Recent studies by the US Department of Energy (DOE) and others have shown that oxycombustion has the potential to be the greenfield option with the highest efficiency at the lowest cost of electricity (2). IGCC cannot be retrofit to existing plants, nor is it suitable for repowering high pressure steam cycles. Thus retrofit and repowering of existing pulverized coal fired plants will be with either OCC or PCC.

Early confidential studies to retrofit small existing units in the 100-300 MWe range showed OCC to be an expensive retrofit ${ }^{5}$ so a general impression prevailed that OCC was not a suitable retrofit technology. Simultaneously those developing post combustion capture (PCC) were touting lower costs, partial capture, and ease of retrofit so PCC seemed more suitable for retrofit application. However, a recent reevaluation indicates that small units typically have no primary $\mathrm{SO}_{2}$ removal and very tight site conditions requiring the Air Separation Unit (ASU) and Compression and Purification Unit (CPU) to be located a significant distance from the boiler. These and other factors such as high air infiltration due to non-membrane enclosed designs and/or age drove up cost.

More detailed evaluations of PCC retrofit requirements and cost by DOE and others has shown it not to be as simple and inexpensive as initially projected. In fact, the current requirement for a primary $\mathrm{SO}_{2}$ removal device, $\mathrm{SO}_{2}$ polishing, moisture reduction, and space for the $\mathrm{CPU}$ are essentially identical between OCC and PCC. Therefore, the economic advantages of PCC for retrofit compared to OCC perceived earlier are not valid. Also, OCC needs about the same amount of space for the ASU as PCC needs for the absorption and regeneration equipment. So basic site requirements for both are about the same but PCC has the disadvantage of needing a significant amount of low pressure steam. This steam would be provided by either major changes to the low pressure steam turbine or the addition of an auxiliary boiler.

${ }^{5}$ Due to confidentiality these studies cannot be referenced, but the results that led to the conclusion were that due to site constraints, lack of an existing scrubber, and the economy of scale small unit retrofits are much more costly on a $\$ / \mathrm{kW}$ basis than large scale retrofits, especially if at the large scale there is an existing scrubber and space at the site to efficiently arrange the ASU and CPU. 
PCC may still have a partial capture advantage due to lower capital cost but that is not clear. Depending upon legislation and the owner's system, partial capture on an individual unit itself may not beneficial. Oxy-combustion can be operated in a manner that provides partial capture but at a higher capital cost. This is accomplished by operating in oxy-combustion mode to achieve the desired amount of $\mathrm{CO}_{2}$ capture and air firing the remainder of the time. If this scenario is coordinated with peak and off-peak periods so operation in the oxy-combustion mode is during off-peak periods when the price of electricity is low and air fired during peak periods when the selling price is high, revenue is maximized (these techniques are being patented by Air Liquide). Some capital can also be saved by under sizing the ASU and CPU for the lower loads desired during off-peak hours when generation is not as valuable. If advantageous, a smaller ASU with liquid oxygen (LOX) storage could be run during air firing to store oxygen for the offpeak oxy firing periods if economically attractive compared to the lost generation to run the ASU during peak operation. If full capture is desired at a later date, additional ASU and CPU modules could be installed.

Many think that partial capture may not be desirable for a single unit. In addition, power prices are low in off-peak periods, sometimes even negative so minimizing net output during those periods may be desirable. To accommodate the load profile while operating in oxy mode, a swing plant design could be adopted. This approach with oxy-combustion may not be available with the other CCS options. In the swing mode the ASU sizing is matched to the load profile for the plant so that the net power to the grid is maximized during peak periods and minimized during off-peak periods. When in the oxy-combustion mode during peak periods, the ASU output is supplemented from a LOX storage tank to achieve full output and the CPU is in operation. When operating during off-peak periods the ASU operates at a level necessary to make and store oxygen for the next peak period and the boiler generates sufficient power to supply the house load with little or no power to the grid. The CPU operates with the boiler output. If the load profile changes, additional ASU capacity can be added to ensure maximum net output during peak periods.

No direct comparison of this method against PCC has been made. If partial capture is a permanent solution at a site, PCC may have a lower capital cost advantage. But studies by DOE and others have shown that as capture decreases, the cost of $\mathrm{CO}_{2}$ removed and avoided increase compared to $90 \%$ capture. If full capture is in the longer term plan, oxy-combustion is expected to have an advantage overall. A comprehensive analysis (outside the scope of this project) is required to determine the magnitude of the advantage of oxy-combustion.

As a result, interest in the potential for oxy-combustion for retrofit application is renewed and this study was undertaken to evaluate that potential.

\subsubsection{Performance Basis}

The basis for the performance analysis of the various Base and Sensitivity Cases is explained in the following sections at three levels; the plant, the power block, and the ASU and CPU. The plant basis addresses site conditions and assumptions concerning the existing balance of plant equipment (not including the steam cycle). The power block defines the existing boiler, air quality control system, and steam cycle equipment. The design basis for the ASU and CPU is also described. 


\subsubsection{1. $\quad \underline{\text { Plant Basis }}$}

A gross plant output of $650 \mathrm{MWe}$ was selected as the basis for this study for all cases except Case 10, which is identical to Case 5 except that the gross output is $780 \mathrm{MWe}$ to assess the impact of scale. Cases were evaluated for three coals; an Illinois \#6 bituminous, Decker subbituminous, and North Dakota lignite, whose properties are given in Table 3.22. The bituminous coal and its properties were selected to allow direct comparison of the results of this study with the results from DOE's "Carbon Dioxide Capture from Existing Coal-Fired Power Plant” study DOE/NETL-401-110907, "Cost and Performance Baseline for Fossil Energy Plants" DOE/NETL-2007/1281, and "Pulverized Coal Oxy-combustion Power Plants" DOE/NETL-2007/1291 revised August 2008. These are references (26),(27), and (2) respectively in this report. As will be discussed in more detail later, financial assumptions and cost estimating timeframe were also selected to match these studies to allow direct comparison of results.

The retrofit site conditions are assumed to be reasonably favorable for retrofit, similar to those existing at the American Electric Power (AEP) Conesville site which was the basis for DOE/NETL-401/110907 Post Combustion Capture (PCC) study. It was assumed that the plant was at or near sea level for ambient conditions including barometric pressure, and wet and dry bulb temperatures. It is also assumed that sufficient space for the ASU and CPU is available at a reasonable distance from the power block.

\begin{tabular}{|l|r|r|r|r|r|r|}
\cline { 2 - 7 } \multicolumn{1}{c|}{} & \multicolumn{2}{c|}{} & \multicolumn{2}{c|}{$\begin{array}{c}\text { Sub-bituminous (PRB) } \\
\text { Lignite ND Lignite }\end{array}$} & \multicolumn{2}{c|}{$\begin{array}{c}\text { Bituminous } \\
\text { Ilinois \#6 }\end{array}$} \\
\hline \multicolumn{1}{c|}{ item } & Wt\% dry & Wt\% wet & Wt\% dry & Wt \% wet & Wt\% dry & Wt\% wet \\
\hline $\mathrm{H} 2 \mathrm{O}$ & & 33.30 & & 23.40 & & 11.12 \\
\hline $\mathrm{C}$ & 63.3 & 42.22 & 72.00 & 55.15 & 71.73 & 63.75 \\
\hline $\mathrm{H} 2$ & 4.5 & 3.00 & 5.00 & 3.83 & 5.06 & 4.50 \\
\hline $\mathrm{O} 2$ & 19 & 12.67 & 16.41 & 12.57 & 7.74 & 6.88 \\
\hline $\mathrm{S}$ & 1.1 & 0.73 & 0.44 & 0.34 & 3.04 & 2.70 \\
\hline $\mathrm{N} 2$ & 1 & 0.68 & 0.95 & 0.73 & 1.41 & 1.25 \\
\hline Ash & 11.1 & 7.40 & 5.20 & 3.98 & 11.02 & 9.80 \\
\hline TOTAL & $\mathbf{1 0 0}$ & $\mathbf{1 0 0}$ & $\mathbf{1 0 0}$ & $\mathbf{1 0 0}$ & $\mathbf{1 0 0}$ & $\mathbf{1 0 0}$ \\
\hline $\mathrm{HHV}$ & 10630 & 7090 & 12450 & 9540 & 13126 & 11666 \\
\hline
\end{tabular}

Table 3.22 Coal properties

\subsubsection{2. $\quad$ Power Block Basis}

As shown in Table 3.23, twelve (12) base retrofit (Retro) cases, and five (5) greenfield (GF) cases were evaluated. Base Cases 1-3 assume the existing plant has a subcritical 2535 psig, $1000^{\circ} \mathrm{F}$ main, $1000^{\circ} \mathrm{F}$ reheat steam cycle yielding a pre-retrofit net plant efficiency of $35 \%$ to match the AEP Conesville Unit 5 basis in DOE/NETL-401/110907. Retrofit Cases 4-10 employ a 3500 psig supercritical steam cycle based on the DOE/NETL-1291 Case 5 study with $1110^{\circ} \mathrm{F}$ main and $1150^{\circ} \mathrm{F}$ reheat steam temperatures. Greenfield Cases 11-14 employ advanced USC conditions of $4000 \mathrm{psi}, 1350^{\circ} \mathrm{F}, 1400^{\circ} \mathrm{F}$, also to match the DOE/NETL-1291 Case 6 study and compare to the DOE/NETL-1291 air fired base Case 2 for cost of $\mathrm{CO}_{2}$ removed and avoided. 


\begin{tabular}{|c|c|c|c|c|c|c|c|c|c|c|}
\hline Case & $\begin{array}{c}\text { Steam } \\
\text { Cycle }\end{array}$ & $\begin{array}{l}\text { Recycle } \\
\text { Process } \\
\end{array}$ & $\begin{array}{c}\text { Size MWe } \\
\text { Gross }\end{array}$ & Site & Fuel & Firing & $\begin{array}{l}\text { Primary } \\
\text { SO2/ Part }\end{array}$ & $\begin{array}{l}\text { Polishing } \\
\mathrm{SO} 2+\mathrm{H} 2 \mathrm{O} \\
\end{array}$ & ASU & $\begin{array}{c}\text { CPU } \\
\text { or } \\
\text { Comp } \\
\end{array}$ \\
\hline 1 & SubC & Cool & 650 & Retro & IIlinois \#6 & PC & FF/WFGD & Pri + CPU & ASU-C & CPU -C \\
\hline 1A & SubC & Cool & 650 & Retro & Illinois \#6 & PC & FF/WFGD & Pri + CPU & ASU-F & CPU -F \\
\hline 2 & SubC & Cool & 650 & Retro & Decker & PC & SDA/FF & Pri + CPU & ASU-C & CPU -C \\
\hline 3 & SubC & Cool & 650 & Retro & ND Lignite & PC & SDA/FF & Pri + CPU & ASU-C & CPU -C \\
\hline 4 & SC & Cool & 650 & Retro & Illinois \#6 & PC & FF/WFGD & Pri + CPU & ASU-C & CPU -C \\
\hline 5 & SC & Cool & 650 & Retro & Decker & PC & SDA/FF & Pri + CPU & ASU-C & CPU -C \\
\hline $5 A$ & SC & Cool & 650 & Retro & Decker & PC & SDA/FF & Pri + CPU & ASU-F & CPU -F \\
\hline 6 & SC & Cool & 650 & Retro & ND Lignite & PC & SDA/FF & Pri + CPU & ASU-C & CPU -C \\
\hline 7 & SC & Cool & 650 & Retro & Decker & CYC & FF/no FGD & CPU & ASU-C & CPU -C \\
\hline 8 & SC & Cool & 650 & Retro & Decker & CYC & FF/no FGD & CPU & ASU-C & Comp-C \\
\hline 9 & SC & Cool & 650 & Retro & Decker & PC & FF/no SDA & Pri + CPU & ASU-C & CPU -C \\
\hline 10 & SC & Cool & 780 & Retro & Decker & PC & SDA/FF & Pri + CPU & ASU-C & CPU -C \\
\hline 11 & USC & Warm & 650 & GF & Illinois \#6 & PC & SI, FF/WFGD & Pri + CPU & ASU-F & CPU -F \\
\hline 12 & USC & Warm & 650 & GF & Decker & PC & SDA/FF & Pri + CPU & ASU-C & CPU -C \\
\hline 13 & USC & Warm & 650 & GF & Decker & CYC & SDA/FF & Pri + CPU & ASU-F & CPU -F \\
\hline 13A & USC & Warm & 650 & GF & Decker & CYC & FF/no SDA & $\mathrm{CPU}\left(\mathrm{H}_{2} \mathrm{O}\right)$ & ASU-F & CPU -F \\
\hline 14 & USC & Warm & 650 & GF & Decker & PC & SDA/FF & Pri + CPU & ASU-F & CPU -F \\
\hline & & & & & & \multicolumn{3}{|c|}{$\begin{array}{l}\text { Existing for retrofit } \\
\text { New for Greenfield }\end{array}$} & \multicolumn{2}{|c|}{$\begin{array}{l}-\mathrm{C}=\text { Current Improvements } \\
-\mathrm{F}=\text { Future Improvements } \\
\text { Comp = Compression only }\end{array}$} \\
\hline
\end{tabular}

Table 3.23 Definition of base cases

A summary of the base cases and associated Gas Quality Control System (GQCS) equipment and CPU assumptions are shown in Table 3.23. For all retrofit cases it is assumed that the base plant already has an existing Air Quality Control System (AQCS) including particulate and primary $\mathrm{SO}_{2}$ removal equipment. In all retrofit cases, full, cool recycle was assumed (see Figure 3.92 and Figure 3.93). In other words, the recycle mass flow approximately matches the mass flow for air firing so that no heat transfer surfaces need be changed in the existing boiler and all of the recycle is treated by the primary GQCS before being returned to the boiler as primary or secondary recycle. For most cases (as indicated in Table 3.23) both the primary recycle and the flow to the CPU are also polished in a sodium-bicarbonate based direct contact cooler with integrated direct sulfur polishing (DCCPS, aka sodium scrubber/quench cooler or polishing scrubber) to about 1 ppmv $\mathrm{SO}_{2}$ (in the table this is referred to as "Pri + CPU"). The temperature is also reduced to $100^{\circ} \mathrm{F}$ to limit moisture.

ASPEN was employed to model the process and provide the gas composition from the power block to the CPU. The base cases were modeled assuming an air infiltration, defined as a percentage of wet theoretical air, of $2 \%$ in the boiler and an additional $3 \%$ between the boiler outlet and the Induced Draft (ID) fan inlet. The result of the ASPEN modeling for these conditions is given in Table 3.24. For Case 11, 12, 13, and 14 reduced air infiltration was assumed for the ultra-supercritical with warm flue gas recycle producing the gas compositions shown in Table 3.25 and for Case 13A the composition in Table 3.25 was modified to assume no $\mathrm{SO}_{2}$ removal resulting in the composition shown in Table 3.26. 


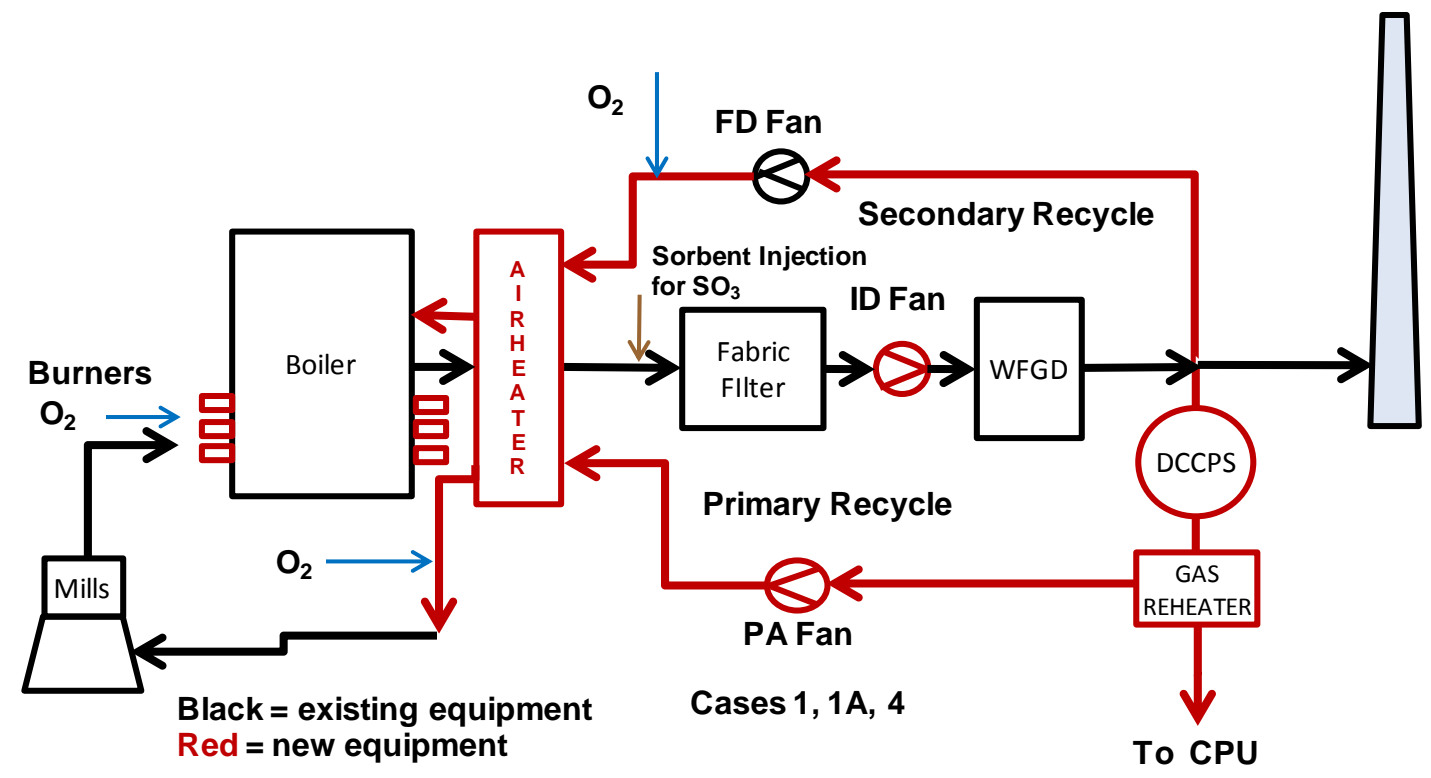

Figure 3.92 Cool recycle process configuration for bituminous retrofit cases

All base cases assume $95 \%$ oxidant purity with a composition as shown in Table 3.27. For all cases it was also assumed that the boiler would be operated to maintain $3 \%$ excess oxygen at the boiler outlet (dry basis).

For the processes shown in Figure 3.92 and Figure 3.93, the existing primary GQCS equipment was assumed to be fabric filter (FF) with a limestone wet scrubber (WFGD) for bituminous coal cases and a hydrated lime spray dryer absorber (SDA) followed by a fabric filter for subbituminous and lignite cases. For cases with a WFGD, limestone with $80.4 \% \mathrm{CaCO}_{3}$ and $98 \% \mathrm{SO}_{2}$ removal were assumed. For cases with a SDA, pebble lime with $90 \%$ available $\mathrm{CaO}$ and $95 \% \mathrm{SO}_{2}$ removal were assumed. $\mathrm{An} \mathrm{SO}_{2}$ removal of $99.8 \%$ was assumed in bicarbonate based DCCPS taking the $\mathrm{SO}_{2}$ concentration in the gas to the CPU down to $1 \mathrm{ppmv}^{6}$ and quenchcooled to $100^{\circ} \mathrm{F}$ saturated.

${ }^{6}$ The reasons for 1 ppmv at the outlet of the DCCPS are a) to precondition the gas for Air Liquide's CPU design to avoid corrosion in CPU components, and b) to minimize sulfur in the primary stream which acts to dilute the $\mathrm{SO}_{2}$ in the boiler to levels manageable in regard to corrosion especially with high sulfur coals. Depending on the CPU design and sulfur level in the coal, lower removals may be tolerable. 

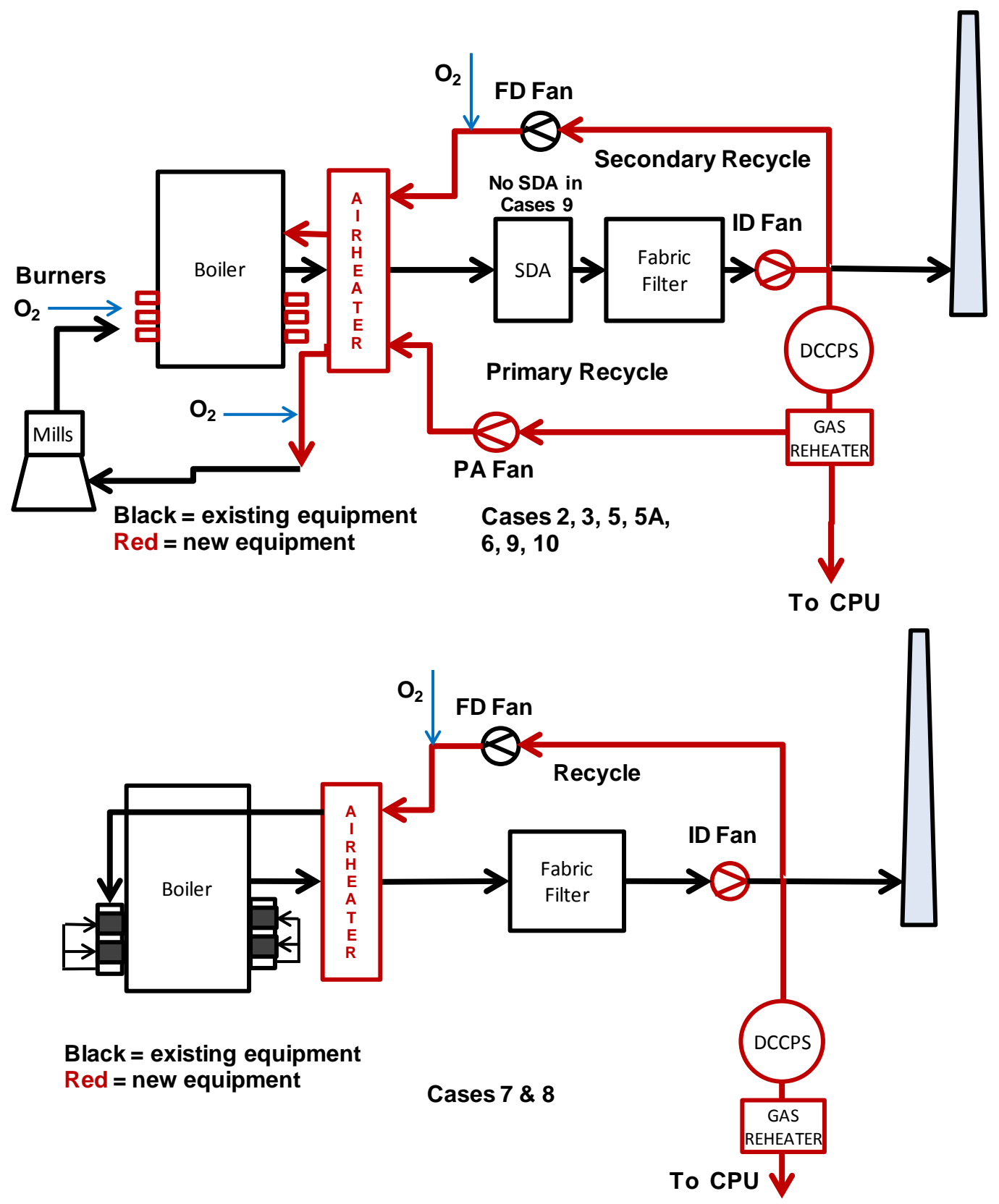

Figure 3.93 Cool recycle processes for PRB and North Dakota Lignite retrofit cases 


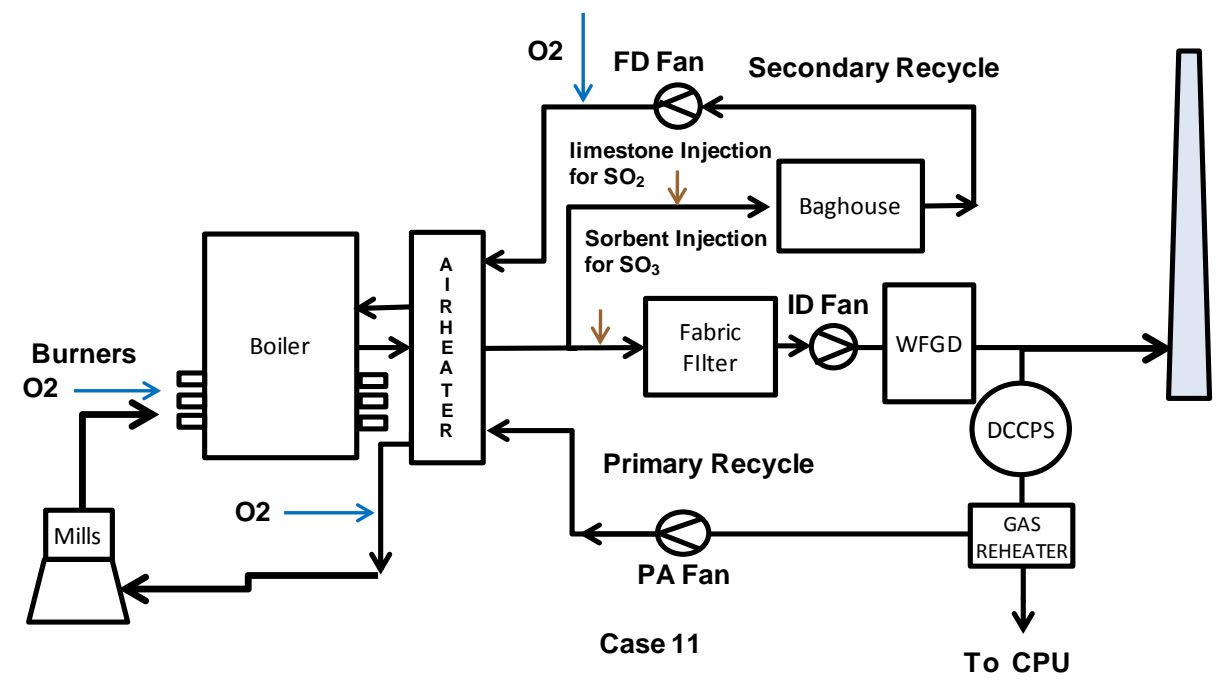

Figure 3.94 Warm recycle for process configuration for bituminous greenfield case

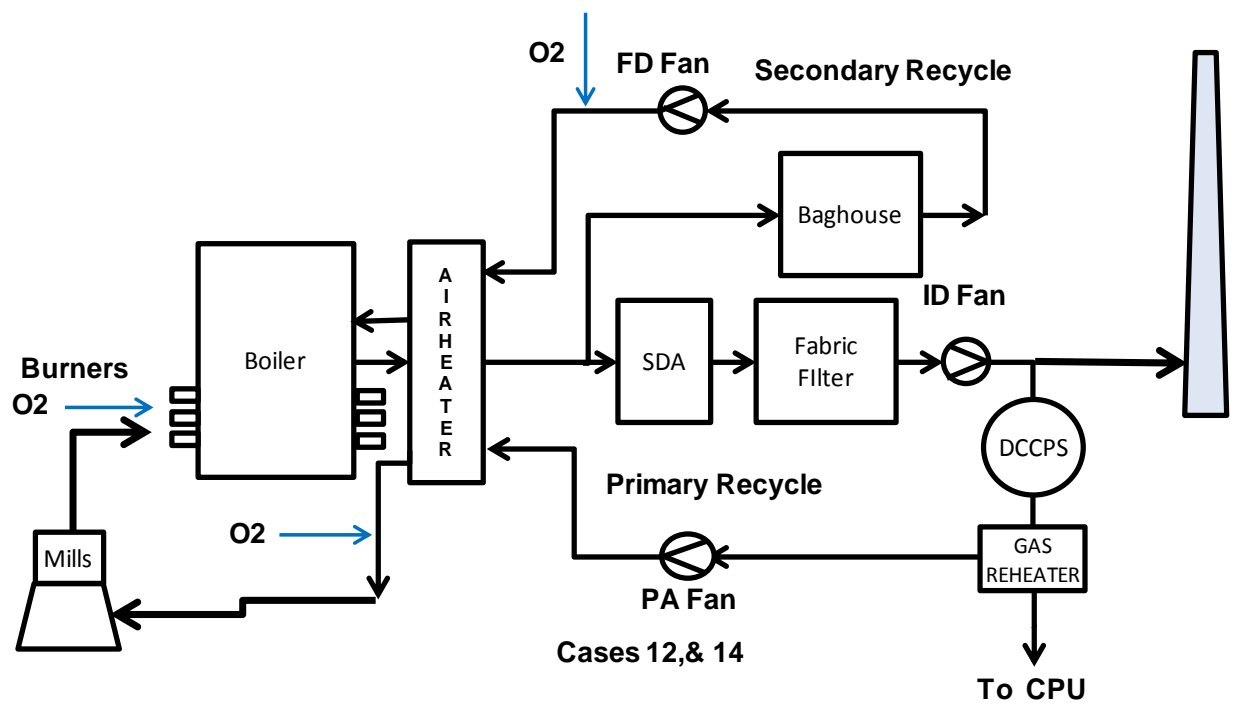

Figure 3.95 Warm recycle for PRB and North Dakota Lignite for greenfield PC Cases 12 and 14 

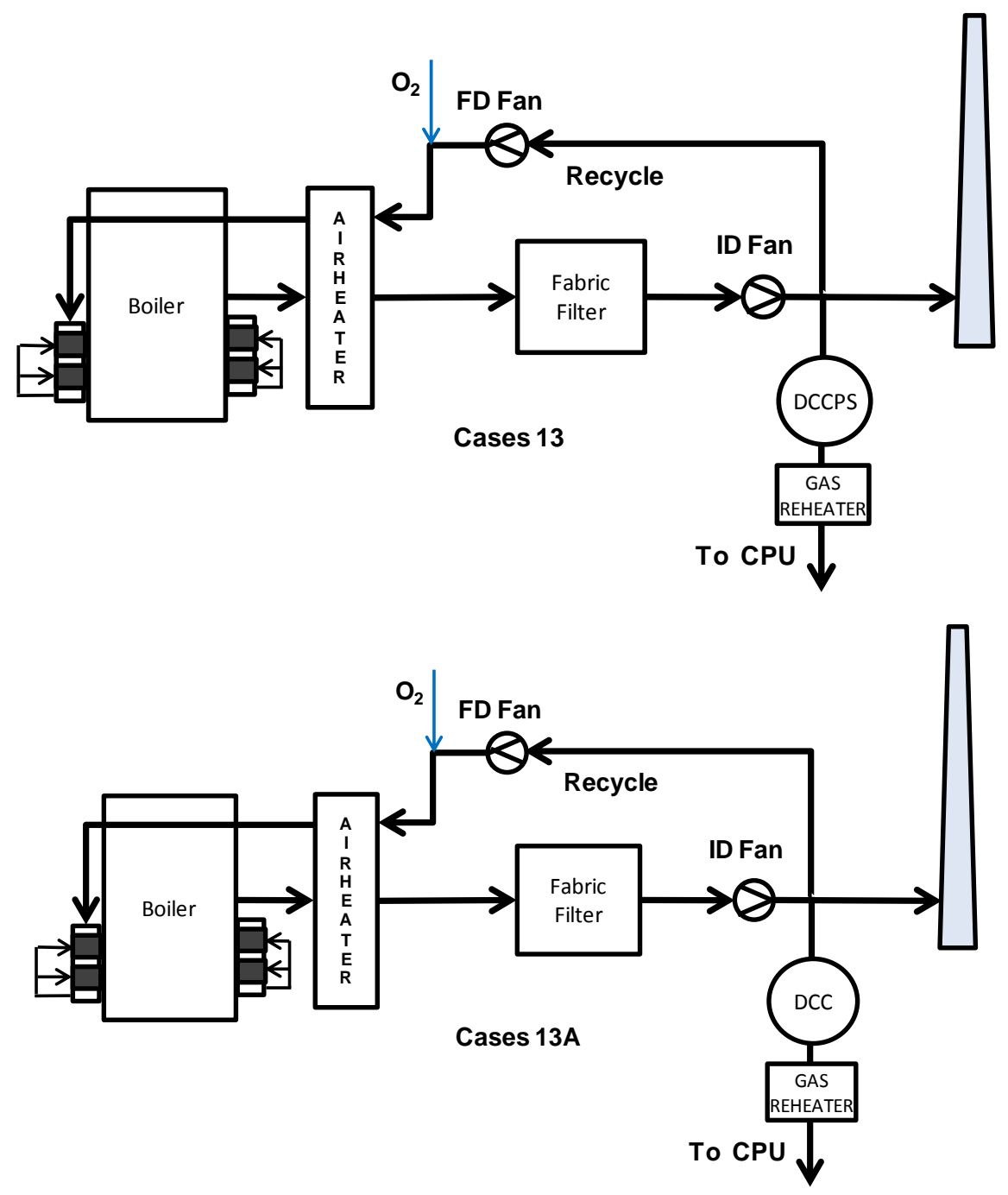

Figure 3.96 Warm recycle for PRB and North Dakota Lignite for greenfield Cyclone Cases 13 and 13A

\begin{tabular}{|c|c|c|c|c|c|c|c|c|c|c|c|c|}
\hline \multirow{3}{*}{\begin{tabular}{|l} 
Component \\
\end{tabular}} & \multicolumn{4}{|c|}{ ND Lignite } & \multicolumn{4}{|c|}{ Decker } & \multicolumn{4}{|c|}{ Illinois \#6 } \\
\hline & \multicolumn{2}{|c|}{ Wet } & \multicolumn{2}{|c|}{ Dry } & \multicolumn{2}{|c|}{ Wet } & \multicolumn{2}{|c|}{ Dry } & \multirow{2}{*}{$\begin{array}{c}\text { Wet } \\
\text { Mol \% }\end{array}$} & \multirow{2}{*}{\multicolumn{2}{|c|}{$\begin{array}{c}\text { Dry } \\
\text { Mol \% }\end{array}$}} & \multirow[b]{2}{*}{ Wt. \% } \\
\hline & Mol \% & Wt. \% & Mol \% & Wt. \% & Mol \% & Wt. \% & Mol \% & Wt. \% & & & & \\
\hline $\mathrm{H} 2 \mathrm{O}$ & 6.55 & 3.01 & 0.00 & 0.00 & 6.55 & 3.02 & 0.00 & 0.00 & 6.55 & 3.02 & 0.00 & 0.00 \\
\hline N2 & 16.42 & 11.75 & 17.57 & 12.12 & 16.56 & 11.86 & 17.72 & 12.23 & 17.19 & 12.35 & 18.40 & 12.73 \\
\hline $\mathrm{O} 2$ & 3.27 & 2.67 & 3.49 & 2.75 & 3.40 & 2.78 & 3.64 & 2.87 & 3.52 & 2.89 & 3.76 & 2.98 \\
\hline NO (ppm) & 600.80 & 461.02 & 642.88 & 475.34 & 476.37 & 385.51 & 509.74 & 397.50 & 316.07 & 243.19 & 338.20 & 250.78 \\
\hline $\mathrm{SO} 2(\mathrm{ppm})$ & 1.23 & 2.01 & 1.31 & 2.07 & 1.22 & 2.00 & 1.31 & 2.07 & 1.26 & 2.07 & 1.35 & 2.13 \\
\hline $\mathrm{CO}(\mathrm{ppm})$ & 70.23 & 50.16 & 75.15 & 51.72 & 50.05 & 37.81 & 53.56 & 38.99 & 123.84 & 88.95 & 132.52 & 91.73 \\
\hline $\mathrm{CO} 2$ & 70.44 & 79.19 & 75.38 & 81.65 & 70.23 & 79.02 & 75.14 & 81.47 & 69.46 & 78.39 & 74.32 & 80.83 \\
\hline $\mathrm{AR}$ & 3.26 & 3.32 & 3.49 & 3.43 & 3.21 & 3.28 & 3.44 & 3.38 & 3.24 & 3.32 & 3.47 & 3.43 \\
\hline \multicolumn{4}{|c|}{ Oxidant Flow (lb/klb coal) } & 1318.68 & & & & 1748.64 & & & & 2130.63 \\
\hline \multicolumn{3}{|c|}{ CPU Flow (lb/klb coal) } & & 1964.59 & & & & 2562.02 & & & & 3025.70 \\
\hline & \multicolumn{12}{|c|}{$\begin{array}{l}2 \% \text { Boiler Infiltration } 3 \% \text { Boiler Outlet O2 (dry) } \\
3 \% \text { Back End Infiltration } \\
95 \% \text { Oxidant Purity from ASU }\end{array}$} \\
\hline
\end{tabular}

Table 3.24 Gas composition to the CPU for each coal for retrofit cases 


\begin{tabular}{|c|c|c|c|c|c|c|c|c|}
\hline \multirow{3}{*}{\begin{tabular}{|l|} 
Component \\
\end{tabular}} & \multicolumn{4}{|c|}{ Illinois \#6 } & \multicolumn{4}{|c|}{ Decker } \\
\hline & \multicolumn{2}{|c|}{ Wet } & \multicolumn{2}{|c|}{ Dry } & \multicolumn{2}{|c|}{ Wet } & \multicolumn{2}{|c|}{ Dry } \\
\hline & Mol \% & Wt. \% & Mol \% & Wt. \% & Mol \% & Wt. \% & Mol \% & Wt. \% \\
\hline $\mathrm{H} 2 \mathrm{O}$ & 6.55 & 2.93 & 0.00 & 0.00 & 6.55 & 2.92 & 0.00 & 0.00 \\
\hline N2 & 9.12 & 6.34 & 9.76 & 6.54 & 8.68 & 6.02 & 9.29 & 6.20 \\
\hline $\mathrm{O} 2$ & 3.56 & 2.83 & 3.81 & 2.91 & 3.30 & 2.62 & 3.53 & 2.70 \\
\hline NO (ppm) & 256.82 & 191.35 & 274.81 & 197.12 & 413.27 & 307.15 & 442.22 & 316.39 \\
\hline $\mathrm{SO} 2$ (ppm) & 1.35 & 2.14 & 1.44 & 2.21 & 1.35 & 2.15 & 1.45 & 2.21 \\
\hline $\mathrm{CO}(\mathrm{ppm})$ & 104.64 & 72.78 & 111.98 & 74.98 & 47.95 & 33.27 & 51.31 & 34.27 \\
\hline $\mathrm{CO} 2$ & 77.18 & 84.34 & 82.58 & 86.89 & 77.90 & 84.92 & 83.36 & 87.48 \\
\hline AR & 3.56 & 3.53 & 3.81 & 3.64 & 3.52 & 3.48 & 3.77 & 3.59 \\
\hline \multicolumn{2}{|c|}{ Oxidant Flow (lb/klb coal) } & & & 2181.19 & & & & 1791.61 \\
\hline \multicolumn{2}{|c|}{ CPU Flow (lb/klb coal) } & & & 2806.47 & & & & 2383.60 \\
\hline \multicolumn{2}{|c|}{\begin{tabular}{|l|}
$0 \%$ Boiler Infiltration \\
$2 \%$ Back End Infiltration \\
$95 \%$ ASU Oxidant Purity
\end{tabular}} & \multicolumn{2}{|c|}{$3 \%$ Boiler Outlet O2 (dry) } & & \multicolumn{2}{|c|}{$\begin{array}{l}0 \% \text { Boiler Infiltration } \\
2 \% \text { Back End Infiltration } \\
95 \% \text { ASU Oxidant Purity }\end{array}$} & \multicolumn{2}{|c|}{ 3\% Boiler Outlet O2 (dry) } \\
\hline
\end{tabular}

Table 3.25 Gas composition to the CPU for Cases 11, 12, 13 and 14

\begin{tabular}{|c|c|c|c|c|}
\hline & \multicolumn{4}{|c|}{ Decker } \\
\hline \multirow[t]{2}{*}{ Component } & \multicolumn{2}{|c|}{ Wet } & \multicolumn{2}{|c|}{ Dry } \\
\hline & Mol \% & Wt. \% & Mol \% & Wt. \% \\
\hline \multirow{8}{*}{$\begin{array}{l}\mathrm{H} 2 \mathrm{O} \\
\mathrm{N} 2 \\
\mathrm{O} 2 \\
\mathrm{NO}(\mathrm{ppm}) \\
\mathrm{SO} 2(\mathrm{ppm}) \\
\mathrm{CO}(\mathrm{ppm}) \\
\mathrm{CO} 2 \\
\mathrm{AR}\end{array}$} & 6.55 & 2.92 & 0.00 & 0.00 \\
\hline & 8.68 & 6.02 & 9.29 & 6.20 \\
\hline & 3.30 & 2.62 & 3.53 & 2.69 \\
\hline & 414.00 & 307.00 & 443.01 & 316.23 \\
\hline & 1712.00 & 2715.00 & 1831.96 & 2796.65 \\
\hline & 48.00 & 33.00 & 51.36 & 33.99 \\
\hline & 77.73 & 84.66 & 83.17 & 87.21 \\
\hline & 3.52 & 3.48 & 3.77 & 3.58 \\
\hline \multicolumn{4}{|c|}{ Oxidant Flow (lb/klb coal) } & 1791.61 \\
\hline \multicolumn{4}{|c|}{ CPU Flow (lb/klb coal) } & 2386.32 \\
\hline \multicolumn{2}{|c|}{$\begin{array}{l}\text { 0\% Boiler Infiltration } \\
\text { 2\% Back End Infiltration } \\
95 \% \text { ASU Oxidant Purity }\end{array}$} & $\%$ Boiler O & O2 (dry) & \\
\hline
\end{tabular}

Table 3.26 Gas composition to the CPU for Case 13A

Fuel (boiler) efficiency was adjusted based on fuel characteristics. For the pulverized coal (PC) cases firing Illinois \#6 bituminous coal, $88.12 \%$ was used for fuel (boiler) efficiency which is based on DOE/NETL's study of AEP Conesville Unit \#5 in DOE/NETL-401/110907 and in the "Pulverized Coal Oxy-combustion Power Plants" DOE/NETL-2007/1291 revised August 2008 report. For the subbituminous Decker coal, a $2 \%$ reduction in fuel efficiency from bituminous was assumed yielding $86.12 \%$. For North Dakota Lignite, a $4 \%$ reduction in fuel efficiency from bituminous was assumed yielding $84.12 \%$.

The Cyclone boiler cases all fired subbituminous Decker coal and due to the lower excess oxygen and other minor differences, the fuel efficiency was reduced by $1.82 \%$ from bituminous instead of the $2 \%$ for PC firing yielding $86.3 \%$. This slight improvement is based on internal studies by B\&W showing slightly less reduction in fuel efficiency between bituminous and Decker coal for Cyclone firing compared to PC firing. 


\begin{tabular}{|r|c|c|c|c|}
\hline \multicolumn{5}{|c|}{ ASU Oxygen Concentration } \\
\hline Composition & $95 \%$ & $90 \%$ & $85 \%$ & $80 \%$ \\
\hline N2 & $1.70 \%$ & $6.80 \%$ & $12.00 \%$ & $17.10 \%$ \\
\hline Ar & $3.30 \%$ & $3.20 \%$ & $3.00 \%$ & $2.90 \%$ \\
\hline O2 & $95.00 \%$ & $90.00 \%$ & $85.00 \%$ & $80.00 \%$ \\
\hline Composition & (mass) & & & \\
\hline N2 & $1.50 \%$ & $6.00 \%$ & $10.50 \%$ & $15.20 \%$ \\
\hline $\mathrm{Ar}$ & $4.00 \%$ & $3.90 \%$ & $3.80 \%$ & $3.70 \%$ \\
\hline $\mathrm{O} 2$ & $94.40 \%$ & $90.10 \%$ & $85.60 \%$ & $81.10 \%$ \\
\hline
\end{tabular}

Table 3.27 Oxidant composition

Base plant auxiliary power was based on an assumption of $6.4 \%$ of gross power for the base plant PC cases which was derived from the AEP Conesville Unit \#5 PCC study in DOE/NETL$401 / 110907$ study using a fuel efficiency of $88.12 \%$ and net plant efficiency before retrofit of $35 \%$. This resulted in a turbine cycle (gross) heat rate of $8040 \mathrm{Btu} / \mathrm{kWh}$ which was used for all retrofit cases with subcritical steam conditions.

The base plant auxiliary power was adjusted based on B\&W data to compensate for WFGD, SDA, or no FGD. Auxiliary power for the ASU and CPU were provided by Air Liquide and added. Additional power was also added for the DCCPS and its associated wet cooling tower and for additional cooling capacity for the ASU and CPU compressors. No benefit from heat integration was assumed for retrofit cases, though a benefit is possible in reality depending upon the existing equipment. This would increase electricity generation without additional fuel input resulting in an increase in plant performance without significant added cost.

Using this turbine cycle heat rate, fuel efficiency, and the total auxiliary power, the heat rate and net plant efficiency under oxy-combustion conditions was calculated. The fuel flow was unchanged from the base air-fired plant and the oxidant requirement was calculated based on oxidant purity and theoretical oxygen required (fuel dependent) assuming $99.9 \%$ combustion efficiency and $3 \%$ excess oxygen at the boiler outlet. The total flue gas flow to the CPU was determined by calculating the $\mathrm{CO}_{2}$ produced from the fuel flow and composition divided by the mass percentage of $\mathrm{CO}_{2}$ wet from the ASPEN base calculation of the gas composition (see Table 3.24). These flows and compositions were provided to Air Liquide for each case to determine the ASU and CPU auxiliary power and CAPEX. Since the boiler heat input does not change with auxiliary power this information could be determined directly.

Cases 1A and 5A are identical to Cases 1 and 5 respectively except the A cases use ASU and CPU power and CAPEX based on future technological improvements. The five (5) greenfield base Cases 11-14 (see Figure 3.94 thru Figure 3.96) were also evaluated for comparison of performance and cost with each other and with studies done by DOE. The bituminous Case 11 was also compared with the results of the aforementioned DOE studies which were done on the same performance and financial basis.

For the USC greenfield cases an additional gross generation of 5\% of the base gross power (650 MWe) was added to account for steam turbine advancements, deep integration of heat from 
the ASU, gas coolers, and gas reheaters reducing extraction steam for feedwater heating, and by other power recovery methods within the processes. This value is based on an internal integration study by B\&W and Air Liquide completed in 2008. Case 13A is identical to Case 13 except it has no primary scrubber and only moisture is removed in the stream to the CPU so the CPU accepts the full sulfur loading.

\subsubsection{3. $\quad$ ASU and CPU Basis}

\subsection{ASU Basis}

Air Liquide has a long history in developing Air Separation Units (ASUs) based on cryogenic distillation of air gases. A traditional ASU typically produces $99 \%+$ purity oxygen. The most efficient ASUs today consume about $200 \mathrm{kWh} / \mathrm{tm}$ of oxygen produced. In recent years, Air Liquide has optimized this ASU specifically for oxy-combustion to further reduce the energy requirement of this unit (see Figure 3.97). This section provides details of the Air Liquide approach.

\section{ASU for oxy-combustion and specific energy}

The oxy-combustion process does not require nitrogen. Also, internal Air Liquide-B\&W studies have shown that there is no real benefit to supplying very high purity oxygen to an oxycombustion boiler (the next section provides details). Air Liquide has modified the ASU design, taking into consideration the factors mentioned above to decrease the cost of oxygen production. An optimized ASU for oxy-combustion producing 95\% purity oxygen can be offered today at less than $160 \mathrm{kWh} / \mathrm{tm}$ including heat integration. Heat integration means that heat from compression is utilized by transferring the heat energy to streams within the power block and steam cycle.

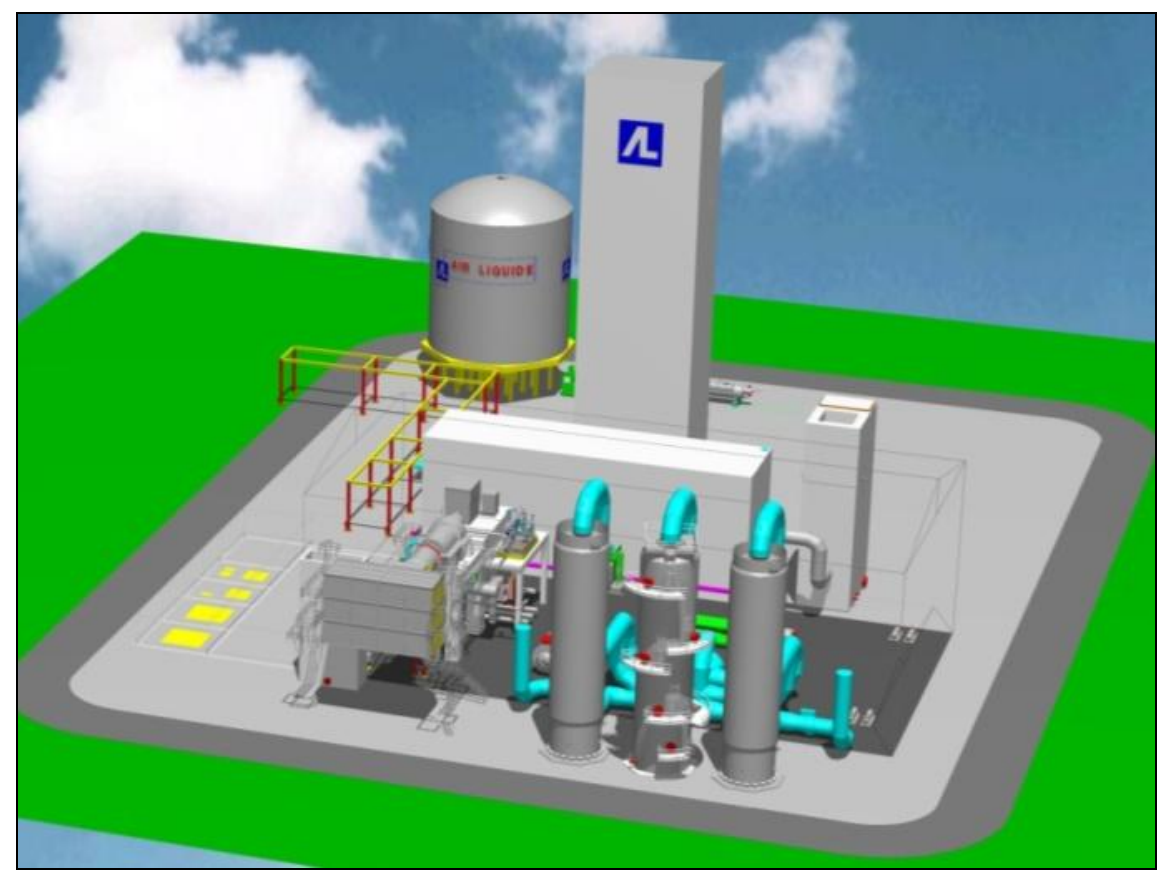

Figure 3.97 3D model of ASU for oxy-combustion 


\section{Oxygen Purity}

The specific energy of oxygen separation from air by cryogenic distillation increases with increase in the purity requirement of the oxygen product. In particular, beyond $95 \%$ oxygen purity the separation energy requirement increases exponentially (Figure 3.98). As a result, the energy requirement of the ASU increases.

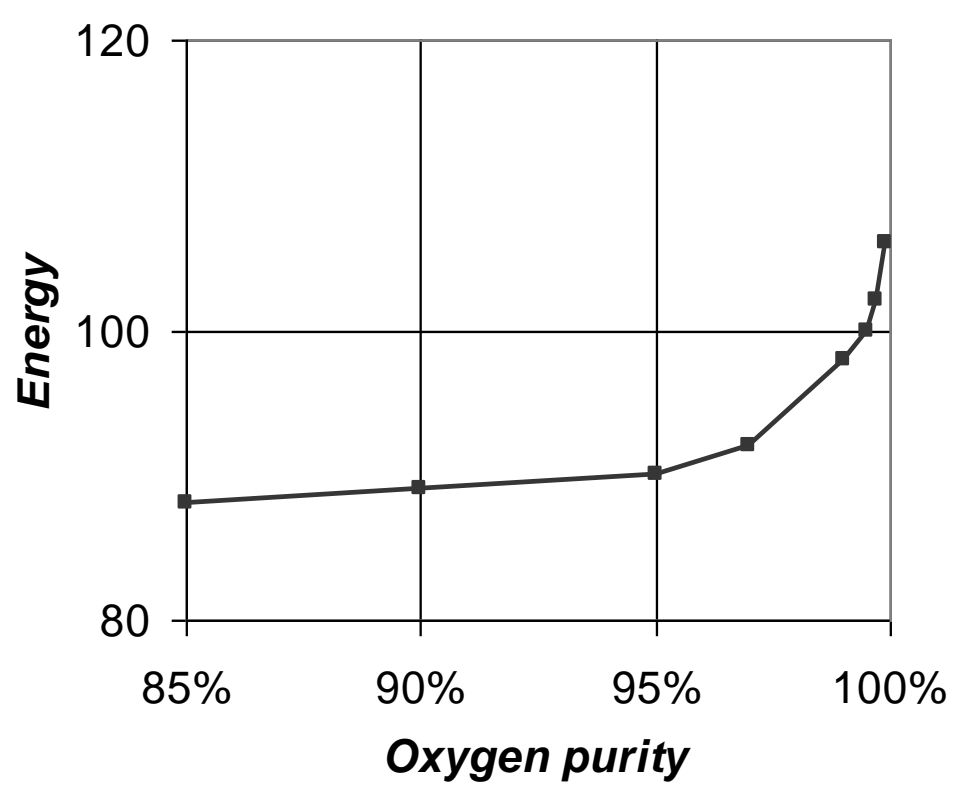

Figure 3.98 Specific energy consumption of ASU as a function of product oxygen purity

Higher purity oxygen though decreases the size of the flue gas stream to the CPU hence decreasing the capital cost of the CPU. From Figure 3.99, the reduction in flue gas volume leads to a marginal decrease in overall capital cost of the ASU and CPU. However, from Figure 3.100, the additional power requirement to produce high purity oxygen beyond $96.5 \%$ purity more than compensates for the reduction in power requirement of the CPU due to processing of smaller flow rates of flue gas.

The increase in power consumption beyond $96.5 \%$ in Figure 3.100 is more abrupt than in Figure 3.98 because Figure 3.98 shows the theoretical energy change for additional purification while Figure 3.100 shows the power consumption of an actual unit wherein an additional distillation column is required to separate argon (the main contaminant remaining in the oxygen stream) from oxygen. 


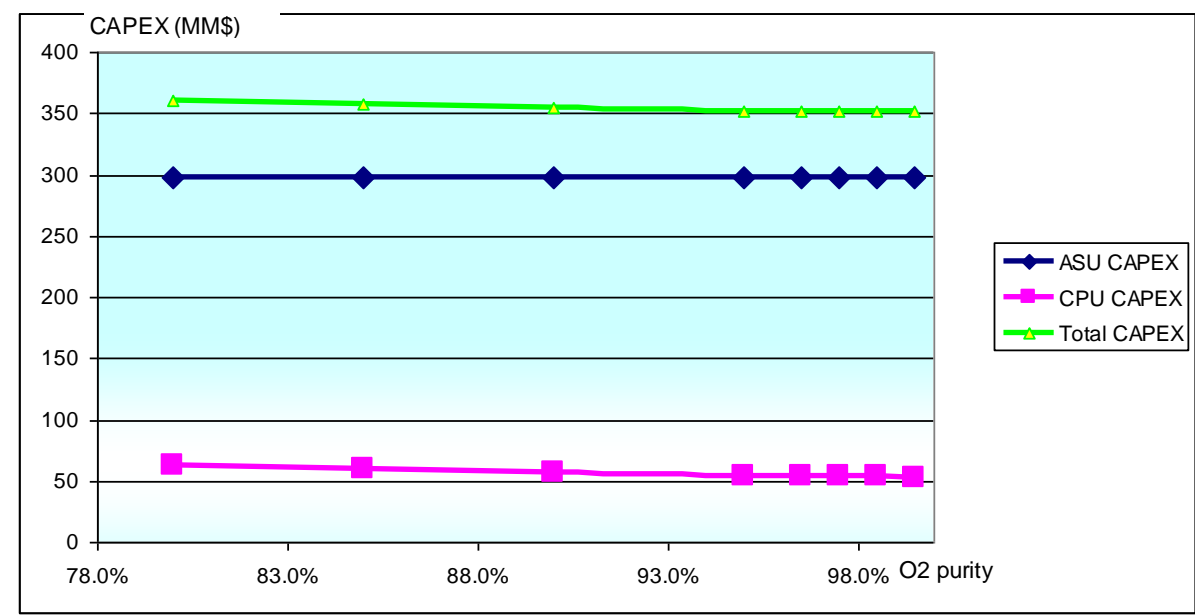

Figure 3.99 Capital cost of ASU and CPU as a function of product oxygen purity

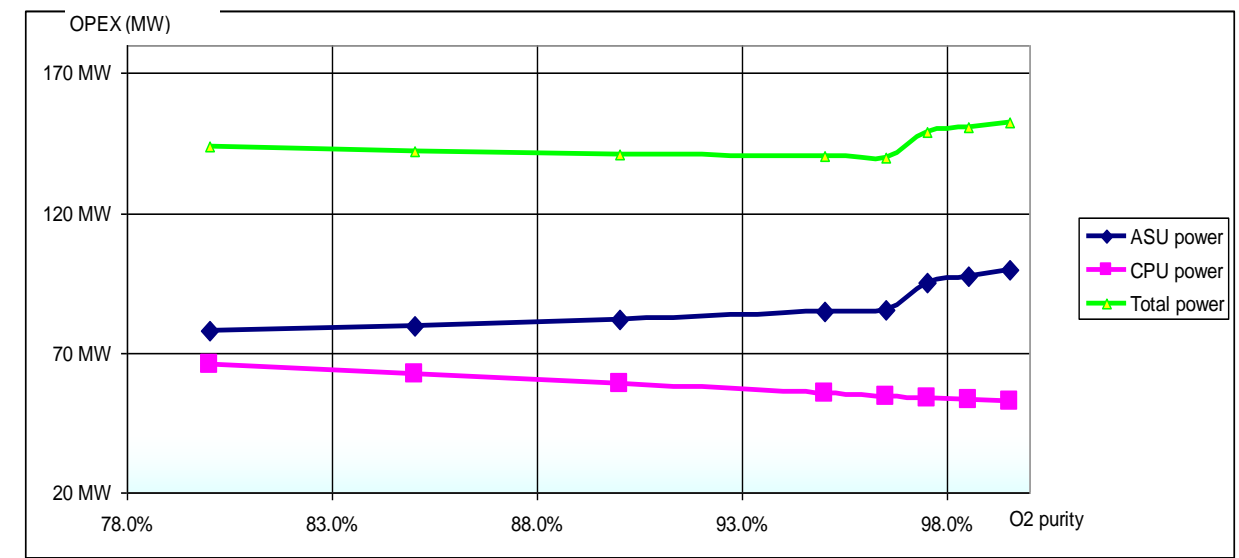

Figure 3.100 Power consumption of ASU and CPU as a function of product oxygen purity

Between $95 \%$ and $96.5 \%$, there is negligible change in overall costs and power requirements. Therefore, for this study, $95 \%$ oxygen purity was assumed for all standard cases. $95 \%$ purity oxygen has a balance of $3.3 \%$ argon and $1.7 \%$ nitrogen.

\subsubsection{2. $\quad C P U$ Basis}

The goal of the $\mathrm{CO}_{2}$ Compression and Purification unit is to process flue gas from the power block and recover $90 \%$ of the $\mathrm{CO}_{2}$ at a composition suitable for sequestration. A typical $\mathrm{CO}_{2}$ CPU scheme, as shown in Figure 3.101, consists of the following steps:

- Treatment for $\mathrm{SO}_{\mathrm{X}}$ reduction to $1 \mathrm{ppmv}$ (if required) and dust removal to levels acceptable by compressors

- Compression of wet flue gas

- Drying of the flue gas at the outlet of the "wet compression" step

- Flue gas purification

- Compression of the dry product gas to a pressure at which it condenses at $20^{\circ} \mathrm{C}$

- Pumping of the condensed product to pipeline pressure 


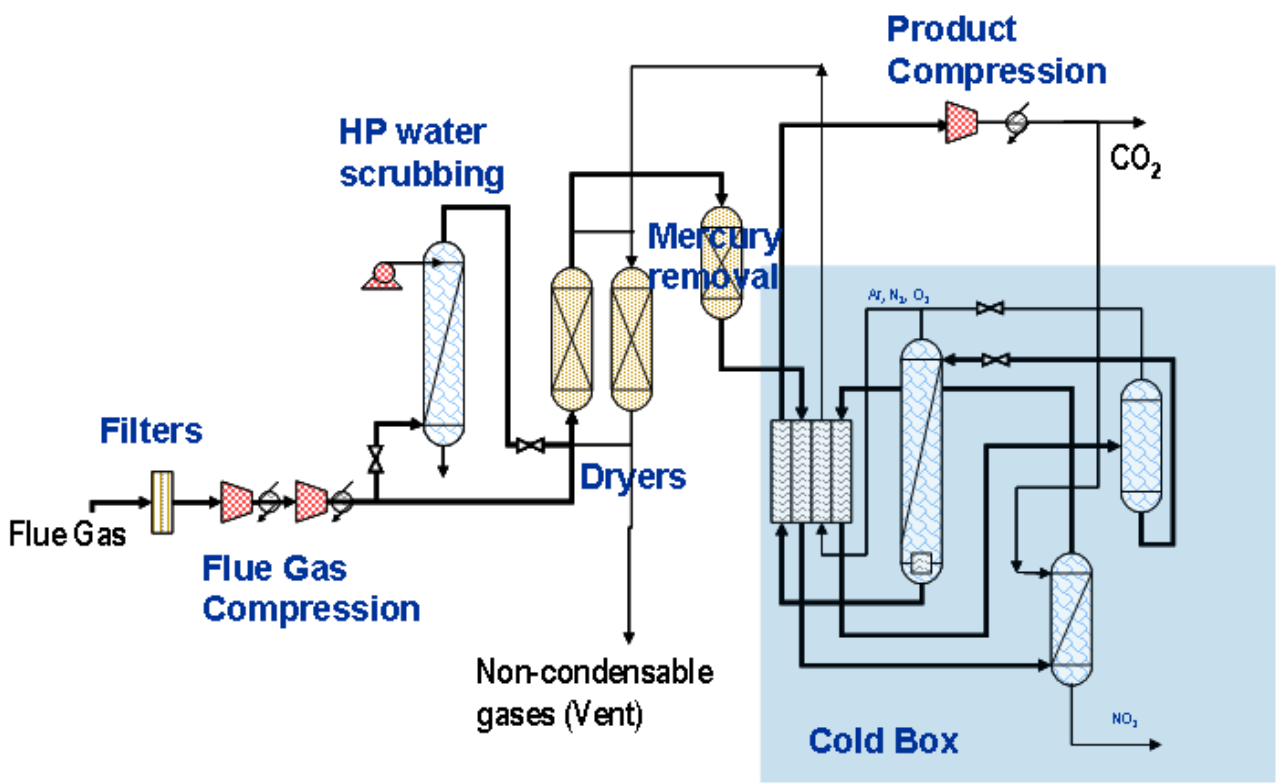

Figure 3.101 Schematic diagram of a typical $\mathrm{CO}_{2} \mathrm{CPU}$ scheme

The specifications for a "sequestration-ready" stream are not clearly defined today, except for the particular case of $\mathrm{CO}_{2}$ for enhanced oil recovery applications. In that case too, there is no specification on $\mathrm{SO}_{\mathrm{X}}$ and $\mathrm{NO}_{\mathrm{X}}$ in the gas stream. To understand the influence of the level of purification on overall cost, two extreme cases were considered:

1) Compression only (Case 8) -The flue gas, after treatment to reduce $\mathrm{SO}_{\mathrm{X}}$ to $1 \mathrm{ppm}$ and reduce dust loading, is compressed and dried to the required water specifications. The gas is further compressed and then cooled down to the desired product temperature. This process can lead to $100 \% \mathrm{CO}_{2}$ recovery.

2) Partial condensation and distillation (all other cases) - This case involves the following purification operations after the wet compression step:

- Water scrubbing of compressed flue gas to simultaneously cool it down and remove some impurities (typically $\mathrm{NO}_{2}$ )

- $\quad$ Drying using a classical TSA (Temperature Swing Adsorption) process as commonly used in ASUs

- Mercury removal in a single adsorption bed

- Cryogenic purification using a multi-step partial condensation and distillation process to recover $90 \%$ of the $\mathrm{CO}_{2}$ in the flue gas. A different extent of $\mathrm{CO}_{2}$ recovery might be a more economical option but was not considered in this study

The main advantage of adding a distillation column is the increase in product purity. Without a distillation column, the oxygen content in the $\mathrm{CO}_{2}$ product remains close to $1 \%$ (molar) or higher. As nitrogen, argon, carbon monoxide, and $\mathrm{NO}$ are removed with $\mathrm{O}_{2}$ in the distillation column, $\mathrm{CO}_{2}$ product purity is increased to nearly $100 \%$. In terms of energy requirements adding 
the distillation column is a small increment that is second order of magnitude (i. e. the energy consumption of the CPU is increased by $3 \%$ to $4 \%$ ).

\section{CPU Performance}

For the CPU, the additional assumptions shown in Table 3.28 have been taken into account. As previously mentioned, all cases assume $90 \%$ of the $\mathrm{CO}_{2}$ is captured. In order to achieve this, the compressor outlet pressure is chosen appropriately. The lower the $\mathrm{CO}_{2}$ concentration in the flue gas, the higher the pressure required and the higher the specific energy consumption.

\begin{tabular}{|l|l|}
\hline Cooling water temperature in $\left({ }^{\circ} \mathrm{C}\right)$ & 15 \\
\hline Cooling water temperature out $\left({ }^{\circ} \mathrm{C}\right)$ & 25 \\
\hline Inlet pressure after $\mathrm{SO}_{\mathrm{x}}$ removal $(\mathrm{bar})$ & 1.01325 \\
\hline
\end{tabular}

\section{Table 3.28 CPU design assumptions}

All retrofit cases have similar $\mathrm{CO}_{2}$ concentrations. For all retrofit cases the energy requirement of the CPU is the same: $138 \mathrm{kWh} / \mathrm{tm}$ of $\mathrm{CO}_{2}$ captured. When the $\mathrm{CO}_{2}$ concentration is reduced or increased (infiltration or oxygen purity changed), specific energy consumption of the CPU changes accordingly. Table 3.29 shows all $\mathrm{CO}_{2}$ concentrations assumed and associated specific energy:

\begin{tabular}{|l|l|l|}
\hline $\begin{array}{l}\mathrm{CO}_{2} \text { concentration } \\
(\% \text { mol, dry basis })\end{array}$ & $\begin{array}{l}\text { Specific energy of } \\
\mathrm{CPU}(\mathrm{kWh} / \mathrm{tm})\end{array}$ & $\begin{array}{l}\text { Specific energy of } \\
2020 \mathrm{CPU} \\
(\mathrm{kWh} / \mathrm{tm})\end{array}$ \\
\hline 83.36 & 120 & 108 \\
\hline 75.00 & 138 & 124 \\
\hline 71.06 & 141 & 127 \\
\hline 70.40 & 143 & 129 \\
\hline 67.10 & 148 & 133 \\
\hline 63.16 & 155 & 140 \\
\hline
\end{tabular}

Table 3.29 Assumed $\mathrm{CO}_{2}$ concentrations and associated specific energy

\section{Utility Consumption}

The primary utility consumption of the CPU is electricity. The main secondary utilities are cooling water and steam. These can be considered proportional to the amount of $\mathrm{CO}_{2}$ produced. Table 3.30 summarizes secondary utility consumption:

\begin{tabular}{|l|l|}
\hline Cooling water (tm/tm of $\mathrm{CO}_{2}$ captured) & 23.2 \\
\hline HP Steam (sat @ $148 \mathrm{psig}$ ) (lbs/tm of $\mathrm{CO}_{2}$ captured) & 9.26 \\
\hline MP Steam (sat @ $60 \mathrm{psig}$ ( $\mathrm{lbs} / \mathrm{tm}$ of $\mathrm{CO}_{2}$ captured) & 3.7 \\
\hline LP Steam (sat @ $19 \mathrm{psig}$ ) (lbs/tm of $\mathrm{CO}_{2}$ captured) & 34.5 \\
\hline
\end{tabular}

\section{Table 3.30 Secondary utility consumptions}

\section{Future CPU}

The CPU described in the previous paragraph corresponds to current CPU technology which can be offered at commercial scale today. Air Liquide is actively working to improve this scheme in terms of capital and operating costs. Improvements are expected in process optimization, rotating 
equipment performance improvement and cost reduction. The so-called future cases (Cases 1A, $11,13,13 \mathrm{~A}, 14)$ include such expected improvements.

The Future cases assume a plant built after 2020. By then the following modification are expected in the CPU which will decrease energy consumption:

- Compressor efficiencies (Ramgen compressors for example)

- Expansion turbines efficiencies

- Pressure drop optimization

- Refrigeration cycle improvement

As a result of these efficiency improvements, specific energy is expected to decrease by $10 \%$. Greenfield cases are also considered to have low air infiltration ( $83.36 \% \mathrm{CO}_{2}$ (dry molar basis) for Decker coal in Table 3.25), specific energy in these cases will be $108 \mathrm{kWh} / \mathrm{tm}$ of $\mathrm{CO}_{2}$.

\subsubsection{4. $\quad$ Sensitivity Studies}

Two sensitivity studies were undertaken with four (4) cases each; 1) an evaluation of the impact of air infiltration and 2) an assessment of the impact of oxidant purity on performance and cost. For both studies, Case 5 was chosen as the basis. Case 5 is retrofit of a $650 \mathrm{MW}$ gross supercritical boiler burning subbituminous Decker coal with a spray dryer absorber (SDA) followed by a fabric filter as the existing primary GQCS and having a direct contact cooler with integral polishing scrubber (DCCPS) treating the primary recycle and CPU streams along with current ASU and CPU technology. It should be noted that the greatest impact is on the ASU and CPU CAPEX and power with negligible impact on the power block.

\subsection{Air Infiltration Study}

It is believed that air infiltration will be higher for retrofit applications and, whether retrofit or greenfield, it is likely to increase as the unit ages. Air infiltration introduces additional nitrogen and additional mass into the process which has a minor impact on $\mathrm{NO}_{\mathrm{X}}$ but much more importantly must be handled by the ID fan and CPU. This increases power consumption and capital cost since both have to be sized to accommodate an upper limit on air infiltration. Since air infiltration also introduces some oxygen, the ASU demand will slightly decrease if the boiler is operated at the same outlet oxygen level. This means that the ASU can be sized for the lower air infiltration of a tight unit knowing that as air infiltration increases over time, the ASU output will reduce by the amount of additional oxygen gained from air infiltration and ASU power consumption will decrease slightly. Evaluation of the net impact of these factors is the intent of the air infiltration cases.

The impact of air infiltration on performance and cost was evaluated in Cases AI-1 to AI-4 based on retrofit Case 5. Air infiltration flow is based on a percentage of wet theoretical air flow. Air infiltration is either intentionally introduced as a cooling or sealing medium or unintentionally introduced through equipment leakage in areas in the process that operate below atmospheric pressure. Examples of intentional air infiltration are scanner or instrument cooling air, pulverizer seal air, and fabric filter back pulsing air. These sources can be greatly reduced by using clean dry $\mathrm{CO}_{2}$ instead of air. Unintentional sources can be incomplete welds in equipment and flues, and poor sealing of openings and access doors where the internal operating pressure is sub- 
atmospheric. By using $\mathrm{CO}_{2}$ for cooling, sealing, and back pulsing, air infiltration can be maintained at relatively low levels.

\begin{tabular}{|c|c|c|c|c|c|c|c|c|c|c|c|c|c|c|c|c|}
\hline \multirow[b]{3}{*}{ Component } & \multicolumn{4}{|c|}{ Case AI-1 } & \multicolumn{4}{|c|}{ Case AI-2 } & \multicolumn{4}{|c|}{ Case AI-3 } & \multicolumn{4}{|c|}{ Case AI-4 } \\
\hline & \multicolumn{2}{|c|}{ Wet } & \multicolumn{2}{|c|}{ Dry } & \multicolumn{2}{|c|}{ Wet } & \multicolumn{2}{|c|}{ Dry } & \multicolumn{2}{|c|}{ Wet } & \multicolumn{2}{|c|}{ Dry } & \multicolumn{2}{|c|}{ Wet } & \multicolumn{2}{|c|}{ Dry } \\
\hline & Mol \% & Wt. $\%$ & Mol \% & Wt. $\%$ & Mol \% & Wt. $\%$ & Mol \% & Wt. $\%$ & Mol \% & Wt. \% & Mol \% & Wt. \% & Mol \% & Wt. \% & Mol \% & Wt. \% \\
\hline $\mathrm{H}_{2} \mathrm{O}$ & 6.54 & 3.15 & 0.00 & 0.00 & 6.55 & 3.02 & 0.00 & 0.00 & 6.55 & 2.96 & 0.00 & 0.00 & 6.55 & 2.92 & 0.00 & 0.00 \\
\hline $\mathrm{N}_{2}$ & 26.52 & 19.84 & 28.38 & 20.49 & 16.56 & 11.86 & 17.72 & 12.23 & 11.47 & 8.05 & 12.28 & 8.30 & 8.68 & 6.02 & 9.29 & 6.20 \\
\hline $\mathrm{O}_{2}$ & 4.17 & 3.56 & 4.46 & 3.68 & 3.40 & 2.78 & 3.64 & 2.87 & 3.47 & 2.78 & 3.71 & 2.87 & 3.30 & 2.62 & 3.53 & 2.70 \\
\hline NO (ppm) & 610.90 & 489.58 & 653.68 & 505.49 & 476.37 & 385.51 & 509.74 & 397.50 & 463.25 & 348.29 & 495.71 & 358.90 & 413.27 & 307.15 & 442.22 & 316.39 \\
\hline $\mathrm{SO}_{2}(\mathrm{ppm})$ & 1.09 & 1.86 & 1.16 & 1.92 & 1.22 & 2.00 & 1.31 & 2.07 & 1.31 & 2.11 & 1.40 & 2.17 & 1.35 & 2.15 & 1.45 & 2.21 \\
\hline $\mathrm{CO}(\mathrm{ppm})$ & 46.16 & 34.53 & 49.39 & 35.66 & 50.05 & 37.81 & 53.56 & 38.99 & 46.16 & 32.40 & 49.39 & 33.38 & 47.95 & 33.27 & 51.31 & 34.27 \\
\hline $\mathrm{CO}_{2}$ & 59.89 & 70.39 & 64.08 & 72.68 & 70.23 & 79.02 & 75.14 & 81.47 & 75.05 & 82.76 & 80.31 & 85.28 & 77.90 & 84.92 & 83.36 & 87.48 \\
\hline $\mathrm{AR}$ & 2.82 & 3.01 & 3.01 & 3.10 & 3.21 & 3.28 & 3.44 & 3.38 & 3.41 & 3.41 & 3.65 & 3.52 & 3.52 & 3.48 & 3.77 & 3.59 \\
\hline $\begin{array}{l}\text { Oxidant Flow } \\
\text { (lb/klb coal) }\end{array}$ & \multicolumn{4}{|c|}{1695.11} & \multicolumn{4}{|c|}{1748.64} & \multicolumn{4}{|c|}{1780.25} & \multicolumn{4}{|c|}{1791.61} \\
\hline \begin{tabular}{|l|}
$\begin{array}{l}\text { CPU Flow } \\
\text { (b/klb coal) }\end{array}$ \\
\end{tabular} & \multicolumn{4}{|c|}{2877.00} & \multicolumn{4}{|c|}{2562.02} & \multicolumn{4}{|c|}{2446.60} & \multicolumn{4}{|c|}{2383.60} \\
\hline Assumptions & \multicolumn{4}{|c|}{$\begin{array}{l}\text { Coal: Decker } \\
3 \% \text { Boiler Outlet } \mathrm{O}_{2} \text { (dry) } \\
2 \% \text { Boiler Infiltration } \\
8 \% \text { Back End Infiltration } \\
95 \% \text { ASU Oxidant Purity }\end{array}$} & \multicolumn{4}{|c|}{$\begin{array}{l}\text { Coal: Decker } \\
3 \% \text { Boiler Outlet } \mathrm{O}_{2} \text { (dry) } \\
2 \% \text { Boiler Infiltration } \\
3 \% \text { Back End Infiltration } \\
95 \% \text { ASU Oxidant Purity }\end{array}$} & \multicolumn{4}{|c|}{$\begin{array}{l}\text { Coal: Decker } \\
3 \% \text { Boiler Outlet } \mathrm{O}_{2} \text { (dry) } \\
0 \% \text { Boiler Infiltration } \\
\text { 3\% Back End Infiltration } \\
95 \% \text { ASU Oxidant Purity }\end{array}$} & \multicolumn{4}{|c|}{$\begin{array}{l}\text { Coal: Decker } \\
3 \% \text { Boiler Outlet } \mathrm{O}_{2} \text { (dry) } \\
0 \% \text { Boiler Infiltration } \\
2 \% \text { Back End Infiltration } \\
95 \% \text { ASU Oxidant Purity }\end{array}$} \\
\hline
\end{tabular}

Table 3.31 Gas composition to the CPU for air infiltration cases

Case AI-1 assumes 2\% air infiltration in the boiler and $8 \%$ between the boiler outlet and ID fan inlet. Case AI-2 assumes $2 \%$ and $3 \%$ respectively (the base case assumption), Case AI-3 assumes $0 \%$ and $3 \%$ respectively and Case AI-4 assumed $0 \%$ and $2 \%$. In all of these cases, boiler outlet excess oxygen was held to $3 \%$ dry. Again, ASPEN was used to determine the gas composition to the CPU and the results are shown in Table 3.31.

\subsection{Oxidant Purity Study}

Although several studies have been made to identify the optimum oxidant purity, some questions remain. To confirm the widely accepted conclusion that $95 \%$ oxidant purity is optimum, Case 5 was again evaluated using the four purities and compositions shown in Table 3.27, the 95\% being the same as the base Case 5 analysis. The resulting gas compositions are shown in Table 3.32. The impact of oxidant purity on the capital cost and power consumption for the ASU and CPU is discussed above in Section 3.2.2.3.1 (under the heading "Oxygen Purity"). Based on those parameters alone, which are believed to govern the outcome, a maximum purity of about $96.5 \% \mathrm{O}_{2}$ is economical. At that point, due largely to the great difference in flows handled by the ASU compared to the CPU, the cost and power consumption for the ASU outweighs any savings in the CPU.

It is also clear that the ASU and CPU contribute the largest portion of the incremental cost and power consumption by far. The analysis in this sensitivity study attempts to account for all impacts at the plant level rather than just the two components to assess potential benefits of reducing oxidant purity from the current $95 \%$ to as low as $80 \%$ oxygen. 


\begin{tabular}{|c|c|c|c|c|c|c|c|c|c|c|c|c|c|c|c|c|}
\hline \multirow[b]{3}{*}{ Component } & \multicolumn{4}{|c|}{ ASU $\mathrm{O}_{2}$ Purity: $95 \%$} & \multicolumn{4}{|c|}{ ASU $\mathrm{O}_{2}$ Purity: $90 \%$} & \multicolumn{4}{|c|}{ ASU $\mathrm{O}_{2}$ Purity: $85 \%$} & \multicolumn{4}{|c|}{ ASU $\mathrm{O}_{2}$ Purity: $80 \%$} \\
\hline & \multicolumn{2}{|c|}{ Wet } & \multicolumn{2}{|c|}{ Dry } & Wet & \multicolumn{3}{|c|}{ Dry } & \multicolumn{2}{|c|}{ Wet } & \multicolumn{2}{|c|}{ Dry } & \multicolumn{2}{|c|}{ Wet } & \multicolumn{2}{|c|}{ Dry } \\
\hline & $\mathrm{Mol} \%$ & Wt. $\%$ & $\mathrm{Mol} \%$ & Wt. $\%$ & $\mathrm{Mol} \%$ & Wt. $\%$ & $\mathrm{Mol} \%$ & 6 Wt. $\%$ & Mol \% & Wt. $\%$ & Mol \% & Wt. \% & Mol \% & Wt. $\%$ & Mol \% & Wt. \% \\
\hline $\mathrm{H}_{2} \mathrm{O}$ & 6.55 & 3.02 & 0.00 & 0.00 & 6.55 & 3.06 & 0.00 & 0.00 & 6.59 & 3.13 & 0.00 & 0.00 & 6.54 & 3.16 & 0.00 & 0.00 \\
\hline $\mathrm{N}_{2}$ & 16.56 & 11.86 & 17.72 & 12.23 & 20.41 & 14.85 & 21.84 & 15.32 & 24.35 & 18.01 & 26.06 & 18.60 & 28.20 & 21.19 & 30.17 & 21.89 \\
\hline $\mathrm{O}_{2}$ & 3.40 & 2.78 & 3.64 & 2.87 & 3.47 & 2.88 & 3.71 & 2.97 & 3.41 & 2.89 & 3.66 & 2.98 & 3.37 & 2.89 & 3.60 & 2.99 \\
\hline NO (ppm) & 476.37 & 385.51 & 509.74 & 397.50 & 602.32 & 469.54 & 644.51 & 484.38 & 665.03 & 527.01 & 711.94 & 544.06 & 720.02 & 579.70 & 770.45 & 598.63 \\
\hline $\mathrm{SO}_{2}(\mathrm{ppm})$ & 1.22 & 2.00 & 1.31 & 2.07 & 1.19 & 1.97 & 1.27 & 2.03 & 1.13 & 1.92 & 1.21 & 1.98 & 1.07 & 1.84 & 1.15 & 1.90 \\
\hline $\mathrm{CO}(\mathrm{ppm})$ & 50.05 & 37.81 & 53.56 & 38.99 & 49.56 & 36.06 & 53.03 & 37.20 & 46.59 & 34.47 & 49.88 & 35.58 & 43.86 & 32.96 & 46.93 & 34.04 \\
\hline $\mathrm{CO}_{2}$ & 70.23 & 79.02 & 75.14 & 81.47 & 66.41 & 75.93 & 71.06 & 78.33 & 62.68 & 72.85 & 67.10 & 75.21 & 59.03 & 69.70 & 63.16 & 71.98 \\
\hline $\mathrm{AR}$ & 3.21 & 3.28 & 3.44 & 3.38 & 3.10 & 3.22 & 3.32 & 3.32 & 2.90 & 3.06 & 3.10 & 3.16 & 2.79 & 2.99 & 2.99 & 3.09 \\
\hline $\begin{array}{l}\begin{array}{l}\text { Oxidant Flow } \\
\text { (lb/klb coal) }\end{array} \\
\end{array}$ & \multicolumn{4}{|c|}{1748.64} & \multicolumn{4}{|c|}{1848.87} & \multicolumn{4}{|c|}{1956.09} & \multicolumn{4}{|c|}{2077.01} \\
\hline \begin{tabular}{|l|} 
CPU Flow \\
(lb/klb coal)
\end{tabular} & \multicolumn{4}{|c|}{2562.02} & \multicolumn{4}{|c|}{2666.74} & \multicolumn{4}{|c|}{2779.45} & \multicolumn{4}{|c|}{2905.28} \\
\hline & \multicolumn{4}{|c|}{$\begin{array}{l}2 \% \text { Boiler Infiltration } \\
3 \% \text { Boiler Outlet } \mathrm{O}_{2} \text { (dry) } \\
3 \% \text { Back End Infiltration } \\
95 \% \text { ASU Oxidant Purity }\end{array}$} & \multicolumn{4}{|c|}{$\begin{array}{l}2 \% \text { Boiler Infiltration } \\
3 \% \text { Boiler Outlet } \mathrm{O}_{2} \text { (dry) } \\
3 \% \text { Back End Infiltration } \\
90 \% \text { ASU Oxidant Purity }\end{array}$} & \multicolumn{4}{|c|}{$\begin{array}{l}2 \% \text { Boiler Infiltration } \\
3 \% \text { Boiler Outlet } \mathrm{O}_{2} \text { (dry) } \\
3 \% \text { Back End Infiltration } \\
85 \% \text { ASU Oxidant Purity }\end{array}$} & \multicolumn{4}{|c|}{$\begin{array}{l}2 \% \text { Boiler Infiltration } \\
3 \% \text { Boiler Outlet } \mathrm{O}_{2} \text { (dry) } \\
3 \% \text { Back End Infiltration } \\
80 \% \text { ASU Oxidant Purity }\end{array}$} \\
\hline
\end{tabular}

Table 3.32 Gas composition to the CPU for oxidant purity cases

\subsubsection{Financial Basis}

In order to permit direct comparison of the results of this study with DOE's "Carbon Dioxide Capture from Existing Coal-Fired Power Plant" study DOE/NETL-401-110907, "Cost and Performance Baseline for Fossil Energy Plants" DOE/NETL-2007/1281, and "Pulverized Coal Oxy-combustion Power Plants" DOE/NETL-2007/1291 revised August 2008, the same financial conditions were assumed. The basis for calculating levelized cost of electricity (LCOE) is identical to that used in the DOE/NETL-2007/1291 study and the financial assumptions and methodology for determining the Capital Charge and Levelization factors are explained in detail in Section 2.9 of the Final Report for that study. All estimates are in January 2007 dollars and the assumptions for determining the levelization factors are shown in Table 3.33. The financial structure for the High Risk scenario was selected and is shown in Table 3.34. The resulting Capital Charge factor used for calculating LCOE is 0.175 and the levelization factor for fixed and variable O\&M is 1.16 and 1.20 was used for fuel as shown in Table 3.35.

The cost of transport and storage of $\mathrm{CO}_{2}$ is also estimated using the same basis as the DOE/NETL-2007/1291 study assuming 50 miles of pipeline, wells, and 100 years of monitoring costs. This resulted in $0.26 \phi / \mathrm{kW}$ for transport, $0.04 \phi / \mathrm{kW}$ for wells and $0.10 \phi / \mathrm{kW}$ for storage costs. The cost of these contributions for a given Case was determined by converting these levelized costs backward to a CAPEX using the net $\mathrm{kW}$ for each Case. It was assumed that these do not change due to fuel.

LCOE for all retrofit cases includes makeup power to achieve the same net output as the base air fired plant in the form of variable O\&M cost. The rate used for the incremental power is the levelized rate from the DOE/NETL 401/11/0907 "Carbon Dioxide Capture from Existing CoalFired Power Plants (rev. Nov.2007) report of $6.4 \phi / \mathrm{kW}$. The LCOE reported for all retrofit cases is based on incremental LCOE meaning it assumed the plant is fully depreciated and there is no 
capital remaining and no costs associated with the base plant operation are included in the O\&M costs. Although this does not produce an LCOE comparable to a greenfield unit, it is consistent with previous DOE studies. When retrofit cases are compared to greenfield cases, such as shown in Figure 3.109, the base plant O\&M costs are included.

\begin{tabular}{|l|l|}
\hline Parameter & Value \\
\hline Income Tax Rate & $\begin{array}{l}38 \% \text { effective (34\%Federal, } 6 \% \\
\text { State less 1\% Property and } 1 \% \\
\text { insurance) }\end{array}$ \\
\hline Repayment Term of Debt & 15 years \\
\hline Grace Period on Debt Repayment & 0 years \\
\hline Debt Reserve Fund & None \\
\hline Depreciation & 20 years, 150\% declining balance \\
\hline Working Capital & zero for all parameters \\
\hline Plant Economic Life & 30 years \\
\hline Investment Tax Credit & $0 \%$ \\
\hline Tax Holiday & 0 years \\
\hline Start-up Costs (\% of EPC) & $2 \%$ \\
\hline All other additional capital costs (\$) & 0 \\
\hline EPC escalation & $0 \%$ \\
\hline Duration of Construction & 3 years \\
\hline
\end{tabular}

Table 3.33 Parameter assumptions for capital charge factors

\begin{tabular}{|l|l|l|l|l|}
\hline $\begin{array}{l}\text { Type of } \\
\text { Security }\end{array}$ & $\begin{array}{l}\text { \% of } \\
\text { Total }\end{array}$ & $\begin{array}{l}\text { Current } \\
\text { (nominal) } \\
\text { Dollar } \\
\text { Cost }\end{array}$ & $\begin{array}{l}\text { Weighted } \\
\text { Current } \\
\text { (nominal) } \\
\text { Cost }\end{array}$ & $\begin{array}{l}\text { After Tax } \\
\text { Weighted } \\
\text { Cost of } \\
\text { Capital }\end{array}$ \\
\hline Debt & 45 & $11 \%$ & $4.95 \%$ & $3.07 \%$ \\
\hline Equity & 55 & $12 \%$ & $6.6 \%$ & $6.6 \%$ \\
\hline Total & & & $11.55 \%$ & $9.67 \%$ \\
\hline
\end{tabular}

Table 3.34 Financial structure for investor owned utility high risk projects

\begin{tabular}{|l|l|}
\hline & Factor \\
\hline Capital Charge Factor & 0.175 \\
\hline Coal Levelization Factor & 1.2022 \\
\hline General O\&M Levelization Factor & 1.1618 \\
\hline
\end{tabular}

Table 3.35 Economic parameters for LCOE calculation high risk projects

The costs of $\mathrm{CO}_{2}$ removed (captured) and avoided (mitigated) are calculated in the same manner as given in DOE/NETL-401/110907 meaning that the LCOE is incremental and does not include the cost of operation and maintenance or fuel costs for the base plant being retrofit.

\subsection{4. $\quad$ Cost Basis}

\subsubsection{1. $\quad$ Power Block and BOP Basis}

All equipment contributing costs to the retrofit or the greenfield cases were either factored from the DOE Case 5 (SC) or Case 6 (USC) base costs from the DOE/NETL-2007/1291 Revised study, generated for the B\&W-AL Integration Study, or developed in support of this effort. The 
basis for the detailed costs including explanation of the factoring applied to correct for plant size, fuel type and GQCS configuration are provided in Table 3.36 for the retrofit cases and Table 3.37 and Table 3.38 for the greenfield cases. The resulting costs are shown in Table 3.40 and Table 3.41.

\begin{tabular}{|c|c|c|c|c|}
\hline & Account & $\begin{array}{l}\text { D\&E Cost } \\
\text { Basis }\end{array}$ & $\begin{array}{c}\text { Case Correction } \\
\text { Factor }\end{array}$ & $\mid \begin{array}{c}\text { Project } \\
\text { Contingency }\end{array}$ \\
\hline \multicolumn{2}{|c|}{1.0 COAL \& SORBENT HANDLING } & Exisiting & & \\
\hline \multicolumn{2}{|r|}{ 2.0 COAL \& SORBENT PREP \& FEED } & Exisiting & & \\
\hline \multicolumn{2}{|r|}{ 3.0 FEEDWATER \& MISC BOP SYSTEMS } & Exisiting & & \\
\hline \multicolumn{5}{|c|}{ 4.0 PC BOILER \& ACCESSORIES } \\
\hline & 4.1 Boiler & $\begin{array}{l}\text { B\&W estimated modifications; } \\
\text { burners, fans, airheater }\end{array}$ & (DOE Case 5 fuel $\eta /$ Case fuel $\eta)^{\wedge} 0.6$ & $10.0 \%$ \\
\hline & 4.2 ASU/Oxidant Compression & Air Liquide Estimate for each case & none & $10.0 \%$ \\
\hline \multicolumn{5}{|c|}{ 5.0 FLUE GAS CLEANUP } \\
\hline & 5.1 Absorber Vessels \& Accessories & Exisiting & & $10.0 \%$ \\
\hline & 5.2 Other FGD & Exisiting & & $10.0 \%$ \\
\hline & 5.3 Baghouse \& Accessories & Exisiting & & $10.0 \%$ \\
\hline & 5.4 Other Particulate Removal Materials & Exisiting & & $10.0 \%$ \\
\hline & 5.5 Gypsum Dewatering System & Exisiting & & $10.0 \%$ \\
\hline & 5.6 Mercury Removal System & Exisiting & & $10.0 \%$ \\
\hline & 5.7 Sodium Scrubber/Quench Cooler (DCCPS) & B\&W estimate & (Case flue gas flow/DOE Case 5 flow) 0.5 & $10.0 \%$ \\
\hline & 5.8 Trona Injection System & B\&W estimate & $($ Case sulfur flow/DOE Case 5 sulfur flow)^ 0.6 & $10.0 \%$ \\
\hline \multicolumn{5}{|c|}{ 5.0B CO2 REMOVAL \& COMPRESSION } \\
\hline & 5B.1 CO2 Removal System & combined with 5B.2 & & $15.0 \%$ \\
\hline & 5B.2 Compression \& Drying & Air Liquide Estimate for each case & none & $20.0 \%$ \\
\hline \multirow{2}{*}{\multicolumn{2}{|c|}{$\begin{array}{l}6.0 \text { COMBUSTION TURBINE/ACCESSORIES } \\
7.0 \mathrm{HR} \text {, DUCTING \& STACK }\end{array}$}} & \begin{tabular}{|c|} 
Not Applicable \\
\end{tabular} & & \\
\hline & & \multicolumn{3}{|c|}{ 7.0 HR, DUCTING \& STACK } \\
\hline & 7.1 Flue Gas Recycle Heat Exchanger & B\&W estimate & (Case MWeg/DOE Case $5 \mathrm{MWeg})^{\wedge} 0.6$ & $15.0 \%$ \\
\hline & 7.2 SCR System & Exisiting & & $20.0 \%$ \\
\hline & 7.3 Ductwork & B\&W estimate & & $15.0 \%$ \\
\hline & 7.4 Stack & Exisiting & & $10.0 \%$ \\
\hline & 7.9 Duct \& Stack Foundations & B\&W estimate & & $20.0 \%$ \\
\hline $8.0 \mathrm{~s}$ & STEAM TURBINE GENERATOR & Exisiting & & \\
\hline \multicolumn{5}{|c|}{9.0 COOLING WATER SYSTEM } \\
\hline & 9.1 Cooling Towers & $\begin{array}{l}\text { DOE Case } 5 *(\text { New heat duty/DOE } \\
\text { Case } 5 \text { Heat Duty) }\end{array}$ & & $10.0 \%$ \\
\hline & 9.2 Circulating Water Pumps & same as 9.1 & & $10.0 \%$ \\
\hline & 9.3 Circ. Water System Auxiliaries & same as 9.1 & & $10.0 \%$ \\
\hline & 9.4 Circ. Water Piping & same as 9.1 & & $15.0 \%$ \\
\hline & 9.5 Make-up Water System & Exisiting & & $15.0 \%$ \\
\hline & 9.6 Component Cooling Water Sys & Exisiting & & $15.0 \%$ \\
\hline & 9.9 Circ. Water System Foundations & same as 9.1 & & $20.0 \%$ \\
\hline 10.0 & ASH/SPENT SORBENT HANDLING SYS & Exisiting & & \\
\hline \multicolumn{5}{|c|}{ 11.0 ACCESSORY ELECTRIC PLANT } \\
\hline & 11.1 Generator Equipment & Exisiting & & $7.5 \%$ \\
\hline & 11.2 Station Service Equipment & Exisiting & & $7.5 \%$ \\
\hline & 11.3 Switchgear \& Motor Control & Exisiting & & $10.0 \%$ \\
\hline & 11.4 Conduit \& Cable Tray & Exisiting & & $15.0 \%$ \\
\hline & 11.5 Wire \& Cable & $50 \%$ of DOE Case 5 & $\begin{array}{l}\text { Case oxidant flow/DOE Case } 5 \text { oxidant } \\
\text { flow) } 0.5\end{array}$ & $15.0 \%$ \\
\hline & 11.6 Protective Equipment & Exisiting & & $10.0 \%$ \\
\hline & 11.7 Standby Equipment & Exisiting & & $10.0 \%$ \\
\hline & 11.8 Main Power Transformers & $80 \%$ of DOE Case 5 & (Case MWeg/DOE Case $5 \mathrm{MWeg})^{\wedge} 0.6$ & $10.0 \%$ \\
\hline & 11.9 Electrical Foundations & $80 \%$ of DOE Case 5 & (Case MWeg/DOE Case $5 \mathrm{MWeg})^{\wedge} 0.6$ & $20.0 \%$ \\
\hline \multicolumn{5}{|c|}{12.0 INSTRUMENTATION \& CONTROLS } \\
\hline & 12.1 PC Control Equipment & Exisiting & & $10.0 \%$ \\
\hline & 12.2 Combustion Turbine Control & Exisiting & & $10.0 \%$ \\
\hline & 12.3 Steam Turbine Control & Exisiting & & $10.0 \%$ \\
\hline & 12.4 Other Major Component Control & Exisiting & & $10.0 \%$ \\
\hline & 12.5 Signal Processing Equipment & Exisiting & & $10.0 \%$ \\
\hline & 12.6 Control Boards, Panels \& Racks & $50 \%$ of DOE Case 5 & none & $15.0 \%$ \\
\hline & 12.7 Computer \& Accessories & $50 \%$ of DOE Case 5 & none & $10.0 \%$ \\
\hline & 12.8 Instrument Wiring \& Tubing & $50 \%$ of DOE Case 5 & none & $15.0 \%$ \\
\hline & 12.9 Other I \& C Equipment & $50 \%$ of DOE Case 5 & none & $10.0 \%$ \\
\hline \multicolumn{5}{|c|}{ 13.0 IMPROVEMENTS TO SITE } \\
\hline & 13.1 Site Preparation & $50 \%$ of DOE Case 5 & $(\text { MWeg/DOE Case } 5 \mathrm{MWeg})^{\wedge} 0.6$ & $20.0 \%$ \\
\hline & 13.2 Site Improvements & $50 \%$ of DOE Case 5 & $(\text { MWeg/DOE Case } 5 \mathrm{MWeg})^{\wedge} 0.6$ & $20.0 \%$ \\
\hline & 13.3 Site Facilities & Exisiting & & $20.0 \%$ \\
\hline \multirow[t]{2}{*}{14.0} & BUILDINGS \& STRUCTURES & Exisiting & & \\
\hline & & & & \\
\hline \multicolumn{5}{|c|}{ 15.0 TRANSPORTATION, STORAGE \& MONITORING } \\
\hline & 15.1 Transport & $\begin{array}{l}\text { DOE Case } 5 \text { LCOE converted to } \\
\text { dollars }\end{array}$ & $\begin{array}{r}\text { none } \\
\end{array}$ & \\
\hline & 15.2 Storage Wells & same as 15.1 & Case Carbon flow/DOE Case 5 Carbon flow) & \\
\hline & 15.3 Monitoring & same as 15.1 & none & \\
\hline
\end{tabular}

NOTE: DOE Case 5 refers to Case 5 in the DOE study "Pulverized Coal Oxycombustion Power Plants" DOE/NETL-2007/1291 revised August 2008

Table 3.36 Detailed cost basis for retrofit cases 


\begin{tabular}{|c|c|c|c|c|}
\hline Account & $\begin{array}{l}\text { D\&E Cost } \\
\text { Basis }\end{array}$ & $\begin{array}{c}\text { Case Correction } \\
\text { Factor } \\
\end{array}$ & $\mid \begin{array}{c}\text { Project } \\
\text { Contingency }\end{array}$ & Comments \\
\hline \multirow{2}{*}{\multicolumn{5}{|c|}{ 1.0 COAL \& SORBENT HANDLING }} \\
\hline & & & & \\
\hline \begin{tabular}{l|l} 
& 1.1 Coal Receive \& Unload \\
\end{tabular} & DOE Case 6 & (Case coal flow/DOE Case & $15.0 \%$ & DOE Case 6 coal flow $=488097 \mathrm{lb} / \mathrm{h}$ \\
\hline 1.2 Coal Stackout \& Reclaim & DOE Case 6 & Same as 1.1 & $15.0 \%$ & Same as 1.1 \\
\hline 1.3 Coal Conveyors \& Yard Breaker & DOE Case 6 & Same as 1.1 & $15.0 \%$ & Same as 1.1 \\
\hline 1.4 Other Coal Handling & DOE Case 6 & Same as 1.1 & $15.0 \%$ & Same as 1.1 \\
\hline 1.5 Sorbent Receive \& Unload & DOE Case 6 & (Case sulfur flow/DOE & $15.0 \%$ & DOE Case 6 sulfir flow $=$ \\
\hline 1.6 Sorbent stackout \& Reclaim & DOE Case 6 & Same as 1.5 & $15.0 \%$ & Same as 1.5 \\
\hline 1.7 Sorbent Conveyors & DOE Case 6 & Same as 1.5 & $15.0 \%$ & Same as 1.5 \\
\hline 1.8 Other Sorbent Handling & DOE Case 6 & Same as 1.5 & $15.0 \%$ & Same as 1.5 \\
\hline \begin{tabular}{l|l} 
& 1.9 Coal \& Sorbent Hnd. Foundations
\end{tabular} & DOE Case 6 & Same as 1.1 & $15.0 \%$ & Same as 1.1 \\
\hline \multicolumn{5}{|l|}{ 2.0 COAL \& SORBENT PREP \& FEED } \\
\hline \begin{tabular}{|l|l} 
& 2.1 Coal Crushing \& Drying \\
\end{tabular} & DOE Case 6 & (Case coal flow/DOE Case & $15.0 \%$ & DOE Case 6 coal flow $=488097 \mathrm{lb} / \mathrm{h}$ \\
\hline 2.2 Coal Conveyor to Storage & DOE Case 6 & Same as 2.1 & $15.0 \%$ & Same as 2.1 \\
\hline 2.3 Coal Injection System & Not Applicable & & $15.0 \%$ & \\
\hline 2.4 Misc. Coal Prep Equipment & Not Applicable & & $15.0 \%$ & \\
\hline 2.5 Sorbent Prep Equipment & DOE Case 6 & $\begin{array}{l}\text { (Case sulfur flow/DOE } \\
\text { Case } 6 \text { sulfur flow)^ } 0.6\end{array}$ & $15.0 \%$ & $\begin{array}{l}\text { DOE Case } 6 \text { sulfir flow }= \\
488097^{\star} 0.0251 \mathrm{lb} / \mathrm{h}\end{array}$ \\
\hline 2.6 Sorbent Storage \& Feed & DOE Case 6 & Same as 2.5 & $15.0 \%$ & Same as 2.5 \\
\hline 2.7 Sorbent Injection System & Not Applicable & & $15.0 \%$ & \\
\hline 2.8 Booster Air Supply System & Not Applicable & & $15.0 \%$ & \\
\hline 2.9 Coal \& sorbent Feed Foundation & DOE Case 6 & Same as 2.1 & $15.0 \%$ & Same as 2.1 \\
\hline \multicolumn{5}{|l|}{ 3.0 FEEDWATER \& MISC BOP SYSTEMS } \\
\hline \begin{tabular}{|l|l|} 
& 3.1 Feedwater System \\
\end{tabular} & DOE Case 6 & (Case MWeg/DOE Case 6 & $15.0 \%$ & DOE Case $6 \mathrm{MWeg}=759200 \mathrm{lb} / \mathrm{h}$ \\
\hline 3.2 Water Makeup \& Pretreating & DOE Case 6 & Same as 3.1 & $20.0 \%$ & Same as 3.1 \\
\hline 3.3 Other Feedwater Subsystems & DOE Case 6 & Same as 3.1 & $15.0 \%$ & Same as 3.1 \\
\hline 3.4 Senvice Water Systems & DOE Case 6 & Same as 3.1 & $20.0 \%$ & Same as 3.1 \\
\hline 3.5 Other Boiler Plant Systems & DOE Case 6 & Same as 3.1 & $15.0 \%$ & Same as 3.1 \\
\hline 3.6 FO Supply Sys \& Net Gas & DOE Case 6 & Same as 3.1 & $15.0 \%$ & Same as 3.1 \\
\hline 3.7 Waste Treatment Equipment & DOE Case 6 & Same as 3.1 & $20.0 \%$ & Same as 3.1 \\
\hline 3.9 Misc. Power Plant Equipment & DOE Case 6 & Same as 3.1 & $20.0 \%$ & Same as 3.1 \\
\hline \multicolumn{5}{|l|}{ 4.0 PC BOILER \& ACCESSORIES } \\
\hline 4.1 Boiler & DOE Case 6 & $\begin{array}{l}((\text { Case HR/DOE Case } 6 \\
\mathrm{HR})^{*}(\mathrm{MWeg} / \mathrm{DOE} \text { Case } 6\end{array}$ & $10.0 \%$ & $\begin{array}{l}\text { DOE Case } 6 \mathrm{HR}=10353 \mathrm{Btu} / \mathrm{kWh} \text {, } \\
\text { MWeg }=759200\end{array}$ \\
\hline 4.2 ASU/Oxidant Compression & Air Liquide Estimate & none & $10.0 \%$ & \\
\hline \multicolumn{5}{|l|}{ 5.0 FLUE GAS CLEANUP } \\
\hline 5.1 Absorber Vessels \& Accessories & $\begin{array}{l}\text { B\&W Integration } \\
\text { Study }\end{array}$ & $\begin{array}{l}\text { (Case coal flow/B\&W } \\
\text { Integration Study coal }\end{array}$ & $10.0 \%$ & $\begin{array}{l}\text { B\&W Integration Study Coal Flow } \\
=744646 \mathrm{lb} / \mathrm{h}\end{array}$ \\
\hline 5.2 Other FGD & B\&W Integration & Same as 5.1 & $10.0 \%$ & Same as 5.1 \\
\hline 5.3 Baghouse \& Accessories & B\&W Integration & Same as 5.1 & $10.0 \%$ & Same as 5.1 \\
\hline 5.4 Other Particulate Removal Materials & DOE Case 6 & none & $10.0 \%$ & \\
\hline 5.5 Gypsum Dewatering System & incl in 5.1 & & $10.0 \%$ & \\
\hline 5.6 Mercury Removal System & incl in 5.1 & & $10.0 \%$ & \\
\hline 5.7 Sodium Scrubber/Quench Cooler (DCCPS) & B\&W estimate & (Case flue gas flow/DOE & $10.0 \%$ & DOE Case 5 flue gas flow $=2992988$ \\
\hline 5.8 Trona Injection System & B\&W estimate & Case 5 sulfur flow)^ 0.6 & $10.0 \%$ & $549470 * 0.0251$ \\
\hline \multicolumn{5}{|l|}{ 5.0B CO2 REMOVAL \& COMPRESSION } \\
\hline \begin{tabular}{|l|l|} 
& 5B.1 CO2 Removal System \\
\end{tabular} & combined with 5B.2 & & $15.0 \%$ & \\
\hline \begin{tabular}{|l|l|} 
5B.2 Compression \& Drying \\
\end{tabular} & Air Liquide Estimate & none & $20.0 \%$ & \\
\hline 6.0 COMBUSTION TURBINE/ACCESSORIES & Not Applicable & & & \\
\hline \multicolumn{5}{|l|}{ 7.0 HR, DUCTING \& STACK } \\
\hline 7.1 Flue Gas Recycle Heat Exchanger & DOE Case 6 & $\begin{array}{l}((\text { Case HR/DOE Case } 6 \\
\mathrm{HR})^{\star}(\mathrm{MWeg} / \mathrm{DOE} \text { Case } 6\end{array}$ & $15.0 \%$ & $\begin{array}{l}\text { DOE Case } 6 \mathrm{HR}=10353 \mathrm{Btu} / \mathrm{kWh}, \\
\text { MWeg }=759200\end{array}$ \\
\hline 7.2 SCR System & Not Applicable & & $20.0 \%$ & \\
\hline 7.3 Ductwork & DOE Case 6 & Same as 7.1 & $15.0 \%$ & Same as 7.1 \\
\hline 7.4 Stack & DOE Case 6 & Same as 7.1 & $10.0 \%$ & Same as 7.1 \\
\hline 7.9 Duct \& Stack Foundations & DOE Case 6 & Same as 7.1 & $20.0 \%$ & Same as 7.1 \\
\hline \multicolumn{5}{|l|}{ 8.0 STEAM TURBINE GENERATOR } \\
\hline 8.1 Steam TG \& Accessories & DOE Case 6 & $\begin{array}{l}((\text { Case HR/DOE Case } 6 \\
\mathrm{HR})^{\star}(\mathrm{MWeg} / \mathrm{DOE} \text { Case } 6\end{array}$ & $10.0 \%$ & $\begin{array}{l}\text { DOE Case } 6 \mathrm{HR}=10353 \mathrm{Btu} / \mathrm{kWh}, \\
\mathrm{MWeg}=759200\end{array}$ \\
\hline 8.2 Turbine Plant Auxiliaries & DOE Case 6 & Same as 8.1 & $10.0 \%$ & Same as 8.1 \\
\hline 8.3 Condenser \& Auxiliaries & DOE Case 6 & Same as 8.1 & $10.0 \%$ & Same as 8.1 \\
\hline 8.4 Steam Piping & DOE Case 6 & Same as 8.1 & $15.0 \%$ & Same as 8.1 \\
\hline 8.9 TG Foundations & DOE Case 6 & Same as 8.1 & $20.0 \%$ & Same as 8.1 \\
\hline \multicolumn{5}{|l|}{ 9.0 COOLING WATER SYSTEM } \\
\hline 9.1 Cooling Towers & $\begin{array}{l}\text { DCCPS/Case } 6 \\
\text { condenser duty) }\end{array}$ & $\begin{array}{l}\mathrm{HR})^{\star}(\mathrm{MWeg} / \mathrm{DOE} \text { Case } 6 \\
\mathrm{Mweg}))^{\wedge} 0.6\end{array}$ & $10.0 \%$ & $\begin{array}{l}\text { MWeg }=759200, \text { Case } 6 \text { Condernser } \\
\text { duty }=2408 \mathrm{MBtu} / \mathrm{h}\end{array}$ \\
\hline 9.2 Circulating Water Pumps & Same as 9.1 & Same as 9.1 & $10.0 \%$ & Same as 9.1 \\
\hline 9.3 Circ. Water System Auxiliaries & Same as 9.1 & Same as 9.1 & $10.0 \%$ & Same as 9.1 \\
\hline 9.4 Circ. Water Piping & DOE Case 6 & Same as 9.1 & $15.0 \%$ & Same as 9.1 \\
\hline 9.5 Make-up Water System & Same as 9.1 & Same as 9.1 & $15.0 \%$ & Same as 9.1 \\
\hline 9.6 Component Cooling Water Sys & DOE Case 6 & Same as 9.1 & $15.0 \%$ & Same as 9.1 \\
\hline 9.9 Circ. Water System Foundations & DOE Case 6 & Same as 9.1 & $20.0 \%$ & Same as 9.1 \\
\hline
\end{tabular}

Table 3.37 Detailed cost basis for greenfield cases 


\begin{tabular}{|c|c|c|c|c|c|}
\hline & Account & $\begin{array}{l}\text { D\&E Cost } \\
\text { Basis }\end{array}$ & $\begin{array}{c}\text { Case Correction } \\
\text { Factor } \\
\end{array}$ & $\mid \begin{array}{c}\text { Project } \\
\text { Contingency }\end{array}$ & Comments \\
\hline \multicolumn{6}{|c|}{ 10.0 ASH/SPENT SORBENT HANDLING SYS } \\
\hline & 10.1 Ash Coolers & Not Applicable & & & \\
\hline & 10.2 Cyclone Ash Letdown & Not Applicable & & & \\
\hline & 10.3 HGCU Ash Letdown & Not Applicable & & & \\
\hline & 10.4 High Temperature Ash Piping & Not Applicable & & & \\
\hline & 10.5 Other Ash Recovery Equipment & Not Applicable & & & \\
\hline & 10.6 Ash Storage Silos & DOE Case 6 & (Case ash flow/DOE Case & & DOE Case 6 ash flow $=488097^{*} 0.097$ \\
\hline & 10.7 Ash Transport \& Feed Equipment & DOE Case 6 & Same as 10.6 & & Same as 10.6 \\
\hline & 10.8 Misc. Ash Handling Equipment & DOE Case 6 & & & \\
\hline & 10.9 Ash/Spent Sorbent Foundations & DOE Case 6 & Same as 10.6 & & Same as 10.6 \\
\hline \multicolumn{6}{|c|}{ 11.0 ACCESSORY ELECTRIC PLANT } \\
\hline & 11.1 Generator Equipment & DOE Case 6 & $\begin{array}{l}((\text { Case HR/DOE Case } 6 \\
\mathrm{HR})^{*}(\mathrm{MWeg} / \mathrm{DOE} \text { Case } 6\end{array}$ & $7.5 \%$ & $\begin{array}{l}\text { DOE Case } 6 \mathrm{HR}=10353 \mathrm{Btu} / \mathrm{kWh} \text {, } \\
\mathrm{MWeg}=759200\end{array}$ \\
\hline & 11.2 Station Service Equipment & DOE Case 6 & Same as 11.1 & $7.5 \%$ & Same as 11.1 \\
\hline & 11.3 Switchgear \& Motor Control & DOE Case 6 & Same as 11.1 & $10.0 \%$ & Same as 11.1 \\
\hline & 11.4 Conduit \& Cable Tray & DOE Case 6 & Same as 11.1 & $15.0 \%$ & Same as 11.1 \\
\hline & 11.5 Wire \& Cable & DOE Case 6 & Same as 11.1 & $15.0 \%$ & Same as 11.1 \\
\hline & 11.6 Protective Equipment & DOE Case 6 & Same as 11.1 & $10.0 \%$ & Same as 11.1 \\
\hline & 11.7 Standby Equipment & DOE Case 6 & Same as 11.1 & $10.0 \%$ & Same as 11.1 \\
\hline & 11.8 Main Power Transformers & DOE Case 6 & Same as 11.1 & $10.0 \%$ & Same as 11.1 \\
\hline & 11.9 Electrical Foundations & DOE Case 6 & Same as 11.1 & $20.0 \%$ & Same as 11.1 \\
\hline \multicolumn{6}{|c|}{ 12.0 INSTRUMENTATION \& CONTROLS } \\
\hline & 12.1 PC Control Equipment & $\mathrm{w} / 12.7$ & & $10.0 \%$ & \\
\hline & 12.2 Combustion Turbine Control & Not Applicable & & $10.0 \%$ & \\
\hline & 12.3 Steam Turbine Control & $\mathrm{w} / 8.1$ & & $10.0 \%$ & \\
\hline & 12.4 Other Major Component Control & 0 & & $10.0 \%$ & \\
\hline & 12.5 Signal Processing Equipment & w/12.7 & & $10.0 \%$ & \\
\hline & 12.6 Control Boards, Panels \& Racks & DOE Case 6 & none & $15.0 \%$ & \\
\hline & 12.7 Computer \& Accessories & DOE Case 6 & none & $10.0 \%$ & \\
\hline & 12.8 Instrument Wiring \& Tubing & DOE Case 6 & none & $15.0 \%$ & \\
\hline & 12.9 Other I \& C Equipment & DOE Case 6 & none & $10.0 \%$ & \\
\hline \multicolumn{6}{|c|}{ 13.0 IMPROVEMENTS TO SITE } \\
\hline & 13.1 Site Preparation & DOE Case 6 & none & $20.0 \%$ & DOE Case $5 \mathrm{Mweg}=785900$ \\
\hline & 13.2 Site Improvements & DOE Case 6 & none & $20.0 \%$ & DOE Case $5 \mathrm{Mweg}=785900$ \\
\hline & 13.3 Site Facilities & DOE Case 6 & none & $20.0 \%$ & \\
\hline \multicolumn{6}{|c|}{ 14.0 BUILDINGS \& STRUCTURES } \\
\hline & 14.1 Boiler Building & DOE Case 6 & (Case coal flow/DOE Case & $15.0 \%$ & DOE Case 6 coal flow $=488097 \mathrm{lb} / \mathrm{h}$ \\
\hline & 14.2 Turbine Building & DOE Case 6 & (Case MWeg/DOE Case 6 & $15.0 \%$ & DOE Case $6 \mathrm{MWeg}=759200 \mathrm{lb} / \mathrm{h}$ \\
\hline & 14.3 Adminstration Building & DOE Case 6 & none & $15.0 \%$ & \\
\hline & 14.4 Circulation Water Pumphouse & DOE Case 6 & Same as 14.2 & $15.0 \%$ & Same as 14.2 \\
\hline & 14.5 Water Treatment Buildings & DOE Case 6 & Same as 14.2 & $15.0 \%$ & Same as 14.2 \\
\hline & 14.6 Machine Shop & DOE Case 6 & none & $15.0 \%$ & \\
\hline & 14.7 Warehouse & DOE Case 6 & none & $15.0 \%$ & \\
\hline & 14.8 Other Building s \& Structures & DOE Case 6 & none & $15.0 \%$ & \\
\hline & 14.9 Waste Treating Building \& Str. & DOE Case 6 & Same as 14.2 & $15.0 \%$ & Same as 14.2 \\
\hline \multicolumn{6}{|c|}{ 15.0 TRANSPORTATION, STORAGE \& MONITORING } \\
\hline & 15.1 Transport & $\begin{array}{l}\text { DOE Case } 5 \text { LCOE } \\
\text { converted to dollars }\end{array}$ & none & & \\
\hline & 15.2 Storage Wells & same as 15.1 & $\begin{array}{l}\text { Case Carbon flow/DOE } \\
\text { Case } 5 \text { Carbon flow) }\end{array}$ & & $\begin{array}{l}\text { DOE Case } 5 \text { CO2 }=549470 * 0.6375 \\
\mathrm{lb} / \mathrm{h}\end{array}$ \\
\hline & 15.3 Monitoring & same as 15.1 & none & & \\
\hline
\end{tabular}

NOTE: DOE Case 6 refers to Case 6 in the DOE study "Pulverized Coal Oxycombustion Power Plants" DOE/NETL-2007/1291 revised August 2008 DOE Case 5 refers to Case 5 in the DOE study "Pulverized Coal Oxycombustion Power Plants" DOE/NETL-2007/1291 revised August 2008

Table 3.38 Detailed cost basis for greenfield cases

\subsubsection{2. $\quad$ ASU and CPU Basis}

\subsubsection{1. $\quad$ ASU Cost Basis}

\section{Present Cases}

The ASU was based on Air Liquide's ASU design for oxy-combustion applications as described in Section 3.2.2.3.1. The equipment and installation costs were estimated assuming installation in the US Gulf Coast region. Detailed cost calculations were performed for a single ASU train with a nominal supply capacity of 3,700 tm/day of oxygen. If the oxidant requirement was slightly different, the ASU cost was scaled based on the required oxidant flow rate to the 0.65 power, based on Air Liquide's prior experience with costs of such systems. For significantly higher 
oxidant requirements, multiple ASUs in parallel were used. For current ASU cases, three ASU trains in parallel were required for a 650 MWe power plant.

\section{Future Cases}

The greenfield future ASU was assumed to be available in the year 2020. In these ultrasupercritical steam cycle plants, the oxygen requirement is lower. The lower oxygen requirement coupled with higher forecasted efficiency of future ASUs results in a design of only 2 ASU trains in parallel for a $650 \mathrm{MWe}$ power plant. On the basis of economy of scale (Nth of a kind plant) and reduction in manufacturing cost, a $15 \%$ reduction was estimated in the capital cost of the ASU.

\subsubsection{2. $\quad C P U$ Cost Basis}

\section{Present Cases}

The $\mathrm{CO}_{2} \mathrm{CPU}$ is a single train unit that can process all the flue gas from the power plant. The engineering basis for this system was the same as for the ASU (US Gulf Coast). Detailed cost calculations were performed for several cases. Costs for certain cases, which closely resembled cases for which detailed cost calculations had been performed, were scaled proportional to the flue gas flow rate to the 0.6 power. The lower scaling power for CPU relative to ASU is due to higher economies of scale for the larger size of equipment (single train) for the CPU.

\section{Future Cases}

Future cases were presumed to be constructed in the year 2020. As they are greenfield plants, much lower air infiltration was assumed, resulting in a higher $\mathrm{CO}_{2}$ concentration in the flue gas (see Table 3.25 for composition). This results in some reduction in capital cost. More importantly, significant improvements in materials of construction and their cost are forecasted. Currently, compressors for flue gas compression cost approximately three times the cost of equivalent air compressors due to the use of stainless steel to avoid corrosion. Considerable research and development is current in progress to avoid corrosion and permit the use of less costly carbon steels. Also, the current CPU is a very conservative design today. An "Nth of a kind" unit in 2020 will have lower safety margins based on the operational experience gained through the operation of these units at demonstration projects, such as the Callide project in Australia. Overall, a 30\% reduction in the capital cost of the CPU is forecasted for future greenfield cases.

\subsubsection{Base Case Performance and Economic Results and Discussion}

Performance and economic analyses were run in accordance with the fuel, firing system, existing equipment, $\mathrm{SO}_{2}$ polishing and moisture requirement, and type of ASU and CPU (current technology, future technology, or compression only) for each of the cases shown in Table 3.23. For discussion purposes the base cases are broken into retrofit and greenfield categories.

Table 3.39 shows the impact of the case variations on plant performance and Table 3.42 shows the same for LCOE calculation. The detailed costs for these cases, developed as described in Section 3.2.4.1, are given in Table 3.40 and Table 3.41.

These results are displayed graphically and observations and conclusions identified in the sections that follow. Figure 3.102 shows the performance as net plant efficiency for the retrofit 
Cases 1 to 10 and Figure 3.103 shows LCOE. Figure 3.104 shows the cost of $\mathrm{CO}_{2}$ avoided and removed for the retrofit cases.

Figure 3.105 shows the performance for the greenfield Cases 11 to 14 and Figure 3.106 shows LCOE. The blue bars in the performance charts represent the base air fired unit with no $\mathrm{CO}_{2}$ capture and the red bars show the impact of retrofitting oxy-combustion. The legend for the components of LCOE is shown on the charts. The conditions for each case are summarized at the bottom of the chart to simplify comparison. It is interesting to note that except for Case 8, the efficiency loss for retrofitting oxy-PC ranges between 7.9 and 8.9 percentage points and is fairly consistent whether for a subcritical or supercritical plant.

\subsubsection{1. $\quad \underline{\text { Retrofit Cases 1-10 }}$}

Refer to Figure 3.102 for performance, Figure 3.103 for LCOE and Figure 3.104 for Cost of $\mathrm{CO}_{2}$ Removed and Avoided. LCOE for all retrofit cases includes makeup power to achieve the same net output as the base air fired plant in the form of variable O\&M cost. The rate used for the incremental power is the levelized rate from the DOE/NETL 401/11/0907 "Carbon Dioxide Capture from Existing Coal-Fired Power Plants (rev. Nov.2007) report of $6.4 \phi / \mathrm{kW}$.

Cases 1-3 employ subcritical steam conditions. Cases 1 and $1 \mathrm{~A}$ show the difference between current and expected future ASU and CPU technology plus addition of heat integration which is assumed to increase gross generation by $2 \%$ of the base gross power $(650 \mathrm{MWe})$. In the retrofit scenario the improvements would provide about a 0.90 percentage point improvement in net efficiency. The greatest impact, however, is in the reduction in LCOE which drops by about $1.44 \varnothing / \mathrm{kW}$ mostly due to lower capital cost (CAPEX) for the future ASU and CPU but also reduced operating and maintenance cost $(\mathrm{O} \& \mathrm{M})$ from higher efficiency.

Cases 2 and 3 show the impact of fuel and Gas Quality Control System (GQCS) changes which are somewhat fuel related. The bituminous cases (1 and 1A) use FF with WFGD while the subbituminous and North Dakota lignite, Cases 2 and 3, have SDA-FF as the existing equipment. It can be observed by comparing Cases 1, 2 and 3, that the loss in percentage points of efficiency due to the impact of fuel is about the same for air firing and oxy firing ( $0.7 \%$ for subbituminous and $1.7 \%$ for North Dakota Lignite). As would be expected, lower grade fuels also increase LCOE. For this study the impact from Case 1 bituminous to subbituminous Case 2 is about $0.08 \notin / \mathrm{kW}$ and going from bituminous Case 1 to North Dakota Lignite Case 3 increases LCOE by $0.5 \notin / \mathrm{kW}$.

Cases 4-10 employ supercritical steam conditions. Cases 4, 5, and 6 again compare the impact of fuel. As with the subcritical cases, the reductions in efficiency are essentially the same for air or oxy firing. Cases 5 and $5 \mathrm{~A}$ show the promise of improving net efficiency by about 0.80 percentage points as a result of using expected future ASU and CPU technology plus addition of heat integration assumed to increase gross generation by $3 \%$ of the base gross power $(650 \mathrm{MWe})$ to the retrofit scenario. Interestingly, the improvement for supercritical is slightly less than for subcritical due to the better turbine cycle heat rate for supercritical (NPHR $=$ TCHR/[ $\eta$ fuel*(1$\mathrm{AP} / \mathrm{GP})]$ where $\mathrm{AP}=$ aux power and $\mathrm{GP}=$ gross power). Since the effect is an increase in GP, the term (1-AP/GP) becomes larger decreasing the heat rate and increasing the net efficiency but since the TCHR is significantly lower for supercritical (10\% lower) the impact is diminished. Though the efficiency improvement is modest, the impact on LCOE is significant at about 
$1.42 \varnothing / \mathrm{kW}$, essentially the same as for the subcritical Cases 1 and $1 \mathrm{~A}$. As with the subcritical cases, comparing Cases 4, 5 and 6 shows an increase in LCOE with lower fuel rank. From bituminous to subbituminous LCOE increased by $0.11 \propto / \mathrm{kW}$ and from bituminous to North Dakota Lignite it increased $0.44 \phi / \mathrm{kW}$, similar in magnitude to the subcritical cases.

In the tables and figures that follow the following abbreviations and acronyms are used:

ASU-C

ASU-F

Cool

CPU-C

CPU -F

PC

Pri + CPU

SC

SDA

SubC

Warm

WFGD

$\mathrm{x} \% \mathrm{GP}-\mathrm{HI}$
Air separation unit (Conventional design)

Air separation unit (Future design)

Cool recycle

Compression and purification unit (Conventional design)

Compression and purification unit (Future design)

Pulverized Coal

The combined primary recycle and CPU streams

Supercritical (steam conditions)

Spray dryer absorber (dry scrubber)

Subcritical (steam conditions)

Warm recycle

Wet flue gas desulfurization (wet scrubber)

specified percentage of Gross Power being used for Heat Integration

Note that all retrofit cases are incremental, i.e. the incremental cost is added to the existing plant costs if oxy-firing is retrofitted. 


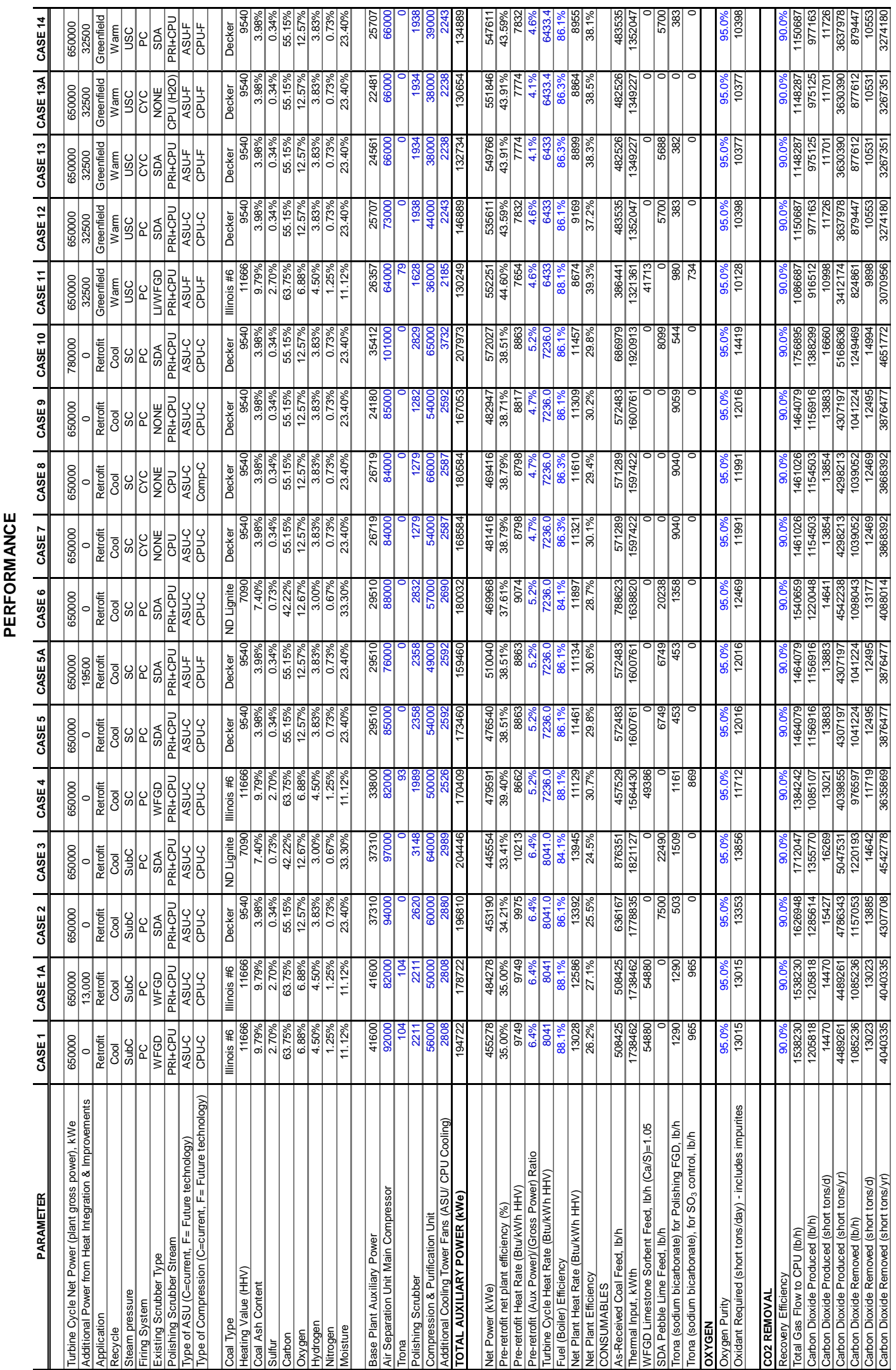

Table 3.39 Performance results for all cases 


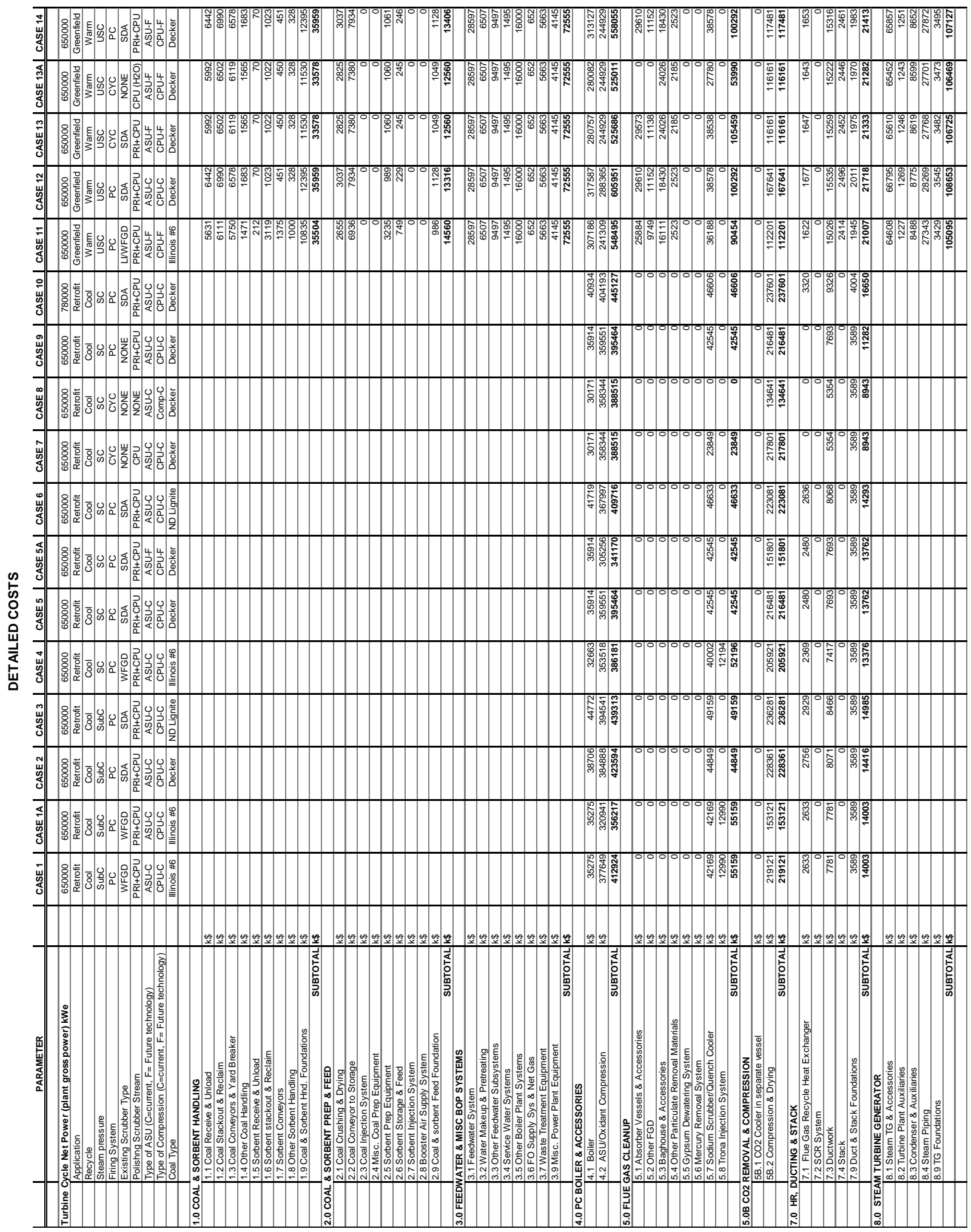

\section{Table 3.40 Detailed cost results for all cases}




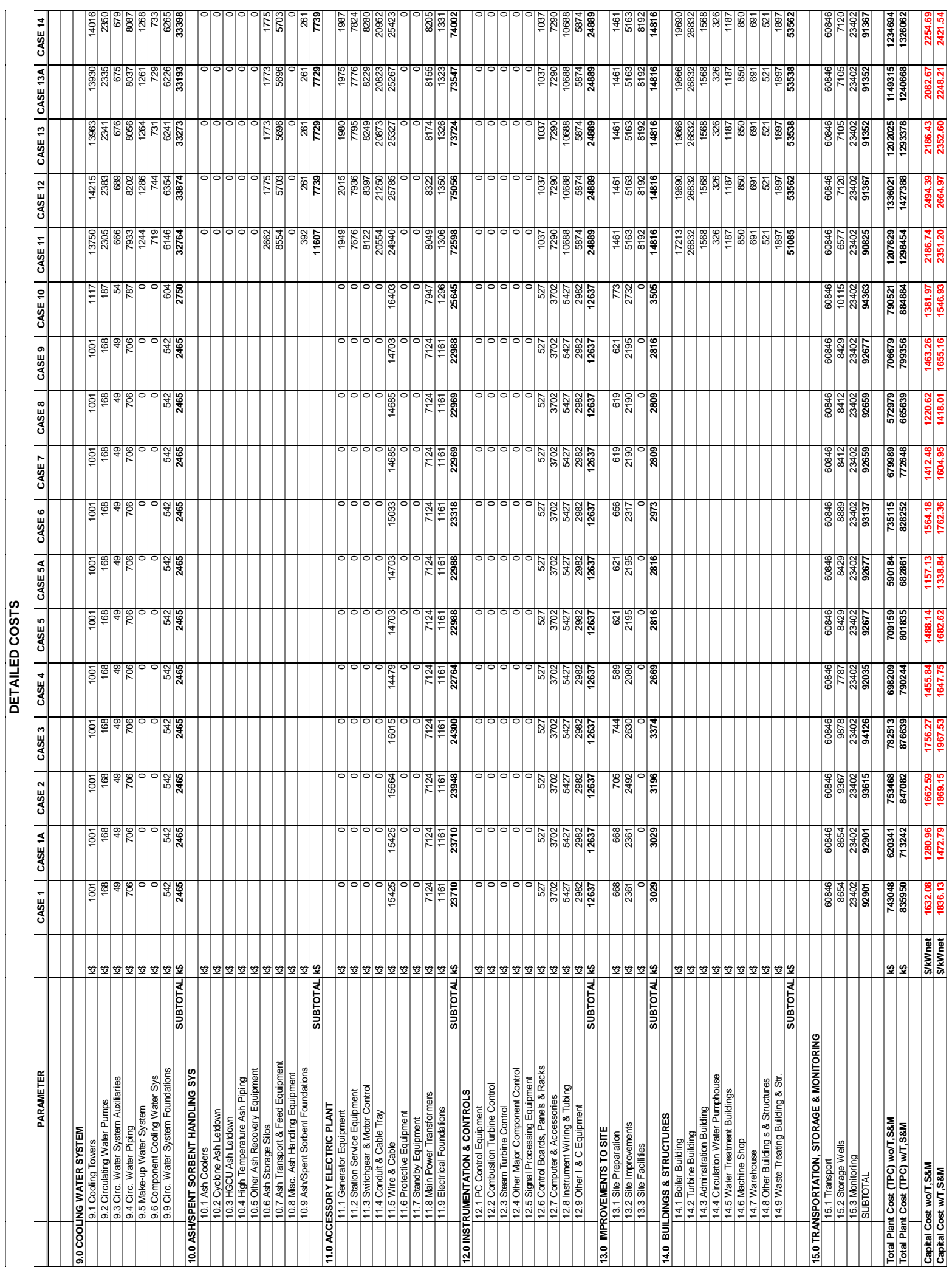

Table 3.41 Detailed cost results for all cases 


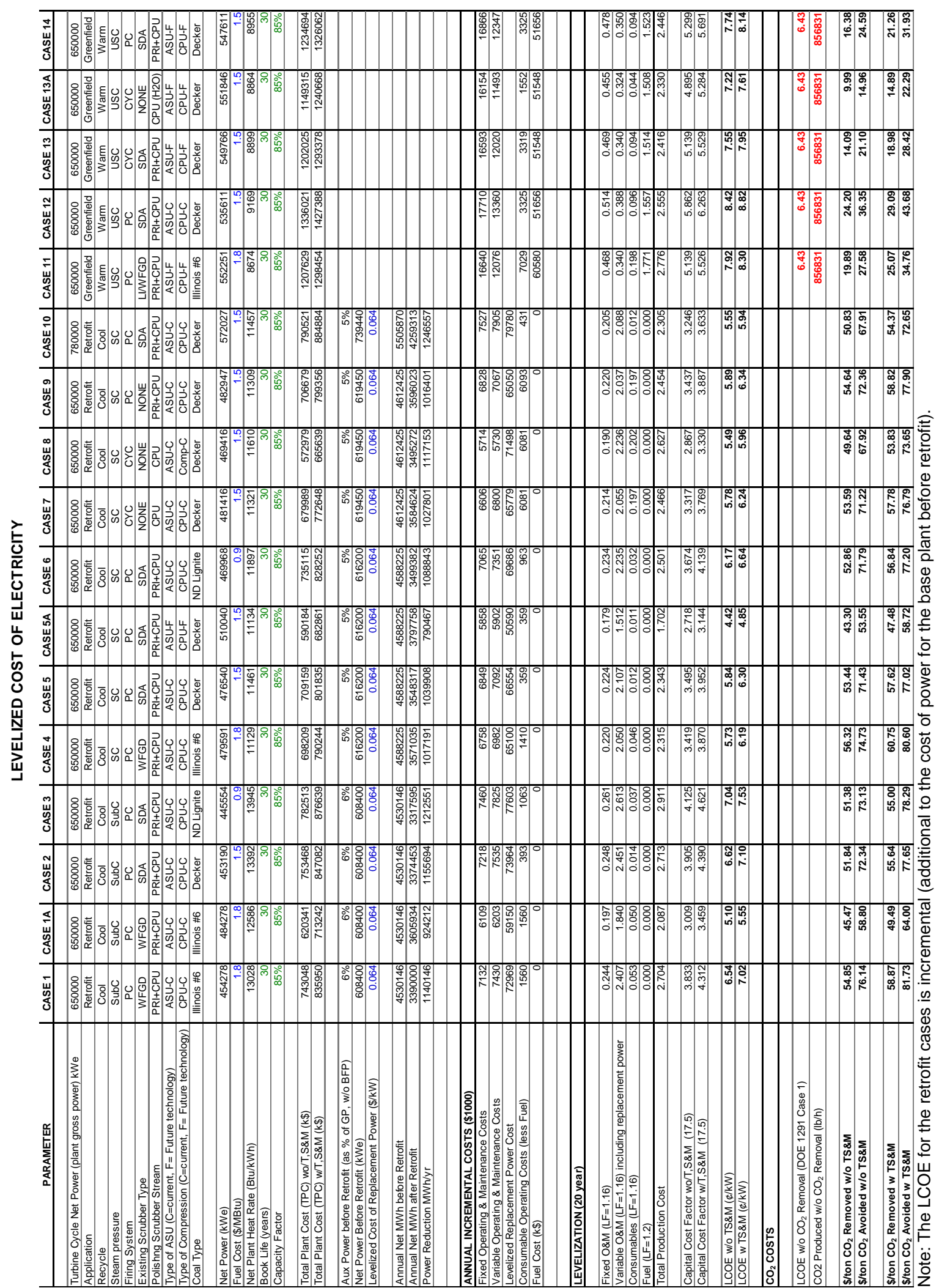

Table 3.42 Economic results for all cases 
Case 7 shows the impact of having Cyclone firing with no existing scrubber leaving the recycle untreated and treating only the CPU stream to remove $\mathrm{SO}_{2}$ and moisture and using current CPU technology. Moisture does not need to be removed for Cyclone firing as it does for PC where it is used to dry and convey coal to the burners. In addition, for all Cyclone cases there is only one recycle stream rather than two. It must also be recognized that the $\mathrm{SO}_{2}$ level in the furnace may become excessive with no sulfur removal in the recycle. This would result in potentially aggressive corrosion and use of higher grade materials in the furnace and high temperature sections of the superheaters and potentially aggressive corrosion not fully accounted for in this study.

Assuming the $\mathrm{SO}_{2}$ concentration in the furnace could be tolerated without noticeable economic impact on the boiler, comparison of Case 7 (Cyclone) with Case 5 (PC) indicates about a 0.3 percentage point net efficiency improvement. As indicated previously, Cyclone firing also produces a slightly better fuel efficiency, slightly higher aux power and slightly lower boiler cost compared to a PC firing system. However, as Figure 3.103 shows, the LCOE for Case 7 without consumables is $0.25 \phi / \mathrm{kW}$ lower than Case 5 without consumables. This indicates that removing all of the sulfur in the DCCPS, which uses more costly bicarbonate reagent, increases the consumable component of the LCOE making Case 7 only $0.06 \phi / \mathrm{kW}$ lower overall.

Case 8 considers the same scenario as Case 7 but does no purification in the compression step (compression only). This results in a significant increase in compression power as shown in Table 3.36 and Figure 3.102 which produces a 0.4 percentage point reduction in net efficiency compared to Case 5. However, in spite of the higher auxiliary power consumption and higher consumable cost, the much lower capital cost for compression versus a CPU results in a $0.29 \notin / \mathrm{kW}$ lower LCOE than Case 7 and $0.35 \notin / \mathrm{kW}$ lower LCOE than PC Case 5.

Case 9 is based on Case 5 but assumes future ASU and CPU technology is applied to a plant without an existing scrubbing system but since it is PC fired the DCCPS must remove $\mathrm{SO}_{2}$ and moisture from both the primary and CPU streams. This would result in acceptable conditions for $\mathrm{PC}$ firing and furnace corrosion and results in a 0.4 percentage point improvement in net efficiency compared to Case 5. However, since the consumable cost is increased, the total LCOE is $0.05 \varnothing / \mathrm{kW}$ higher than Case 5 with only current ASU and CPU technology and an existing scrubber.

Case 10 is identical to Case 5 but scaled up to $780 \mathrm{MWe}$ instead of $650 \mathrm{MWe}$ gross. From a performance perspective this makes no difference. However, as expected there is some economy of scale economic advantage of about $0.29 \notin / \mathrm{kW}$.

The costs of $\mathrm{CO}_{2}$ removed (captured) and avoided (mitigated) are given in Figure 3.104. It should be noted that in they are calculated in the same manner as given in DOE/NETL$401 / 110907$ meaning that the LCOE is incremental and they do not include the cost of operation and maintenance or fuel costs for the base plant being retrofit. 


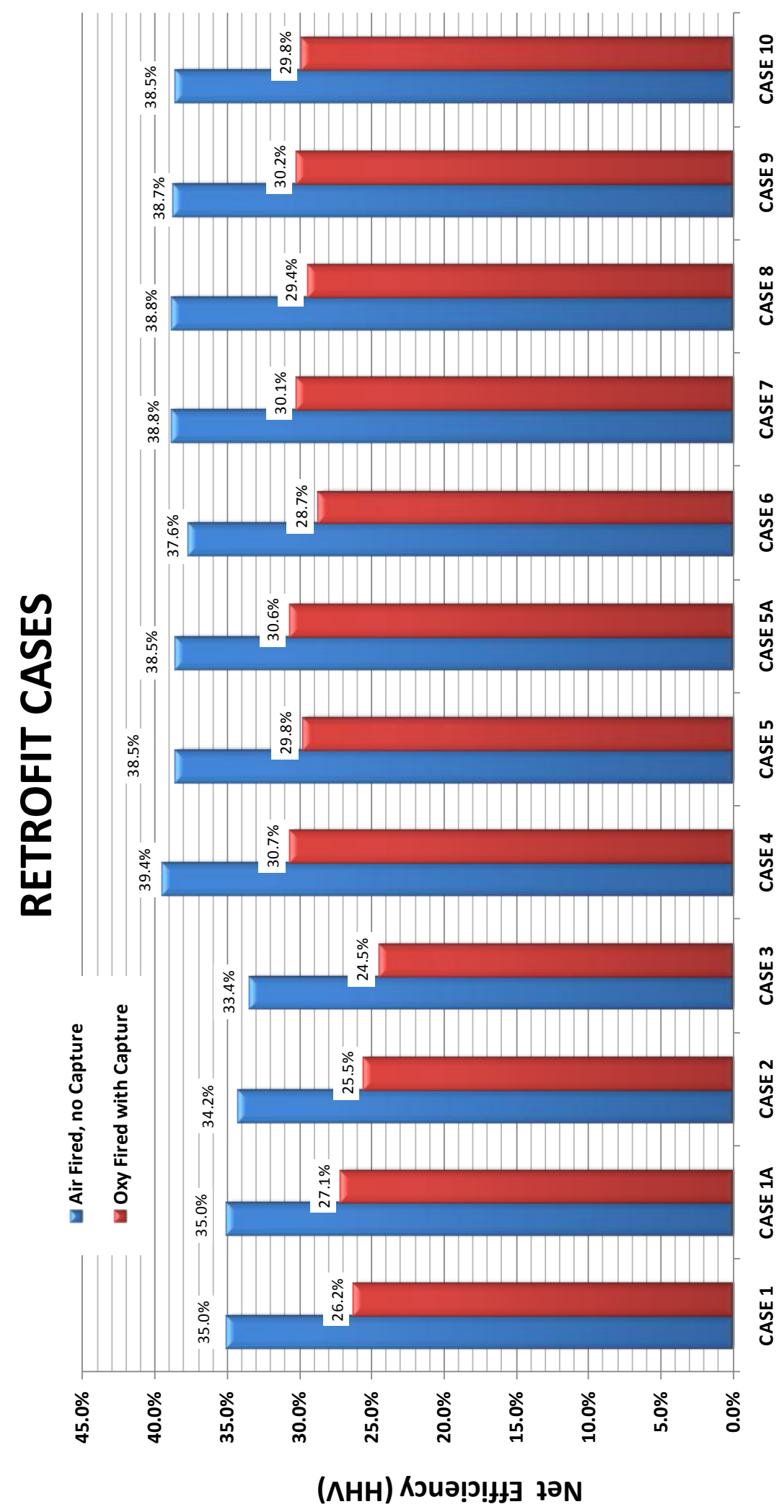

Figure 3.102 Performance results for retrofit cases - net plant efficiency 


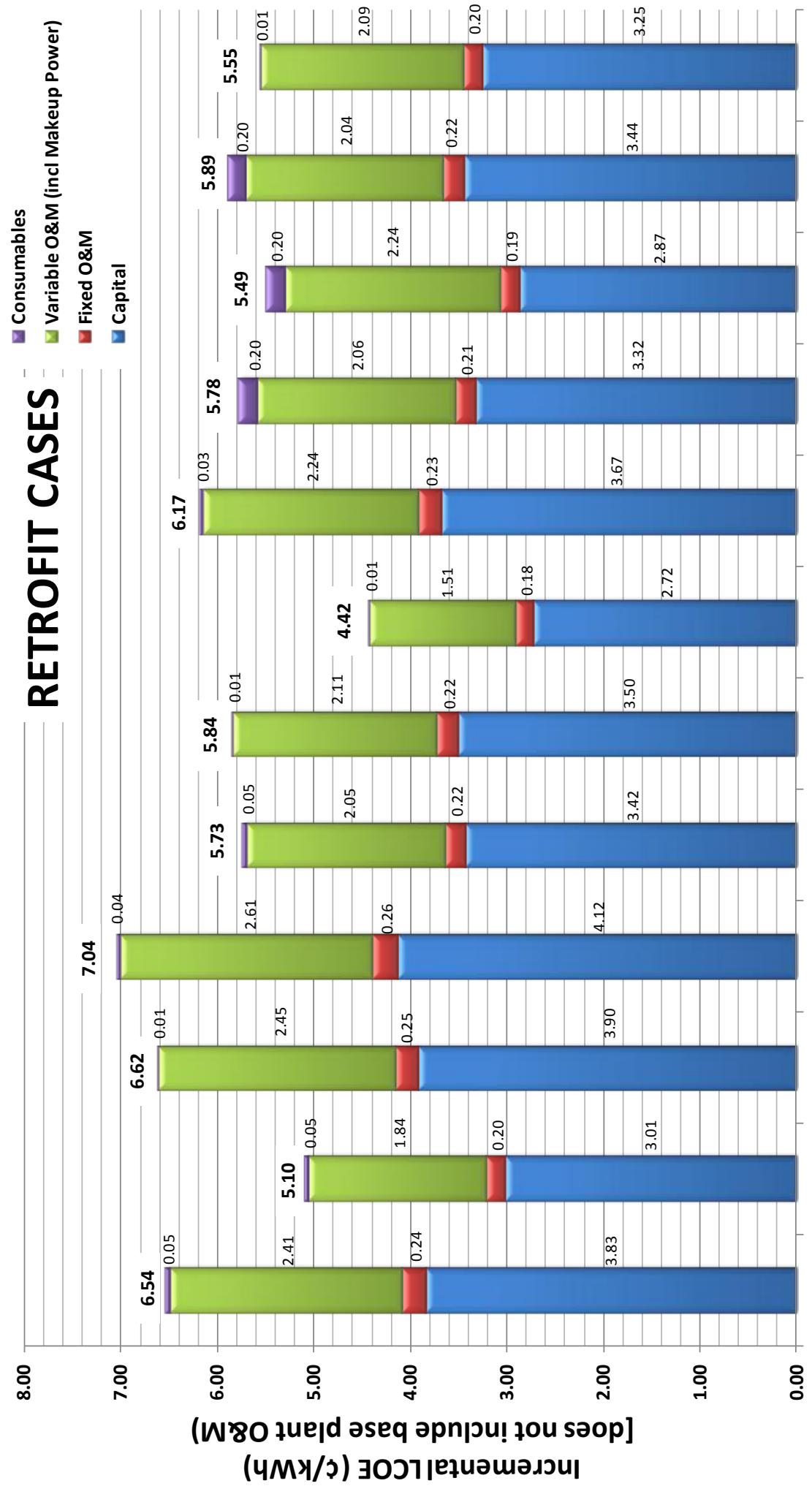

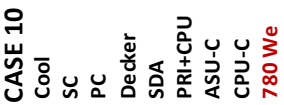

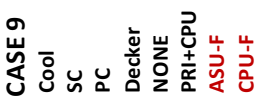

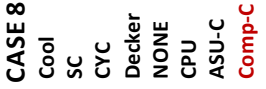

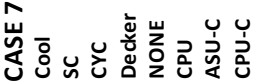

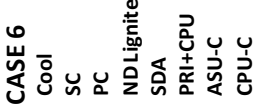

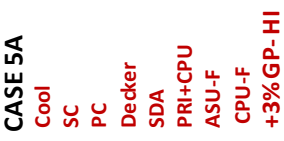

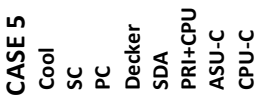

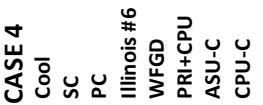

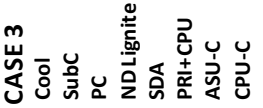

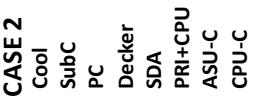

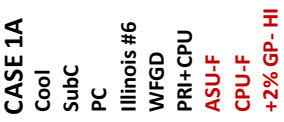

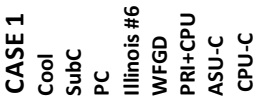

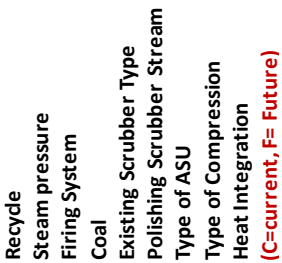

Figure 3.103 Economic results for retrofit cases (incremental LCOE) 


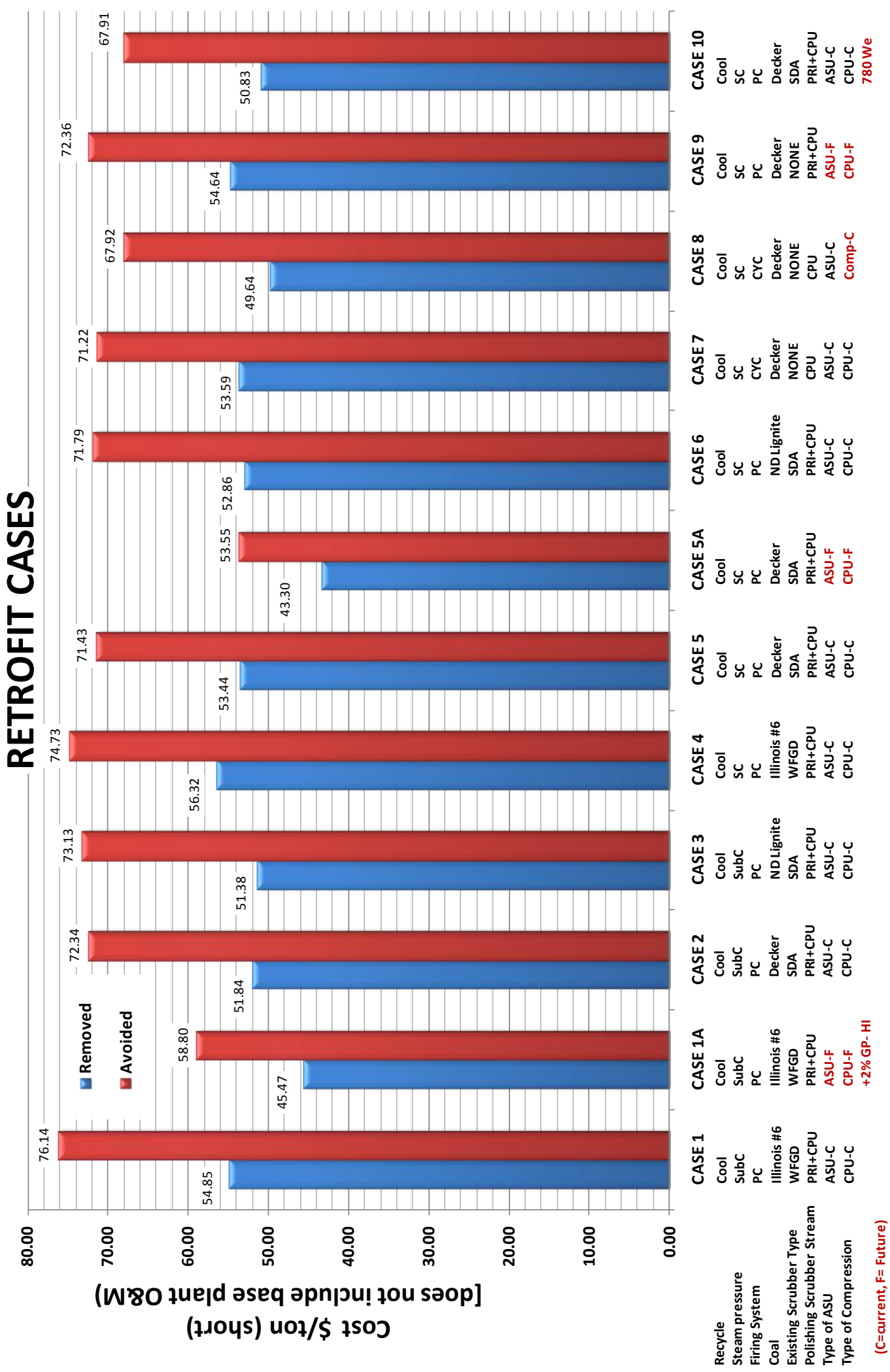

Figure 3.104 Cost of $\mathrm{CO}_{2}$ removed and avoided for retrofit cases 


\subsubsection{Greenfield Cases 11-14}

All of the greenfield cases were analyzed assuming warm instead of cool recycle because warm recycle offers higher cycle efficiency and is therefore what would be used commercially provided $\mathrm{SO}_{2}$ levels in the furnace can be maintained at acceptable levels for corrosion. This configuration returns the secondary recycle to the 'air heater' and boiler at a higher temperature removing only particulate in that stream. For Case 11 firing high sulfur bituminous coal, it is assumed that the sorbent injection ahead of the secondary recycle baghouse achieves sufficient $\mathrm{SO}_{2}$ removal along with the primary recycle (in which $\mathrm{SO}_{2}$ is reduced to 1 ppmv) to result in an acceptable $\mathrm{SO}_{2}$ concentration in the furnace. Sorbent injection is not employed for subbituminous or North Dakota Lignite. Figure 3.94, Figure 3.95, and Figure 3.96 show the warm recycle process configurations for these cases.

Refer to Figure 3.105 for performance, Figure 3.106 for LCOE and Figure 3.107 for cost of $\mathrm{CO}_{2}$ removed or avoided for greenfield Cases 11 to 14 . All of these cases employ ultra-supercritical steam conditions of $4000 \mathrm{psi}, 1350^{\circ} \mathrm{F}, 1400^{\circ} \mathrm{F}$. Again, the performance is given as net plant efficiency, the blue bars on Figure 3.104 represent the base air fired unit with no $\mathrm{CO}_{2}$ capture and the red bars show the impact of oxy-combustion. The case conditions are summarized at the bottom of the chart to facilitate comparison.

The penalty for oxy-PC in greenfield applications is considerably lower than for retrofit ranging between 5.3 and 6.4 percentage points. This is due to the ability to better integrate heat into the steam cycle and the higher efficiency of the steam cycle which reduces coal, oxidant, and $\mathrm{CO}_{2}$ flows and all associated power requirements.

Case 11 shows the results for a unit burning bituminous coal using sorbent injection in the secondary recycle stream to control $\mathrm{SO}_{2}$ concentration in the boiler and employing warm recycle and a dry scrubber-fabric filter combination for $\mathrm{SO}_{2}$ removal in the combined primary and CPU streams. Due to the high sulfur and chlorine content in Illinois \#6 coal, achieving acceptable furnace and superheater corrosion conditions at USC steam conditions will be challenging but it is assumed to be achievable.

Future technology for the ASU and CPU is also incorporated. Compared to the other cases it provides the highest net efficiency due both to the fuel and the future ASU and CPU which have lower power and costs than the current technology in Case 12. Case 14 is identical to Case 12 except it applies the advanced ASU and CPU designs. The difference between these cases is about 0.9 percentage points of net efficiency. Case 14 is identical to Case 11 except for a fuel difference of Decker for Case 14 versus Illinois \#6 for Case 11. This fuel difference results in a 1.2 percentage points reduction in net efficiency but the lower consumable cost as a result of much lower sulfur content and lower fuel cost $(\$ 1.8$ per MBtu for bituminous vs. \$1.5 per MBtu for subbituminous) results in $0.18 \varnothing / \mathrm{kW}$ lower LCOE for the subbituminous coal in Case 14 .

Cases 13 and 13A both employ Cyclone firing systems which provide slight increases in both fuel efficiency and auxiliary power and reduces significantly boiler cost relative to PC (about $10 \%$ ). The distinction between these two cases is that for Case 13A there is no primary scrubber in Case 13A and only moisture is removed from the CPU stream so no sulfur is removed in any of the recycle streams. Figure 3.105 shows that this produces only a $0.2 \%$ improvement in net efficiency and Figure 3.106 shows a $0.33 \phi / \mathrm{kW}$ reduction in LCOE. However, the high $\mathrm{SO}_{2}$ 
concentration in the furnace coupled with the USC steam conditions in Case 13A will be very challenging in regard to furnace and superheater corrosion even with subbituminous coal and may be impractical. In addition, the pipeline and storage reservoir must be able to accommodate the sulfur.

The cost of $\mathrm{CO}_{2}$ removed and avoided is shown in Figure 3.107. The impact of Cyclone firing coupled with future ASU and CPU benefits are quite evident when comparing Cases 12 and 13.

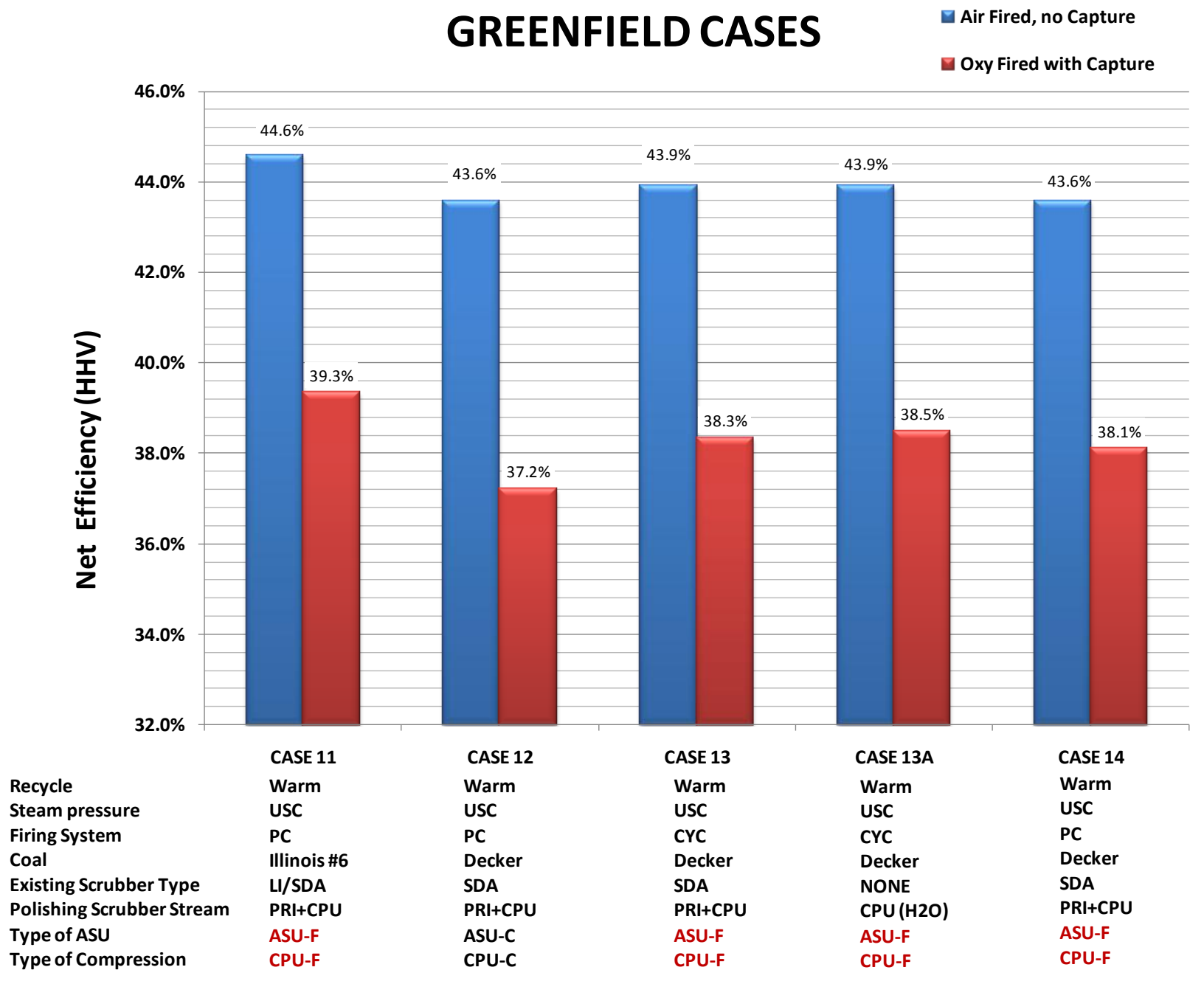

( $C=$ current, $F=$ Future)

Figure 3.105 Performance results for greenfield cases - net plant efficiency 


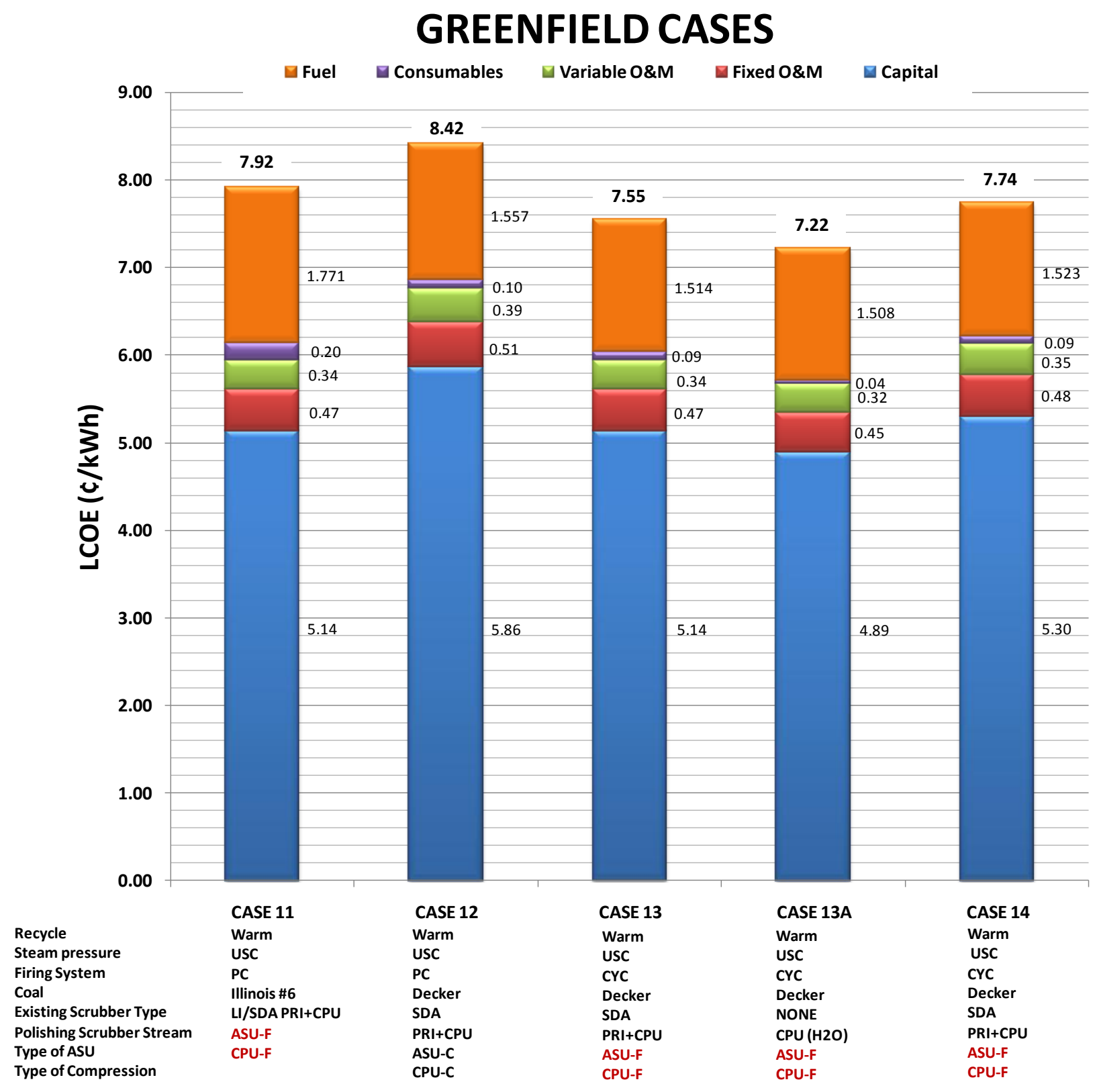

(C=current, F= Future)

Figure 3.106 Economic results for greenfield cases (LCOE) (See Section 3.2.6 for comparisons with other studies and base cases) 


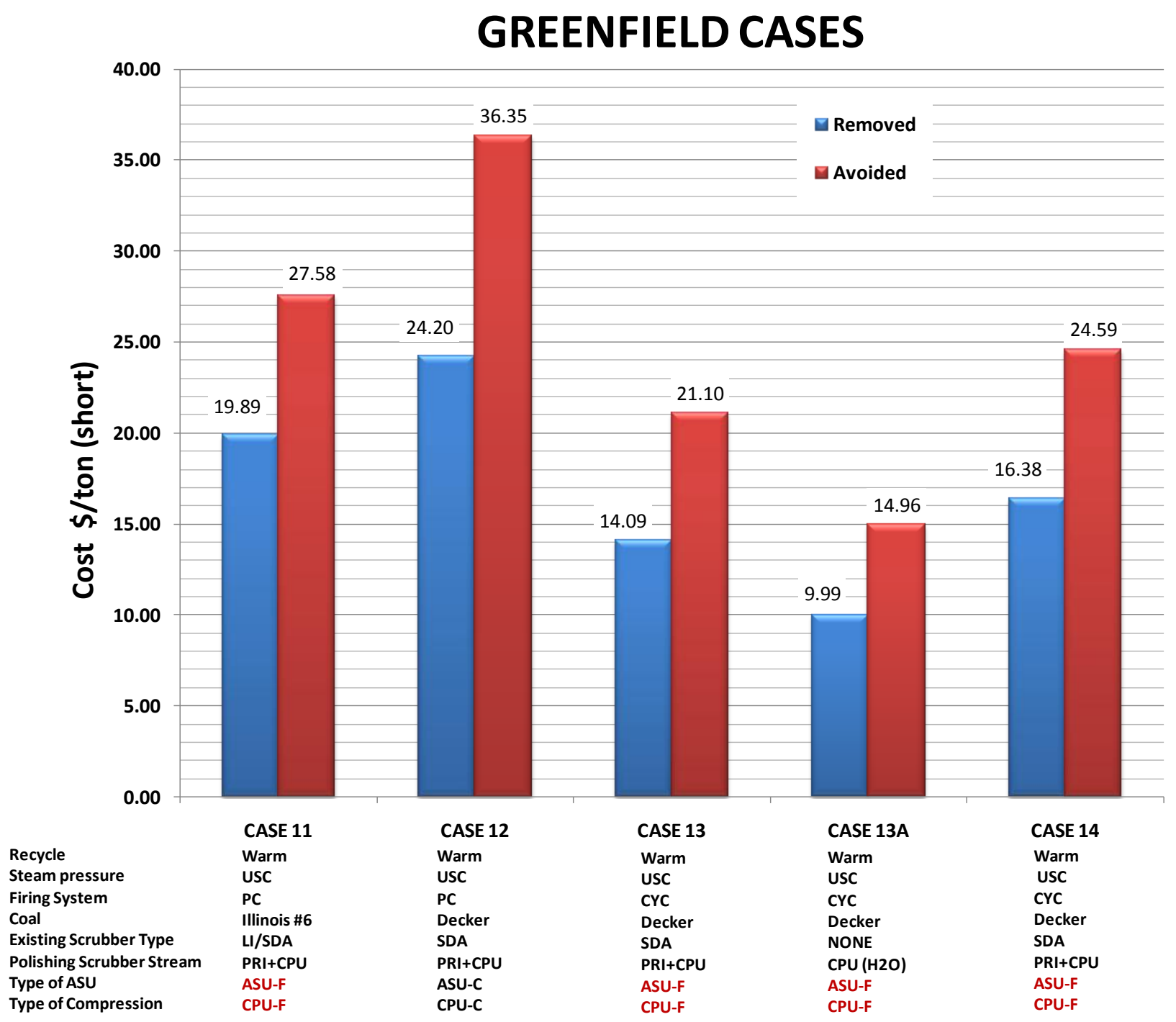

(C=current, F= Future)

Figure 3.107 Cost of $\mathrm{CO}_{2}$ removed and avoided for greenfield cases (See Section 3.2.6 for comparisons with other studies and base cases)

\subsubsection{Comparison of Performance and Economic Results with Other Studies}

\subsubsection{DOE Oxy-firing Study (DOE/NETL-2007/1291)}

Refer to Figure 3.108 for performance, Figure 3.109 for LCOE and Figure 3.110 for cost of $\mathrm{CO}_{2}$ removed or avoided. These graphs compare the results from Oxy-PC retrofit Case 4, employing supercritical steam conditions and firing Illinois \#6 bituminous coal, with Cases 1 (air fired), and Case 5 (oxy PC fired) from the DOE study "Pulverized Coal Oxy-combustion Power Plants" DOE/NETL-2007/1291 revised August 2008. Comparing the Case 4 retrofit with the DOE Case 5 net efficiencies shows about a 1.4 percentage point gain since the DOE study primarily as a result of improvements to ASU and CPU designs since 2007. It should also be noted that Cases 5 and 6 from the DOE/NETL-2007/1291 indicate cold recycle while the process for this study is called cool recycle. The cold recycle process takes the secondary recycle stream after moisture 
removal and at a somewhat lower temperature than cool recycle. As described earlier, cool recycle takes the secondary recycle stream after the primary scrubber which is at moisture saturation temperature for wet scrubbers and about $30^{\circ} \mathrm{F}$ higher for dry scrubbers.

In the LCOE graph only, to make the retrofit Case 4 comparable to the greenfield cases, the O\&M and fuel costs for the base plant (base plant capital assumed fully depreciated) have been added to the incremental retrofit costs to calculate LCOE. Note that the retrofit Case 4 also shows a variable cost component which is the makeup power to achieve the net output of the airfired unit without CCS. It is believed that with these corrections the retrofit Case 4 LCOE can be directly compared to the other greenfield cases.

Greenfield Cases 11 to 14 are also comparable with DOE Case 6 (oxy PC) from the DOE study DOE/NETL-2007/1291employing the same USC steam conditions. Case 2 from the DOE study DOE/NETL-2007/1291 (not shown on the chart) yielded 44.6\% net efficiency with air firing. Incorporation of warm recycle, expected future improvements to the ASU and CPU, along with deep integration of heat into the steam cycle (not considered in the DOE study) show potential for reduction of the penalty for oxy-PC with USC steam conditions from 11.6 percentage points to about 5.4 percentage points.

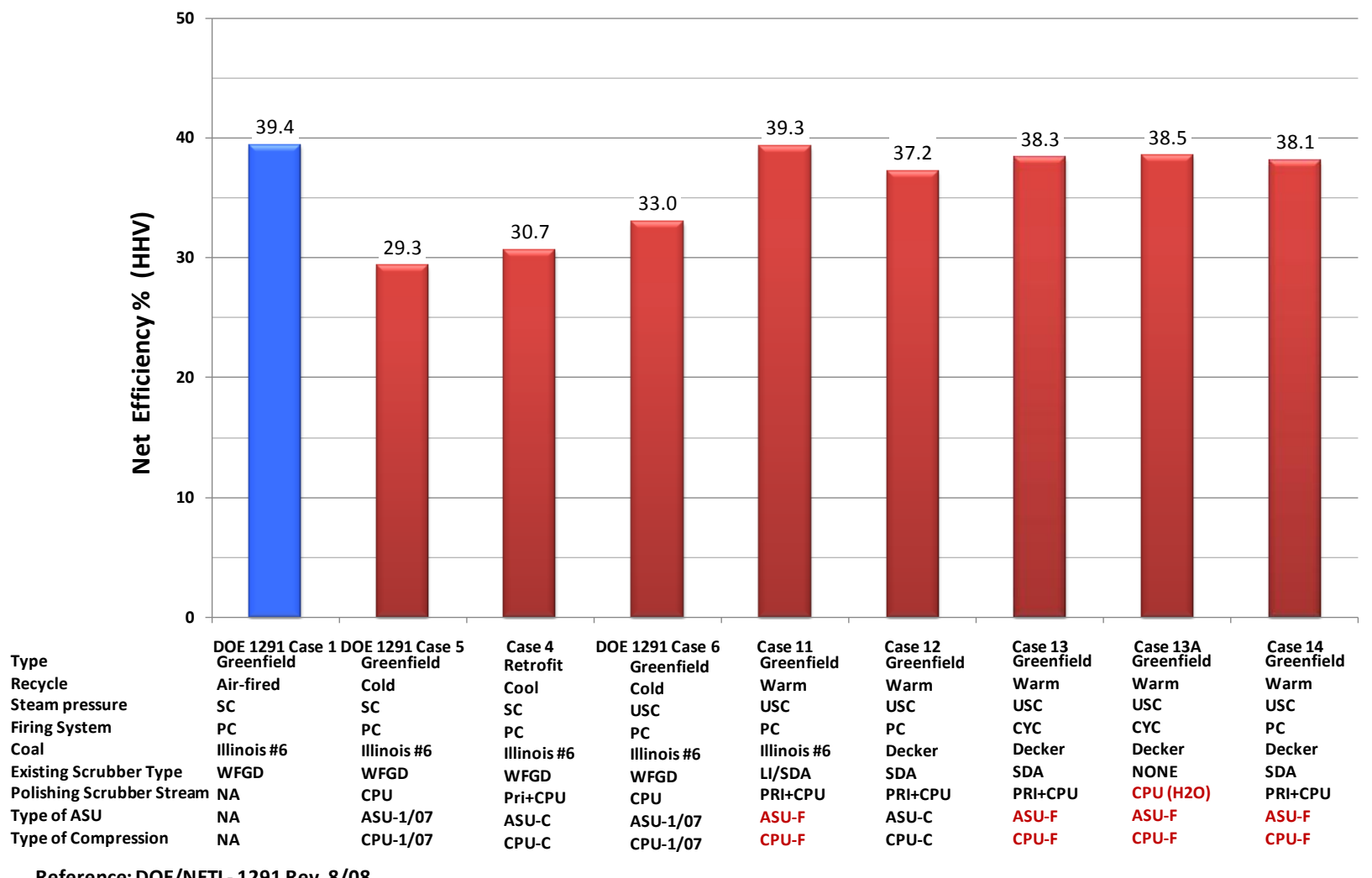

Figure 3.108 Performance comparisons with other studies

Even with the penalty of carbon capture, Case 11 shows that with USC steam conditions, warm recycle, heat integration, and future ASU and CPU benefits there is potential to achieve the same 
net plant efficiencies achieved by current day state-of-the-art SC plants without carbon capture. The net efficiency for the DOE Case 1is 39.4\% and the predicted efficiency for Case 11 in this study is $39.3 \%$ so the performance is essentially the same. The LCOE for DOE Case 1 is $6.32 \phi / \mathrm{kW}$ and the LCOE for Case 11 of this study is $7.92 \phi / \mathrm{kW}$. This shows the potential to reduce the cost of oxy-combustion to about $25.3 \%$ more than an equivalent air fired plant - well below the current DOE target of 35\%. If this can be achieved it will mean that future USC oxyPC plants with carbon capture can operated at the same net efficiency as modern air fired supercritical plants today for a $25 \%$ increase in LCOE.

Case 12 indicates the possibilities with subbituminous coal and USC conditions using current ASU and CPU technology. The 7.9 percentage point improvement in net efficiency and $1.65 \phi / \mathrm{kW}$ lower LCOE for Case 12 of this study compared to the 2007 DOE Case 5 can be attributed to the beneficial impact of lower sulfur fuel in Case 12 on cost (but is detrimental to efficiency) and three major advancements that primarily improve efficiency, 1) warm recycle which provides some fuel efficiency and power gain, 2) integration of ASU and process heat which provides a significant increase in power generated, and 3) 2010 ASU and CPU technology which has greatly reduced the power requirements and costs for the ASU and CPU since 2007.

The impact of these improvements on cost of $\mathrm{CO}_{2}$ removed and avoided is apparent in Figure 3.110. As might be expected, the costs removed and avoided for Case 4 are much higher than for a greenfield application. 


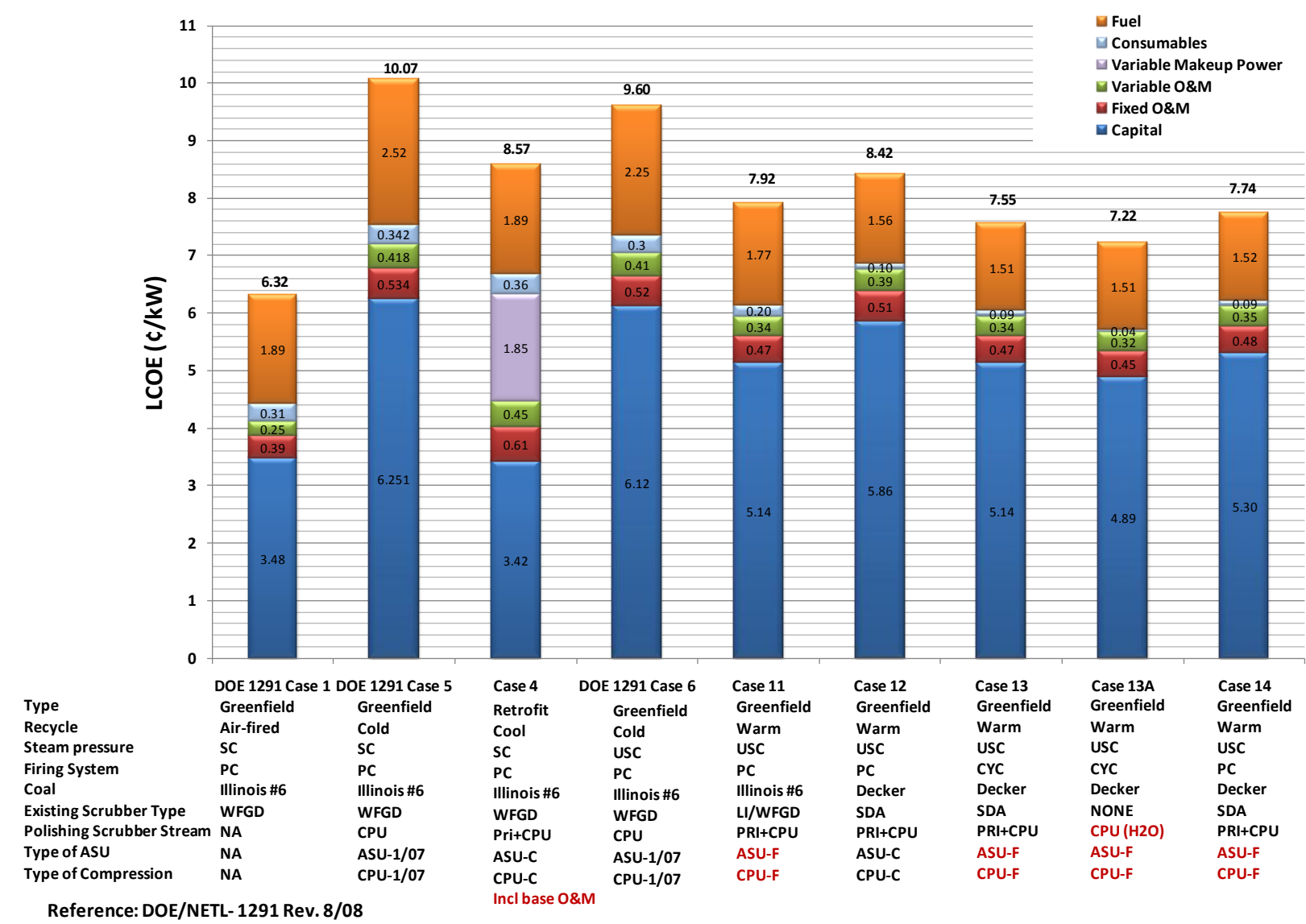

Figure 3.109 Economic comparisons with other studies (LCOE) 


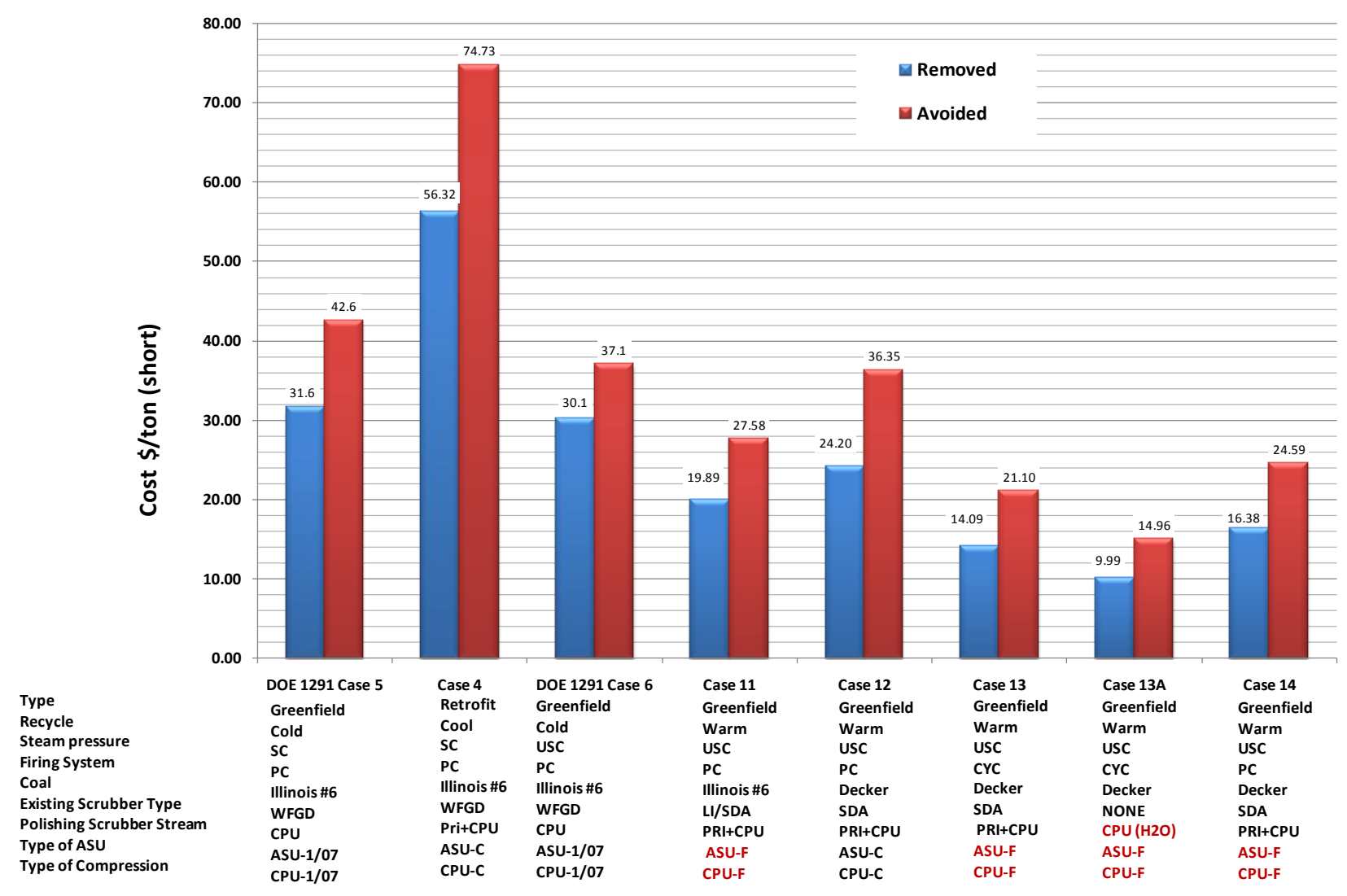

Reference: DOE/NETL- 1291 Rev. 8/08

Figure 3.110 Cost of $\mathrm{CO}_{2}$ removed and avoided for comparison cases

\subsubsection{DOE Post Combustion Capture Study (DOE/NETL-401/110907)}

Refer to Figure 3.111 for performance, Figure 3.112 for LCOE, and Figure 3.113 for cost of $\mathrm{CO}_{2}$ removed or avoided comparing the results from this study with results from DOE/NETL 401/11/0907 "Carbon Dioxide Capture from Existing Coal-Fired Power Plants rev. Nov.2007.

The first three bars in Figure 3.111, Figure 3.112, and Figure 3.113 labeled Case 1, Case 1-R1 and Case 1-R2 are Case 1 from this study and two modifications to improve oxy-PC retrofit performance in the mid-term and the longer-term. The mid-term improvement consists of integration of ASU and process heat to achieve a $2 \%$ increase in gross power and is labeled Case $1-\mathrm{R} 1$. The longer-term improvement is the same heat integration plus future ASU and CPU designs and is labeled Case 1-R2.

The last three bars in Figure 3.111 labeled DOE 401 Case 1, DOE 401 Case 1-R1 and DOE 401 Case 1-R2 are Case 1 from the DOE/NETL 401/11/0907 study and two modifications to improve PCC retrofit performance and cost in the mid-term and longer-term. The mid-term improvement consists of a reduction in the solvent cost by $50 \%$ and is labeled Case DOE 401 Case 1-R1. The longer-term improvement consists of a reduction in the solvent cost by $50 \%$ plus a $10 \%$ reduction in auxiliary power consumption and is labeled Case DOE 401 Case 1-R2. 
The performance results indicate that oxy-PC currently provides a potential 1.8 percentage point advantage over post combustion capture as defined in the DOE/NETL 401/11/0907 study (Case 1 vs. DOE 401 Case1). To assess the impact of potential advancements in the near to midterm, the oxy-PC retrofit Case 1 was modified as described previously. As Figure 3.111 shows, even with a $10 \%$ reduction in auxiliary power, the current oxy retrofit provides a 0.7 percentage point efficiency advantage (Case 1 vs. DOE 401 Case 1-R2).

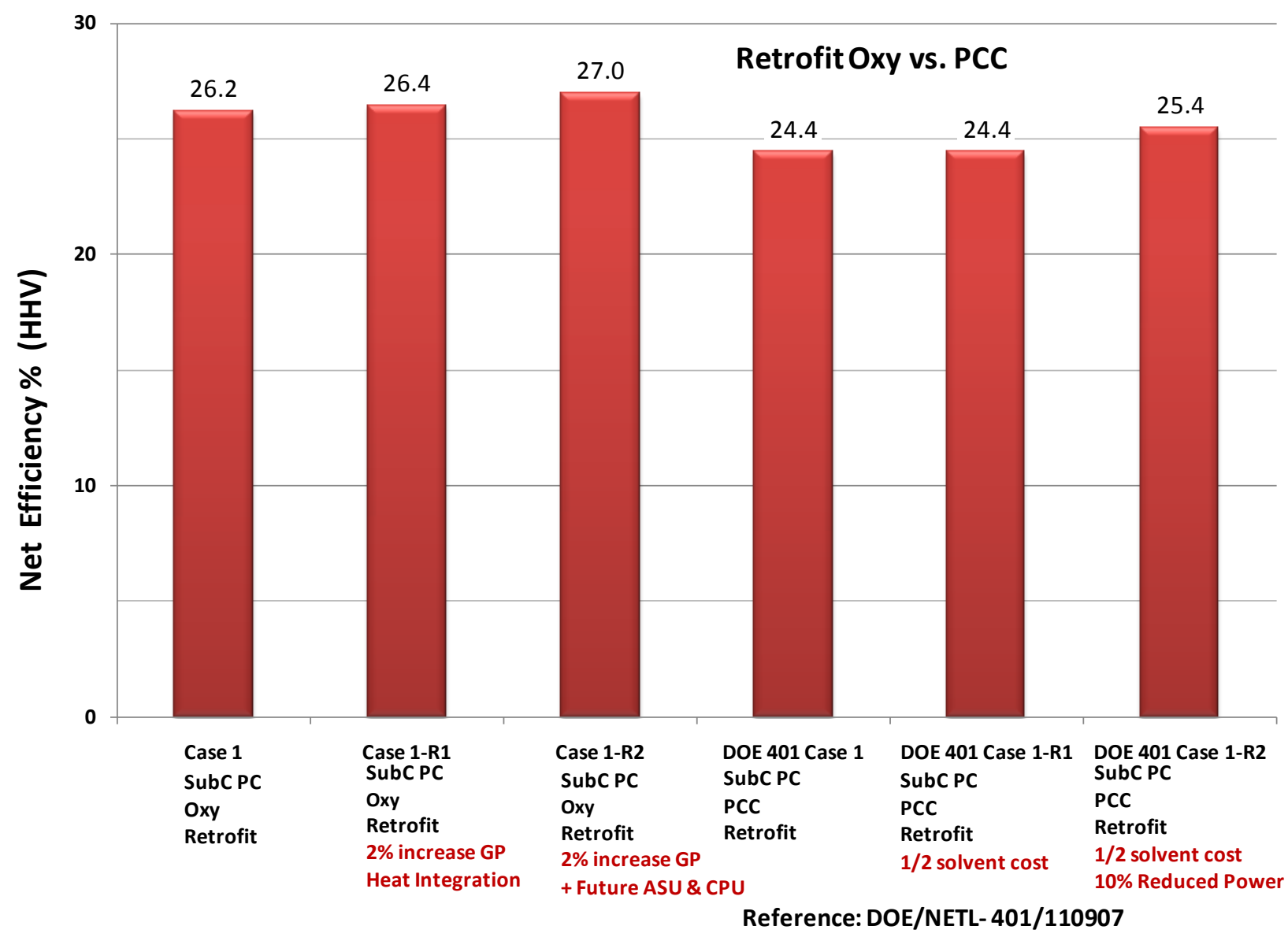

Figure 3.111 Performance comparisons with post combustion capture study 


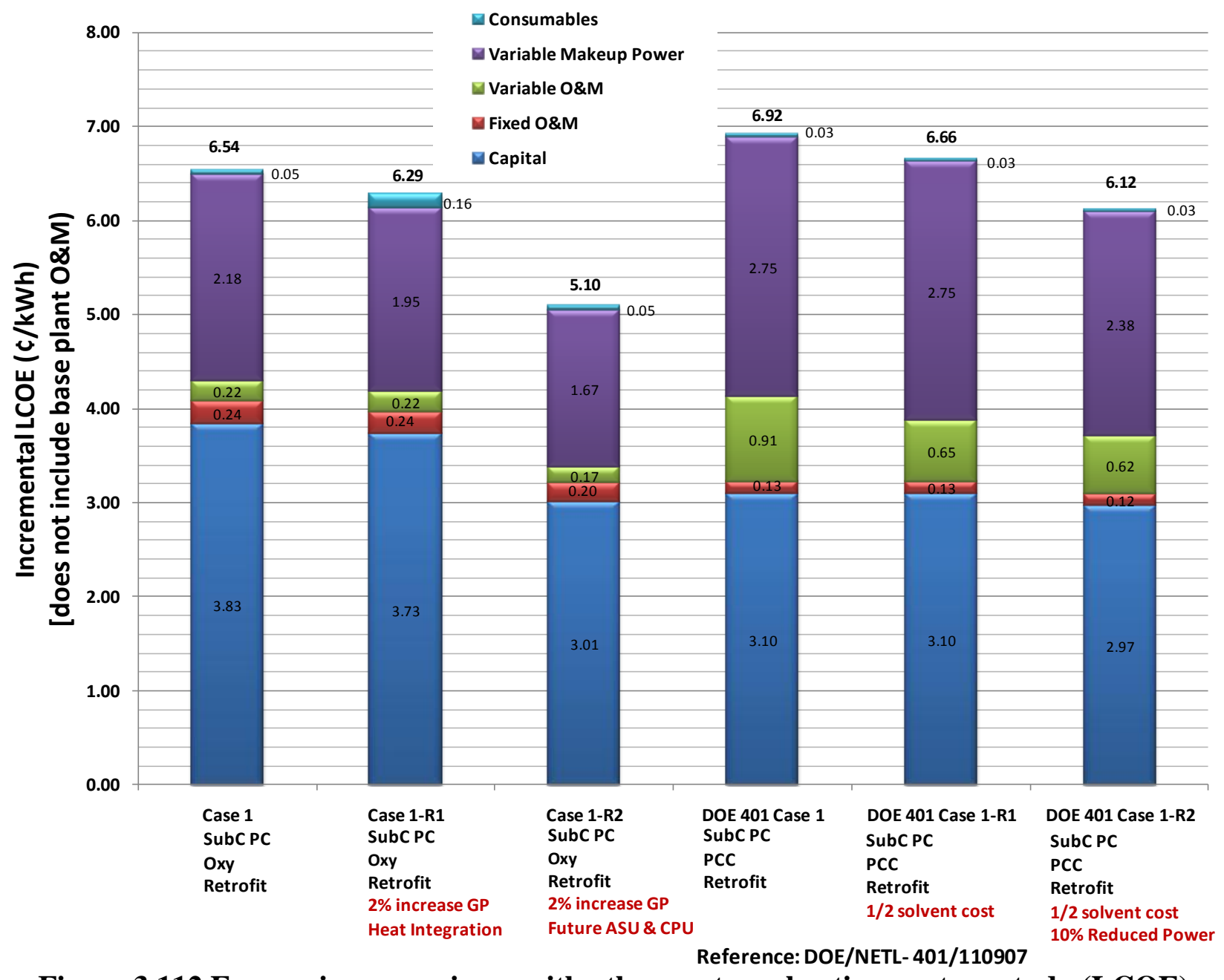

Figure 3.112 Economic comparisons with other post combustion capture study (LCOE)

In regard to LCOE, current oxy retrofit also has a $0.38 \phi / \mathrm{kW}$ advantage over current PCC retrofit (Case 1 vs. DOE 401 Case1). Case 1-R2 shows that with future advancements, the oxy retrofit could have about a $1.02 \notin / \mathrm{kW}$ advantage over PCC retrofit (Case 1-R2 vs. Case 401 1-R2).

According to these comparisons of performance and cost, oxy-PC has a potential advantage over PCC for retrofit. The trends in costs of $\mathrm{CO}_{2}$ removed and avoided are similar to the efficiency and LCOE graphs showing oxy retrofit as having an advantage. Considering the uncertainty band for these studies it is at least fair to say that oxy-PC does not indicate any disadvantage in performance relative to PCC and as indicated above, it also shows potential cost advantages.

\subsubsection{Performance and Economic Results for Sensitivity Studies}

\subsubsection{1. $\quad$ Sensitivity to Air Infiltration}

Four cases were evaluated to assess the impact of air infiltration on performance and cost as described in Section 3.2.2.4.1. The gas compositions for the four air infiltration cases are shown in Table 3.31. Retrofit Case 5 employing the cool recycle configuration with supercritical steam conditions firing Decker subbituminous coal with a dry primary scrubber and current ASU and 
CPU technology was used as the basis for all four comparative cases. Case AI- 1 assumes $2 \%$ of theoretical air (wet) in the furnace and $8 \%$ in the backend of the process between the boiler and ID fan inlet where the process pressure is below atmospheric. This total of $10 \%$ air infiltration is believed to be quite high and much lower levels are readily achievable. Case AI-2 assumes the same infiltration in the boiler but only $3 \%$ in the backend for a total of $5 \%$ air infiltration. Cases AI-3 and AI-4 reduce the boiler infiltration to $0 \%$ assuming a tight enclosure construction operating very slightly positive in the boiler (pressure balance point at the boiler outlet) and using dry, clean $\mathrm{CO}_{2}$ for all sealing and cooling gas needs. Case AI-3 considers $3 \%$ infiltration in the backend and Case AI-4 assumes 2\%.

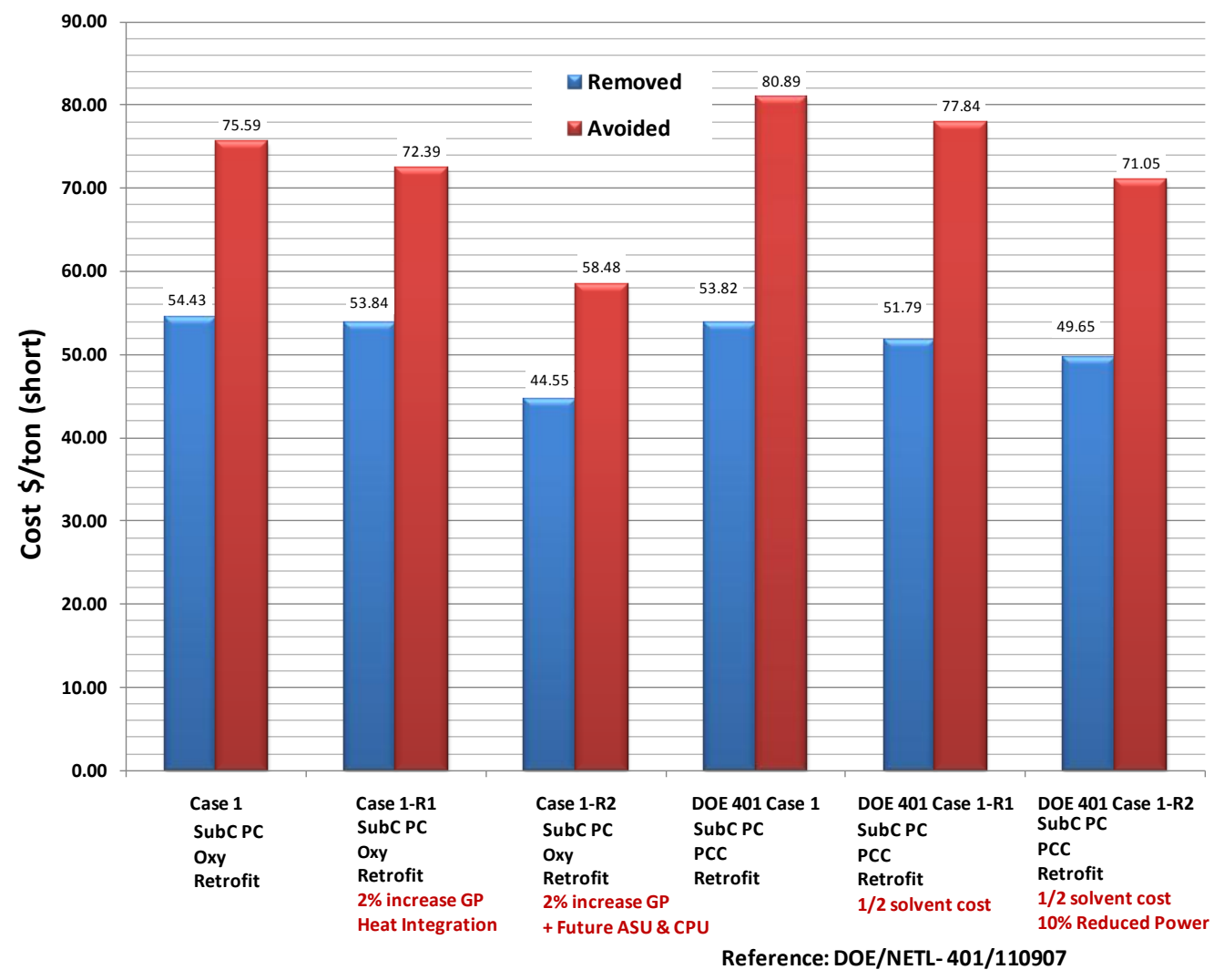

Figure 3.113 Cost of $\mathrm{CO}_{2}$ removed and avoided for comparison cases

Table 3.43 shows the performance for these four cases and Figure 3.114 shows the net efficiencies. Table 3.44 shows the cost breakdown, Table 3.45 provides the LCOE details and Figure 3.115 compares LCOE graphically. As Figure 3.114 shows, the impact of $10 \%$ air infiltration versus $2 \%$ air infiltration is about 0.82 percentage points of efficiency. However, the impact on cost is significant resulting in a $0.46 \notin / \mathrm{kW}$ lower LCOE, or a $7.7 \%$ reduction. 


\section{PERFORMANCE}

\begin{tabular}{|c|c|c|c|c|}
\hline PARAMETER & $\begin{array}{c}\text { CASE } 5 \\
\text { Al-1 } \\
\end{array}$ & $\begin{array}{c}\text { CASE } 5 \\
\text { Al-2 } \\
\end{array}$ & $\begin{array}{c}\text { CASE } 5 \\
\text { Al-3 } \\
\end{array}$ & $\begin{array}{c}\text { CASE } 5 \\
\text { Al-4 } \\
\end{array}$ \\
\hline Turbine Cycle Net Power (plant gross power), kWe & 650000 & 650000 & 650000 & 650000 \\
\hline Application & Retrofit & Retrofit & Retrofit & Retrofit \\
\hline Recycle & Cool & Cool & Cool & Cool \\
\hline Steam pressure & $\mathrm{SC}$ & $\mathrm{SC}$ & $\mathrm{SC}$ & $\mathrm{SC}$ \\
\hline Firing System & $\mathrm{PC}$ & $\mathrm{PC}$ & $\mathrm{PC}$ & $\mathrm{PC}$ \\
\hline Existing Scrubber Type & SDA & SDA & SDA & SDA \\
\hline Polishing Scrubber Stream & $\mathrm{PRI}+\mathrm{CPU}$ & $\mathrm{PRI}+\mathrm{CPU}$ & $\mathrm{PRI}+\mathrm{CPU}$ & $\mathrm{PRI}+\mathrm{CPU}$ \\
\hline Type of ASU ( $\mathrm{C}=$ current, $\mathrm{F}=$ Future technology) & ASU-C & ASU-C & ASU-C & ASU-C \\
\hline Type of Compression ( $\mathrm{C}=$ current, $\mathrm{F}=$ Future technology) & CPU-C & CPU-C & CPU-C & CPU-C \\
\hline Coal Type & Decker & Decker & Decker & Decker \\
\hline Heating Value (HHV) & 9540 & 9540 & 9540 & 9540 \\
\hline Coal Ash Content & $3.98 \%$ & $3.98 \%$ & $3.98 \%$ & $3.98 \%$ \\
\hline Sulfur & $0.34 \%$ & $0.34 \%$ & $0.34 \%$ & $0.34 \%$ \\
\hline Carbon & $55.15 \%$ & $55.15 \%$ & $55.15 \%$ & $55.15 \%$ \\
\hline Oxygen & $12.57 \%$ & $12.57 \%$ & $12.57 \%$ & $12.57 \%$ \\
\hline Hydrogen & $3.83 \%$ & $3.83 \%$ & $3.83 \%$ & $3.83 \%$ \\
\hline Nitrogen & $0.73 \%$ & $0.73 \%$ & $0.73 \%$ & $0.73 \%$ \\
\hline Moisture & $23.40 \%$ & $23.40 \%$ & $23.40 \%$ & $23.40 \%$ \\
\hline Base Plant Auxiliary Power & 29510 & 29510 & 29510 & 29510 \\
\hline Air Separation Unit Main Compressor & 85000 & 85000 & 85000 & 85000 \\
\hline Trona & 0 & 0 & 0 & \\
\hline Polishing Scrubber & 2482 & 2358 & 2319 & 2295 \\
\hline Compression \& Purification Unit & 56000 & 54000 & 49000 & 43000 \\
\hline Additional Cooling Tower Fans (ASU/ CPU Cooling) & 2513 & 2592 & 2639 & 2656 \\
\hline TOTAL AUXILIARY POWER (kWe) & 175505 & 173460 & 168468 & 162460 \\
\hline Net Power (kWe) & 474495 & 476540 & 481540 & 487540 \\
\hline Pre-retrofit net plant efficiency (\%) & $38.51 \%$ & $38.51 \%$ & $38.51 \%$ & $38.51 \%$ \\
\hline Pre-retrofit Heat Rate (Btu/kWh HHV) & 8863 & 8863 & 8863 & 8863 \\
\hline Pre-retrofit (Aux Power)/(Gross Power) Ratio & $5.2 \%$ & $5.2 \%$ & $5.2 \%$ & $5.2 \%$ \\
\hline Turbine Cycle Heat Rate (Btu/kWh HHV) & 7236.0 & 7236.0 & 7236.0 & 7236.0 \\
\hline Fuel (Boiler) Efficiency & $86.1 \%$ & $86.1 \%$ & $86.1 \%$ & $86.1 \%$ \\
\hline Net Plant Heat Rate (Btu/kWh HHV) & 11510 & 11461 & 11342 & 11202 \\
\hline Net Plant Efficiency & $29.64 \%$ & $29.77 \%$ & $30.08 \%$ & $30.46 \%$ \\
\hline \multicolumn{5}{|l|}{ CONSUMABLES } \\
\hline As-Received Coal Feed, Ib/h & 572483 & 572483 & 572483 & 572483 \\
\hline Thermal Input, kWth & 1600761 & 1600761 & 1600761 & 1600761 \\
\hline WFGD Limestone Sorbent Feed, Ib/h $(\mathrm{Ca} / \mathrm{S})=1.05$ & 0 & 0 & 0 & 0 \\
\hline SDA Pebble Lime Feed, lb/h & 6749 & 6749 & 6749 & 6749 \\
\hline Trona (sodium bicarbonate) for Polishing FGD, Ib/h & 1926 & 1829 & 1829 & 1829 \\
\hline Trona (sodium bicarbonate), for $\mathrm{SO}_{3}$ control, lb/h & 0 & 0 & 0 & \\
\hline \multicolumn{5}{|l|}{ OXYGEN } \\
\hline Oxygen Purity & $95.0 \%$ & $95.0 \%$ & $95.0 \%$ & $95.0 \%$ \\
\hline Oxidant Required (short tons/day) - includes impurites & 11648 & 12016 & 12233 & 12311 \\
\hline \multicolumn{5}{|l|}{ CO2 REMOVAL } \\
\hline Recovery Efficiency & $90.0 \%$ & $90.0 \%$ & $90.0 \%$ & $90.0 \%$ \\
\hline Total Gas Flow to CPU (lb/h) & 1644076 & 1464079 & 1398133 & 1362120 \\
\hline Carbon Dioxide Produced (lb/h) & 1156916 & 1156916 & 1156916 & 1156916 \\
\hline Carbon Dioxide Produced (short tons/d) & 13883 & 13883 & 13883 & 13883 \\
\hline Carbon Dioxide Produced (short tons/yr) & 4307197 & 4307197 & 4307197 & 4307197 \\
\hline Carbon Dioxide Removed (lb/h) & 1041224 & 1041224 & 1041224 & 1041224 \\
\hline Carbon Dioxide Removed (short tons/d) & 12495 & 12495 & 12495 & 12495 \\
\hline Carbon Dioxide Removed (short tons/yr) & 3876477 & 3876477 & 3876477 & 3876477 \\
\hline
\end{tabular}

Table 3.43 Performance results for variations of air infiltration 


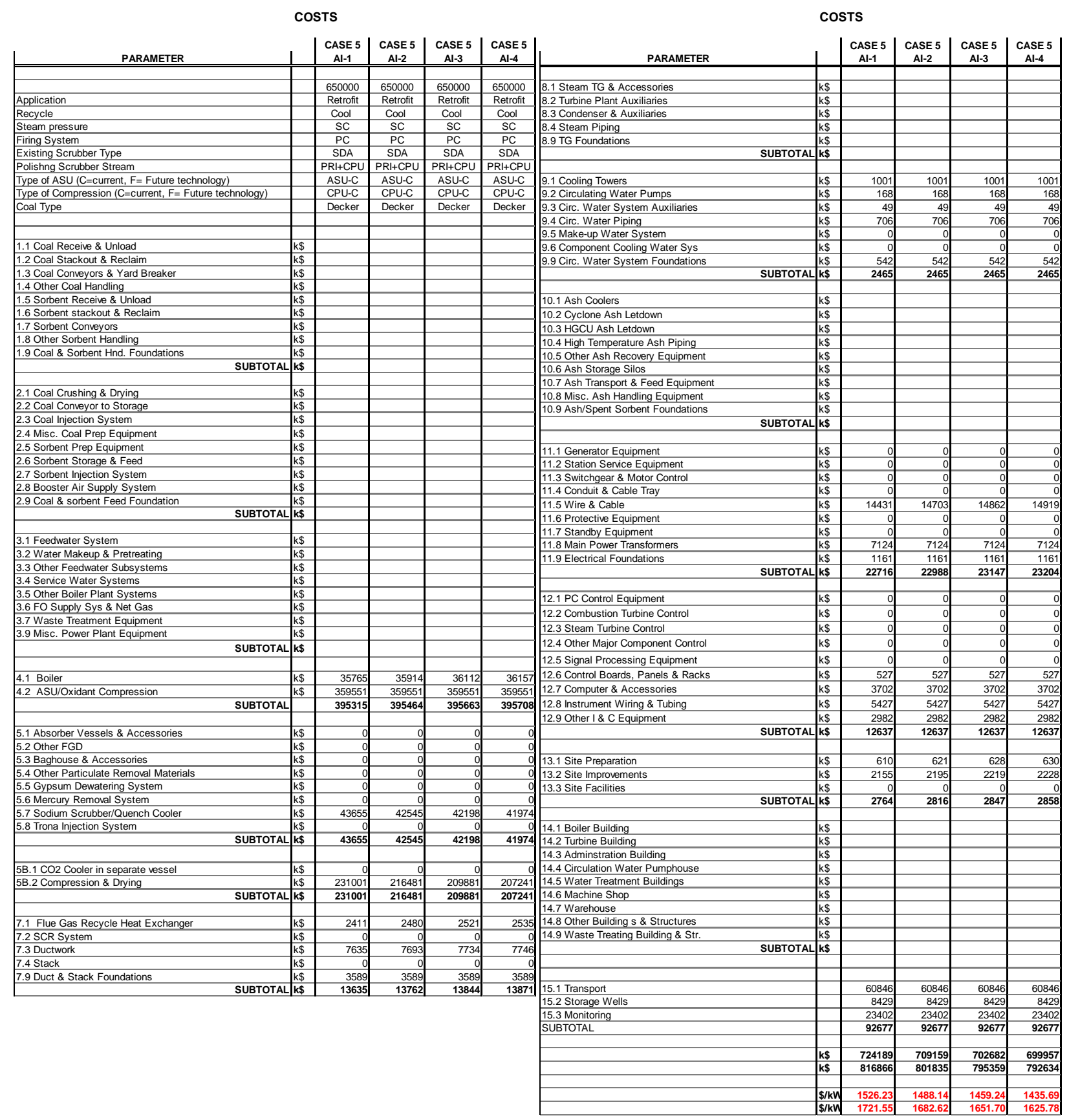

Table 3.44 Cost summary results for variations of air infiltration 


\section{LCOE}

\begin{tabular}{|c|c|c|c|c|}
\hline PARAMETER & $\begin{array}{c}\text { CASE } 5 \\
\text { Al-1 } \\
\end{array}$ & $\begin{array}{c}\text { CASE } 5 \\
\text { Al-2 } \\
\end{array}$ & $\begin{array}{c}\text { CASE } 5 \\
\text { Al-3 } \\
\end{array}$ & $\begin{array}{c}\text { CASE } 5 \\
\text { Al-4 } \\
\end{array}$ \\
\hline Turbine Cycle Net Power (plant gross power) kWe & 650000 & 650000 & 650000 & 650000 \\
\hline Application & Retrofit & Retrofit & Retrofit & Retrofit \\
\hline Recycle & Cool & Cool & Cool & Cool \\
\hline Steam pressure & SC & SC & SC & SC \\
\hline Firing System & PC & PC & PC & PC \\
\hline Existing Scrubber Type & SDA & SDA & SDA & SDA \\
\hline Polishng Scrubber Stream & $\mathrm{PRI}+\mathrm{CPU}$ & $\mathrm{PRI}+\mathrm{CPU}$ & $\mathrm{PRI}+\mathrm{CPU}$ & $\mathrm{PRI}+\mathrm{CPU}$ \\
\hline Type of ASU (C=current, F= Future technology) & ASU-C & ASU-C & ASU-C & ASU-C \\
\hline Type of Compression ( $\mathrm{C}=$ current, $\mathrm{F}=$ Future technology) & CPU-C & CPU-C & CPU-C & CPU-C \\
\hline Coal Type & Decker & Decker & Decker & Decker \\
\hline Net Power (kWe) & 474495 & 476540 & 481540 & 487540 \\
\hline Fuel Cost (\$/MBtu) & 1.5 & 1.5 & 1.5 & 1.5 \\
\hline Net Plant Heat Rate (Btu/kWh) & 11510 & 11461 & 11342 & 11202 \\
\hline Book Life (years) & 30 & 30 & 30 & 30 \\
\hline Capacity Factor & $85 \%$ & $85 \%$ & $85 \%$ & $85 \%$ \\
\hline Total Plant Cost (TPC) wo/T,S\&M (k\$) & 724189 & 709159 & 702682 & 699957 \\
\hline Total Plant Cost (TPC) w/T,S\&M (k\$) & 816866 & 801835 & 795359 & 792634 \\
\hline Aux Power before Retrofit (as $\%$ of GP, w/o BFP) & $5 \%$ & $5 \%$ & $5 \%$ & $5 \%$ \\
\hline Net Power Before Retrofit (kWe) & 616200 & 616200 & 616200 & 616200 \\
\hline Levelized Cost of Replacement Power $(\$ / k W)$ & 0.064 & 0.064 & 0.064 & 0.064 \\
\hline Annual Net MWh before Retrofit & 4588225 & 4588225 & 4588225 & 4588225 \\
\hline Annual Net MWh after Retrofit & 3533090 & 3548317 & 3585547 & 3630223 \\
\hline Power Reduction MWh/yr & 1055135 & 1039908 & 1002678 & 958002 \\
\hline Makeup Power CO2 (36\% fleet avg. efficiency) lb/h & 241825 & 238335 & 229803 & 219563 \\
\hline \multicolumn{5}{|l|}{ ANNUAL INCREMENTAL COSTS $(\$ 1000)$} \\
\hline Fixed Operating \& Maintenance Costs & 6974 & 6849 & 6795 & 6772 \\
\hline Variable Operating \& Maintenance Costs & 7242 & 7092 & 7027 & 7000 \\
\hline Levelized Replacement Power Cost & 67529 & 66554 & 64171 & 61312 \\
\hline Consumable Operating Costs (less Fuel) & 359 & 359 & 359 & 359 \\
\hline Fuel Cost $(\mathrm{k} \$)$ & 0 & 0 & 0 & 0 \\
\hline & & & & \\
\hline \multicolumn{5}{|l|}{ LEVELIZATION (20 year) } \\
\hline Fixed $\mathrm{O} \& \mathrm{M}(\mathrm{LF}=1.16)$ & 0.229 & 0.224 & 0.220 & 0.216 \\
\hline Variable O\&M (LF=1.16) including replacement power & 2.149 & 2.107 & 2.017 & 1.913 \\
\hline Consumables (LF=1.16) & 0.012 & 0.012 & 0.012 & 0.011 \\
\hline Fuel $(L F=1.2)$ & 0.000 & 0.000 & 0.000 & 0.000 \\
\hline Total Production Cost & 2.390 & 2.343 & 2.249 & 2.140 \\
\hline Capital Cost Factor wo/T,S\&M (17.5) & 3.585 & 3.495 & 3.427 & 3.372 \\
\hline Capital Cost Factor w/T,S\&M (17.5) & 4.043 & 3.952 & 3.879 & 3.818 \\
\hline & & & & \\
\hline LCOE w/o TS\&M (\$/kW) & 5.97 & 5.84 & 5.68 & 5.51 \\
\hline LCOE w TS\&M (\$/kW) & 6.43 & 6.30 & 6.13 & 5.96 \\
\hline \multicolumn{5}{|l|}{$\mathrm{CO}_{2}$ COSTS } \\
\hline & & & & \\
\hline \multicolumn{5}{|l|}{ LCOE w/o CO 2 Removal (DOE 1291 Case 1) } \\
\hline \multicolumn{5}{|l|}{$\mathrm{CO} 2$ Produced w/o CO $\mathrm{CO}_{2}$ Removal (lb/h) } \\
\hline$\$ /$ ton $\mathrm{CO}_{2}$ Removed w/o TS\&M & 54.45 & 53.44 & 52.50 & 51.62 \\
\hline$\$ /$ ton $\mathrm{CO}_{2}$ Avoided w/o TS\&M & 73.14 & 71.43 & 69.33 & 67.22 \\
\hline$\$ /$ ton $\mathrm{CO}_{2}$ Removed w TS\&M & 58.63 & 57.62 & 56.68 & 55.80 \\
\hline \$/ton $\mathrm{CO}_{2}$ Avoided w TS\&M & 78.76 & 77.02 & 74.85 & 72.66 \\
\hline
\end{tabular}

Table 3.45 Economic results for variations of air infiltration

Page 207 of 279 


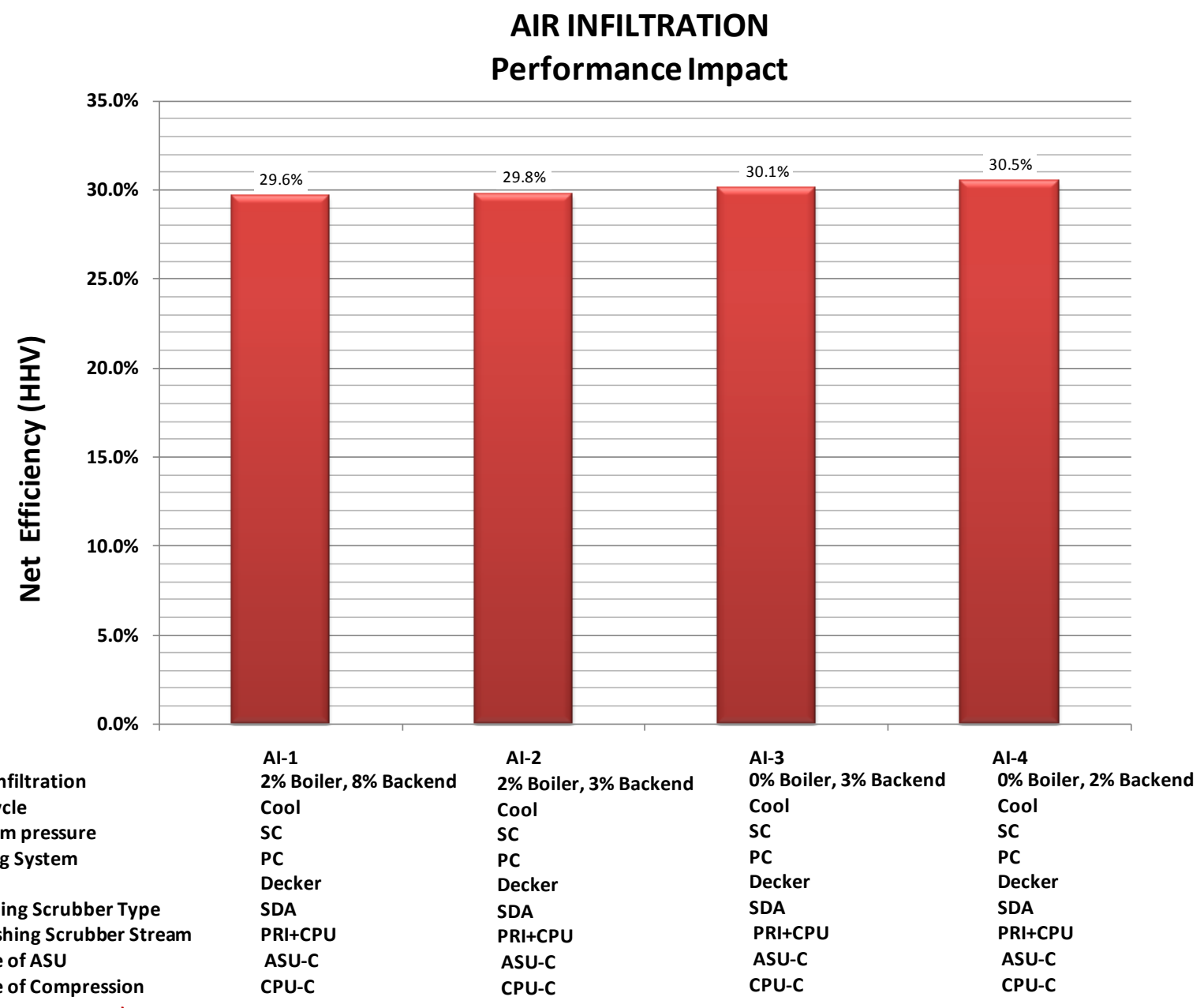

Figure 3.114 Performance results for variations of air infiltration 


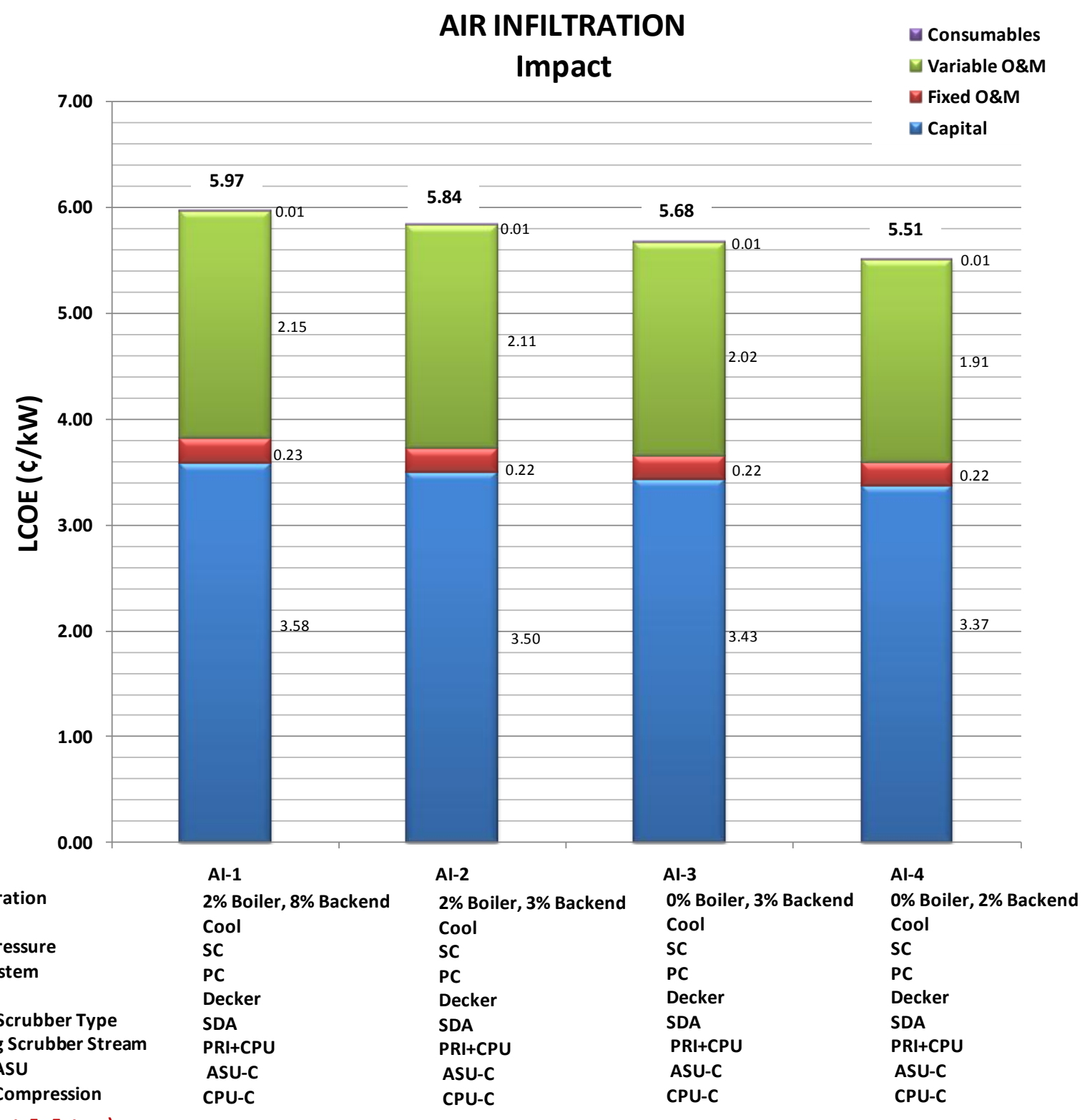

Air Infiltration

\section{Recycle}

Steam pressure

Firing System

Coal

Existing Scrubber Type Polishing Scrubber Stream

Type of ASU

Type of Compression

( $C=$ current, $F=$ Future)
Al-2

Cool

Decker
- Consumables

$\square$ Variable O\&M

$\square$ Fixed O\&M

$\square$ Capital

Figure 3.115 Economic results for variations of air infiltration 


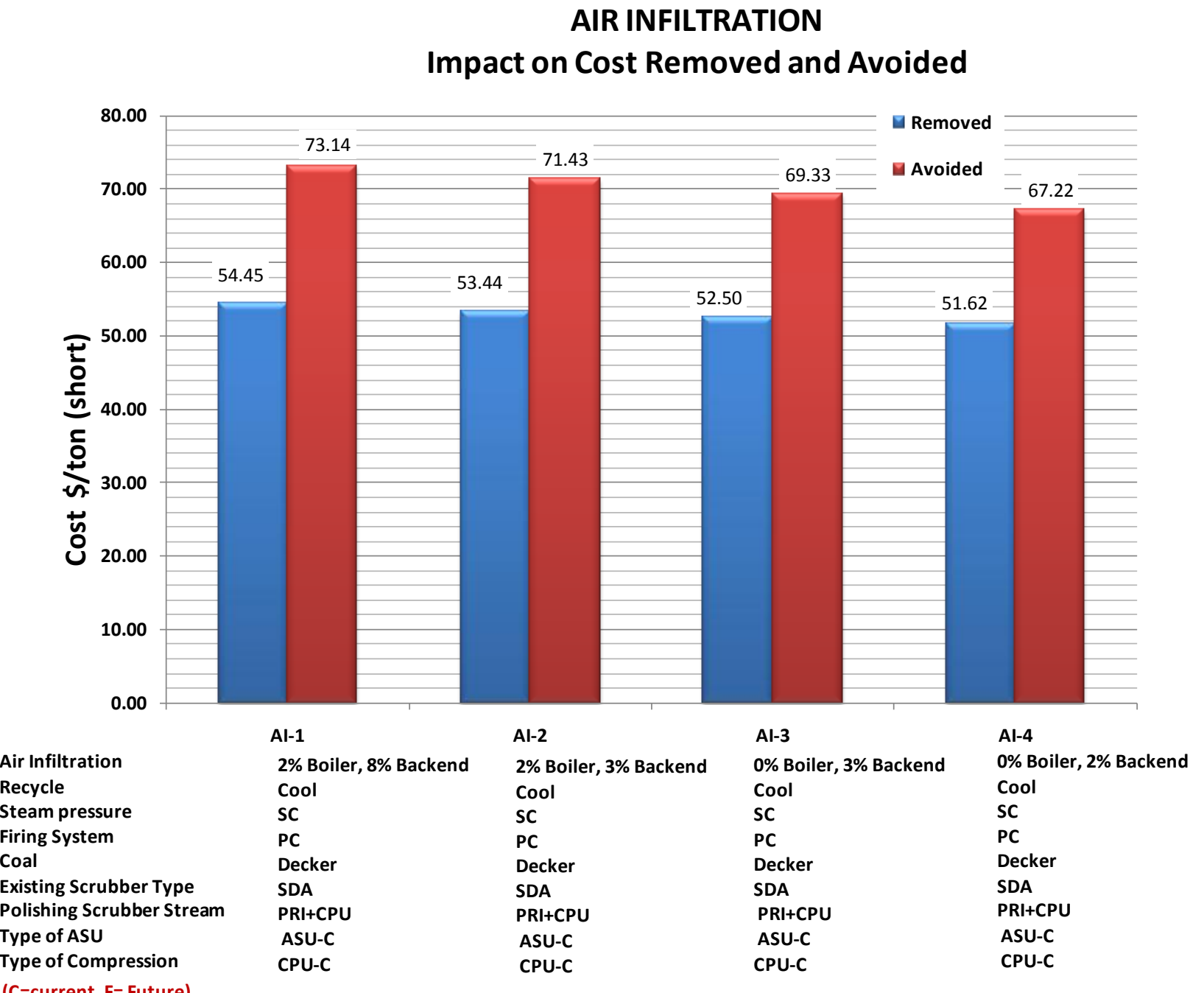

( $C=$ current, F= Future)

Figure 3.116 Cost of $\mathrm{CO}_{2}$ removed and avoided for variations of air infiltration

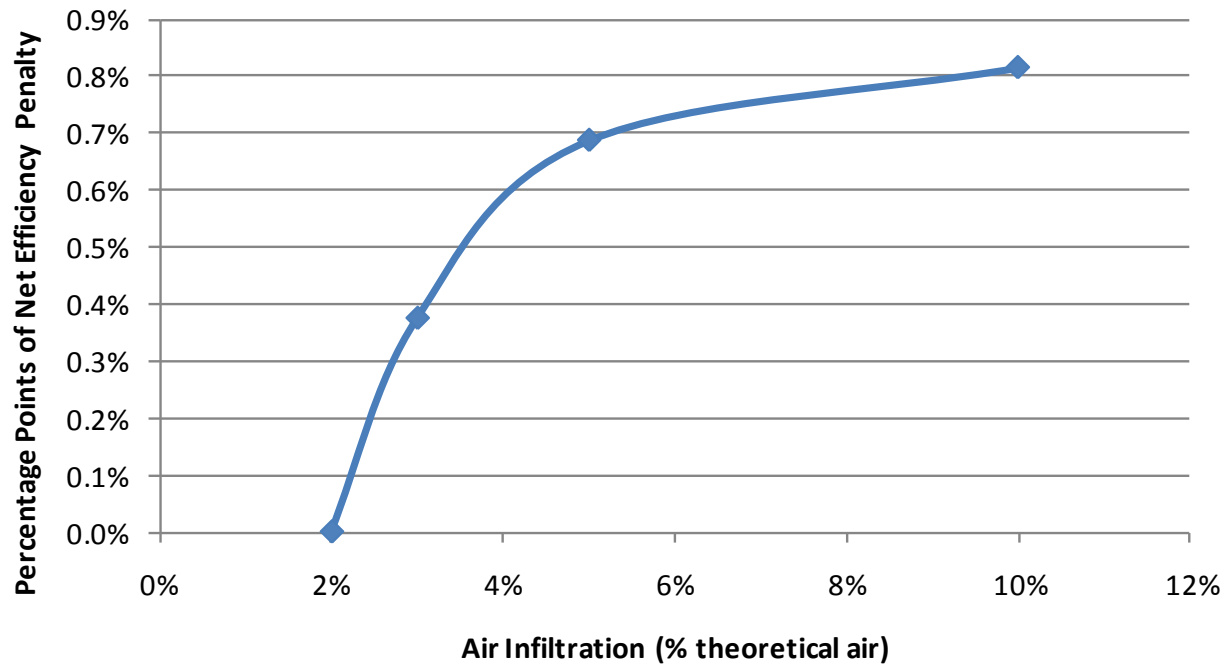

Figure 3.117 Impact of air infiltration on net plant efficiency 


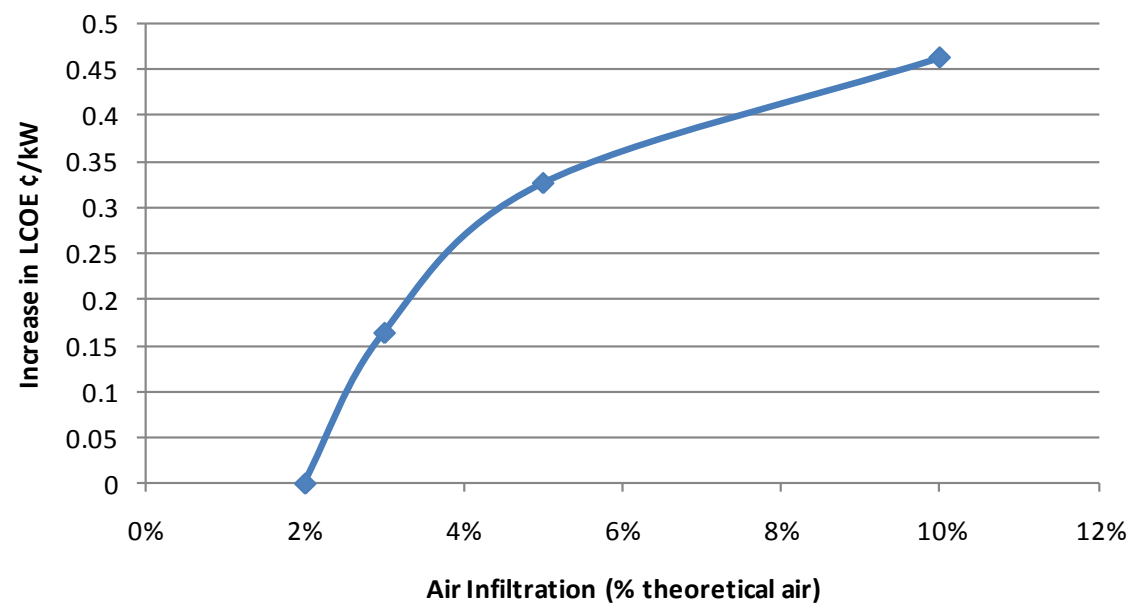

Figure 3.118 Impact of air infiltration on LCOE

Figure 3.117 shows the impact of air infiltration on net plant efficiency and Figure 3.118 shows the impact on LCOE graphically. The impact on efficiency from $2 \%$ to $5 \%$ air infiltration is 0.7 percentage points of efficiency loss, a $2.7 \%$ reduction in net plant efficiency, along with an increase in LCOE of $0.46 \phi / \mathrm{kW}$, a or $7.7 \%$ increase in LCOE. Beyond $5 \%$ air infiltration the impact on performance is much more moderate at 0.1 percentage point loss between $5 \%$ and $10 \%$. The impact on LCOE is again of greater significance than the impact on efficiency but the curve is not as steep as between $2 \%$ and $5 \%$ air infiltration.

\subsubsection{Sensitivity to Oxidant Purity}

Four cases were evaluated to assess the impact of reducing oxidant purity on performance and cost as described in Section 3.2.2.4.2. The gas compositions for the four oxidant purity cases are shown in Table 3.32. Retrofit Case 5 employing the cool recycle configuration with supercritical steam conditions firing Decker subbituminous coal with a dry primary scrubber and current ASU and CPU technology was used as the basis for all four comparative cases. Air infiltration of $2 \%$ in the boiler and 3\% in the backend equipment for a total of 5\% was assumed and excess oxygen was held at $3 \%$ at the boiler outlet for all cases.

Case OP-1 assumes 95\% oxidant purity (\% oxygen in the oxidant from the ASU; the remainder is nitrogen and argon), which was the basis for the study, Case OP-2 assumes 90\%, Case OP-3 assumes $85 \%$ and Case OP-4 assumes $80 \%$. Table 3.46 shows the performance for these four cases and Figure 3.119 compares the net efficiencies. Table 3.47 shows the cost breakdown, Table 3.48 provides the LCOE details, and Figure 3.120 shows LCOE graphically.

Section 3.2.2.3.1 above (under the heading "Oxygen Purity") discusses the impact of oxidant purity on the capital cost and power consumption for the ASU and CPU. Based on those parameters alone, which are believed to govern the outcome, a maximum purity of about $96.5 \%$ $\mathrm{O}_{2}$ is believed economical. This is based on the premise that the great difference in flows handled by the ASU compared to the CPU results in the cost and power consumption for the ASU outweighing any savings in the CPU. 
PERFORMANCE

\begin{tabular}{|c|c|c|c|c|}
\hline PARAMETER & $\begin{array}{c}\text { CASE } 5 \\
\text { OP-1 }\end{array}$ & $\begin{array}{c}\text { CASE } 5 \\
\text { OP-2 }\end{array}$ & $\begin{array}{c}\text { CASE } 5 \\
\text { OP-3 }\end{array}$ & $\begin{array}{c}\text { CASE } 5 \\
\text { OP-4 }\end{array}$ \\
\hline Turbine Cycle Net Power (plant gross power), kWe & 650000 & 650000 & 650000 & 650000 \\
\hline Application & Retrofit & Retrofit & Retrofit & Retrofit \\
\hline Recycle & Cool & Cool & Cool & Cool \\
\hline Steam pressure & SC & SC & SC & SC \\
\hline Firing System & $\mathrm{PC}$ & $\mathrm{PC}$ & $\mathrm{PC}$ & $\mathrm{PC}$ \\
\hline Existing Scrubber Type & SDA & SDA & SDA & SDA \\
\hline Polishing Scrubber Stream & $\mathrm{PRI}+\mathrm{CPU}$ & $\mathrm{PRI}+\mathrm{CPU}$ & $\mathrm{PRI}+\mathrm{CPU}$ & $\mathrm{PRI}+\mathrm{CPU}$ \\
\hline Type of ASU (C=current, F= Future technology) & ASU-C & ASU-C & ASU-C & ASU-C \\
\hline Type of Compression ( $\mathrm{C}=$ current, $\mathrm{F}=$ Future technology) & CPU-C & CPU-C & CPU-C & CPU-C \\
\hline Coal Type & Decker & Decker & Decker & Decker \\
\hline Heating Value (HHV) & 9540 & 9540 & 9540 & 9540 \\
\hline Coal Ash Content & $3.98 \%$ & $3.98 \%$ & $3.98 \%$ & $3.98 \%$ \\
\hline Sulfur & $0.34 \%$ & $0.34 \%$ & $0.34 \%$ & $0.34 \%$ \\
\hline Carbon & $55.15 \%$ & $55.15 \%$ & $55.15 \%$ & $55.15 \%$ \\
\hline Oxygen & $12.57 \%$ & $12.57 \%$ & $12.57 \%$ & $12.57 \%$ \\
\hline Hydrogen & $3.83 \%$ & $3.83 \%$ & $3.83 \%$ & $3.83 \%$ \\
\hline Nitrogen & $0.73 \%$ & $0.73 \%$ & $0.73 \%$ & $0.73 \%$ \\
\hline Moisture & $23.40 \%$ & $23.40 \%$ & $23.40 \%$ & $23.40 \%$ \\
\hline Base Plant Auxiliary Power & 29510 & 29510 & 29510 & 29510 \\
\hline Air Separation Unit Main Compressor & 85000 & 82000 & 80000 & 78000 \\
\hline Trona & 0 & 0 & 0 & 0 \\
\hline Polishing Scrubber & 2358 & 2543 & 2753 & 3000 \\
\hline Compression \& Purification Unit & 54000 & 57000 & 60000 & 63000 \\
\hline Additional Cooling Tower Fans (ASU/ CPU Cooling) & 2592 & 2911 & 3282 & 3726 \\
\hline TOTAL AUXILIARY POWER (kWe) & 173460 & 173964 & 175545 & 177236 \\
\hline Net Power (kWe) & 476540 & 476036 & 474455 & 472764 \\
\hline Pre-retrofit net plant efficiency (\%) & $38.51 \%$ & $38.51 \%$ & $38.51 \%$ & $38.51 \%$ \\
\hline Pre-retrofit Heat Rate (Btu/kWh HHV) & 8863 & 8863 & 8863 & 8863 \\
\hline Pre-retrofit (Aux Power)/(Gross Power) Ratio & $5.2 \%$ & $5.2 \%$ & $5.2 \%$ & $5.2 \%$ \\
\hline Turbine Cycle Heat Rate (Btu/kWh HHV) & 7236.0 & 7236.0 & 7236.0 & 7236.0 \\
\hline Fuel (Boiler) Efficiency & $86.1 \%$ & $86.1 \%$ & $86.1 \%$ & $86.1 \%$ \\
\hline Net Plant Heat Rate (Btu/kWh HHV) & 11461 & 11473 & 11511 & 11552 \\
\hline Net Plant Efficiency & $29.77 \%$ & $29.74 \%$ & $29.64 \%$ & $29.54 \%$ \\
\hline \multicolumn{5}{|l|}{ CONSUMABLES } \\
\hline As-Received Coal Feed, lb/h & 572483 & 572483 & 572483 & 572483 \\
\hline Thermal Input, kWth & 1600761 & 1600761 & 1600761 & 1600761 \\
\hline WFGD Limestone Sorbent Feed, $\mathrm{lb} / \mathrm{h}(\mathrm{Ca} / \mathrm{S})=1.05$ & 0 & 0 & 0 & 0 \\
\hline SDA Pebble Lime Feed, Ib/h & 6749 & 6749 & 6749 & 6749 \\
\hline Trona (sodium bicarbonate) for Polishing FGD, Ib/h & 1829 & 1973 & 2136 & 2328 \\
\hline Trona (sodium bicarbonate), for $\mathrm{SO}_{3}$ control, lb/h & 0 & 0 & 0 & 0 \\
\hline \multicolumn{5}{|l|}{ OXYGEN } \\
\hline Oxygen Purity & $95.0 \%$ & $90.0 \%$ & $85.0 \%$ & $80.0 \%$ \\
\hline Oxidant Required (short tons/day) - includes impurites & 12016 & 13497 & 15215 & 17275 \\
\hline \multicolumn{5}{|l|}{ CO2 REMOVAL } \\
\hline Recovery Efficiency & $90.0 \%$ & $90.0 \%$ & $90.0 \%$ & $90.0 \%$ \\
\hline Total Gas Flow to CPU (lb/h) & 1464079 & 1523922 & 1588331 & 1660237 \\
\hline Carbon Dioxide Produced $(\mathrm{lb} / \mathrm{h})$ & 1156916 & 1156916 & 1156916 & 1156916 \\
\hline Carbon Dioxide Produced (short tons/d) & 13883 & 13883 & 13883 & 13883 \\
\hline Carbon Dioxide Produced (short tons/yr) & 4307197 & 4307197 & 4307197 & 4307197 \\
\hline Carbon Dioxide Removed (lb/h) & 1041224 & 1041224 & 1041224 & 1041224 \\
\hline Carbon Dioxide Removed (short tons/d) & 12495 & 12495 & 12495 & 12495 \\
\hline Carbon Dioxide Removed (short tons/yr) & 3876477 & 3876477 & 3876477 & 3876477 \\
\hline
\end{tabular}

Table 3.46 Performance results for variations of oxidant purity 


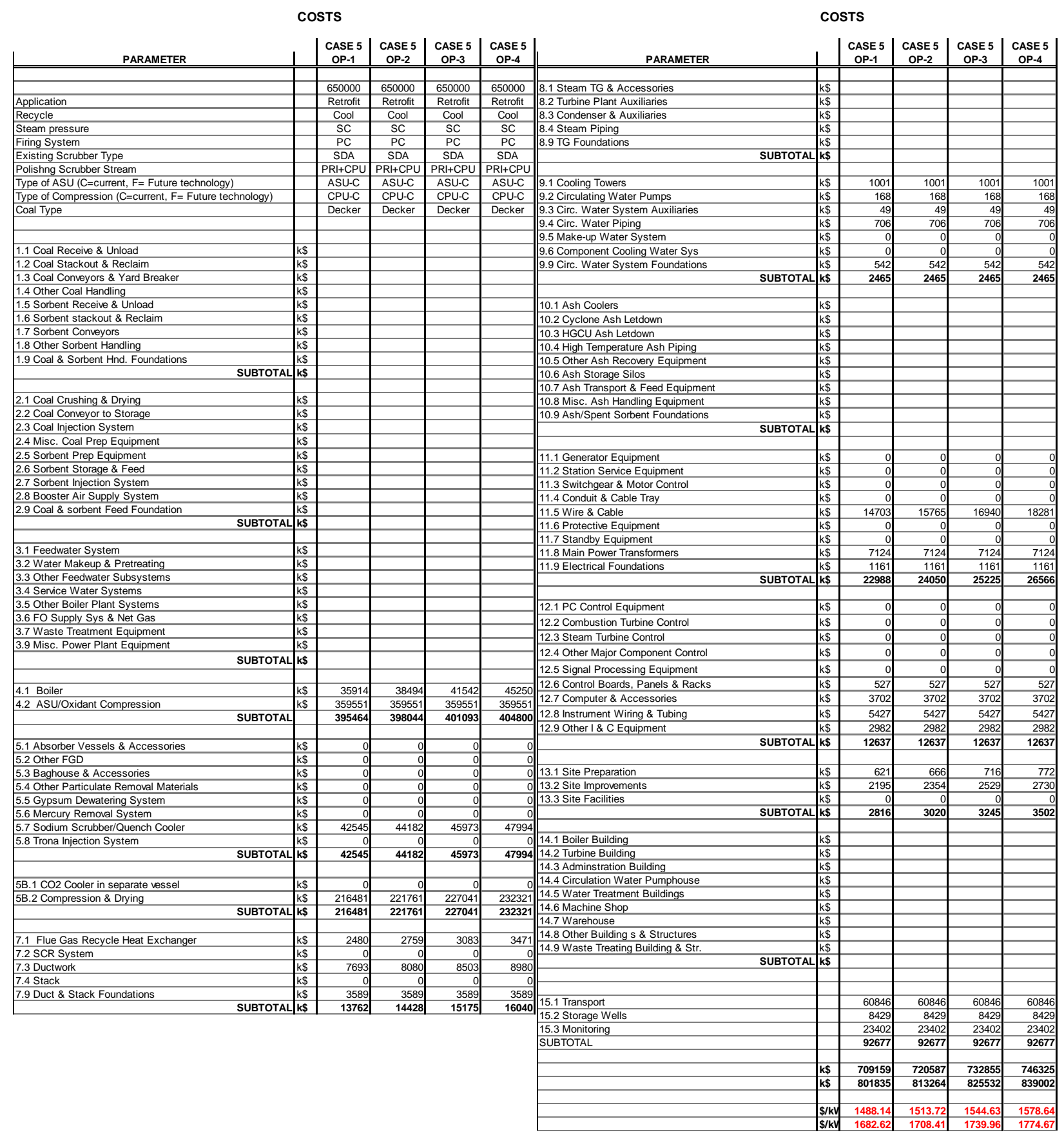

Table 3.47 Cost summary results for variations of oxidant purity 


\begin{tabular}{|c|c|c|c|c|}
\hline \multicolumn{5}{|l|}{ LCOE } \\
\hline PARAMETER & $\begin{array}{c}\text { CASE } 5 \\
\text { OP-1 } \\
\end{array}$ & $\begin{array}{c}\text { CASE } 5 \\
\text { OP-2 }\end{array}$ & $\begin{array}{c}\text { CASE } 5 \\
\text { OP-3 }\end{array}$ & $\begin{array}{c}\text { CASE } 5 \\
\text { OP-4 }\end{array}$ \\
\hline Turbine Cycle Net Power (plant gross power) kWe & 650000 & 650000 & 650000 & 650000 \\
\hline Application & Retrofit & Retrofit & Retrofit & Retrofit \\
\hline Recycle & Cool & Cool & Cool & Cool \\
\hline Steam pressure & SC & SC & SC & SC \\
\hline Firing System & PC & PC & PC & PC \\
\hline Existing Scrubber Type & SDA & SDA & SDA & SDA \\
\hline Polishng Scrubber Stream & $\mathrm{PRI}+\mathrm{CPU}$ & $\mathrm{PRI}+\mathrm{CPU}$ & $\mathrm{PRI}+\mathrm{CPU}$ & $\mathrm{PRI}+\mathrm{CPU}$ \\
\hline Type of ASU (C=current, F= Future technology) & ASU-C & ASU-C & ASU-C & ASU-C \\
\hline Type of Compression ( $\mathrm{C}=$ current, $\mathrm{F}=$ Future technology) & CPU-C & CPU-C & CPU-C & CPU-C \\
\hline Coal Type & Decker & Decker & Decker & Decker \\
\hline Net Power (kWe) & 476540 & 476036 & 474455 & 472764 \\
\hline Fuel Cost (\$/MBtu) & 1.5 & 1.5 & 1.5 & 1.5 \\
\hline Net Plant Heat Rate (Btu/kWh) & 11461 & 11473 & 11511 & 11552 \\
\hline Book Life (years) & 30 & 30 & 30 & 30 \\
\hline Capacity Factor & $85 \%$ & $85 \%$ & $85 \%$ & $85 \%$ \\
\hline Total Plant Cost (TPC) wo/T,S\&M (k\$) & 709159 & 720587 & 732855 & 746325 \\
\hline Total Plant Cost (TPC) w/T,S\&M (k\$) & 801835 & 813264 & 825532 & 839002 \\
\hline Aux Power before Retrofit (as \% of GP w/o BFP) & $5 \%$ & $5 \%$ & $5 \%$ & $5 \%$ \\
\hline Net Power Before Retrofit (kWe) & 616200 & 616200 & 616200 & 616200 \\
\hline Levelized Cost of Replacement Power ( $\$ / \mathrm{kW})$ & 0.064 & 0.064 & 0.064 & 0.064 \\
\hline Annual Net MWh before Retrofit & 4588225 & 4588225 & 4588225 & 4588225 \\
\hline Annual Net MWh after Retrofit & 3548317 & 3544564 & 3532792 & 3520201 \\
\hline Power Reduction MWh/yr & 1039908 & 1043661 & 1055433 & 1068024 \\
\hline Makeup Power CO2 (36\% fleet avg. efficiency) lb/h & 238335 & 239195 & 241894 & 244779 \\
\hline \multicolumn{5}{|l|}{ ANNUAL INCREMENTAL COSTS $(\$ 1000)$} \\
\hline Fixed Operating \& Maintenance Costs & 6849 & 6944 & 7047 & 7159 \\
\hline Variable Operating \& Maintenance Costs & 7092 & 7206 & 7329 & 7463 \\
\hline Levelized Replacement Power Cost & 66554 & 66794 & 67548 & 68354 \\
\hline Consumable Operating Costs (less Fuel) & 359 & 359 & 359 & 359 \\
\hline Fuel Cost $(\mathrm{k} \$)$ & 0 & 0 & 0 & 0 \\
\hline & & & & \\
\hline \multicolumn{5}{|l|}{ LEVELIZATION (20 year) } \\
\hline & & & & \\
\hline Fixed O\&M (LF=1.16) & 0.224 & 0.227 & 0.231 & 0.236 \\
\hline Variable O\&M $(L F=1.16)$ including replacement power & 2.107 & 2.120 & 2.153 & 2.188 \\
\hline Consumables $(\mathrm{LF}=1.16)$ & 0.012 & 0.012 & 0.012 & 0.012 \\
\hline Fuel $(\mathrm{LF}=1.2)$ & 0.000 & 0.000 & 0.000 & 0.000 \\
\hline Total Production Cost & 2.343 & 2.359 & 2.396 & 2.435 \\
\hline Capital Cost Factor wo/T,S\&M (17.5) & 3.495 & 3.555 & 3.628 & 3.708 \\
\hline Capital Cost Factor w/T,S\&M (17.5) & 3.952 & 4.012 & 4.087 & 4.168 \\
\hline LCOE w/o TS\&M ( $(/ \mathrm{kW})$ & 5.84 & 5.91 & 6.02 & 6.14 \\
\hline LCOE w TS\&M $(\Phi / k W)$ & 6.30 & 6.37 & 6.48 & 6.60 \\
\hline \multicolumn{5}{|l|}{$\mathrm{CO}_{2}$ COSTS } \\
\hline & & & & \\
\hline \multicolumn{5}{|l|}{ LCOE w/o CO 2 Removal (DOE 1291 Case 1) } \\
\hline \multicolumn{5}{|l|}{$\mathrm{CO} 2$ Produced w/o $\mathrm{CO}_{2}$ Removal (lb/h) } \\
\hline$\$ /$ ton $\mathrm{CO}_{2}$ Removed w/o TS\&M & 53.44 & 54.08 & 54.90 & 55.79 \\
\hline$\$ /$ ton $\mathrm{CO}_{2}$ Avoided w/o TS\&M & 71.43 & 72.37 & 73.74 & 75.25 \\
\hline$\$ /$ ton $\mathrm{CO}_{2}$ Removed w TS\&M & 57.62 & 58.26 & 59.08 & 59.97 \\
\hline$\$ /$ ton $\mathrm{CO}_{2}$ Avoided w TS\&M & 77.02 & 77.97 & 79.36 & 80.89 \\
\hline
\end{tabular}

Table 3.48 Economic results for variations of oxidant purity 


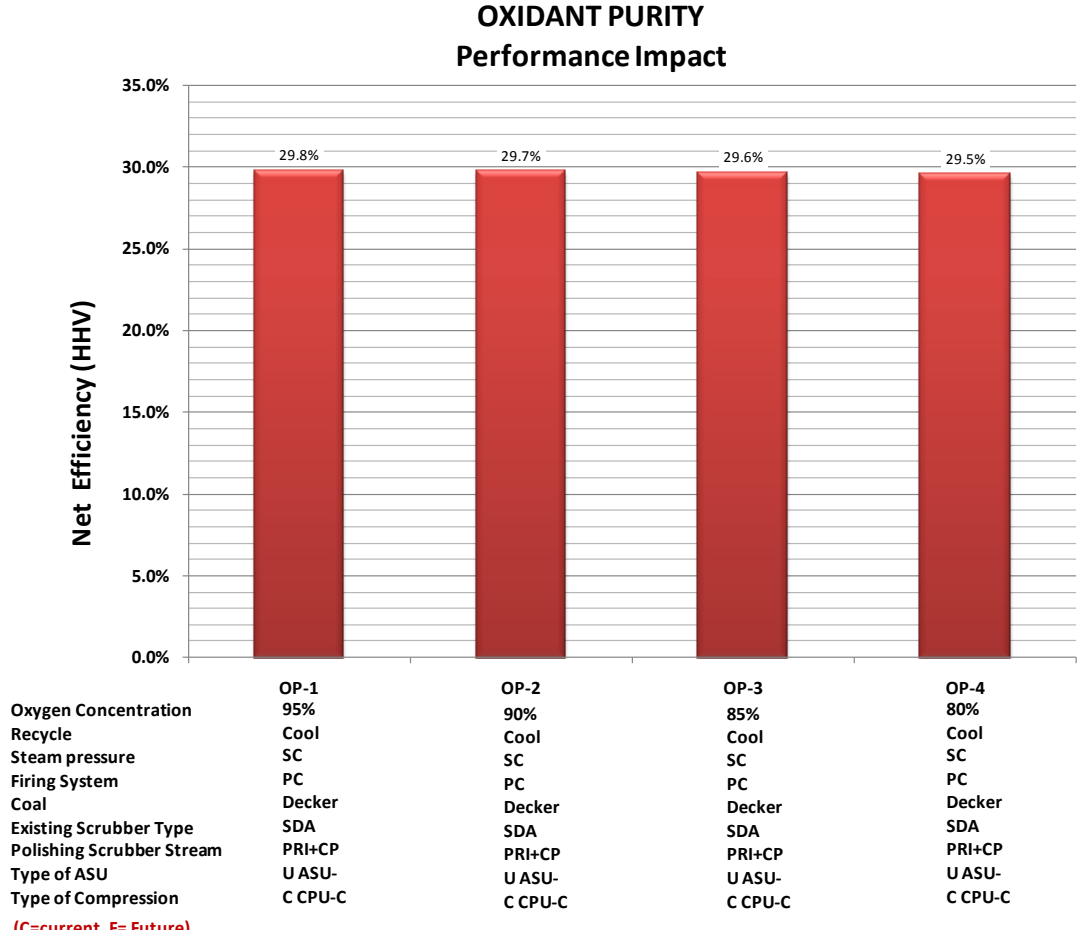

Figure 3.119 Performance results for variations of oxidant purity

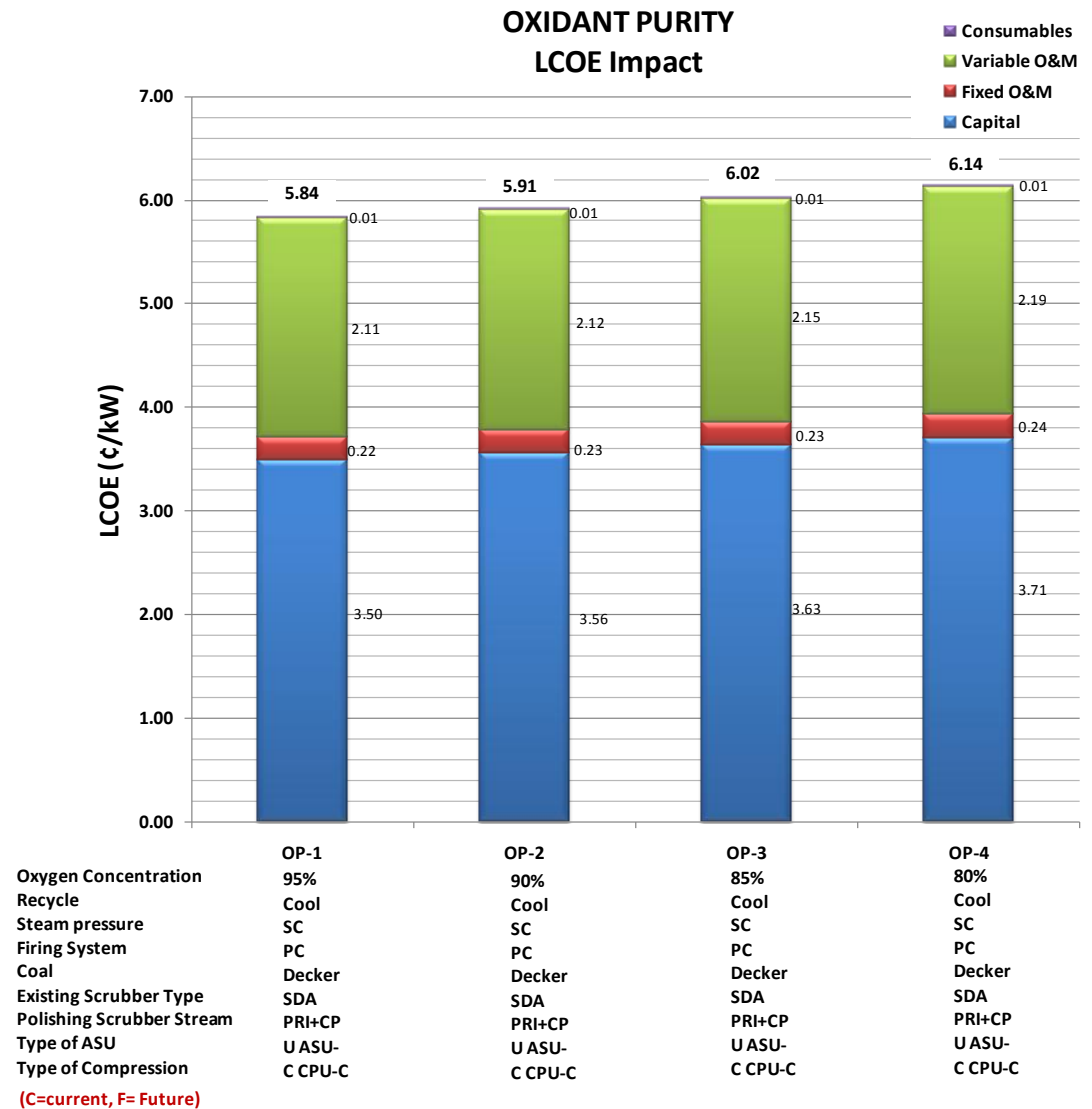

Figure 3.120 Economic results for variations of oxidant purity 


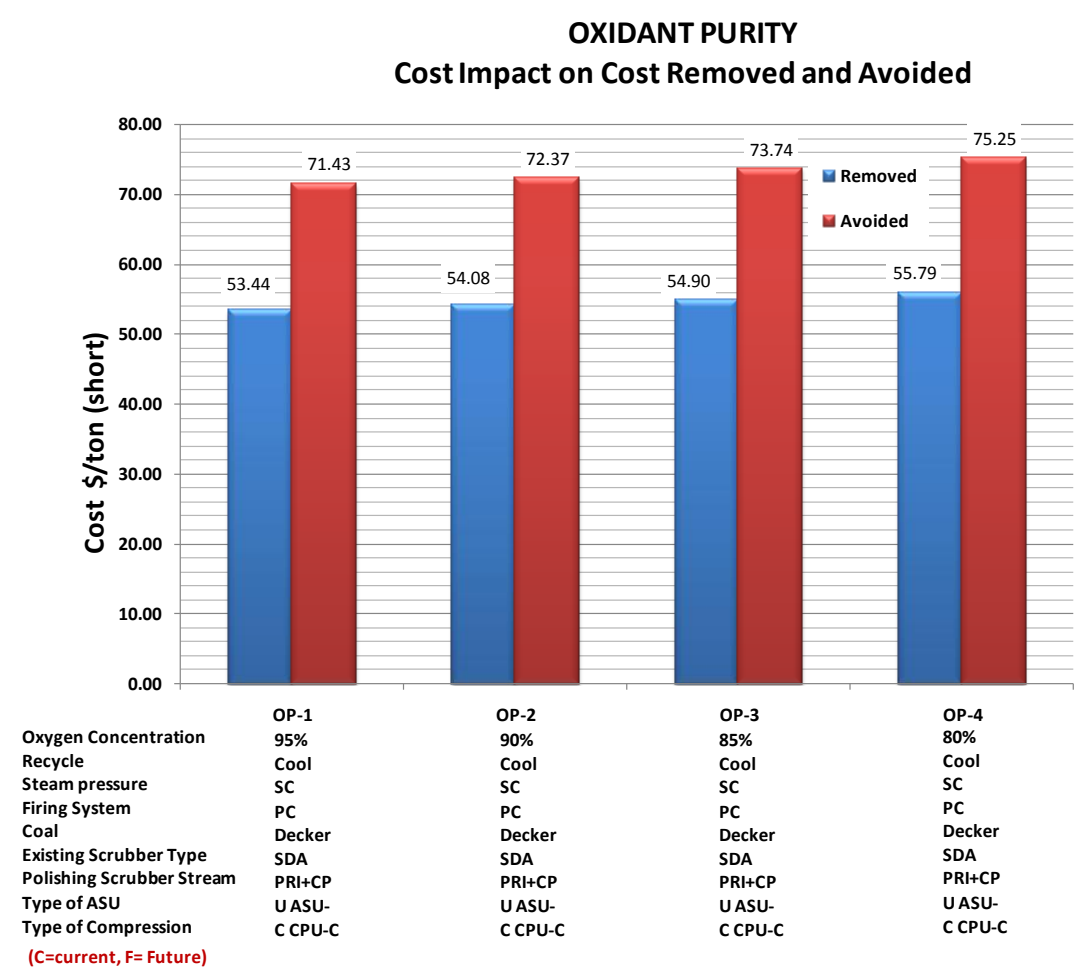

Figure 3.121 Cost of $\mathrm{CO}_{2}$ removed and avoided for variations of oxidant purity

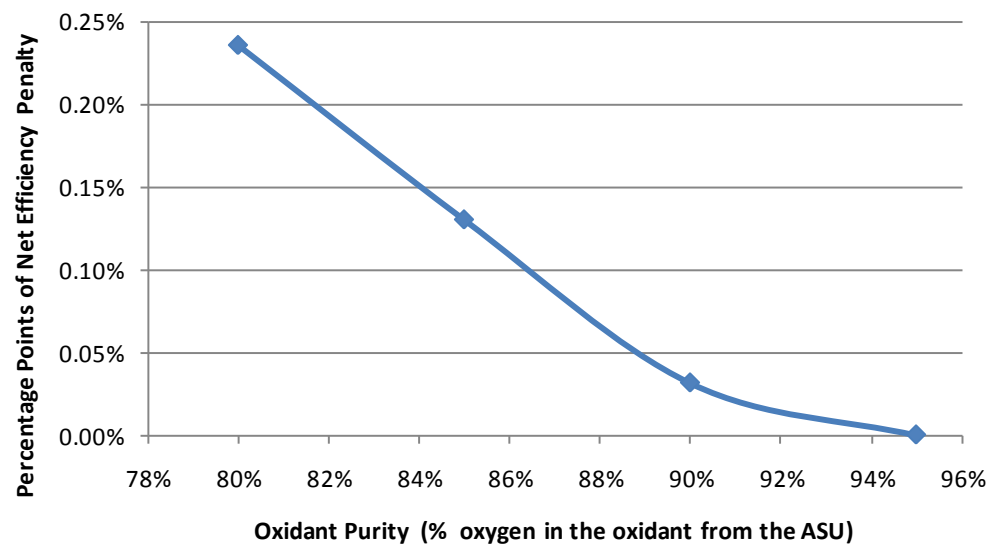

Figure 3.122 Impact of oxidant purity on net plant efficiency 


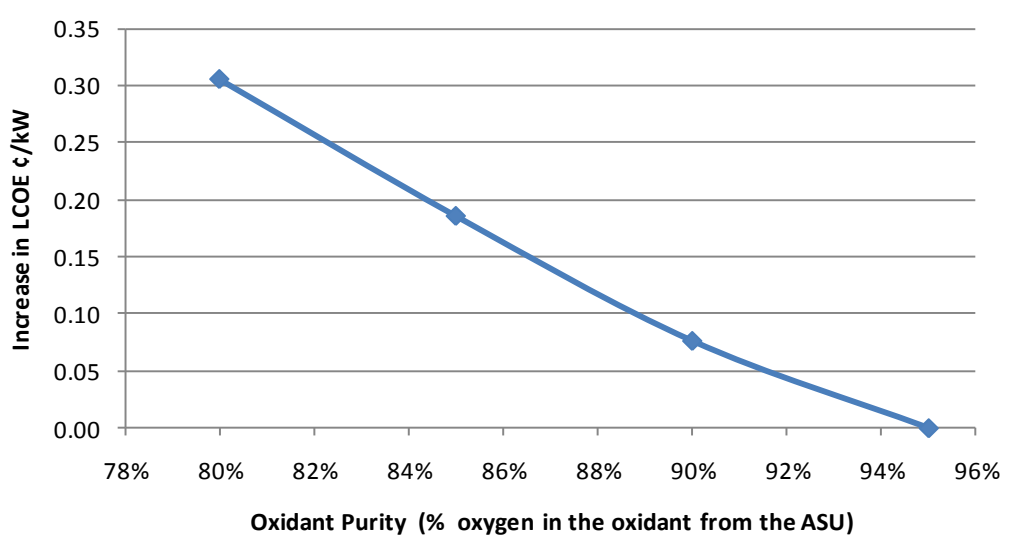

Figure 3.123 Impact of oxidant purity on LCOE

Figure 3.122 shows the impact of oxidant purity on net plant efficiency and Figure 3.123 shows the impact on LCOE graphically. The impact on efficiency between $95 \%$ and $80 \%$ oxidant purity is a loss of 0.23 percentage points of efficiency loss, a $0.7 \%$ reduction in net plant efficiency, along with an increase in LCOE of $0.30 \propto / \mathrm{kW}$, a or $4.9 \%$ increase in LCOE. The loss in net efficiency appears nearly linear down to about $90 \%$ purity and then flattens out while the LCOE penalty is nearly linear over the entire range.

\subsubsection{Summary and Conclusions}

This study provides the ability to compare a variety of retrofit conditions in terms of performance and LCOE. The impact of fuel, type of primary scrubber, combustion system type (PC or Cyclone), and ASU and CPU technology can be readily understood. Though the costs are estimated by modifying the detailed cost components from the previous study "Pulverized Coal Oxy-combustion Power Plants" DOE/NETL-2007/1291 revised August 2008, it is believed they are sufficiently accurate to draw general observations and perhaps conclusions at this level. Certainly they are sufficiently accurate to show that oxy-combustion has the potential to be a lower cost retrofit or greenfield option compared to current PCC technology as reported in the study "Carbon Dioxide Capture from Existing Coal-Fired Power Plant" study DOE/NETL-401110907.

The results of this study should provide strong motivation to pursue further and more in-depth investigation into the cost of oxy-combustion as a retrofit technology for the existing fleet. Although oxy-combustion may not provide as simple an avenue to partial capture on an individual unit as PCC, it is questionable whether an owner would install partial capture for anything except a demonstration since regulations are likely to require full capture at some future point and that would increase cost significantly. Partial capture aside, this study at $90 \% \mathrm{CO}_{2}$ capture shows oxy-combustion has the potential to be as low or lower in cost than PCC even with reasonable future improvements (see Figure 3.112).

The air infiltration sensitivity analysis shows that air infiltration should be kept as low as possible and that the impact is steep between $2 \%$ and $5 \%$ and then moderates out to $10 \%$. Clearly no air infiltration is best but the amount of effort (cost) to minimize air infiltration must be weighed against the life-cycle cost. Figure 3.124 shows the breakeven capital investment to 
mitigate air infiltration. This figure is based on back-calculation of the capital investment represented by the incremental increase in LCOE as air infiltration increases relative to the $2 \%$ air infiltration base. It shows that an investment on the order of $\$ 90$ million dollars could be justified to reduce air infiltration from $10 \%$ down to $2 \%$. This represents about $12 \%$ of the total plant cost without $\mathrm{CO}_{2}$ transportation, storage, and monitoring (TS\&M).

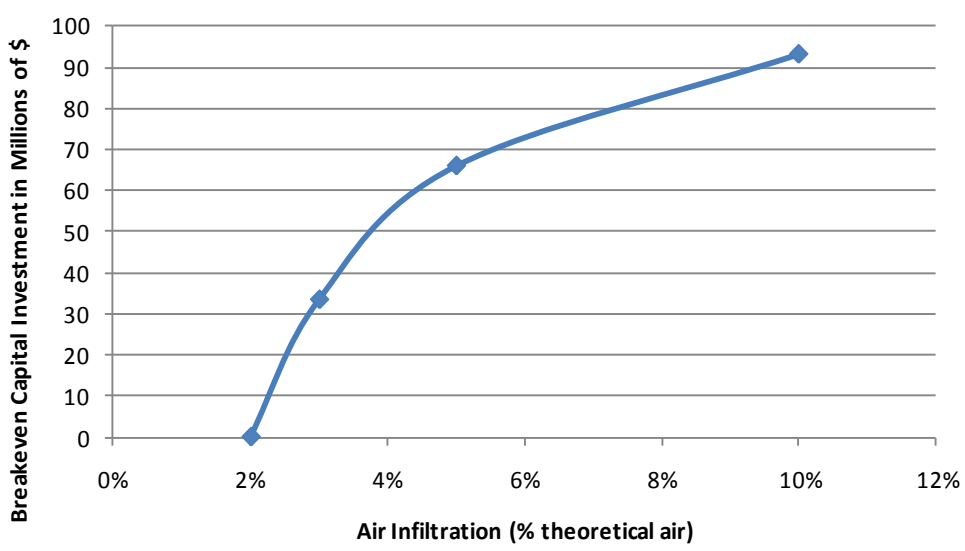

Figure 3.124 Breakeven capital investment to mitigate air infiltration

The oxidant purity sensitivity analysis shows that oxidant purity has considerably less impact than air infiltration and the trends in both net efficiency and LCOE are nearly linear. However, decreasing oxidant purity below $95 \%$ has no benefit in that it not only reduces net efficiency but it also raises LCOE. This demonstrates that at least $95 \%$ purity is beneficial, and higher purity may further increase benefits. However, current thinking is that $96.5 \%$ may become the standard in that above $96.5 \%$ there is a technology change that has a drastic impact on ASU cost.

\subsection{Phase II, Part B - Assessment of Potential for Geologic $\mathrm{CO}_{2}$ Storage for Existing US Power Plants}

For Phase II of the project, Battelle assessed the potential for storing $\mathrm{CO}_{2}$ from existing US power plants in deep geologic formations. The assessment was based on a review of geologic data in the vicinities of selected existing boilers. These data were used to qualitatively determine the suitability of each selected plant for $\mathrm{CO}_{2}$ storage. Parameters that were considered critical to the process were identified and established as criteria for distinguishing between plants that may be acceptable for storage, vs. plants that may be unacceptable. The National Energy Technology Laboratory's (NETL) Coal Power Plant Database (CPPDB) was the main source for plant data. This database contains information on 1924 boilers and associated units; 191 fields provide information on plant parameters. In the interest of controlling project cost, the number of plants to be considered was reduced by selecting boilers above $200 \mathrm{MWe}^{7}$. The key data to be used in

${ }^{7}$ As explained above (Section 3.2.1) the reasons for not considering $200 \mathrm{MWe}$ and smaller boilers are that retrofit is too costlywas explained on top of page 139 - retrofit was found to be too costly because most of these smaller units have no scrubber, are site constrained and economy of scale works against them. 
this investigation are: plant identification, plant location, and boiler capacity (MWe). Several candidate sites for $\mathrm{CO}_{2}$ storage were identified based on a qualitative assessment of each plant's suitability for storage. The locations of each candidate plant site that met screening criteria were plotted on geologic maps.

\subsubsection{Site Screening to Identify Potentially Suitable Sequestration Demonstration Sites}

Another important aspect of the overall geologic storage task was to consider high-level screening criteria to identify potentially suitable site locations. The criteria selected by the project team to evaluate plant sites for $\mathrm{CO}_{2}$ storage potential were: boiler specifications; location in relation to deep sedimentary basins; and degree of seismic hazard (Figure 3.125). The boiler specification included nameplate rating (all exceeding $200 \mathrm{MWe}$ generating capacity), boiler manufacturer, and $\mathrm{CO}_{2}$ emission rate. Location, and especially distance of less than 50 miles to a deep sedimentary basin, is an important consideration to avoid long run pipelines. Seismic hazard was selected as a screening parameter to avoid expenses of additional construction requirements.

\section{Cyclone or Wall-Fired Coal Boiler > $200 \mathrm{MW}$}

(no alternate natural gas

or fuel oil boilers)

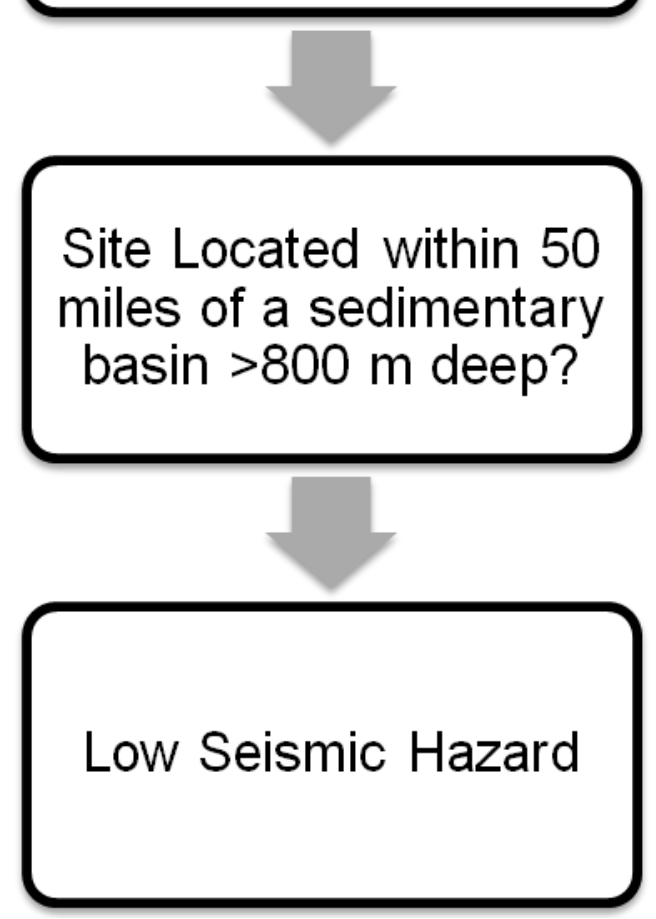

Figure 3.125. Screening Flow Diagram. 
The current screening is a high-level evaluation of boilers in relation to regional geological setting. Overall, the screening, site assessment, and sequestration design are a multiphase, multiyear effort. Once a site is identified, a more detailed feasibility study may be completed to identify storage intervals. If the project proceeds further, the future phases may consist of sitespecific seismic surveys, drilling and characterization, detailed reservoir modeling and system design. The results of this initial assessment should not be viewed or interpreted as a definitive assessment of suitability of candidate geologic $\mathrm{CO}_{2}$ storage formations, the presence of suitable caprock, or sufficient injectivity to allow $\mathrm{CO}_{2}$ sequestration to be carried out in an economic manner. Rather, this should be used as an initial screening assessment for potential storage opportunities for the boiler sites.

\subsubsection{1. $\quad \underline{\text { Boiler Size }}$}

Boiler information for the screening was obtained from the National Energy Technology Laboratory (NETL) Coal Power Plant Database (CPPDB). This database details emissions, generation, location, and firing information for all coal power plants in the United States. The database lists 1,924 boilers and provides 191 fields of information. The information is based on the most recent release of the Annual Steam-Electric Plant Operation and Design data form, Energy Information Agency (EIA) form 767. The most current data available from DOE is from 2005. Data used in this investigation were obtained from a spreadsheet (netl_cppdb_2007__public_-_boiler_list___rev1) amended by B\&W. Data is listed for individual boilers, and many plants have multiple boilers. Note that the screening is based on individual boilers, not plant sites.

\subsubsection{2. $\quad$ Proximity to Deep Sedimentary Basins}

The deep saline basins shape file used to determine if a boiler location was in or near a deep saline formation was provided by NatCarb, a project funded by the US Department of Energy's National Energy Technology Laboratory. This work was performed using ESRI Arc Map 9.3.1, a part of ArcGIS Desktop 9.3.1.

\subsubsection{Seismic Hazards}

Seismic hazard represents items related to earthquake ground shaking, faults, seismicity, and geodesy. Areas with high seismic hazard may be unsuitable for $\mathrm{CO}_{2}$ storage due to fault leakage pathways, seismic instability, and or ground instability which would preclude deep well injection. It should be noted that $\mathrm{CO}_{2}$ storage may be applied in areas of low to moderate seismic hazard with proper system design, operation, and monitoring (28). However, areas with higher seismic hazard may have higher cost and risk associated with construction, operation, and public outreach. Therefore, seismic hazard is a useful screening criterion for evaluating $\mathrm{CO}_{2}$ storage sites.

The USGS Earthquake Seismic Hazards program provided the seismic hazard contour lines used to assign a seismic hazard value to each boiler location. The US Geological Survey (USGS) National Seismic Hazard Maps (29) display earthquake ground motions for various probability levels across the United States and are applied in seismic provisions of building codes, insurance rate structures, risk assessments, and other public policy (Figure 3.126). The resulting maps are derived from seismic hazard curves calculated on a grid of sites across the United States that describe the frequency of exceeding a set of ground motions. Hazard ratings expressed as levels 
of horizontal shaking in $\% \mathrm{~g}$ have a 2 -in-100 chance of being exceeded in a 50-year period. In general, areas with more earthquake activity such as the west coast of California have higher seismic hazard. Areas near the New Madrid Fault zone in the Midwest also have a high seismic hazard.

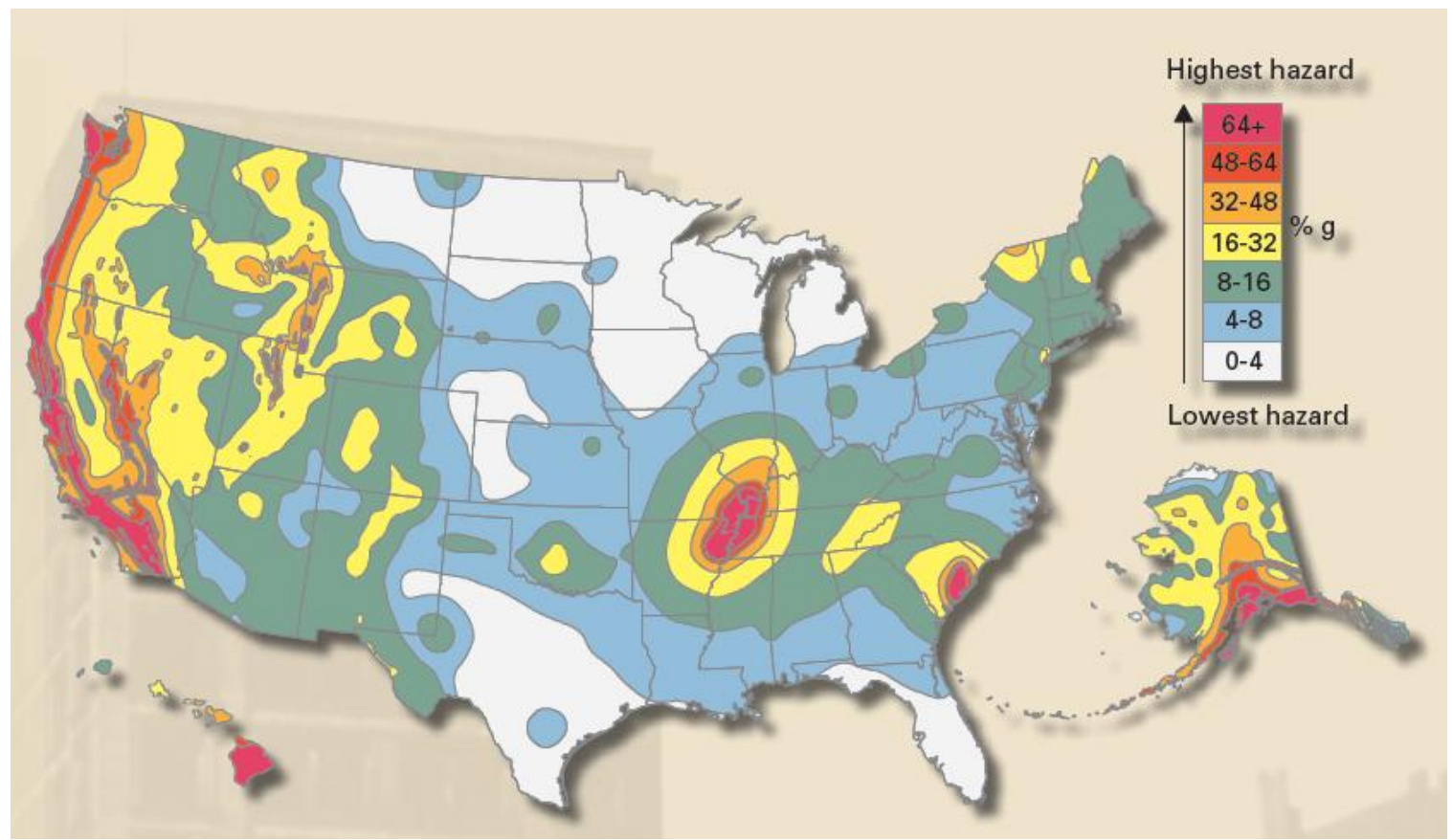

Figure 3.126. USGS Seismic Hazard Map (Petersen et al., 2008)

\subsubsection{Results of Applying High-Level Screening Criteria}

The first screening step involved selecting coal burning wall-fired or Cyclone boilers with generator nameplate rating over $200 \mathrm{MWe}$. In addition, twelve boilers with natural gas or distillate fuel oil listed as a primary alternate fuel that can be burned were screened out, because these plants have readily available options for reducing $\mathrm{CO}_{2}$ emissions. The initial screening reduced the population of boilers from 1924 to 251. Many facilities have multiple boilers. The 251 boilers are located at 143 plants and are listed in the Appendix (Section 8.3).

The next screening step involved identifying boilers located within 50 miles of sedimentary basins deeper than $800 \mathrm{~m}$. These sedimentary basins may have suitable deep saline reservoirs or depleted oil and gas formations capable of $\mathrm{CO}_{2}$ storage in supercritical phase. Deep saline formation maps were based on the US DOE 2008 Carbon Sequestration Atlas database (8) developed as part of the Carbon Sequestration Partnership program. Maps generally outline the major sedimentary basins throughout the US with suitable depth for $\mathrm{CO}_{2}$ storage $(>800 \mathrm{~m})$. This screening step reduced the boiler population to 183 .

The final screening step involved identifying locations with low seismic hazard. Boiler sites were plotted against the seismic hazard maps from the USGS National Seismic Hazards map (29). 
Boiler sites with seismic hazard of greater than $6 \% \mathrm{~g}$ were removed from the database. This screening step reduced the list of boiler sites to 143 .

Figure 3.127 summarizes the screening population according to generator nameplate rating. As shown, the general list of boilers follows a bi-modal distribution with most boilers less than $700 \mathrm{MW}$ capacity. Figure 3.128 summarizes the screening process according to boiler $\mathrm{CO}_{2}$ output. The initial population is weighted toward plants with emissions less than $3,000,000$ tons $\mathrm{CO}_{2}$ per year. However, the screened list trends toward boilers with emissions more than 3,000,000 tons $\mathrm{CO}_{2}$ per year. Overall, the screening suggests that there may be a large amount of less efficient boilers in suitable locations for $\mathrm{CO}_{2}$ storage. These boilers may have higher $\mathrm{CO}_{2}$ emissions, but lower generating capacity. A detailed assessment of boiler design and $\mathrm{CO}_{2}$ storage feasibility would be required to qualify sites for CCS.

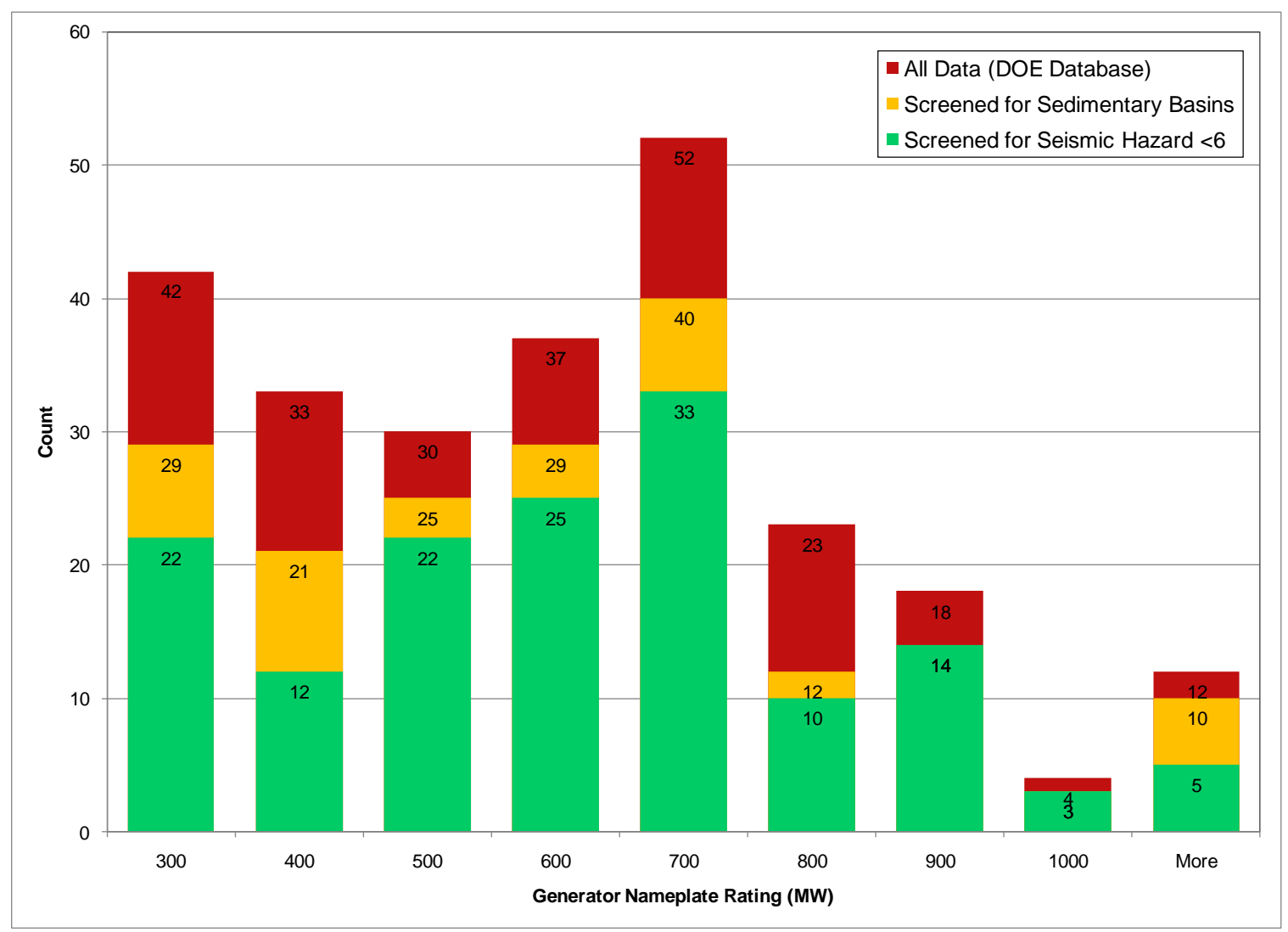

Figure 3.127. Screening Population by Generator Nameplate Rating. 


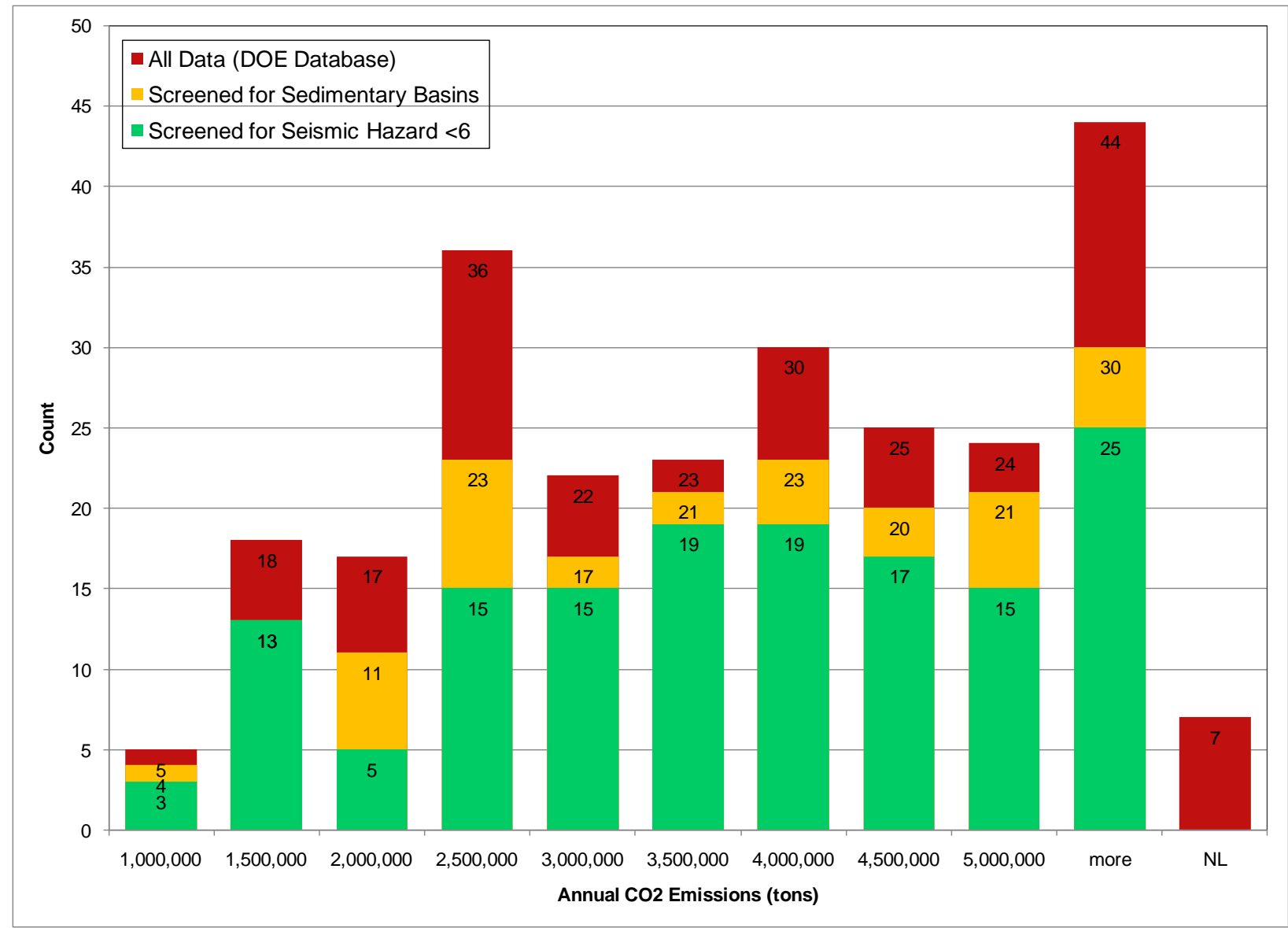

Figure 3.128. Screening population by boiler annual $\mathrm{CO}_{2}$ emissions

\subsubsection{Geographic Information System (GIS) Results}

The initial database started with 1924 boilers located throughout the continental United States as shown in Figure 3.129. The first selection criterion was to choose only those boilers that were wall fired and Cyclone boilers above 200 MWe nameplate rating. Twenty two boilers with ability to burn natural gas or distillate fuel oil were not counted. This brought the total number of eligible boilers down to 251 as shown in Figure 3.130. 


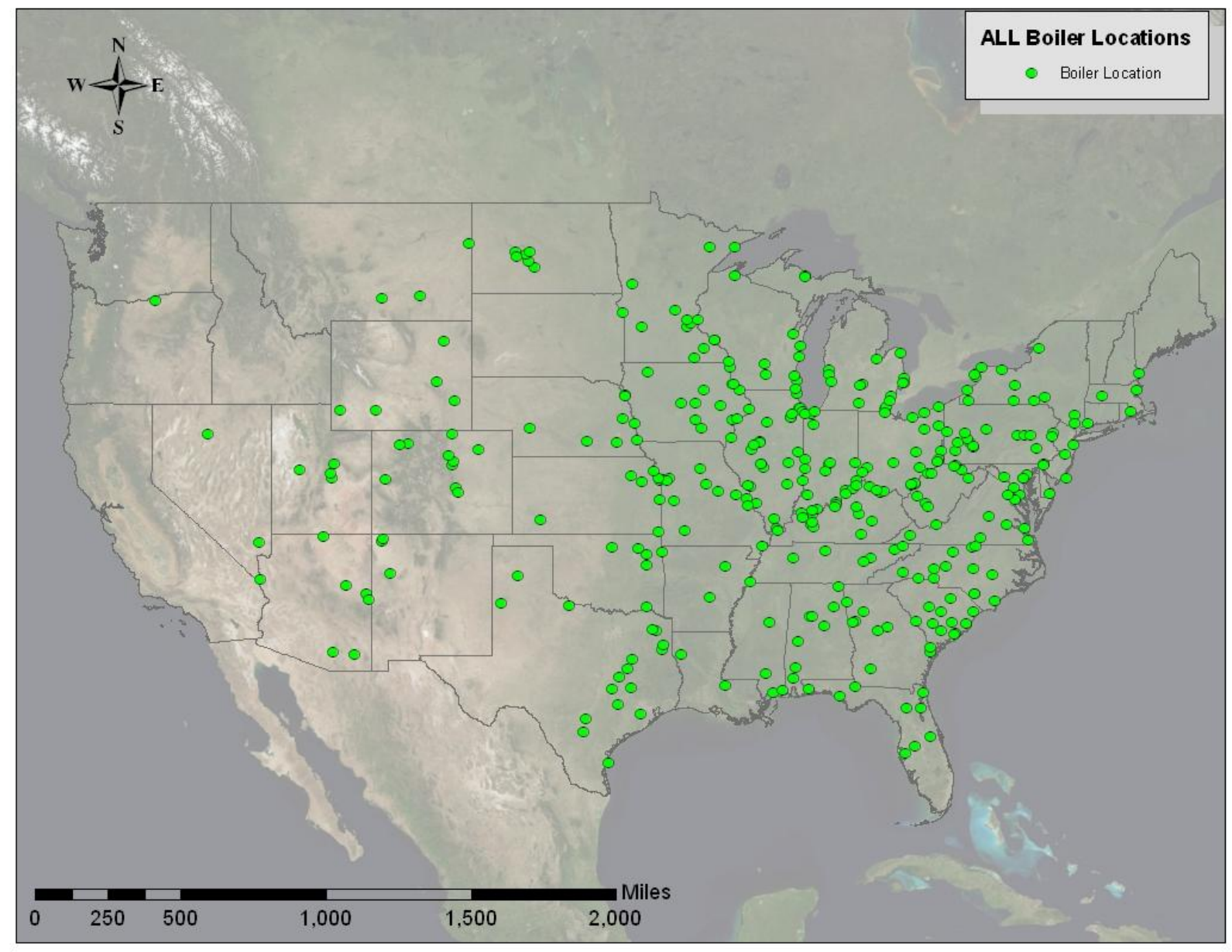

Figure 3.129. Locations of boilers in the original database before screening 


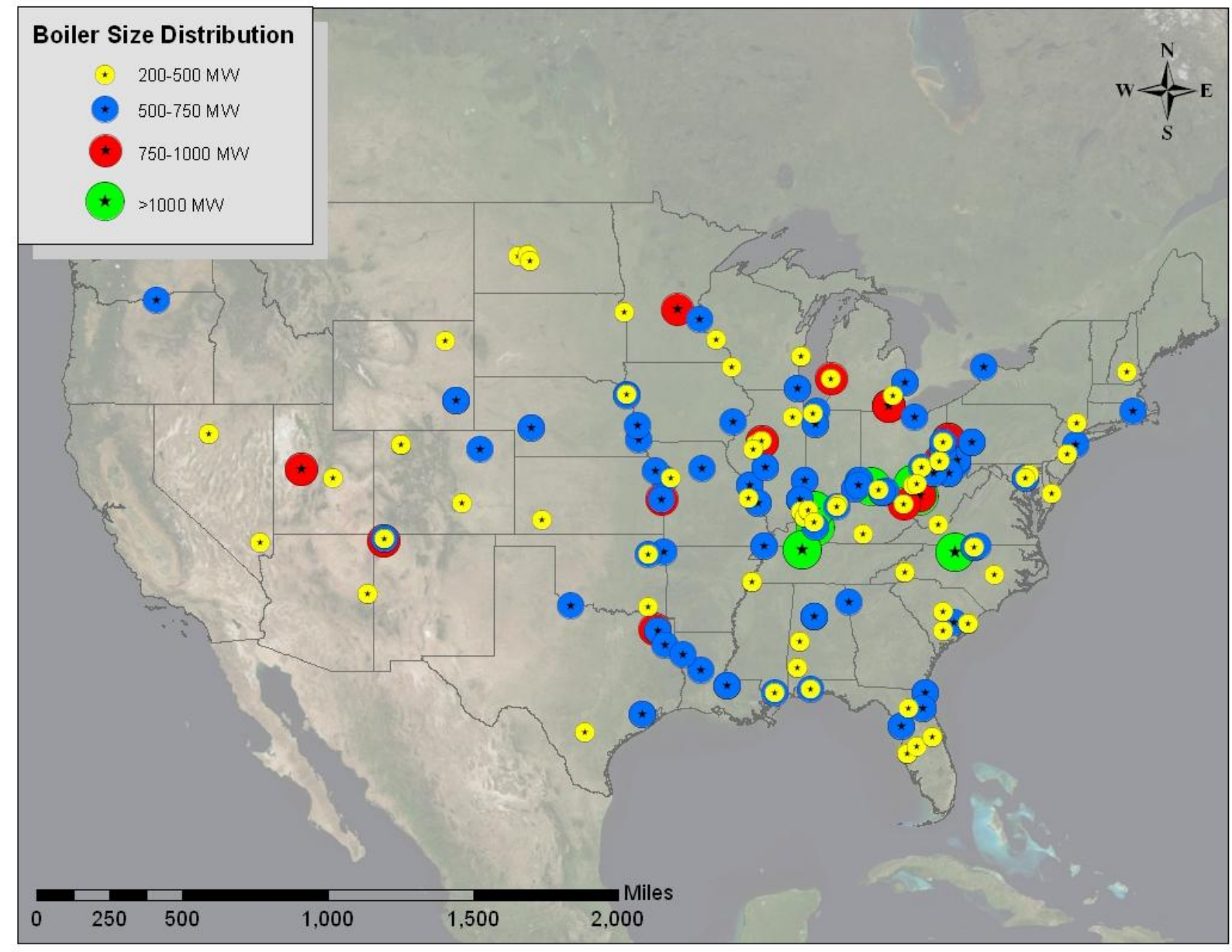

Figure 3.130. Boilers meeting size requirements (>200 MWe)

The next selection criterion was to choose those boilers located within 50 miles of a deep sedimentary basin. Deep sedimentary basin maps were based on the US DOE 2008 Carbon Sequestration Atlas (8) database developed as part of the Carbon Sequestration Partnership program. These maps outline the presence of porous rock saturated with brine which may be candidates for $\mathrm{CO}_{2}$ storage. Maps generally outline the major sedimentary basins throughout the US with suitable depth for $\mathrm{CO}_{2}$ storage $(>800 \mathrm{~m})$. By applying these criteria, the number of boilers was brought down to 183 as shown in Figure 3.131. 


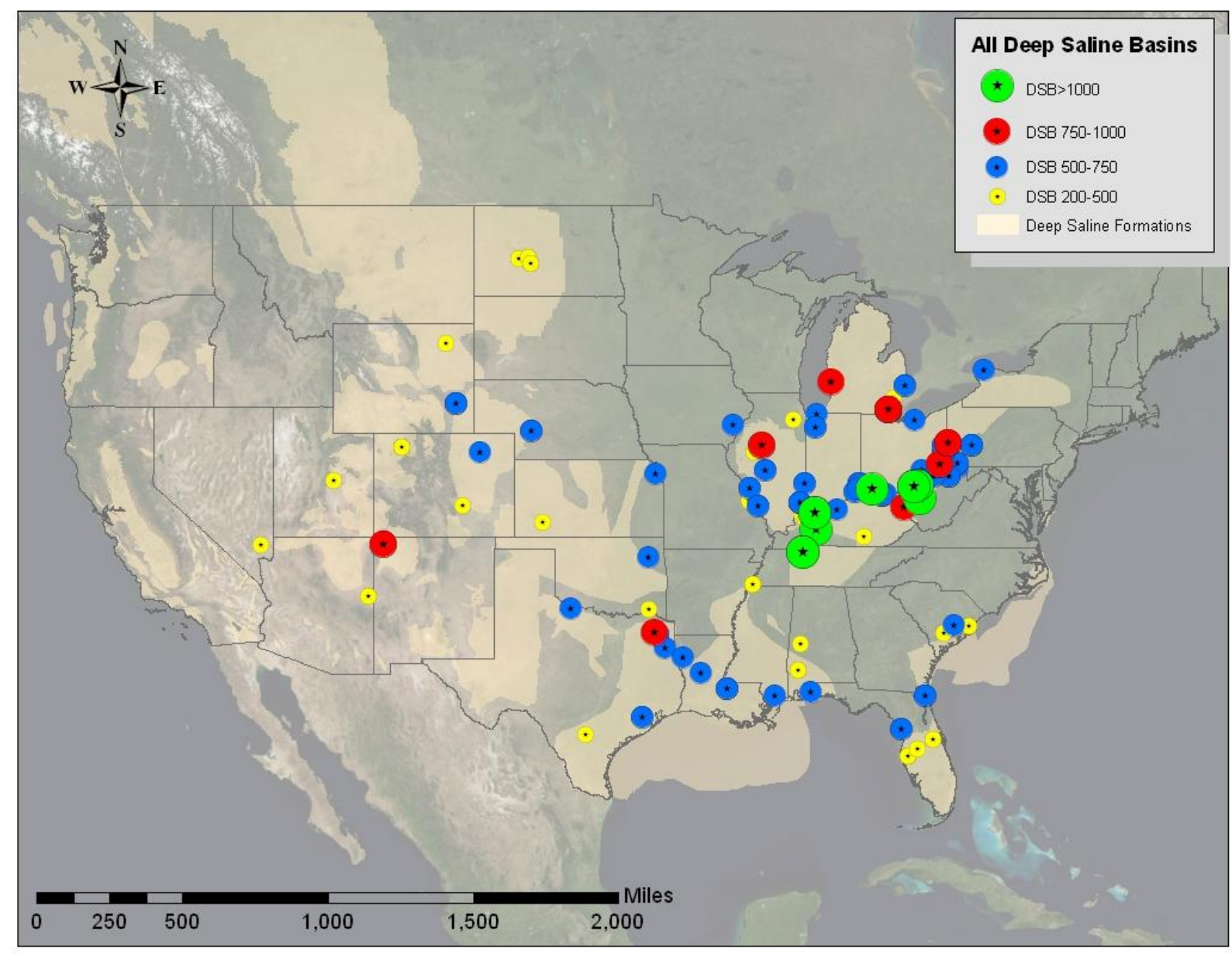

Figure 3.131. Plant locations in close proximity to deep sedimentary basins

The final selection criterion was based on seismic risk. The US Geological Survey (USGS) National Seismic Hazard Maps display earthquake ground motions for various probability levels across the United States. The maps are derived from seismic hazard curves calculated on a grid of sites across the United States that describe the frequency of exceeding a set of ground motions. Hazard ratings expressed as levels of horizontal shaking in \% g that have a 2-in-100 chance of being exceeded in a 50-year period. Figure 3.132 shows a seismic hazard of 1-2 and has 66 boilers that qualify. Figure 3.133 shows a seismic hazard of $1-4$ and has 136 boilers that qualify. Figure 3.134 shows a seismic hazard of 1-6 and has 146 boilers that qualify. 


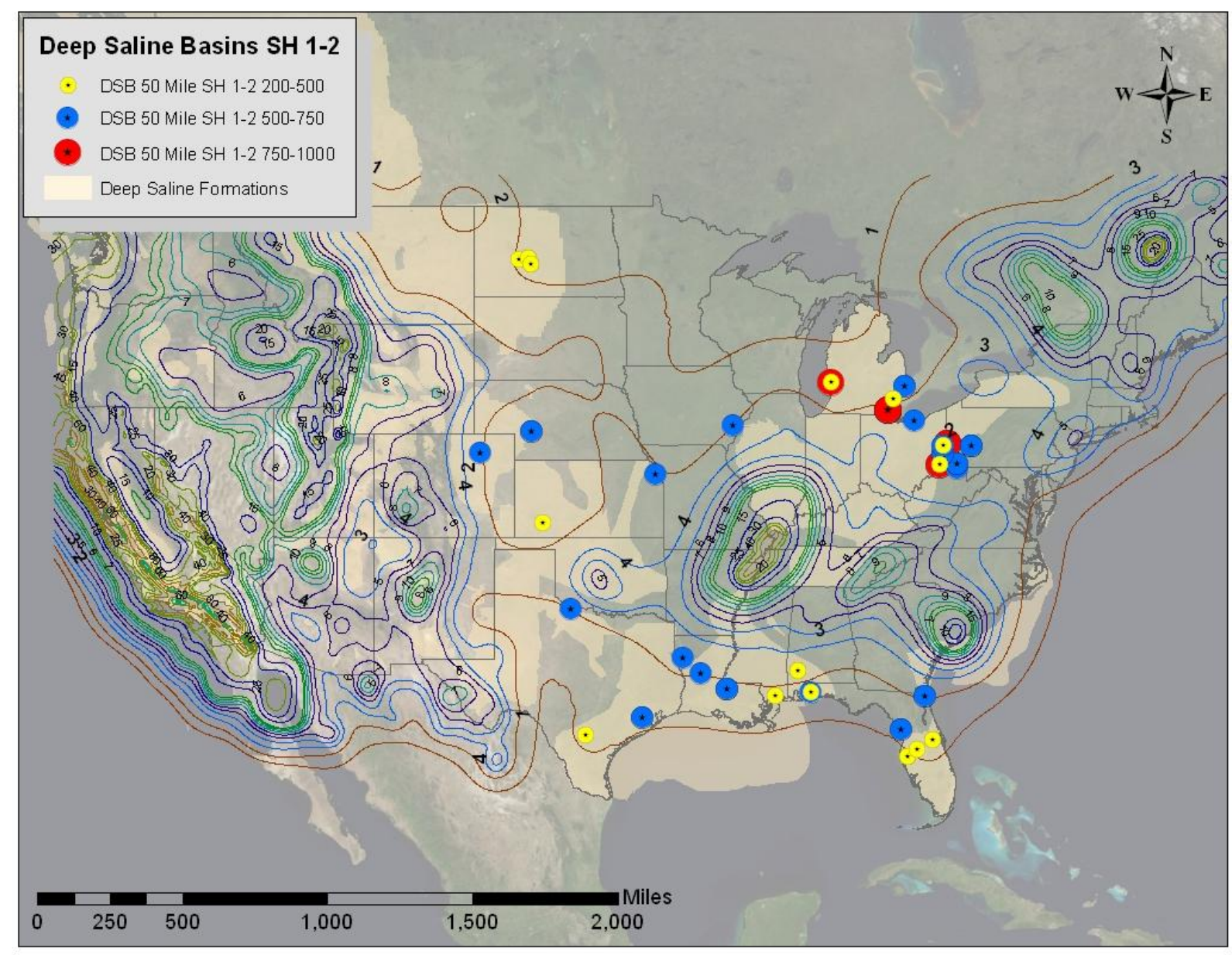

Figure 3.132. Plant locations in areas with low seismic risk, SH 1-2 


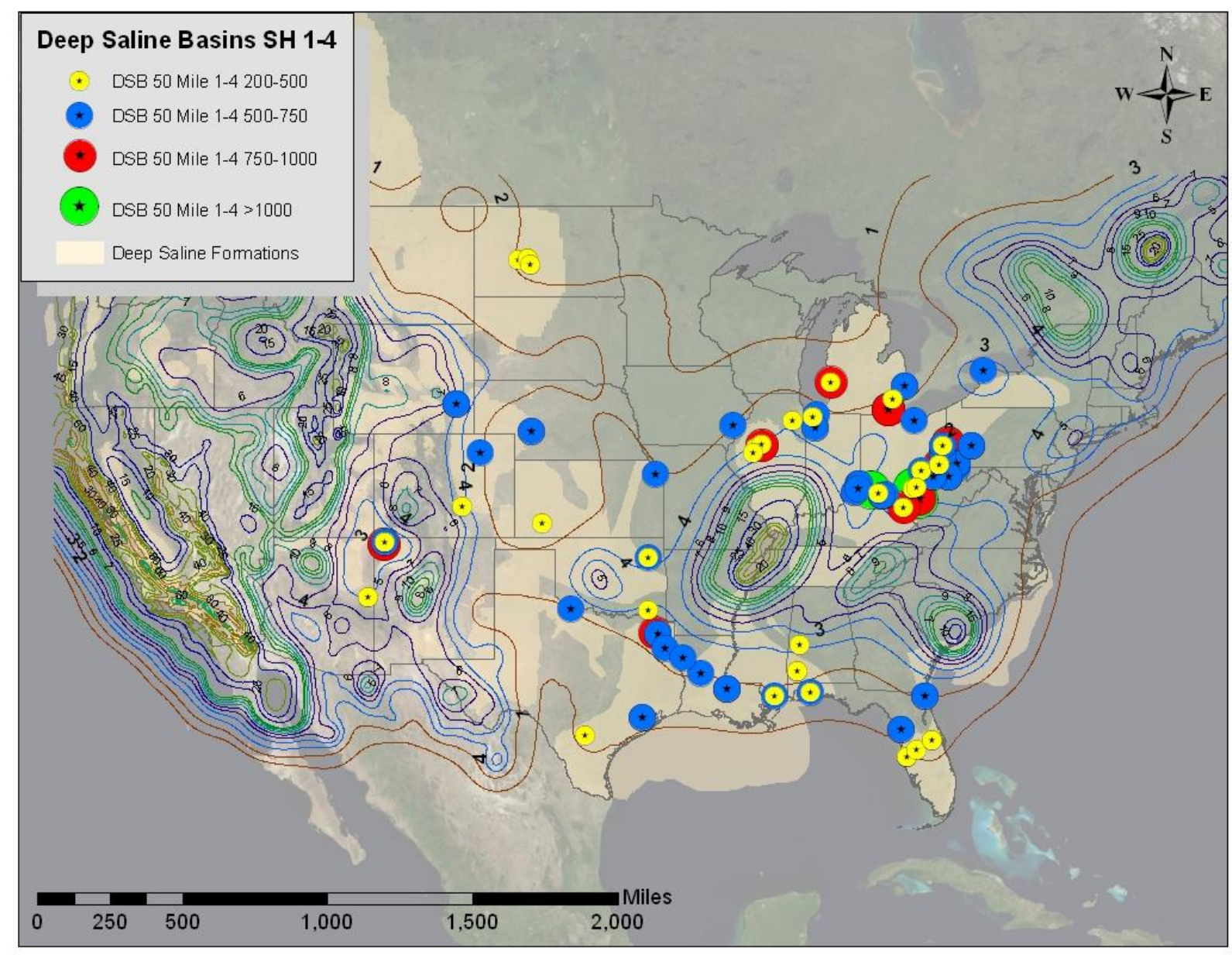

Figure 3.133. Plant locations in areas with seismic risk, SH 1-4 


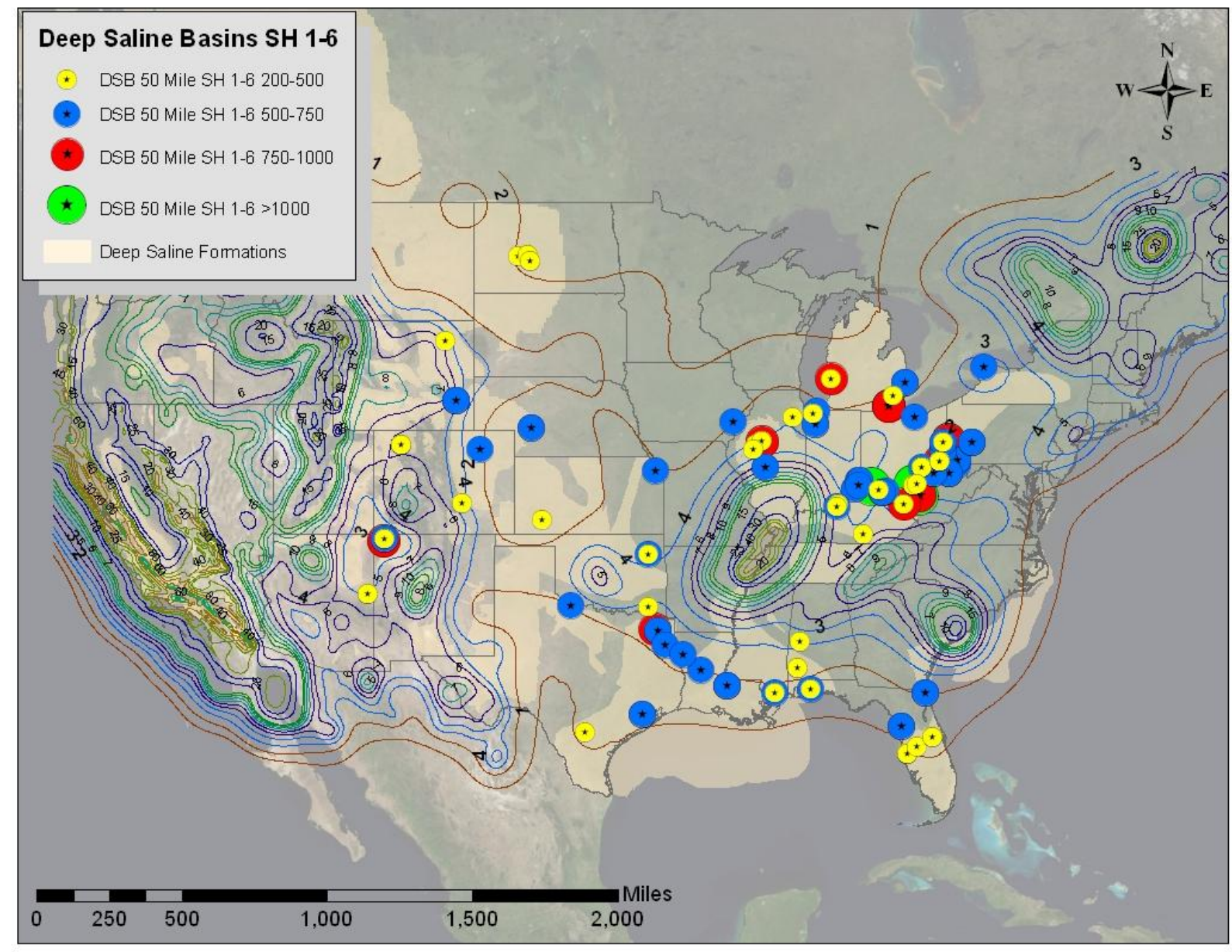

Figure 3.134. Plant locations in areas with seismic risk, SH 1-6

\subsubsection{Implications for Oxy-combustion Retrofitting of Coal-fired Power Plants in the Continental US}

The criteria selected by the project team to evaluate plant sites for $\mathrm{CO}_{2}$ storage potential were: boiler specifications; location in relation to deep sedimentary basins; and degree of seismic hazard. These criteria reduced the number of applicable boilers from 1924 down to 146. These boilers were predominantly located in the Ohio River Valley and the Gulf Coast with a few scattered around the inter-mountain West and the Dakotas. The boilers located near the Ohio River Valley and the Gulf Coast are especially good sites for potential CCS projects as they are located in areas with heavy $\mathrm{CO}_{2}$ emissions due to power plants and refineries. For each of the 146 indentified boilers, a more detailed feasibility study may be completed to identify storage intervals. If the project proceeds further, the future phases may consist of site-specific seismic surveys, drilling and characterization, detailed reservoir modeling and system design. It should be mentioned that this does not mean that oxy-combustion in other boilers is not feasible. The locations of the existing plants have been examined when the units were constructed and have been running for decades. These 146 boilers are especially good and should be considered for demonstration of the technology. 


\section{CONCLUSIONS AND RECOMMENDATIONS}

From the work performed in this project, the following conclusions and recommendations are derived.

\subsection{Conclusions}

From the pilot-scale evaluation:

- Oxy-firing is a technically viable technology for wall-fired and Cyclone boilers.

- Flame stability and Cyclone slagging characteristics were not negatively impacted by oxy-firing.

- Boiler $\mathrm{NO}_{\mathrm{X}}$ and $\mathrm{CO}$ emissions, and unburned combustibles are lower for oxy-firing than air-firing.

- Radiant boiler and convection pass heat absorptions under oxy-firing conditions can be similar to air-firing by controlling flue gas recycle and oxygen flow rates.

- Flue gas concentrations of $\mathrm{CO}_{2}$ (up to $90 \%$, dry volume basis) were achieved when air leakage was minimized by minimizing pressure drop in the boiler back-end equipment.

- For application of oxy-firing to high sulfur coals, $\mathrm{SO}_{2}$ must be scrubbed from recycle gas to minimize boiler corrosion.

- Higher flue gas $\mathrm{SO}_{3}$ emissions were generated at the convection pass exit with oxy-firing than air-firing. The $\mathrm{SO}_{3}$ concentrations were reduced by operation of the wet scrubber and condensing heat exchanger Higher $\mathrm{SO}_{3}$ concentrations could increase corrosion if the flue gas temperature goes below the acid dew point.

From compression, purification, transportation and sequestration evaluation:

- Co-sequestration of $\mathrm{CO}_{2}$ and $\mathrm{SO}_{2}$ might be feasible in deep geological reservoirs.

- Pipeline transportation corrosion caused by acid gases can be minimized by removing the moisture from the flue gas.

- CPU modeling demonstrated that the overall energy requirement is lower if flue gas inerts are removed in the CPU rather than compressing the entire flue gas for pipeline transport.

From the feasibility and economics evaluation:

- Oxy-firing is an economically viable CCS technology for existing boilers. The predicted incremental cost of oxy-firing for existing boilers (subcritical and super-critical) varies between 5 to $7 \varnothing / \mathrm{kWh}$ which is competitive with other CCS technologies.

- Cost of electricity for greenfield boilers using oxy-firing coupled with ultra-supercritical boilers was $25 \%$ higher than COE for a supercritical boiler under air-firing, well below the DOE target of $35 \%$.

- Oxy-firing can be applied to the majority of the existing wall-fired and Cyclone boilers depending on space and existing equipment. The site requirements are very similar to those for post combustion capture but without process steam requirements. 
- Units with 200 MWe or larger generating capacity were considered for oxy-firing retrofit. A study of these units indicated that majority of these units are within 50 miles of a major geological storage site.

\subsection{Recommendations}

The following recommendations are derived:

- Oxy-firing $\mathrm{SO}_{3}$ emissions are important to corrosion but difficult to measure. Little data are available on $\mathrm{SO}_{3}$ emissions under oxy-combustion conditions and processes for effective control are not well understood. Additional testing of $\mathrm{SO}_{3}$ formation and removal is highly recommended.

- Testing of wet scrubbing systems in oxy-firing has been performed by B\&W and others but little test data of dry scrubbing systems is available under oxy-firing conditions. Pilot testing with a dry scrubbing system is recommended since dry systems use less water and have lower capital cost. A better understanding of $\mathrm{SO}_{2}$ removal, operation, and operating costs is needed.

- Testing of a direct contact cooler polishing scrubber added to the oxy-firing process is also recommended. These studies are necessary to determine the performance of the polishing $\mathrm{SO}_{2}$ scrubber especially if very low levels of $\mathrm{SO}_{2}$ are a required specification for the CPU.

- An evaluation of the need for extremely low $\mathrm{SO}_{2}$ concentrations in the flue gas entering the compression and purification unit (CPU) is recommended. Currently, compressor manufactures require very low levels of $\mathrm{SO}_{2}(<1 \mathrm{ppm})$.

- A site-specific engineering and economic oxy-firing retrofit study of an existing coalfired utility unit is recommended. This study would aid in developing a more reliable cost analysis for retrofitting a unit with oxy-firing. A potential site for this engineering study is the AEP Conesville unit which would enable comparison with existing DOE studies. 


\section{GRAPHICAL MATERIALS LISTS}

\subsection{List of Figures}

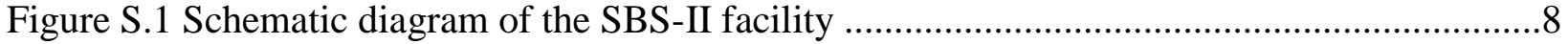

Figure S.2 $\mathrm{CO}_{2}$ at convection pass outlet as a function of infiltrated air.....................................10

Figure S.3 Comparison of LOI, and emitted $\mathrm{NO}_{\mathrm{X}}$ and $\mathrm{CO}$ for optimum operating

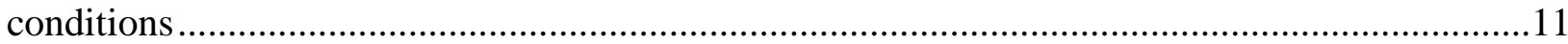

Figure S.4 Comparison of the Cyclone, furnace, and convection pass heat absorption for

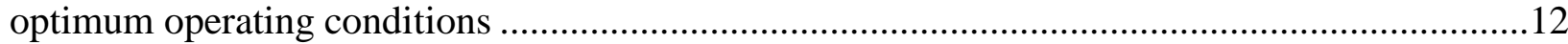

Figure S.5 Comparison of air and oxy-firing $\mathrm{SO}_{2}$ and moisture concentrations (convection pass exit) showing the effect of $\mathrm{SO}_{2}$ scrubbing of the recycle gas ..........................13

Figure S.6 Comparison of air and oxy-firing $\mathrm{SO}_{2}$ and moisture concentrations (convection pass exit) showing the effect of switching to warm recycle .................................13

Figure S.7 Comparison of $\mathrm{CO}_{2}$ yield (recovery), $\mathrm{CO}_{2}$ purity and specific energy of the 3 $\mathrm{CO}_{2}$ capture processes for case of low air infiltration ..................................................15

Figure S.8 Process description for flue gas interactions ......................................................

Figure S.9 Performance results for retrofit cases - net plant efficiency ...................................18

Figure S.10 Performance results for greenfield cases - net plant efficiency .............................18

Figure S.11 Breakeven capital investment to mitigate air infiltration ......................................19

Figure S.12 Power consumption of ASU and CPU as a function of product oxygen purity.........19

Figure S.13 Comparison of Levelized Cost of Electricity ...................................................20

Figure S.14 Boilers meeting size requirements (>200 MWe) .............................................22

Figure 2.1 General layout of SBS-II pilot scale facility

Figure 2.2 Schematic diagram of the SBS-II facility with selected instrumentation. The

WFGD and/or CHX may be bypassed. Locations of valves, flow measurement, and in situ $\mathrm{H}_{2} \mathrm{O}$ and $\mathrm{O}_{2}$ sensors are shown.

Figure 2.3 The liquid oxygen storage tank and vaporizer (left) and the oxygen flow

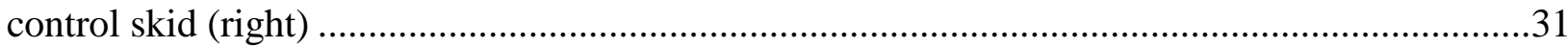

Figure 2.4 Diagram of the Cyclone furnace internal volume ....................................................32

Figure 2.5 Rendering of the Cyclone furnace external features ................................................33

Figure 2.6 Drawing excerpt showing the location of firebrick installed in the SBS-II ...............34

Figure 2.7 Internal volume of the SBS-II in Cyclone configuration .......................................35

Figure 2.8 Schematic diagram of the wet scrubber absorber tower........................................36

Figure 2.9 P\&ID for SBS-II water-side/blowdown system ................................................40

Figure 2.10 Furnace and convection pass heat transfer data illustrating the cyclic nature

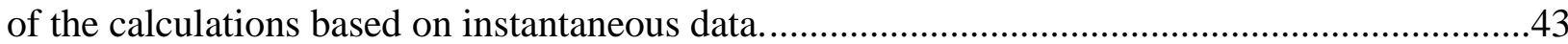

Figure 2.11 Comparison of measured and calculated coal flow rates ......................................44

Figure 3.1 Schematic diagram for Case A: compression and drying only ...............................53

Figure 3.2 Schematic diagram for Case B: partial condensation ...........................................54

Figure 3.3 Schematic diagram for Case $\mathrm{C}$ : partial condensation and distillation ........................54

Figure 3.4 Comparison of $\mathrm{CO}_{2}$ yield (recovery), $\mathrm{CO}_{2}$ purity and specific energy of the 3 $\mathrm{CO}_{2}$ capture processes for North Dakota Lignite .56

Figure 3.5 Comparison of $\mathrm{CO}_{2}$ yield (recovery), $\mathrm{CO}_{2}$ purity and specific energy of the 3 $\mathrm{CO}_{2}$ capture processes for Decker coal. .56 
Figure 3.6 Comparison of $\mathrm{CO}_{2}$ yield (recovery), $\mathrm{CO}_{2}$ purity and specific energy of the 3

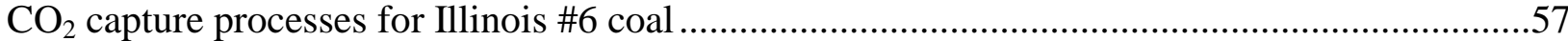
Figure 3.7 Comparison of $\mathrm{CO}_{2}$ yield (recovery), $\mathrm{CO}_{2}$ purity and specific energy of the 3 $\mathrm{CO}_{2}$ capture processes for case of low air infiltration

Figure 3.8 Specific energy requirement of the 3 processes as a function of the product (pipeline) pressure for North Dakota Lignite.

Figure 3.9 Specific energy requirement of the 3 processes as a function of the product (pipeline) pressure for Decker coal....

Figure 3.10 Specific energy requirement of the 3 processes as a function of the product (pipeline) pressure for Illinois \#6 coal .

Figure 3.11 Specific energy requirement of the 3 processes as a function of the product (pipeline) pressure for the low air infiltration case

Figure 3.12 Cross-over pressures for the 4 flue gas compositions of this study. Below the cross-over pressure, the compression only process requires lower specific energy than the particular purification process, while above the cross-over pressure, the purification scheme has a lower specific energy requirement.

Figure 3.13 Process description for flue gas interactions

Figure 3.14 Corrosion rate of carbon steel exposed to different $\mathrm{H}_{2} \mathrm{SO}_{4}$ concentrations in terms of $\mathrm{pH}$ at different $\mathrm{CO}_{2}$ pressures (static conditions) ..... .68

Figure 3.15 Corrosion rate of carbon steel exposed to different $\mathrm{O}_{2}$ concentrations at different $\mathrm{CO}_{2}$ pressures (static conditions)

Figure 3.16. Water content vs. number of potential corrosion sites (per square meter for a corrosion rate of $0.2 \mathrm{~mm} / \mathrm{yr}$ )

Figure 3.17. Kinematic viscosity of approximate flue gas mixture divided by the kinematic viscosity of pure $\mathrm{CO}_{2}$. Shown for various temperatures $\left(50^{\circ} \mathrm{F}\right.$ steps $)$ and pressures (500 psi steps). Calculations were performed with NIST REFPROP v8.0. Mole fractions used: $0.7259 \mathrm{CO}_{2}, 0.1948 \mathrm{~N}_{2}, 0.0292 \mathrm{Ar}, 0.0002 \mathrm{CO}, 0.0499 \mathrm{O}_{2}$.

Figure 3.18. Density of approximate flue gas mixture divided by the density of pure $\mathrm{CO}_{2}$. Shown for various temperatures and pressures. See Figure 3.17 for additional notes. A large decrease in the density ratio occurs near the $\mathrm{CO}_{2}$ critical point 73

Figure 3.19. Injection well components.....

Figure 3.20. Gas-phase saturation after 60 days of flue gas injection ....................................86

Figure 3.21. Gas-phase saturation after 60 days of $\mathrm{CO}_{2}$ injection...........................................86

Figure 3.22. Aqueous-phase $\mathrm{CO}_{2}$ mass fraction after 60 days of flue gas injection....................87

Figure 3.23. Aqueous-phase air mass fraction after 60 days of flue gas injection ......................87

Figure 3.24. Aqueous-phase $\mathrm{CO}_{2}$ mass fraction after 60 days of pure $\mathrm{CO}_{2}$ injection ................87

Figure 3.25. Gas-phase pressure after 60 days of flue gas injection.......................................8

Figure 3.26. Gas-phase pressure after 60 days of $\mathrm{CO}_{2}$ injection ...........................................8

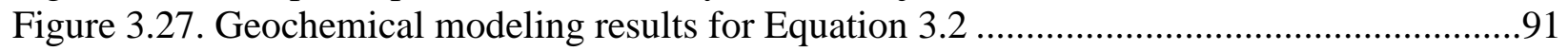

Figure 3.28 Comparison of $\mathrm{NO}_{\mathrm{X}}$ emissions between air and oxy-firing for three coals

fired.

Figure 3.29 Expected reductions in $\mathrm{NO}_{\mathrm{X}}$ emissions when changing from air to oxy-firing for the three coals based on trend lines at a Cyclone stoichiometric ratio of 0.9

Figure 3.30 Data showing the enrichment of pollutants $\mathrm{NO}_{\mathrm{X}}$ and $\mathrm{SO}_{2}$ by flue gas recycling for the lignite tests.... 
Figure 3.31 Example CO concentration data at the convection pass exit: Subbituminous

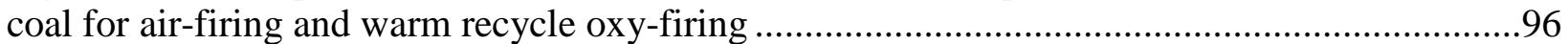

Figure 3.32 CO emissions data for all tests as a function of Cyclone stoichiometry ..................97

Figure 3.33 LOI data for all tests as a function of Cyclone stoichiometry ...............................98

Figure 3.34 Comparison of LOI, and emitted $\mathrm{NO}_{\mathrm{X}}$ and $\mathrm{CO}$ for optimum operating

conditions

Figure 3.35 Comparison of flue gas $\mathrm{SO}_{2}$ and moisture concentrations (convection pass

exit) between air and oxy-firing for bituminous coal and lignite

Figure 3.36 Comparison of flue gas $\mathrm{SO}_{2}$ and moisture concentrations (convection pass

exit) between air and oxy-firing for subbituminous coal (warm and cold recycle).

Figure 3.37 Average $\mathrm{SO}_{2}$ emitted between air and oxy-firing for each coal

Figure 3.38 Total $\mathrm{SO}_{3}$ concentration after environmental equipment (bituminous coal, vapor and non-vapor $\mathrm{SO}_{3}$ forms combined)

Figure 3.39 Total $\mathrm{SO}_{3}$ concentration before environmental equipment (bituminous coal,

vapor and non-vapor $\mathrm{SO}_{3}$ forms combined)

Figure 3.40 Vapor and non-vapor $\mathrm{SO}_{3}$ concentrations at the air heater outlet during oxy-

firing.

Figure 3.41 Vapor and non-vapor $\mathrm{SO}_{3}$ concentrations at the air heater outlet during air-

firing

Figure 3.42 Mercury analyzer calibration data

Figure 3.43 Mercury concentration at the outlet and inlet of the wet scrubber for tests

performed on July 21, 2009 (Qualitative data only) Ohio \#5 bituminous coal, air-firing.....

Figure 3.44 Mercury concentration for tests performed on September 3, 2009 firing

lignite

Figure 3.45 Mercury and $\mathrm{CO}_{2}$ concentration data obtained during warm recycle tests

(September 17 2009) firing PRB coal

Figure 3.46 Average elemental and oxidized mercury results from the warm recycle test

series (PRB subbituminous coal)...

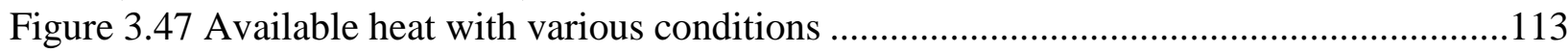

Figure 3.48 Overall heat absorption

Figure 3.49 Cyclone furnace heat absorption

Figure 3.50 Primary furnace heat absorption.

Figure 3.51 Convection pass heat absorption

Figure 3.52 Comparison of heat absorption in Cyclone, primary furnace and convection

pass.....

Figure 3.53 FlameView images and temperature maps for subbituminous coal ....

Figure 3.54 FlameView images and temperature maps for bituminous coal ...........................120

Figure 3.55 FlameView temperature maps for lignite ..............................................121

Figure 3.56 Calculated adiabatic flame temperatures for various conditions..........................122

Figure 3.57 Experimental flame temperature data for various conditions (compare Figure

3.56)

Figure 3.58 Comparison of FEGT for various conditions ..............................................123

Figure 3.59 Comparison of FEGT for bituminous coal ................................................. 124

Figure 3.60 Effect of reduced flue gas recycle on FEGT .................................................124

Figure 3.61 Oxygen measurements in the flue gas path compared to simultaneous

measurements of convection pass exit $\mathrm{O}_{2}(7 / 29 / 2009)$ 
Figure 3.62 Effect of air infiltration on $\mathrm{CO}_{2}$ concentration ................................................126

Figure $3.63 \mathrm{CO}_{2}$ concentrations achieved with various coals and oxy-firing process................127

Figure 3.64 Comparison of FEGT between model predictions and measurements: air-

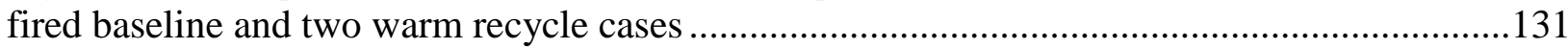

Figure 3.65 Predicted heat flux distribution on the Cyclone wall surfaces .............................132

Figure 3.66 Predicted particle deposition rates on the Cyclone wall surfaces..........................133

Figure 3.67 Predicted oxidation rate of deposited carbon on the Cyclone wall surfaces ............134

Figure 3.68 Predicted gasification rate of deposited carbon on the Cyclone wall surfaces.........135

Figure 3.69 Predicted oxygen concentration profiles in the Cyclone .....................................136

Figure 3.70 Predicted gas temperature profiles in the Cyclone ............................................136

Figure 3.71 Comparison of measured and predicted heat absorption in the Cyclone: air-

fired baseline and two warm recycle cases

Figure 3.72 Comparison of measured and predicted heat absorption in the furnace

(including the first two tube banks of the convection pass): air-fired baseline and two

warm recycle cases

Figure 3.73 Comparison of measured and predicted heat absorption in the convection

pass: air-fired baseline and two warm recycle cases (excluding tube banks 1 and 2)....

Figure 3.74 Path for extracting local gas properties in the Cyclone and SBS-II ....

Figure 3.75 Predicted local gas temperature along the path shown in Figure 3.74: air-fired

baseline and two warm recycle cases.

Figure 3.76 Predicted gas temperature profiles under air and two warm recycle oxy-firing conditions

Figure 3.77 Predicted local gas emissivity along the path shown in Figure 3.74: air-fired

baseline and two warm recycle cases....

Figure 3.78 Predicted local gas heat capacity along the path shown in Figure 3.74: air-

fired baseline and two warm recycle cases

Figure 3.79 Predicted local gas density along the path shown in Figure 3.74: air-fired

baseline and two warm recycle cases.......

Figure $3.80 \mathrm{~B} \& W$ 's $30 \mathrm{MW}_{\text {th }}$ Clean Environment Development Facility ...

Figure 3.81 Clean Environment Development Facility process flow diagram

Figure 3.82 Oxygen supply system.

Figure 3.83 Comparison of air-fired and oxy-combustion primary flow to coal flow for the direct-fired fuels .

Figure 3.84 Reductions in $\mathrm{NO}_{\mathrm{X}}$ in the CEDF switching from air-firing to oxy-combustion .......154

Figure 3.85 Impact of oxy-firing on heat transfer in the CEDF ......................................155

Figure 3.86 Effect of oxy-firing on $\mathrm{SO}_{2}$ removal performance of the wet scrubber .................156

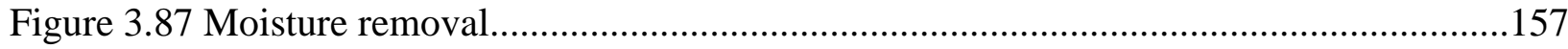

Figure 3.88 Effect of oxy-combustion on ESP operating characteristics ...............................158

Figure 3.89 Oxygen mixing in the flue gas ducts ........................................................159

Figure 3.90 ASPEN simulation results of the effect of air infiltration on flue gas $\mathrm{CO}_{2}$

concentration....

Figure 3.91 Operational data for transition between air and oxy-firing .

Figure 3.92 Cool recycle process configuration for bituminous retrofit cases .....

Figure 3.93 Cool recycle processes for PRB and North Dakota Lignite retrofit cases

Figure 3.94 Warm recycle for process configuration for bituminous greenfield case.

.167 
Figure 3.95 Warm recycle for PRB and North Dakota Lignite for greenfield PC Cases 12 and 14

Figure 3.96 Warm recycle for PRB and North Dakota Lignite for greenfield Cyclone

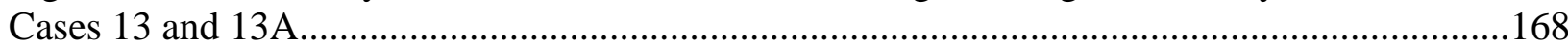

Figure 3.97 3D model of ASU for oxy-combustion ........................................................171

Figure 3.98 Specific energy consumption of ASU as a function of product oxygen purity ........172

Figure 3.99 Capital cost of ASU and CPU as a function of product oxygen purity ...................173

Figure 3.100 Power consumption of ASU and CPU as a function of product oxygen

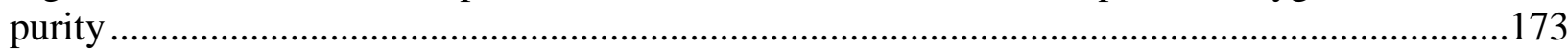

Figure 3.101 Schematic diagram of a typical $\mathrm{CO}_{2} \mathrm{CPU}$ scheme.........................................174

Figure 3.102 Performance results for retrofit cases - net plant efficiency .............................191

Figure 3.103 Economic results for retrofit cases (incremental LCOE) .................................192

Figure 3.104 Cost of $\mathrm{CO}_{2}$ removed and avoided for retrofit cases .....................................193

Figure 3.105 Performance results for greenfield cases - net plant efficiency ...........................195

Figure 3.106 Economic results for greenfield cases (LCOE) (See Section 3.2.6 for

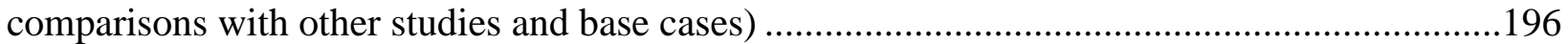

Figure 3.107 Cost of $\mathrm{CO}_{2}$ removed and avoided for greenfield cases (See Section 3.2.6

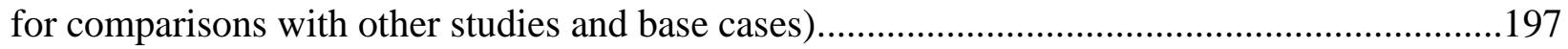

Figure 3.108 Performance comparisons with other studies ................................................198

Figure 3.109 Economic comparisons with other studies (LCOE) ........................................200

Figure 3.110 Cost of $\mathrm{CO}_{2}$ removed and avoided for comparison cases ...............................201

Figure 3.111 Performance comparisons with post combustion capture study........................202

Figure 3.112 Economic comparisons with other post combustion capture study (LCOE) .........203

Figure 3.113 Cost of $\mathrm{CO}_{2}$ removed and avoided for comparison cases ...............................204

Figure 3.114 Performance results for variations of air infiltration ......................................208

Figure 3.115 Economic results for variations of air infiltration ........................................209

Figure 3.116 Cost of $\mathrm{CO}_{2}$ removed and avoided for variations of air infiltration .....................210

Figure 3.117 Impact of air infiltration on net plant efficiency .............................................210

Figure 3.118 Impact of air infiltration on LCOE .........................................................211

Figure 3.119 Performance results for variations of oxidant purity ...................................215

Figure 3.120 Economic results for variations of oxidant purity ......................................215

Figure 3.121 Cost of $\mathrm{CO}_{2}$ removed and avoided for variations of oxidant purity...................216

Figure 3.122 Impact of oxidant purity on net plant efficiency ...........................................216

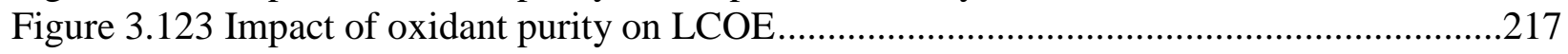

Figure 3.124 Breakeven capital investment to mitigate air infiltration ................................218

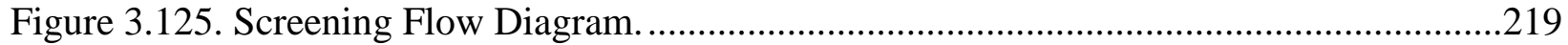

Figure 3.126. USGS Seismic Hazard Map (Petersen et al., 2008) .........................................221

Figure 3.127. Screening Population by Generator Nameplate Rating...................................222

Figure 3.128. Screening population by boiler annual $\mathrm{CO}_{2}$ emissions ..................................223

Figure 3.129. Locations of boilers in the original database before screening .........................224

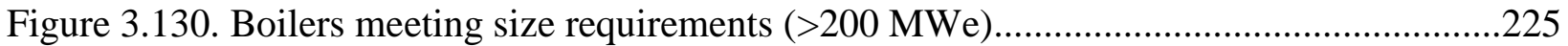

Figure 3.131. Plant locations in close proximity to deep sedimentary basins .........................226

Figure 3.132. Plant locations in areas with low seismic risk, SH 1-2 ..................................227

Figure 3.133. Plant locations in areas with seismic risk, SH 1-4 .......................................228

Figure 3.134. Plant locations in areas with seismic risk, SH 1-6.......................................229 


\subsection{List of Tables}

Table S.1 Proximate, ultimate, and miscellaneous analyses for the coals ................................9

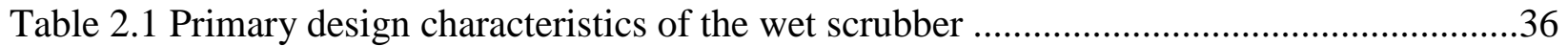

Table 2.2 Standard laboratory methods used in coal analysis ................................................41

Table 2.3 Proximate, ultimate, and miscellaneous analyses for the coals tested.........................49

Table 2.4 Elemental ash analysis of the coals tested ..........................................................49

Table 3.1 Flue gas inlet compositions for three coal types (worst case scenario for air

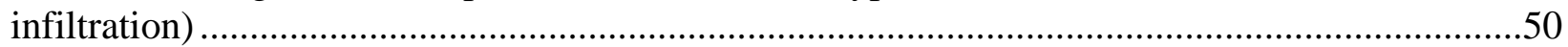

Table 3.2 Flue gas composition (dry) for "low air infiltration" case .........................................54

Table 3.3 Product compositions (dry basis) obtained by subjecting flue gases from the 3

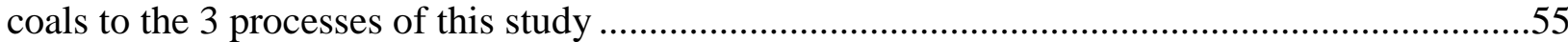

Table 3.4 Product compositions (dry basis) obtained by subjecting flue gases from the low air infiltration case to the 3 processes of this study .........................................................58

Table 3.5 Estimated flue gas composition (molar \%) after cooling to $160^{\circ} \mathrm{F}$.............................65

Table 3.6 Estimated molar flue gas composition following dehydration and oxygen

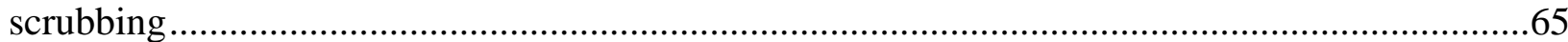

Table 3.7 Critical point conditions for the constituents of the flue gas ...................................66

Table 3.8 Federal Regulation requirements of injection well classifications (6) .......................75

Table 3.9 Definitions of UIC defined classification of injection wells (6) ................................77

Table 3.10 Hazardous waste characteristics and comparison of each with the flue gas

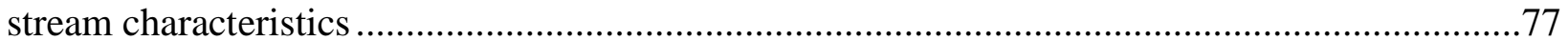

Table 3.11 Maximum concentrations of metal contaminants for toxicity characteristics .............79

Table 3.12 Summary of impurity compatibility with well materials .......................................81

Table 3.13 Casing/tubing materials, applications, and limitations ........................................82

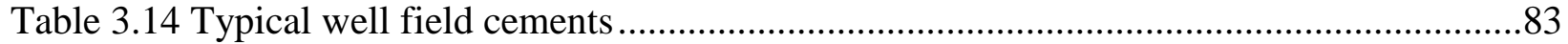

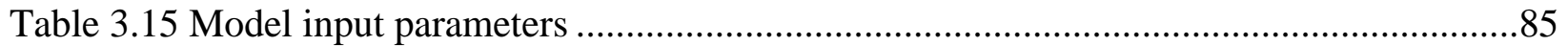

Table 3.16 Comparison of predicted and measured $\mathrm{SO}_{2}$ levels in the flue gas .........................102

Table $3.17 \mathrm{SO}_{3}$ test names and corresponding names in the Tabulated Pilot-scale Test

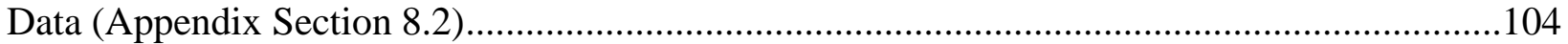

Table 3.18 List of pilot scale tests modeled with CFD .....................................................128

Table 3.19 Summary of modeling predictions compared to available pilot-scale test data. .......130

Table 3.20 Predictions of heat transfer divided into radiative, convective, and deposition process components: air-fired baseline and two warm recycle cases ....................................146

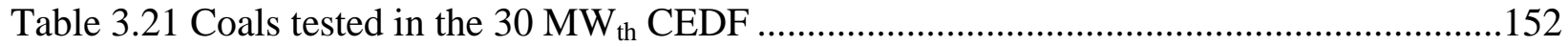

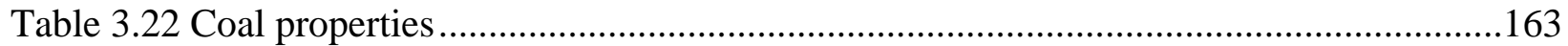

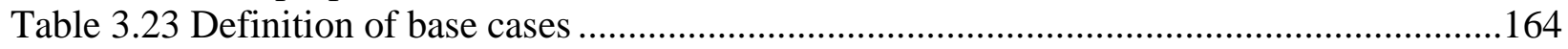

Table 3.24 Gas composition to the CPU for each coal for retrofit cases ..................................168

Table 3.25 Gas composition to the CPU for Cases 11, 12, 13 and 14 ....................................169

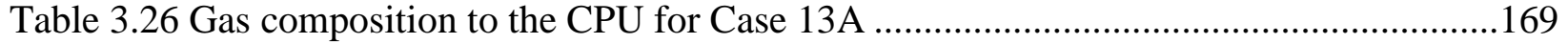

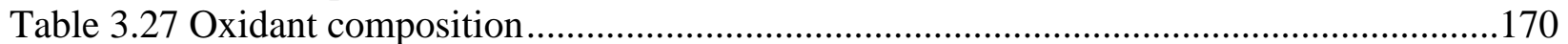

Table 3.28 CPU design assumptions ..................................................................................... 175

Table 3.29 Assumed $\mathrm{CO}_{2}$ concentrations and associated specific energy ...............................175

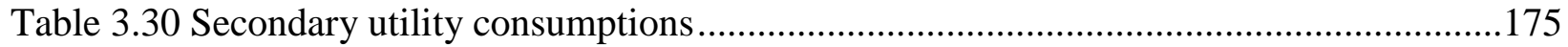

Table 3.31 Gas composition to the CPU for air infiltration cases .........................................177

Table 3.32 Gas composition to the CPU for oxidant purity cases .........................................178 
Table 3.33 Parameter assumptions for capital charge factors.............................................179

Table 3.34 Financial structure for investor owned utility high risk projects ...........................179

Table 3.35 Economic parameters for LCOE calculation high risk projects ............................179

Table 3.36 Detailed cost basis for retrofit cases ..............................................................180

Table 3.37 Detailed cost basis for greenfield cases ...........................................................181

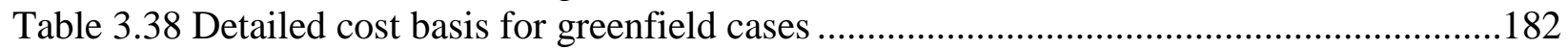

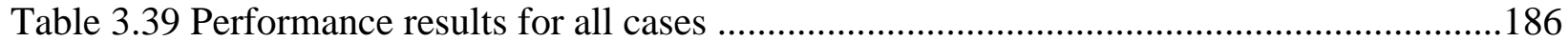

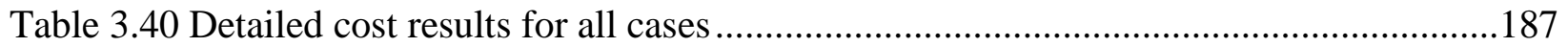

Table 3.41 Detailed cost results for all cases ..................................................................188

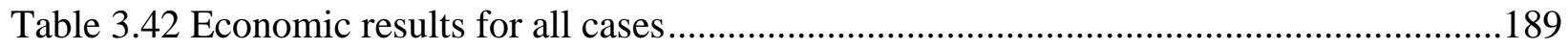

Table 3.43 Performance results for variations of air infiltration ........................................205

Table 3.44 Cost summary results for variations of air infiltration .....................................206

Table 3.45 Economic results for variations of air infiltration..........................................207

Table 3.46 Performance results for variations of oxidant purity ...........................................212

Table 3.47 Cost summary results for variations of oxidant purity .......................................213

Table 3.48 Economic results for variations of oxidant purity .............................................214

Table 8.1 Pilot scale test data for lignite - table 1 of 5: test parameters, ambient

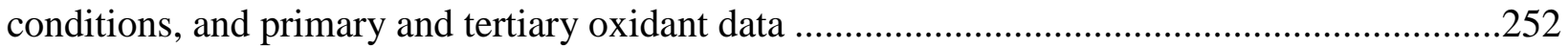

Table 8.2 Pilot scale test data for lignite - table 2 of 5: Secondary and overfire oxidant, Cyclone lance oxygen, and fuel test data ....................................................................253

Table 8.3 Pilot scale test data for lignite - table 3 of 5: Convection pass and stack gases,

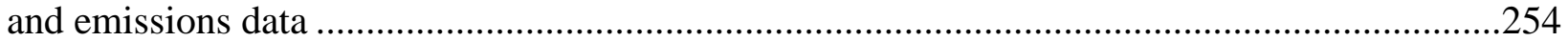

Table 8.4 Pilot scale test data for lignite - table 4 of 5: Heat transfer and temperature data ......255

Table 8.5 Pilot scale test data for lignite - table 5 of 5: Static and differential pressures

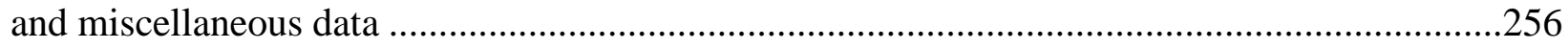

Table 8.6 Pilot scale test data for subbituminous coal - table 1 of 5: test parameters, ambient conditions, and primary and tertiary oxidant data.....

Table 8.7 Pilot scale test data for subbituminous coal - table 2 of 5: Secondary and overfire oxidant, Cyclone lance oxygen, and fuel test data ..............................................258

Table 8.8 Pilot scale test data for subbituminous coal - table 3 of 5: Convection pass and stack gases, and emissions data

Table 8.9 Pilot scale test data for subbituminous coal - table 4 of 5: Heat transfer and temperature data.

Table 8.10 Pilot scale test data for subbituminous coal - table 5 of 5: Static and differential pressures and miscellaneous data

Table 8.11 Pilot scale test data for subbituminous coal (warm recycle) - table 1 of 5: test parameters, ambient conditions, and primary and tertiary oxidant data

Table 8.12 Pilot scale test data for subbituminous coal (warm recycle) - table 2 of 5:

Secondary and overfire oxidant, Cyclone lance oxygen, and coal test data...

Table 8.13 Pilot scale test data for subbituminous coal (warm recycle) - table 3 of 5:

Natural gas flow, convection pass and stack gases, and emissions data.

Table 8.14 Pilot scale test data for subbituminous coal (warm recycle) - table 4 of 5: Heat

transfer and temperature data.

Table 8.15 Pilot scale test data for subbituminous coal (warm recycle) - table 5 of 5:

Static and differential pressures and miscellaneous data 
Table 8.16 Pilot scale test data for bituminous coal - table 1 of 5: test parameters, ambient conditions, and primary and tertiary oxidant data .267

Table 8.17 Pilot scale test data for bituminous coal - table 2 of 5: Secondary and overfire oxidant, Cyclone lance oxygen, and coal test data 268

Table 8.18 Pilot scale test data for bituminous coal - table 3 of 5: Natural gas flow, convection pass and stack gases, and emissions data

Table 8.19 Pilot scale test data for bituminous coal - table 4 of 5: Heat transfer and temperature data.

Table 8.20 Pilot scale test data for bituminous coal - table 5 of 5: Static and differential pressures and miscellaneous data.

Table 8.21 A list of the 251 boilers evaluated for geologic $\mathrm{CO}_{2}$ storage potential 


\section{REFERENCES}

1. White, M.D. and Oostrom, M. STOMP: Subsurface Transport Over Multiple Phases, Version 4.0, User's Guide. Richland, WA : Pacific Northwest National Laboratory, 2006.

2. United States Department of Energy / NETL. Pulverized Coal Oxycombustion Power Plants. Revision 2, August 2008. Final Report. DOE/NETL-2007/1291.

3. Lemmon, E.W., Huber, M.L. and McLinden, M.O. NIST Standard Reference Database 23: Reference Fluid Thermodynamic and Transport Properties-REFPROP, Version 8.0. [Online] National Institute of Standards and Technology, Gaithersburg MD, 2007. http://www.nist.gov/srd/nist23.cfm.

4. Equations of state for the calculation of fluid-phase equilibria. Wei, Y.S. and Sadus, R.J. 2000, AIChE Journal, Vol. 46, pp. 469-196.

5. Fetter, C.W. Applied Hydrogeology, 4th Edition. s.l. : Prentice Hall, 2000.

6. United States Environmental Protection Agency. Technical Program Overview: Underground Injection Control Regulations. [Online] December 2002. http://www.epa.gov/ogwdw/uic/pdfs/techguide_uic_tech_overview_uic_regs.pdf. EPA 816-R02-025.

7. United States Federal Government. 40 CFR Part 261 Subpart D. Hazardous Waste Management System; Land Disposal Restrictions; Final Rule. [Online] (51FR40572, November 7, 1986). http://www.access.gpo.gov/cgi-bin/cfrassemble.cgi?title=200540. 40 C.F.R. Parts 144, $148,260,261,262,264,265,268,270$, and 271.

8. National Energy Technology Laboratory. Carbon Sequestration Atlas of the United States and Canada. United States : s.n., 2007.

9. - Carbon Sequestration Atlas of the United States and Canada, Third Edition. United States : s.n., 2010.

10. Wellbore Integrity Study. Christopher, C. and Crow, W. Alexandria, VA : s.n., May 7-10, 2007. Sixth Annual Conference on Carbon Capture and Sequestration.

11. In-situ characteristics of acid-gas injection operations in the Alberta basin, Western Canada: Demonstration of CO2 geological storage. Bachu, S. and Haug, K. [ed.] S.M. Benson. London : Elsevier, 2005, Carbon Dioxide capture for Storage in Deep Geologic Formations Results from the CO2 Capture Project, Vol. 2: Geologic Storage of Carbon Dioxide with Monitoring and Verification, pp. 867-876.

12. Carbon dioxide corrosion in oilwell cements. SPE. . Bruckdorfer, R. Billings, Montana : s.n., 19-21 May 1986. Society of Petroleum Engineers, Rocky Mountain Regional Meeting. Paper 15176-MS. 
13. The potential for $\mathrm{CO} 2$ leakage from storage sites in geological media: analysis of well distribution in mature sedimentary basins. Gasda, S.E., Bachu, S. and Celia, M.A. 2004, Environmental Geology, Vols. 46(6-7), pp. 707-720.

14. Scherer, G.W., et al. Leakage of CO2 through Abandoned Wells: Role of Corrosion of Cement. [ed.] D.C. Thomas and S.M. Benson. The CO2 Capture and Storage Project (CCP), Volume II. 2005, pp. 823-844.

15. Pruess, K., et al. Intercomparison of Numerical Simulation Codes for Geologic Disposal of CO2. Berkeley, CA : Lawrence Berkeley National Laboratory, 2002. p. 86.

16. Assessment of CO2 Injection Potential and Monitoring Well Location at the Mountaineer Power Plant Site. Bacon, D.H. et al. Trondheim, Norway : Elsevier, 2006. 8th International Conference on Greenhouse Gas Control Technologies.

17. Oxy-fuel Combustion: Progress and Remaining Issues. Sarofim, A.F. Windsor, CT : s.n., January 25-26, 2007. 2nd IEAGHG International Oxy-Combustion Workshop.

18. Summary of Test Results from Babcock \& Wilcox's 30-MWth Oxy-Coal Pilot Plant. Palo Alto, CA : EPRI, 2009. EPRI Document \#1017508.

19. The Babcock \& Wilcox Company. Chapter 40: Pressure, Temperature, Quality and Flow Measurement. [ed.] J.J. Kitto and S.C. Stultz. Steam: Its generation and use, Edition 41. 2005.

20. Overview of Australian-Japanese Callide - An oxy-fuel demonstration project. Spero, C. Cottbus, Germany : s.n., November 29-30, 2005. The IEA Greenhouse Gas R\&D Program Inaugural Workshop, Oxy-Fuel Combustion Research Network.

21. Adaptation of gas emissivity models for CFD based radiative transfer in large air-fired and oxy-fired furnaces. Gupta, R., et al. Clearwater, FL : s.n., 2006. The 31st International Technical Conference on Coal Utilization and Fuel Systems, Coal Technology: What is Next?

22. Combustion tests and modeling of oxy-fuel process. Anderson, K. Hilton Garden Inn, Windsor CT : s.n., January 25-26, 2007. The 2nd Workshop of the International OxyCombustion Research Network.

23. Flame and radiation characteristics of gas-fired O2/CO2 combustion. Andersson, K. and Johnsson, F. 2007, Fuel, Vol. 86. pp. 656-668.

24. Chen, Z., Sayre, A.N. and Wessel, R.A. CFD modeling of the CEDF under oxy-firing and air-firing conditions. The Babcock \& Wilcox Power Generation Group, Inc. July 15, 2009. Project Final Report.

25. CFD modeling of oxy-fuel combustion in coal-fired utility boiler. Chen, Z., et al. Pittsburgh, PA : s.n., September 29 - October 2, 2008. The 25th Annual International Pittsburgh Coal Conference. 
26. United States Department of Energy / NETL. Carbon Dioxide Capture from Existing Coal-Fired Power Plants. (Original Issue Date, December 2006), Revision Date, November 2007. Final Report. DOE/NETL-401/110907.

27. - Cost and Performance Baseline for Fossil Energy Plants. (Original Issue Date, May 2007), Revision 1, August 2007. Final Report. DOE/NETL-2007/1281.

28. Aspects of induced seismic activity and deep-well sequestration of carbon dioxide.

Sminchak, J.R. and Gupta, N. 2003, Environmental Geosciences, Vols. 10, No. 2, pp. 81-89.

29. Petersen, M.D., et al. Documentation for the 2008 Update of the United States National Seismic Hazrd Maps. US Geological Survey Open-File Report 2008-1128, 61 p..

30. Ahmed, Tarek. Reservoir Engineering Handbook, 2nd Edition. s.1. : Elsevier, 2001. ISBN 978-0-88415-770-0.

31. Questions and Answers on Using the Class V Experimental Technology Well Classification for Pilot Geologic Sequestration Projects. [Online] United States Environmental Protection Agency. http://www.epa.gov/safewater/uic/wells_sequestration_questions.html.

32. Safe Water Drinking Act, 1980. SDWA Statute, Regulations \& Enforcement. [Online] Updated 1996. http://www.epa.gov/compliance/civil/sdwa/sdwaenfstatreq.html>..

33. The low cost of geological assessment for underground CO2 storage: Policy and economic implications. Fiedman, J., et al. 2006, Energy Conversion and Management, Vol. 47, pp. 18941901.

34. Gordon, S. and McBride, B.J. Computer Program for Calculation of Complex Chemical Equilibrium Compositions and Applications: I. Analysis. Lewis Research Center, National Aeronautics and Space Administration. 1994. NASA RP-1311.

35. Well Leakage Pathways and Their Importance to CO2/Cement Reactions: Analysis of LongTerm Cement Competence as Part of a Certification Framework for CO2 Sequestration Projects. Huerta, J. Alexandria, VA : s.n., May 7-10 2007. 6th Annual Conference on Carbon Capture and Sequestration.

36. International Energy Agency. IEA Energy Technology Essentials: CO2 Capture and Storage . [Online] www.iea.org/Textbase/techno/essentials.htm. IEA Document ETE01.

37. Kee, R.J., et al. CHEMKIN-III: A Fortran Chemical Kinetics Package for the Analysis of Gas-Phase Chemical and Plasma Kinetics. Sandia National Laboratories. 1996. Report SAND 96-8216.

38. Challenges For Offshore Transport Of Anthropogenic Carbon Dioxide. Race, J.M, Seevam, P.N. and M.J., Downie. 2007. Proceedings of OMAE2007, 26th International Conference on Offshore Mechanics and Arctic Engineering. 
39. Cost and Performance of Fossil Fuel Power Plants with CO2 Capture and Storage. Rubin, E., Chen, C. and Rao, A. September 2007, Energy Policy, Vols. 35, Issue 9, pp. 4444-4454.

40. Calculating Critical Transitions of Fluid Mixtures: Theory vs. Experiment. Sadus, R.J. August 1994, AIChE Journal, Vols. 40, No. 8.

41. Construction Of A CO2 Pipeline Test Rig For R\&D And Operator Training. de Koeijer, G., et al. Amsterdam : Global Pipeline Monthly and Clarion Technical Conferences, May 2007. Transmission of $\mathrm{CO} 2, \mathrm{H} 2$, and biogas: exploring new uses for natural gas pipelines.

42. Carbon Dioxide Pipelines for Sequestration in the UK: Engineering Gap Analysis. Seevam, P.N., Race, J.M. and Downie, M.J. Amsterdam : Global Pipeline Monthly and Clarion Technical Conferences, May 2007. Transmission of CO2, H2, and biogas: exploring new uses for natural gas pipelines.

43. Developing a Better Understanding of the Cost of CO2 Transport and Storage: Moving Beyond a Fixed Storage Cost Assumption. Sminchak, J., et al. Pittsburgh, PA : s.n., 2007. Proceedings of the Sixth Annual Conference on Carbon Capture and Sequestration.

44. Engineering and Economic Assessment of Carbon Dioxide Sequestration in Saline

Formations. Smith, L.A., et al. Journal of Energy \& Environmental Research, Vol. 2, pp. 5-22.

45. United States Environmental Protection Agency. Using the Class V Experimental Technology Well Classification for Pilot Carbon Geologic Sequestration Projects- UIC Program Guidance. 2007. UICPG \#83. 


\section{LIST OF ACRONYMS AND ABBREVIATIONS}

AEP

$\mathrm{AL}$

AP

API

AQCS

AR

ART

ASPEN

ASTM

ASU

ASU-C

ASU-F

$\mathrm{B} \& \mathrm{~W}$

$\mathrm{Ca}$

CAPEX

CCS

CEDF

$\operatorname{CEM}(\mathrm{S})$

CFD

CHX

$\phi$

Comp

$\mathrm{CO}$

Cool
American Electric Power

Air Liquide

Auxiliary power

American Petroleum Institute

Air quality control system

Argon

Absorber recirculation tank

Process analysis software

American Society for Testing and Materials

Air Separation Unit

Air separation unit (Conventional design)

Air separation unit (Future design)

The Babcock \& Wilcox Company

Calcium

Capital expense

Carbon Capture and Storage

Clean Environment Development Facility

Continuous emissions monitoring (system)

Computational fluid dynamics

Condensing heat exchanger

Cents

Compression

Carbon monoxide

Cool recycle 
COMO

$\mathrm{CO}_{2}$

CPPDB

CPU

CPU-C

CPU-F

CVAAS

CYC

${ }^{\circ} \mathrm{C}$

DAS

DCCPS

D\&E

DOE

EOR

EOS

EPA

EPC

ESP

${ }^{\circ} \mathrm{F}$

FCV

FD

FE

FEGT

FF
B\&W's proprietary COmbustion MOdel CFD code Carbon dioxide NETL's Coal Power Plant Database Compression and Purification Unit Compression and purification unit (Conventional design) Compression and purification unit (Future design) Cold vapor atomic absorption spectrometry Cyclone Degrees Celsius Data acquisition system Direct contact cooler and polishing scrubber (aka sodium scrubber/quench cooler or polishing scrubber Delivered and Erected US Department of Energy Enhanced oil recovery Equation of State US Environmental Protection Agency Engineer, procure, construct Electrostatic precipitator Degrees Fahrenheit Flow control valve Forced Draft Flow (measuring) element Furnace exit gas temperature Fabric Filter 
FGD

FTMA

GF

GP

GQCS

GS

$\mathrm{H}_{2} \mathrm{O}$

HI

HMI

HP

HVT

ID

IR

IGCC

$\mathrm{k}$

$\mathrm{kW}$

$\mathrm{kWh}$

$\mathrm{lb}$

$\mathrm{lb} / \mathrm{h}$

LCOE

LI

LF

LOI

LOX

MFT
Flue gas desulfurization

Field transportable mercury analyzer

Greenfield

Gross power

Gas quality control system

Geologic sequestration

Water

Heat Integration

Human-machine interface

High pressure

High velocity thermocouple

Induced Draft

Infrared (light)

Integrated Gasification Combined Cycle

Kilo, one thousand

Kilowatts

Kilowatt hours

Pounds

Pounds per hour

Levelized cost of electricity

Limestone Injection

Levelization Factor

Loss on ignition

Liquid oxygen

Master fuel trip 
MMSCF

MWe

MRCSP

$\mathrm{N}_{2}$

ND

NDIR

NETL

NIST

NO

$\mathrm{NO}_{2}$

NPHR

NTU

$\mathrm{O}_{2}$

OCC

ODS

OFA

OPEX

O\&M

Oxy

PA

PC

PCC

PHREEQC

P\&ID

ppm
Million standard cubic feet

Mega-watts electric

Midwestern Regional Carbon Sequestration Partnership

Nitrogen

North Dakota

Nondispersive infrared

National Energy Technology Laboratory National Institute of Standards and Technology

Nitrogen oxide

Nitrogen dioxide

Net plant heat rate

Number of (gas phase) Transfer Units (equal to $-\ln (1-\mathrm{E})$, where $\mathrm{E}$ is the overall $\mathrm{SO}_{2}$ removal efficiency)

Oxygen

Oxy-combustion capture Oxygen distribution system

Overfire air Operating expense Operating and maintenance Oxy-combustion Primary air (Wall-fired) Pulverized Coal Post-combustion capture A computer program for geochemical calculations Process and Instrumentation Diagram Parts per million 
ppmv

PRB

Pri

Pri + CPU

Retro

RCSP

RFG

S

SBS-II

SC

SDA

SI

$\mathrm{SO}_{2}$

$\mathrm{SO}_{3}$

SR

STOMP

STOMP-WCS-R

SubC

TCHR

TE

tm

Ton

TSA

TS\&M

UIC
Parts per million by volume

Powder River Basin

Primary

The combined primary recycle and CPU streams

Retrofit

Regional Carbon Sequestration Partnerships

Recycled flue gas

Sulfur

Small Boiler Simulator II Supercritical (steam conditions) Spray dryer absorber (dry scrubber)

Sorbent Injection

Sulfur dioxide

Sulfur trioxide

Stoichiometric ratio

Subsurface Transport Over Multiple Phases (computer model) STOMP-Water, $\mathrm{CO}_{2}$, salt-reactions Subcritical (steam conditions)

Turbine cycle heat rate

Temperature (measuring) element or thermocouple

Metric ton

Short ton

Temperature Swing Absorption Transportation, storage and monitoring Underground Injection Control 
USC

USDW

UV

WAG

Warm

WFGD
Ultra-supercritical (steam conditions)

Underground source of drinking water

Ultravoilet (light)

Water alternating gas (process)

Warm recycle

Wet flue gas desulfurization (wet scrubber) 


\section{APPENDIX}

\subsection{Methods for Flue Gas Purification \& Compression Train Study}

The compositions of the flue gases for the 3 coals were obtained from $\mathrm{B} \& \mathrm{~W}$ and are listed in Table A.1. For these simulations, the dry basis compositions were used.

General assumptions (for all coals):

Mass flow rates: $1,200 \mathrm{klb} / \mathrm{h}$

Temperature: $137^{\circ} \mathrm{F}$

Pressure: $15.24 \mathrm{psia}$

Barometric pressure: $14.69 \mathrm{psia}$

Assumptions on pollutants emissions downstream the flue gas treatment units:

200ppmv of CO dry basis for all coals

750,300 and 460ppmv $\mathrm{NO}_{\mathrm{X}}$ dry basis (accounted for as $100 \% \mathrm{NO}_{2}$ in simulations and not $\left.\left(80 \% \mathrm{NO}, 20 \% \mathrm{NO}_{2}\right)\right)$ for ND Lignite, Decker and Ill\#6 coals respectively

$\mathrm{Hg}$ and particulates are not taken into account.

It must be stressed that the compositions in Table A.1 represent a worst-case-scenario of air infiltration into the boiler unit (i.e. boiler, ducts and air heaters) and it is possible that nitrogen levels in the flue gas will be up to $50 \%$ lower than those shown above.

Power calculations

Power consumption in various stages of each process is calculated as follows:

Dry and wet compression: The compression power in these stages is calculated by the "log formula":

$P=0.1 \times Q \times \log (\tau)$

where $\mathrm{P}=$ Power $(\mathrm{kW})$;

$Q=$ molar flow $\left(\mathrm{Nm}^{3} / \mathrm{h}\right)$ on a dry basis; 
$\tau=$ compression ratio $\left(\mathrm{P}_{\text {outlet }} / \mathrm{P}_{\text {inlet }}\right.$ in absolute pressure units $)$.

This formula depicts a compressor with a total adiabatic efficiency close to $70 \%$, including mechanical and electrical losses.

Recovered energy from vent gas expansion: In the purification schemes, non-condensable gases are vented from the process. These gases are at high pressure and therefore contain energy which can be recovered in a turbo-expander. The power recovered from these gases is calculated as follows:

$P=0.05 \times Q \times \log (\tau)$

This formula assumes that only half the power is recoverable, and is a good approximation when accounting for the energy of the boiling feed water used to heat the gases before the turbo expander.

Liquid pump: The power required by the liquid pump was calculated in HySys with an adiabatic efficiency of $85 \%$.

The overall specific energy required by the process is the net power consumed per ton of $\mathrm{CO}_{2}$ captured in the product stream.

$E(k W h /$ ton $)=\frac{P(k W)}{\dot{m}(\text { ton } / h)}$

where $\mathrm{E}$ is the specific energy, $\mathrm{P}$ is the net power and $\dot{m}$ is the $\mathrm{CO}_{2}$ flow rate in the product. 


\subsection{Tabulated Pilot-scale Test Data}

The rows of the tables in this appendix are ordered first by air/oxy-firing, then nominal load (5 or $6 \mathrm{MBtu} / \mathrm{h})$, then Cyclone stoichiometric ratio.

\begin{tabular}{|c|c|c|c|c|c|c|c|c|c|c|c|c|c|c|c|c|c|c|c|c|c|}
\hline & & st Pa & amete & & & & $\begin{array}{l}\text { Amb } \\
\text { Condi }\end{array}$ & $\begin{array}{l}\text { jient } \\
\text { itions }\end{array}$ & & & & & Prim & lary and & d Terti & iary Oxi & kidant & & & & \\
\hline Test Name & Start of Test & 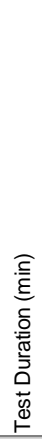 & 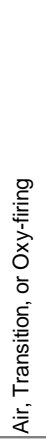 & 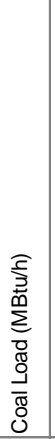 & 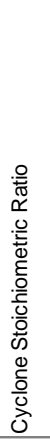 & 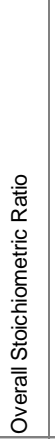 & 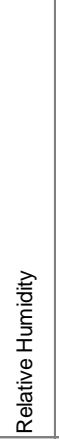 & 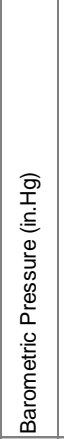 & 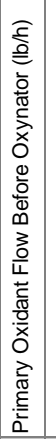 & 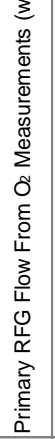 & 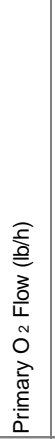 & 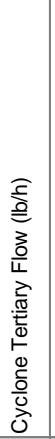 & 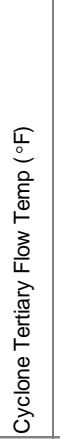 & 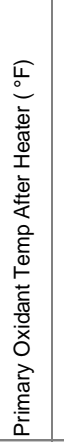 & 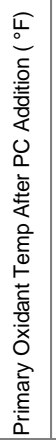 & 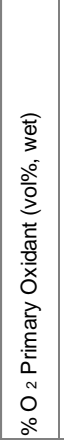 & 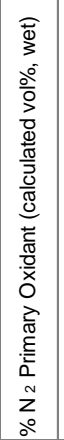 & 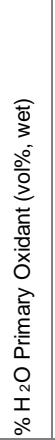 & 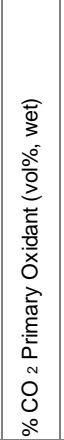 & 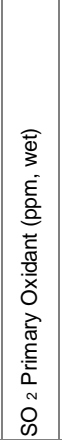 & 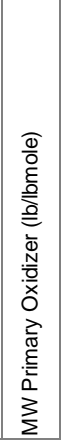 \\
\hline Lignite Air 5 MM/BTU & 9/1/2009 8:35 & 45 & Air & 4.87 & 0.91 & 1.20 & $51 \%$ & 29.34 & 744 & & & 11 & 55 & 323 & 163 & 20.75 & 78.17 & 1.08 & & & 28.72 \\
\hline Lignite Air test \#4 & 8/27/2009 13:27 & 22 & Air & 4.80 & 0.92 & 1.22 & $71 \%$ & 29.12 & 807 & & & 9 & 71 & 314 & 157 & 20.54 & 77.41 & 2.05 & & & 28.62 \\
\hline Lignite Air test \#4B & 8/31/2009 13:33 & 38 & Air & 4.60 & 0.92 & 1.22 & $37 \%$ & 28.58 & 842 & & & 14 & 66 & 320 & 171 & 20.75 & 78.18 & 1.07 & & & 28.72 \\
\hline Lignite Air Test 2 6MBtu/hr a & 9/3/2009 10:21 & 60 & Air & 5.47 & 0.99 & 1.28 & $51 \%$ & 29.18 & 795 & & & 32 & 83 & 315 & 155 & 20.68 & 77.92 & 1.41 & & & 28.69 \\
\hline Lignite Air Test \#3 & 9/2/2009 13:17 & 30 & Air & 5.01 & 1.11 & 1.48 & $31 \%$ & 29.26 & 776 & & & 5 & 71 & 309 & 159 & 20.75 & 78.18 & 1.07 & & & 28.72 \\
\hline Lignite Air Test \#2 & 9/2/2009 12:30 & 34 & Air & 5.06 & 1.12 & 1.42 & $34 \%$ & 29.28 & 769 & & & 5 & 69 & 309 & 158 & 20.74 & 78.14 & 1.12 & & & 28.72 \\
\hline lignite air test 1 & 9/2/2009 14:01 & 31 & Air & 5.08 & 1.15 & 1.37 & $33 \%$ & 29.25 & 723 & & & 4 & 73 & 307 & 150 & 20.73 & 78.12 & 1.14 & & & 28.72 \\
\hline lignite air test1B & 9/2/2009 14:58 & 40 & Air & 5.88 & 1.00 & 1.20 & $30 \%$ & 29.23 & 732 & & & 5 & 74 & 311 & 149 & 20.75 & 78.18 & 1.07 & & & 28.72 \\
\hline lignight oxy test 09/01/09 & 9/1/2009 19:32 & 16 & Oxy & 4.15 & 1.03 & 1.29 & $42 \%$ & 29.25 & 813 & 785 & 104 & 6 & 71 & 321 & 183 & 17.29 & 14.30 & 4.42 & 63.69 & 1530 & 38.45 \\
\hline lignite oxy test 4.3Mbtu & 8/31/2009 18:49 & 6 & Oxy & 4.08 & 1.23 & 1.39 & $51 \%$ & 29.21 & 846 & 810 & 82 & 13 & 76 & 321 & 177 & 15.55 & 13.51 & 4.87 & 65.75 & 1498 & 38.66 \\
\hline lignite oxy test 16b & 8/27/2009 18:09 & 21 & Oxy & 4.68 & 0.93 & 1.15 & $67 \%$ & 29.08 & 818 & 823 & 116 & 13 & 81 & 313 & 156 & 16.17 & 24.03 & 4.99 & 54.57 & 1839 & 36.93 \\
\hline lignite oxy test 6 & 9/3/2009 17:20 & 13 & Oxy & 5.47 & 0.94 & 1.14 & $35 \%$ & 29.09 & 825 & 842 & 166 & 18 & 87 & 312 & 147 & 20.49 & 14.98 & 6.74 & 57.59 & 1935 & 37.43 \\
\hline lignite oxy test 5 & 9/3/2009 16:37 & 33 & Oxy & 5.40 & 1.04 & 1.17 & $34 \%$ & 29.09 & 822 & 837 & 166 & 20 & 89 & 313 & 146 & 21.04 & 15.09 & 6.66 & 57.05 & 1639 & 37.36 \\
\hline Lignite Oxy Test 16 & 8/27/2009 17:37 & 24 & Oxy & 4.57 & 1.06 & 1.32 & $65 \%$ & 29.08 & 812 & 808 & 116 & 10 & 80 & 313 & 158 & 18.39 & 21.81 & 4.85 & 54.61 & 1610 & 37.00 \\
\hline lignite oxy test 9 & 9/2/2009 19:01 & 20 & Oxy & 5.55 & 1.04 & 1.26 & $38 \%$ & 29.20 & 847 & 844 & 122 & 5 & 76 & 308 & 185 & 17.38 & 13.87 & 5.77 & 62.21 & 1615 & 37.96 \\
\hline
\end{tabular}

Table 8.1 Pilot scale test data for lignite - table 1 of 5: test parameters, ambient conditions, and primary and tertiary oxidant data 


\begin{tabular}{|c|c|c|c|c|c|c|c|c|c|c|c|c|c|c|c|c|c|c|c|c|c|c|c|}
\hline & \multicolumn{14}{|c|}{ Secondary and Overfire Oxidant } & \multicolumn{3}{|c|}{ Cyclone Lance Oxygen } & \multicolumn{6}{|c|}{ Fuel } \\
\hline Test Name & 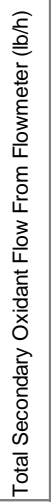 & 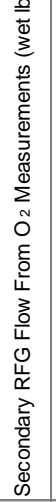 & 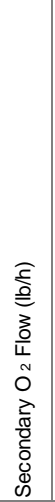 & 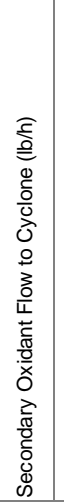 & 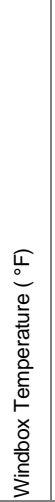 & 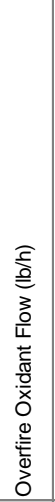 & 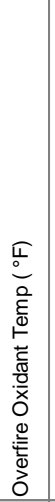 & 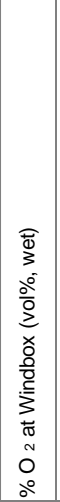 & 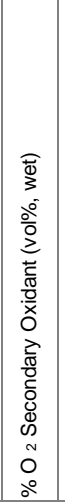 & 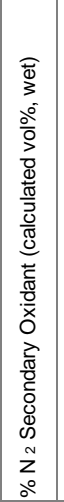 & 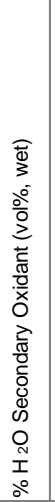 & 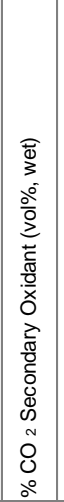 & 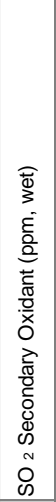 & 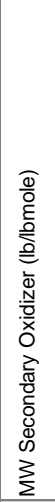 & 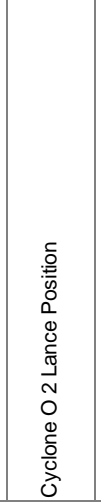 & 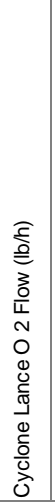 & 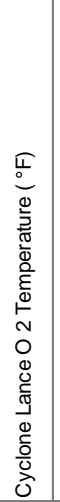 & 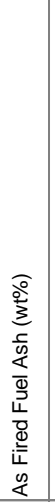 & 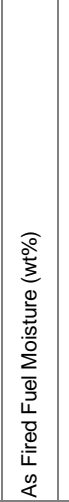 & 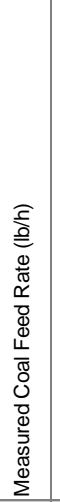 & 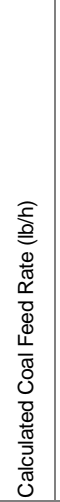 & 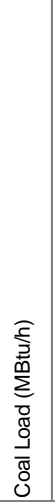 & 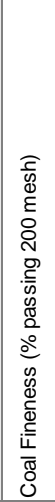 \\
\hline Lignite Air 5 MM/BTU A & 3898 & & & 2792 & 684 & 1118 & 684 & 20.51 & 20.74 & 78.18 & 1.08 & & & 28.72 & Sec. Duct & & 59 & 8.05 & 23.66 & 595 & 592 & 4.87 & 44.19 \\
\hline Lignite Air test \#4 & 3897 & & & 2756 & 684 & 1151 & 684 & 20.30 & 20.54 & 77.41 & 2.05 & & & 28.62 & Sec. Duct & & 75 & 8.05 & 23.66 & 620 & 584 & 4.80 & 45.86 \\
\hline Lignite Air test \#4B & 3668 & & & 2599 & 682 & 1080 & 682 & 20.39 & 20.74 & 78.19 & 1.07 & & & 28.72 & Sec. Duct & & 69 & 8.33 & 23.66 & 613 & 562 & 4.60 & 44.19 \\
\hline Lignite Air Test 2 6MBtu/hr a & 4706 & & & 3485 & 689 & 1234 & 689 & 20.56 & 20.67 & 77.92 & 1.40 & & & 28.69 & Sec. Duct & & 69 & 8.05 & 23.66 & 670 & 665 & 5.47 & 44.19 \\
\hline Lignite Air Test \#3 & 5030 & & & 3594 & 691 & 1450 & 691 & 20.69 & 20.74 & 78.19 & 1.07 & & & 28.72 & Sec. Duct & & 76 & 8.33 & 23.66 & 608 & 612 & 5.01 & 44.19 \\
\hline Lignite Air Test \#2 & 4853 & & & 3663 & 689 & 1204 & 689 & 20.72 & 20.73 & 78.15 & 1.12 & & & 28.72 & Sec. Duct & & 75 & 8.33 & 23.66 & 611 & 618 & 5.06 & 44.19 \\
\hline lignite air test 1 & 4657 & & & 3789 & 690 & 882 & 690 & 20.84 & 20.73 & 78.13 & 1.14 & & & 28.72 & 2 Sec. Duct & & 77 & 8.33 & 23.66 & 605 & 620 & 5.08 & 44.19 \\
\hline lignite air test1B & 4740 & & & 3848 & 690 & 905 & 690 & 20.83 & 20.74 & 78.19 & 1.07 & & & 28.72 & Sec. Duct & & 78 & 8.33 & 23.66 & 694 & 718 & 5.88 & 44.19 \\
\hline lignight oxy test 09/01/09 & 3530 & 3121 & 450 & 2554 & 681 & 1173 & 681 & 19.81 & $\mid 19.22$ & $\mid 13.97$ & 4.32 & 62.20 & 1495 & 38.30 & Sec. Duct & 200 & 71 & 8.33 & 23.66 & 567 & 507 & 4.15 & 44.19 \\
\hline lignite oxy test 4.3Mbtu & 3881 & 3416 & 456 & 3423 & 684 & 726 & 684 & 19.51 & 18.81 & 12.99 & 4.68 & 63.20 & 1440 & 38.40 & Sec. Duct & 209 & 68 & 8.33 & $\mid 23.66$ & 590 & 498 & 4.08 & 44.19 \\
\hline lignite oxy test 16b & 3575 & 3116 & 587 & 2739 & 682 & 1030 & 682 & 21.16 & 20.86 & 22.68 & 4.71 & 51.51 & 1736 & 36.65 & Sec. Duct & 120 & 74 & 8.05 & 23.66 & 644 & 569 & 4.68 & 45.86 \\
\hline lignite oxy test 6 & 4225 & 3457 & 778 & 3501 & 686 & 969 & 686 & 23.91 & 23.07 & 14.49 & 6.52 & 55.73 & 1873 & 37.25 & Sec. Duct & 0 & 80 & 8.05 & 23.66 & 620 & 666 & 5.47 & 57.83 \\
\hline lignite oxy test 5 & 3999 & 3241 & 777 & 3655 & 685 & 586 & 685 & 25.42 & 24.58 & 14.42 & 6.36 & 54.49 & 1566 & 37.12 & Sec. Duct & 0 & 81 & 8.05 & 23.66 & 595 & 657 & 5.40 & 57.83 \\
\hline Lignite Oxy Test 16 & 3540 & 3039 & 582 & 2700 & 681 & 1032 & 681 & 23.30 & 22.92 & 20.60 & 4.58 & 51.58 & 1520 & 36.72 & Sec. Duct & 146 & 75 & 8.05 & 23.66 & 625 & 555 & 4.57 & 45.86 \\
\hline lignite oxy test 9 & 4827 & 4063 & 690 & 3905 & 690 & 1232 & 690 & 20.73 & 19.81 & 13.46 & 5.60 & 60.38 & 1567 & 37.78 & Sec. Duct & 193 & 74 & 8.33 & 23.66 & 703 & 677 & 5.55 & 44.19 \\
\hline
\end{tabular}

Table 8.2 Pilot scale test data for lignite - table 2 of 5: Secondary and overfire oxidant, Cyclone lance oxygen, and fuel test data 


\begin{tabular}{|c|c|c|c|c|c|c|c|c|c|c|c|c|c|c|c|c|}
\hline & \multicolumn{9}{|c|}{ Convection Pass Gases } & \multicolumn{7}{|c|}{ Stack/Emissions } \\
\hline Test Name & 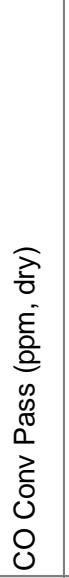 & 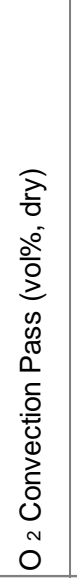 & 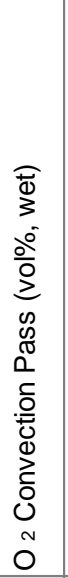 & 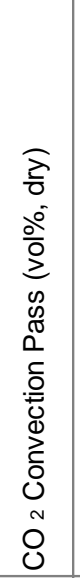 & 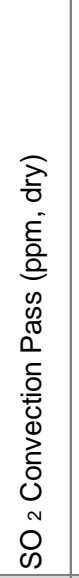 & 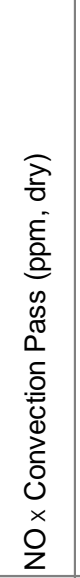 & 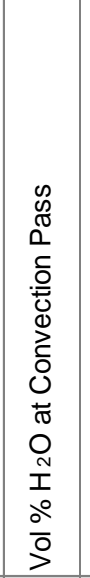 & 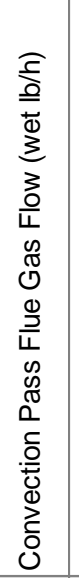 & 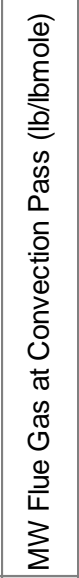 & 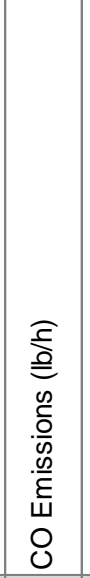 & 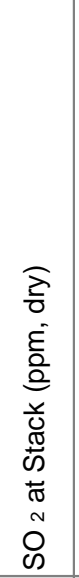 & 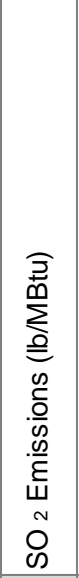 & 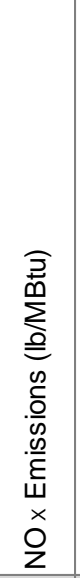 & 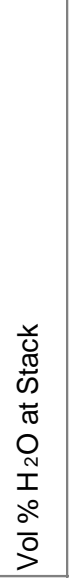 & 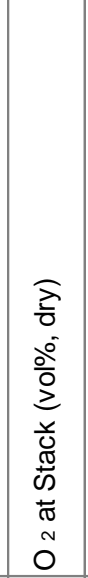 & 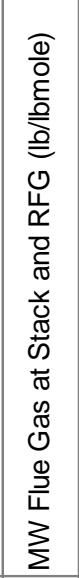 \\
\hline Lignite Air 5 MM/BTU a & 27 & 3.40 & 3.18 & 16.39 & 642 & 452 & 11.38 & 5198 & 29.33 & 0.119 & 578 & 1.185 & 0.668 & 5.89 & 5.144 & 30.27 \\
\hline Lignite Air test \#4 & 6 & 3.74 & 3.34 & 16.09 & 663 & 473 & 11.99 & 5252 & 29.22 & 0.028 & 592 & 1.242 & 0.714 & 4.39 & 5.227 & 30.31 \\
\hline Lignite Air test \#4B & 86 & 3.67 & 3.33 & 16.20 & 677 & 392 & 11.13 & 5036 & 29.35 & 0.364 & 600 & 1.265 & 0.596 & 4.18 & 5.352 & 30.45 \\
\hline Lignite Air Test $26 \mathrm{MBtu} / \mathrm{hr}$ & 652 & 4.61 & 3.79 & 15.05 & 614 & 483 & 11.10 & 6156 & 29.22 & 3.376 & 532 & 1.162 & 0.766 & 6.61 & 6.080 & 29.97 \\
\hline Lignite Air Test \#3 & 90 & 6.80 & 5.98 & 13.21 & 473 & 536 & 9.69 & 6382 & 29.20 & 0.499 & 411 & 1.044 & 0.982 & 4.34 & 7.959 & 29.88 \\
\hline Lignite Air Test \#2 & 155 & 6.26 & 5.64 & 13.66 & 493 & 599 & $\mid 10.07$ & 6201 & 29.20 & 0.818 & 429 & 1.039 & 1.047 & 4.33 & 7.625 & 29.95 \\
\hline lignite air test 1 & 5 & 5.78 & 5.34 & 14.13 & 548 & 710 & 10.48 & 5962 & 29.20 & 0.027 & 484 & 1.109 & 1.174 & 4.32 & 7.154 & 30.04 \\
\hline lignite air test1B & 6 & 3.55 & 3.26 & 16.27 & 652 & 712 & 11.62 & 6144 & 29.29 & 0.033 & 582 & 1.168 & 1.028 & 4.67 & 5.156 & 30.33 \\
\hline lignight oxy test 09/01/09 & 27 & 5.57 & 4.97 & 79.04 & 2023 & 915 & 14.71 & 5404 & 37.57 & 0.019 & 1840 & 0.736 & 0.263 & 5.05 & 6.420 & 39.42 \\
\hline lignite oxy test 4.3Mbtu & 27 & 6.73 & 5.76 & 78.76 & 1937 & 1196 & 14.12 & 5838 & 37.71 & 0.019 & 1754 & 0.689 & 0.338 & 5.39 & 7.202 & 39.43 \\
\hline lignite oxy test $16 b$ & 60 & 3.14 & 2.78 & 69.81 & 2432 & 659 & 15.90 & 5444 & 35.99 & 0.054 & 2241 & 0.956 & 0.202 & 5.73 & 4.205 & 37.69 \\
\hline lignite oxy test 6 & 25 & 3.13 & 2.91 & 79.41 & 2725 & 716 & 18.21 & 6185 & 36.76 & 0.023 & 2558 & 1.004 & 0.202 & 8.18 & 4.015 & 38.59 \\
\hline lignite oxy test 5 & 27 & 3.98 & 3.64 & 78.33 & 2329 & 1254 & 18.34 & 5948 & 36.61 & 0.024 & 2163 & 0.850 & 0.354 & 8.07 & 4.873 & 38.51 \\
\hline Lignite Oxy Test 16 & 24 & 6.35 & 5.63 & 68.21 & 2156 & 985 & 15.54 & 5417 & 35.95 & 0.019 & 1962 & 0.803 & 0.289 & 5.58 & 7.014 & 37.81 \\
\hline lignite oxy test 9 & 896 & 5.07 & 4.17 & 80.03 & 2206 & 995 & 16.10 & 7039 & 37.37 & 0.879 & 1997 & 0.816 & 0.290 & 6.66 & 5.766 & 39.08 \\
\hline
\end{tabular}

Table 8.3 Pilot scale test data for lignite - table 3 of 5:

Convection pass and stack gases, and emissions data 


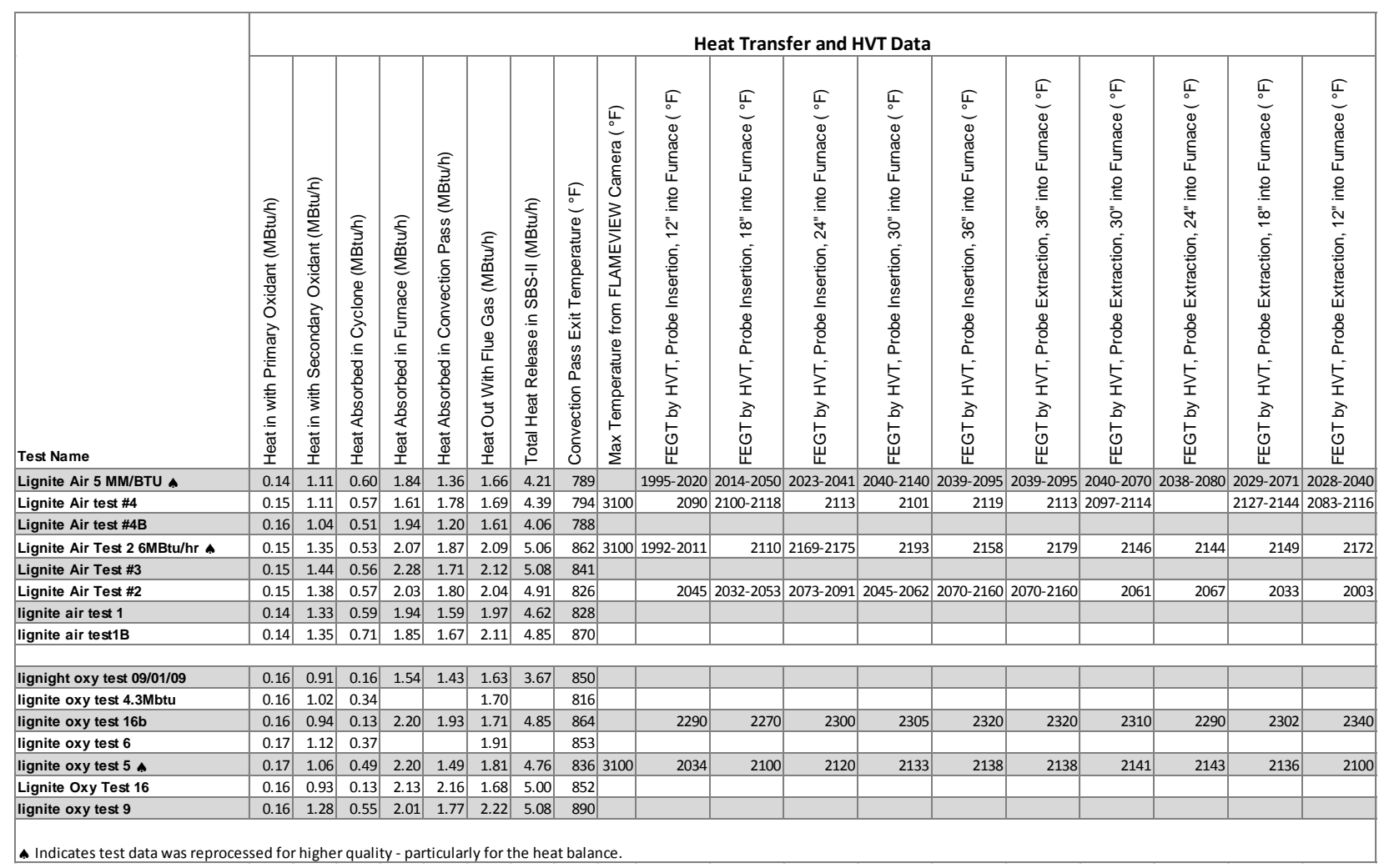

Table 8.4 Pilot scale test data for lignite - table 4 of 5:

Heat transfer and temperature data 


\begin{tabular}{|c|c|c|c|c|c|c|c|c|c|c|c|c|c|c|}
\hline & \multicolumn{9}{|c|}{ System Static and Differential Pressures } & \multicolumn{5}{|c|}{ Miscellaneous } \\
\hline Test Name & 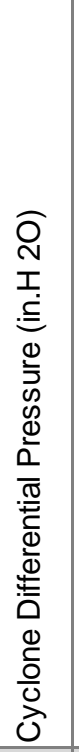 & 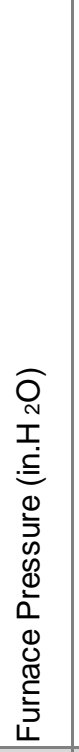 & 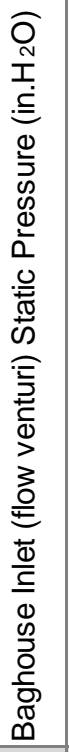 & 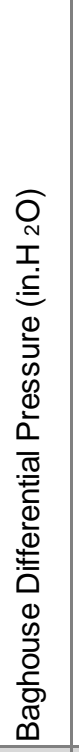 & 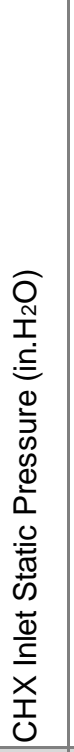 & 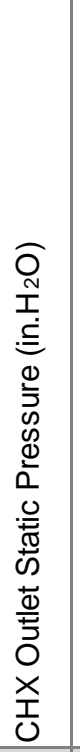 & 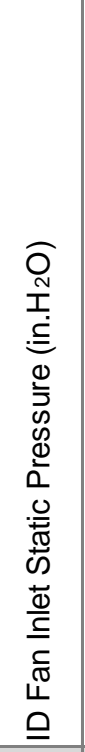 & 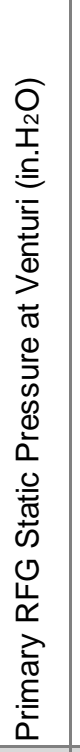 & 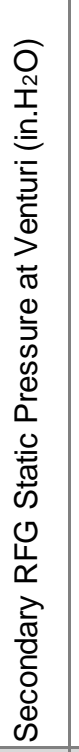 & 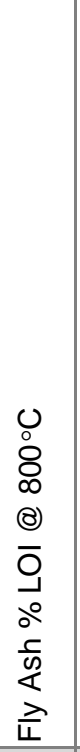 & 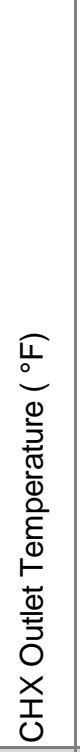 & 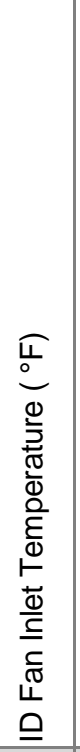 & 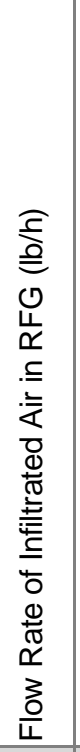 & 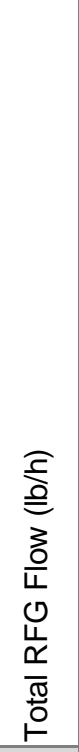 \\
\hline Lignite Air 5 MM/BTU A & 8.1 & 0.6 & $>0$ & 6.2 & -6.2 & 8.4 & -22.5 & 0.2 & 0.2 & 0.91 & 86 & 97 & & \\
\hline Lignite Air test \#4 & 8.1 & 0.2 & $>0$ & 3.6 & -3.8 & 8.8 & -18.4 & 0.3 & 0.4 & 1.12 & 88 & 105 & & \\
\hline Lignite Air test \#4B & 7.2 & 0.5 & $>0$ & 6.9 & -5.3 & 7.3 & -19.6 & 0.2 & 0.2 & 0.81 & 85 & 97 & & \\
\hline Lignite Air Test 2 6MBtu/hr & 10.4 & -0.5 & $>0$ & 7.1 & -6.5 & 14.7 & -30.5 & 0.3 & 0.3 & 1.04 & 102 & 102 & & \\
\hline Lignite Air Test \#3 & 11.3 & -0.2 & $>0$ & 6.7 & -7.9 & 15.5 & -34.8 & 0.3 & 0.3 & & 88 & 103 & & \\
\hline Lignite Air Test \#2 & 12.0 & -0.2 & $>0$ & 6.4 & -7.3 & 14.7 & -32.1 & 0.3 & 0.3 & 0.80 & 88 & 103 & & \\
\hline lignite air test 1 & 12.8 & 1.3 & $>0$ & 6.0 & -6.7 & 14.9 & -31.6 & 0.2 & 0.3 & 0.96 & 88 & 103 & & \\
\hline lignite air test1B & 13.5 & 0.1 & $>0$ & 6.8 & -7.5 & 15.1 & -33.8 & 0.2 & 0.3 & 0.80 & 90 & 106 & & \\
\hline lignight oxy test 09/01/09 & 4.3 & -0.5 & $>0$ & 3.5 & 0.5 & 9.8 & -9.9 & -0.2 & -0.4 & & 92 & 106 & 92 & 3906 \\
\hline lignite oxy test 4.3Mbtu & 7.6 & -0.6 & $>0$ & 3.2 & 1.6 & 11.9 & -9.8 & -0.3 & -0.7 & & 95 & 108 & 74 & 4226 \\
\hline lignite oxy test $16 \mathrm{~b}$ & 4.7 & 0.0 & $>0$ & 3.3 & -0.7 & 8.4 & -11.3 & -0.2 & -0.5 & & 96 & 116 & 142 & 3940 \\
\hline lignite oxy test 6 & 6.7 & 0.7 & $>0$ & 3.6 & 1.5 & 13.0 & -11.5 & -0.3 & -0.7 & & 109 & 109 & 134 & 4299 \\
\hline lignite oxy test 5 & 8.2 & -0.3 & $>0$ & 3.6 & 1.0 & 12.0 & -11.5 & -0.3 & -0.6 & 1.00 & 108 & 108 & 121 & 4077 \\
\hline Lignite Oxy Test 16 & 4.7 & 0.5 & $>0$ & 3.7 & -0.6 & 8.6 & -11.3 & -0.2 & -0.5 & 1.32 & 95 & 116 & 73 & 3846 \\
\hline lignite oxy test 9 & 9.8 & 0.8 & $>0$ & 5.0 & 0.4 & 20.1 & -21.7 & -0.5 & -1.2 & 1.13 & 102 & 117 & 145 & 4907 \\
\hline
\end{tabular}

Table 8.5 Pilot scale test data for lignite - table 5 of 5: Static and differential pressures and miscellaneous data 


\begin{tabular}{|c|c|c|c|c|c|c|c|c|c|c|c|c|c|c|c|c|c|c|c|c|c|}
\hline & & est $\mathrm{Pa}$ & ramete & & & & $\begin{array}{r}\text { Amb } \\
\text { Condi }\end{array}$ & $\begin{array}{l}\text { bient } \\
\text { litions }\end{array}$ & & & & & Prin & nary and & d Terti & iary Oxi & xidant & & & & \\
\hline Test Name & Start of Test & 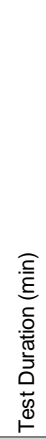 & 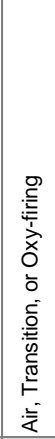 & 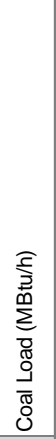 & 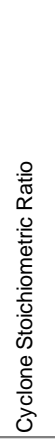 & 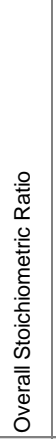 & 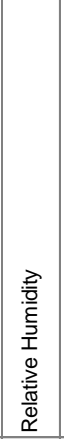 & 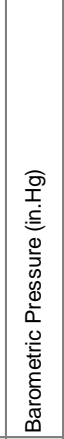 & 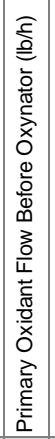 & 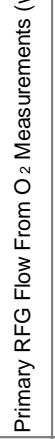 & 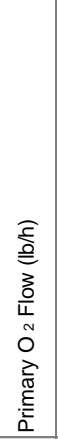 & 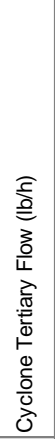 & 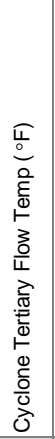 & 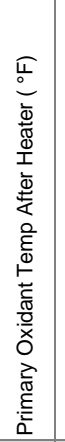 & 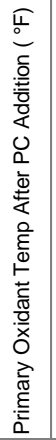 & 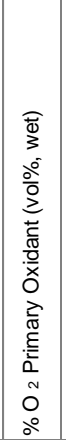 & 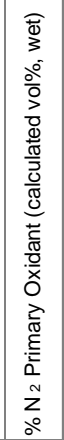 & 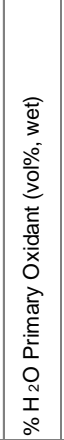 & 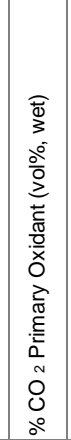 & 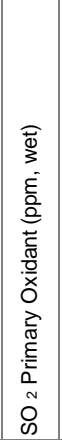 & 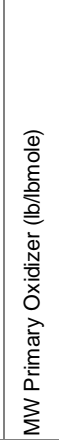 \\
\hline PRB AIR 01 & 8/4/2009 15:18 & 66 & Air & 5.25 & 0.91 & 1.18 & $59 \%$ & 28.88 & 798 & & & 41 & 85 & 1870 & data & 20.51 & 77.28 & 2.21 & & & 28.60 \\
\hline PRB Air Cyclone Test 2 A & 8/25/2009 9:28 & 57 & Air & 5.60 & 0.98 & 1.25 & $64 \%$ & 27.85 & 904 & & & 42 & 84 & 269 & 156 & 20.60 & 77.64 & 1.75 & & & 28.65 \\
\hline PRB Air Test \#3C & 8/13/2009 8:29 & 27 & Air & 5.78 & 0.87 & 1.20 & $66 \%$ & 29.12 & 867 & & & 6 & 63 & 269 & 150 & 20.60 & 77.61 & 1.79 & & & 28.64 \\
\hline PRB Air Test \#3C(Redo) & 8/13/2009 8:56 & 3 & Air & 5.91 & 0.88 & 1.20 & $66 \%$ & 29.12 & 883 & & & 6 & 63 & 269 & 150 & 20.59 & 77.58 & 1.84 & & & 28.64 \\
\hline PRB air test $2 a$ & 8/5/2009 10:08 & 60 & Air & 6.01 & 0.90 & 1.17 & $52 \%$ & 29.02 & 849 & & & 43 & 75 & 1640 & data & 20.70 & 78.00 & 1.30 & & & 28.70 \\
\hline PRB Air test 3 & 8/11/2009 8:08 & 32 & Air & 5.71 & 0.91 & 1.21 & $71 \%$ & 28.95 & 907 & & & 40 & 83 & 247 & 135 & 20.47 & 77.13 & 2.40 & & & 28.58 \\
\hline PRB Air Test \#3B & 8/12/2009 9:12 & 80 & Air & 5.80 & 0.92 & 1.21 & $59 \%$ & 29.02 & 881 & & & 26 & 78 & 280 & 153 & 20.55 & 77.43 & 2.03 & & & 28.62 \\
\hline PRB-OXY 15b & 8/11/2009 12:03 & 26 & Oxy & 5.47 & 0.84 & 1.10 & $64 \%$ & 28.94 & 840 & 713 & 122 & 45 & 95 & 261 & 156 & 15.00 & 10.91 & 6.00 & 67.95 & 1357 & 38.92 \\
\hline $\begin{array}{l}\text { PRB Oxy Open Tube on } \\
\text { Tertiary Line }\end{array}$ & 8/12/2009 17:50 & 30 & Oxy & 5.92 & 0.84 & 1.11 & $50 \%$ & 29.01 & 815 & 839 & 145 & 4 & 75 & 266 & 157 & 18.66 & 20.41 & 5.53 & \begin{tabular}{|l|l|}
3 & 55.28 \\
\end{tabular} & 1229 & 37.08 \\
\hline PRB-OXY 15 & $8 / 11 / 2009$ 11:48 & 13 & Oxy & 5.73 & 0.86 & 1.10 & $69 \%$ & 28.95 & 886 & 788 & 123 & 44 & 96 & 262 & 156 & 15.96 & 12.54 & 6.38 & 65.00 & 1276 & 38.45 \\
\hline prboxy16 08/11/09 & 8/11/2009 16:34 & 37 & Oxy & 6.02 & 0.88 & 1.13 & $59 \%$ & 28.87 & 850 & 887 & 157 & 44 & 95 & 263 & 155 & 19.99 & 10.37 & 5.47 & 764.05 & 1175 & 38.54 \\
\hline prb oxy cyclone test13 & 8/25/2009 14:53 & 51 & Oxy & 5.56 & 0.90 & 1.06 & $50 \%$ & 27.82 & 756 & 787 & 147 & 37 & 91 & 266 & 151 & 19.64 & 9.08 & 7.19 & 63.96 & 1285 & 38.35 \\
\hline PRB OXY Cyclone test \#6 & 8/25/2009 13:00 & 39 & Oxy & 5.76 & 0.90 & 1.11 & $50 \%$ & 27.83 & 775 & 799 & 120 & 39 & 96 & 269 & 152 & 17.36 & 16.00 & 5.72 & 60.81 & 1096 & 37.89 \\
\hline PRB Oxy Test 6 a & 8/6/2009 16:08 & 55 & Oxy & 5.65 & 0.90 & 1.11 & $51 \%$ & 29.02 & 852 & 832 & 112 & 43 & 99 & 248 & 150 & 15.03 & 22.57 & 10.96 & 51.35 & 973 & 35.76 \\
\hline PRB Oxy Heat Balance \#5 & 8/13/2009 18:55 & 30 & Oxy & 5.56 & 0.92 & 1.09 & $44 \%$ & 29.09 & 863 & 892 & 152 & 52 & 97 & 267 & 168 & 18.80 & 9.07 & 5.45 & 66.53 & 1186 & 38.89 \\
\hline PRB OXY 01 & 8/5/2009 17:45 & 54 & Oxy & 6.18 & 0.92 & 1.12 & $39 \%$ & 29.00 & 847 & 830 & 118 & 46 & 101 & 231 & & 15.97 & 17.74 & 8.98 & 57.19 & 1158 & 36.93 \\
\hline prb oxy heat balance 3 & 8/13/2009 15:28 & 33 & Oxy & 6.02 & 0.92 & 1.13 & $41 \%$ & 29.10 & 851 & 881 & 173 & 3 & 78 & 269 & 172 & 21.25 & 11.02 & 5.98 & 61.65 & 1004 & 38.15 \\
\hline prb oxy $15 c 08 / 11 / 09$ & $8 / 11 / 200914: 40$ & 113 & Oxy & 5.68 & 0.93 & 1.19 & $55 \%$ & 28.89 & 867 & 900 & 142 & 44 & 95 & 263 & 156 & 19.18 & 12.30 & 5.46 & 62.92 & 1259 & 38.33 \\
\hline PRB Oxy Heat Transfer 1 & 8/13/2009 12:32 & 13 & Oxy & 5.98 & 0.94 & 1.15 & $48 \%$ & 29.12 & 885 & 898 & 137 & 5 & 73 & 268 & 169 & 18.06 & 12.63 & 6.05 & 63.12 & 1302 & 38.26 \\
\hline PRB Oxy Heat Transfer 2 & 8/13/2009 12:44 & 36 & Oxy & 5.95 & 0.95 & 1.16 & $48 \%$ & 29.11 & 891 & 903 & 133 & 4 & 74 & 268 & 170 & 17.75 & 12.00 & 6.19 & 63.93 & 1242 & 38.37 \\
\hline PRB Oxy Heat Transfer $1 \& 2$ & 8/13/2009 12:32 & 48 & Oxy & 5.96 & 0.95 & 1.16 & $48 \%$ & 29.12 & 889 & 901 & 134 & 4 & 74 & 268 & 170 & 17.83 & 12.17 & 6.15 & 63.72 & 1258 & 38.34 \\
\hline prb oxy heat transfer 4 & 8/13/2009 17:44 & 30 & Oxy & 5.56 & 0.95 & 1.14 & $38 \%$ & 29.09 & 845 & 873 & 151 & 51 & 97 & 267 & 165 & 19.63 & 10.89 & 5.67 & 63.69 & 1144 & 38.45 \\
\hline PRB Oxy Test 7 & 8/6/2009 18:25 & 45 & Oxy & 5.70 & 0.95 & 1.16 & $43 \%$ & 29.03 & 900 & 886 & 112 & 46 & 99 & 248 & 152 & 15.39 & 22.14 & 8.46 & 53.91 & 991 & 36.43 \\
\hline
\end{tabular}

Table 8.6 Pilot scale test data for subbituminous coal - table 1 of 5: test parameters, ambient conditions, and primary and tertiary oxidant data 


\begin{tabular}{|c|c|c|c|c|c|c|c|c|c|c|c|c|c|c|c|c|c|c|c|c|c|c|c|c|}
\hline & \multicolumn{15}{|c|}{ Secondary and Overfire Oxidant } & \multicolumn{3}{|c|}{ Cyclone Lance Oxygen } & \multicolumn{6}{|c|}{ Fuel } \\
\hline Test Name & 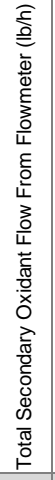 & 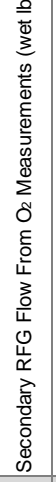 & 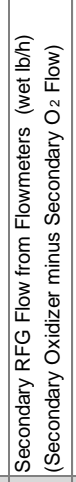 & 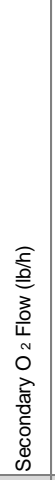 & 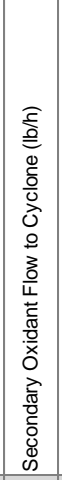 & 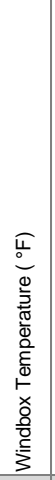 & 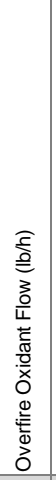 & 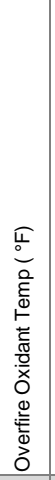 & 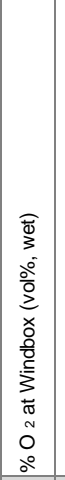 & 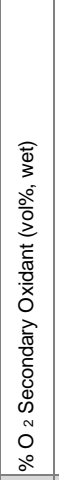 & 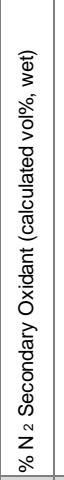 & 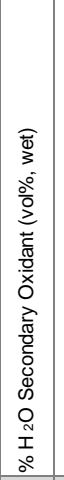 & 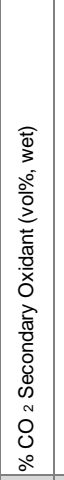 & 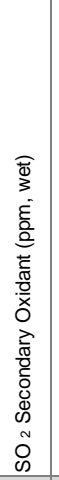 & 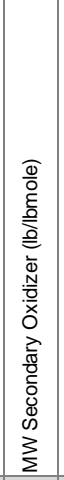 & 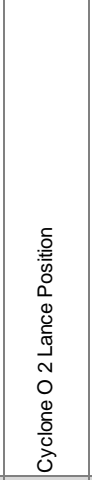 & 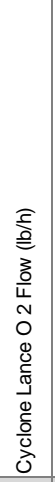 & 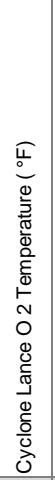 & 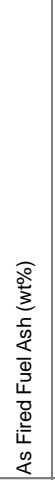 & 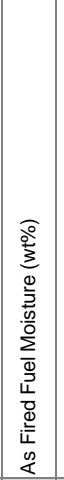 & 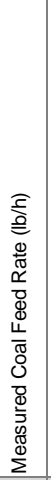 & 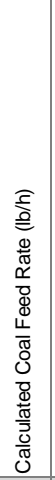 & 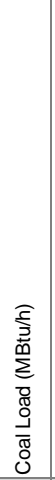 & 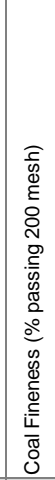 \\
\hline PRB AIR 01 & 4066 & & & & 2964 & 685 & 1113 & 685 & 20.13 & 20.50 & 77.28 & 2.21 & & & 28.60 & Sec. Duct & & 83 & 5.68 & 15.60 & 454 & 517 & 5.25 & 58.12 \\
\hline PRB Air Cyclone Test $2 a$ & 4454 & & & & 3303 & 688 & 1164 & 688 & 20.49 & 20.60 & 77.65 & 1.75 & & & 28.65 & Sec. Duct & & 70 & 5.55 & 17.50 & 589 & 564 & 5.60 & 34.20 \\
\hline PRB Air Test \#3C & 4473 & & & & 3039 & 697 & 1446 & 697 & 20.42 & 20.59 & 77.62 & 1.79 & & & 28.64 & Sec. Duct & & 68 & 5.68 & 15.60 & 589 & 569 & 5.78 & 46.46 \\
\hline PRB Air Test \#3C(Redo) & 4592 & & & & 3162 & 698 & 1444 & 698 & 20.39 & 20.58 & 77.58 & 1.84 & & & 28.64 & Sec. Duct & & 69 & 5.68 & 15.60 & 596 & 582 & 5.91 & 46.46 \\
\hline PRB air test $2 A$ & 4482 & & & & 3274 & 688 & 1221 & 688 & 20.65 & 20.69 & 78.01 & 1.30 & & & 28.70 & Sec. Duct & & 72 & 5.68 & 15.60 & 586 & 592 & 6.01 & 58.12 \\
\hline PRB Air test 3 & 4450 & & & & 3154 & 698 & 1309 & 698 & 20.27 & 20.46 & 77.14 & 2.40 & & & 28.58 & Sec. Duct & & 74 & 5.68 & 15.60 & 580 & 562 & 5.71 & 58.12 \\
\hline PRB Air Test \#3B & 4519 & & & & 3225 & 698 & 1306 & 698 & 20.39 & 20.54 & 77.43 & 2.03 & & & 28.62 & Sec. Duct & & 74 & 5.68 & 15.60 & 557 & 570 & 5.80 & 58.12 \\
\hline & & & & & & & & & & & & & & & & & & & & & & & & \\
\hline PRB-OXY 15b & 4228 & & 3487 & 741 & 2947 & 697 & 1292 & 697 & 22.53 & 21.28 & 10.11 & 5.56 & 62.92 & 1257 & 38.41 & Sec. Duct & 118 & 84 & 5.68 & 15.60 & 594 & 538 & 5.47 & 58.12 \\
\hline $\begin{array}{l}\text { PRB Oxy Open Tube on } \\
\text { Tertiary Line }\end{array}$ & 4291 & & 3499 & 792 & 3149 & 696 & 1364 & 696 & 23.41 & 23.06 & 19.33 & 5.23 & 52.26 & 1162 & 36.80 & Tertiary & 50 & 79 & 5.68 & 15.60 & 568 & 582 & 5.92 & 50.11 \\
\hline PRB-OXY 15 & 4253 & & 3497 & 756 & 3193 & 697 & 1294 & 697 & 22.80 & 22.49 & 11.57 & 5.88 & 59.95 & 1177 & 37.94 & Sec. Duct & 94 & 80 & 5.68 & 15.60 & 591 & 564 & 5.73 & 58.12 \\
\hline prboxy16 08/11/09 & 4382 & & 3552 & 830 & 3385 & 697 & 1243 & 697 & 24.56 & 24.24 & 9.83 & 5.18 & 60.64 & 1112 & 38.19 & Sec. Duct & 50 & 85 & 5.68 & 15.60 & 567 & 593 & 6.02 & 58.12 \\
\hline prb oxy cyclone test13 $\wedge$ & 3169 & 2762 & 2570 & 600 & 2566 & 680 & 836 & 680 & 23.18 & 22.90 & 8.71 & 6.90 & 61.36 & 1233 & 38.09 & Sec. Duct & 209 & 84 & 5.55 & 17.50 & 620 & 560 & 5.56 & 34.20 \\
\hline PRB OXY Cyclone test \#6 & 4047 & & 3314 & 733 & 3202 & 686 & 1099 & 686 & 22.84 & 22.78 & 14.95 & 5.34 & 56.82 & 1024 & 37.50 & Sec. Duct & 137 & 85 & 5.55 & 17.50 & 621 & 580 & 5.76 & 34.20 \\
\hline PRB Oxy Test 6 & 4082 & 3480 & 3355 & 727 & 3307 & 685 & 1084 & 685 & 22.01 & 21.72 & 20.80 & 10.09 & 47.30 & 896 & 35.46 & Sec. Duct & 82 & 76 & 5.68 & 15.60 & 551 & 557 & 5.65 & 58.12 \\
\hline PRB Oxy Heat Balance \#5 & 3649 & & 3056 & 593 & 2902 & 692 & 973 & 692 & 21.33 & 20.76 & 8.85 & 5.32 & 64.93 & 1158 & 38.72 & Sec. Duct & 202 & 80 & 5.68 & 15.60 & 592 & 547 & 5.56 & 50.11 \\
\hline PRB OXY 01 & 3748 & & 3009 & 739 & 3406 & 682 & 1008 & 682 & 24.34 & 22.47 & 16.38 & 8.28 & 52.76 & 1068 & 36.55 & Sec. Duct & 96 & 78 & 5.68 & 15.60 & 566 & 608 & 6.18 & 58.12 \\
\hline prb oxy heat balance 3 & 4260 & & 3470 & 790 & 3440 & 697 & 1079 & 697 & 24.11 & 23.58 & 10.69 & 5.80 & 59.83 & 975 & 37.97 & Sec. Duct & 63 & 86 & 5.68 & 15.60 & 573 & 593 & 6.02 & 50.11 \\
\hline prb oxy $15 c 08 / 11 / 09$ & 4338 & & 3571 & 766 & 3295 & 697 & 1282 & 697 & 23.86 & 23.52 & 11.63 & 5.16 & 59.54 & 1192 & 37.99 & Sec. Duct & 74 & 86 & 5.68 & 15.60 & 551 & 559 & 5.68 & 58.12 \\
\hline PRB Oxy Heat Transfer 1 & 4209 & & 3421 & 788 & 3383 & 696 & 1059 & 696 & 24.74 & 24.26 & 11.69 & 5.59 & 58.34 & 1204 & 37.79 & Sec. Duct & 101 & 81 & 5.68 & 15.60 & 590 & 589 & 5.98 & 50.11 \\
\hline PRB Oxy Heat Transfer 2 & 4248 & & 3461 & 787 & 3417 & 696 & 1069 & 696 & 24.61 & 24.11 & 11.08 & 5.71 & 58.99 & 1146 & 37.87 & Sec. Duct & 101 & 83 & 5.68 & 15.60 & 587 & 586 & 5.95 & 50.11 \\
\hline PRB Oxy Heat Transfer $1 \& 2$ & 4238 & & 3450 & 787 & 3408 & 696 & 1066 & 696 & 24.65 & 24.15 & 11.24 & 5.68 & 58.82 & 1161 & 37.85 & Sec. Duct & 101 & 83 & 5.68 & 15.60 & 588 & 587 & 5.96 & 50.11 \\
\hline prb oxy heat transfer 4 & 4051 & & 3459 & 592 & 3189 & 696 & 1119 & 696 & 20.18 & 19.54 & 10.90 & 5.67 & 63.77 & 1145 & 38.46 & Sec. Duct & 201 & 82 & 5.68 & 15.60 & 588 & 547 & 5.56 & 50.11 \\
\hline PRB Oxy Test 7 & 3900 & & 3323 & 577 & 3394 & 683 & 1233 & 683 & 19.72 & 18.30 & 21.38 & 8.17 & 52.06 & 957 & 36.28 & Sec. Duct & 186 & 75 & 5.68 & 15.60 & 555 & 561 & 5.70 & 58.12 \\
\hline
\end{tabular}

Table 8.7 Pilot scale test data for subbituminous coal - table 2 of 5: Secondary and overfire oxidant, Cyclone lance oxygen, and fuel test data 


\begin{tabular}{|c|c|c|c|c|c|c|c|c|c|c|c|c|c|c|c|c|}
\hline & \multicolumn{9}{|c|}{ Convection Pass Gases } & \multicolumn{7}{|c|}{ Stack/Emissions } \\
\hline Test Name & 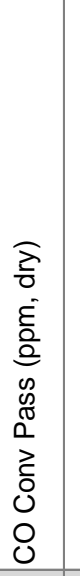 & 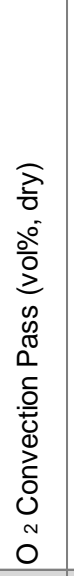 & 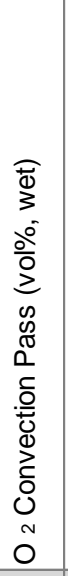 & 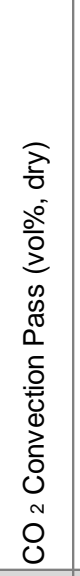 & 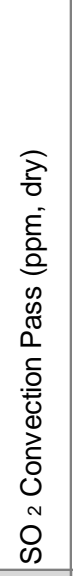 & 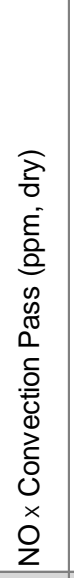 & 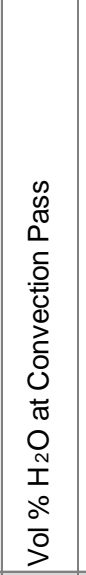 & 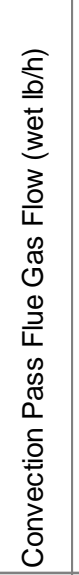 & 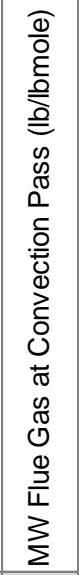 & 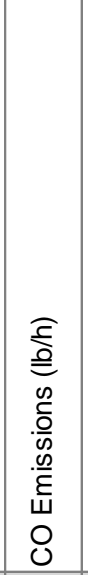 & 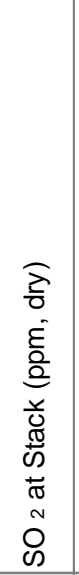 & 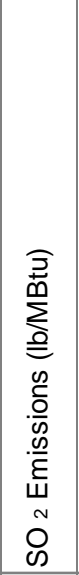 & 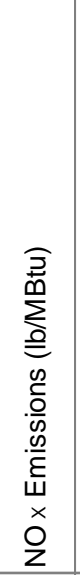 & 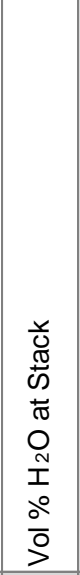 & 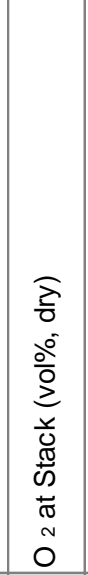 & 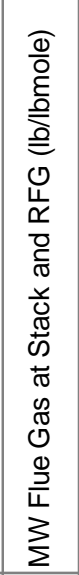 \\
\hline PRB AIR 01 & 32 & 3.13 & 2.89 & 16.34 & 372 & 438 & 10.75 & 5363 & 29.39 & 0.144 & 331 & 0.770 & 0.732 & 6.17 & 5.118 & 29.71 \\
\hline PRB Air Cyclone Test 2 A & 38 & 4 & 3.81 & 15.32 & 276 & 546 & 10.37 & 5904 & 29.32 & 0.190 & 245 & 0.505 & 0.810 & 8.67 & 6.086 & 29.60 \\
\hline PRB Air Test \#3C & 13 & 3.48 & 3.21 & 16.07 & 471 & 412 & 10.39 & 5889 & 29.41 & 0.067 & 419 & 0.832 & 0.589 & 4.89 & 5.394 & 30.17 \\
\hline PRB Air Test \#3C(Redo) & 12 & 3.48 & 3.14 & 16.06 & 462 & 387 & 10.41 & 6036 & 29.41 & 0.062 & 404 & 0.803 & 0.553 & 4.93 & 5.660 & 30.17 \\
\hline PRB air test 2 a & 112 & 3.07 & 2.82 & 16.33 & 401 & 468 & 10.27 & 5902 & 29.45 & 0.567 & 358 & 0.684 & 0.644 & 5.82 & 5.000 & 29.74 \\
\hline PRB Air test 3 & 45 & 3.66 & 3.27 & 15.83 & 374 & 353 & 10.80 & 5899 & 29.33 & 0.227 & 343 & 0.689 & 0.511 & 5.88 & 5.108 & 29.99 \\
\hline PRB Air Test \#3B & 57 & 3.64 & 3.27 & 15.87 & 372 & 376 & 10.54 & 5951 & 29.37 & 0.279 & 352 & 0.704 & 0.544 & 5.00 & 4.572 & 30.10 \\
\hline PRB-OXY 15b & 39 & 2.25 & 1.99 & 87.55 & 1729 & 525 & 15.61 & 5932 & 38.39 & 0.035 & 1665 & 0.755 & 0.171 & 6.86 & 2.951 & 35.48 \\
\hline $\begin{array}{l}\text { PRB Oxy Open Tube on } \\
\text { Tertiary Line }\end{array}$ & 431 & 2.50 & 2.29 & 75.88 & 1704 & 506 & 15.45 & 6188 & 36.86 & 0.412 & 1559 & 0.662 & 0.161 & 6.55 & 4.074 & 38.03 \\
\hline PRB-OXY 15 & 194 & 2.34 & 1.98 & 85.84 & 1672 & 520 & 15.95 & 6234 & 38.08 & 0.181 & 1588 & 0.621 & 0.146 & 7.35 & 3.286 & 39.43 \\
\hline prboxy16 08/11/09 & 67 & 2.97 & 2.68 & 87.15 & 1577 & 518 & 15.73 & 6348 & 38.33 & 0.066 & 1515 & 0.587 & 0.144 & 6.59 & 3.683 & 39.89 \\
\hline prb oxy cyclone test13 & 168 & 1.78 & 1.72 & 89.44 & 1804 & 1036 & 18.81 & 5136 & 37.85 & 0.146 & 1709 & 0.628 & $>0.27$ & 8.73 & 2.782 & 39.71 \\
\hline PRB OXY Cyclone test \#6 & 295 & 2.66 & 2.44 & 81.11 & 1486 & 425 & 16.13 & 5978 & 37.41 & 0.282 & 1371 & 0.555 & & 6.68 & 4.077 & 38.88 \\
\hline PRB Oxy Test 6 a & 391 & 2.51 & 2.03 & 75.24 & 1394 & 484 & 19.34 & 6101 & 35.91 & 0.427 & 1252 & 0.618 & 0.172 & 12.36 & 4.394 & 36.24 \\
\hline PRB Oxy Heat Balance \#5 & 166 & 2.26 & 2.01 & 88.70 & 1586 & 976 & 15.97 & 5708 & 38.46 & 0.142 & 1521 & 0.559 & 0.258 & 6.53 & 3.021 & 40.26 \\
\hline PRB OXY 01 & 58 & 2.86 & 2.39 & 80.66 & 1607 & 640 & 18.64 & 6186 & 36.78 & 0.059 & 1472 & 0.622 & 0.194 & 10.24 & 4.378 & 37.63 \\
\hline prb oxy heat balance 3 & 52 & 3.03 & 2.79 & 85.60 & 1386 & 699 & 16.30 & 6268 & 37.98 & 0.050 & 1327 & 0.500 & 0.189 & 7.32 & 3.797 & 39.53 \\
\hline prb oxy $15 c 08 / 11 / 09$ & 220 & 4.02 & 3.56 & 83.94 & 1660 & 645 & 15.10 & 6293 & 38.08 & 0.199 & 1590 & 0.627 & 0.185 & 6.44 & 4.737 & 39.48 \\
\hline PRB Oxy Heat Transfer 1 & 63 & 3.64 & 3.34 & 83.85 & 1724 & 767 & 16.07 & 6231 & 37.83 & 0.064 & 1639 & 0.634 & 0.213 & 7.08 & 4.502 & 39.32 \\
\hline PRB Oxy Heat Transfer 2 & 34 & 3.72 & 3.42 & 84.45 & 1634 & 755 & 16.08 & 6273 & 37.91 & 0.033 & 1559 & 0.597 & 0.208 & 7.20 & 4.512 & 39.42 \\
\hline PRB Oxy Heat Transfer $1 \& 2$ & 42 & 3.70 & 3.40 & 84.29 & 1657 & 758 & 16.07 & 6262 & 37.89 & 0.041 & 1580 & 0.607 & 0.209 & 7.17 & 4.506 & 39.39 \\
\hline prb oxy heat transfer 4 & 36 & 3.18 & 2.95 & 85.55 & 1527 & 668 & 15.47 & 6119 & 38.19 & 0.032 & 1472 & 0.546 & 0.178 & 6.80 & 3.818 & 39.74 \\
\hline PRB Oxy Test 7 & 93 & 3.38 & 2.95 & 75.45 & 1366 & 714 & 17.01 & 6491 & 36.48 & 0.101 & 1232 & 0.581 & 0.242 & 9.52 & 5.112 & 36.99 \\
\hline
\end{tabular}

Table 8.8 Pilot scale test data for subbituminous coal - table 3 of 5: Convection pass and stack gases, and emissions data 


\begin{tabular}{|c|c|c|c|c|c|c|c|c|c|c|c|c|c|c|c|c|c|c|c|}
\hline & \multicolumn{19}{|c|}{ Heat Transfer and HVT Data } \\
\hline Test Name & 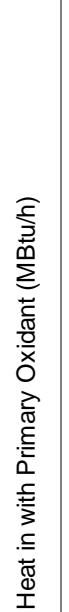 & 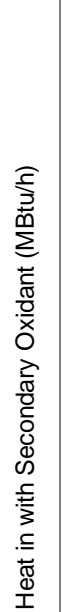 & 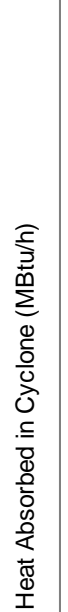 & 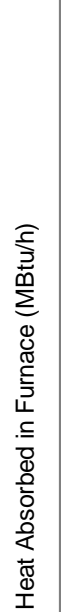 & 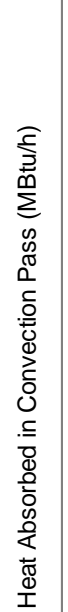 & 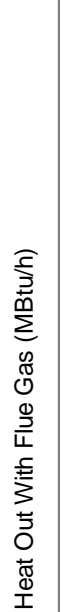 & 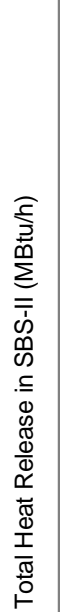 & 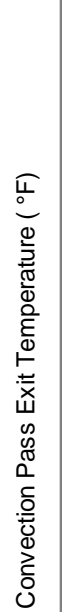 & 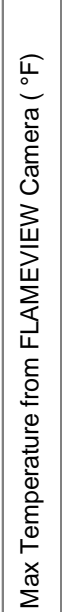 & 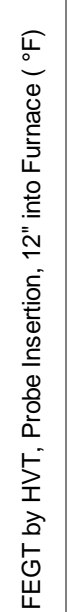 & 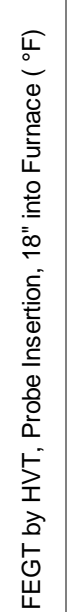 & 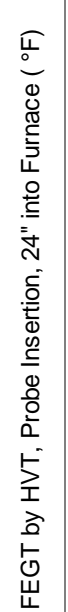 & 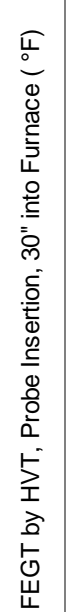 & 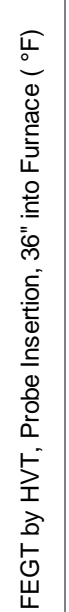 & 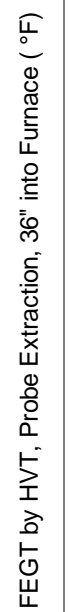 & 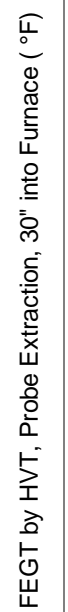 & 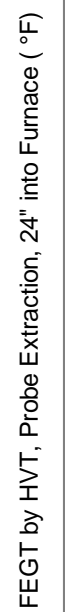 & 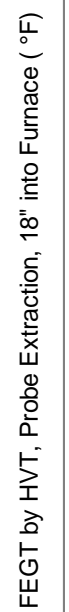 & 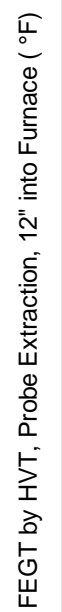 \\
\hline PRB AIR 01 & 0.13 & 1.16 & 0.61 & 2.13 & 1.58 & 1.67 & 4.70 & 763 & 3100 & & & & & & & & & & \\
\hline PRB Air Cyclone Test 2 A & 0.16 & 1.27 & 0.67 & 2.10 & 1.67 & 2.00 & 5.01 & 861 & 3100 & 2163 & 2174 & 2179 & 2173 & 2173 & 2168 & 2173 & 2177 & 2187 & 2160 \\
\hline PRB Air Test \#3C & 0.16 & 1.29 & 0.36 & 2.22 & 1.36 & 1.84 & 4.33 & 766 & & 2220 & 2240 & 2241 & 2254 & 2250 & 2250 & 2250 & 2245 & 2235 & 2236 \\
\hline PRB Air Test \#3C(Redo) & 0.16 & 1.32 & 0.24 & & & 1.91 & & 780 & & & & & & & & & & & \\
\hline PRB air test $2 \wedge$ & 0.13 & 1.28 & 0.55 & 2.51 & 1.71 & 1.90 & 5.27 & 805 & & 2163 & 2159 & 2180 & 2165 & 2170 & 2169 & 2168 & 2164 & 2166 & 2170 \\
\hline PRB Air test 3 & 0.16 & 1.29 & 0.21 & 2.58 & 2.19 & 1.90 & 5.43 & 800 & & & & & & & & & & & \\
\hline PRB Air Test \#3B & 0.16 & 1.30 & 0.19 & 2.81 & 1.55 & 1.92 & 5.01 & 804 & & 2295 & 2306 & 2316 & 2313 & 2306 & 2306 & 2286 & 2309 & 2304 & 2301 \\
\hline & & & & & & & & & & & & & & & & & & & \\
\hline PRB-OXY 15b & 0.15 & 1.05 & 0.18 & 2.69 & 2.31 & 1.77 & 5.75 & 844 & 3000 & & & & & & & & & & \\
\hline $\begin{array}{l}\text { PRB Oxy Open Tube on } \\
\text { Tertiary Line }\end{array}$ & 0.16 & 1.14 & 0.18 & 2.46 & 2.48 & 1.86 & 5.68 & 834 & & & & & & & & & & & \\
\hline PRB-OXY 15 & 0.16 & 1.12 & 0.18 & & & 1.86 & & 835 & & & & & & & & & & & \\
\hline prboxy16 08/11/09 & 0.16 & 1.15 & 0.15 & 2.63 & 2.16 & 1.95 & 5.58 & 871 & & & & & & & & & & & \\
\hline prb oxy cyclone test13 & 0.14 & 0.84 & 0.60 & 2.48 & 1.71 & 1.51 & 5.30 & 810 & 3200 & 2260 & 2329 & 2367 & 2381 & 2385 & 2385 & 2375 & 2366 & 2350 & 2298 \\
\hline PRB OXY Cyclone test \#6 & 0.14 & 1.07 & 0.42 & 2.44 & 2.20 & 1.85 & 5.68 & 868 & 3000 & 2282 & 2296 & 2277 & 2271 & 2326 & 2326 & 2345 & 2353 & 2309 & 2267 \\
\hline PRB Oxy Test 6 & 0.16 & 1.14 & 0.19 & 2.60 & 2.03 & 1.90 & 5.41 & 845 & 3100 & 2136 & 2197 & 2203 & 2210 & 2206 & 2206 & 2209 & 2209 & 2205 & 2209 \\
\hline PRB Oxy Heat Balance \#5 & 0.16 & 0.95 & 0.30 & 2.55 & 2.71 & 1.69 & 6.11 & 833 & 3200 & 2260 & 2394 & 2409 & 2414 & 2404 & 2404 & 2382 & 2390 & 2412 & 2402 \\
\hline PRB OXY 01 & 0.15 & 1.12 & 0.18 & 3.04 & 1.87 & 1.89 & 5.69 & 837 & 3100 & & & & & & & & & & \\
\hline prb oxy heat balance 3 & 0.16 & 1.13 & 0.18 & 3.27 & 1.90 & 1.88 & 5.93 & 839 & & & & & & & & & & & \\
\hline prb oxy $15 c 08 / 11 / 09$ & 0.16 & 1.14 & 0.18 & 2.62 & 2.09 & 1.90 & 5.47 & 851 & 3100 & & & & & & & & & & \\
\hline PRB Oxy Heat Transfer 1 & 0.16 & 1.11 & 0.19 & & & 1.84 & & 824 & & & & & & & & & & & \\
\hline PRB Oxy Heat Transfer 2 & 0.16 & 1.12 & 0.20 & 2.46 & 2.33 & 1.86 & 5.55 & 828 & & 2360 & 2364 & 2363 & 2370 & 2372 & 2372 & 2378 & 2386 & 2376 & 2367 \\
\hline PRB Oxy Heat Transfer 1 \& 2 & 0.16 & 1.12 & 0.19 & 2.24 & 2.65 & 1.85 & 5.65 & 827 & & & & & & & & & & & \\
\hline prb oxy heat transfer 4 & 0.15 & 1.07 & 0.25 & 2.78 & 2.21 & 1.84 & 5.83 & 847 & & & & & & & & & & & \\
\hline PRB Oxy Test 7 & 0.17 & 1.18 & 0.19 & 2.57 & 2.13 & 2.01 & 5.54 & 853 & & 2204 & 2221 & 2221 & 2232 & 2240 & 2240 & 2247 & 2238 & 2238 & 2202 \\
\hline
\end{tabular}

Table 8.9 Pilot scale test data for subbituminous coal - table 4 of 5: Heat transfer and temperature data 


\begin{tabular}{|c|c|c|c|c|c|c|c|c|c|c|c|c|c|c|}
\hline & \multicolumn{9}{|c|}{ System Static and Differential Pressures } & \multicolumn{5}{|c|}{ Miscellaneous } \\
\hline Test Name & 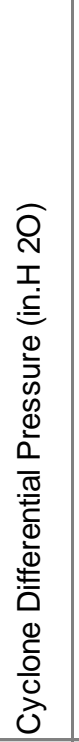 & 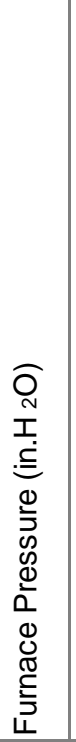 & 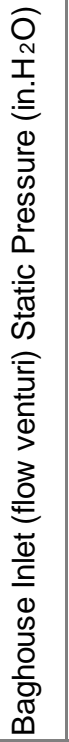 & 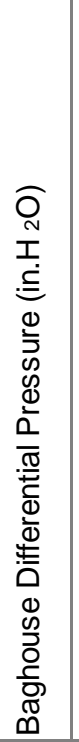 & 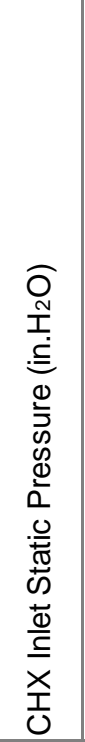 & 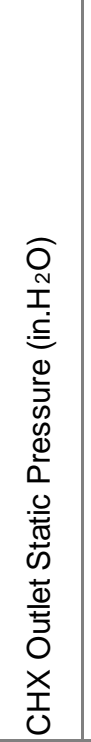 & 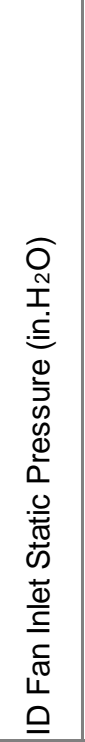 & 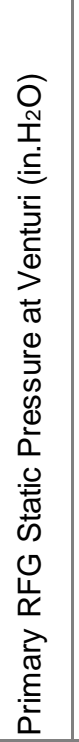 & 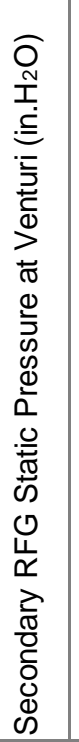 & 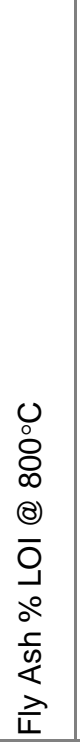 & 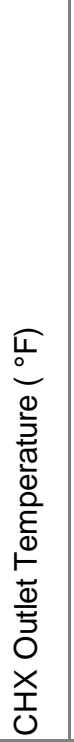 & 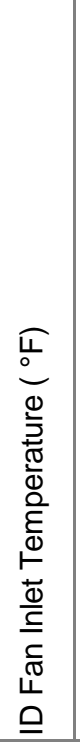 & 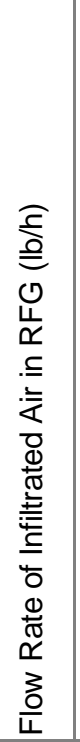 & 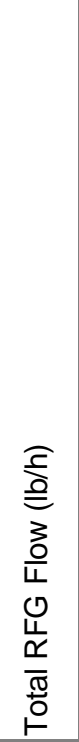 \\
\hline PRB AIR 01 & 8.9 & 0.6 & $>0$ & 11.8 & -16.1 & -22.7 & -29.6 & 0.2 & 0.3 & 3.04 & 96 & 108 & & \\
\hline PRB Air Cyclone Test 2 A & 10.7 & 0.3 & $>0$ & 11.9 & 0.0 & 8.0 & -31.1 & 0.3 & 0.3 & 2.18 & 109 & 109 & & \\
\hline PRB Air Test \#3C & 8.1 & 0.6 & $>0$ & 9.0 & -16.1 & -22.7 & -29.7 & 0.3 & 0.3 & & 88 & 101 & & \\
\hline PRB Air Test \#3C(Redo) & 8.0 & 0.2 & $>0$ & 10.1 & -17.3 & -23.9 & -31.7 & 0.3 & 0.3 & & 89 & 101 & & \\
\hline PRB air test 2 & 11.2 & 0.4 & $>0$ & 5.6 & -16.8 & -23.4 & -31.0 & 0.4 & 0.5 & 2.05 & 94 & 107 & & \\
\hline PRB Air test 3 & 8.5 & 1.2 & $>0$ & 8.1 & -12.6 & -19.1 & -24.2 & 0.2 & 0.3 & 2.22 & 95 & 108 & & \\
\hline PRB Air Test \#3B & 8.5 & 0.8 & $>0$ & 4.8 & -4.4 & -11.0 & -10.4 & 0.3 & 0.3 & 1.73 & 90 & 102 & & \\
\hline PRB-OXY 15b & 6.0 & 1.1 & $>0$ & 10.0 & -0.1 & -6.7 & -1.5 & -0.3 & -0.6 & 1.24 & 101 & 114 & 148 & 4200 \\
\hline $\begin{array}{l}\text { PRB Oxy Open Tube on } \\
\text { Tertiary Line }\end{array}$ & 5.4 & 0.0 & $>0$ & 3.6 & -3.7 & -10.3 & -8.4 & -0.4 & -0.7 & & 99 & 112 & 258 & 4338 \\
\hline PRB-OXY 15 & 6.2 & 0.7 & $>0$ & 9.3 & -0.1 & -6.7 & -1.5 & -0.3 & -0.6 & & 103 & 116 & 190 & 4284 \\
\hline prboxy16 08/11/09 & 5.4 & 1.4 & $>0$ & 3.5 & 0.1 & -6.5 & -0.9 & -0.2 & -0.6 & 1.42 & 99 & 113 & 171 & 4439 \\
\hline prb oxy cyclone test13 & 6.6 & -0.8 & $>0$ & 3.3 & 0.0 & 6.0 & -1.1 & -0.1 & -0.3 & 1.81 & 109 & 109 & 120 & 3549 \\
\hline PRB OXY Cyclone test \#6 & 7.2 & -0.2 & $>0$ & 9.4 & 0.0 & -1.2 & -12.2 & -0.3 & -0.6 & 1.63 & 99 & 113 & 195 & 4113 \\
\hline PRB Oxy Test 6 & 6.7 & 1.2 & $>0$ & 3.1 & -11.2 & -17.8 & -21.2 & -0.4 & -0.7 & 2.56 & 120 & 120 & 401 & 4312 \\
\hline PRB Oxy Heat Balance \#5 & 4.9 & 0.8 & $>0$ & 3.3 & -0.3 & -6.9 & -1.9 & -0.2 & -0.4 & 1.21 & 99 & 112 & 112 & 3948 \\
\hline PRB OXY 01 & 5.4 & 0.4 & $>0$ & 7.7 & -7.0 & -13.6 & -14.3 & -0.3 & -0.5 & 1.28 & 114 & 125 & 321 & 3839 \\
\hline prb oxy heat balance 3 & 6.4 & 0.6 & $>0$ & 3.6 & -0.2 & -6.8 & -1.8 & -0.3 & -0.6 & 1.32 & 103 & 116 & 156 & 4352 \\
\hline prb oxy $15 c 08 / 11 / 09$ & 5.9 & 0.8 & $>0$ & 3.5 & 0.1 & -6.5 & -0.9 & -0.3 & -0.7 & & 99 & 112 & 179 & 4472 \\
\hline PRB Oxy Heat Transfer 1 & 6.3 & 0.8 & $>0$ & 4.0 & -0.2 & -6.8 & -1.7 & -0.3 & -0.6 & 1.04 & 102 & 115 & 171 & 4319 \\
\hline PRB Oxy Heat Transfer 2 & 6.4 & 0.6 & $>0$ & 3.6 & -0.2 & -6.8 & -1.7 & -0.3 & -0.6 & & 103 & 116 & 162 & 4363 \\
\hline PRB Oxy Heat Transfer $1 \& 2$ & 6.4 & 0.7 & $>0$ & 3.7 & -0.2 & -6.8 & -1.7 & -0.3 & -0.6 & & 102 & 116 & 165 & 4352 \\
\hline prb oxy heat transfer 4 & 6.7 & 0.8 & $>0$ & 3.7 & -0.2 & -6.8 & -1.8 & -0.3 & -0.6 & 1.35 & 101 & 114 & 135 & 4332 \\
\hline PRB Oxy Test 7 & 5.4 & 1.5 & $>0$ & 3.5 & -11.6 & -18.2 & -21.9 & -0.3 & -0.7 & 1.38 & 111 & 121 & 407 & 4209 \\
\hline
\end{tabular}

Table 8.10 Pilot scale test data for subbituminous coal - table 5 of 5: Static and differential pressures and miscellaneous data 


\begin{tabular}{|c|c|c|c|c|c|c|c|c|c|c|c|c|c|c|c|c|c|c|c|c|c|}
\hline \multirow{2}{*}{\begin{tabular}{|l} 
Test Name \\
Tem \\
\end{tabular}} & \multicolumn{6}{|c|}{ Test Parameters } & \multicolumn{2}{|c|}{$\begin{array}{c}\text { Ambient } \\
\text { Conditions }\end{array}$} & \multicolumn{13}{|c|}{ Primary and Tertiary Oxidant } \\
\hline & Start of Test & 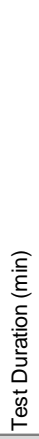 & 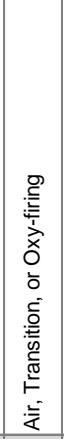 & 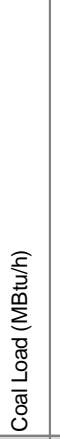 & 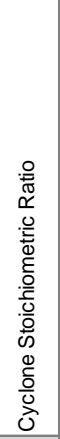 & 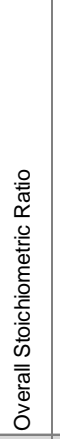 & 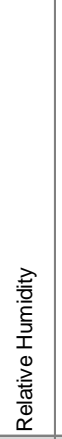 & 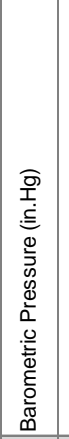 & 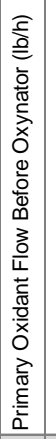 & 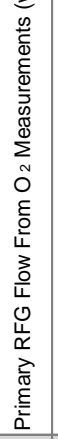 & 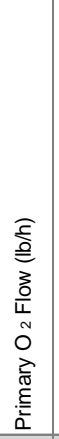 & 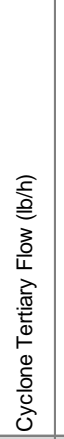 & 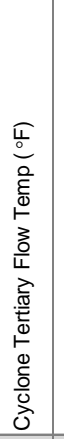 & 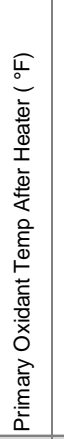 & 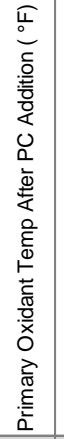 & 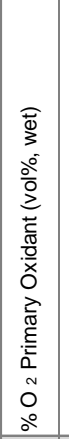 & 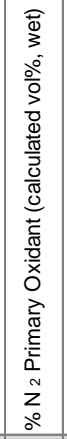 & 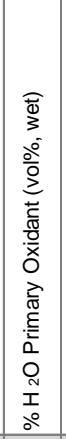 & 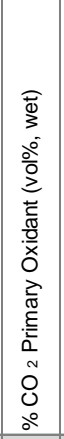 & 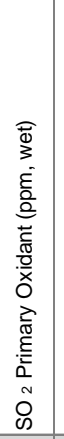 & 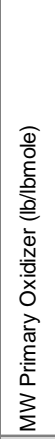 \\
\hline Warm Rec-PRB Air Test 2a & 9/14/2009 11:32 & 25 & Air & 5.93 & 0.87 & 1.14 & $54 \%$ & 28.23 & 791 & & & 14 & 83 & 334 & 153 & 20.59 & 77.57 & 1.84 & & & 28.64 \\
\hline warm recycle prb air test $2 d$ & 9/14/2009 15:10 & 40 & Air & 5.83 & 0.93 & 1.19 & $42 \%$ & 29.03 & 802 & & & 31 & 133 & 301 & 171 & 20.61 & 77.65 & 1.74 & & & 28.65 \\
\hline Warm Rec-PRB Air Test 2e & 9/15/2009 8:44 & 56 & Air & 5.56 & 0.96 & 1.23 & $59 \%$ & 29.03 & 842 & & & 35 & 121 & 324 & 149 & 20.57 & 77.52 & 1.91 & & & 28.63 \\
\hline warm recycle prb air test $2 c$ & 9/14/2009 14:01 & 69 & Air & 5.98 & 0.99 & 1.20 & $44 \%$ & 29.05 & 824 & & & 32 & 135 & 303 & 179 & 20.60 & 77.63 & 1.76 & & & 28.65 \\
\hline Warm Rec-PRB Air Test 2b & 9/14/2009 12:56 & 62 & Air & 6.14 & 0.99 & 1.18 & $47 \%$ & 29.08 & 838 & & & 34 & 121 & 332 & 170 & 20.60 & 77.63 & 1.76 & & & 28.65 \\
\hline $\begin{array}{l}\text { Warm Rec-PRB Quick Baseline } \\
9-17-09\end{array}$ & 9/17/2009 10:02 & 13 & Air & 5.77 & 1.00 & 1.16 & $59 \%$ & 29.19 & 791 & & & 23 & 76 & 321 & 142 & 20.70 & 78.00 & 1.30 & & & 28.70 \\
\hline Warm Rec-PRB Air Test 2f & 9/16/2009 8:22 & 54 & Air & 6.14 & 1.12 & 1.21 & $65 \%$ & 29.16 & 817 & & & 21 & 86 & 323 & 148 & 20.69 & 77.96 & 1.35 & & & 28.69 \\
\hline warm rec-prb oxy test $5 b$ & 9/14/2009 18:00 & 12 & Trans. & 5.42 & 1.04 & 1.16 & $51 \%$ & 29.00 & 936 & & & 36 & 137 & 286 & 184 & 20.59 & 77.61 & 1.80 & & & 28.64 \\
\hline Warm Rec-PRB secondary trans & 9/15/2009 12:40 & 35 & Trans. & 5.41 & 1.05 & 1.21 & $44 \%$ & 29.04 & 809 & 75 & 16 & 15 & 102 & 338 & 149 & 98.68 & 0.95 & 0.16 & 0.21 & 2 & 31.96 \\
\hline warm rec-prb oxy test $5 a$ & 9/14/2009 17:17 & 43 & Trans. & 5.35 & 1.06 & 1.18 & $42 \%$ & 29.01 & 917 & & & 35 & 138 & 288 & 185 & 20.61 & 77.65 & 1.74 & & & 28.65 \\
\hline $\begin{array}{l}\text { Warm Rec-PRB Secondary } \\
\text { Trans } 3\end{array}$ & 9/17/2009 11:41 & 19 & Trans. & 5.65 & 0.99 & 1.15 & $50 \%$ & 29.18 & 824 & & & 22 & 103 & 323 & 145 & 20.68 & 77.92 & 1.40 & & & 28.69 \\
\hline $\begin{array}{l}\text { Warm Rec-PRB Secondary } \\
\text { Trans2 }\end{array}$ & 9/16/2009 12:16 & 50 & Trans. & 6.00 & 1.02 & 1.14 & $45 \%$ & 29.19 & 840 & & & 20 & 102 & 315 & 146 & 20.73 & 78.13 & 1.14 & & & 28.72 \\
\hline warm rec-prb oxy test5c & 9/14/2009 19:30 & 25 & Oxy & 5.37 & 1.13 & 1.26 & $60 \%$ & 29.00 & 779 & 668 & 139 & 31 & 142 & 230 & 164 & 30.00 & 12.40 & 23.69 & 33.86 & 244 & 32.25 \\
\hline warm rec oxy prb 6 & 9/17/2009 19:31 & 12 & Oxy & 6.12 & 0.92 & 1.07 & $58 \%$ & 29.08 & 735 & 752 & 171 & 14 & 137 & 307 & 183 & 19.50 & 8.79 & 26.95 & 44.71 & 464 & 33.25 \\
\hline Warm Rec PRB Oxy 1 ^ & 9/17/2009 12:45 & 61 & Oxy & 5.76 & 0.97 & 1.13 & $45 \%$ & 29.15 & 736 & 748 & 166 & 17 & 137 & 341 & 186 & 20.52 & 11.25 & 24.43 & 43.75 & 359 & 33.39 \\
\hline warm rec prb oxy 2 & 9/17/2009 14:11 & 57 & Oxy & 5.94 & 0.98 & 1.14 & $45 \%$ & 29.13 & 746 & 761 & 166 & 13 & 136 & 347 & 187 & 20.31 & 10.26 & 24.95 & 44.43 & 379 & 33.44 \\
\hline warm rec oxy prb 5 A & 9/17/2009 18:02 & 43 & Oxy & 5.84 & 0.98 & 1.16 & $43 \%$ & 29.09 & 712 & 743 & 168 & 14 & 136 & 306 & 179 & 20.71 & 9.00 & 25.71 & 44.54 & 374 & 33.40 \\
\hline warm rec oxy prb 4 a & 9/17/2009 16:34 & 58 & Oxy & 5.70 & 0.98 & 1.15 & $42 \%$ & 29.10 & 719 & 752 & 167 & 14 & 136 & 307 & 179 & 20.39 & 9.27 & 25.61 & 44.68 & 397 & 33.42 \\
\hline warm rec prb oxy 3 & 9/17/2009 15:08 & 24 & Oxy & 5.64 & 1.00 & 1.14 & $42 \%$ & 29.11 & 735 & 755 & 167 & 13 & 135 & 348 & 186 & 20.51 & 9.86 & 24.78 & 44.79 & 407 & 33.52 \\
\hline
\end{tabular}

Table 8.11 Pilot scale test data for subbituminous coal (warm recycle) - table 1 of 5: test parameters, ambient conditions, and primary and tertiary oxidant data 


\begin{tabular}{|c|c|c|c|c|c|c|c|c|c|c|c|c|c|c|c|c|c|c|c|c|c|c|c|}
\hline & \multicolumn{14}{|c|}{ Secondary and Overfire Oxidant } & \multicolumn{3}{|c|}{ Cyclone Lance Oxygen } & \multicolumn{6}{|c|}{ Fuel - Coal } \\
\hline Test Name & 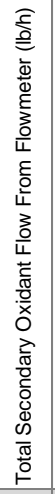 & 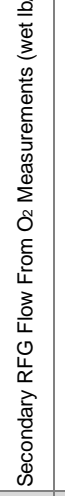 & 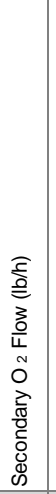 & 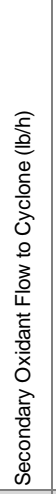 & 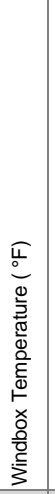 & 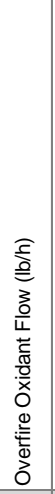 & 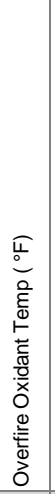 & 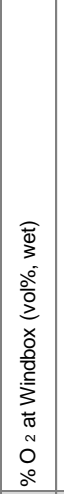 & 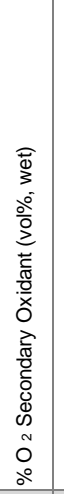 & 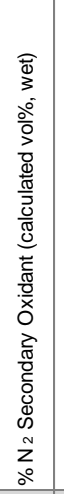 & 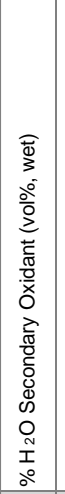 & 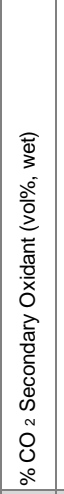 & 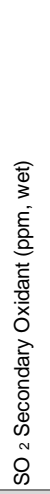 & 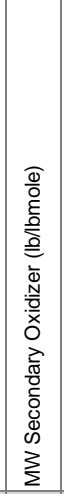 & 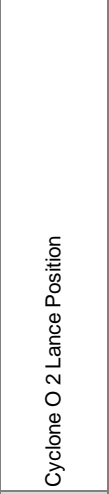 & 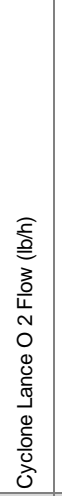 & 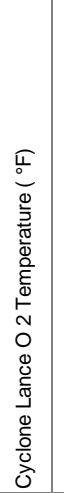 & 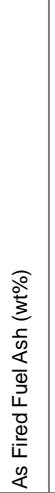 & 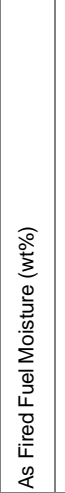 & 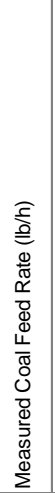 & 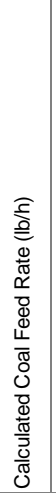 & 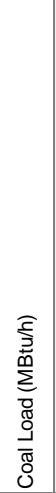 & 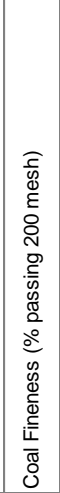 \\
\hline Warm Rec-PRB Air Test 2a & 4421 & & & 3218 & 688 & 1215 & 688 & 20.34 & 20.58 & 77.58 & 1.84 & & & 28.64 & Scroll & & 74 & 5.51 & 18.16 & 592 & 602 & 5.93 & 31.15 \\
\hline warm recycle prb air test $2 d$ & 4548 & & & 3391 & 689 & 1170 & 689 & 20.42 & 20.60 & 77.66 & 1.74 & & & 28.65 & Withdrawn & & 80 & 5.51 & 18.16 & 577 & 592 & 5.83 & 31.15 \\
\hline Warm Rec-PRB Air Test 2e & 4527 & & & 3369 & 688 & 1170 & 688 & 20.38 & 20.57 & 77.53 & 1.91 & & & 28.63 & Scroll & & 72 & 5.13 & 18.34 & 574 & 570 & 5.56 & 54.49 \\
\hline warm recycle prb air test 2c & 4676 & & & 3728 & 690 & 960 & 690 & 20.51 & 20.60 & 77.64 & 1.76 & & & 28.65 & Withdrawn & & 79 & 5.51 & 18.16 & 583 & 607 & 5.98 & 31.15 \\
\hline Warm Rec-PRB Air Test 2b & 4650 & & & 3800 & 689 & 862 & 689 & 20.55 & 20.60 & 77.64 & 1.76 & & & 28.65 & Withdrawn & & 77 & 5.51 & 18.16 & 597 & 623 & 6.14 & 31.15 \\
\hline $\begin{array}{l}\text { Warm Rec-PRB Quick Baseline } \\
9-17-09\end{array}$ & 4249 & & & 3556 & 739 & 705 & 739 & 20.73 & 20.69 & 78.01 & 1.30 & & & 28.70 & Sec. Duct & & 65 & 5.49 & 18.34 & 573 & 587 & 5.77 & 39.51 \\
\hline Warm Rec-PRB Air Test 2f & 4701 & & & 4299 & 690 & 414 & 690 & 20.90 & 20.68 & 77.97 & 1.35 & & & 28.69 & None & & 66 & 5.49 & 18.34 & 577 & 624 & 6.14 & 46.00 \\
\hline warm rec-prb oxy test $5 b$ & 4012 & 3238 & 899 & 3703 & 686 & 552 & 686 & 23.63 & 23.16 & 29.45 & 20.89 & 26.45 & 218 & 31.07 & Scroll & 28 & 81 & 5.51 & 18.16 & 475 & 550 & 5.42 & 31.15 \\
\hline Warm Rec-PRB secondary trans & 4252 & 3318 & 975 & 3916 & 687 & 597 & 687 & 25.96 & 25.13 & 29.63 & 18.69 & 26.53 & 221 & 31.39 & Withdrawn & & 82 & 5.49 & 18.34 & 521 & 550 & 5.41 & 46.00 \\
\hline warm rec-prb oxy test $5 a$ & 4170 & 3387 & 888 & 3856 & 687 & 562 & 687 & 22.42 & 21.97 & 29.83 & 21.55 & 26.47 & 219 & 30.99 & Scroll & 32 & 82 & 5.51 & 18.16 & 473 & 543 & 5.35 & 31.15 \\
\hline $\begin{array}{l}\text { Warm Rec-PRB Secondary } \\
\text { Trans } 3\end{array}$ & 3046 & 2426 & 750 & 2607 & 728 & 580 & 728 & 26.28 & 26.14 & 28.84 & $\mid 16.43$ & 28.52 & 239 & 31.96 & Sec. Duct & 98 & 75 & 5.49 & 18.34 & 571 & 575 & 5.65 & 39.51 \\
\hline $\begin{array}{l}\text { Warm Rec-PRB Secondary } \\
\text { Trans2 }\end{array}$ & 3371 & 2577 & 887 & 3097 & 733 & 441 & 733 & 27.54 & 27.23 & 28.82 & 17.57 & 26.34 & 235 & 31.55 & Sec. Duct & & 74 & 5.49 & 18.34 & 574 & 610 & 6.00 & 46.00 \\
\hline warm rec-prb oxy test5c & 4047 & 3288 & 882 & 3768 & 687 & 502 & 687 & 25.36 & 24.86 & 12.35 & 25.92 & 36.83 & 268 & 32.30 & Scroll & 27 & 76 & 5.51 & 18.16 & 485 & 545 & 5.37 & 31.15 \\
\hline warm rec oxy prb 6 & 3561 & 2927 & 800 & 3162 & 737 & 680 & 737 & 23.98 & 23.04 & 8.40 & 25.77 & 42.74 & 444 & 33.20 & Sec. Duct & 47 & 70 & 5.49 & 18.34 & 566 & 622 & 6.12 & 39.51 \\
\hline Warm Rec PRB Oxy 1 A & 3120 & 2463 & 773 & 2624 & 729 & 612 & 729 & 27.50 & 27.44 & 10.28 & 22.30 & 39.94 & 328 & 33.27 & Sec. Duct & 94 & 76 & 5.13 & 18.34 & 597 & 590 & 5.76 & 39.51 \\
\hline warm rec prb oxy 2 & 3321 & 2699 & 740 & 2897 & 733 & 650 & 733 & 25.17 & 24.38 & 9.74 & 23.68 & 42.16 & 359 & 33.36 & Sec. Duct & 111 & 77 & 5.49 & 18.34 & 601 & 605 & 5.94 & 39.51 \\
\hline warm rec oxy prb 5 & 3861 & 3043 & 855 & 3172 & 740 & 725 & 740 & 25.65 & 25.50 & 8.46 & 24.15 & 41.85 & 351 & 33.31 & Sec. Duct & 30 & 73 & 5.13 & 18.34 & 572 & 598 & 5.84 & 39.51 \\
\hline warm rec oxy prb 4 A & 3586 & 2851 & 778 & 2954 & 737 & 676 & 737 & 25.15 & 24.94 & 8.89 & 24.54 & 42.13 & 375 & 33.34 & Sec. Duct & 77 & 76 & 5.13 & 18.34 & 599 & 584 & 5.70 & 39.51 \\
\hline warm rec prb oxy 3 & 3240 & 2727 & 643 & 2819 & 732 & 651 & 732 & 22.91 & 22.09 & 9.67 & 24.29 & 43.91 & 399 & 33.49 & Sec. Duct & 155 & 77 & 5.49 & 18.34 & 607 & 573 & 5.64 & 39.51 \\
\hline
\end{tabular}

Table 8.12 Pilot scale test data for subbituminous coal (warm recycle) - table 2 of 5: Secondary and overfire oxidant, Cyclone lance oxygen, and coal test data 


\begin{tabular}{|c|c|c|c|c|c|c|c|c|c|c|c|c|c|c|c|c|c|c|}
\hline & \multicolumn{2}{|c|}{$\begin{array}{c}\text { Fuel - } \\
\text { Natural Gas }\end{array}$} & \multicolumn{9}{|c|}{ Convection Pass Gases } & \multicolumn{7}{|c|}{ Stack/Emissions } \\
\hline Test Name & 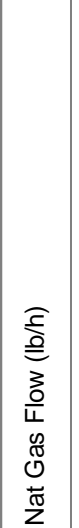 & 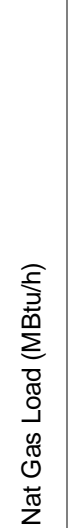 & 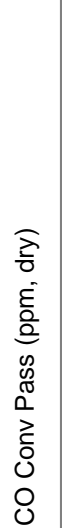 & 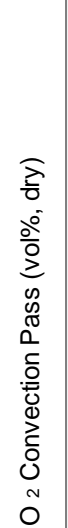 & 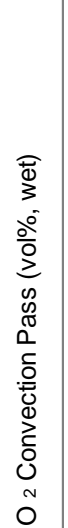 & 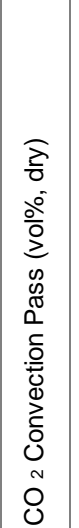 & 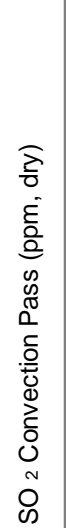 & 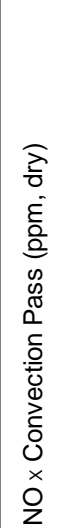 & 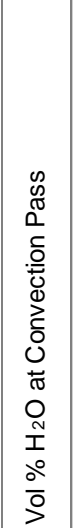 & 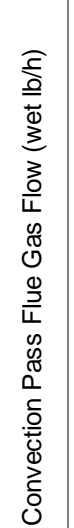 & 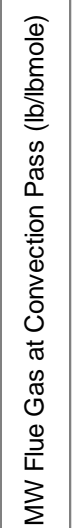 & 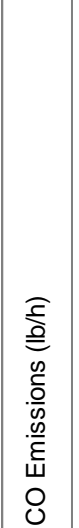 & 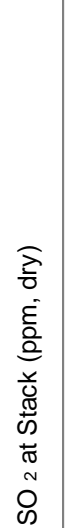 & 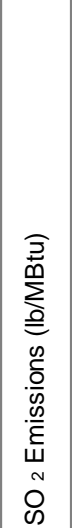 & 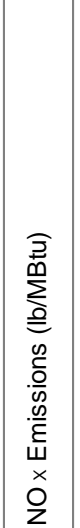 & 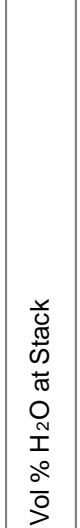 & 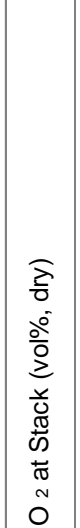 & 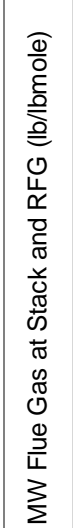 \\
\hline Warm Rec-PRB Air Test 2a & & & 428 & 2.48 & 2.09 & 16.88 & 254 & 430 & 11.29 & 5793 & 29.37 & 2.091 & 227 & 0.427 & 0.581 & 9.56 & 4.408 & 29.80 \\
\hline warm recycle prb air test $2 \mathrm{~d}$ & & & 74 & 3.35 & 2.94 & 16.12 & 200 & 493 & 10.82 & 5922 & 29.35 & 0.376 & 189 & 0.373 & 0.699 & 9.58 & 4.311 & 29.57 \\
\hline Warm Rec-PRB Air Test 2e & & & 23 & 3.98 & 3.55 & 15.52 & 185 & 631 & 10.60 & 5922 & 29.31 & 0.116 & 172 & 0.358 & 0.943 & 9.52 & 5.114 & 29.50 \\
\hline warm recycle prb air test $2 c$ & & & 12 & 3.57 & 3.27 & 15.92 & 188 & 603 & 10.84 & 6086 & 29.32 & 0.062 & 177 & 0.349 & 0.856 & 9.38 & 4.661 & 29.57 \\
\hline Warm Rec-PRB Air Test 2b & & & 280 & 3.16 & 2.80 & 16.24 & 212 & 657 & 11.07 & 6090 & 29.33 & 1.455 & 195 & 0.376 & 0.911 & 9.44 & 4.519 & 29.62 \\
\hline $\begin{array}{l}\text { Warm Rec-PRB Quick Baseline } \\
\text { 9-17-09 }\end{array}$ & & & 8 & 2.92 & 2.66 & 16.59 & 195 & 686 & 10.89 & 5607 & 29.39 & 0.036 & 178 & 0.333 & 0.925 & 9.07 & 4.508 & 29.76 \\
\hline Warm Rec-PRB Air Test 2f & & & 36 & 3.78 & 3.49 & 15.73 & 185 & 844 & 10.68 & 6121 & 29.33 & 0.189 & 170 & 0.331 & 1.178 & 8.88 & 5.100 & 29.59 \\
\hline warm rec-prb oxy test $5 b$ & 40.9 & 0.95 & 54 & 4.12 & 3.06 & 46.44 & 398 & 1344 & 27.49 & 5780 & 30.77 & 0.094 & 373 & 0.225 & 0.583 & 26.29 & 5.197 & 30.84 \\
\hline Warm Rec-PRB secondary trans & 25.4 & 0.59 & 17 & 5.89 & 4.50 & 46.29 & 407 & 1431 & 29.33 & 5075 & 30.48 & 0.018 & 368 & 0.148 & 0.415 & 23.72 & 7.330 & 31.23 \\
\hline warm rec-prb oxy test 5a & 40.8 & 0.95 & 40 & 3.99 & 2.83 & 46.25 & 391 & 1252 & 27.76 & 5920 & 30.73 & 0.066 & 371 & 0.225 & 0.538 & 26.78 & 4.840 & 30.78 \\
\hline $\begin{array}{l}\text { Warm Rec-PRB Secondary } \\
\text { Trans } 3\end{array}$ & & & 86 & 4.05 & 3.16 & 48.78 & 425 & 1497 & 23.87 & 4654 & 31.69 & 0.127 & 399 & 0.249 & 0.671 & 21.49 & 5.111 & 31.97 \\
\hline $\begin{array}{l}\text { Warm Rec-PRB Secondary } \\
\text { Trans2 }\end{array}$ & & & 50 & 3.83 & 2.95 & 47.34 & 439 & 1534 & 25.01 & 4955 & 31.31 & 0.084 & 408 & 0.255 & 0.690 & 23.35 & 5.056 & 31.41 \\
\hline warm rec-prb oxy test5c & 25.3 & 0.59 & 23 & 7.27 & 5.04 & 71.16 & 545 & 1170 & 35.08 & 5696 & 32.08 & 0.022 & 505 & 0.185 & 0.308 & 32.74 & 8.292 & 32.39 \\
\hline warm rec oxy prb 6 & & & 114 & 2.07 & 1.58 & 84.49 & 888 & 1335 & 35.28 & 5465 & 33.30 & 0.103 & 843 & 0.296 & 0.336 & 32.87 & 3.024 & 33.53 \\
\hline Warm Rec PRB Oxy 1 & & & 28 & 4.25 & 3.06 & 79.03 & 672 & 1649 & 32.75 & 4869 & 33.36 & 0.026 & 621 & 0.238 & 0.454 & 29.68 & 5.517 & 33.69 \\
\hline warm rec prb oxy 2 & & & 27 & 4.23 & 3.10 & 80.41 & 707 & 1686 & 33.32 & 5218 & 33.38 & 0.025 & 659 & 0.240 & 0.441 & 30.26 & 5.368 & 33.75 \\
\hline warm rec oxy prb 5 A & & & 27 & 4.66 & 3.40 & 81.22 & 702 & 1650 & 33.56 & 5477 & 33.42 & 0.025 & 663 & 0.245 & 0.438 & 31.30 & 5.562 & 33.70 \\
\hline warm rec oxy prb 4 A & & & 27 & 4.46 & 3.21 & 81.06 & 743 & 1662 & 33.48 & 5249 & 33.42 & 0.024 & 700 & 0.258 & 0.440 & 31.09 & 5.402 & 33.72 \\
\hline warm rec prb oxy 3 & & & 36 & 4.27 & 3.11 & 80.76 & 756 & 1767 & 33.11 & 5152 & 33.47 & 0.031 & 708 & 0.255 & 0.457 & 30.14 & 5.316 & 33.86 \\
\hline
\end{tabular}

Table 8.13 Pilot scale test data for subbituminous coal (warm recycle) - table 3 of 5: Natural gas flow, convection pass and stack gases, and emissions data 


\begin{tabular}{|c|c|c|c|c|c|c|c|c|c|c|c|c|c|c|c|c|c|c|c|}
\hline & \multicolumn{19}{|c|}{ Heat Transfer and HVT Data } \\
\hline Test Name & 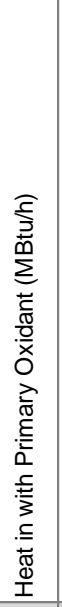 & 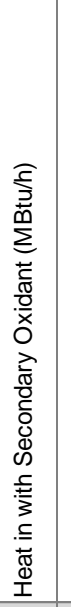 & 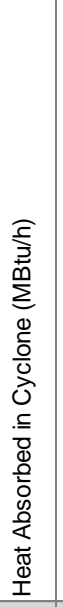 & 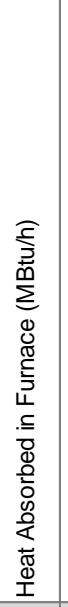 & 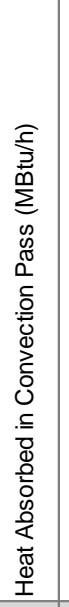 & 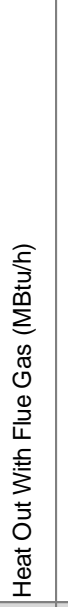 & 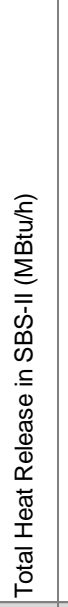 & 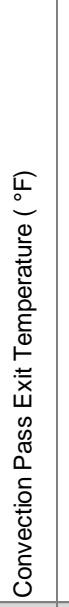 & 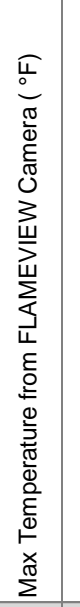 & 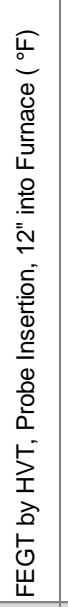 & 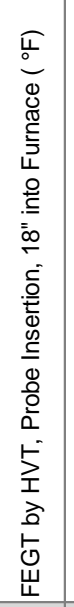 & 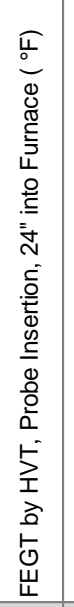 & 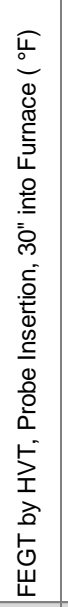 & 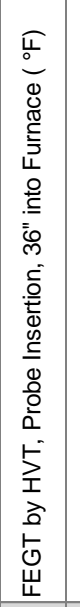 & 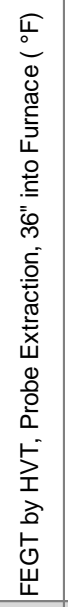 & 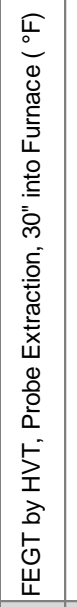 & 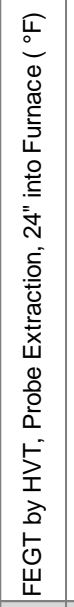 & 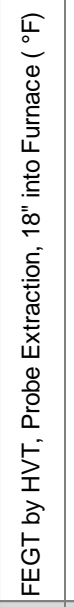 & 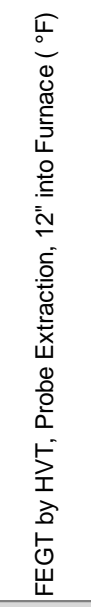 \\
\hline Warm Rec-PRB Air Test 2a & 0.15 & 1.26 & 0.55 & 1.98 & 1.42 & 1.98 & 4.51 & 870 & & & & & & & & & & & \\
\hline warm recycle prb air test $2 \mathrm{~d}$ & 0.15 & 1.30 & 0.48 & 2.47 & 1.94 & 2.02 & 5.46 & 866 & & 2345 & 2349 & 2335 & 2319 & 2350 & 2344 & 2315 & 2320 & 2318 & 2300 \\
\hline Warm Rec-PRB Air Test 2e & 0.16 & 1.29 & 0.45 & 2.26 & 1.76 & 1.94 & 4.96 & 821 & & 2132 & 2196 & 2199 & 2205 & 2206 & 2206 & 2211 & 2208 & 2195 & plugged \\
\hline warm recycle prb air test 2c & 0.15 & 1.34 & 0.50 & 2.52 & 2.02 & 2.07 & 5.61 & 867 & & & & & & & & & & & \\
\hline Warm Rec-PRB Air Test 2b & 0.16 & 1.33 & 0.55 & 2.41 & 2.07 & 2.11 & 5.65 & 886 & & 2329 & 2333 & 2353 & 2331 & 2343 & 2335 & 2314 & 2324 & 2332 & 2281 \\
\hline $\begin{array}{l}\text { Warm Rec-PRB Quick Baseline } \\
\text { 9-17-09 }\end{array}$ & 0.15 & 1.27 & 0.71 & & & 1.81 & & 801 & & & & & & & & & & & \\
\hline Warm Rec-PRB Air Test 2f & 0.16 & 1.34 & 0.65 & 1.93 & 1.53 & 2.02 & 4.64 & 831 & 3100 & 2141 & 2155 & 2162 & 2164 & 2166 & 2166 & 2166 & 2165 & 2167 & 2156 \\
\hline warm rec-prb oxy test $5 b$ & 0.17 & 1.22 & 0.52 & & & 1.98 & & 842 & & & & & & & & & & & \\
\hline Warm Rec-PRB secondary trans & 0.00 & 1.28 & 0.51 & 2.81 & 1.89 & 1.72 & 5.64 & 814 & & & & & & & & & & & \\
\hline warm rec-prb oxy test $5 a$ & 0.17 & 1.27 & 0.51 & 2.68 & 1.78 & 2.04 & 5.58 & 848 & & & & & & & & & & & \\
\hline $\begin{array}{l}\text { Warm Rec-PRB Secondary } \\
\text { Trans } 3\end{array}$ & 0.16 & 0.92 & 0.66 & 2.23 & 1.80 & 1.47 & 5.06 & 777 & & & & & & & & & & & \\
\hline $\begin{array}{l}\text { Warm Rec-PRB Secondary } \\
\text { Trans2 }\end{array}$ & 0.16 & 1.04 & 0.66 & 2.46 & 1.64 & 1.57 & 5.12 & 771 & 3200 & 2276 & 2273 & 2271 & 2276 & 2279 & 2281 & 2290 & 2282 & 2274 & 2240 \\
\hline warm rec-prb oxy test5c & 0.14 & 1.22 & 0.23 & 2.24 & 2.11 & 1.96 & 5.19 & 847 & & & & & & & & & & & \\
\hline warm rec oxy prb 6 & 0.17 & 1.13 & 0.45 & 2.49 & 1.70 & 1.81 & 5.14 & 824 & & & & & & & & & & & \\
\hline Warm Rec PRB Oxy 1 & 0.18 & 0.94 & 0.64 & 2.67 & 1.69 & 1.58 & 5.46 & 809 & 3200 & 2300 & 2325 & 2312 & 2310 & 2311 & 2311 & 2311 & 2309 & 2306 & 2279 \\
\hline warm rec prb oxy 2 & 0.18 & 1.03 & 0.60 & 2.74 & 1.77 & 1.73 & 5.62 & 833 & & 2310 & 2301 & 2303 & 2306 & 2304 & 2304 & 2297 & 2295 & 2296 & 2279 \\
\hline warm rec oxy prb 5 a & 0.17 & 1.14 & 0.49 & 2.54 & 1.84 & 1.82 & 5.37 & 831 & 3100 & 2180 & 2183 & 2190 & 2191 & 2190 & 2190 & 2191 & 2186 & 2183 & 2175 \\
\hline warm rec oxy prb 4 a & 0.17 & 1.06 & 0.53 & 2.51 & 1.75 & 1.77 & 5.31 & 847 & & 2227 & 2246 & 2254 & 2260 & 2260 & 2260 & 2260 & 2267 & 2261 & 2255 \\
\hline warm rec prb oxy 3 & 0.18 & 1.01 & 0.56 & 2.41 & 1.80 & 1.70 & 5.27 & 829 & & & & & & & & & & & \\
\hline
\end{tabular}

Table 8.14 Pilot scale test data for subbituminous coal (warm recycle) - table 4 of 5: Heat transfer and temperature data 


\begin{tabular}{|c|c|c|c|c|c|c|c|c|c|c|c|}
\hline & \multicolumn{7}{|c|}{ System Static and Differential Pressures } & \multicolumn{4}{|c|}{ Miscellaneous } \\
\hline Test Name & 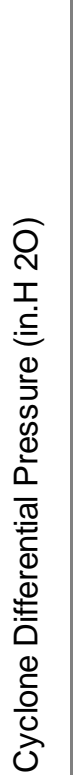 & 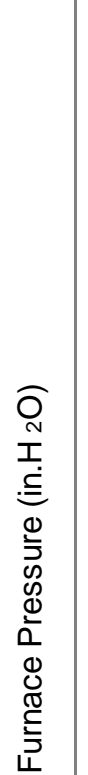 & 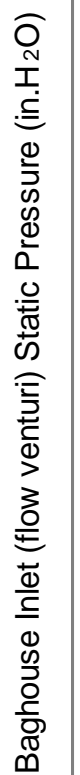 & 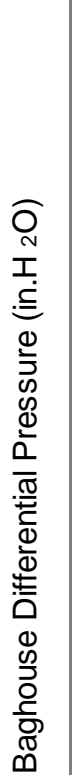 & 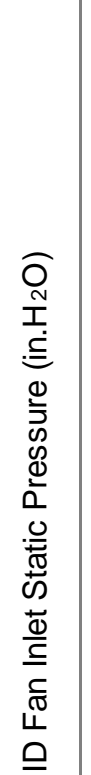 & 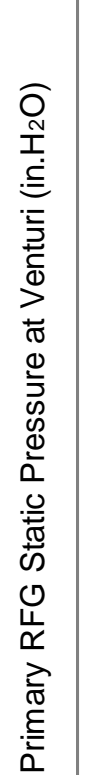 & 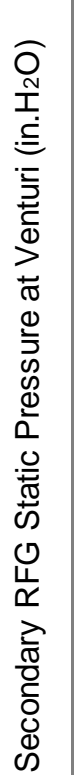 & 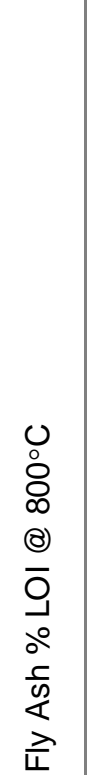 & 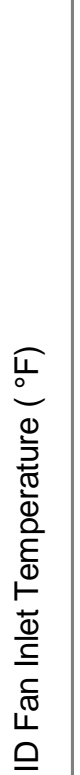 & 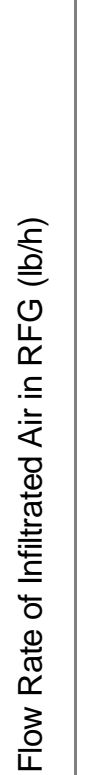 & 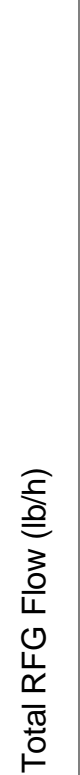 \\
\hline Warm Rec-PRB Air Test 2a & 9.8 & -0.5 & $>0$ & 5.7 & -10.1 & 0.2 & 0.2 & 1.20 & 261 & & \\
\hline warm recycle prb air test $2 d$ & 10.7 & -0.5 & 6.0 & 5.0 & -3.6 & 0.3 & 0.4 & 1.02 & 297 & & \\
\hline Warm Rec-PRB Air Test 2e & 10.7 & -0.6 & 6.7 & 8.0 & -6.2 & 0.3 & 0.4 & 1.26 & 277 & & \\
\hline warm recycle prb air test $2 c$ & 12.5 & -0.4 & 6.0 & 5.4 & -4.3 & 0.3 & 0.4 & 1.29 & 298 & & \\
\hline Warm Rec-PRB Air Test 2b & 13.0 & -0.1 & 3.8 & 5.9 & -7.2 & 0.3 & 0.4 & 1.3 & 294 & & \\
\hline $\begin{array}{l}\text { Warm Rec-PRB Quick Baseline } \\
\text { 9-17-09 }\end{array}$ & 13.4 & 0.3 & 3.1 & 6.8 & -7.8 & 0.2 & 0.2 & & 215 & & \\
\hline Warm Rec-PRB Air Test $2 f$ & 17.2 & -0.2 & 5.1 & 6.3 & -6.0 & 0.3 & 0.4 & 1.36 & 264 & & \\
\hline warm rec-prb oxy test $5 b$ & 10.6 & -1.4 & 4.8 & 4.1 & -3.2 & -0.6 & -1.2 & & 303 & 65 & 3239 \\
\hline Warm Rec-PRB secondary trans & 13.9 & -1.1 & 4.5 & 5.7 & -5.1 & -0.4 & -1.0 & 2.66* & 283 & 117 & 3393 \\
\hline warm rec-prb oxy test $5 a$ & 11.2 & -0.5 & 5.3 & 4.5 & -3.2 & -0.6 & -1.4 & & 299 & 68 & 3387 \\
\hline $\begin{array}{l}\text { Warm Rec-PRB Secondary } \\
\text { Trans } 3\end{array}$ & 7.9 & -2.0 & 5.2 & 4.1 & -1.3 & -0.1 & -0.4 & & 262 & 46 & 2427 \\
\hline $\begin{array}{l}\text { Warm Rec-PRB Secondary } \\
\text { Trans2 }\end{array}$ & 8.1 & -1.6 & 5.4 & 4.0 & -1.3 & -0.2 & -0.5 & 1.78 & 269 & 68 & 2578 \\
\hline warm rec-prb oxy test5c & 6.5 & -0.1 & 4.5 & 4.1 & -3.4 & -0.8 & -1.2 & & 310 & 64 & 3957 \\
\hline warm rec oxy prb 6 & 12.5 & -0.1 & 6.0 & 3.9 & -0.9 & -0.6 & -0.9 & & 304 & 88 & 3679 \\
\hline Warm Rec PRB Oxy 1 & 6.4 & -0.4 & 4.7 & 3.6 & -1.3 & -0.4 & -0.6 & 1.44 & 280 & 87 & 3211 \\
\hline warm rec prb oxy 2 & 8.6 & & 5.3 & 3.7 & -1.2 & -0.5 & -0.7 & 1.37 & 289 & 86 & 3460 \\
\hline warm rec oxy prb 5 A & 13.1 & & 6.4 & 4.0 & -0.8 & -0.6 & -1.0 & 2.74* & 311 & 65 & 3786 \\
\hline warm rec oxy prb 4 a & 11.4 & & 5.8 & 3.8 & -1.0 & -0.6 & -0.9 & 1.65 & 305 & 68 & 3603 \\
\hline warm rec prb oxy 3 & 8.7 & & 5.3 & 3.7 & -1.1 & -0.5 & -0.7 & 1.64 & 295 & 76 & 3482 \\
\hline
\end{tabular}

Table 8.15 Pilot scale test data for subbituminous coal (warm recycle) - table 5 of 5 : Static and differential pressures and miscellaneous data 


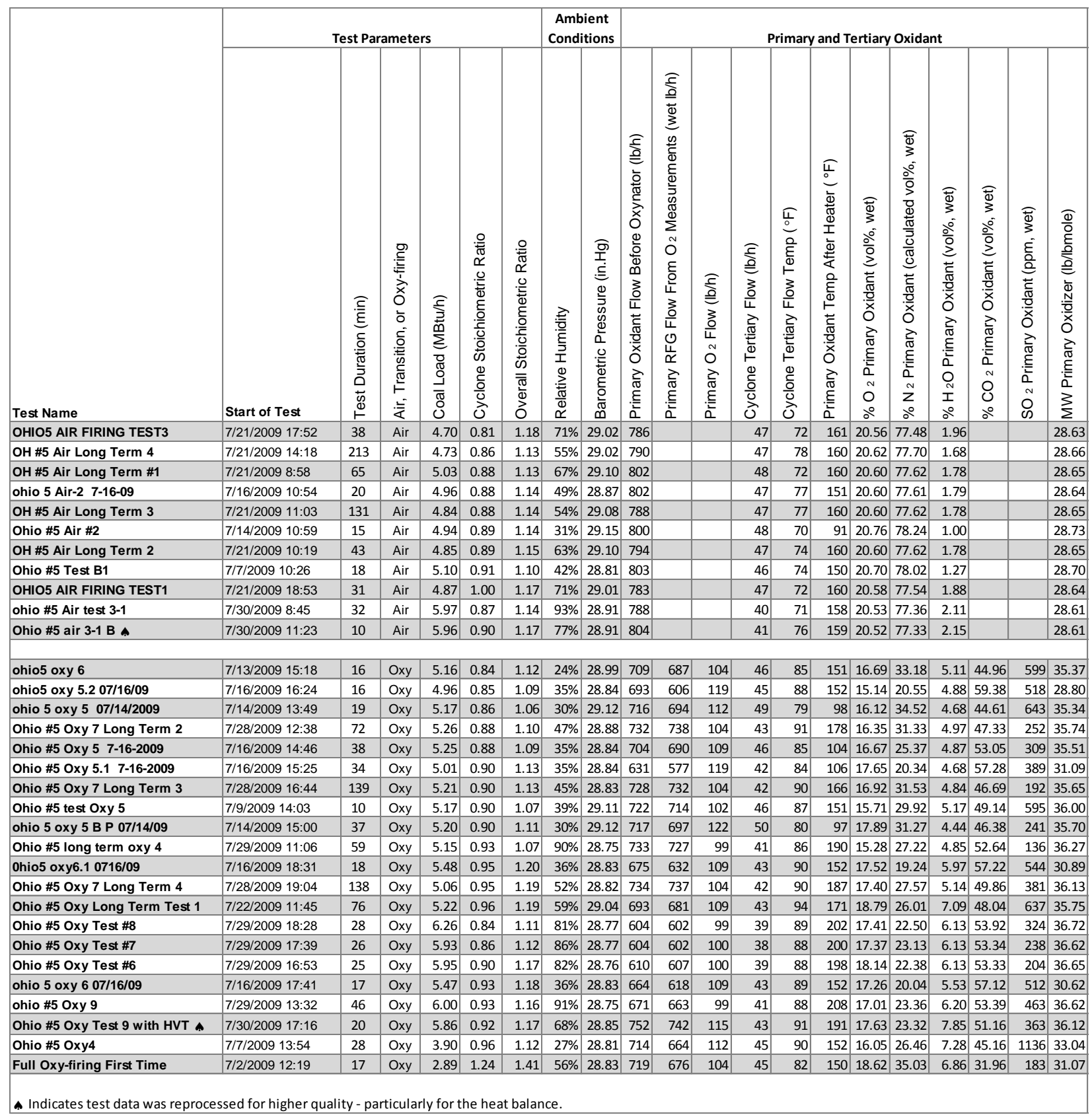

\section{Table 8.16 Pilot scale test data for bituminous coal - table 1 of 5: test parameters,} ambient conditions, and primary and tertiary oxidant data 


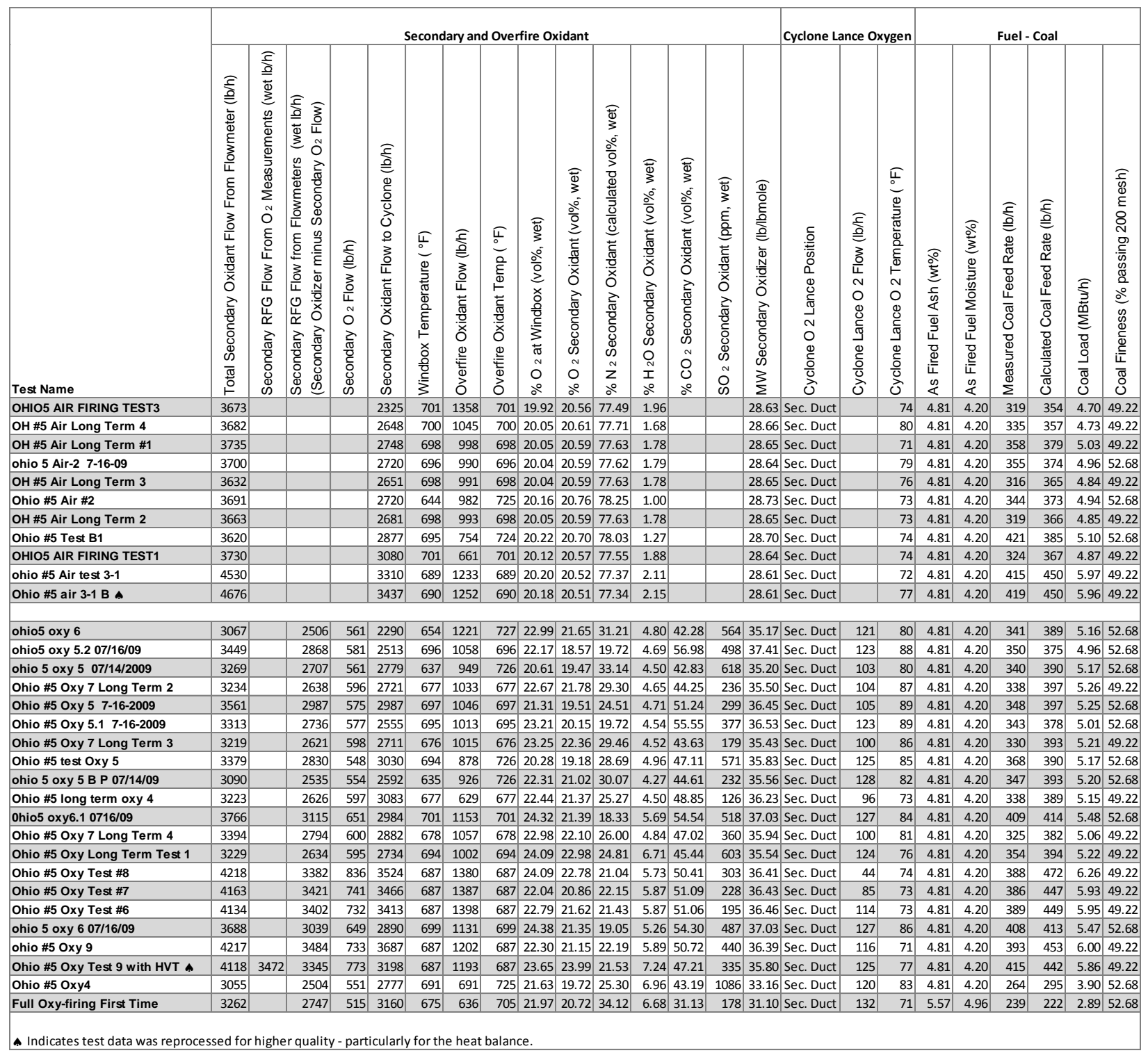

Table 8.17 Pilot scale test data for bituminous coal - table 2 of 5: Secondary and overfire oxidant, Cyclone lance oxygen, and coal test data 


\begin{tabular}{|c|c|c|c|c|c|c|c|c|c|c|c|c|c|c|c|c|c|c|}
\hline & $\begin{array}{l}\text { Fue } \\
\text { Nature }\end{array}$ & $\begin{array}{l}\text { el - } \\
\text { al Gas }\end{array}$ & & & & onvecti & ion Pass & s Gase & & & & & & Stack & k/Emiss & ions & & \\
\hline Test Name & 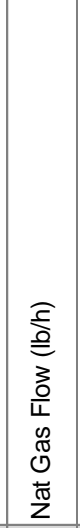 & 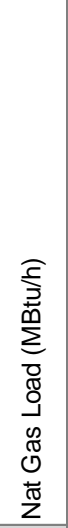 & $\begin{array}{l}\widehat{z} \\
0 \\
\varepsilon \\
\overline{0} \\
0 \\
0 \\
0 \\
\tilde{0} \\
0 \\
\geq \\
0 \\
0 \\
0 \\
0 \\
0\end{array}$ & 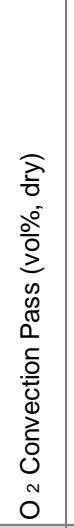 & 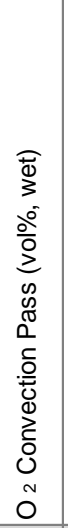 & 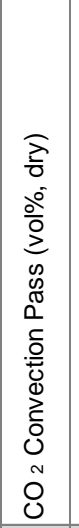 & 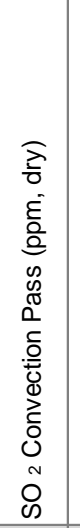 & 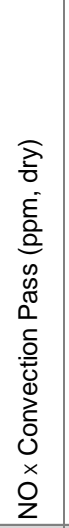 & 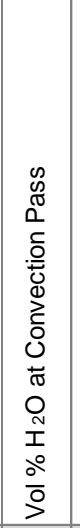 & 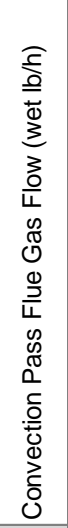 & 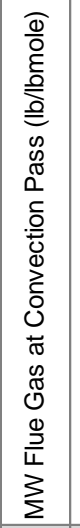 & 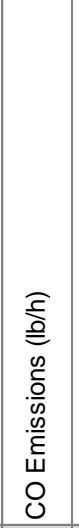 & 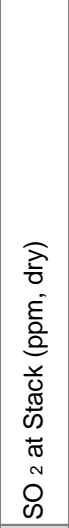 & 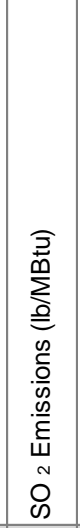 & 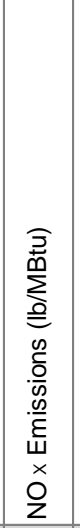 & 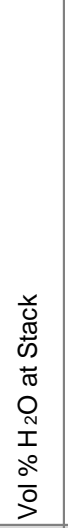 & 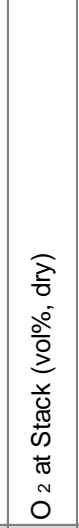 & 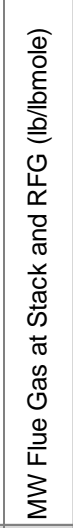 \\
\hline OHIO5 AIR FIRING TEST3 & & & 44 & 3.10 & 2.74 & 15.57 & 1914 & 289 & 8.04 & 4807 & 29.67 & 0.182 & 352 & 0.827 & 0.489 & 7.93 & 4.878 & 29.43 \\
\hline $\mathrm{OH} \# 5$ Air Long Term 4 & & & 26 & 3.19 & 2.81 & 15.49 & 1901 & 550 & 7.81 & 4823 & 29.69 & 0.108 & 380 & 0.954 & 0.932 & 7.20 & 5.013 & 29.51 \\
\hline OH \#5 Air Long Term \#1 & & & 38 & 2.38 & 2.16 & 16.26 & 1982 & 518 & 8.19 & 4909 & 29.73 & 0.160 & 368 & 0.851 & 0.863 & 4.43 & 4.196 & 29.88 \\
\hline ohio 5 Air-2 7-16-09 & & & 67 & 2.48 & 2.17 & 16.29 & 1943 & 444 & 8.18 & 4869 & 29.74 & 0.284 & 551 & 1.303 & 0.753 & 3.84 & 4.289 & 29.94 \\
\hline $\mathrm{OH} \# 5$ Air Long Term 3 & & & 35 & 2.58 & 2.32 & 16.07 & 1982 & 531 & 8.12 & 4778 & 29.72 & 0.142 & 509 & 1.167 & 0.876 & 6.33 & 4.518 & 29.66 \\
\hline Ohio \#5 Air \#2 & & & 41 & 2.53 & 2.16 & 16.13 & 2007 & 578 & 7.42 & 4857 & 29.81 & 0.174 & 397 & 0.917 & 0.960 & 4.72 & 4.302 & 29.85 \\
\hline OH \#5 Air Long Term 2 & & & 32 & 2.70 & 2.42 & 15.94 & 1959 & 554 & 8.09 & 4816 & 29.71 & 0.133 & 429 & 0.988 & 0.917 & 5.55 & 4.710 & 29.74 \\
\hline Ohio \#5 Test B1 & & & 78 & 1.91 & 1.80 & 16.20 & 2146 & 507 & 7.96 & 4801 & 29.74 & 0.321 & 564 & 1.282 & 0.827 & 6.31 & 3.598 & 29.60 \\
\hline OHIO5 AIR FIRING TEST1 & & & 22 & 3.02 & 2.70 & 15.68 & 1907 & 664 & 8.11 & 4874 & 29.68 & 0.095 & 347 & 0.778 & 1.069 & 8.22 & 4.750 & 29.44 \\
\hline ohio \#5 Air test 3-1 & & & 36 & 2.50 & 2.37 & 16.14 & 2071 & 438 & 8.58 & 5760 & 29.67 & 0.181 & 178 & 0.393 & 0.695 & 5.33 & 4.242 & 29.80 \\
\hline Ohio \#5 air 3-1 B A & & & 16 & 3.04 & 2.82 & 15.60 & 1959 & 482 & 8.42 & 5922 & 29.62 & 0.083 & 136 & 0.266 & 0.681 & 7.95 & 4.611 & 29.73 \\
\hline ohio5 oxy 6 & & & 53 & 2.86 & 2.42 & 62.66 & 3340 & 1036 & 12.47 & 4931 & 35.74 & 0.053 & 726 & 0.367 & 0.376 & 5.83 & 5.280 & 35.85 \\
\hline ohio5 oxy 5.2 07/16/09 & & & 52 & 2.00 & 1.94 & 79.45 & 3192 & 755 & 12.25 & 4997 & 30.67 & 0.066 & 622 & 0.398 & 0.345 & 5.54 & 3.562 & 29.95 \\
\hline ohio 5 oxy 5 07/14/2009 & & & 149 & 1.28 & 1.27 & 61.65 & 3188 & 369 & 11.87 & 5145 & 35.66 & 0.151 & 782 & 0.386 & 0.131 & 5.39 & 3.496 & 35.84 \\
\hline Ohio \#5 Oxy 7 Long Term 2 & & & 50 & 2.36 & 2.09 & 67.69 & 2901 & 798 & 12.23 & 5211 & 36.47 & 0.053 & 304 & 0.168 & 0.316 & 5.64 & 4.458 & 36.25 \\
\hline Ohio \#5 Oxy 5 7-16-2009 & & & 186 & 2.08 & 1.90 & 73.83 & 2893 & 651 & 12.05 & 5461 & 37.35 & 0.257 & 377 & 0.197 & 0.241 & 5.60 & 4.201 & 36.59 \\
\hline Ohio \#5 Oxy 5.1 7-16-2009 & & & 110 & 2.99 & 2.78 & 78.34 & 3147 & 887 & 12.30 & 4926 & 34.24 & 0.157 & 476 & 0.282 & 0.376 & 5.42 & 4.532 & 32.28 \\
\hline Ohio \#5 Oxy 7 Long Term 3 & & & 57 & 2.93 & 2.82 & 67.09 & 2811 & 840 & 12.10 & 5165 & 36.43 & 0.063 & 231 & 0.130 & 0.344 & 5.50 & 5.049 & 36.17 \\
\hline Ohio \#5 test Oxy 5 & & & 136 & 1.60 & 1.35 & 69.25 & 3161 & 789 & 12.18 & 5355 & 36.67 & 0.138 & 719 & 0.373 & 0.294 & 5.88 & 3.166 & 36.55 \\
\hline ohio 5 oxy 5 B P 07/14/09 & & & 81 & 2.51 & 2.34 & 63.68 & 2964 & 693 & 12.00 & 4974 & 35.95 & 0.079 & 297 & 0.138 & 0.231 & 5.18 & 4.346 & 36.32 \\
\hline Ohio \#5 long term oxy 4 & & & 190 & 1.67 & 1.64 & 72.17 & 2800 & 924 & 12.17 & 5138 & 37.08 & 0.188 & 163 & 0.079 & 0.319 & 5.50 & 3.659 & 37.17 \\
\hline Ohio5 oxy6.1 0716/09 & & & 57 & 4.68 & 4.19 & 78.24 & 3384 & 1036 & 13.10 & 5583 & 37.68 & 0.079 & 665 & 0.378 & 0.423 & 6.80 & 6.150 & 33.68 \\
\hline Ohio \#5 Oxy 7 Long Term 4 & & & 39 & 4.14 & 3.79 & 69.46 & 2826 & 995 & 11.97 & 5373 & 36.83 & 0.039 & 461 & 0.240 & 0.374 & 5.84 & 5.768 & 36.73 \\
\hline Ohio \#5 Oxy Long Term Test 1 & & & 58 & 4.55 & 3.70 & 70.43 & 3238 & 973 & 14.13 & 5159 & 36.53 & 0.059 & 802 & 0.429 & 0.373 & 8.19 & 6.545 & 36.34 \\
\hline Ohio \#5 Oxy Test \#8 & & & 80 & 2.58 & 2.52 & 75.18 & 2876 & 548 & 13.44 & 6227 & 37.25 & 0.086 & 404 & 0.180 & 0.175 & 7.11 & 4.183 & 37.48 \\
\hline Ohio \#5 Oxy Test \# & & & 77 & 2.56 & 2.46 & 74.41 & 2729 & 586 & 13.13 & 6192 & 37.21 & 0.085 & 297 & 0.135 & 0.191 & 7.11 & 4.078 & 37.36 \\
\hline Ohio \#5 Oxy Test \#6 & & & 60 & 3.72 & 3.54 & 74.40 & 2725 & 880 & 13.13 & 6187 & 37.25 & 0.067 & 254 & 0.117 & 0.290 & 7.10 & 5.132 & 37.39 \\
\hline ohio 5 oxy 6 07/16/09 & & & 89 & 4.17 & 3.74 & 78.21 & 3390 & 1036 & 12.87 & 5455 & 36.86 & 0.131 & 623 & 0.365 & 0.436 & 6.31 & 5.700 & 33.22 \\
\hline ohio \#5 Oxy 9 & & & 98 & 3.43 & 3.32 & 73.65 & 2989 & 921 & 13.04 & 6334 & 37.16 & 0.107 & 571 & 0.263 & 0.306 & 7.10 & 4.855 & 37.29 \\
\hline Ohio \#5 Oxy Test 9 with HVT & & & 39 & 3.90 & 3.36 & 73.00 & 2968 & 913 & 14.55 & 5940 & 36.76 & 0.044 & 458 & 0.226 & 0.324 & 9.02 & 5.367 & 36.74 \\
\hline Ohio \#5 Oxy4 & 44.5 & 1.03 & 49 & 2.74 & 2.23 & 64.55 & 2630 & 987 & 16.22 & 4847 & 35.21 & 0.059 & 1407 & 0.934 & 0.460 & 8.26 & 4.717 & 31.58 \\
\hline Full Oxy-firing First Time & 75.9 & 1.77 & 66 & 7.71 & 6.39 & 44.59 & 2091 & 1036 & 15.89 & 5140 & 32.72 & & 223 & 0.128 & 0.428 & 7.70 & 8.877 & 30.96 \\
\hline
\end{tabular}

Table 8.18 Pilot scale test data for bituminous coal - table 3 of 5: Natural gas flow, convection pass and stack gases, and emissions data 


\begin{tabular}{|c|c|c|c|c|c|c|c|c|c|c|c|c|c|c|c|c|c|c|c|}
\hline & \multicolumn{19}{|c|}{ Heat Transfer and HVT Data } \\
\hline Test Name & 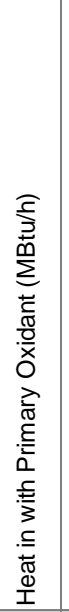 & 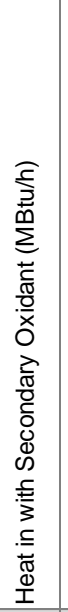 & 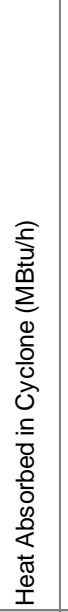 & 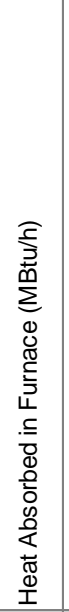 & 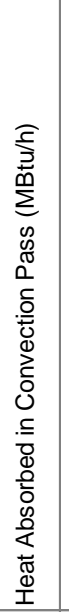 & 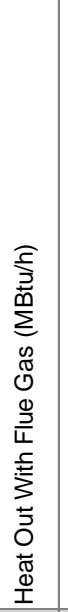 & 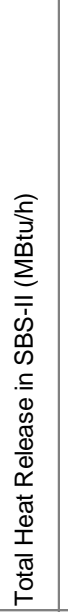 & 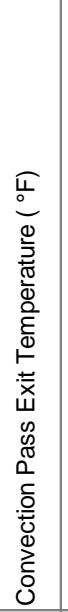 & 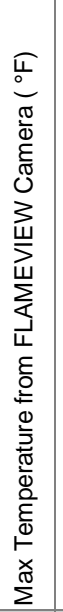 & 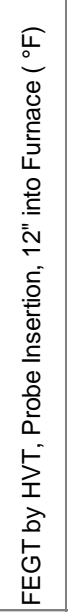 & 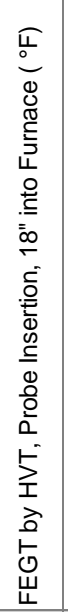 & 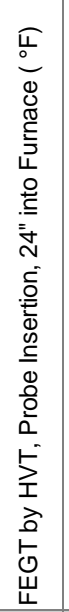 & 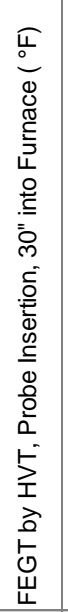 & 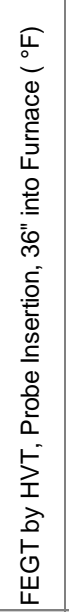 & 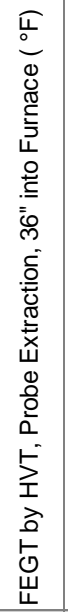 & 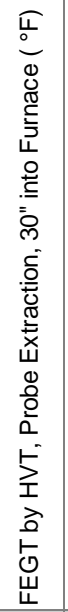 & 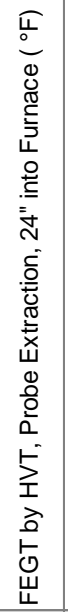 & 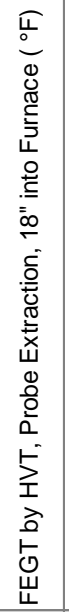 & 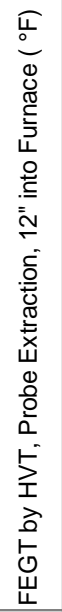 \\
\hline OHIO5 AIR FIRING TEST3 & 0.12 & 1.06 & 0.71 & 1.89 & & 1.52 & & 795 & 3000 & & & & & & & & & & \\
\hline OH \#5 Air Long Term 4 & 0.12 & 1.06 & 0.73 & 2.06 & & 1.52 & & 795 & 2900 & & & & & & & & & & \\
\hline $\mathrm{OH} \# 5$ Air Long Term \#1 & 0.12 & 1.08 & 0.74 & & & 1.49 & & 754 & & & & & & & & & & & \\
\hline ohio 5 Air-2 7-16-09 & 0.12 & 1.07 & 0.86 & & & 1.43 & & 715 & & & & & & & & & & & \\
\hline $\mathrm{OH} \# 5$ Air Long Term 3 & 0.12 & 1.05 & 0.73 & & & 1.49 & & 781 & & & & & & & & & & & \\
\hline Ohio \#5 Air \#2 & 0.11 & 1.01 & 0.69 & & & 1.47 & & 749 & & & & & & & & & & & \\
\hline $\mathrm{OH}$ \#5 Air Long Term 2 & 0.12 & 1.06 & 0.73 & & & 1.49 & & 772 & & & & & & & & & & & \\
\hline Ohio \#5 Test B1 & 0.12 & 1.04 & 0.93 & & & 1.38 & & 688 & & & & & & & & & & & \\
\hline OHIO5 AIR FIRING TEST1 & 0.12 & 1.08 & 0.70 & & & 1.55 & & 803 & 3300 & & & & & & & & & & \\
\hline ohio \#5 Air test 3-1 & 0.12 & 1.30 & 0.82 & 2.10 & 1.45 & 1.99 & 4.94 & 897 & 3100 & & & & & & & & & & \\
\hline Ohio \#5 air 3-1 B A & 0.12 & 1.34 & 0.83 & 1.86 & 1.42 & 2.01 & 4.66 & 878 & & 2225 & 2235 & 2235 & 2231 & 2254 & 2254 & 2258 & 2245 & 2244 & 2240 \\
\hline ohio 5 oxy 6 & 0.12 & 0.87 & 0.58 & & & 1.35 & & 731 & & & & & & & & & & & \\
\hline ohio5 oxy 5.2 07/16/09 & 0.14 & 0.90 & 0.70 & & & 1.78 & & 798 & & & & & & & & & & & \\
\hline ohio 5 oxy 5 07/14/2009 & 0.11 & 0.91 & 0.50 & & & 1.45 & & 763 & & & & & & & & & & & \\
\hline Ohio \#5 Oxy 7 Long Term 2 & 0.13 & 0.95 & 0.73 & 2.00 & 1.17 & 1.51 & 4.31 & 796 & & & & & & & & & & & \\
\hline Ohio \#5 Oxy 5 7-16-2009 & 0.11 & 1.03 & 0.73 & & & 1.54 & & 784 & & & & & & & & & & & \\
\hline Ohio \#5 Oxy 5.1 7-16-2009 & 0.11 & 0.92 & 0.73 & & & 1.55 & & 777 & & & & & & & & & & & \\
\hline Ohio \#5 Oxy 7 Long Term 3 & 0.12 & 0.94 & 0.70 & & & 1.50 & & 800 & 3300 & & & & & & & & & & \\
\hline Ohio \#5 test Oxy 5 & 0.12 & 1.00 & 0.86 & & & 1.43 & & 718 & & & & & & & & & & & \\
\hline ohio 5 oxy 5 B P 07/14/09 & 0.11 & 0.85 & 0.63 & & & 1.40 & & 761 & & & & & & & & & & & \\
\hline Ohio \#5 long term oxy 4 & 0.13 & 0.93 & 0.63 & & & 1.49 & & 807 & & & & & & & & & & & \\
\hline Ohio5 oxy6.1 0716/09 & 0.13 & 1.05 & 0.77 & & & 1.68 & & 846 & & & & & & & & & & & \\
\hline Ohio \#5 Oxy 7 Long Term 4 & 0.13 & 0.99 & 0.69 & & & 1.56 & & 810 & & & & & & & & & & & \\
\hline Ohio \#5 Oxy Long Term Test 1 & 0.12 & 0.97 & 0.60 & & & 1.46 & & 772 & & & & & & & & & & & \\
\hline Ohio \#5 Oxy Test \#8 & 0.11 & 1.24 & 0.55 & 2.55 & 1.41 & 1.96 & 5.12 & 894 & & & & & & & & & & & \\
\hline Ohio \#5 Oxy Test \#7 & 0.11 & 1.23 & 0.59 & 2.60 & 1.44 & 1.94 & 5.23 & 887 & & & & & & & & & & & \\
\hline Ohio \#5 Oxy Test \#6 & 0.11 & 1.22 & 0.65 & 2.10 & 1.42 & 1.93 & 4.76 & 884 & & & & & & & & & & & \\
\hline ohio 5 oxy 6 07/16/09 & 0.13 & 1.02 & 0.78 & & & 1.68 & & 841 & & & & & & & & & & & \\
\hline ohio \#5 Oxy 9 & 0.12 & 1.24 & 0.65 & 2.20 & 1.42 & 1.98 & 4.89 & 888 & 3300 & & & & & & & & & & \\
\hline Ohio \#5 Oxy Test 9 with HVT & 0.13 & 1.12 & 0.64 & 2.41 & 1.55 & 1.82 & 5.16 & 857 & 3000 & 2113 & 2121 & 2133 & 2124 & 2120 & 2122 & 2129 & 2135 & 2123 & 2106 \\
\hline Ohio \#5 Oxy4 & 0.12 & 0.91 & 0.90 & & & 1.28 & & 681 & & & & & & & & & & & \\
\hline Full Oxy-firing First Time & 0.12 & 0.99 & 0.93 & & & 1.42 & & 684 & & & & & & & & & & & \\
\hline
\end{tabular}

Table 8.19 Pilot scale test data for bituminous coal - table 4 of 5: Heat transfer and temperature data 


\begin{tabular}{|c|c|c|c|c|c|c|c|c|c|c|c|c|c|c|c|c|c|c|c|}
\hline & \multicolumn{12}{|c|}{ System Static and Differential Pressures } & \multicolumn{7}{|c|}{ Miscellaneous } \\
\hline Test Name & 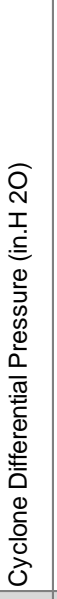 & 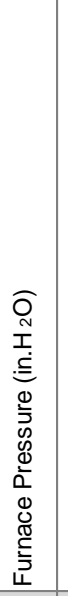 & 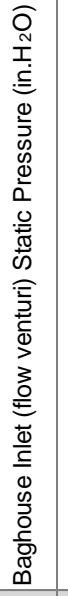 & 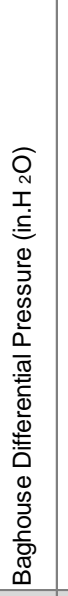 & 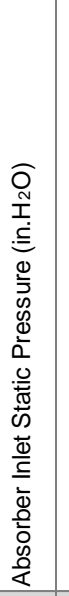 & 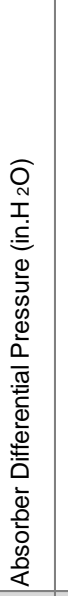 & 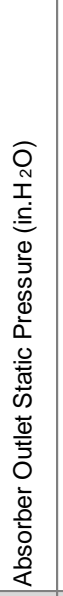 & 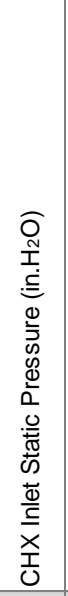 & 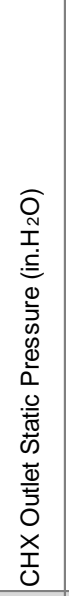 & 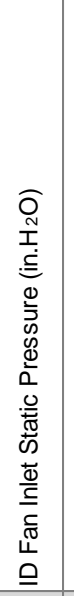 & 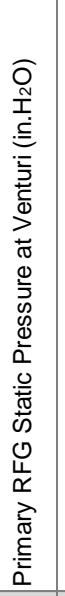 & 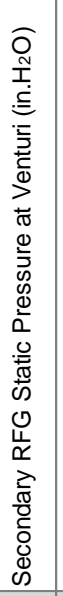 & 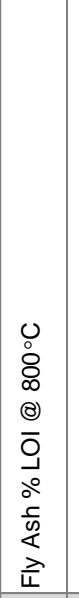 & 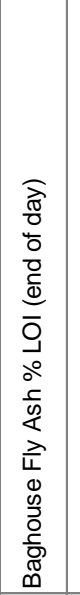 & 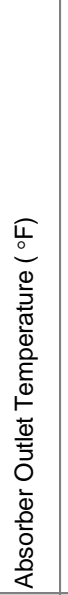 & 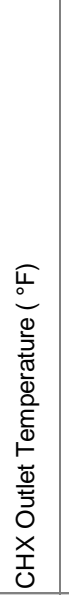 & 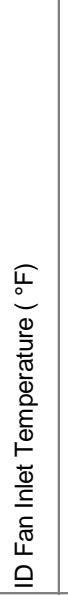 & 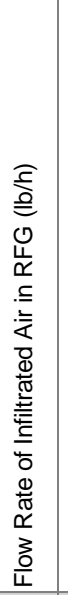 & 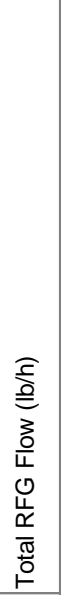 \\
\hline OHIO5 AIR FIRING TEST3 & 5.4 & 1.0 & $>0$ & 4.9 & -2.2 & 4.7 & -6.9 & -10.9 & -14.2 & -21.7 & 0.1 & 0.2 & 30.62 & 23.09 & 119 & 105 & 113 & & \\
\hline OH \#5 Air Long Term 4 & 6.9 & 0.6 & $>0$ & 4.0 & -1.8 & 4.6 & -6.3 & -10.4 & -13.9 & -20.9 & 0.1 & 0.2 & 13.74 & 23.09 & 116 & 102 & 109 & & \\
\hline OH \#5 Air Long Term \#1 & 7.1 & 0.6 & $>0$ & 3.4 & -3.4 & 3.9 & -7.3 & -9.5 & -11.0 & -19.4 & 0.2 & 0.2 & 45.34 & 23.09 & 100 & 86 & 94 & & \\
\hline ohio 5 Air-2 7-16-09 & 6.9 & 0.6 & $>0$ & 2.7 & -3.0 & 6.7 & -9.7 & -10.9 & -11.5 & -21.7 & 0.3 & 0.3 & & & 102 & 81 & 90 & & \\
\hline $\mathrm{OH} \# 5$ Air Long Term 3 & 7.0 & 0.8 & $>0$ & 5.6 & -2.5 & 3.9 & -6.4 & -9.6 & -12.1 & -19.5 & 0.1 & 0.2 & 21.97 & 23.09 & 112 & 98 & 105 & & \\
\hline Ohio \#5 Air \#2 & 7.0 & 0.1 & $>0$ & 2.8 & -2.8 & 4.1 & -7.0 & -9.9 & -12.2 & -19.9 & 0.1 & 0.2 & & & 112 & 88 & 97 & & \\
\hline $\mathrm{OH} \# 5$ Air Long Term 2 & 7.1 & 0.8 & $>0$ & 4.2 & -1.1 & 4.0 & -5.1 & -8.6 & -11.4 & -17.8 & 0.1 & 0.2 & 18.08 & 23.09 & 108 & 94 & 101 & & \\
\hline Ohio \#5 Test B1 & 8.6 & & -1.1 & 3.1 & -3.3 & 3.5 & -6.8 & -8.9 & -10.2 & -18.6 & 0.2 & 0.2 & & & 101 & 98 & 104 & & \\
\hline OHIO5 AIR FIRING TEST1 & 8.9 & 0.5 & $>0$ & 3.6 & -1.4 & 4.8 & -6.3 & -10.9 & -15.0 & -21.6 & 0.1 & 0.2 & 11.42 & 23.09 & 120 & 106 & 114 & & \\
\hline ohio \#5 Air test 3-1 & 10.9 & 1.1 & $>0$ & 5.0 & -4.6 & 6.8 & -11.4 & -17.5 & -23.9 & -32.6 & 0.2 & 0.3 & 12.33 & & 112 & 91 & 99 & & \\
\hline Ohio \#5 air 3-1 B A & 11.9 & -0.2 & $>0$ & 3.9 & -4.8 & 7.4 & -12.3 & -19.7 & -26.3 & -37.7 & 0.4 & 0.4 & & & 116 & 104 & 104 & & \\
\hline ohio 5 oxy 6 & 3.5 & 0.0 & $>0$ & 3.7 & -4.1 & 3.5 & -7.6 & -7.7 & -7.4 & -15.8 & -0.1 & -0.3 & & & 127 & 95 & 104 & 387 & 3193 \\
\hline ohio5 oxy 5.2 07/16/09 & 5.7 & 3.7 & $>0$ & 4.8 & 0.3 & 3.6 & -3.2 & -5.1 & -6.9 & -11.3 & -0.2 & -0.5 & & & 124 & 94 & 103 & 375 & 3474 \\
\hline ohio 5 oxy 5 07/14/2009 & 5.3 & 0.3 & $>0$ & 2.9 & -2.7 & 4.6 & -7.3 & -7.8 & -7.9 & -16.0 & -0.1 & -0.4 & & & 123 & 93 & 102 & 378 & 3402 \\
\hline Ohio \#5 Oxy 7 Long Term 2 & 5.7 & 0.5 & $>0$ & 1.7 & 0.2 & 5.5 & -5.3 & -6.8 & -7.9 & -14.1 & -0.2 & -0.4 & 11.18 & 18.24 & 124 & 94 & 104 & 498 & 3376 \\
\hline Ohio \#5 Oxy 5 7-16-2009 & 5.9 & 0.6 & $>0$ & 4.4 & -2.9 & 4.1 & -6.9 & -8.0 & -8.6 & -16.2 & -0.2 & -0.5 & & & 122 & 94 & 103 & 460 & 3677 \\
\hline Ohio \#5 Oxy 5.1 7-16-2009 & 5.3 & 2.2 & $>0$ & 4.2 & -0.1 & 3.5 & -3.6 & -5.2 & -6.4 & -11.2 & -0.1 & -0.4 & & & 124 & 93 & 102 & 386 & 3313 \\
\hline Ohio \#5 Oxy 7 Long Term 3 & 5.4 & 1.0 & $>0$ & 2.1 & 0.6 & 5.3 & -4.8 & -6.4 & -7.8 & -13.4 & -0.2 & -0.4 & 7.66 & 18.24 & 123 & 93 & 103 & 509 & 3353 \\
\hline Ohio \#5 test Oxy 5 & 5.8 & 0.3 & $>0$ & 3.7 & -2.8 & 4.5 & -7.3 & -8.0 & -8.3 & -16.5 & -0.1 & -0.4 & & & 126 & 96 & 105 & 459 & 3545 \\
\hline ohio 5 oxy 5 В P 07/14/09 & 4.9 & 0.4 & $>0$ & 3.2 & 0.1 & 4.6 & -4.4 & -5.6 & -6.5 & -12.0 & -0.1 & -0.3 & & & 124 & 92 & 101 & 311 & 3232 \\
\hline Ohio \#5 long term oxy 4 & 7.0 & -0.3 & $>0$ & 5.3 & -2.2 & 5.1 & -7.3 & -7.8 & -7.9 & -15.9 & -0.1 & -0.3 & & & 124 & 93 & 102 & 379 & 3353 \\
\hline Ohio5 oxy6.1 0716/09 & 6.8 & 4.0 & $>0$ & 7.5 & -0.8 & 4.7 & -5.6 & -7.9 & -9.8 & -16.1 & -0.2 & -0.6 & & & 127 & 100 & 109 & 441 & 3746 \\
\hline Ohio \#5 Oxy 7 Long Term 4 & 5.9 & 0.8 & $>0$ & 3.6 & 0.0 & 5.4 & -5.4 & -7.0 & -8.4 & -14.5 & -0.2 & -0.4 & 10.89 & 18.24 & 125 & 95 & 105 & 429 & 3531 \\
\hline Ohio \#5 Oxy Long Term Test 1 & 5.3 & 1.3 & $>0$ & 2.2 & -2.1 & 4.8 & -6.9 & -8.5 & -9.6 & -17.4 & -0.2 & -0.4 & 6.47 & & 141 & 107 & 116 & 422 & 3316 \\
\hline Ohio \#5 Oxy Test \#8 & 6.6 & 3.9 & $>0$ & 6.2 & -0.7 & 6.3 & -7.0 & -9.8 & -12.0 & -19.5 & -0.3 & -0.7 & 8.52 & & 129 & 101 & 110 & 375 & 3984 \\
\hline Ohio \#5 Oxy Test \#7 & 6.5 & 4.0 & $>0$ & 5.9 & -0.5 & 6.2 & -6.7 & -9.8 & -12.2 & -19.4 & -0.2 & -0.6 & 10.70 & & 128 & 101 & 110 & 382 & 4024 \\
\hline Ohio \#5 Oxy Test \#6 & 6.6 & 4.0 & $>0$ & 5.4 & -0.2 & 6.5 & -6.6 & -9.7 & -12.3 & -19.4 & -0.2 & -0.6 & 10.48 & & 128 & 101 & 110 & 384 & 4009 \\
\hline ohio 5 oxy 6 07/16/09 & 6.4 & 4.8 & $>0$ & 6.4 & -1.2 & 5.0 & -6.2 & -8.0 & -9.3 & -16.2 & -0.1 & -0.5 & & & 126 & 98 & 106 & 453 & 3656 \\
\hline ohio \#5 Oxy 9 & 8.4 & 1.8 & $>0$ & 2.9 & 0.2 & 6.7 & -6.5 & -10.0 & -13.0 & -20.1 & -0.3 & -0.7 & 8.84 & & 128 & 101 & 110 & 395 & 4147 \\
\hline Ohio \#5 Oxy Test 9 with HVT & 8.2 & 0.5 & $>0$ & 2.9 & -0.7 & 7.1 & -7.8 & -12.2 & -15.9 & -23.4 & -0.3 & -0.7 & 11.75 & & 135 & 109 & 109 & 385 & 4214 \\
\hline Ohio \#5 Oxy4 & 5.8 & & -1.8 & 3.6 & -2.9 & 3.1 & -6.0 & -7.0 & -7.6 & -14.7 & -0.2 & -0.5 & 15.46 & & 129 & 107 & 115 & 465 & 3168 \\
\hline Full Oxy-firing First Time & 7.8 & & -2.2 & 5.9 & -5.0 & 2.9 & -7.9 & -10.2 & -11.7 & -20.6 & -0.3 & -0.6 & & & 126 & 104 & 112 & 434 & 3423 \\
\hline
\end{tabular}

Table 8.20 Pilot scale test data for bituminous coal - table 5 of 5: Static and differential pressures and miscellaneous data 


\subsection{List of Boilers Evaluated for Geologic $\mathrm{CO}_{2}$ Storage Potential}

Table 8.21 below lists all 251 boilers evaluated by Battelle for geologic $\mathrm{CO}_{2}$ storage potential. Boiler ID refers to a specific boiler at a plant. In some cases more than one boiler per plant are present. 


\section{Plant Name}

Muskingum River

Canadys Steam

Muskingum River

Muskingum River

Lovett

Muskingum River

Cane Run

Kammer

Asheville

River Rouge

Kammer

C P Crane

Kammer

Asheville

Cooper

Glen Lyn

Kyger Creek

Kyger Creek

Big Sandy

Lee

Kyger Creek

Kyger Creek

Jack Watson

Kyger Creek

Lansing

PSEG Mercer Generating Station

Deerhaven Generating Station

A B Brown

Allen Steam Plant

Duck Creek

Allen Steam Plant

PSEG Mercer Generating Station

Allen Steam Plant

E D Edwards

A B Brown

Charles R Lowman

R D Green

North Valmy

Crist

George Neal North
Utility EIA

Code

14006

17539

14006

14006

12792

14006

11249

14006

3046

5109

14006

4161

14006

3046

5580

733

14015

14015

22053

3046

14015

14015

12686

14015

9417

15147

6909

17633

18642

49756

18642

15147

18642

49756

17633

189

20546

17166

7801

12341
State

$\mathrm{OH}$

SC

$\mathrm{OH}$

$\mathrm{OH}$

NY

$\mathrm{OH}$

KY

WV

NC

MI

WV

MD

WV

NC

KY

VA

$\mathrm{OH}$

$\mathrm{OH}$

KY

NC

$\mathrm{OH}$

$\mathrm{OH}$

MS

$\mathrm{OH}$

IA

$\mathrm{NJ}$

FL

IN

TN

IL

TN

$\mathrm{NJ}$

TN

IL

IN

AL

KY

NV

FL

IA
Generator

Nameplate

Rating

(MW)

Washington 2220

Colleton CAN3 218

Washington $\quad 3 \quad 238$

Washington 4238

Rockland $\quad 5 \quad 201$

Washington 1220

Jefferson $\quad 5 \quad 209$

$\begin{array}{lll}\text { Marshall } & 1 & 238\end{array}$

Buncombe $\quad 1 \quad 207$

Wayne $\quad 3 \quad 358$

$\begin{array}{lll}\text { Marshall } & 3 & 238\end{array}$

Baltimore 209

$\begin{array}{lll}\text { Marshall } \quad 2 & 238\end{array}$

Buncombe 207

$\begin{array}{lll}\text { Pulaski } 230 & 2\end{array}$

Giles $\quad 6 \quad 238$

Gallia $\quad 3 \quad 217$

Gallia $\quad 1 \quad 217$

Lawrence $\quad$ BSU1 281

Wayne $\quad 3 \quad 252$

Gallia $\quad 5 \quad 217$

Gallia $\quad 4 \quad 217$

Harrison $\quad 4 \quad 250$

Gallia $\quad 2 \quad 217$

Allamakee $\quad 4 \quad 275$

$\begin{array}{lll}\text { Mercer } \quad 2 & 326\end{array}$

$\begin{array}{lll}\text { Alachua } & \text { B2 } & 251\end{array}$

$\begin{array}{lll}\text { Posey } & 2 & 265\end{array}$

Shelby 330

Fulton $\quad 1 \quad 441$

Shelby $2 \quad 330$

$\begin{array}{lll}\text { Mercer } & 1 & 326\end{array}$

Shelby $\quad 1 \quad 330$

$\begin{array}{lll}\text { Peoria } & 2 & 281\end{array}$

Posey $\quad 1 \quad 265$

Washington 2236

Webster G2 264

Humboldt $\quad 1 \quad 254$

Escambia $6 \quad 370$

Woodbury $2 \quad 349$ 


\begin{tabular}{|c|c|c|c|c|c|}
\hline Plant Name & $\begin{array}{l}\text { Utility EIA } \\
\text { Code }\end{array}$ & State & County & $\begin{array}{l}\text { Boiler } \\
\text { ID }\end{array}$ & $\begin{array}{l}\text { Rating } \\
\text { (MW) }\end{array}$ \\
\hline W H Sammis & 13998 & $\mathrm{OH}$ & Jefferson & 5 & 334 \\
\hline Greene County & 195 & $A L$ & Greene & 1 & 299 \\
\hline Indian River Generating Station & 9332 & $\mathrm{DE}$ & Sussex & 4 & 442 \\
\hline Winyah & 17543 & SC & Georgetown & 1 & 315 \\
\hline Philip Sporn & 3277 & WV & Mason & 51 & 496 \\
\hline Charles R Lowman & 189 & $A L$ & Washington & 3 & 236 \\
\hline Big Bend & 18454 & $\mathrm{FL}$ & Hillsborough & BB03 & 446 \\
\hline Leland Olds & 1307 & ND & Mercer & 1 & 216 \\
\hline Joliet 9 & 12384 & IL & Will & 5 & 360 \\
\hline R D Green & 20546 & KY & Webster & G1 & 264 \\
\hline Roxboro & 3046 & NC & Person & 3B & 745 \\
\hline H L Spurlock & 5580 & KY & Mason & 1 & 358 \\
\hline Hatfields Ferry Power Station & 23279 & PA & Greene & 1 & 576 \\
\hline Greene County & 195 & $A L$ & Greene & 2 & 269 \\
\hline F B Culley & 17633 & IN & Warrick & 3 & 265 \\
\hline Roxboro & 3046 & NC & Person & $4 \mathrm{~A}$ & 745 \\
\hline Tanners Creek & 9324 & IN & Dearborn & U4 & 580 \\
\hline Winyah & 17543 & SC & Georgetown & 2 & 315 \\
\hline Roxboro & 3046 & NC & Person & $3 A$ & 745 \\
\hline Milton R Young & 12658 & ND & Oliver & B1 & 257 \\
\hline J H Campbell & 4254 & MI & Ottawa & 2 & 404 \\
\hline Winyah & 17543 & SC & Georgetown & 4 & 315 \\
\hline Edgewater & 20856 & WI & Sheboygan & 4 & 330 \\
\hline Wateree & 17539 & SC & Richland & WAT2 & 386 \\
\hline Meramec & 19436 & MO & St Louis & 4 & 359 \\
\hline Bailly & 13756 & IN & Porter & 8 & 413 \\
\hline Edgewater & 20856 & WI & Sheboygan & 5 & 380 \\
\hline Herbert A Wagner & 4161 & MD & Anne Arundel & 3 & 359 \\
\hline Reid Gardner & 13407 & NV & Clark & 4 & 270 \\
\hline E D Edwards & 49756 & IL & Peoria & 3 & 364 \\
\hline Sibley & 770 & MO & Jackson & 3 & 419 \\
\hline Big Bend & 18454 & $\mathrm{FL}$ & Hillsborough & BB01 & 446 \\
\hline Winyah & 17543 & SC & Georgetown & 3 & 315 \\
\hline North Valmy & 17166 & NV & Humboldt & 2 & 267 \\
\hline Merrimack & 15472 & $\mathrm{NH}$ & Merrimack & 2 & 346 \\
\hline Big Bend & 18454 & $\mathrm{FL}$ & Hillsborough & BB02 & 446 \\
\hline Powerton & 12384 & IL & Tazewell & 61 & 893 \\
\hline Crist & 7801 & $\mathrm{FL}$ & Escambia & 7 & 578 \\
\hline San Juan & 15473 & NM & San Juan & 2 & 369 \\
\hline Wateree & 17539 & SC & Richland & WAT1 & 386 \\
\hline
\end{tabular}




\section{Plant Name}

Roxboro

Comanche

Powerton

Jack Watson

San Juan

Mayo

Mitchell

Miami Fort

Warrick

Holcomb

John P Madgett

C D Mclntosh Jr

Sioux

Fort Martin Power Station

Hammond

Welsh

J M Stuart

Michigan City

Allen S King

Mill Creek

Kincaid Generation LLC

Ghent

Coronado

R M Schahfer

Avon Lake

J M Stuart

Hatfields Ferry Power Station

Ghent

Craig

Mill Creek

Cardinal

R M Schahfer

Hatfields Ferry Power Station

Wyodak

Stanton Energy Center

Big Stone

Miami Fort

Baldwin Energy Complex

Hunter

Cardinal
Utility EIA

Code

3046

15466

12384

12686

15473

3046

14006

3542

306

18315

4716

10623

19436

12796

7140

17698

4922

13756

13781

11249

5269

10171

16572

13756

14181

4922

23279

10171

30151

11249

3006

13756

23279

14354

14610

14232

3542

5517

14354

3006
State

NC

$\mathrm{CO}$

IL

MS

NM

NC

WV

$\mathrm{OH}$

IN

KS

WI

FL

$\mathrm{MO}$

WV

GA

TX

$\mathrm{OH}$

IN

MN

KY

IL

KY

AZ

IN

$\mathrm{OH}$

$\mathrm{OH}$

PA

KY

CO

KY

$\mathrm{OH}$

IN

PA

WY

FL

$S D$

$\mathrm{OH}$

IL

UT

$\mathrm{OH}$
Generator Nameplate

Rating

(MW)

411

396

893

500

369

$\begin{array}{lll}\text { San Juan } & 1 & 369 \\ \text { Person } & \text { 1A } & 736\end{array}$

$\begin{array}{lll}\text { Marshall } & 2 & 816\end{array}$

Hamilton $\quad 7 \quad 557$

Warrick 4323

Finney SGU1 349

$\begin{array}{lll}\text { Buffalo } & \text { B1 } & 387\end{array}$

Polk 364

St Charles $\quad 1 \quad 550$

Monongalia $2 \quad 576$

Floyd $\quad 4 \quad 578$

$\begin{array}{lll}\text { Titus } & 2 & 558\end{array}$

Adams $\quad 3 \quad 610$

La Porte $\quad 12 \quad 540$

Washington 11598

Jefferson 3463

$\begin{array}{lll}\text { Christian } & 1 & 660\end{array}$

$\begin{array}{lll}\text { Carroll } & 3 & 557\end{array}$

Apache U2B 411

Jasper $\quad 14 \quad 540$

Lorain $\quad 12 \quad 680$

Adams $\quad 1 \quad 610$

Greene $\quad 3 \quad 576$

Carroll $\quad 4 \quad 556$

Moffat $\quad$ C3 446

Jefferson $\quad 4 \quad 544$

Jefferson $\quad 1 \quad 615$

Jasper $\quad 15 \quad 556$

Greene $\quad 2 \quad 576$

Campbell BW91 362

Orange $\quad 2 \quad 465$

Grant $\quad 1 \quad 456$

Hamilton 8558

Randolph $\quad 1 \quad 623$

Emery $3 \quad 496$

Jefferson $2 \quad 615$ 


\section{Plant Name}

Hugo

Coronado

Merom

Havana

J M Stuart

Pawnee

New Madrid

Muskingum River

Sioux

Gibson

Killen Station

Brandon Shores

Flint Creek

East Bend

W H Sammis

New Madrid

Stanton Energy Center

Harrison Power Station

Brayton Point

Monroe

San Miguel

Coyote

PSEG Hudson Generating

Station

Mitchell

San Juan

Leland Olds

Welsh

Merom

Milton $\mathrm{R}$ Young

Kincaid Generation LLC

Boardman

Welsh

San Juan

Craig

GRDA

Gibson

J M Stuart

Cardinal

Pleasants Power Station
Utility EIA

Code

20447

16572

9267

5517

4922

15466

924

14006

19436

15470

4922

4161

17698

3542

13998

924

14610

12796

23106

5109

16624

14232

15147

14006

15473

1307

17698

9267

12658

5269

15248

17698

15473

30151

7490

15470

4922

3006

12796

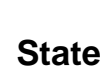

OK

AZ

IN

IL

$\mathrm{OH}$

CO

$\mathrm{MO}$

$\mathrm{OH}$

$\mathrm{MO}$

IN

$\mathrm{OH}$

MD

AR

KY

$\mathrm{OH}$

$\mathrm{MO}$

FL

WV

MA

MI

TX

ND

NJ

WV

NM

ND

TX

IN

ND

IL

OR

TX

NM

CO

OK

IN

$\mathrm{OH}$

$\mathrm{OH}$

WV
Generator Nameplate

Rating

(MW)

Choctaw $\quad 1 \quad 446$

Apache U1B 411

Sullivan $\quad$ 1SG1 540

$\begin{array}{lll}\text { Mason } & 9 & 488\end{array}$

Adams $2 \quad 610$

Morgan $\quad 1 \quad 552$

New Madrid 1600

Washington $5 \quad 615$

St Charles $2 \quad 550$

Gibson $\quad 1 \quad 668$

Adams $\quad 2 \quad 666$

Anne Arundel $1 \quad 685$

Benton $\quad 1 \quad 558$

Boone 2669

Jefferson 660

New Madrid 2600

Orange $\quad 1 \quad 465$

Harrison $\quad 1 \quad 684$

Bristol $\quad 3 \quad 643$

Monroe $\quad 2 \quad 823$

Atascosa $\quad$ SM-1 410

$\begin{array}{lll}\text { Mercer } & \text { B1 } & 450\end{array}$

$\begin{array}{lll}\text { Hudson } & 2 & 660\end{array}$

Marshall $\quad 1 \quad 816$

San Juan $\quad 4 \quad 555$

Mercer 2440

$\begin{array}{lll}\text { Titus } & 1 & 558\end{array}$

Sullivan 2SG1 540

$\begin{array}{lll}\text { Oliver } & \text { B2 } & 477\end{array}$

Christian $2 \quad 660$

Morrow $\quad 1 S G \quad 601$

$\begin{array}{lll}\text { Titus } & 3 & 558\end{array}$

San Juan $\quad 3 \quad 555$

Moffat $\quad$ C2 446

Mayes $\quad 1 \quad 490$

Gibson $\quad 2 \quad 668$

Adams $\quad 4 \quad 610$

Jefferson $3 \quad 650$

Pleasants $\quad 2 \quad 684$ 


\section{Plant Name}

Rodemacher

Belle River

D B Wilson

Louisa

John E Amos

George Neal North

Homer City Station

Hawthorn

Craig

GRDA

St Johns River Power Park

George Neal South

La Cygne

Paradise

Big Cajun 2

Belle River

Brandon Shores

Gibson

Harrison Power Station

Monroe

Homer City Station

Big Cajun 2

Homer City Station

Pleasant Prairie

Big Cajun 2

Bruce Mansfield

Harrison Power Station

Laramie River Station

Pleasants Power Station

Baldwin Energy Complex

Monroe

Gibson

Paradise

Cross

Gibson

Oklaunion

Seminole

AES Somerset LLC
Utility EIA

Code

3265

5109

20546

12341

733

12341

12520

10000

30151

7490

9617

12341

10000

18642

11252

5109

4161

15470

12796

5109

12520

11252

12520

20847

11252

14716

12796

1307

12796

5517

5109

15470

18642

17543

15470

20404

21554

22129
State

LA

MI

KY

IA

WV

IA

PA

MO

$\mathrm{CO}$

OK

FL

IA

KS

KY

LA

MI

MD

IN

WV

MI

PA

LA

PA

WI

LA

PA

WV

WY

WV

IL

MI

IN

KY

$\mathrm{SC}$

IN

TX

FL

NY
Generator Nameplate

Rating

(MW)

558

698

St Clair $2 \quad 2 \quad 698$

Ohio W1 440

$\begin{array}{lll}\text { Louisa } & 101 & 738\end{array}$

$\begin{array}{lll}\text { Putnam } & 1 & 816\end{array}$

Woodbury $\quad 3 \quad 550$

Indiana $\quad 1 \quad 660$

Jackson $\quad 5 A \quad 594$

Moffat $\quad$ C1 446

Mayes $\quad 2 \quad 520$

Duval $\quad 1 \quad 679$

Woodbury $\quad 4 \quad 640$

Linn $\quad 1 \quad 893$

$\begin{array}{lll}\text { Muhlenberg } & 1 & 704\end{array}$

Pointe

Coupee $\quad$ 2B3 619

$\begin{array}{lll}\text { St Clair } & 1 & 698\end{array}$

Anne Arundel $2 \quad 685$

Gibson $\quad 5 \quad 668$

Harrison $\quad 3 \quad 684$

$\begin{array}{lll}\text { Monroe } & 1 & 817\end{array}$

Indiana $\quad 3 \quad 692$

Pointe

Coupee $\quad 2 B 1 \quad 626$

Indiana $2 \quad 660$

$\begin{array}{lll}\text { Kenosha } & 1 & 617\end{array}$

Pointe

Coupee 2B2 626

$\begin{array}{lll}\text { Beaver } & 1 & 914\end{array}$

Harrison 2684

Platte $\quad 3 \quad 570$

Pleasants $\quad 1 \quad 684$

Randolph $2 \quad 635$

Monroe $\quad 3 \quad 823$

Gibson $\quad 3 \quad 668$

Muhlenberg $3 \quad 1150$

Berkeley $\quad 1 \quad 591$

Gibson $\quad 4 \quad 668$

Wilbarger $\quad 1 \quad 720$

$\begin{array}{lll}\text { Putnam } & 1 & 715\end{array}$

$\begin{array}{lll}\text { Niagara } & 1 & 655\end{array}$ 


\section{Plant Name}

Nebraska City

John E Amos

Monroe

W H Sammis

Thomas Hill

W A Parish

St Johns River Power Park

Seminole

Four Corners

Laramie River Station

James H Miller Jr

Laramie River Station

latan

Pleasant Prairie

W A Parish

Paradise

Gerald Gentleman

Big Sandy

James H Miller Jr

Sherburne County

Four Corners

James $\mathrm{H}$ Miller Jr

Council Bluffs

Gerald Gentleman

La Cygne

Crystal River

Pirkey

J H Campbell

James H Miller Jr

Dolet Hills

Crystal River

Bruce Mansfield

Bruce Mansfield

Monticello

Belews Creek

Belews Creek

Intermountain Power Project

Intermountain Power Project

Cumberland

Rockport
Utility EIA

Code

14127

733

5109

13998

924

18717

9617

21554

803

1307

195

1307

10000

20847

18717

18642

13337

22053

195

13781

803

195

12341

13337

10000

6455

17698

4254

195

3265

6455

14716

14716

44372

5416

5416

11208

11208

18642

9324
State

NE

WV

MI

$\mathrm{OH}$

$\mathrm{MO}$

TX

FL

FL

NM

WY

AL

WY

MO

WI

TX

KY

NE

KY

AL

MN

NM

AL

IA

NE

KS

FL

TX

MI

$\mathrm{AL}$

LA

FL

PA

PA

TX

NC

NC

UT

UT

TN

IN
Generator Nameplate

Rating

(MW)

652

816

817

680

Jefferson

Randolph $\quad$ MB3 670

Fort Bend WAP5 734

Duval $\quad 2 \quad 679$

$\begin{array}{lll}\text { Putnam } & 2 & 715\end{array}$

San Juan $\quad 5 \quad 818$

Platte $\quad 1 \quad 570$

Jefferson $\quad 4 \quad 706$

Platte 2570

$\begin{array}{lll}\text { Platte } & 1 & 726\end{array}$

$\begin{array}{lll}\text { Kenosha } & 2 & 617\end{array}$

Fort Bend WAP6 734

Muhlenberg $2 \quad 704$

Lincoln $\quad 2 \quad 681$

Lawrence $\quad$ BSU2 816

Jefferson $\quad 3 \quad 706$

Sherburne $\quad 3 \quad 809$

San Juan $\quad 4 \quad 818$

Jefferson $\quad 1 \quad 706$

Pottawattamie $3 \quad 726$

Lincoln $\quad 1 \quad 681$

Linn $\quad 2 \quad 685$

Citrus $\quad 4 \quad 739$

$\begin{array}{lll}\text { Harrison } & 1 & 721\end{array}$

Ottawa $\quad 3 \quad 871$

Jefferson $2 \quad 706$

De Soto $\quad 1 \quad 721$

$\begin{array}{lll}\text { Citrus } & 5 & 739\end{array}$

Beaver $\quad 3 \quad 914$

Beaver $\quad 2 \quad 914$

$\begin{array}{lll}\text { Titus } & 3 & 793\end{array}$

Stokes $\quad 1 \quad 1080$

Stokes $\quad 2 \quad 1080$

Millard 1SGA 820

Millard 2SGA 820

Stewart 11300

Spencer $\quad$ MB1 1300 


\begin{tabular}{llllll} 
& & & & & \multicolumn{1}{c}{$\begin{array}{l}\text { Generator } \\
\text { Nameplate }\end{array}$} \\
Plant Name & Utility EIA & & & Boiler & $\begin{array}{l}\text { Rating } \\
\text { (MW) }\end{array}$ \\
John E Amos & Code & State & County & ID & 1300 \\
General James M Gavin & 733 & WV & Putnam & 3 & 1300 \\
Cumberland & 14006 & OH & Gallia & 1 & 1300 \\
W H Zimmer & 18642 & TN & Stewart & 2 & 1426 \\
Rockport & 3542 & OH & Clermont & 1 & MB2 \\
Mountaineer & 9324 & IN & Spencer & 1300 \\
General James M Gavin & 733 & WV & Mason & 1 & 1300 \\
Bonanza & 14006 & OH & Gallia & 2 & 1300 \\
Indiantown Cogeneration LP & 40230 & UT & Uintah & $1-1$ & 500 \\
Chambers Cogeneration LP & 9253 & FL & Martin & AAB01 & 395 \\
Logan Generating Plant & 3325 & NJ & Salem & BOIL1 & 285 \\
Council Bluffs & 11132 & NJ & Gloucester & B01 & 242 \\
Coffeen & 12341 & IA & Pottawattamie & 4 & 923 \\
Coffeen & 520 & IL & Montgomery & 02 & 617
\end{tabular}

Table 8.21 A list of the 251 boilers evaluated for geologic $\mathrm{CO}_{2}$ storage potential 